\title{
International Evaluation of
}

\section{Neutron Cross-Section Standards}

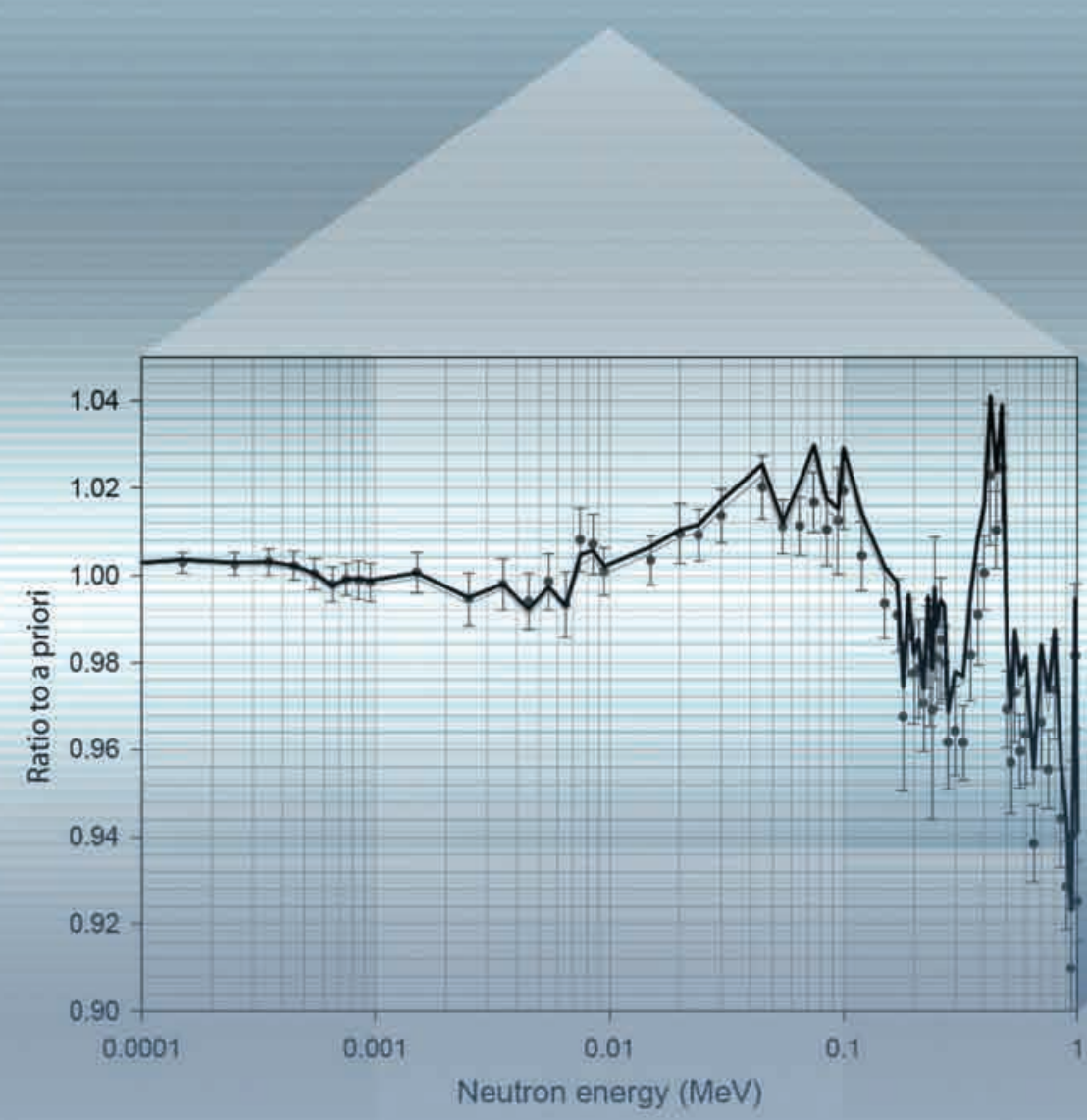




\section{INTERNATIONAL EVALUATION OF NEUTRON CROSS-SECTION STANDARDS}


The following States are Members of the International Atomic Energy Agency:

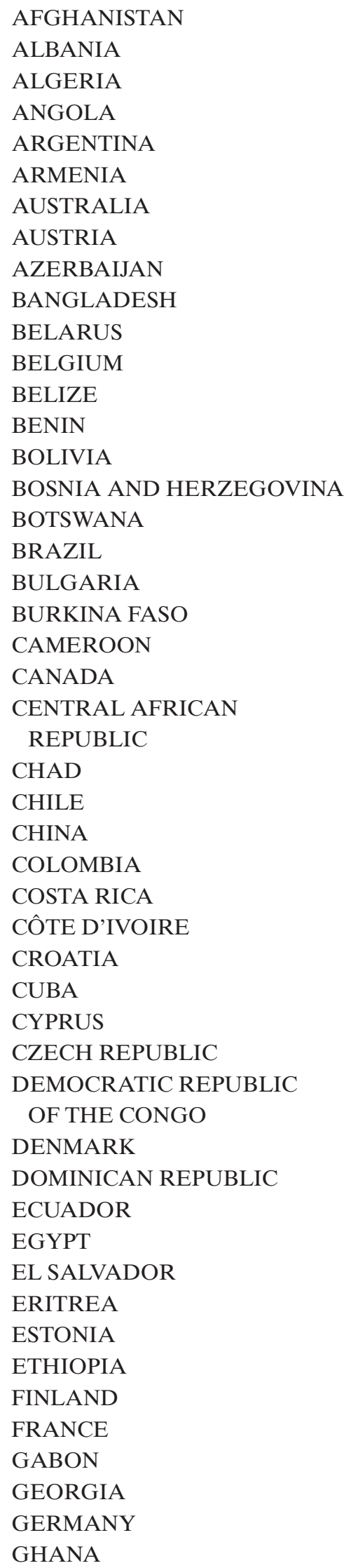

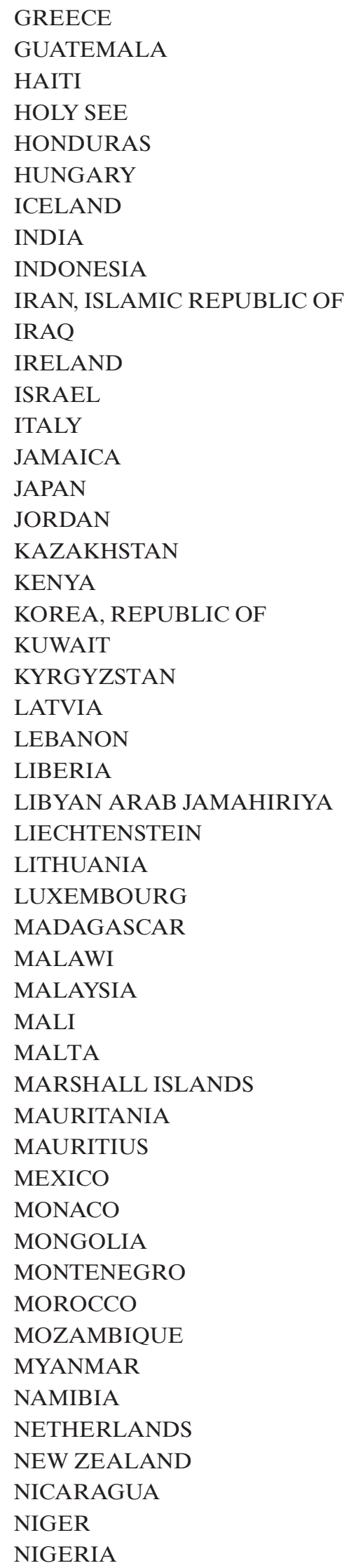

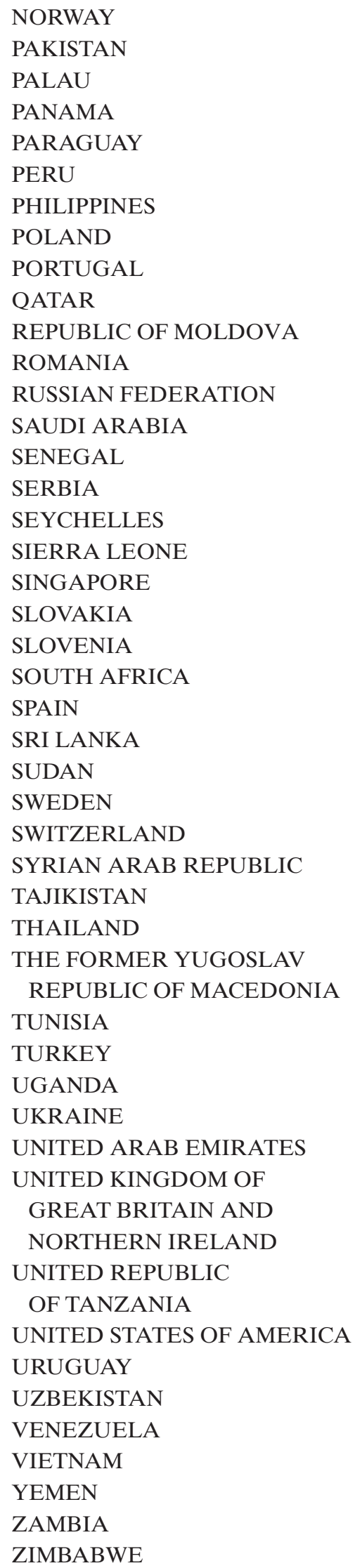

The Agency's Statute was approved on 23 October 1956 by the Conference on the Statute of the IAEA held at United Nations Headquarters, New York; it entered into force on 29 July 1957. The Headquarters of the Agency are situated in Vienna. Its principal objective is "to accelerate and enlarge the contribution of atomic energy to peace, health and prosperity throughout the world". 


\section{INTERNATIONAL EVALUATION OF NEUTRON CROSS-SECTION STANDARDS}




\section{COPYRIGHT NOTICE}

All IAEA scientific and technical publications are protected by the terms of the Universal Copyright Convention as adopted in 1952 (Berne) and as revised in 1972 (Paris). The copyright has since been extended by the World Intellectual Property Organization (Geneva) to include electronic and virtual intellectual property. Permission to use whole or parts of texts contained in IAEA publications in printed or electronic form must be obtained and is usually subject to royalty agreements. Proposals for non-commercial reproductions and translations are welcomed and considered on a case-by-case basis. Enquiries should be addressed to the IAEA Publishing Section at:

Sales and Promotion, Publishing Section

International Atomic Energy Agency

Wagramer Strasse 5

P.O. Box 100

1400 Vienna, Austria

fax: +431260029302

tel.: +431260022417

email: sales.publications@iaea.org

http://www.iaea.org/books

(C) IAEA, 2007

Printed by the IAEA in Austria

November 2007

STI/PUB/1291

\section{IAEA Library Cataloguing in Publication Data}

International evaluation of neutron cross-section standards. - Vienna :

International Atomic Energy Agency, 2007.

$$
\text { p. ; } 29 \mathrm{~cm} \text {. }
$$

$\mathrm{STI} / \mathrm{PUB} / 1291$

ISBN 92-0-100807-4

Includes bibliographical references.

1. Neutron cross section standards. I. International Atomic Energy Agency.

IAEAL

07-00494 


\section{FOREWORD}

Neutron cross-section standards are important in the valid measurement and evaluation of all other neutron reaction cross-sections. Not many cross-sections can be defined as absolute - most cross-sections are measured relative to the cross-section standards for normalization to absolute values. Previous evaluations of the neutron cross-section standards were completed in 1987 and disseminated as the NEANDC/INDC and ENDF/B standards. R matrix model fits for the light elements and non-model least squares fits for the heavy elements were the basis of the combined fits for all of the data. Some important reactions and constants are not standards, but assist greatly in the determination of the standard cross-sections and reduce their uncertainties - these data were also included in the combined fits. The experimental database prepared by Poenitz included about 400 sets of experimental data with covariance matrices of uncertainties that account for all cross-energy, cross-reaction and cross-material correlations. GMA is a least squares code developed by Poenitz to fit all types of crosssection (absolute and shape), their ratios, spectrum averaged cross-sections and thermal constants in one full analysis. Unfortunately, the uncertainties derived in this manner, and especially those obtained in the R matrix model fits, have been judged to be too low and unrealistic. These uncertainties were substantially increased prior to their release in the recommended data files of 1987. Modified percentage uncertainties were reassigned by experts for a wide range of energies, and no covariance (or correlation) matrices were supplied at that time.

The need to re-evaluate the cross-section standards is based on the appearance of a significant amount of precise experimental data and developments in the methodology of analysis and evaluation. An IAEA consultants meeting was held in 2001 to consider the major tasks to be undertaken in order to improve the 1987 standards evaluation. The recommendation to formulate an IAEA coordinated research project (CRP) entitled Improvement of Standards Cross-Sections for Light Elements was strongly endorsed by the International Nuclear Data Committee (technical advisory body to the IAEA), and this project was initiated in 2002. The main objective was to study and determine the reasons leading to the significant reduction in the uncertainties as derived by the R matrix model fits of the data. Three research coordination meetings were held between 2002 and 2004, and the scope of the CRP was substantially extended through debate in 2003 with the inclusion of tasks to evaluate the cross-section standards for heavy elements.

The evaluations of the neutron cross-section standards were finalized in October 2005. Previous difficulties experienced with a data evaluation problem known as Peelle's pertinent puzzle create biases in the fit of correlated data, and have been addressed to reduce this phenomenon. The new evaluations of the cross-section standards also include covariance matrices of the uncertainties that contain fully justifiable values.

Significant contributions to the experimental database were made by participants of Subgroup 7 of the OECD Nuclear Energy Agency Working Party on International Nuclear Data Evaluation Co-operation (WPEC). Furthermore, the evaluations could not have been carried out without access to the original GMA database and related computer codes given to the IAEA by the US Cross Section Evaluation Working Group (CSEWG). The IAEA officer responsible for this report was A.L. Nichols of the Division of Physical and Chemical Sciences. 


\section{CONTRIBUTING AUTHORS}

S.A. Badikov

Chen Zhenpeng

A.D. Carlson

E.V. Gai

G.M. Hale

F.-J. Hambsch

H.M. Hofmann

T. Kawano

N.M. Larson

V.G. Pronyaev

D.L. Smith

Soo-Youl Oh

S. Tagesen

H. Vonach

A.L. Nichols
Institute of Physics and Power Engineering, Russian Federation

Tsinghua University, China

National Institute of Standards and Technology, United States of America

Institute of Physics and Power Engineering, Russian Federation

Los Alamos National Laboratory, United States of America

EC Joint Research Centre, Institute for Reference Materials and Measurements, Belgium

Universität Erlangen-Nürnberg, Germany

Los Alamos National Laboratory, United States of America

Oak Ridge National Laboratory, United States of America

International Atomic Energy Agency

Argonne National Laboratory, United States of America

Korea Atomic Energy Research Institute, Republic of Korea

Institut für Isotopenforschung und Kernphysik, Austria

Institut für Isotopenforschung und Kernphysik, Austria

\section{TECHNICAL ASSISTANCE}

International Atomic Energy Agency

\section{EDITORIAL NOTE}

Although great care has been taken to maintain the accuracy of information contained in this publication, neither the IAEA nor its Member States assume any responsibility for consequences which may arise from its use.

The use of particular designations of countries or territories does not imply any judgement by the publisher, the IAEA, as to the legal status of such countries or territories, of their authorities and institutions or of the delimitation of their boundaries.

The mention of names of specific companies or products (whether or not indicated as registered) does not imply any intention to infringe proprietary rights, nor should it be construed as an endorsement or recommendation on the part of the IAEA.

The authors are responsible for having obtained the necessary permission for the IAEA to reproduce, translate or use material from sources already protected by copyrights.

Material prepared by authors who are in contractual relation with governments is copyrighted by the IAEA, as publisher, only to the extent permitted by the appropriate national regulations. 


\section{CONTENTS}

1. INTRODUCTION $\ldots \ldots \ldots \ldots \ldots \ldots \ldots \ldots \ldots \ldots \ldots \ldots \ldots \ldots \ldots$

A.D. Carlson

1.1. The need for standards $\ldots \ldots \ldots \ldots \ldots \ldots \ldots \ldots \ldots \ldots \ldots$

1.2. Early evaluation methods ...................... 1

1.3. ENDF/B-VI ............................ 1

1.3.1. ENDF/B-VI evaluation procedure for the light element standards not used in the global evaluation procedure ......................... 2

1.3.2. Global evaluation procedure for the

ENDF/B-VI standards .................... 3

1.4. Suggested improvements for future standards evaluations based on the ENDF/B-VI standards evaluation process .... 5

1.5. Work leading to the new international standards evaluation. . 6

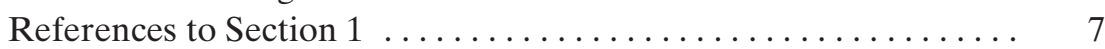

2. EVALUATION METHODOLOGY AND CODES ........... 9

V.G. Pronyaev, S.A. Badikov, A.D. Carlson, Chen Zhenpeng,

E.V. Gai, G.M. Hale, F.-J. Hambsch, H.M. Hofmann, T. Kawano,

N.M. Larson, D.L. Smith, Soo-Youl Oh, S. Tagesen, H. Vonach

2.1. Evaluation methodology $\ldots \ldots \ldots \ldots \ldots \ldots \ldots \ldots . \ldots$

2.2. Updates in the methodology $\ldots \ldots \ldots \ldots \ldots \ldots \ldots \ldots . \ldots$

2.3. Evaluation codes ......................... 10

2.4. TEST1 intercomparison of codes $\ldots \ldots \ldots \ldots \ldots \ldots \ldots . \ldots . \ldots . \ldots 11$

2.5. TEST2b intercomparison of codes $\ldots \ldots \ldots \ldots \ldots \ldots \ldots . \ldots \ldots$

2.6. Test with full GMA database $\ldots \ldots \ldots \ldots \ldots \ldots \ldots \ldots . \ldots \ldots$

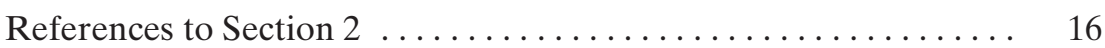

3. THE EXPERIMENTAL DATABASE .................. 17

A.D. Carlson, F.-J. Hambsch, D.L. Smith, H. Vonach

3.1. $\mathrm{H}(\mathrm{n}, \mathrm{p}),{ }^{3} \mathrm{He}(\mathrm{n}, \mathrm{p})$ and $\mathrm{C}(\mathrm{n}, \mathrm{n})$ cross-sections $\ldots \ldots \ldots \ldots \ldots \ldots \ldots$

3.2. ${ }^{10} \mathrm{~B}(\mathrm{n}, \alpha),{ }^{10} \mathrm{~B}\left(\mathrm{n}, \alpha_{1} \gamma\right)$ and ${ }^{6} \mathrm{Li}(\mathrm{n}, \mathrm{t})$ cross-sections $\ldots \ldots \ldots \ldots .19$

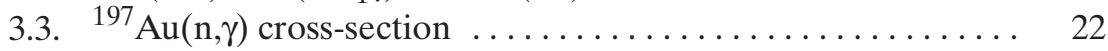

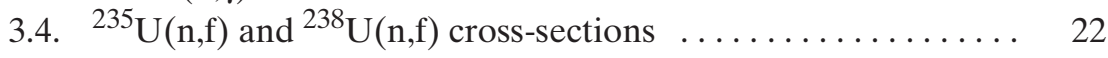

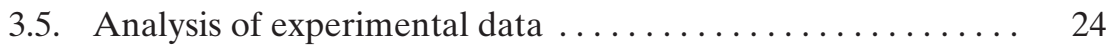

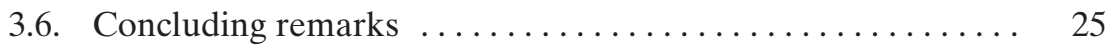

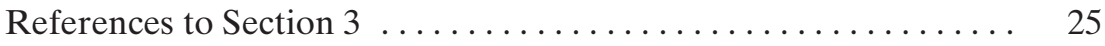

4. MICROSCOPIC NUCLEAR MODELS AND LIGHT ELEMENT

STANDARD CROSS-SECTIONS $\ldots \ldots \ldots \ldots \ldots \ldots \ldots . \ldots . \ldots$

H.M. Hofmann, G.M. Hale

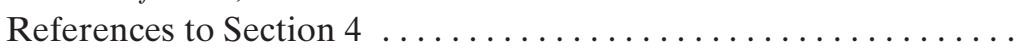

5. R MATRIX THEORY AND LIGHT ELEMENT STANDARDS

EVALUATION $\ldots \ldots \ldots \ldots \ldots \ldots \ldots \ldots \ldots \ldots \ldots \ldots \ldots . \quad 40$

G.M. Hale, Chen Zhenpeng, N.M. Larson, S.A. Badikov,

V.G. Pronyaev

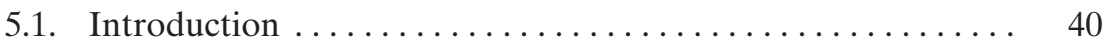

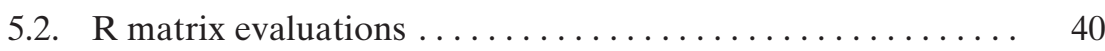


5.2.1. Sensitivity coefficients $\ldots \ldots \ldots \ldots \ldots \ldots \ldots \ldots$

5.2.2. Systematic uncertainties $\ldots \ldots \ldots \ldots \ldots \ldots \ldots \ldots, 40$

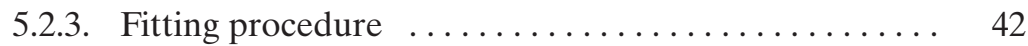

5.3. Comparison of results ..................... 42

5.4. Practical computational considerations ............. 43

References to Section $5 \ldots \ldots \ldots \ldots \ldots \ldots \ldots \ldots \ldots \ldots \ldots$

6. PERSPECTIVES ON PEELLE'S PERTINENT PUZZLE ..... 46 D.L. Smith, S.A. Badikov, E.V. Gai, Soo-Youl Oh, T. Kawano, N.M. Larson, V.G. Pronyaev

6.1. Introduction

6.2. Background and some characteristics of the Peelle's pertinent

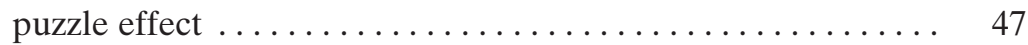

6.2.1. Probabilistic data evaluation $\ldots \ldots \ldots \ldots \ldots \ldots \ldots .47$

6.2.2. Probability density functions and their moments .... 47

6.2.3. Ordinary and generalized least squares methods ..... 48

6.2.4. Issues associated with least squares data evaluation... 48

6.2.5. The dilemma posed by Peelle's specific problem..... 49

6.2.6. Mini-PPP and maxi-PPP ................... 49

6.2.7. Earlier discussions on the Peelle's pertinent puzzle issue ........................ 51

6.2.8. An independent examination of Peelle's pertinent puzzle............................ 51

6.2.9. Practical approximate methods to minimize the Peelle's pertinent puzzle effect................... 52

6.3. Peelle's pertinent puzzle viewed from the perspective

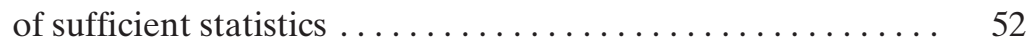

6.3.1. Sufficient statistics and Peelle's pertinent puzzle..... 52 6.3.1.1. Information matrix and sufficient statistics .. 53 6.3.1.2. Analysis of Peelle's pertinent puzzle on the basis of sufficient statistics ....... 53

6.3.2. Concluding remarks $\ldots \ldots \ldots \ldots \ldots \ldots \ldots \ldots \ldots$

6.4. Peelle's pertinent puzzle cause and effect and small

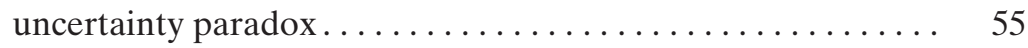

6.4.1. Background comments ................. 55

6.4.2. Formulation of the problem in the case of two

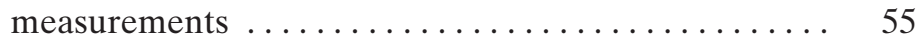

6.4.2.1. Notation .................... 55

6.4.2.2. Case of uncorrelated errors ......... 56

6.4.2.3. Case of correlated errors ........... 57

6.4.2.4. Peelle's pertinent puzzle in the case of correlated errors .............. 58

6.4.3. Least squares method problem with an explicit account of the systematic error $\ldots \ldots \ldots \ldots \ldots \ldots \ldots . \ldots 5$

6.4.3.1. Statement of the problem, its solution and its connection with the classical approach ..... 59

6.4.3.2. Uncertainty of the systematic error estimate................... 60

6.4.3.3. Estimation of the regression function ...... 61

6.4.4. The difference approach ................ 62

6.4.5. The inverse problem ................. 63

6.4.6. The case of relative experimental uncertainties ..... 63

6.4.7. Concluding remarks and recommendations ...... 65 
6.5. Chiba-Smith method to minimize Peelle's pertinent puzzle . . 66

6.5.1. Method and rationale ................ 66

6.5.2. Implementation of the Chiba-Smith approach . . . . . 66

6.6. Box-Cox transformation to minimize Peelle's

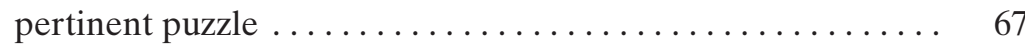

6.6.1. Reminder: least squares $\operatorname{method} \ldots \ldots \ldots \ldots \ldots \ldots 67$

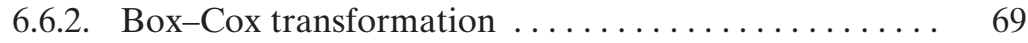

6.6.3. Solution to Peelle's pertinent puzzle .......... 70

6.6.4. Justification for the logarithmic transformation . . . . 71

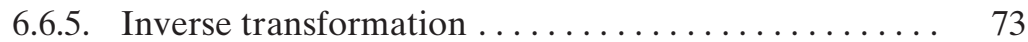

6.7. Logarithm transformation to minimize Peelle's

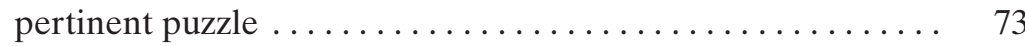

6.8. The propagated uncertainty parameter method......... 74

6.8.1. Derivation of propagated uncertainty parameter

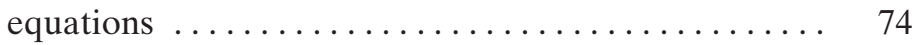

6.8.2. Comparison with methods in common use. . . . . . . 75

6.8.3. Application to Peelle's pertinent puzzle......... . 75

6.8.4. Implementation in the SAMMY code . . . . . . . 76

6.8.5. Implicit data covariance method for solving Bayes'

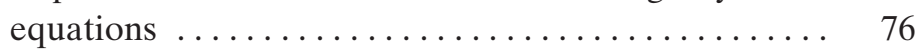

6.9. Minimization of Peelle's pertinent puzzle in the standards

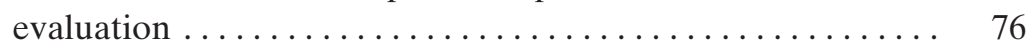

6.10. Comparison of technical approaches to Peelle's pertinent puzzle minimization $\ldots \ldots \ldots \ldots \ldots \ldots \ldots \ldots \ldots$

6.11. Summary $\ldots \ldots \ldots \ldots \ldots \ldots \ldots \ldots \ldots \ldots \ldots \ldots \ldots \ldots \ldots$

References to Section $6 \ldots \ldots \ldots \ldots \ldots \ldots \ldots \ldots \ldots \ldots \ldots$

7. RESULTS OF THE EVALUATION: COMPARISONS WITH PREVIOUS STANDARDS AND EXPERIMENTAL DATA . . . . V.G. Pronyaev, S.A. Badikov, A.D. Carlson, Chen Zhenpeng, E.V. Gai, G.M. Hale, F.-J. Hambsch, H.M. Hofmann, T. Kawano, N.M. Larson, D.L. Smith, Soo-Youl Oh, S. Tagesen, H. Vonach

7.1. Introduction $\ldots \ldots \ldots \ldots \ldots \ldots \ldots \ldots \ldots \ldots \ldots \ldots \ldots \ldots$

7.2. Reaction cross-section standards $\ldots \ldots \ldots \ldots \ldots \ldots \ldots \ldots$

7.3. Cross-section ratios $\ldots \ldots \ldots \ldots \ldots \ldots \ldots \ldots \ldots \ldots \ldots \ldots \ldots$

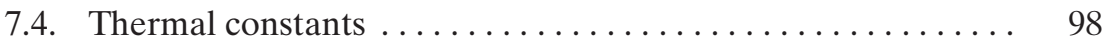

7.5. Additional remarks ....................... 99

References to Section $7 \ldots \ldots \ldots \ldots \ldots \ldots \ldots \ldots \ldots \ldots \ldots$

8. RESULTING STANDARDS DATA ................ 122 V.G. Pronyaev, S.A. Badikov, A.D. Carlson, Chen Zhenpeng, E.V. Gai, G.M. Hale, F.-J. Hambsch, H.M. Hofmann, T. Kawano, N.M. Larson, D.L. Smith, Soo-Youl Oh, S. Tagesen, H. Vonach

\section{JUSTIFICATION FOR RECOMMENDED}

UNCERTAINTIES . . . . . . . . . . . . . . . . . . . . 154

V.G. Pronyaev, S.A. Badikov, A.D. Carlson, Chen Zhenpeng,

E.V. Gai, G.M. Hale, F.-J. Hambsch, H.M. Hofmann, T. Kawano,

N.M. Larson, D.L. Smith, Soo-Youl Oh, S. Tagesen, H. Vonach

9.1. Low uncertainties for evaluated data . . . . . . . . . . . . 154

9.2. Recommended uncertainties: are they realistic? . . . . . . . 156

References to Section $9 \ldots \ldots \ldots \ldots \ldots \ldots \ldots \ldots$ 
APPENDIX: AMBIGUITIES IN THE UNCERTAINTIES OF

CROSS-SECTION DATA .................... 161

E.V. Gai

ANNEX I: CONSTANT SHIFT MODEL......... 168

ANNEX II: CONSTANT FACTOR MODEL . . . . . . . 169

ANNEX III: GENERAL MEASURE OF

UNCERTAINTY APPROXIMATION .. 170

ANNEX IV: APPROXIMATE INVARIANTS

171

LIST OF PARTICIPANTS IN THE COORDINATED

RESEARCH PROJECT $\ldots \ldots \ldots \ldots \ldots \ldots \ldots \ldots \ldots \ldots \ldots . \ldots . \ldots . \ldots$ 


\section{INTRODUCTION}

A.D. Carlson

\subsection{THE NEED FOR STANDARDS}

Neutron cross-section standards are important because they can eliminate the need for a direct measurement of the neutron fluence. The accuracy of cross-section or fluence measurements is limited by the uncertainty in the standard cross-section relative to which it is measured. Improvements in the standard cause all measurements relative to that standard to be improved. This is the reason for the emphasis on increasing the quality of neutron crosssection standards. They must be evaluated first in the process of developing a new version of an evaluated nuclear data file library. Measurement programmes have continuously improved the database of the standards, and therefore it is important to re-evaluate these cross-sections taking into account new experimental data and improved evaluation techniques.

The cross-section standards in the ENDF/BVI library are the $\mathrm{H}(\mathrm{n}, \mathrm{n}),{ }^{3} \mathrm{He}(\mathrm{n}, \mathrm{p}),{ }^{6} \mathrm{Li}(\mathrm{n}, \mathrm{t})$, ${ }^{10} \mathrm{~B}(\mathrm{n}, \alpha),{ }^{10} \mathrm{~B}\left(\mathrm{n}, \alpha_{1} \gamma\right), \mathrm{C}(\mathrm{n}, \mathrm{n}), \mathrm{Au}(\mathrm{n}, \gamma)$ and ${ }^{235} \mathrm{U}(\mathrm{n}, \mathrm{f})$ reactions. The Nuclear Energy Agency Nuclear Data Committee/International Nuclear Data Committee (NEANDC/INDC) Nuclear Standards File includes the ${ }^{238} \mathrm{U}(\mathrm{n}, \mathrm{f})$ cross-section as a standard, but does not consider the ${ }^{3} \mathrm{He}(\mathrm{n}, \mathrm{p})$ crosssection to be a standard. These particular reactions have gained the status of standards over the years and have been widely used to normalize the data from neutron cross-section ratio experiments, each reaction identified with the specific energy ranges over which they are well known. Sample materials can be acquired with good purity, yield strong and easily distinguishable signals in commonly used neutron detectors.

\subsection{EARLY EVALUATION METHODS}

Evaluations have improved with time; however, there were significant weaknesses in earlier evaluations. In some cases evaluations were performed by qualitatively or semi-quantitatively combining different kinds of data sets by simply drawing smooth curves through the existing data. Such evaluations are difficult to document and it is not clear how to determine meaningful uncertainties and covariance information.

Prior to ENDF/B-VI [1.1-1.4], a hierarchical evaluation approach was followed in standards evaluations. Lighter element cross-section standards were generally considered to be better known. The $\mathrm{H}(\mathrm{n}, \mathrm{n})$ cross-section was considered the best known standard and was evaluated first and independently of the other standards. This standard is considered to be so well known that measurements relative to it are often called absolute measurements. The ${ }^{6} \mathrm{Li}(\mathrm{n}, \mathrm{t})$ cross-section evaluation was performed next. The only ${ }^{6} \mathrm{Li}(\mathrm{n}, \mathrm{t})$ data that were used were absolute measurements or those measured relative to the $\mathrm{H}(\mathrm{n}, \mathrm{n})$ standard, which were converted to cross-sections using the adopted hydrogen evaluation. The ${ }^{10} \mathrm{~B}+\mathrm{n}$ standard crosssections were then evaluated. The only ${ }^{10} \mathrm{~B}$ data that were used were absolute measurements and those relative to $\mathrm{H}(\mathrm{n}, \mathrm{n})$ and ${ }^{6} \mathrm{Li}(\mathrm{n}, \mathrm{t})$, which were converted using the new hydrogen and lithium evaluations. This process was continued for each of the standards. This method for using ratio measurements does not use all the information available and does not include absolute and ratio data on the same basis as they were measured; for example, the ratio of the ${ }^{10} \mathrm{~B}(\mathrm{n}, \alpha)$ to ${ }^{6} \mathrm{Li}(\mathrm{n}, \mathrm{t})$ cross-sections would be used in the ${ }^{10} \mathrm{~B}(\mathrm{n}, \alpha)$ cross-section evaluation but not in the ${ }^{6} \operatorname{Li}(\mathrm{n}, \mathrm{t})$ evaluation.

\section{3. $\mathrm{ENDF} / \mathrm{B}-\mathrm{VI}$}

The difficulties with the hierarchical evaluation procedure and the work by Poenitz [1.5], using comprehensive data combination techniques, led to a more global approach for the standards evaluations for ENDF/B-VI [1.6] than had been used earlier. The method of Poenitz using least squares procedures to combine the input data consistent with experimental uncertainties was adopted for the evaluation. Each experiment was evaluated in detail to represent it fairly in this process. The method handled the full information content of the database and the data were evaluated simultaneously to ensure proper use of the available information. Thus ratio measurements of standard cross-sections had an impact on each of the cross- 
sections in the ratio. Correlations among the experimental data were taken into account in this simultaneous evaluation.

A new aspect of the ENDF/B-VI standards evaluation was the use of some absolute crosssection measurements of high quality that are not normally considered to be standards. It was recognized that for those cases where accurate ratio measurements of these cross-sections to those of standards exist, the evaluation of the cross-section should be performed simultaneously with the standards evaluation since, in principle, it will affect the values of the evaluated standards and their uncertainties. Thus the standards and other well known cross-sections would be evaluated using the same procedure. As a practical matter, the addition of data from many nuclides can become a very large problem, albeit one that can be overcome. It was determined that few cross-sections, apart from other standards, would have an appreciable impact on the determination of a standard cross-section. It was decided to include data on ${ }^{238} \mathrm{U}(\mathrm{n}, \gamma),{ }^{238} \mathrm{U}(\mathrm{n}, \mathrm{f})$ and ${ }^{239} \mathrm{Pu}(\mathrm{n}, \mathrm{f})$, since precise absolute measurements exist and many ratio measurements relative to the standards are available. Of course, there was the additional benefit that evaluations of these important nuclear reactor fuel cross-sections would be obtained. It was also considered that the evaluation should include the use of average crosssections over selected energy intervals for appropriate heavy element cross-sections to take advantage of data sets that extend down to thermal energies.

The existence of shape measurements that extend to thermal energies, in addition to absolute data, implies that an evaluation of the standards will provide information on the thermal constants that will have an impact on the normalization of data above thermal energies. Thus it was decided to evaluate the thermal constants simultaneously with the standards.

The success of $\mathrm{R}$ matrix evaluations in nuclear data evaluations suggested that these analyses should be used in the ENDF/B-VI standards evaluation process. Such analyses could provide coupling to reaction theory and give a smooth, meaningful analytical expression for the energy dependence of the cross-sections. Data in addition to angle integrated neutron cross-sections, such as differential cross-sections, polarizations and charged particle measurements involving the same compound nucleus, can have a significant impact on the standard cross-sections.
To perform the ENDF/B-VI standards evaluation, a single fitting code that would use all the experimental data involving these reactions was considered. This would be the ideal way to perform the evaluation. The evaluation would then provide output covariance data that are consistent with the cross-section evaluation that weights input data with the inverse of its variance-covariance matrix. The output for the light elements would be the $\mathrm{R}$ matrix parameters, and the output for the heavy element cross-sections would be the average crosssections at many energies. It was decided that the $\mathrm{H}(\mathrm{n}, \mathrm{n}),{ }^{3} \mathrm{He}(\mathrm{n}, \mathrm{p})$ and $\mathrm{C}(\mathrm{n}, \mathrm{n})$ cross-sections would not be evaluated in this analysis. The cross-section for $\mathrm{H}(\mathrm{n}, \mathrm{n})$ was considered to be so well known that data on the other nuclides would have very little impact. Thus this cross-section was treated as absolute in the evaluation. Very few ratio measurements relative to other standards exist for the ${ }^{3} \mathrm{He}(\mathrm{n}, \mathrm{p})$ and $\mathrm{C}(\mathrm{n}, \mathrm{n})$ cross-sections, and so little would be gained by introducing them into the evaluation. Separate $\mathrm{R}$ matrix evaluations were performed for each of these standards. The single fitting code was not implemented because it was considered to be quite difficult. Instead the decision was made that the evaluation would be the result of combining a simultaneous evaluation using generalized least squares procedures with separate $\mathrm{R}$ matrix analyses. This approach took advantage of the strengths of the two different analysis modes that can make use of separate classes of experimental information to impact upon the evaluation of the standard cross-sections. It should be noted that under proper conditions a global fitting procedure can be achieved by combining the output of the simultaneous and R matrix analyses.

\subsubsection{ENDF/B-VI evaluation procedure for the light element standards not used in the global evaluation procedure}

For ENDF/B-VI the hierarchical approach was retained for the $H(n, n)$ cross-section to the extent that measurements relative to it were treated as absolute. A nucleon-nucleon cross-section evaluation by Dodder and Hale [1.7] was performed. This charge independent $\mathrm{R}$ matrix evaluation made use of a large database of $n-p$ and $\mathrm{p}-\mathrm{p}$ experimental data at energies below $30 \mathrm{MeV}$. This database included measurements not used in the Hopkins-Breit phase shift analysis [1.8], which was the basis for the hydrogen evaluation for versions II, III, IV and V of ENDF/B. A coherent 
scattering length evaluation by Holden was included in the $\mathrm{R}$ matrix analysis [1.9]. The new data led to changes in the shapes of the angular distributions compared with those of ENDF/B-V. Of concern are changes in the backangle cross-section in the $14 \mathrm{MeV}$ energy region. The difference in the cross-sections at $180^{\circ}$ in the centre of mass system between ENDF/B-V and ENDF/B-VI is significant. This angle corresponds to proton recoils at $0^{\circ}$ in the laboratory system that is commonly used for proton recoil detectors.

The ${ }^{3} \mathrm{He}(\mathrm{n}, \mathrm{p})$ cross-section evaluation for ENDF/B-VI was a significant improvement on the previous evaluation, which was originally undertaken in 1968. The new evaluation was carried out by Hale [1.10] using all possible two-body reactions in the ${ }^{4} \mathrm{He}$ system, and is in much better agreement with the newer measurements than ENDF/B-V.

The carbon standard is the elastic scattering cross-section of natural carbon for energies less than $1.8 \mathrm{MeV}$. In ENDF/B-V, the evaluation was based on an $\mathrm{R}$ matrix analysis for ${ }^{12} \mathrm{C}$ using natural carbon data. When using this standard, it was necessary to note that two resonances in ${ }^{13} \mathrm{C}$ could cause problems since they were not included in the evaluation. A revision of the ENDF/B-V evaluation by $\mathrm{Fu}$ was made for ENDF/B-VI to include the effects of these two resonances [1.11]. The revision was also an R matrix analysis based on the available data.

\subsubsection{Global evaluation procedure for the ENDF/B-VI standards}

The procedure that was used for the evaluation of the standards (except the $H(n, n)$, ${ }^{3} \mathrm{He}(\mathrm{n}, \mathrm{p})$ and $\mathrm{C}(\mathrm{n}, \mathrm{n})$ cross-sections) and some other important cross-sections involved combining the results of a simultaneous evaluation and $\mathrm{R}$ matrix analyses with a code written by Peelle [1.12]. An energy grid was defined that is the same for all cross-sections involved in the evaluation, and the fitting parameters were the values of the crosssections for these grid points. The basis for the code was that the individual fitting for the simultaneous and R matrix evaluations would include computations of sums that could be combined to produce the same overall output parameters as would have been obtained from a global least squares fit of all the input data. Owing to possible problems with handling the common data sets used in both the $\mathrm{R}$ matrix and the simultaneous evaluations, it was decided that the boron and lithium experimental data should be separated into two uncorrelated groups, one to be used in the $\mathrm{R}$ matrix analysis and the other in the simultaneous analysis. All ratio measurements other than those relative to the hydrogen standard were used in the simultaneous evaluation. Experiments that were correlated were put into the simultaneous evaluation database.

The least squares GMA code was used for the simultaneous evaluation [1.5]. A version of this code had been used successfully for the evaluation of the ${ }^{235} U(n, f)$ cross-section for ENDF/B-V. For the ENDF/B-VI evaluation, GMA was used to evaluate the ${ }^{6} \mathrm{Li}(\mathrm{n}, \mathrm{t}),{ }^{6} \mathrm{Li}(\mathrm{n}, \mathrm{n}),{ }^{10} \mathrm{~B}\left(\mathrm{n}, \alpha_{0}\right),{ }^{10} \mathrm{~B}\left(\mathrm{n}, \alpha_{1}\right),{ }^{10} \mathrm{~B}(\mathrm{n}, \mathrm{n})$, $\mathrm{Au}(\mathrm{n}, \gamma),{ }^{235} \mathrm{U}(\mathrm{n}, \mathrm{f}),{ }^{238} \mathrm{U}(\mathrm{n}, \mathrm{f}),{ }^{238} \mathrm{U}(\mathrm{n}, \gamma)$ and ${ }^{239} \mathrm{Pu}(\mathrm{n}, \mathrm{f})$ cross-sections. The input data for this evaluation were composed of two independent subsets. The first of these was a large database of pointwise measurements assembled by Poenitz that included both shape and absolute cross-section measurements and their ratios. Total cross-section measurements for ${ }^{6} \mathrm{Li}$ and ${ }^{10} \mathrm{~B}$ were also included because the scattering and reaction data are interrelated in these measurements. Furthermore, the database contained measurements of the ${ }^{235} \mathrm{U}$ and ${ }^{239} \mathrm{Pu}$ fission cross-sections in the ${ }^{252} \mathrm{Cf}$ spontaneous fission neutron spectrum, which can be obtained with high accuracy and are only weakly dependent on the uncertainties in the ${ }^{252} \mathrm{Cf}$ spontaneous neutron fission spectrum. These data can have an important effect on the normalization of the evaluated cross-sections. Considerable effort was spent on examining the various experiments looking for corrections, etc., that were not fully documented in the published papers. Ratio measurements other than those relative to the hydrogen standard that had been converted to cross-section values were reinstated to the originally measured ratios. Measurements relative to hydrogen were converted using the ENDF/B-VI values for the hydrogen cross-section. Perhaps the most difficult part of this work was the determination of the uncertainties and correlations for each experiment, and the correlations with other experiments. This information was used to produce covariance matrices for the measurements so that a full covariance analysis could be performed for the evaluation. The second subset was for the thermal constants. However, rather than include the entire database for the thermal constants, the results of the evaluation by Axton [1.13], with the associated variancecovariance data, were used as the second independent data input subset to the GMA analysis. 
The $\mathrm{Au}(\mathrm{n}, \gamma)$ and ${ }^{10} \mathrm{~B}(\mathrm{n}, \alpha)$ cross-sections at thermal energy were treated as constants in the Axton evaluation, although they are parameters in the present evaluation procedure. However, these quantities are quite well known, and so this inconsistency had only a small effect on the evaluations.

The $\mathrm{R}$ matrix coupled channel EDA code was used by Hale for the evaluations of the ${ }^{6} \mathrm{Li}$ and ${ }^{10} \mathrm{~B}$ cross-sections for both ENDF/B-IV and ENDF/B-V [1.14]. It was decided that EDA would be a suitable $\mathrm{R}$ matrix code for the ENDF/B-VI evaluation process if all experiments that are correlated and all ratio measurements (except those relative to the hydrogen standard) were put into the database used for the simultaneous evaluation. The $\mathrm{R}$ matrix fits were undertaken by Hale. In these analyses the experimental data were used as measured with weighting normally based on the quoted uncertainties. It was assumed that no correlations other than those due to the normalization were present among the data from a particular experiment. Only normalization (long range) and statistical (short range) uncertainties were taken into account. The code used automated search routines to minimize the $\chi^{2}$ of the fits to the input data. In addition to the $\mathrm{R}$ matrix parameters, derivatives of fitted crosssections with respect to these parameters and the covariance matrix were available as output. Following the fitting process, the cross-sections were calculated for the energy grid used for the simultaneous evaluation to permit combination of the results. The parameters deduced from these analyses provide neutron cross-sections well beyond the standards region. The ${ }^{6} \mathrm{Li}+\mathrm{n}$ and ${ }^{10} \mathrm{~B}+\mathrm{n}$ analyses were each performed separately using this code. The database for the ${ }^{7} \mathrm{Li}$ system included ${ }^{6} \mathrm{Li}$ total, ${ }^{6} \mathrm{Li}(\mathrm{n}, \mathrm{n})$ integrated, ${ }^{6} \mathrm{Li}(\mathrm{n}, \mathrm{n})$ differential, ${ }^{6} \mathrm{Li}(\mathrm{n}, \mathrm{n})$ polarization, ${ }^{6} \mathrm{Li}(\mathrm{n}, \mathrm{t})$ integrated, ${ }^{6} \mathrm{Li}(\mathrm{n}, \mathrm{t})$ differential, ${ }^{4} \mathrm{He}(\mathrm{t}, \mathrm{t})$ differential and ${ }^{4} \mathrm{He}(\mathrm{t}, \mathrm{t})$ polarization data. The database for the ${ }^{11} \mathrm{~B}$ system included ${ }^{10} \mathrm{~B}$ total, ${ }^{10} \mathrm{~B}(\mathrm{n}, \mathrm{n})$ integrated, ${ }^{10} \mathrm{~B}(\mathrm{n}, \mathrm{n})$ differential, ${ }^{10} \mathrm{~B}(\mathrm{n}, \mathrm{n})$ polarization, ${ }^{10} \mathrm{~B}\left(\mathrm{n}, \alpha_{0}\right)$ integrated, ${ }^{10} \mathrm{~B}\left(\mathrm{n}, \alpha_{0}\right)$ differential, ${ }^{10} \mathrm{~B}\left(\mathrm{n}, \alpha_{1}\right)$ integrated, ${ }^{10} \mathrm{~B}\left(\mathrm{n}, \alpha_{1}\right)$ differential, ${ }^{7} \operatorname{Li}\left(\alpha, \alpha_{0}\right) \quad$ differential, ${ }^{7} \operatorname{Li}\left(\alpha, \alpha_{1}\right) \quad$ differential and ${ }^{7} \mathrm{Li}(\alpha, \mathrm{n})$ differential data.

For the lithium and boron standard crosssections, partitioning of the databases was implemented to provide the highest quality data for the $\mathrm{R}$ matrix analyses so that convergence could be more easily obtained. Thus the simultaneous evaluation results for those standards were poorly defined, had large uncertainties and had a much smaller effect on the combination output than the $\mathrm{R}$ matrix results. For the heavy element standards, the $\mathrm{R}$ matrix output impacted on the combination results only through ratio measurements relative to the ${ }^{6} \mathrm{Li}$ and ${ }^{10} \mathrm{~B}$ standard cross-sections. However, including the $\mathrm{R}$ matrix results reduced the uncertainties and changed the combination results.

Although efforts were made to include the uncertainties properly in the experimental data used in the evaluation of the standards, often the documentation did not have enough detail to allow full determination of the required input data covariance matrix $[1.15,1.16]$. In addition, inconsistencies among input data commonly occur since some experimental uncertainties are unrecognized or underestimated. This can lead to output uncertainties that are too small and inconsistencies in the output from the evaluation process. To account to some degree for unknown systematic errors, separate factors of the square root of the $\chi^{2}$ /(degree of freedom) were determined for the simultaneous evaluation, the $\mathrm{R}$ matrix evaluation of lithium and the $\mathrm{R}$ matrix evaluation of boron. Each of these factors was applied to the analyses, where they were determined as a scale factor to increase the output uncertainties. For the GMA analysis, data greater than three standard deviations away from the output results were down weighted in the GMA analysis. This adjustment had the effect of reducing the $\chi^{2} /($ degree of freedom) quantity to approximately unity. This process was not performed for the $\mathrm{R}$ matrix evaluations, where this quantity was 4.00 for the lithium analysis and 1.25 for the boron analysis. Instead, the parameter covariance matrices from the EDA analyses were scaled by the $\chi^{2} /$ (degree of freedom) factors.

Although the results of the combination process should be independent of the partitioning of the input data, the desire to run only one iteration led to a partitioning where similar results were obtained for both the $\mathrm{R}$ matrix and simultaneous analyses. Also, to allow a single iteration to be used, an effort was made to select initial estimates of the output variables that were sufficiently close to the output values.

The combining procedure made use of the variance-covariance matrices from the separate fits as well as the derivatives with respect to the evaluation parameters of the fitted values corresponding to the input data elements. Thus the input data sets are taken into account in a consistent manner. The output was adjusted $\mathrm{R}$ matrix parameters for the ${ }^{6} \mathrm{Li}+\mathrm{n}$ and ${ }^{10} \mathrm{~B}+\mathrm{n}$ systems and final point cross-sections for the remaining 
reactions. It had been anticipated that the adjusted $\mathrm{R}$ matrix parameters would be used to calculate the ${ }^{6} \mathrm{Li}+\mathrm{n}$ and ${ }^{10} \mathrm{~B}+\mathrm{n}$ cross-sections for ENDF/B-VI. However, since the $\mathrm{R}$ matrix formulations for some of the parameters were quite non-linear, the final parameters for lithium and boron were obtained from $\mathrm{R}$ matrix fits to the cross-sections obtained from the combination output.

The lithium and boron cross-sections obtained from this evaluation process are smooth since they were dominated by the $\mathrm{R}$ matrix data. However, in some cases the results obtained for the heavy element standards showed fluctuations that seemed unreasonable based on expectations from the theory of average cross-sections. Although possible methods for fitting the capture and fission crosssections were considered, such methods were only used to provide insight into how to do the smoothing.

The reviewers of the ENDF/B-VI standards evaluation expressed concern that the uncertainties obtained in the evaluation appeared too small in most cases [1.17]. It was stated that users of the standards might not use these uncertainties but instead increase them arbitrarily to what they considered a more acceptable level. A strong statement was made that the CSEWG (United States Cross-section Evaluation Working Group) Standards Subcommittee should provide such expanded uncertainties since they have had the closest contact with the database and could make better estimates of more 'acceptable' values. Such expanded uncertainties were provided. These uncertainties were qualitative estimates such that if a modern experiment were performed on a given standard using the best techniques, most of the standards results would be expected to fall within these expanded uncertainties [1.18]. They were intended to take into account data inconsistencies and concerns about R matrix parameters. Complete covariance files for the combination output were obtained but were very large. Based on the number of experimental data points it was clear that the covariance matrix was much larger than necessary and could be collapsed. Unfortunately, the work of collapsing the matrix was not completed. Covariance results were provided for the ${ }^{6} \mathrm{Li}(\mathrm{n}, \mathrm{t})$, ${ }^{10} \mathrm{~B}(\mathrm{n}, \alpha), \mathrm{Au}(\mathrm{n}, \gamma),{ }^{235} \mathrm{U}(\mathrm{n}, \mathrm{f}),{ }^{238} \mathrm{U}(\mathrm{n}, \gamma),{ }^{238} \mathrm{U}(\mathrm{n}, \mathrm{f})$ and ${ }^{239} \mathrm{Pu}(\mathrm{n}, \mathrm{f})$ cross-sections as part of the International Reactor Dosimetry File [1.19].
The cross-sections used in the ENDF/B-VI standards evaluation procedure and additional information are shown in Table 1.1.

\subsection{SUGGESTED IMPROVEMENTS FOR FUTURE STANDARDS EVALUATIONS BASED ON THE ENDF/B-VI STANDARDS EVALUATION PROCESS}

The ENDF/B-VI standards evaluation produced improved cross-section standards. The methods employed were the most sophisticated ever used in cross-section evaluations. However, there are still a number of weaknesses, and the following improvements to the evaluation process were suggested:

(a) In the evaluation of the thermal constants by Axton, the $\mathrm{Au}(\mathrm{n}, \gamma)$ and ${ }^{10} \mathrm{~B}(\mathrm{n}, \alpha)$ cross-sections, which were standards for the thermal constants measurements, were treated as constants. The thermal constants from the Axton evaluation were imported into the ENDF/B-VI standards evaluation, where these standards were treated as variables. The effect of this transgression is small since the uncertainties on these cross-sections at thermal energy are small. However, a consistent treatment should be considered for future work.

(b) The $\mathrm{H}(\mathrm{n}, \mathrm{n}),{ }^{3} \mathrm{He}(\mathrm{n}, \mathrm{p})$ and $\mathrm{C}(\mathrm{n}, \mathrm{n})$ crosssections were not used in the combining process to obtain the ENDF/B-VI standards. Future evaluations should consider including them.

(c) More work should be done on models that could be used to fit fission and capture data. Such efforts could possibly improve the quality of the evaluations and reduce or eliminate the need to smooth the output results.

(d) Methods should be considered that would permit the entire process to be carried out on one computer system, and make the iterations easier.

(e) More work should to be done to obtain realistic uncertainties and correlations for the experimental data. Such work could possibly reduce or eliminate discrepancies in the database, leading to improved uncertainties in the evaluated results. 
TABLE 1.1. CROSS-SECTIONS INVOLVED IN THE ENDF/B-VI EVALUATION

\begin{tabular}{|c|c|c|c|c|c|}
\hline $\begin{array}{l}\text { Cross- } \\
\text { section }\end{array}$ & $\begin{array}{l}\text { ENDF } \\
\text { standard }\end{array}$ & $\begin{array}{l}\text { NEANDC/INDC } \\
\text { standard }\end{array}$ & $\begin{array}{l}\text { Energy range } \\
\text { of standard }\end{array}$ & $\begin{array}{l}\text { Energy range in } \\
\text { gobal evaluation }\end{array}$ & Comments \\
\hline $\mathrm{H}(\mathrm{n}, \mathrm{n})$ & Yes & Yes & $1 \mathrm{keV}$ to $20 \mathrm{MeV}$ & - & $\begin{array}{l}\text { Independent R matrix fit } \\
\text { for ENDF/B-VI }\end{array}$ \\
\hline${ }^{3} \mathrm{He}(\mathrm{n}, \mathrm{p})$ & Yes & No & Thermal to $50 \mathrm{keV}$ & - & $\begin{array}{l}\text { Independent R matrix fit } \\
\text { for ENDF/B-VI }\end{array}$ \\
\hline${ }^{6} \operatorname{Li}(\mathrm{n}, \mathrm{t})$ & Yes & Yes & Thermal to $1 \mathrm{MeV}$ & Below $2.8 \mathrm{MeV}$ & Used in global evaluation \\
\hline${ }^{6} \mathrm{Li}(\mathrm{n}, \mathrm{n})$ & No & No & - & Below $2.8 \mathrm{MeV}$ & Used in global evaluation \\
\hline${ }^{10} \mathrm{~B}\left(\mathrm{n}, \alpha_{1} \gamma\right)$ & Yes & Yes & Thermal to $250 \mathrm{keV}$ & Below 1.0 MeV & Used in global evaluation \\
\hline${ }^{10} \mathrm{~B}\left(\mathrm{n}, \mathrm{\alpha}_{0}\right)$ & No & No & Thermal to $250 \mathrm{keV}$ & Below 1.0 MeV & Used in global evaluation \\
\hline${ }^{10} \mathrm{~B}(\mathrm{n}, \alpha)$ & Yes & Yes & Thermal to $250 \mathrm{keV}$ & Below $1.0 \mathrm{MeV}$ & $\begin{array}{l}\text { Used in global evaluation, } \\
{ }^{10} \mathrm{~B}(\mathrm{n}, \alpha)={ }^{10} \mathrm{~B}\left(\mathrm{n}, \alpha_{1} \gamma\right)+ \\
{ }^{10} \mathrm{~B}\left(\mathrm{n}, \alpha_{0}\right) \text { cross-sections }\end{array}$ \\
\hline${ }^{10} \mathrm{~B}(\mathrm{n}, \mathrm{n})$ & No & No & - & Below 1.0 MeV & Used in global evaluation \\
\hline$C(n, n)$ & Yes & Yes & Below $1.8 \mathrm{MeV}$ & - & $\begin{array}{l}\text { Independent R matrix fit } \\
\text { for ENDF/B-VI }\end{array}$ \\
\hline${ }^{197} \mathrm{Au}(\mathrm{n}, \gamma)$ & Yes & Yes & $\begin{array}{l}\text { Thermal and } 0.2 \mathrm{MeV} \\
\text { to } 2.5 \mathrm{MeV}\end{array}$ & Below $2.8 \mathrm{MeV}$ & Used in global evaluation \\
\hline${ }^{235} \mathrm{U}(\mathrm{n}, \mathrm{f})$ & Yes & Yes & $\begin{array}{l}\text { Thermal and } 0.15 \\
\mathrm{MeV} \text { to } 20 \mathrm{MeV}\end{array}$ & Below $20 \mathrm{MeV}$ & Used in global evaluation \\
\hline${ }^{238} \mathrm{U}(\mathrm{n}, \mathrm{f})$ & No & Yes & Threshold to $20 \mathrm{MeV}$ & $1 \mathrm{MeV}$ to $20 \mathrm{MeV}$ & Used in global evaluation \\
\hline${ }^{238} \mathrm{U}(\mathrm{n}, \gamma)$ & No & No & - & Below $2.2 \mathrm{MeV}$ & Used in global evaluation \\
\hline${ }^{239} \mathrm{Pu}(\mathrm{n}, \mathrm{f})$ & No & No & - & Below $20 \mathrm{MeV}$ & Used in global evaluation \\
\hline
\end{tabular}

\subsection{WORK LEADING TO THE NEW INTERNATIONAL STANDARDS EVALUATION}

Prior to the present international evaluation effort, the standards were evaluated for each version of the ENDF/B library by the CSEWG and accepted by evaluation projects throughout the world to ensure that the same set of standards was used worldwide. The most recent general evaluation of neutron cross-section standards, which was undertaken for ENDF/B-VI, was completed almost 20 years ago. That evaluation removed many of the weaknesses of earlier evaluations by being more thorough and logically consistent. However, as indicated above, some technical problems persisted that warranted further attention by nuclear data evaluators.

The large number of new standards experiments and the concern about the small uncertainties for the ENDF/B-VI standards evaluation were important factors leading to the decision to perform a new standards evaluation. Significant experimental activity had occurred, especially for the $\mathrm{H}(\mathrm{n}, \mathrm{n}),{ }^{10} \mathrm{~B}(\mathrm{n}, \alpha),{ }^{10} \mathrm{~B}\left(\mathrm{n}, \alpha_{1} \gamma\right)$ and uranium fission reactions. With the improved experimental database, significant changes can be expected to occur for a number of the standards when a new evaluation is performed. However, these experiments have not produced a new evaluation of the standards in the past because the policy has been that the standards should not change for a given version of $\mathrm{ENDF} / \mathrm{B}$; considerable confusion could occur if the standards changed too often. The decision to produce a new US evaluation (ENDF/BVII) along with new standards was a motivating factor in the decision to produce new evaluations of the standards. The interest in cross-sections for neutron energies above $20 \mathrm{MeV}$ suggested that a new evaluation of the standards should extend to approximately $200 \mathrm{MeV}$ for some of these reactions. The need to improve the standards led to the formation of a CSEWG task force to investigate how to obtain the resources and techniques necessary to perform such a new evaluation. Owing to limited resources in the USA, it became clear 
that such an evaluation should be done internationally, so that full worldwide capabilities could be utilized. A proposal was presented to the OECD Nuclear Energy Agency Working Party on International Nuclear Data Evaluation Co-operation (WPEC) to enlist its international support for the evaluation. In response to the proposal, the WPEC formed a new subgroup to promote international cooperation on the nuclear data standards. This subgroup was very helpful in the initial developmental stages and motivated necessary experimental work, especially on the ${ }^{10} \mathrm{~B}$ cross-sections. However, the necessary human resources for the complete evaluation process were not available from that source.

Historically, the IAEA has shown an interest in improving the standards, since such improvements are of general interest to the nuclear community. An IAEA coordinated research project (CRP) was established to assist in the evaluation process, and the major effort in producing the standards evaluations was provided through this route.

Topics to be addressed in this report include the following:

(a) Methods used for the evaluations/codes:

(i) Justification for the Poenitz method adopted for ENDF/B-VI being used for the new evaluations;

(ii) Improvements in the Poenitz method;

(iii) Uncertainties of discrepant data;

(iv) Methods for reducing Peelle's pertinent puzzle (PPP);

(v) Method for combining the R matrix and simultaneous evaluations;

(vi) Discussion of codes used in the evaluations (EDA, RAC, SAMMY, GLUCS, GMA);

(vii) Intercomparisons and tests of codes used in the evaluations.

(b) Experimental database:

(i) Original ENDF/B-VI database;

(ii) Additional experiments since the ENDF/ B-VI evaluation;

(iii) Corrections for 'particle leaking' with Frisch gridded ionization chambers;

(iv) Extending the database to energies above $20 \mathrm{MeV}$;

(v) Revision of uncertainties of 'discrepant' data.

(c) Microscopic nuclear models for the light element standard cross-sections: (i) RGM, RRGM, NN, NNN;

(ii) Intercomparison of the methods;

(iii) Methods for improving $\mathrm{R}$ matrix analyses;

(iv) Results for ${ }^{4} \mathrm{He}$ and ${ }^{7} \mathrm{Li}$ systems.

(d) $\mathrm{R}$ matrix theory and evaluation of the light element standards:

(i) Use of charged particle database;

(ii) Comparison of EDA and RAC results for ${ }^{7} \mathrm{Li}$ and ${ }^{11} \mathrm{~B}$ systems consistency;

(iii) Uncertainties of results with $\mathrm{R}$ matrix fits;

(iv) Problems with positive definiteness of the covariance matrix.

(e) PPP:

(i) History and reasons for PPP;

(ii) Presence of PPP in fits to multipoint data sets from the GMA database;

(iii) Methods to reduce PPP;

(iv) Updating of codes to minimize PPP;

(v) Comparison of different methods to reduce $\mathrm{PPP}$ (consistent results).

(f) Evaluation of the standards and the combining procedure:

(i) Use of GMA with R matrix evaluations treated like data sets in the GMA fit.

(ii) Handling of additional components of the uncertainty, $\mathrm{R}$ matrix numerical solution uncertainty and uncertainty of the method used to minimize PPP.

(iii) Results of the evaluation: central values, uncertainties, cross-energy and crossreaction correlations.

(g) Comparison and presentation of results:

(i) Original results;

(ii) Smoothed results;

(iii) Thinned covariance matrices (more easily readable);

(iv) Plots of new standards compared with previous standards.

(h) Justification for the recommended uncertainties.

\section{REFERENCES TO SECTION 1}

[1.1] CARLSON, A.D., "The ENDF/B standards", Proc. 35th Anniversary Symp. of the Cross Section Evaluation Working Group, Rep. BNL-52675, Brookhaven Natl Lab., Upton, NY (2001).

[1.2] DRAKE, M.K., ENDF/B-III Cross Section Measurement Standards, Rep. BNL-17188, Brookhaven Natl Lab., Upton, NY (1972). 
[1.3] MAGURNO, B.A., ENDF/B-IV Dosimetry File, Rep. BNL-NCS-50446, Brookhaven Natl Lab., Upton, NY (1975).

[1.4] CARLSON, A.D., BHAT, M.R., ENDF/B-V Cross Section Measurement Standards, Rep. BNL-NCS-51619, Brookhaven Natl Lab., Upton, NY (1982).

[1.5] POENITZ, W.P., "Evaluation methods for neutron cross section standards", Proc. Conf. Nuclear Data Evaluation Methods and Procedures, Rep. BNL-NCS-51363, Vol. 1, Brookhaven Natl Lab., Upton, NY (1981) 249-290.

[1.6] CARLSON, A.D., et al., ENDF/B-VI Neutron Cross Section Measurement Standards, Rep. NISTIR-5177, National Institute of Standards and Technology, Gaithersburg, MD (1993); also ENDF/B-VI Neutron Cross Section Measurement Standards, Rep. ENDF-351, Brookhaven Natl Lab., Upton, NY (1993).

[1.7] DODDER, D.C., HALE, G.M., Los Alamos Natl Lab., personal communication, 1987.

[1.8] HOPKINS, J.C., BREIT, G., The ${ }^{1} \mathrm{H}(\mathrm{n}, \mathrm{n})^{1} \mathrm{H}$ scattering observables required for high-precision fast-neutron measurements, Nucl. Data Tables A9 (1971) 137-145.

[1.9] HOLDEN, N.E., Brookhaven Natl Lab., personal communication, 1987.

[1.10] HALE, G.M., Los Alamos Natl Lab., personal communication, 1987.

[1.11] FU, C.Y., Evaluated cross sections for neutron scattering from natural carbon below $2 \mathrm{MeV}$, including $\mathrm{R}$ matrix fits to ${ }^{13} \mathrm{C}$ resonances, Nucl. Sci. Eng. 106 (1990) 494-500.

[1.12] PEELLE, R.W., ENDF/B-VI Neutron Cross Section Measurement Standards, Appendix C, Rep. NISTIR-5177, National Institute of Standards and Technology, Gaithersburg, MD (1993).
[1.13] AXTON, E.J., Central Bureau for Nuclear Measurements, personal communication, 1986.

[1.14] HALE, G.M., "R-matrix analysis of the ${ }^{7} \mathrm{Li}$ system", Neutron Standards and Applications (BOWMAN, C.D., CARLSON, A.D., LISKIEN, H.O., STEWART, L., Eds) (Proc. Conf. Gaithersburg, MD, 1977), NBS Special Publication 493, National Bureau of Standards, Gaithersburg, MD (1977) 30; see also HALE, G.M., "R-matrix analysis of the light element standards", Nuclear Cross Sections and Technology (Proc. Conf. Washington, DC, 1975) (SCHRACK, R.A., BOWMAN, C.D., Eds), NBS Special Publication 425, National Bureau of Standards, Gaithersburg, MD (1975) 302-308; see also HALE, G.M., "Use of R-matrix methods for light element evaluations", Nuclear Data Evaluation Methods and Procedures (Proc. Conf. New York, 1980), Rep. BNL-NCS-51363, Vol. 2, Brookhaven Natl Lab., Upton, NY (1981) 509-531.

[1.15] POENITZ, W.P., "The simultaneous evaluation of interrelated cross-sections by generalized leastsquares and related data file requirements", Nuclear Standard Reference Data, IAEATECDOC-335, IAEA, Vienna (1985) 426-430.

[1.16] PEELLE, R.W., "Requirements on experiment reporting to meet evaluation needs", Fast Neutron Fission Cross Sections of ${ }^{233} \mathrm{U},{ }^{235} \mathrm{U},{ }^{238} \mathrm{U}$ and ${ }^{239} \mathrm{Pu}$ (Proc. Specialists Mtg Argonne, IL, 1976), Rep. ANL-76-90, Argonne Natl Lab., IL (1976) 421430.

[1.17] SOWERBY, M.G., AERE Harwell, personal communication, 1987.

[1.18] DUNFORD, C.L., Enclosure 3A, Summary of CSWEG Meeting, 8-10 May 1990, Brookhaven Natl Lab., Upton, NY (1990).

[1.19] KOCHEROV, N., McLAUGHLIN, P.K., International Reactor Dosimetry File (IRDF-90), Rep. IAEA-NDS-141, IAEA, Vienna (1990). 


\title{
2. EVALUATION METHODOLOGY AND CODES
}

\author{
V.G. Pronyaev, S.A. Badikov, A.D. Carlson, Chen Zhenpeng, E.V. Gai, G.M. Hale, F.-J. Hambsch, \\ H.M. Hofmann, T. Kawano, N.M. Larson, D.L. Smith, Soo-Youl Oh, S. Tagesen, H. Vonach
}

\subsection{EVALUATION METHODOLOGY}

There are various important reasons why the evaluation methodology adopted in the preparation of the previous cross-section standards was used as the basis for the present evaluation [2.1-2.3]:

(a) Reaction standards selected for the least squares fit procedures include optimal and complete sets of reactions coupled through ratio measurements [2.4].

(b) $\mathrm{R}$ matrix model fits of reaction standards for the light nuclides permit the use of additional experimental data for inverse reaction channels [2.2] and produce cross-section shapes justified by the physical model.

(c) Non-model fits of the cross-section standards for heavy nuclides [2.1] are also justified because there are no physical models that can predict the shape of the non-resonance fission and capture cross-sections with the certainties needed for standards.

(d) Different methods were proposed and studied to combine the fits of the reactions for the light and heavy nuclides [2.3].

(e) Data for the reactions used as standards and other reactions coupled strongly with them through ratio measurements (and used in the least squares fits) were transformed by Poenitz to the form in which they were measured (i.e. absolute, shape, absolute ratio and shape of ratio data [2.4]). All data available up to 1997 have been compiled within the GMA database [2.4]; in some cases information on components of the data uncertainties (for the preparation of the covariance matrices for the experimental data) was not available within the original publications or the EXFOR database, and had to be obtained directly from the authors.

\subsection{UPDATES IN THE METHODOLOGY}

The following evaluation methodology, codes and database were used after the introduction of some changes and updates: (a) The TEST1 data set was used to assess the different least square codes [2.5]. The results obtained with the GMA code were compared with the results obtained with the SOK and GLUCS Bayesian codes. As a consequence of an error in the GMA code, only the final data of each type in the input stream were considered in the adjustment of the vector of the evaluated data. Thus the evaluated central values obtained by means of GMA had incorrectly been dependent on the order in which the input data were assembled and used. After correcting the code, the results obtained with GMA and GLUCS agreed on average to within $0.3 \%$. Random differences between two results can be explained in terms of numerical inaccuracies in the solution of the different equations. The covariance matrices of the evaluated data obtained from GMA and GLUCS calculations agree very well.

(b) Data obtained with GMA and GLUCS for TEST1 are about 10\% lower than the equivalent values obtained by means of SOK. This bias is explained by the effect of Peelle's pertinent puzzle (PPP) in the fit of the TEST1 data. SOK uses the 'experimental' TEST1 data and covariance matrices transformed in logarithmic space, which leads to a strong reduction of PPP. The Chiba-Smith approach was implemented in the GMA code to minimize PPP [2.6] and is based on deriving the absolute uncertainties of the experimental data on the basis of their percentage uncertainties relative to the evaluated data. Since the final evaluation is not known, an iterative procedure was used with an initial value taken at the first step of the evaluation. Detailed discussions of PPP with respect to the standards database can be found in Section 6 .

(c) Results of R matrix fits of simple TEST2b [2.7] data sets for ${ }^{6} \mathrm{Li}(\mathrm{n}, \mathrm{n}),{ }^{6} \mathrm{Li}(\mathrm{n}, \mathrm{t})$ and total cross-section reactions with EDA, RAC and SAMMY codes have been compared. Both the EDA and RAC codes minimize different $\chi^{2}$ functions: RAC works with full covariance matrices of the experimental data, while EDA utilizes only the independent contributions of 
the systematic uncertainty in the normalizations and the statistical uncertainties of the measurements. SAMMY contains options that allow the use of both types of minimizing function. A detailed description of the $\mathrm{R}$ matrix codes and data fitting procedures is given in Section 5. Tests have shown rather good consistency between the different $\mathrm{R}$ matrix model fits. A non-model GMA fit of the TEST2b data gives evaluated values that are close on average to those obtained in the EDA, RAC and SAMMY fits, but produces very different covariance matrices for the uncertainties.

(d) There are ambiguities in the evaluated crosssections of the light nuclide reactions when different $\mathrm{R}$ matrix codes are used. This conflict is mainly caused by different presentations of the uncertainties in the experimental data - a simple average of the cross-sections obtained in the EDA and RAC fits was used in the final evaluations. An additional component of the uncertainty equal to half the difference between the EDA and RAC evaluated values was added to the components of the total uncertainty, and the correlation matrix obtained from the RAC analysis was used in the combined fit (see Section 7). Various attempts were made to understand the origins of the differences and to reduce them.

(e) The GMA code was used to combine the R matrix results with data from the GMA database for the heavy nuclides and ratios between light and heavy nuclide crosssections. Two non-redundant and correlated sets of neutron induced cross-sections $\left({ }^{6} \mathrm{Li}(\mathrm{n}, \mathrm{n}),{ }^{6} \mathrm{Li}(\mathrm{n}, \mathrm{t})\right.$ and ${ }^{10} \mathrm{~B}(\mathrm{n}, \mathrm{n}),{ }^{10} \mathrm{~B}\left(\mathrm{n}, \mathrm{\alpha}_{0}\right)$, $\left.{ }^{10} \mathrm{~B}\left(\mathrm{n}, \alpha_{1}\right)\right)$ evaluated by means of the $\mathrm{R}$ matrix approach were used as input to the GMA code along with all other data from the GMA database. Double counting was avoided by excluding from the GMA databases those data used in the $\mathrm{R}$ matrix fit. Since the number of reconstructed cross-section points was higher than the evaluated $\mathrm{R}$ matrix parameters, the covariance matrix of uncertainty of the cross-sections was semipositive definite. However, this situation did not cause problems in the combined data fit, and the covariance matrix of evaluated combined data was positive definite. The large correlations between neighbouring cross- section points in the combined fit by the $\mathrm{R}$ matrix model cannot destroy the smoothness of the model evaluations of these crosssections.

(f) Data compiled in the GMA database were somewhat discrepant, with a $\chi^{2}$ per degree of freedom value close to 4 for the GMA nonmodel least squares fit, enforcing the PPP effect and leading to underestimated uncertainties for the evaluated values. The analysis included a search for outlying data and the assignment of additional uncertainties. However, outlying experimental data should be determined on a relative basis, and not be known a priori - an appropriate prior and iterative procedure should be used, with a new posterior variation at each step of the additional uncertainty assignment to the outlying data. The previous standards were used a priori in the present evaluations. Outliers were defined for isolated points deviating by more than $2 \sigma$, and for a few consecutive points deviating by more than $1 \sigma$ from the posterior evaluation. This additional uncertainty component, with correlations assigned expertly to outlying experimental data, brings the $\chi^{2}$ value per degree of freedom in the final fit to a value close to 1 (Section 7).

(g) The GMA database was substantially increased in size by the addition of results from new experiments. Neutron induced fission reaction cross-sections $\left({ }^{235} \mathrm{U}(\mathrm{n}, \mathrm{f})\right.$, ${ }^{238} \mathrm{U}(\mathrm{n}, \mathrm{f}),{ }^{239} \mathrm{Pu}(\mathrm{n}, \mathrm{f})$ and their ratios) were extended to a neutron energy of $200 \mathrm{MeV}$ with the inclusion of all available intermediate energy experimental data in the GMA database. The evaluation of the ${ }^{235} \mathrm{U}$ fission standard over the intermediate neutron energy of $20<E_{\mathrm{n}}<200 \mathrm{MeV}$ was derived through a common fit with the low energy data for $E_{\mathrm{n}}<20 \mathrm{MeV}$ (Section 3).

\subsection{EVALUATION CODES}

The following codes were used in the evaluation of the cross-section standards:

(a) GMA is a non-parametric non-model least squares code that implements an error propagation law based on the use of full covariance matrices for the experimental data $[2.1,2.4]$. Fitted data (reaction cross-sections 
and their ratios) are reduced to the nodes of the energy grid. Covariance matrices of the experimental data are obtained that account for the contribution of statistical (short energy range (SERC)), systematic (long energy range (LERC)) and medium energy range (MERC) correlation components. Different types of data can be handled together: absolute, shape, absolute ratio and ratio shape, as well as thermal constants and fission spectrum averaged data.

(b) EDA is an R matrix least squares fitting code that contains the option of either relativistic or non-relativistic kinematics with minimization of the $\chi^{2}$ function [2.2], which utilizes the contributions from statistical and normalization (systematic) components of the uncertainties. However, EDA is unable to account for the MERC uncertainty component in the experimental data. All channels can be modelled that lead to the formation of the same compound system of the standard reaction. Absolute and shape type data characterize the different physical observables such as integral and differential cross-sections and polarizations, and can be used in the least squares fit.

(c) RAC is a non-relativistic R matrix least squares fitting code based on the implementation of the error propagation law [2.8]. Differential and integral cross-sections, crosssection ratios and polarizations can be used as physical observables in the fit. The code works with the covariance matrices of the experimental uncertainties, which can include any correlation components. All channels leading to the same compound system as the evaluated standard reaction can be accommodated in the least squares fit.

(d) SAMMY is a Bayesian non-relativistic $\mathrm{R}$ matrix least squares fitting code [2.9] based on the implementation of the error propagation law in different forms. Experimental data for the standard and all other neutron induced reactions with the same target nuclei (including differential and integral crosssections and polarizations) can be used as physical observables in the fit. Covariance matrices of the experimental uncertainties can be prepared by an external code or obtained from the fit of the raw (primarily measured) data by means of known data reduction relationships and uncertainties. (e) PADE2 is least squares fitting code based on the error propagation law and Pade analytical expansion as the mathematical model for the evaluated data [2.10]. Covariance matrices for the experimental uncertainties can be prepared through either an expert evaluation of the correlation coefficients between the uncertainties of the data in different energy ranges or by means of any external code. The unrecognized systematic uncertainty can be assigned to the experimental data when considered to be representing a statistical ensemble of the measurements.

(f) SOK is a Bayesian least squares fitting code that includes the implementation of the full error propagation law [2.11]. Transformation of the experimental data in the space of the logarithm variables is used to reduce the PPP within the fit.

\subsection{TEST1 INTERCOMPARISON OF CODES}

The TEST1 data set [2.5] was prepared in order to compare the fits obtained with different least squares codes. Five pseudo-experimental data sets for the ${ }^{6} \mathrm{Li}(\mathrm{n}, \mathrm{t})$ reaction in the energy range from 2.5 to $800 \mathrm{keV}$ were selected, as shown in Fig. 2.1. These data show a strong $1 / v$ energy dependence at low energies and the resonance at about $245 \mathrm{keV}$. All data were treated as absolute cross-sections. The covariance matrix of uncertainties for each data set arises from only two components: statistical (no cross-energy correlations) and systematic (100\% cross-energy correlations). Strong ambiguity had been expected in the search of the $\mathrm{R}$ matrix parameters for this single channel case, and therefore only the RAC R matrix code was used in the intercomparison. The data were rather discrepant, with a $\chi^{2}$ value of approximately 10 .

There are large differences in shape between the different data sets with long energy range uncertainty correlations, and therefore the results obtained with the standard non-model least squares fit are affected by PPP. As shown in Fig. 2.2, the data evaluated with the original GMA and GLUCS codes lay significantly below the bulk of all the experimental data - data in Fig. 2.2 are shown relative to the GMA fit obtained with the ChibaSmith option that minimizes PPP (see Section 6). As can be seen from Fig. 2.2, the model fits are also not free from PPP. 


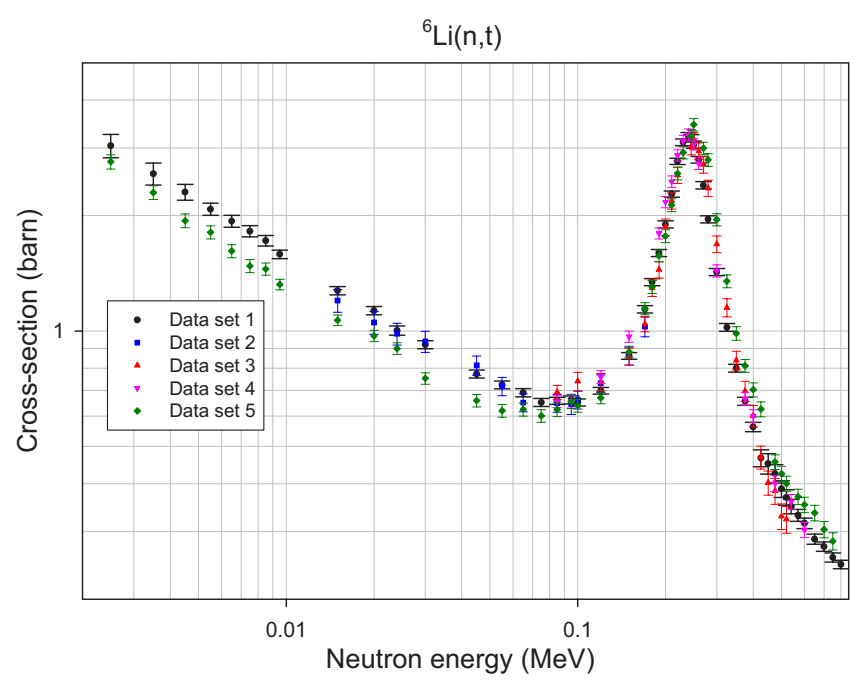

FIG. 2.1. TEST1 pseudo-experimental data sets chosen to test the least squares codes.

A comparison of the GMA and GLUCS (implementing the Bayesian approach) fits is shown in Fig. 2.3. Both codes were used without the option to minimize PPP. As indicated in Fig. 2.2, both sets of results are biased by about $10 \%$ due to the PPP effect. The uncertainties of the evaluated data vary between $1.4 \%$ and $3.4 \%$, although point to point differences between GLUCS and GMA are random at $0.2-0.3 \%$ on average. GLUCS and GMA solve different equations that can be reduced to each other [2.12]. One of the experimental data sets from
TEST1 (set 1) that covers all of the energy range was taken as a priori cross-section in GLUCS, and there were no actual differences in the data used as input for both codes. All calculations were undertaken with double accuracy on 64 bit computers. Thus the difference in the fits can be explained in terms of the numerical uncertainty of the solutions of different equations and probably arises as a consequence of operations with large matrices.

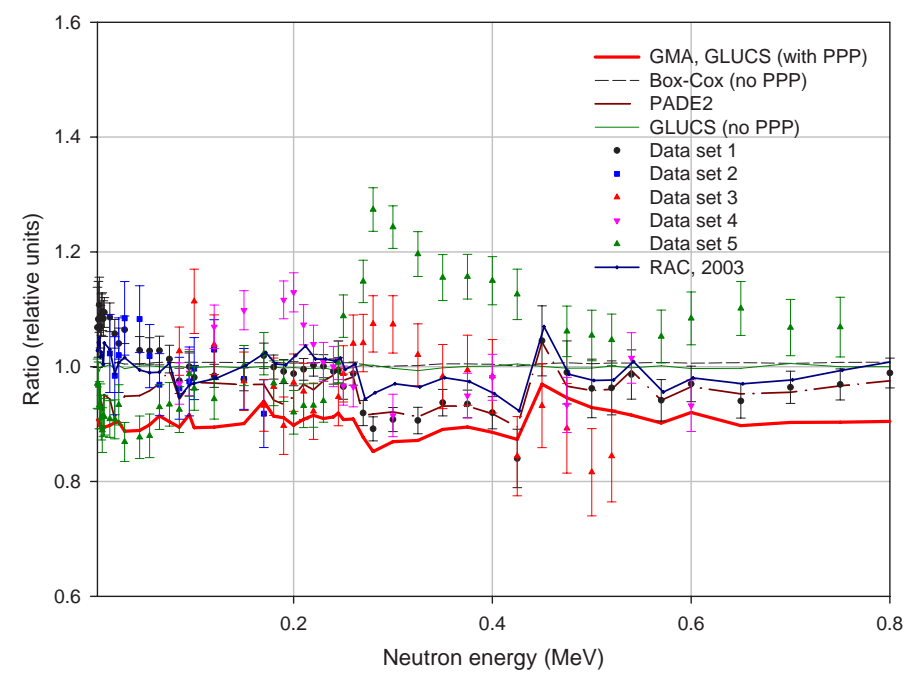

FIG. 2.2. Different fits obtained for TEST1 data depicted as ratios relative to the GMA fit, with Chiba-Smith minimization of $P P P$ - model fits are shown with the RAC R matrix code and PADE2 analytical expansion code, and results obtained for the non-model fitting codes GMA and GLUCS (with PPP) and GLUCS (no PPP); a least squares fit is also shown based on a Box-Cox transformation of TEST1 data (close to a logarithm transformation for these data). 


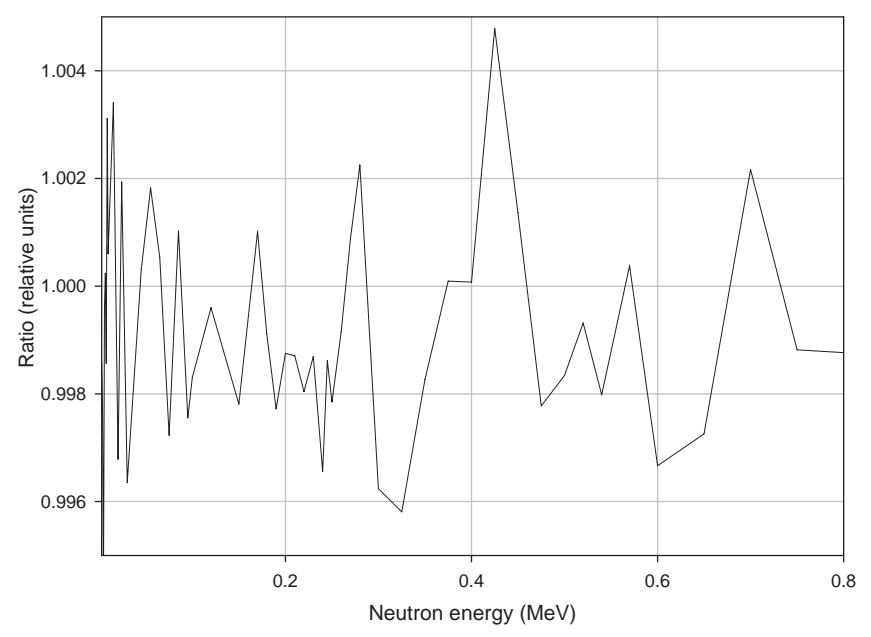

FIG. 2.3. Ratio of GMA fit to Bayesian GLUCS fit of the TEST1 data.

\subsection{TEST2b INTERCOMPARISON OF CODES}

Data for TEST2b [2.7] included four pseudoexperimental data sets for the ${ }^{6} \mathrm{Li}(\mathrm{n}, \mathrm{t})$ reaction cross-section taken from TEST1 (data sets 1-4, see Fig. 2.1), a highly accurate thermal cross-section for the ${ }^{6} \mathrm{Li}(\mathrm{n}, \mathrm{t})$ reaction, one data set for the ${ }^{6} \mathrm{Li}(\mathrm{n}, \mathrm{n})$ integral cross-section and two data sets of the total cross-sections with large numbers of data points. These data covered the energy range from $0.0253 \mathrm{eV}$ to $1 \mathrm{MeV}$. The main purpose of TEST2b was to compare $\mathrm{R}$ matrix model fits in realistic conditions. Inclusion of the thermal, elastic and total cross-sections reduced the ambiguity in the $\mathrm{R}$ matrix model fits substantially. Three $\mathrm{R}$ matrix codes (EDA, RAC and SAMMY) were included in this intercomparison, along with the non-model
GMA code. However, the experimental data for GMA were reduced to the energy nodes, and therefore comparison of the GMA fit with the R matrix fits of the original (not reduced) data can be only qualitative. The SAMMY code can adopt the EDA $\chi^{2}$ expression (using only independent statistical and normalization contributions version SAMMY3.8) or the RAC expression with full covariance matrices for the uncertainties of the experimental data (version SAMMY4).

Results of the fits of the ${ }^{6} \mathrm{Li}(\mathrm{n}, \mathrm{t})$ reaction cross-section and their uncertainties are shown in Figs 2.4 and 2.5. Differences between the various $R$ matrix model fits are generally less than the uncertainties of the evaluated data. As discussed in Section 9, the evaluated covariance matrices for the uncertainties obtained in the model and non-model
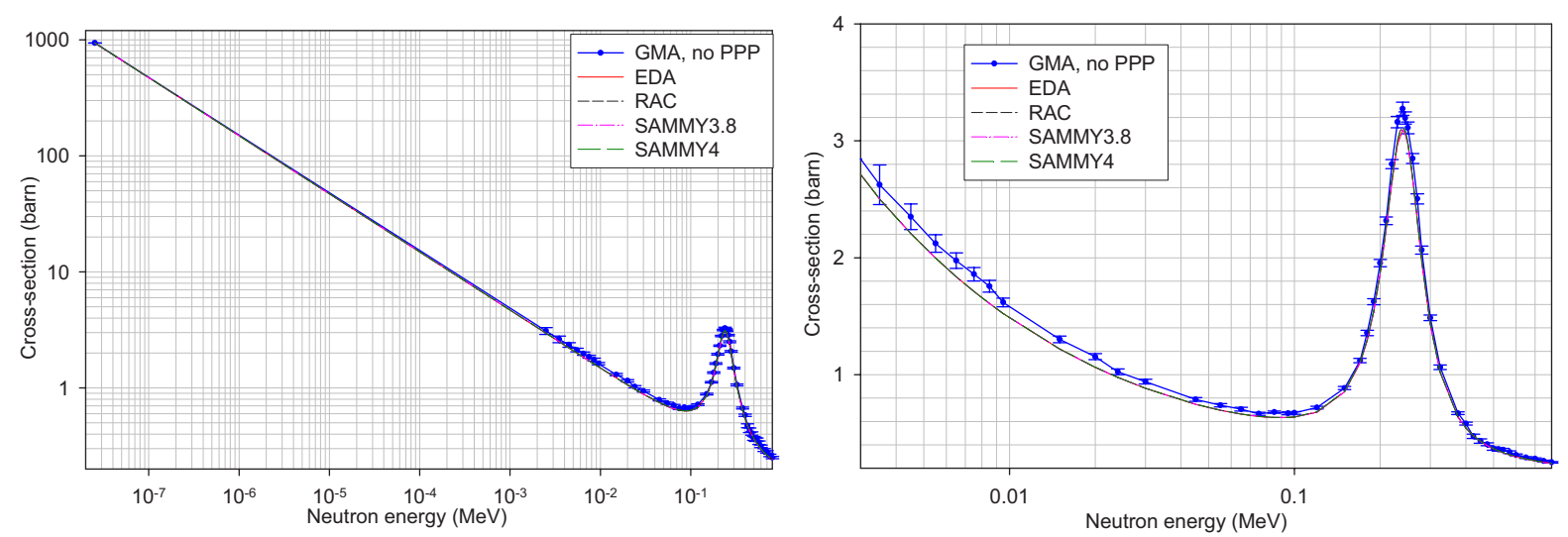

FIG. 2.4. Comparison of the fits of TEST2b data with the least squares non-model GMA code and R matrix model EDA, RAC, SAMMY3.8 ( $\chi^{2}$ expression as in EDA) and SAMMY4 ( $\chi^{2}$ expression as in RAC) codes: left hand side figure - for all of the energy region in which data are fitted; right hand side figure - over the energy range from 30 to $800 \mathrm{keV}$. 

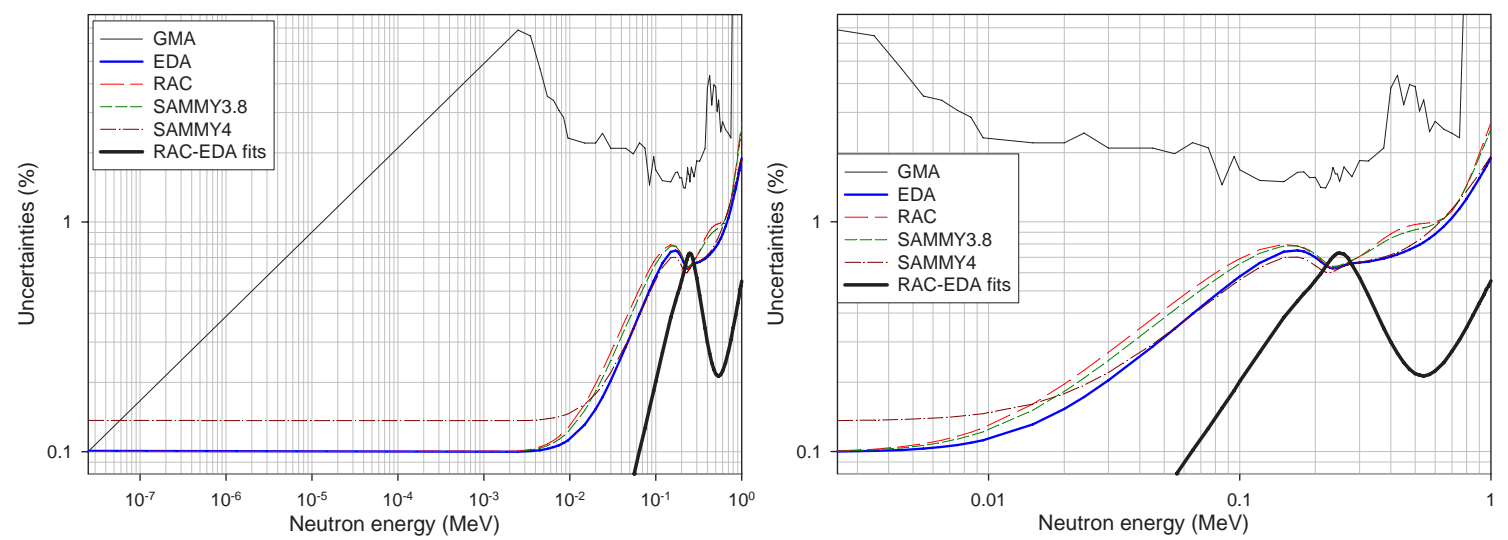

FIG. 2.5. Comparison of the uncertainties of data evaluated with least squares non-model GMA code and $R$ matrix model EDA, RAC, SAMMY3.8 ( $\chi^{2}$ expression as in EDA) and SAMMY4 ( $\chi^{2}$ expression as in RAC) codes: left hand side figure - for all of the energy region in which data are fitted; right hand side figure - over the energy range from 30 to $800 \mathrm{keV}$ (absolute percentage differences between RAC and EDA fits are also shown).

fits differ significantly, whereas the variances and covariances obtained with the RAC, EDA and SAMMY R matrix model codes are very similar. Furthermore, the sum of all elements of the covariance matrix of uncertainties of the evaluated data can be considered as one of the global measures of uncertainty [2.13], and is approximately the same for the different fits. The evaluated uncertainties over the $1 / v$ region are pre-determined in the R matrix fit by the low uncertainty of the experimental value at the thermal point that propagates to higher energies (Fig. 2.5). This behaviour is only possible if the model is adequate for the data (e.g. there are no other resonances that might distort $1 / v$ cross-sections in this energy range).

Analysis of the same TEST2b data set by different $\mathrm{R}$ matrix codes resulted in the generation of very similar evaluated parameters and their uncertainties as well as reconstructed evaluated cross-sections and their covariance matrices of uncertainties. These findings do not depend strongly on the form of the $\chi^{2}$ expression used in a least squares fit; good agreement was achieved by means of a simple sum with separate statistical and systematic (normalization) contributions (as in EDA) or by including full covariance matrices of the uncertainties of the experimental data according to the error propagation law (as in RAC). Thus the sum of all elements of the covariance matrix of uncertainties for the cross-sections evaluated in TEST2b with EDA, RAC and SAMMY agreed to within $1 \%$.

When fitting TEST2b data, the bias due to the presence of PPP is difficult to observe. The form of the $\chi^{2}$ expression in EDA includes only systematic uncertainty of a multiplicative type that minimizes PPP, as shown for the two-point case [2.14]. EDA agrees well with SAMMY3.8, while RAC agrees with SAMMY4 if the anomaly in the SAMMY4 fit at the thermal energy is excluded. Differences between EDA (SAMMY3.8) and RAC (SAMMY4) can be attributed to the PPP effect: a 1\% difference for the ${ }^{6} \mathrm{Li}(\mathrm{n}, \mathrm{t})$ reaction (see the difference between RAC and EDA in Fig. 2.5) is still within the limits of the uncertainties of the evaluated cross-sections. At the same time, the differences between EDASAMMY3.8 and between RAC-SAMMY4 can be explained in terms of the numerical accuracies of the solutions $(0.2-0.3 \%)$, as in TEST1. The component of the uncertainties related to the numerical accuracy of the fits should be added to the final evaluations.

\subsection{TEST WITH FULL GMA DATABASE}

A comparison was made of the results of the least squares fits of all experimental data from the standards database obtained with the GMA and SOK codes. Both codes used the same covariance matrices of uncertainties for the experimental data, while data for the ${ }^{6} \mathrm{Li}(\mathrm{n}, \mathrm{t})$ reaction were replaced by the results of the RAC R matrix fit for this reaction. Two different options for the minimization of PPP were used in the codes: the Chiba-Smith option in GMA and logarithm transformation of the data in SOK. The differences in the fits for the two standard reactions are shown in Fig. 2.6, expressed as ratios to a priori data (ENDF/ $\mathrm{B}$-VI standards values) and differences in the uncertainties of the evaluated data (Fig. 2.7). The uncer- 


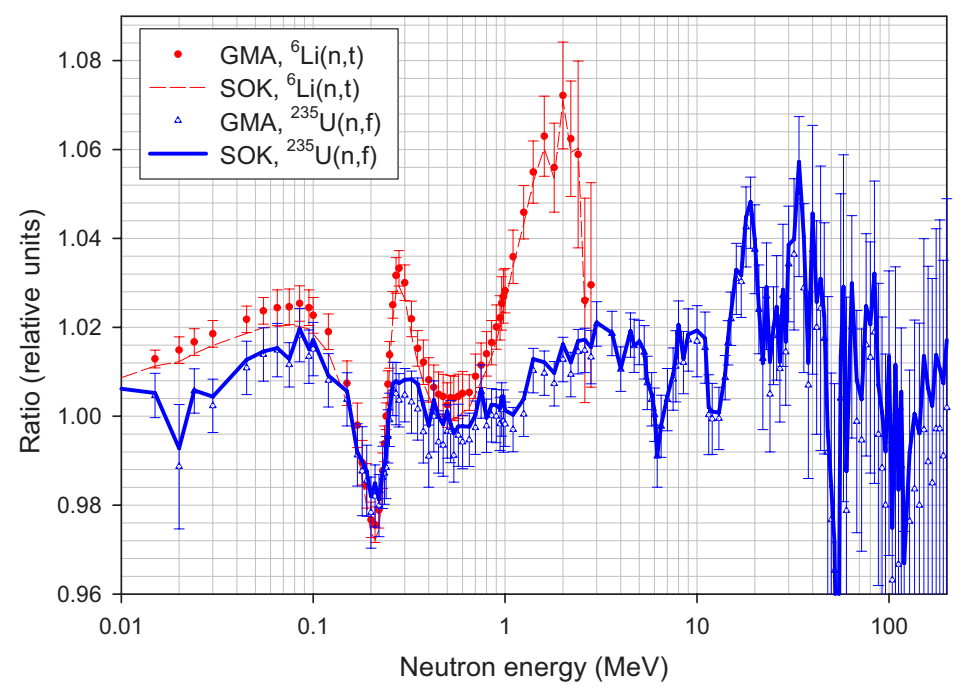

FIG. 2.6. Ratio of the ${ }^{6} \mathrm{Li}(n, t)$ and ${ }^{235} U(n, f)$ reaction cross-sections evaluated with the GMA and SOK codes after adopting a priori values (results of previous standards evaluation).

tainties in the ratios shown in Fig. 2.6 are the uncertainties of the data evaluated with GMA. Agreement between the two fits is generally good. Since the RAC R matrix evaluation that has very strong data correlations in the $1 / v$ region and near the resonance at about $0.245 \mathrm{MeV}$ was used as the pseudo-experimental data set for the ${ }^{6} \mathrm{Li}(\mathrm{n}, \mathrm{t})$ reaction, the PPP effect can be assumed to be large for this reaction. However, the different options used in GMA and SOK for PPP minimization lead only to slightly different results, and these differences should be considered when the final uncertainties are assigned to the evaluated data.

The following conclusions can be made on the basis of the tests and code comparisons:

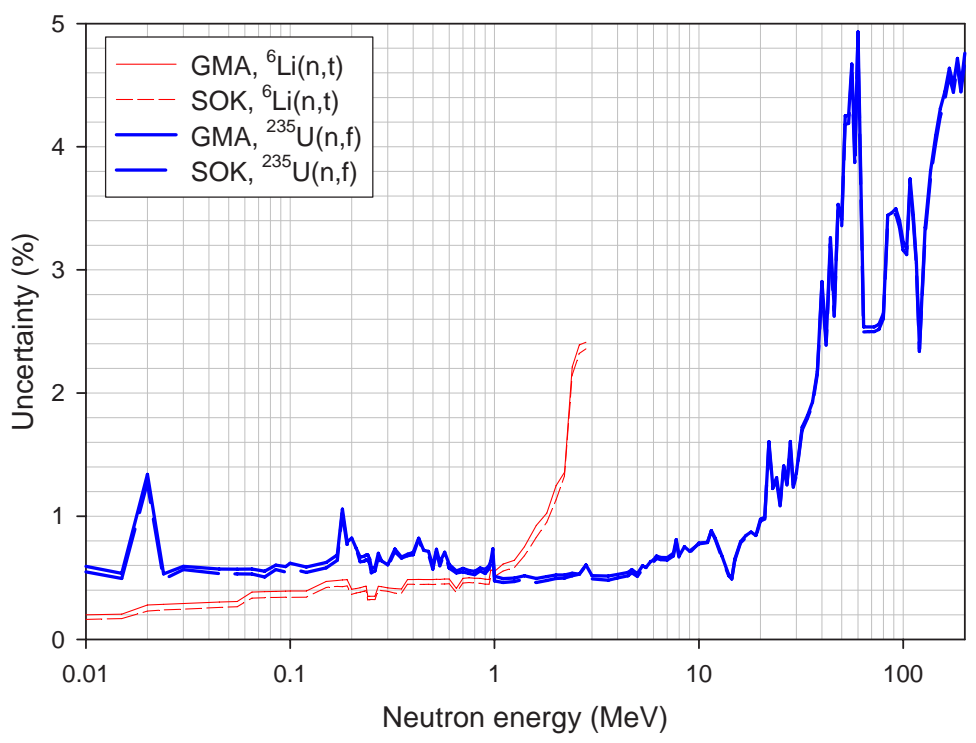

FIG. 2.7. Percentage uncertainties for the evaluated ${ }^{6} \mathrm{Li}(n, t)$ and ${ }^{235} U(n, f)$ reaction cross-sections obtained with $G M A$ and $S O K$ fits of all data available in the GMA database. 
(a) All of the codes give very similar results or distinctive differences that can be readily explained (e.g. model versus non-model fits);

(b) The codes are free from obvious bugs (at least for the cases studied);

(c) The results of the $\mathrm{R}$ matrix fits are somewhat different and arise from a combination of the different forms of minimized $\chi^{2}$ expression, the large number of parameters and the various search procedures;

(d) Evaluated data can exhibit bias due to the PPP effect in both the non-model and the $\mathrm{R}$ matrix model fits;

(e) The average uncertainty of the evaluated values due to the different procedures used in the model fits is about $0.2-0.3 \%$, and should be introduced into the final evaluation.

\section{REFERENCES TO SECTION 2}

[2.1] POENITZ, W.P., "Data interpretation, objective evaluation procedures and mathematical techniques for the evaluation of energy-dependent ratio shape and cross section data", Nuclear Data Evaluation Methods and Procedures (Proc. Workshop, Upton, NY, 1980), Rep. BNL-NCS51363, Vol. 1, Brookhaven Natl Lab., Upton, NY (1981) 249-285.

[2.2] HALE, G.M., "Use of R-matrix methods for light element evaluations", Proc. Conf. Nuclear Data Evaluation Methods and Procedures (Proc. Workshop, Upton, NY, 1980), Rep. BNL-NCS51363, Vol. 2, Brookhaven Natl Lab., Upton, NY (1981) 509-531.

[2.3] PEELlE, R.W., Memorandum to the Cross Section Evaluation Group (1986), ENDF/B-VI Neutron Cross Section Measurement Standards, Appendix C, Rep. NISTIR 5177, National Institute of Standards and Technology, Gaithersburg, MD (1993).

[2.4] POENITZ, W.P., AUMEIER, S.E., The Simultaneous Evaluation of the Standards and Other Cross Sections of Importance for Technology, Rep. ANL/NDM-139, Argonne Natl Lab., IL (1997).

[2.5] PRONYAEV, V.G., "Test and intercomparison of the data fitting with general least squares code GMA versus Bayesian code GLUCS", Summary
Report of the First Research Coordination Meeting on Improvement of the Standards Cross Sections for Light Elements, Rep. INDC(NDS)438, IAEA, Vienna (2003) 159-171.

[2.6] CHIBA, S., SMITH, D.L., A Suggested Procedure for Resolving an Anomaly in Least-squares Data Analysis Known as 'Peelle's Pertinent Puzzle' and the General Implications for Nuclear Data Evaluation, Rep. ANL/NDM-121, Argonne Natl Lab., IL (1991).

[2.7] HALE, G.M., Test2 for Intercomparison of RMatrix Model Codes, unpublished data, 2003.

[2.8] CHEN, Z.P., SUN, Y.Y., ZHANG, R., LIU, T.J., Covariance propagation in R-matrix model fitting, High Energy Phys. Nucl. Phys. 28 (2004) 42-47.

[2.9] LARSON, N.M., Updated Users' Guide for SAMMY: Multilevel R-matrix Fits to Neutron Data Using Bayes' Equation, Rep. ORNL/TM9179/R5, Oak Ridge Natl Lab., TN (2000).

[2.10] BADIKOV, S.A., GAI, E.V., GUSEYNOV, M.A., RABOTNOV, N.S., "Nuclear data processing, analysis, transformation and storage with PADEapproximants", Nuclear Data for Science and Technology (Proc. Int. Conf. Jülich, 1991) (QAIM, S.M., Ed.), Springer-Verlag, Berlin (1992) 182-187.

[2.11] KAWANO, T., et al., Evaluation of Fission Cross Sections and Covariances for ${ }^{233} \mathrm{U},{ }^{235} \mathrm{U},{ }^{238} \mathrm{U},{ }^{239} \mathrm{Pu}$, ${ }^{240} \mathrm{Pu}$ and ${ }^{241} \mathrm{Pu}$, JAERI Research Rep. 2000-004, Japan Atomic Energy Research Institute, Tokaimura (2000).

[2.12] LARSON, N.M., "Proof that Bayes and least squares give exactly equivalent results for arbitrary numbers of data sets (assuming linearity)", Summary Report of the First Research Coordination Meeting on Improvement of the Standards Cross Sections for Light Elements, Rep. INDC(NDS)-438, IAEA, Vienna (2003) 91-95.

[2.13] PRONYAEV, V.G., BYTCHKOVA, A.V., "Subjective judgment on measure of data uncertainty", Summary Report of the Second Research Coordination Meeting on Improvement of the Standards Cross Sections for Light Elements, Rep. INDC(NDS)-453, IAEA, Vienna (2004) 327-331.

[2.14] HANSON, K.M., KAWANO, T., TALOU, P., "Probabilistic interpretation of Peelle's pertinent puzzle and its resolution", Nuclear Data for Science and Technology (Proc. Int. Conf. Santa Fe, NM, 2004), American Institute of Physics Conf. Proc. 769, Part 1 (HAIGHT, R.C., CHADWICK, M.B., KAWANO, T., TALOU, P., Eds), American Institute of Physics, NY (2005) 304-307. 


\title{
3. THE EXPERIMENTAL DATABASE
}

\author{
A.D. Carlson, F.-J. Hambsch, D.L. Smith, H. Vonach
}

The ENDF/B-VI evaluation completed in 1987 used a global approach that combined a simultaneous evaluation with $\mathrm{R}$ matrix fits in which improved statistical procedures were adopted [3.1]. In addition to this global approach, independent $\mathrm{R}$ matrix fits were made for the $\mathrm{H}(\mathrm{n}, \mathrm{n}),{ }^{3} \mathrm{He}(\mathrm{n}, \mathrm{p})$ and $\mathrm{C}(\mathrm{n}, \mathrm{n})$ cross-sections. The database for the ENDF/ $\mathrm{B}-\mathrm{VI}$ evaluation of the neutron cross-section standards was the most comprehensive database ever used in any evaluation (more than 10000 data points). The experiments in this simultaneous evaluation database are detailed in Table 3.1, while the experiments used in the $\mathrm{R}$ matrix database are listed in Table 3.2. The emphasis of this section is on experiments undertaken after the ENDF/B-VI evaluation was completed, with comparisons also being made for a small number of data sets. Extensive graphical comparisons of measurements and evaluations, including the international evaluation, are given in Section 7 of this report.

The first comprehensive examination of the standards database after the ENDF/B-VI evaluation was carried out by Poenitz and Carlson in 1992 [3.2]. They focused on possible problems and discrepancies as a consequence of new data available since the ENDF/B-VI standards evaluation. Subsequent examinations of the standards database have been made [3.3-3.5]. These reviews and additional experimental work undertaken afterwards will be summarized from a retrospective point of view in this section. Due to the large amount of data, emphasis will be placed on the cross-sections for which the most experimental activity has occurred.

\section{1. $\mathrm{H}(\mathrm{n}, \mathrm{p}),{ }^{3} \mathrm{He}(\mathrm{n}, \mathrm{p})$ AND $\mathrm{C}(\mathrm{n}, \mathrm{n})$ CROSS-SECTIONS}

The hydrogen cross-section for ENDF/B-VI was obtained from a charge independent $R$ matrix analysis of $\mathrm{n}-\mathrm{p}$ and $\mathrm{p}-\mathrm{p}$ experimental data below 30 $\mathrm{MeV}$ by Dodder and Hale [3.6]. A hydrogen total neutron cross-section measurement by Priesmeyer et al. [3.7] at $\sim 24 \mathrm{keV}$ is in excellent agreement with the ENDF/B-VI evaluation $(\sim 0.24 \%$ lower than ENDF/B-VI, but with an uncertainty of $0.23 \%$ ). The largest difference between ENDF/B-VI and
ENDF/B-V up to $20 \mathrm{MeV}$ is only $\sim 0.5 \%$. However, the centre of mass system (CMS) scattering crosssections at $180^{\circ}$ differ by almost $2 \%$ near $11 \mathrm{MeV}$. This is significant because the $180^{\circ} \mathrm{CMS}$ neutron angle corresponds to a $0^{\circ}$ laboratory angle for the recoil protons, which is frequently used in proton recoil detectors for neutron fluence measurements. A measurement by Ryves and Kolkowski [3.8] resulted in a $180^{\circ}$ cross-section at $14.5 \mathrm{MeV}$, which is between the ENDF/B-V and ENDF/B-VI evaluations. A $\sigma\left(180^{\circ}\right) / \sigma\left(90^{\circ}\right)$ ratio of $1.053 \pm 0.015$ was also measured in this experiment and is consistent with ENDF/B-V, but not with ENDF/B-VI, for which the value is $1.093 \pm 0.010$.

The rather large difference between the ENDF/B-V and ENDF/B-VI evaluations of the angular distribution has caused considerable experimental activity. A measurement of the hydrogen scattering cross-section was made at a neutron energy of $14.1 \mathrm{MeV}$ by Bürkle and Mertens [3.9]. Data were obtained at six angles between $89.7^{\circ}$ and $155.7^{\circ}$ in the CMS. As a consequence of the limited angular range, which does not extend to $180^{\circ}$, and the $2 \%$ uncertainties, the preferred evaluation is difficult to determine. Preliminary measurements of the angular distribution at $14 \mathrm{MeV}$ have been reported by Baba [3.10]. These data include angles near $180^{\circ}$ in the CMS, and are in good agreement with the ENDF/B-V evaluation.

Measurements of the shape of the $\mathrm{H}(\mathrm{n}, \mathrm{n})$ angular distribution at a neutron energy of $10 \mathrm{MeV}$ were recently completed [3.11]. The data have uncertainties from $0.8 \%$ to $1.7 \%$ for the angular range from $180^{\circ}$ to $60^{\circ}$ in the CMS. The results of this work are shown in Fig. 3.1, and are in better agreement with the ENDF/B-V evaluation and the phase shift analysis of Arndt et al. [3.12] than the ENDF/B-VI evaluation. New measurements are being made by this group at $\sim 15 \mathrm{MeV}$ to improve the database at this important neutron energy (Ohio University, National Institute of Standards and Technology (NIST), Los Alamos National Laboratory (LANL) collaboration).

Some measurements at about $14 \mathrm{MeV}$ with small reported uncertainties have led to the pronounced backward peaking of the cross-sections in the ENDF/B-VI evaluation. An investigation of 


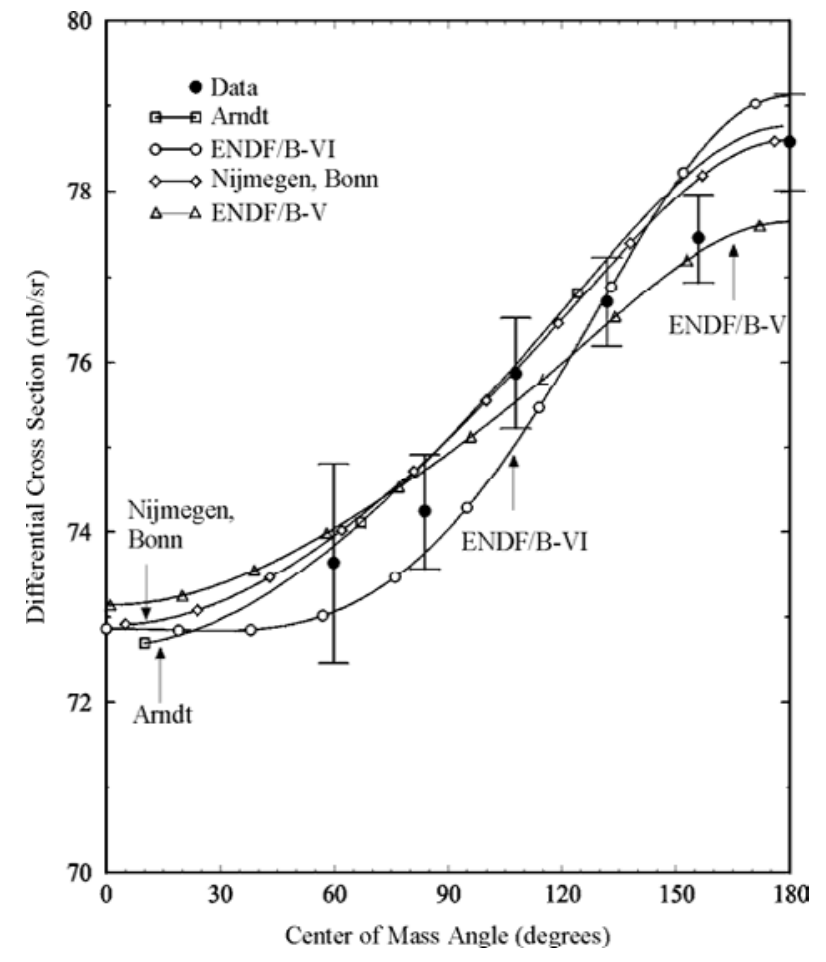

FIG. 3.1. Measurements of the $H(n, n)$ angular distribution at $10 \mathrm{MeV}$ neutron energy [3.11] compared with ArndtSM94 [3.12], Nijmegen, CD-Bonn, ENDF/B-V and ENDF/B-VI results.

the measurements near $14 \mathrm{MeV}$ that had a large impact on the ENDF/B-VI standards evaluation has revealed problems with some angular distribution data [3.11]. Corrections and expanded uncertainties have been suggested for these data.

Measurements of the coherent scattering length have been made for hydrogen [3.13]. The new hydrogen evaluation for the international cross-section standards by Hale included the new experimental angular distribution data, the corrected data referred to above, some additional total cross-section measurements and polarization data. This new hydrogen evaluation is in good agreement with the ENDF/B-V hydrogen evaluation and the new measurements.

Recent measurements by the Uppsala group [3.14] of the differential $\mathrm{H}(\mathrm{n}, \mathrm{n})$ cross-section at 90 and $162 \mathrm{MeV}$ disagree with the evaluated shape given by the Arndt VL40 phase shift solution [3.12]. The Arndt evaluation was accepted by the NEANDC/INDC as a primary standard for crosssection measurements in the $20-350 \mathrm{MeV}$ range. The Uppsala data have a steeper angular shape at backangles by as much as $10 \%$ compared with the VL40 results. A similar disagreement was observed with recent data from the Paul Scherrer Institute
[3.15]. Using a new neutron tagging facility at Indiana University, absolute measurements at 190 $\mathrm{MeV}$ were made of the hydrogen scattering crosssection with an accuracy of $\sim 1 \%$ [3.16]. This experiment yielded absolute cross-section data, and made a significant contribution with respect to both the shape and normalization of the hydrogen scattering cross-section, thereby providing important information to assist in our understanding of the backangle problem. The results of this experiment are shown in Fig. 3.2 together with the data of the Uppsala group, and clearly show a deviation compared with the Uppsala results at backward angles.

The ${ }^{3} \mathrm{He}(\mathrm{n}, \mathrm{p})$ cross-section evaluation for ENDF/B-VI led to a considerable improvement in the quality of the data since the last ENDF evaluation of this cross-section was performed as long ago as 1968 for ENDF/B-III. That evaluation was carried over intact into versions IV and $\mathrm{V}$ of ENDF/B. The ENDF/B-VI evaluation was an $\mathrm{R}$ matrix analysis undertaken by Hale using all possible two-body reactions in the ${ }^{4} \mathrm{He}$ system [3.18]. Measurements have been made of this crosssection by Borzakov et al. from 0.26 to $142 \mathrm{keV}$ neutron energy relative to the ${ }^{6} \mathrm{Li}(\mathrm{n}, \mathrm{t})$ standard crosssection [3.19]. These measurements are in excellent agreement with the ENDF/B-VI evaluation in the higher energy portion of their work, although they disagree at their lowest energies.

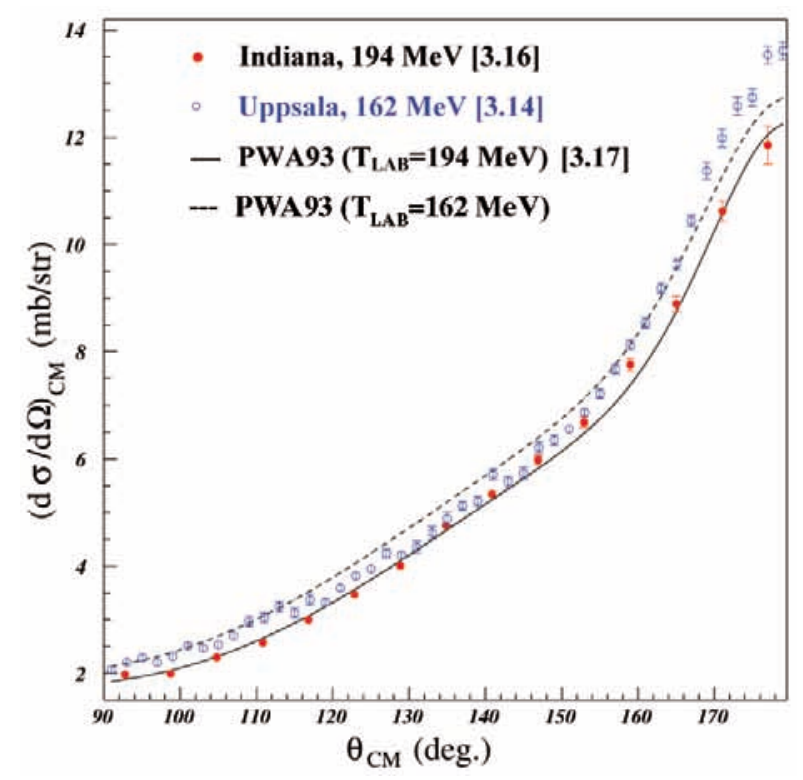

FIG. 3.2. Absolute np scattering differential cross-sections by Vigdor (statistical errors only) [3.16] and the Uppsala group [3.14] compared in each case with partial wave analysis calculations (PWA93) [3.17]. 
Precise measurements of the ${ }^{3} \mathrm{He}$ total crosssection have been made by Keith et al. [3.20] for neutron energies from about 0.1 to $500 \mathrm{eV}$. These data disagree somewhat with the work of AlsNielsen and Dietrich [3.21], although with uncertainties of less than $1 \%$ they are the most precise measurements of this cross-section. The difference between the Keith et al. and the Als-Nielsen and Dietrich data is generally quite small, but they disagree within their very small uncertainties. The total cross-section data of Borzakov et al. have a reported uncertainty of about $1 \%$ [3.19], but are lower than the Keith et al. results by about $8 \%$ and disagree in their common energy region [3.20]. New measurements of the coherent scattering length for ${ }^{3} \mathrm{He}$ have also been carried out [3.22].

The natural carbon scattering cross-section is used as a scattering standard up to $2 \mathrm{MeV}$. The evaluation for ENDF/B-V was based on an $\mathrm{R}$ matrix analysis of ${ }^{12} \mathrm{C}$ by $\mathrm{Fu}$ [3.23], while the evaluation for ENDF/B-VI was modified in order to include two resonances of ${ }^{13} \mathrm{C}(1.1 \%$ abundance $)$ so that the recommended data would be appropriate for natural carbon. New measurements by Schmiedmayer and Moxon [3.24] in the energy region from $50 \mathrm{eV}$ to $100 \mathrm{keV}$ are in excellent agreement with the ENDF evaluation. Furthermore, a filtered beam measurement at $2 \mathrm{keV}$ by Kirilyuk et al. [3.25] is in very good agreement with the evaluation.

\section{2. ${ }^{10} \mathrm{~B}(\mathrm{n}, \alpha),{ }^{10} \mathrm{~B}\left(\mathrm{n}, \alpha_{1} \gamma\right)$ AND ${ }^{6} \operatorname{Li}(\mathrm{n}, \mathrm{t})$ CROSS-SECTIONS}

The ${ }^{10} \mathrm{~B}(\mathrm{n}, \alpha)$ and ${ }^{10} \mathrm{~B}\left(\mathrm{n}, \alpha_{1} \gamma\right)$ standards have received considerable attention as a result of the relatively poor database and the problems they caused in the ENDF/B-VI standards evaluation process. Work has been undertaken on the branching ratio, the ${ }^{10} \mathrm{~B}\left(\mathrm{n}, \alpha_{1} \gamma\right)$ cross-section, the total neutron cross-section and the differential cross-section for the ${ }^{10} \mathrm{~B}(\mathrm{n}, \alpha)^{7} \mathrm{Li}$ reaction. All of these data can be effectively utilized in defining the ${ }^{10} \mathrm{~B}(\mathrm{n}, \alpha)$ and ${ }^{10} \mathrm{~B}\left(\mathrm{n}, \alpha_{1} \gamma\right)$ cross-sections when used in an $\mathrm{R}$ matrix analysis.

Measurements of the branching ratio $\left({ }^{10} \mathrm{~B}\left(\mathrm{n}, \alpha_{0}\right)\right.$ cross-section $/{ }^{10} \mathrm{~B}\left(\mathrm{n}, \alpha_{1} \gamma\right)$ cross-section $)$ by Weston and Todd [3.26] are 10-30\% lower in the 100-600 keV energy region compared with the ratios calculated from the ENDF/B-VI crosssections. These data agree with ENDF/B-VI at the lowest and highest energies of the experiment. The ENDF/B-VI evaluation of the ${ }^{10} \mathrm{~B}\left(\mathrm{n}, \alpha_{0}\right)$ cross- section was strongly influenced by the inverse reaction cross-section measurement of Olson and Kavanagh [3.27].

An important new measurement of the ${ }^{10} \mathrm{~B}\left(\mathrm{n}, \alpha_{0}\right) /{ }^{10} \mathrm{~B}\left(\mathrm{n}, \alpha_{1}\right)$ branching ratio was performed on the GELINA linear accelerator at the Institute for Reference Materials and Measurements (IRMM) [3.28] and is compared with the RAC and ENDF/B-VI evaluations in Fig. 3.3. The measurement was made with a Frisch gridded ionization chamber (FGIC) from which differential cross-section data were obtained. The branching ratio was determined by integrating these spectra, and the differential cross-section data were also made available for the international evaluation of the standards.

This measurement confirms to a large extent the results from the ENDF/B-VI evaluation up to 1 $\mathrm{MeV}$, although slight differences exist (especially in the energy range from 10 to $200 \mathrm{keV}$, where the new branching ratio measurement is lower than ENDF/ B-VI). The experiment of Weston and Todd [3.26] would appear to have some systematic errors that resulted in much lower branching ratio values. Very preliminary branching ratio data have also been obtained at higher energies by Giorginis and Khriachkov at the IRMM van de Graaff facility [3.29].

Schrack et al. have made measurements at the ORELA facility of the shape of the ${ }^{10} \mathrm{~B}\left(\mathrm{n}, \alpha_{1} \gamma\right)$ crosssection from 0.3 to $4.0 \mathrm{MeV}$ neutron energy [3.30]. With the exception of the region near the resonance close to $500 \mathrm{keV}$, the agreement with ENDF/B-VI is very good up to $1 \mathrm{MeV}$, where the global evaluation

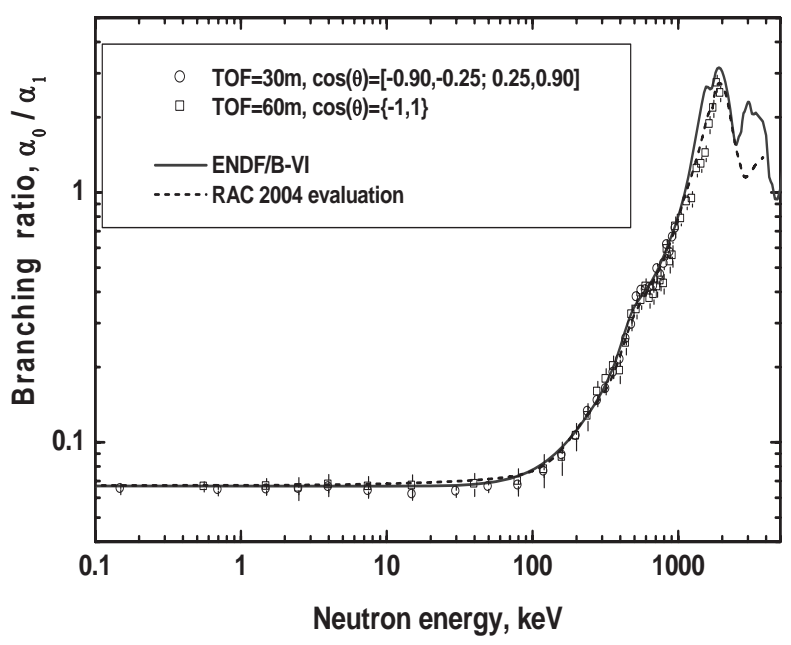

FIG. 3.3. New measurements of the ${ }^{10} B(n, \alpha)$ branching ratio in the neutron energy region up to $5 \mathrm{MeV}$ [3.28]. 
for the ${ }^{10} \mathrm{~B}$ cross-sections ended. Large differences occur compared with ENDF/B-VI above $1.5 \mathrm{MeV}$ (about $+15 \%$ at $\sim 2 \mathrm{MeV}$ and $-30 \%$ at $\sim 3 \mathrm{MeV}$ ). The agreement with the global evaluation up to $1 \mathrm{MeV}$ is important because the ENDF/B-VI values for this cross-section increased relative to ENDF/ B-V by $20 \%$ between $400 \mathrm{keV}$ and $1 \mathrm{MeV}$. A measurement was made on the WNR facility at LANL over the neutron energy range from 0.3 to $20 \mathrm{MeV}$ [3.31]. Generally the results agree with the ORELA experiment referred to above and confirm the discrepancy with ENDF/B-VI in the energy region above $1.5 \mathrm{MeV}$, as shown in Fig. 3.4. An additional measurement at the ORELA facility extended the cross-section to lower energies [3.32], so that better normalization of the shape measurements could be made. The measurement covered the neutron energy range from $10 \mathrm{keV}$ to $1 \mathrm{MeV}$, and the data are lower than ENDF/B-VI by about $5 \%$ in the region above $100 \mathrm{keV}$. The agreement with the new international evaluation is even worse in this energy region.

Measurements of the ${ }^{10} \mathrm{~B}\left(\mathrm{n}, \alpha_{1} \gamma\right)$ cross-section have been made by Märten from a neutron energy of $320 \mathrm{keV}$ to $2.8 \mathrm{MeV}$ at the GELINA facility relative to the ${ }^{235} \mathrm{U}(\mathrm{n}, \mathrm{f})$ and carbon standard crosssections [3.33]. The data are generally in reasonable agreement with the measurements of Schrack et al. [3.30-3.32] and support the observed differences with ENDF/B-VI.
Measurements of the ${ }^{10} \mathrm{~B}$ total cross-section have been made on the IRMM GELINA and van de Graaff facilities. The GELINA work is an extension in energy of the work by Brusegan [3.34], and the new analysis extends the upper energy range of these data to a neutron energy of $730 \mathrm{keV}$. These data deviate from ENDF/B-VI by $\pm 2.5 \%$ below $10 \mathrm{keV}$, with a maximum positive deviation above ENDF/B-VI of $5 \%$ at $100 \mathrm{keV}$ and a maximum negative deviation below ENDF/B-VI of $7 \%$ at $700 \mathrm{keV}$. Additional data have been obtained at the IRMM van de Graaff facility by Plompen [3.35]. The initial measurements used a white source, while more recent data were derived from monoenergetic measurements at selected points to check that the two sets of data were consistent there was generally good agreement between the two data sets. The van de Graaff data are lower than ENDF/B-VI by $3-4 \%$ at 0.3 and $0.4 \mathrm{MeV}$, and by $6-$ $9 \%$ from 0.6 to $1.3 \mathrm{MeV}$, and agree with the ENDF/ B-VI evaluation at 1.7 and $1.9 \mathrm{MeV}$.

Wasson et al. have also made measurements of the ${ }^{10} \mathrm{~B}$ total cross-section through a NIST-Oak Ridge National Laboratory (ORNL) collaboration using ORELA [3.36]. These data extend from about $20 \mathrm{keV}$ to $20 \mathrm{MeV}$ and agree with the ENDF/B-VI evaluation for neutron energies greater than about $2 \mathrm{MeV}$, but are lower by as much as $4 \%$ between 600 $\mathrm{keV}$ and $2 \mathrm{MeV}$, and are higher by as much as about $5 \%$ below $600 \mathrm{keV}$. The data are shown in Fig. 3.5,

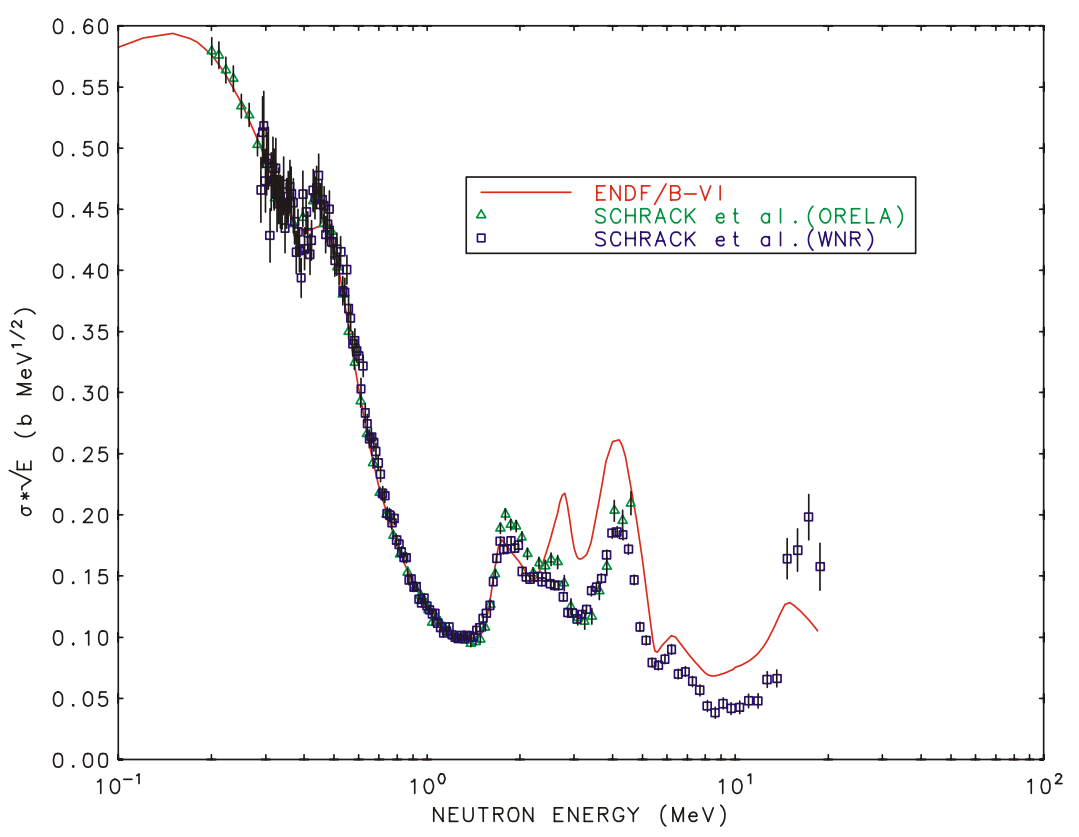

FIG. 3.4. Measurements of the ${ }^{10} B\left(n, \alpha_{1} \gamma\right)$ cross-section by Schrack [3.30, 3.31] compared with the ENDF/B-VI evaluation. 


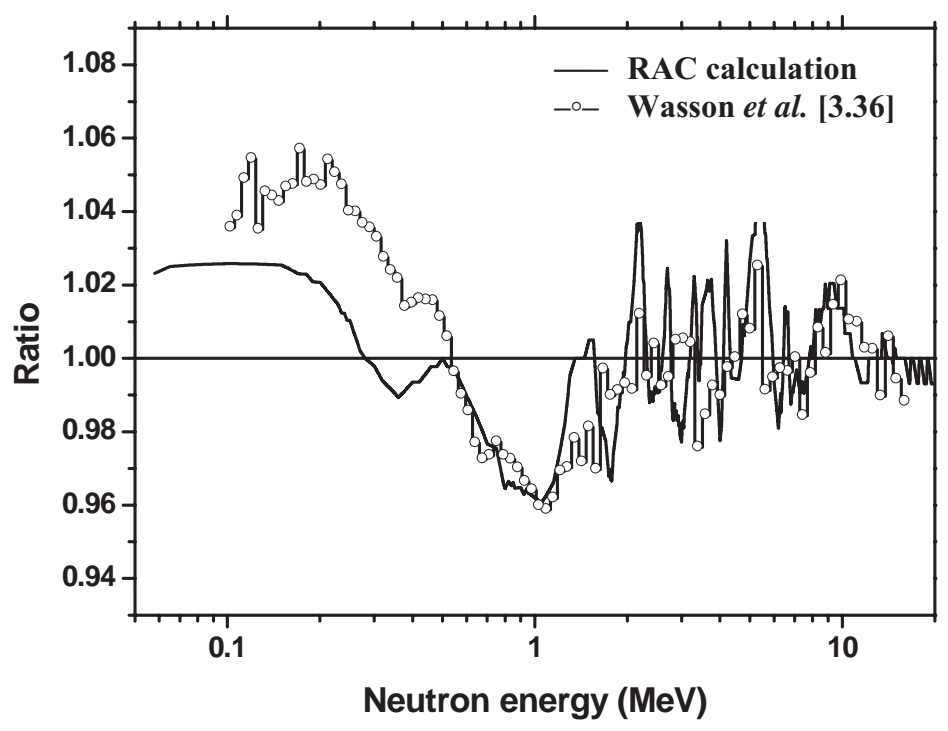

FIG. 3.5. ${ }^{10} \mathrm{~B}$ total cross-section of Wasson et al. [3.36] and a calculation with the RAC code for neutron energies up to $20 \mathrm{MeV}$ - both are relative to $E N D F / B-V I$.

and are compared with an equivalent $\mathrm{RAC}$ calculation. Within the uncertainties of the measurements, there is generally good agreement between the studies at ORELA and on the GELINA and van de Graaff facilities at the IRMM. However, the analyses of the GELINA and IRMM van de Graaff data were not completed in time to be included in this evaluation.

Measurements of the ${ }^{10} \mathrm{~B}(\mathrm{n}, \alpha)$ cross-section were carried out by Giorginis and Khriachkov [3.29]. The data extend from 1.5 to $4.5 \mathrm{MeV}$. These data were obtained on the van de Graaff facility at the IRMM with a FGIC by summing the ${ }^{10} \mathrm{~B}\left(\mathrm{n}, \alpha_{0}\right)$ and ${ }^{10} \mathrm{~B}\left(\mathrm{n}, \alpha_{1} \gamma\right)$ differential cross-section contributions. There are large differences between the measurements and the evaluations, as shown in Fig. 3.6, but the greatest concern is the difference between the measurements of Giorginis and Khriachkov and those of Zhang et al. [3.37] near $4 \mathrm{MeV}$ neutron energy (Zhang et al. data are the three very low data points in Fig. 3.6). Both sets of measurements are recent, and therefore one might expect much better agreement. Giorginis and Khriachkov have proposed that the difference is due to a subtle effect called 'particle leaking' that occurs when both reaction products are emitted in the forward direction.

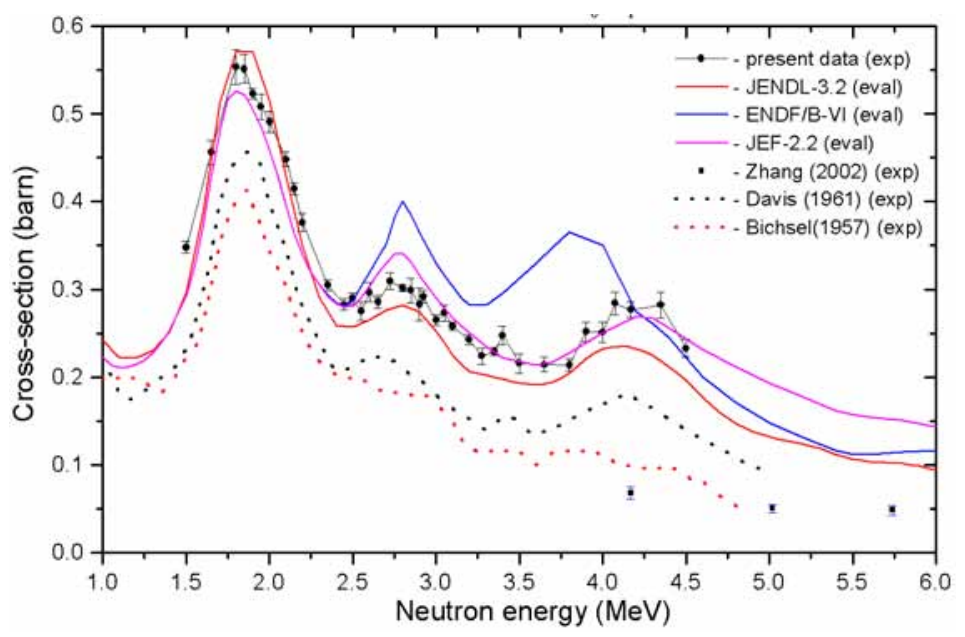

FIG. 3.6. ${ }^{10} \mathrm{~B}(n, \alpha)$ cross-section in the neutron energy region above $1 \mathrm{MeV}$. 'Present data' are the measurements of Giorginis and Khriachkov [3.29]. 
The particle identification feature that is possible with an FGIC treats this behaviour as a quasi ${ }^{7} \mathrm{Li}+\alpha$ particle, which appears in the pile-up portion of the spectrum and is rejected. Data adopted without taking this effect into account are only correct over a limited angular range. Since particles are lost, the integrated cross-section will be lower than the correct value. This effect is not present in the Giorginis and Khriachkov data due to the sophisticated data acquisition system employed [3.29], and indeed the Zhang et al. results are lower than the Giorginis and Khriachkov data. Although calculations indicate the effect increases with increasing neutron energy, the particle leaking effect is unlikely to explain the entire difference between these two data sets. Zhang et al. have recently made new measurements under better conditions, and these studies are being analysed. Unfortunately, these data could not be included in the international standards evaluation.

There has not been much measurement activity for the ${ }^{6} \mathrm{Li}(\mathrm{n}, \mathrm{t})$ cross-section, which is considered to be relatively well defined. Zhang et al. undertook measurements of the ${ }^{6} \mathrm{Li}(\mathrm{n}, \mathrm{t})$ crosssection whereby data were obtained at 3.67 and 4.42 $\mathrm{MeV}$ and at 1.85 and $2.67 \mathrm{MeV}$ in separate experiments [3.38]. All data were obtained with an FGIC, including angular distributions, and corrections must be made to these data to account for the previously mentioned particle leaking effect. Since particles are lost, the integrated cross-section will be lower than the correct value, although the magnitude of this correction is not known for the Zhang et al. data. As with their boron work, Zhang et al. have re-measured the ${ }^{6} \mathrm{Li}(\mathrm{n}, \mathrm{t})$ cross-section at the same energy points with an FGIC to minimize particle leaking effects. However, the full details of this work remain to be published, and these data could not be included in the evaluation of the standards.

\section{3. ${ }^{197} \mathrm{Au}(\mathrm{n}, \gamma) \mathrm{CROSS}-\mathrm{SECTION}$}

${ }^{197} \mathrm{Au}(\mathrm{n}, \gamma)$ is the only capture cross-section standard. New measurements of this cross-section using calibrated photoneutron sources were made by Sakamoto et al. [3.39]. These data are somewhat lower at $23 \mathrm{keV}$ and substantially higher ( 20\%) at $967 \mathrm{keV}$ compared with ENDF/B-VI. At around $1 \mathrm{MeV}$ the ENDF/B-VI evaluation agrees well with most of the absolute measurements and ${ }^{197} \mathrm{Au}(\mathrm{n}, \gamma)$ / ${ }^{235} \mathrm{U}(\mathrm{n}, \mathrm{f})$ data. However, a previous photoneuton source measurement has also resulted in a high value at $967 \mathrm{keV}$ [3.40], similar to that of Sakamoto et al. Data by Davletshin et al. [3.41] and Kazakov et al. [3.42] agree reasonably well with the ENDF/ B-VI evaluation, although a problem near the inelastic levels at $\sim 270 \mathrm{keV}$ may exist. The measurements by Demekhin et al. [3.43] and Voignier et al. [3.44] above $2 \mathrm{MeV}$ are higher than the ENDF/B-VI evaluation.

\section{4. ${ }^{235} \mathrm{U}(\mathrm{n}, \mathrm{f})$ AND ${ }^{238} \mathrm{U}(\mathrm{n}, \mathrm{f})$ CROSS-SECTIONS}

The ease of use of the ${ }^{235} \mathrm{U}(\mathrm{n}, \mathrm{f})$ cross-section makes this standard popular. ${ }^{235} \mathrm{U}(\mathrm{n}, \mathrm{f})$ cross-section data from the Technical University of Dresden (TUD)-Radium Institute of Leningrad (RIL) were used in the ENDF/B-VI evaluation, but have been changed by amounts that often exceed the originally quoted uncertainties [3.45, 3.46]. These revisions were due to changes in the corrections for fission fragment absorption and new measurements of the areal densities of the fissile material. The revised values at $2.56,4.45$ and $14.7 \mathrm{MeV}$ agree very well with the ENDF/B-VI evaluation. Measurements by Buleeva et al. [3.47] agree reasonably well, and data from 1 to $6 \mathrm{MeV}$ by Johnson et al. [3.48] agree very well with ENDF/B-VI. Absolute measurements by Carlson [3.49] from 0.3 to $3 \mathrm{MeV}$ are also in good agreement with ENDF/B-VI, although the data are about $1 \%$ lower from about 450 to $900 \mathrm{keV}$ and about $1 \%$ higher from 1.3 to $3 \mathrm{MeV}$.

${ }^{235} \mathrm{U}(\mathrm{n}, \mathrm{f})$ cross-section measurements by Iwasaki et al. were made with a recoil proton telescope for determination of the neutron fluence to give cross-sections with total uncertainties of about $2.5 \%$ [3.50]. The data as originally reported are ratios to the hydrogen scattering crosssection that were converted by means of the ENDF/ B-IV hydrogen cross-sections, which are the same as those of ENDF/B-V. These values are in very good agreement with the ${ }^{235} \mathrm{U}(\mathrm{n}, \mathrm{f})$ evaluation of ENDF/B-VI. However, when the ratios are converted using the ENDF/B-VI hydrogen crosssections, an increase of $1.7 \%$ occurs. An experimental check was made by determining the fluence with the telescope on the basis of the ENDF/B-IV hydrogen cross-sections and comparing the data with that obtained using the time correlated associated particle technique - agreement was within $1 \%$ with uncertainties of $2 \%$. These measurements suggest that the ENDF/B-VI hydrogen cross-sections may be too high at $14 \mathrm{MeV}$ 


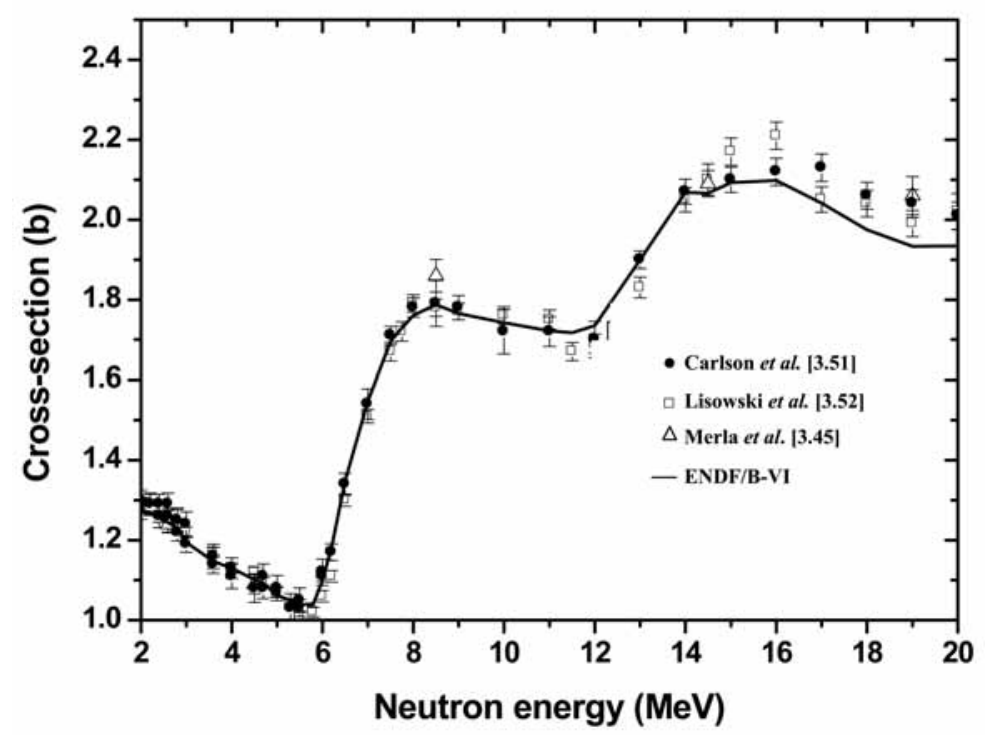

FIG. 3.7. ${ }^{235} \mathrm{U}(n, f)$ cross-section in the neutron energy region up to $20 \mathrm{MeV}$.

for a CMS scattering angle of $180^{\circ}$. However, the uncertainties make this conclusion quite tentative (although this conclusion is confirmed by the work of Ref. [3.11]).

Measurements have been made of the ${ }^{235} \mathrm{U}(\mathrm{n}, \mathrm{f})$ cross-section on the WNR facility at LANL by Carlson et al. [3.51] and Lisowski et al. [3.52]. These data are shown in Fig. 3.7, and are compared with the ENDF/B-VI evaluation and the TUD-RIL data of Merla et al. [3.45]. Clearly above $14 \mathrm{MeV}$ the data deviate from the ENDF/B-VI evaluation. Above $20 \mathrm{MeV}$, measurements are scarce - the most recent work from Nolte et al. [3.53] is compared with that of Lisowski et al. [3.52] in Fig. 3.8 to show that agreement is very good within the error bars. The Nolte et al. data are a very important contribution to the database because they are the only new data in this high energy region and are absolute.

The ${ }^{238} \mathrm{U}(\mathrm{n}, \mathrm{f})$ cross-section has an advantage over ${ }^{235} \mathrm{U}(\mathrm{n}, \mathrm{f})$ because the high effective threshold makes this standard useful when low energy

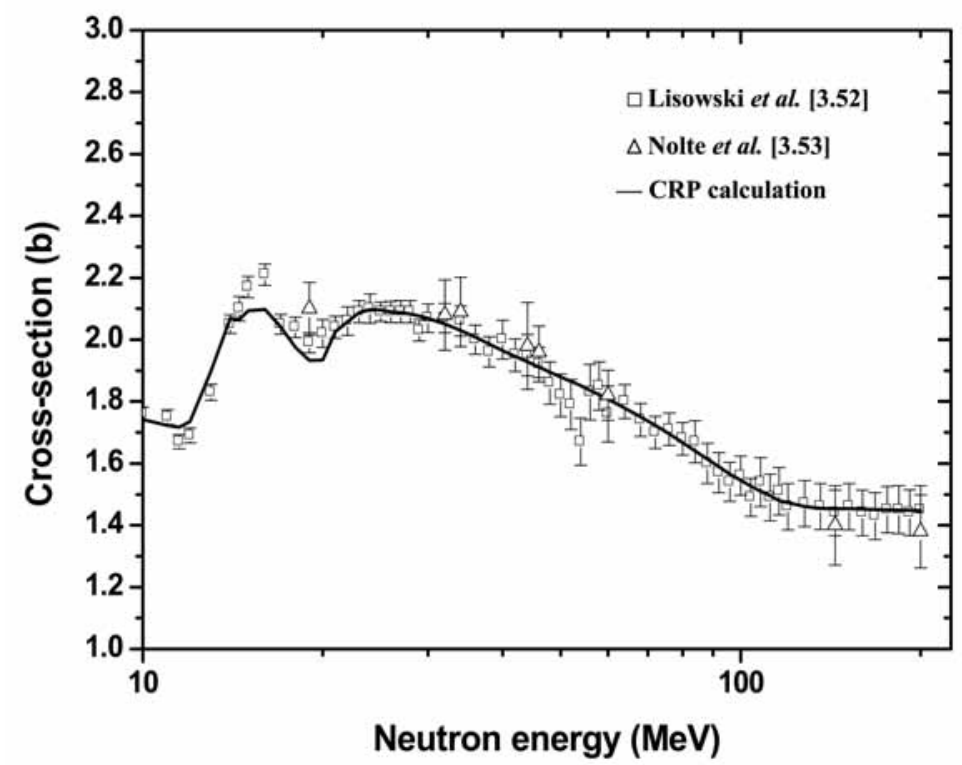

FIG. 3.8. ${ }^{235} U(n, f)$ cross-section in the incident neutron energy range above $10 \mathrm{MeV}$ compared with a CRP calculation. 
neutron backgrounds are present. Revisions in the data for the TUD-RIL collaboration also affected their measurement of the ${ }^{238} \mathrm{U}(\mathrm{n}, \mathrm{f})$ cross-section at 14.7 MeV [3.45]. The value at $14.7 \mathrm{MeV}$ was changed by $+5.2 \%$ compared with that adopted for the ENDF/B-VI evaluation (i.e. 3.7 times the uncertainty quoted originally [3.46]). A new measurement at $14.5 \mathrm{MeV}$ was carried out by Winkler et al. [3.54] in which the neutron fluence was obtained by means of the associated particle technique as well as relative to the ${ }^{27} \mathrm{Al}(\mathrm{n}, \alpha)$ and ${ }^{56} \mathrm{Fe}(\mathrm{n}, \mathrm{p})$ cross-sections, with good agreement being obtained among the three values. The ${ }^{238} \mathrm{U}$ mass was based on alpha counting at four different laboratories. ${ }^{238} \mathrm{U}(\mathrm{n}, \mathrm{f})$ cross-sections obtained were $2-3 \%$ higher than ENDF/B-VI. These revised and new data suggest a ${ }^{238} \mathrm{U}(\mathrm{n}, \mathrm{f})$ cross-section higher than ENDF/B-VI, ranging from $\sim 2.5 \%$ around $5 \mathrm{MeV}$ and $\sim 4.2 \%$ around $14 \mathrm{MeV}$ to $\sim 5.6 \%$ at $18-19 \mathrm{MeV}$. On the other hand, new measurements of the ${ }^{238} \mathrm{U}(\mathrm{n}, \mathrm{f}) /{ }^{235} \mathrm{U}(\mathrm{n}, \mathrm{f})$ cross-section ratio by Lisowski et al. [3.52], Shcherbakov et al. [3.55] and Baba et al. [3.56] do not support such large increases in the cross-section.

The ${ }^{238} \mathrm{U}(\mathrm{n}, \mathrm{f}) /{ }^{235} \mathrm{U}(\mathrm{n}, \mathrm{f})$ cross-section ratio measurements by Nolte et al. [3.53], Shcherbakov et al. [3.55] and Lisowski et al. [3.52] are shown in Fig. 3.9. Although the results of Nolte et al. have rather large uncertainties, they support the data of Lisowski et al., while being higher than the data of Shcherbakov et al. The difference between the
Shcherbakov et al. and the Lisowski et al. measurements is $\sim 2 \%$ at the lowest energies, but becomes more than $5 \%$ at the highest energies. Preliminary measurements have been made by Smirnov et al. at neutron energies of 22 and $75 \mathrm{MeV}$ [3.57]. While these data are low compared with the Lisowski et al. measurements, the two sets of data are generally in good agreement within the rather large uncertainties of the Smirnov et al. measurements. A reduction in the uncertainties of the Smirnov et al. data may not be possible due to the uncertainties in the neutron fluence.

\subsection{ANALYSIS OF EXPERIMENTAL DATA}

A major aspect of the evaluation has been the improvement of the database. One of the most difficult parts of this work was estimating the uncertainties and correlations within a specific experiment and correlations with other experiments. This information was used to form covariance matrices for the measurements so that a full covariance analysis could be performed for the evaluation. These efforts involved establishing and updating uncertainties, and determining how to handle discrepant data. Most of the effort focused on the review and inspection of measurements of standard cross-sections that were made after the ENDF/B-VI evaluation was completed, and some discrepancies were found.

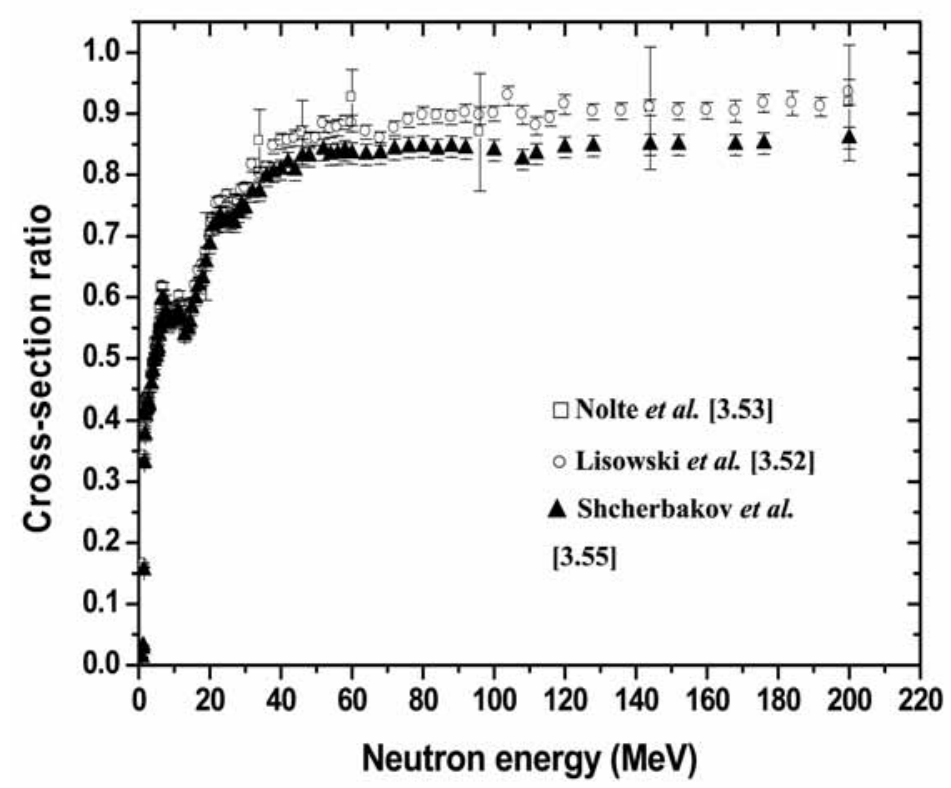

FIG. 3.9. ${ }^{238} U(n, f) f^{235} U(n, f)$ cross-section ratio in the neutron energy region up to $200 \mathrm{MeV}$. 
Deviations of experimental measurements from the output of the evaluation were compared with the uncertainties in the data so as to reduce the effect of discrepant data on the GMA and RAC evaluations. Outliers were defined as those data for which the difference from the true value was above two standard deviations for a single point, or above one standard deviation for a few sequential points. Uncertainties of outliers were increased by adding an additional component to the covariance matrix of the uncertainty of each outlying data set. The length of correlation for this additional medium energy range component was evaluated from an analysis of the energy dependence of the discrepancy.

The large amount of data for charged particle induced reaction channels may be an important factor in the large reduction in the calculated uncertainty. Many charged particle data and differential elastic scattering cross-sections in particular are claimed to have very small uncertainties. However, systematic errors may not have been fully estimated. The option of increasing the uncertainties of outlying data was used in RAC, while the output covariances of outlier data were modified by the $\chi^{2}$ per degree of freedom value of the fit for EDA. This procedure is equivalent to increasing the uncertainty of all the experimental data in the fit, and not just the outliers.

\subsection{CONCLUDING REMARKS}

A large number of new standards measurements have been carried out since the completion of the ENDF/B-VI standards evaluation. Furthermore, some measurements used in that evaluation have undergone changes that also need to be incorporated into the new evaluation of the standards. Measurements now exist for certain standards up to $200 \mathrm{MeV}$. These measurements, as well as those used in the ENDF/B-VI evaluation of the standards, have been included in the database for the new international evaluation of the neutron cross-section standards.

A list of the experiments used in the international evaluation of the neutron cross-section standards for the GMA analysis is given in Section 7. Many of the experiments agree well with the ENDF/B-VI evaluations. However, some problems have been observed: (a) There was conflict with the $\mathrm{H}(\mathrm{n}, \mathrm{n})$ differential cross-section around $14 \mathrm{MeV}$ and at about 190 $\mathrm{MeV}$.

(b) New measurements of the ${ }^{10} \mathrm{~B}$ branching ratio suggested a problem, although additional experimental work indicated that the ENDF/ $\mathrm{B}-\mathrm{VI}$ values are generally reasonable.

(c) Differences were observed for the ${ }^{10} \mathrm{~B}$ total cross-section and the ${ }^{10} \mathrm{~B}\left(\mathrm{n}, \alpha_{1} \gamma\right)$ cross-section.

(d) Except for possible differences near $270 \mathrm{keV}$, the ${ }^{197} \mathrm{Au}(\mathrm{n}, \gamma)$ cross-section measurements are generally in agreement with the ENDF/B-VI evaluation.

(e) New measurements of the ${ }^{235} \mathrm{U}(\mathrm{n}, \mathrm{f})$ crosssection indicate higher values above $15 \mathrm{MeV}$.

(f) There is concern with some new absolute ${ }^{238} \mathrm{U}(\mathrm{n}, \mathrm{f})$ cross-section measurements since they indicate larger values than supportive ${ }^{238} \mathrm{U}(\mathrm{n}, \mathrm{f}) /{ }^{235} \mathrm{U}(\mathrm{n}, \mathrm{f}) \quad$ cross-section ratio measurements in the 5-20 MeV energy region.

(g) At very high energies there are significant differences in the ${ }^{238} \mathrm{U}(\mathrm{n}, \mathrm{f}) /{ }^{235} \mathrm{U}(\mathrm{n}, \mathrm{f})$ crosssection ratio - the maximum difference exceeds $5 \%$ at $200 \mathrm{MeV}$.

\section{REFERENCES TO SECTION 3}

[3.1] CARLSON, A.D., et al., ENDF/B-VI Neutron Cross Section Measurement Standards, Rep. NISTIR-5177, National Institute of Standards and Technology, Gaithersburg, MD (1993); also ENDF/B-VI Neutron Cross Section Measurement Standards, Rep. ENDF-351, Brookhaven Natl Lab., Upton, NY (1993).

[3.2] POENITZ, W.P., CARLSON, A.D., "The database of the standards and related cross sections after ENDF/B-VI", Nuclear Data Evaluation Methodology (Proc. Int. Symp. Brookhaven Natl Lab., Upton, NY, 1992), World Scientific, Singapore (1993) 75.

[3.3] CARLSON, A.D., CHIBA, S., HAMBSCH, F.-J., OLSSON, N., SMIRNOV, A.N., "Update to nuclear data standards for nuclear measurements", Summary Report of a Consultants' Meeting Held in Vienna, Austria, 2-6 December 1996 (WIENKE, H., Ed.), Rep. INDC(NDS)-368, IAEA, Vienna (1997).

[3.4] CARLSON, A.D., "Database studies for the new international evaluation of the neutron cross section standards", Reactor Dosimetry, Reactor Dosimetry in the 21st Century (Proc. Int. Symp. Brussels, 2002), World Scientific, Singapore (2003) 638-645.

[3.5] HAMBSCH, F.-J., CARLSON, A.D., VONACH, H., "Status of the neutron cross section standards 
database", Nuclear Data for Science and Technology (Proc. Int. Conf. Santa Fe, NM, 2004), American Institute of Physics Conf. Proc. 769, Part 1 (HAIGHT, R.C., CHADWICK, M.B., KAWANO, T., TALOU, P., Eds), American Institute of Physics, New York (2005) 826-829.

[3.6] DODDER, D.C., HALE, G.M., Los Alamos National Laboratory, personal communication, 1987.

[3.7] PRIESMEYER, H.G., FISCHER, P., HARZ, U., HENKENS, P., "The total n,p cross section at the iron-titanium filter difference energy", Nuclear Data for Basic and Applied Science (Proc. Conf. Santa Fe, NM, 1985), Vol. 2, Gordon and Breach, New York (1986) 1463-1466.

[3.8] RYVES, T.B., KOLKOWSKI, P., The differential cross section for neutron-proton scattering at 14.5 MeV, Ann. Nucl. Energy 17 (1990) 657-666.

[3.9] BÜRKLE, W., MERTENS, G., Measurement of the neutron-proton differential cross section at 14.1 MeV, Few-Body Systems 22 (1997) 11-25.

[3.10] BABA, M., Tohuko University, personal communication.

[3.11] BOUKHAROUBA, N., et al., Measurement of the n-p elastic scattering angular distribution at $E_{\mathrm{n}}=10 \mathrm{MeV}$, Phys. Rev. C 65 (2002) 014004.

[3.12] ARNDT, R.A., STRAKOVSKY, I.I., WORKMAN, R.L., Updated analysis of $\mathrm{NN}$ elastic scattering data to $1.6 \mathrm{GeV}$, Phys. Rev. C 50 (1994) 2731-2741.

[3.13] SCHOEN, K., et al., Precision neutron interferometric measurements of the $\mathrm{n}-\mathrm{H}$ and $\mathrm{n}-\mathrm{D}$ coherent neutron scattering lengths, Phys. Rev. C 67 (2003) 044005.

[3.14] JOHANSSON, C., et al., "Forward-angle neutronproton scattering at $96 \mathrm{MeV}$ ", Nuclear Data for Science and Technology (Proc. Int. Conf. Santa Fe, NM, 2004), American Institute of Physics Conf. Proc. 769, Part 1 (HAIGHT, R.C., CHADWICK, M.B., KAWANO, T., TALOU, P., Eds), American Institute of Physics, New York (2005) 804-808; also RÖNNQVIST, T., et al., Backward angle n-p differential cross section at $96 \mathrm{MeV}$, Phys. Rev. C 45 (1992) R496-R499; also RAHM, J., et al., np scattering measurements at $162 \mathrm{MeV}$ and the TTNN coupling constant, Phys. Rev. C 57 (1998) 1077-1096.

[3.15] HÜRSTER, W., et al., Neutron-proton charge exchange scattering between $190 \mathrm{MeV}$ and 590 MeV, Phys. Lett. B 90 (1980) 367-370.

[3.16] VIGDOR, S.E., "Measurement of absolute np scattering differential cross sections with a tagged intermediate-energy neutron beam", Nuclear Data for Science and Technology (Proc. Int. Conf. Santa Fe, NM, 2004), American Institute of Physics Conf. Proc. 769, Part 1 (HAIGHT, R.C., CHADWICK, M.B., KAWANO, T., TALOU, P., Eds), American Institute of Physics, New York (2005) 820-825.
[3.17] STOKS, V., DE SWART, J.J., Comparison of potential models with the pp scattering data below 350 MeV, Phys. Rev. C 47 (1993) 761-767.

[3.18] HALE, G.M., Los Alamos National Laboratory, personal communication, 1987.

[3.19] BORZAKOV, S.B., et al., Features of the departure from the $1 / \mathrm{v}$ law of the cross section for the reaction ${ }^{3} \mathrm{He}(\mathrm{n}, \mathrm{p}) \mathrm{T}$ : Excited level of the ${ }^{4} \mathrm{He}$ nucleus, Sov. J. Nucl. Phys. 353 (1982) 307-312.

[3.20] KEITH, C.D., et al., Neutron cross sections for ${ }^{3} \mathrm{He}$ at epithermal energies, Phys. Rev. C 69 (2004) 034005/1-6; also KEITH, C.D., et al., Measurement of the neutron total cross section of ${ }^{3} \mathrm{He}$ in the energy range 0.1-500 eV, Bull. Am. Phys. Soc. DNP (Oct. 1997) paper IG.03; also RICH, D.R., Investigations in the Development and Application of Optically Pumped Polarized ${ }^{3} \mathrm{He}$ Neutron Spin Filters, PhD Thesis, Univ. Indiana, Bloomington (1999).

[3.21] ALS-NIELSEN, J., DIETRICH, O., Slow neutron cross sections for $\mathrm{He}^{3}, \mathrm{~B}$ and $\mathrm{Au}$, Phys. Rev. 133 (1964) B925-B929.

[3.22] HUFFMAN, P.R., et al., Precision neutron interferometric measurement of the $n-{ }^{3} \mathrm{He}$ coherent neutron scattering length, Phys. Rev. C 70 (2004) 014004/1-7.

[3.23] FU, C.Y., Evaluated cross sections for neutron scattering from natural carbon below $2 \mathrm{MeV}$ including R matrix fits to ${ }^{13} \mathrm{C}$ resonances, Nucl. Sci. Eng. 106 (1990) 494-500.

[3.24] SCHMIEDMAYER, J., MOXON, M.C., "The measurement of accurate total cross-sections for lead and carbon in the energy range $50 \mathrm{eV}$ to $100 \mathrm{keV}$ ", Nuclear Data for Science and Technology (Proc. Int. Conf. Mito, Japan, 1988) (IGARASI, S., Ed.), Saikon, Tokyo (1988) 165-168.

[3.25] KIRILYUK, A.L., GREBNEV, A.V., VORONA, P.N., GNIDAK, N.L., "Study of the intermediate neutrons interaction with tritium and hydrogen", Neutron Physics (Proc. Int. Conf. Kiev, 1988), Vol. 2, CNIIatominform, Moscow (1988) 298-302.

[3.26] WESTON, L.W., TODD, J.H., Measurement of the ${ }^{10} \mathrm{~B}\left(\mathrm{n}, \alpha_{0}\right) /{ }^{10} \mathrm{~B}(\mathrm{n}, \alpha \gamma)$ ratio versus neutron energy, Nucl. Sci. Eng. 109 (1991) 113-119.

[3.27] OLSON, M.D., KAVANAGH， R.W., ${ }^{7} \operatorname{Li}(\alpha, n)$ cross section from threshold to $5.67 \mathrm{MeV}$, Phys. Rev. C 30 (1984) 1375-1377.

[3.28] HAMBSCH, F.-J., RUSKOV, I., The ${ }^{10} \mathrm{~B}\left(\mathrm{n}, \alpha_{0}\right) /$ ${ }^{10} \mathrm{~B}\left(\mathrm{n}, \alpha_{1} \gamma\right)$ branching ratio, Nucl. Sci. Eng. 156 (2007) 103-114.

[3.29] GIORGINIS, G., KHRIACHKOV, V., "Particle leaking, cross-section ratio ${ }^{10} \mathrm{~B}(\mathrm{n}, \alpha) /$ ${ }^{238} \mathrm{U}$ (n,fission), and excitation function of the reaction ${ }^{10} \mathrm{~B}(\mathrm{n}, \alpha)^{7} \mathrm{Li}$ at $\mathrm{MeV}$ energies", Nuclear Data For Science and Technology (Proc. Int. Conf. Santa Fe, NM, 2004), American Institute of Physics Conf. Proc. 769, Part 1 (HAIGHT, R.C., CHADWICK, M.B., KAWANO, T., TALOU, P., Eds), American Institute of Physics, New York (2005) 816-819. 
[3.30] SCHRACK, R.A., WASSON, O.A., LARSON, D.C., DICKENS, J.K., TODD, J.H., A relative measurement of the ${ }^{10} \mathrm{~B}\left(\mathrm{n}, \alpha_{1} \gamma\right)^{7} \mathrm{Li}$ cross section between 0.2 and $4.0 \mathrm{MeV}$, Nucl. Sci. Eng. 114 (1993) 352-362.

[3.31] SCHRACK, R.A., National Institute of Standards and Technology, Gaithersburg, MD, personal communication, 1994.

[3.32] SCHRACK, R.A., WASSON, O.A., LARSON, D.C., DICKENS, J.K., TODD, J.H., "The ${ }^{10} \mathrm{~B}\left(\mathrm{n}, \alpha_{1} \gamma\right)^{7} \mathrm{Li}$ cross section from $10 \mathrm{keV}$ to $1 \mathrm{MeV}$ ", Nuclear Data for Science and Technology (Proc. Int. Conf. Gatlinburg, TN, 1994) (DICKENS, J.K., Ed.), American Nuclear Society, IL (1994) 43-46.

[3.33] MÄRTEN, H., Institute for Reference Materials and Measurements, Geel, Belgium, personal communication, 1997.

[3.34] BRUSEGAN, A., Institute for Reference Materials and Measurements, Geel, Belgium, personal communication, 2002.

[3.35] PLOMPEN, A., Institute for Reference Materials and Measurements, Geel, Belgium, personal communication, 2002.

[3.36] WASSON, O.A., CARLSON, A.D., SCHRACK, R.A., HARVEY, J.A., HILL, N.W., "Total neutron cross section measurements of ${ }^{10} \mathrm{~B}$ and ${ }^{11}$ B", Nuclear Data for Science and Technology (Proc. Int. Conf. Gatlinburg, TN, 1994) (DICKENS, J.K., Ed.), American Nuclear Society, IL (1994) 50-52.

[3.37] ZHANG, G., TANG, G., CHEN, J., ZHANG, S., SHI, Z., Differential cross-section measurement for the $\left.{ }^{10} \mathrm{~B}(\mathrm{n}, \alpha)\right)^{7} \mathrm{Li}$ reaction, Nucl. Sci. Eng. 142 (2002) 203-206; also personal communication.

[3.38] ZHANG, G., et al., Communication of Nuclear Data Progress No. 21, China Nuclear Data Center, Beijing (1999); also Differential cross-section measurement for the ${ }^{6} \mathrm{Li}(n, t){ }^{4} \mathrm{He}$ reaction at 3.67 and 4.42 MeV, Nucl. Sci. Eng. 134 (2000) 312-316; also ZHANG, G., et al., Measurement of differential cross sections of the ${ }^{6} \mathrm{Li}(n, t)^{4} \mathrm{He}$ reaction at 1.85 and $2.67 \mathrm{MeV}$, Nucl. Sci. Eng. 143 (2003) 86-89.

[3.39] SAKAMOTO, S., et al., Absolute measurements of the ${ }^{197} \mathrm{Au}\left(\mathrm{n}\right.$, gamma ${ }^{198} \mathrm{Au}$ cross section for fast neutrons, Nucl. Sci. Eng. 109 (1991) 215-220.

[3.40] ROBERTSON, J.C., RYVES, T.B., AXTON, E.J., GOODIER, I., WILLIAMS, A., A measurement of the radiative capture cross section of gold at an energy of $966 \mathrm{keV}$, J. Nucl. Energy 23 (1969) 205-210.

[3.41] DAVLETSHIN, A.N., KORITCHENKO, V.N., TIPUNKOV, A.O., TIKHONOV, S.V., TOLSTIKOV, V.A., Cross section for radiative capture of neutrons by ${ }^{197} \mathrm{Au}$. An analysis of sources of systematic errors in measurement of activation, Sov. J. At. Energy 65 (1988) 913-919.

[3.42] KAZAKOV, L.E., et al., Measurement of the neutron radiative capture cross-sections for ${ }^{236} \mathrm{U}$ and ${ }^{197} \mathrm{Au}$ between $3 \mathrm{keV}$ and $420 \mathrm{keV}$, Yad. Konst. 2 (1985) 44-49.

[3.43] DEMEKHIN, V.L., et al., "Gamma-spectroscopic research of the neutron capture cross-section with $\mathrm{E}_{\mathrm{n}}=2.7 \mathrm{MeV}$ on ${ }^{115} \mathrm{In}$ and ${ }^{197} \mathrm{Au}$ ", Nuclear Spectroscopy and Nuclear Structure (Proc. 36th Conf. Kharkov, 1986), Nauka, Leningrad (1986).

[3.44] VOIGNIER, J., JOLY, S., GRENIER, G., Capture cross sections and gamma-ray spectra from the interaction of 0.5 - to $3.0-\mathrm{MeV}$ neutrons with nuclei in the mass range $A=63$ to 209, Nucl. Sci. Eng. 93 (1986) 43-56.

[3.45] MERLA, K., et al., "Absolute measurements of neutron induced fission cross-sections of ${ }^{235} \mathrm{U},{ }^{238} \mathrm{U}$, ${ }^{237} \mathrm{~Np}$ and ${ }^{239} \mathrm{Pu}$ using the time correlated associated particle method (TCAPM)", Nuclear Data for Science and Technology (Proc. Int. Conf. Jülich, 1992) (QAIM, S.M., Ed.), Springer-Verlag, Berlin (1992) 510-513.

[3.46] DUSHIN, V.N., FOMICHEV, A.V., KOVALENKO, S.S., PETRZHAK, K.A., SHPAKOV, V.I., "Statistical analysis of fission cross section measurements on ${ }^{233,235,238} \mathrm{U},{ }^{237} \mathrm{~Np},{ }^{239,242} \mathrm{Pu}$ at neutron energies of 2.6, 8.5 and $14.7 \mathrm{MeV},{ }^{235} \mathrm{U}$ Fast-neutron Fission Cross Section and the ${ }^{252} \mathrm{Cf}$ Fission Neutron Spectrum (Proc. Mtg Smolenice, Czechoslovakia, 1983) (LEMMEL, H.D., CULLEN, D.E., Eds), Rep. INDC(NDS)-146, IAEA, Vienna (1983) 53-60.

[3.47] BULEEVA, N.N., DAVLETSHIN, A.N., TIPUNKOV, A.O., TIKHONOV, S.V., TOLSTIKOV, V.A., Activation-measured radiative neutron-capture cross sections for ${ }^{236} \mathrm{U},{ }^{238} \mathrm{U}$, and ${ }^{237} \mathrm{~Np}$, Sov. J. At. Energy 65 (1989) 920-924.

[3.48] JOHNSON, R.G., et al., "Measurements of the ${ }^{235} \mathrm{U}(\mathrm{n}, \mathrm{f})$ standard cross section at the National Bureau of Standards", Nuclear Data for Science and Technology (Proc. Int. Conf. Mito, Japan, 1988) (IGARASI, S., Ed.), Saikon, Tokyo (1988) 1037-1040.

[3.49] CARLSON, A.D., "NBS measurements of the ${ }^{235} \mathrm{U}$ fission cross section", ${ }^{235} \mathrm{U}$ Fast-neutron Fission Cross Section and the ${ }^{252} \mathrm{Cf}$ Fission Neutron Spectrum (Proc. Mtg Smolenice, Czechoslovakia, 1983) (LEMMEL, H.D., CULLEN, D.E., Eds), Rep. INDC(NDS)-146, IAEA, Vienna (1983) 61-77.

[3.50] IWASAKI, T., et al., "Measurement of ${ }^{235} \mathrm{U}$ fission cross section around $14 \mathrm{MeV}$ ", Nuclear Data for Science and Technology (Proc. Int. Conf. Mito, Japan, 1988) (IGARASI, S., Ed.), Saikon, Tokyo (1988) 87-90.

[3.51] CARLSON, A.D., et al., "Measurements of the ${ }^{235} \mathrm{U}(\mathrm{n}, \mathrm{f})$ standard neutron cross section for neutron energies from 3 to $30 \mathrm{MeV}$ ", Neutron Cross Section Standards for the Energy Region Above $20 \mathrm{MeV}$ (Specialists Mtg Uppsala, 1991), Rep. NEANDC-305/U, OECD, Paris (1991) 165-176. 
[3.52] LISOWSKI, P.W., et al., "Fission cross sections in the intermediate energy region", Neutron Cross Section Standards for the Energy Region Above $20 \mathrm{MeV}$ (Specialists Mtg Uppsala, 1991), Rep. NEANDC-305/U, OECD, Paris (1991) 177-186.

[3.53] NOLTE, R., et al., "Measurement of ${ }^{235} \mathrm{U},{ }^{238} \mathrm{U}$, ${ }^{209} \mathrm{Bi}$ and ${ }^{\text {nat }} \mathrm{Pb}$ fission cross sections using quasimonoenergetic neutrons with energies from 30 to $150 \mathrm{MeV}$ ", Nuclear Data for Science and Technology (Proc. Int. Conf. Tsukuba, Japan, 2001) (SHIBATA, K., Ed.), Tokai, Ibaraki, Japan, Vol. 1, J. Nucl. Sci. Technol. Suppl. 2 (2002) 311-314.

[3.54] WINKLER, G., LEWIS, V.E., RYVES, T.B., WAGNER, M., "The ${ }^{238} \mathrm{U}(\mathrm{n}, \mathrm{f})$ cross section and its ratio to the ${ }^{27} \mathrm{Al}(\mathrm{n}, \alpha){ }^{24} \mathrm{Na}$ and ${ }^{56} \mathrm{Fe}(\mathrm{n}, \mathrm{p})^{56} \mathrm{Mn}$ cross section in the $14 \mathrm{MeV}$ region", Nuclear Data for Science and Technology (Proc. Int. Conf. Jülich, 1992) (QAIM, S.M., Ed.), Springer-Verlag, Berlin (1992) 514-517.
[3.55] SHCHERBAKOV, O.A., et al., "Neutron induced fission cross sections of some actinides and other heavy nuclei in energy region 1-200 MeV", Nuclear Data for Science and Technology (Proc. Int. Conf. Tsukuba, Japan, 2001) (SHIBATA, K., Ed.), Tokai, Ibaraki, Japan, Vol. 1, J. Nucl. Sci. Technol. Suppl. 2 (2002) 230-233.

[3.56] BABA, M., HIRAKAWA, N., IWASAKI, T., KANDA, K., Measurement of fast neutron induced fission cross section for actinide nuclides, J. Nucl. Sci. Technol. 26 (1989) 11-14.

[3.57] SMIRNOV, A.N., et al., "Application of thin-film breakdown counters for registration of fission fragments in photofission and nuclear reactor physics experiments", Nuclear Data for Science and Technology (Proc. Int. Conf. Jülich, 1992) (QAIM, S.M., Ed.), Springer-Verlag, Berlin (1992) $455-457$.

\section{TABLE 3.1. EXPERIMENTS USED FOR THE SIMULTANEOUS EVALUATION}

(number of data sets in the GMA database for a particular reaction (or ratio) is given in square brackets)

Adamchuk, Yu.V., et al. (1977) Conf. on Neutron Physics, Kiev 2, 192; 238U(n, $\gamma) /{ }^{10} B\left(n, \alpha_{1}\right)$; Sov. J. At. Energy 65 (1988) 356 [445]

Adamov, V.M., et al. (1982) INDC(CCP)-180L; also Adamov, V.M., et al. (1979) Radium Institute Report RI-52; English translation in IAEA Report INDC(CCP)-180L; ${ }^{235} \mathrm{U}(\mathrm{n}, \mathrm{f}) \mathrm{Cf}-\mathrm{AV}$ [575]

Adams, B., et al. (1961) J. Nucl. Energy A/B 14, 85; ${ }^{235} \mathrm{U}(\mathrm{n}, \mathrm{f}) / 238 \mathrm{U}(\mathrm{n}, \mathrm{f})$, shape [836]; ${ }^{238} \mathrm{U}(\mathrm{n}, \mathrm{f})$, shape $[835] ;{ }^{239} \mathrm{Pu}(\mathrm{n}, \mathrm{f}){ }^{238} \mathrm{U}(\mathrm{n}, \mathrm{f})$, shape [837]

Alfimenkov, V.P., et al. (1982) Proc. Int. Conf. on Nuclear Data for Science and Technology, Antwerp, 353; also published in Yad. Fiz. 36, 1089 (1982); English translation in Sov. J. Nucl. Phys. 36, 637; ${ }^{6}$ Li(n,n) [210\#]

Allen, W.D. and Ferguson, A.T.G. (1957) Proc. Phys. Soc. LXX, 573; ${ }^{239} \mathrm{Pu}(\mathrm{n}, \mathrm{f})$, shape [671]; ${ }^{235} \mathrm{U}(\mathrm{n}, \mathrm{f})[735]$; ${ }^{235} \mathrm{U}(\mathrm{n}, \mathrm{f})$, shape [568]; ${ }^{239} \mathrm{Pu}(\mathrm{n}, \mathrm{f})[672]$

Andersson, P., et al. (1985) Nucl. Phys. A 443, 404; ${ }^{197} \mathrm{Au}(\mathrm{n}, \gamma) /{ }^{235} \mathrm{U}(\mathrm{n}, \mathrm{f})$ [363]: these measurements were relative to indium capture - they were converted using measurements made by D.L. Smith and J.W. Meadows, ANL-NDM-14.

Arlt, R., et al. (1984) Nuclear Standard Reference Data, Geel, IAEA-TECDOC-335, 174; ${ }^{235} \mathrm{U}(\mathrm{n}, \mathrm{f})[590]$

Asami, A. and Moxon, M.C. (1969) Harwell Report AERE-R-5980; also J. Nucl. Energy 24, 85 (1970); ${ }^{10}$ B(n,n) [178\#]

Asami, A. and Moxon, M.C. (1970) Nuclear Data for Reactors, Helsinki, STI/PUB/259, I, 153; ${ }^{6} \operatorname{Li}(\mathrm{n}, \mathrm{n})$ [208\#]

Auchampaugh, G.F., et al. (1979) Nucl. Sci. Eng. 69, 30; ${ }^{10}$ B(tot) [180\#]

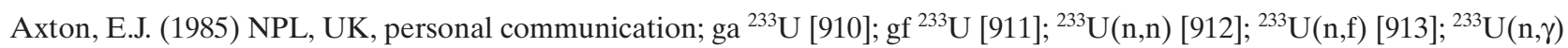
[914]; ${ }^{233} \mathrm{U}$ [915]; ga ${ }^{235} \mathrm{U}$ [916]; gf ${ }^{235} \mathrm{U}$ [917]; ${ }^{235} \mathrm{U}(\mathrm{n}, \mathrm{n})$ [918]; ${ }^{235} \mathrm{U}(\mathrm{n}, \mathrm{f})$ [919]; ${ }^{235} \mathrm{U}(\mathrm{n}, \gamma)$ [920]; $\mathrm{v}{ }^{235} \mathrm{U}$ [921]; ga ${ }^{239} \mathrm{Pu}[922] ; \mathrm{gf}$ ${ }^{239} \mathrm{Pu}[923] ;{ }^{239} \mathrm{Pu}(\mathrm{n}, \mathrm{n})[924] ; ;{ }^{239} \mathrm{Pu}(\mathrm{n}, \mathrm{f})[925] ;{ }^{239} \mathrm{Pu}(\mathrm{n}, \gamma)$ [926]; v ${ }^{239} \mathrm{Pu}[927] ;$ ga ${ }^{241} \mathrm{Pu}[928] ;$ gf ${ }^{241} \mathrm{Pu}[929] ;{ }^{241} \mathrm{Pu}(\mathrm{n}, \mathrm{n})[930]$; ${ }^{241} \mathrm{Pu}(\mathrm{n}, \mathrm{f})[931] ;{ }^{241} \mathrm{Pu}(\mathrm{n}, \gamma)$ [932]; v ${ }^{241} \mathrm{Pu}[933] ; \mathrm{v}{ }^{252} \mathrm{Cf}$ [934]

Barry, J.F., et al. (1964) J. Nucl. Energy A/B 18, 481; ${ }^{238} \mathrm{U}(\mathrm{n}, \gamma){ }^{235} \mathrm{U}(\mathrm{n}, \mathrm{f})$ [415]; Barry, J.F., et al. (1964) J. Nucl. Energy A/B 18, 491; $\mathrm{Au}(\mathrm{n}, \gamma){ }^{235} \mathrm{U}(\mathrm{n}, \mathrm{f})[320]$

Barry, J.F. (1966) Neutron Cross Section Technology, Washington DC, AEC Report Conf-660303, 2, 763; ${ }^{6} \operatorname{Li}(\mathrm{n}, \alpha){ }^{235} \mathrm{U}(\mathrm{n}, \mathrm{f})$, shape [288]

Bartle, C.M. (1979) Nucl. Phys. A 330, $1 ;{ }^{6} \operatorname{Li}(\mathrm{n}, \alpha)[238 \#]$

Barton, D.M., et al. (1976) Nucl. Sci. Eng. 60, 369; ${ }^{235} \mathrm{U}(\mathrm{n}, \mathrm{f})[580]$

Bastian, C. and Riemenschneider, H. (1984) Nuclear Standard Reference Data, Geel, IAEA-TECDOC-335, 118; ${ }^{6} \mathrm{Li}(\mathrm{n}, \alpha) /$ ${ }^{10} \mathrm{~B}(\mathrm{n}, \alpha)$, shape [297]

Becker, R.L. and Barschall, H.H. (1956) Phys. Rev. 102, 1384; ${ }^{10} \mathrm{~B}($ tot) $[185 \#]$

Beer, H. and Spencer, R.R. (1979) Nucl. Sci. Eng. 70, 98; ${ }^{10}$ B(tot) [192\#, 193\#] 
TABLE 3.1. EXPERIMENTS USED FOR THE SIMULTANEOUS EVALUATION (cont.)

(number of data sets in the GMA database for a particular reaction (or ratio) is given in square brackets)

Behrens, J.W. and Carlson, G.W. (1977) Nucl. Sci. Eng. 63, 250; ${ }^{238} \mathrm{U}(\mathrm{n}, \mathrm{f}){ }^{235} \mathrm{U}(\mathrm{n}, \mathrm{f})$ [805]

Belanova, T.S., et al. (1966) J. Nucl. Energy A/B 20, 411; ${ }^{238} \mathrm{U}(\mathrm{n}, \gamma)$ [435]: with reinterpretation by Miller, L.B. and Poenitz, W.P. (1969) Nucl. Sci. Eng. 35, 295, and Dietze, K. (1977) in this table

Bergman, A.A., et al. (1957) Zh. Eksp. Teor. Fiz. 33, 9; English translation in Sov. Phys. JETP 6, 6; ${ }^{6} \mathrm{Li}(\mathrm{n}, \alpha) /{ }^{10} \mathrm{~B}(\mathrm{n}, \alpha)$, shape [160]

Bergman, A.A., et al. (1980) Conf. on Neutron Physics, $\operatorname{Kiev} 3,49 ;{ }^{235} \mathrm{U}(\mathrm{n}, \mathrm{f}) /{ }^{10} \mathrm{~B}(\mathrm{n}, \alpha)$, shape $[550,552] ;\left.{ }^{239} \mathrm{Pu}(\mathrm{n}, \mathrm{f})\right|^{10} \mathrm{~B}(\mathrm{n}, \alpha)$, shape [551]

Berezin, A.A., et al. (1958) At. Energy 5, 659; English translation in Sov. At. Energy 5, 1604; ${ }^{235} \mathrm{U}(\mathrm{n}, \mathrm{f}){ }^{238} \mathrm{U}(\mathrm{n}, \mathrm{f})[870]$

Bichsel, H. and Bonner, T.W. (1957) Phys. Rev. 108, $1025 ;{ }^{10} \mathrm{~B}\left(\mathrm{n}, \alpha_{0}+\alpha_{1}\right)$, shape [124\#]

Block, R.C., et al. (1972) New Developments in Reactor Physics and Shielding, Kiamesha Lake, New York, CONF-720901, 2, 1107; ${ }^{238} \mathrm{U}(\mathrm{n}, \gamma) /{ }^{197} \mathrm{Au}(\mathrm{n}, \gamma)[470]$

Blons, J. (1973) Nucl. Sci. Eng. 51, 130; ${ }^{235} \mathrm{U}(\mathrm{n}, \mathrm{f}){ }^{10} \mathrm{~B}(\mathrm{n}, \alpha)$, shape [718]; ${ }^{239} \mathrm{Pu}(\mathrm{n}, \mathrm{f}) /{ }^{10} \mathrm{~B}(\mathrm{n}, \alpha)$, shape [719]

Blons, J., et al. (1977) CEA Saclay, personal communication, ${ }^{238} \mathrm{U}(\mathrm{n}, \mathrm{f}){ }^{235} \mathrm{U}(\mathrm{n}, \mathrm{f})$, shape [828]

Bockelman, C.K., et al. (1951) Phys. Rev. 84, 69; ${ }^{10} \mathrm{~B}($ tot $)[182 \#]$

Bogart, D. and Nichols, L.L. (1969) Nucl. Phys. A 125, $463 ;{ }^{10} \mathrm{~B}\left(\mathrm{n}, \alpha_{0}+\alpha_{1}\right)$, shape [130\#]

Bollinger, L., et al. (1958) Peaceful Uses of Atomic Energy, Geneva 15, $127 ;{ }^{239} \mathrm{Pu}(\mathrm{n}, \mathrm{f}) /{ }^{10} \mathrm{~B}(\mathrm{n}, \alpha)$, shape [678]

Bowman, C.D., et al. (1963) Phys. Rev. 130, 1482; ${ }^{235} \mathrm{U}(\mathrm{n}, \mathrm{f}) /^{10} \mathrm{~B}(\mathrm{n}, \alpha)$, shape [732]

Cancé, M. and Grenier, G. (1976) Fast Neutron Fission Cross Sections of ${ }^{233} \mathrm{U},{ }^{235} \mathrm{U},{ }^{238} \mathrm{U}$ and ${ }^{239} \mathrm{Pu}$, Argonne National Laboratory Report ANL-76-90, $\left.141 ;{ }^{238} \mathrm{U}(\mathrm{n}, \mathrm{f})\right)^{235} \mathrm{U}(\mathrm{n}, \mathrm{f})[832]$

Cancé, M. and Grenier, G. (1978) Nucl. Sci. Eng. 68, 197; ${ }^{235} \mathrm{U}(\mathrm{n}, \mathrm{f})[596] ;{ }^{239} \mathrm{Pu}(\mathrm{n}, \mathrm{f})[612] ;{ }^{238} \mathrm{U}(\mathrm{n}, \mathrm{f})[812]$

Cancé, M. and Grenier, G. (1981) CEA Saclay Report CEA-N-2194; ${ }^{235} \mathrm{U}(\mathrm{n}, \mathrm{f})$ [597]

Cancé, M. and Grenier, G. (1983) CEA Saclay, personal communication; ${ }^{235} \mathrm{U}(\mathrm{n}, \mathrm{f})[598]$

Carlson, A.D. and Patrick, B.H. (1978) Proc. Conf. on Neutron Physics and Nuclear Data for Reactors and other Applied Purposes, Harwell, 880; ${ }^{235} \mathrm{U}(\mathrm{n}, \mathrm{f})$, shape [508-509]

Carlson, A.D., et al. (1984) Nuclear Standard Reference Data, Geel, IAEA-TECDOC-335, 162; ${ }^{235} \mathrm{U}(\mathrm{n}, \mathrm{f})$ [523]

Carlson, G.W. and Behrens, J.W. (1978) Nucl. Sci. Eng. 66, 205; ${ }^{239} \mathrm{Pu}(\mathrm{n}, \mathrm{f}){ }^{235} \mathrm{U}(\mathrm{n}, \mathrm{f})[600]$

Chen Ying, et al. (1982) Proc. Int. Conf. on Nuclear Data for Science and Technology, Antwerp, 462; ${ }^{197} \mathrm{Au}(\mathrm{n}, \gamma)[370]$;

${ }^{197} \mathrm{Au}(\mathrm{n}, \gamma)$, shape [371]

Cierjacks, S., et al. (1976) Fast Neutron Fission Cross Sections of ${ }^{233} \mathrm{U},{ }^{235} \mathrm{U},{ }^{238} \mathrm{U}$ and ${ }^{239} \mathrm{Pu}$, ANL-76-90, 94; ${ }^{238} \mathrm{U}(\mathrm{n}, \mathrm{f}){ }^{235} \mathrm{U}(\mathrm{n}, \mathrm{f})$, shape [824]

Clements, P.J. and Rickard, I.C. (1972) Harwell Report AERE-R-7075; ${ }^{6} \mathrm{Li}(\mathrm{n}, \alpha)$, shape $[280,281] ;{ }^{6} \mathrm{Li}(\mathrm{n}, \alpha){ }^{238} \mathrm{U}(\mathrm{n}, \mathrm{f})$, shape [282]

Coates, M.S., et al. (1972) Neutron Standard Reference Data, Vienna, STI/PUB/371, $129 ;{ }^{10} \mathrm{~B}\left(\mathrm{n}, \mathrm{\alpha}_{1}\right)$, shape [128\#]

Coates, M.S., et al. (1972) Neutron Standard Reference Data, Vienna, STI/PUB/371, 105; ${ }^{6} \mathrm{Li}(\mathrm{n}, \alpha)$, shape [205\#]

Coates, M.S., et al. (1975) Proc. Conf. on Nuclear Cross Sections and Technology, Washington DC, NBS Spec. Publ. 425, II, 568; also personal communication; ${ }^{238} \mathrm{U}(\mathrm{n}, \mathrm{f}) \mathrm{l}^{235} \mathrm{U}(\mathrm{n}, \mathrm{f})$, shape [826]

Condé, H., et al. (1965) Arkiv Fysik 29, 45; ${ }^{6} \mathrm{Li}(\mathrm{n}, \alpha)[198]$

Condé, H., et al. (1982) Proc. Int. Conf. on Nuclear Data for Science and Technology, Antwerp 447; ${ }^{6} \mathrm{Li}(\mathrm{n}, \alpha)$, shape [226\#]

Coon, J.H., et al. (1952) Phys. Rev. 88, 562; ${ }^{10} \mathrm{~B}($ tot $)[183 \#]$

Corvi, F. (1983) personal communication, ${ }^{235} \mathrm{U}(\mathrm{n}, \mathrm{f}) /{ }^{6} \mathrm{Li}(\mathrm{n}, \alpha)$, shape [530, 531]

Cox, S.A. and Pontet, F.R. (1967) J. Nucl. Energy 21, $271 ;{ }^{10} \mathrm{~B}\left(\mathrm{n}, \alpha_{0}+\alpha_{1}\right)$ [115\#]

Czirr, J.B. and Carlson, A.D. (1980) Proc. Conf. on Nuclear Cross Sections for Technology, Knoxville, NBS Spec. Publ. 594, $\left.84 ;{ }^{6} \mathrm{Li}(\mathrm{n}, \alpha)\right)^{10} \mathrm{~B}(\mathrm{n}, \alpha)$, shape $[120]$

Czirr, J.B. and Carlson, G.W. (1977) Nucl. Sci. Eng. 64, 892; ${ }^{235} \mathrm{U}(\mathrm{n}, \mathrm{f}) /{ }^{6} \mathrm{Li}(\mathrm{n}, \alpha)$, shape $[271,272]$

Czirr, J.B. and Sidhu, G.S. (1975) Nucl. Sci. Eng. 57, $18,{ }^{235} \mathrm{U}(\mathrm{n}, \mathrm{f})$, shape [510] 
TABLE 3.1. EXPERIMENTS USED FOR THE SIMULTANEOUS EVALUATION (cont.)

(number of data sets in the GMA database for a particular reaction (or ratio) is given in square brackets)

Czirr, J.B. and Sidhu, G.S. (1975) Nucl. Sci. Eng. 58, 371; ${ }^{235} \mathrm{U}(\mathrm{n}, \mathrm{f})$, shape [511]

Czirr, J.B. and Sidhu, G.S. (1976) Nucl. Sci. Eng. 60, 383; ${ }^{6} \mathrm{Li}(\mathrm{n}, \alpha){ }^{235} \mathrm{U}(\mathrm{n}, \mathrm{f})$, shape [270]

Czirr, J.B. and Stelts, M.L. (1973) Nucl. Sci. Eng. 52, 299; ${ }^{197} \mathrm{Au}(\mathrm{n}, \gamma){ }^{235} \mathrm{U}(\mathrm{n}, \mathrm{f})$, shape [378]

Davis, E.A., et al. (1961) Nucl. Phys. 27, 448; ${ }^{10} \mathrm{~B}(\mathrm{n}, \alpha)$, abs [121\#]; ${ }^{10} \mathrm{~B}\left(\mathrm{n}, \alpha_{0}\right) /{ }^{10} \mathrm{~B}\left(\mathrm{n}, \alpha_{1}\right)[122 \#]$

Davis, M.C., et al. (1978) Ann. Nucl. Energy 5, 569; ${ }^{235} \mathrm{U}(\mathrm{n}, \mathrm{f})[564] ;{ }^{239} \mathrm{Pu}(\mathrm{n}, \mathrm{f})[640]$

Davis, M.C. and Knoll, G.F. (1978) Ann. Nucl. Energy 5, 583; ${ }^{235}$ U(n,f) Cf-AV [565]; ${ }^{239} \mathrm{Pu}(\mathrm{n}, \mathrm{f}) \mathrm{Cf}-\mathrm{AV}$ [641]

Davletshin, A.N., et al. (1980) At. Energy 48, 87; English translation in Sov. J. At. Energy 48, 97; ${ }^{197} \mathrm{Au}(\mathrm{n}, \gamma)[350] ;{ }^{238} \mathrm{U}(\mathrm{n}, \gamma)$ [436]

Debus, G.H. and De Bievre, P.J. (1967) J. Nucl. Energy 21, 373; ${ }^{10} \mathrm{~B}(\mathrm{n}, \alpha)$ [708\#]

Deruytter, A.J. and Wagemans, C. (1971) J. Nucl. Energy 25, 263; ${ }^{235} \mathrm{U}(\mathrm{n}, \mathrm{f}) /{ }^{10} \mathrm{~B}(\mathrm{n}, \alpha)$, shape [731]

De Saussure, G. and Weston, L.W. (1963) Oak Ridge National Laboratory Report ORNL-3360, 51; ${ }^{238} \mathrm{U}(\mathrm{n}, \gamma){ }^{235} \mathrm{U}(\mathrm{n}, \mathrm{f})[478]$

De Saussure, G., et al. (1966) Nuclear Data for Reactors, Paris, II, $233 ;\left.{ }^{235} \mathrm{U}(\mathrm{n}, \mathrm{f})\right|^{10} \mathrm{~B}(\mathrm{n}, \alpha)$, shape $[578,730]$

De Saussure, G., et al. (1973) Nucl. Sci. Eng. 51, 385; ${ }^{238} \mathrm{U}(\mathrm{n}, \gamma){ }^{10} \mathrm{~B}(\mathrm{n}, \alpha)[408]$

De Saussure, G., et al. (1978) Oak Ridge National Laboratory Report ORNL/TM-6152; ${ }^{238} \mathrm{U}(\mathrm{n}, \gamma)$ evaluation [480]

Dietze, K. (1977) Zentralinst. f. Kernforsch. Rossendorf Report ZFK-341; ${ }^{238} \mathrm{U}(\mathrm{n}, \gamma)[432]$

Difilippo, F.C., et al. (1978) Nucl. Sci. Eng. 68, 43; ${ }^{238} \mathrm{U}(\mathrm{n}, \mathrm{f}) \mathrm{r}^{235} \mathrm{U}(\mathrm{n}, \mathrm{f})[808]$

Diment, K.M. (1967) Harwell Report AERE-R-5224; ${ }^{10}$ B(tot) [194\#, 195\#, 196\#]

Diven, B.C. (1957) Phys. Rev. 105, 1350; ${ }^{235} \mathrm{U}(\mathrm{n}, \mathrm{f})$, shape [572]; ${ }^{235} \mathrm{U}(\mathrm{n}, \mathrm{f})[$ [573]

Dushin, V.N., et al. (1983) The ${ }^{235}$ U Fast-Neutron Fission Cross Section, and the ${ }^{252} \mathrm{Cf}$ Fission Neutron Spectrum, Proc. IAEA Consultants' Meeting, Smolenice, July 1983, INDC(NDS)-146, 53; ${ }^{235} \mathrm{U}(\mathrm{n}, \mathrm{f})[591-595] ;{ }^{238} \mathrm{U}(\mathrm{n}, \mathrm{f})[811] ;{ }^{239} \mathrm{Pu}(\mathrm{n}, \mathrm{f})[611]$

Ferguson, A.T.G. and Paul, E.B. (1959) J. Nucl. Energy A 10, 19; ${ }^{197} \mathrm{Au}(\mathrm{n}, \gamma)$ [355]

Flerov, N.N., et al. (1958) At. Energy 5, 657; English translation in Sov. J. At. Energy 5, 1600; ${ }^{238} \mathrm{U}(\mathrm{n}, \mathrm{f})[860]$

Fort, E. (1970) Nuclear Data for Reactors, Helsinki, STI/PUB/253; Vol. 1; ${ }^{6} \mathrm{Li}(\mathrm{n}, \alpha)$ [294\#]

Fort, E. and Marquette, J.P. (1972) European-American Nuclear Data Committee Report EANDC(E) 148/U; ${ }^{6} \mathrm{Li}(\mathrm{n}, \alpha)$ [290-292\#]

Fort, E. and Le Rigoleur, C. (1975) Proc. Conf. on Nuclear Cross Sections and Technology, Washington DC, NBS Spec. Publ. 425, $957 ;{ }^{197} \mathrm{Au}(\mathrm{n}, \gamma)[345]$

Fricke, M.P., et al. (1970) Nuclear Data for Reactors, Helsinki, June 1970, STI/PUB/259, 2, 265; ${ }^{197} \mathrm{Au}(\mathrm{n}, \gamma){ }^{10} \mathrm{~B}(\mathrm{n}, \alpha)[300]$; ${ }^{197} \mathrm{Au}(\mathrm{n}, \gamma)$, shape [301]

Fricke, M.P., et al. (1971) Proc. Conf. on Neutron Cross Section and Technology, Knoxville, CONF-710301, 1, 252; ${ }^{238} \mathrm{U}(\mathrm{n}, \gamma) /$ ${ }^{10} \mathrm{~B}(\mathrm{n}, \alpha)[400] ;{ }^{238} \mathrm{U}(\mathrm{n}, \gamma)$, shape [401]

Friesenhahn, S.J., et al. (1974) Intelcom Radiation Technology Report INTEL-RT 7011-001; ${ }^{10} \mathrm{~B}\left(\mathrm{n}, \alpha_{0}+\alpha_{1}\right)$, shape [100\#]; ${ }^{10} \mathrm{~B}\left(\mathrm{n}, \mathrm{\alpha}_{1}\right)$, shape [103\#]; ${ }^{6} \mathrm{Li}(\mathrm{n}, \alpha)$, shape [246\#]

Fursov, B.I., et al. (1977) At. Energy 43, 261; English translation in Sov. J. At. Energy 43, 891; ${ }^{239} \mathrm{Pu}(\mathrm{n}, \mathrm{f}){ }^{235} \mathrm{U}(\mathrm{n}, \mathrm{f})[653]$; $\left.{ }^{239} \mathrm{Pu}(\mathrm{n}, \mathrm{f})\right)^{235} \mathrm{U}(\mathrm{n}, \mathrm{f})$ shape $[654]$

Fursov, B.I., et al. (1977) At. Energy 43, 181; English translation in Sov. J. At. Energy 43, 808; ${ }^{238} \mathrm{U}(\mathrm{n}, \mathrm{f}){ }^{235} \mathrm{U}(\mathrm{n}, \mathrm{f})[844]$; $\left.{ }^{238} \mathrm{U}(\mathrm{n}, \mathrm{f})\right)^{235} \mathrm{U}(\mathrm{n}, \mathrm{f})$ shape [845]

Garlea, I., et al. (1983) INDC(ROM)-15, Rev. Roumaine Phys. 26, 643; ${ }^{239} \mathrm{Pu}(\mathrm{n}, \mathrm{f}){ }^{235} \mathrm{U}(\mathrm{n}, \mathrm{f})[633] ;{ }^{238} \mathrm{U}(\mathrm{n}, \mathrm{f}){ }^{235} \mathrm{U}(\mathrm{n}, \mathrm{f})[863]$

Gayther, D.B. (1975) Proc. Conf. on Neutron Cross Sections and Technology, Washington DC, NBS Spec. Publ. 425, 2, 564; ${ }^{235} \mathrm{U}(\mathrm{n}, \mathrm{f})$, shape $[588] ;{ }^{239} \mathrm{Pu}(\mathrm{n}, \mathrm{f})$, shape [589]

Gayther, D.B. (1977) Ann. Nucl. Energy 4, 515; ${ }^{6} \mathrm{Li}(\mathrm{n}, \alpha){ }^{235} \mathrm{U}$, shape [261]

Gibbons, J.G. and Macklin, R.L. (1959) Phys. Rev. 114, 571; ${ }^{10} \mathrm{~B}\left(\mathrm{n}, \alpha_{0}\right)[114 \#]$

Goulding, C., et al. (1972) US Nuclear Data Committee Report USNDC-3, 161; ${ }^{6} \mathrm{Li}($ tot) [257\#]

Goverdovskii, A.A., et al. (1983) Conf. on Neutron Physics, Kiev 2, 159; ${ }^{238} \mathrm{U}(\mathrm{n}, \mathrm{f}){ }^{235} \mathrm{U}(\mathrm{n}, \mathrm{f})[853]$

Goverdovskii, A.A., et al. (1984) At. Energy 56, 162; English translation in Sov. J. At. Energy 56, 173; ${ }^{238} \mathrm{U}(\mathrm{n}, \mathrm{f}) \mathrm{f}^{235} \mathrm{U}(\mathrm{n}, \mathrm{f})[854]$ 
TABLE 3.1. EXPERIMENTS USED FOR THE SIMULTANEOUS EVALUATION (cont.)

(number of data sets in the GMA database for a particular reaction (or ratio) is given in square brackets)

Grench, H.A., et al. (1965) European-American Nuclear Data Committee Report EANDC-79, 72, also personal communication; ${ }^{197} \mathrm{Au}(\mathrm{n}, \gamma){ }^{235} \mathrm{U}(\mathrm{n}, \mathrm{f})[331]$

Guenther, P., et al. (1982) Nucl. Phys. A 373, 305; ${ }^{6} \mathrm{Li}$ (tot) [220-222\#]

Gwin, R., et al. (1976) Nucl. Sci. Eng. 59, 79; ${ }^{197} \mathrm{Au}(\mathrm{n}, \gamma) /{ }^{10} \mathrm{~B}(\mathrm{n}, \alpha)[304] ;{ }^{197} \mathrm{Au}(\mathrm{n}, \gamma) /{ }^{10} \mathrm{~B}(\mathrm{n}, \alpha)[305]$

Gwin, R., et al. (1976) Nucl. Sci. Eng. 45, $25 ;{ }^{239} \mathrm{Pu}(\mathrm{n}, \mathrm{f}) /{ }^{10} \mathrm{~B}(\mathrm{n}, \alpha)$, shape [681, 682]

Gwin, R., et al. (1976) Nucl. Sci. Eng. 61, 116; ${ }^{239} \mathrm{Pu}(\mathrm{n}, \mathrm{f}) /{ }^{10} \mathrm{~B}(\mathrm{n}, \alpha)$, shape [676]

Gwin, R. (1984) Nucl. Sci. Eng. 88, 37; ${ }^{235} \mathrm{U}(\mathrm{n}, \mathrm{f}) \mathrm{l}^{10} \mathrm{~B}(\mathrm{n}, \alpha)$, shape [710-714]

Harris, K.K., et al. (1965) Nucl. Phys. 69, 37; ${ }^{197} \mathrm{Au}(\mathrm{n}, \gamma)$ [332]

Harvey, J. and Hill, N. (1975) Proc. Conf. on Nuclear Cross Sections and Technology, Washington DC, NBS Spec. Publ. 425, 244; also personal communications 1976 and $1981 ;{ }^{6} \mathrm{Li}($ tot $)$ [274\#, 275\#, 276\#, 277\#]

Heaton, H.T., et al. (1975) Proc. Conf. on Nuclear Cross Sections and Technology, Washington DC, NBS Spec. Publ. 425: also Heaton, H.T., et al. (1982) Memo to J. Grundl; ${ }^{235}$ U(n,f) Cf-AV [576]: also Grundl, J.A. and Gilliam, D.M. (1983) Trans. Am. Nucl. Soc. 44, 533; ${ }^{239} \mathrm{Pu}(\mathrm{n}, \mathrm{f}) \mathrm{Cf}-\mathrm{AV}[674]$

Herbach, C.M., et al. (1985) IAEA Report INDC(GDR)-35 and IAEA Report INDC(GDR)-37; ${ }^{239} \mathrm{Pu}(\mathrm{n}, \mathrm{f})$ [615-617]: also ZFK-592, 152 (1986)

Herbach, C.M., et al. (1985) IAEA Report INDC(GDR)-35 and IAEA Report INDC(GDR)-37; ${ }^{235} \mathrm{U}(\mathrm{n}, \mathrm{f})$ [587]: also ZFK-592, 152 (1986)

Holden, N.E. (1981) Brookhaven National Laboratory Report BNL-NCS-51388; ${ }^{197} \mathrm{Au}(\mathrm{n}, \gamma)[704]$

Hughes, D.J., et al. (1958) Report WASH-745, 9; ${ }^{10} \mathrm{~B}$ (tot) [190\#]

Hussain, H.A. and Hunt, S.E. (1983) Int. J. Appl. Radiat. Isot. 34, 731; ${ }^{197} \mathrm{Au}(\mathrm{n}, \gamma)$ [315]

Iyer, R.H. and Sampathkumar, R. (1969) Nuclear Phys. and Solid State Phys., Roorkee, 2, 289; ${ }^{239} \mathrm{Pu}(\mathrm{n}, \mathrm{f}) / 238 \mathrm{U}(\mathrm{n}, \mathrm{f})[668]$; ${ }^{235} \mathrm{U}(\mathrm{n}, \mathrm{f}) /{ }^{238} \mathrm{U}(\mathrm{n}, \mathrm{f})[871]$

James, G.D. (1970) Nuclear Data for Reactors, Helsinki, STI/PUB/259, I, 267; ${ }^{239} \mathrm{Pu}(\mathrm{n}, \mathrm{f}) \mathrm{l}^{10} \mathrm{~B}(\mathrm{n}, \alpha)$, shape [679]

Jarvis, G.A., et al. (1953) Los Alamos National Laboratory Report LA-1571; ${ }^{238} \mathrm{U}(\mathrm{n}, \mathrm{f}){ }^{235} \mathrm{U}(\mathrm{n}, \mathrm{f})[855]$

Johnsrud, A.E., et al. (1959) Phys. Rev. 116, $927 ;{ }^{197} \mathrm{Au}(\mathrm{n}, \gamma){ }^{235} \mathrm{U}(\mathrm{n}, \mathrm{f})$, shape [325]

Joly, S., et al. (1979) Nucl. Sci. Eng. 70, 53; ${ }^{197} \mathrm{Au}(\mathrm{n}, \gamma)[344]$

Käppeler, F. (1973) Karlsruhe Report KFK-1772; ${ }^{235} \mathrm{U}(\mathrm{n}, \mathrm{f})$ [581]; ${ }^{235} \mathrm{U}(\mathrm{n}, \mathrm{f})$, shape [582]

Kalinin, P. and Pankratov, V.M. (1962) Peaceful Uses of Atomic Energy, Geneva 16, 136; ${ }^{238} \mathrm{U}(\mathrm{n}, \mathrm{f})$, shape [875]

Kari, K. (1978) Karlsruhe Report KFK-2673; ${ }^{235} \mathrm{U}(\mathrm{n}, \mathrm{f})[520] ;{ }^{239} \mathrm{Pu}(\mathrm{n}, \mathrm{f})[521]$

Kazakov, L.E., et al. (1986) Yad. Konst. 3, 37; ${ }^{238} \mathrm{U}(\mathrm{n}, \gamma) / 6 \mathrm{Li}(\mathrm{n}, \alpha)[482,483] ;{ }^{238} \mathrm{U}(\mathrm{n}, \gamma) /{ }^{10} \mathrm{~B}(\mathrm{n}, \alpha)$, shape $[484,485]$

Knitter, H.-H. and Coppola, M. (1967) Euratom Report EUR-3454E; ${ }^{6} \mathrm{Li}(\mathrm{n}, \mathrm{n})$ [212\#]

Knitter, H.-H., et al. (1977) Euratom Report EUR-5726E; ${ }^{6} \mathrm{Li}\left(\right.$ tot) [214\#]; ${ }^{6} \mathrm{Li}(\mathrm{n}, \mathrm{n})$ [215\#]

Knoll, G.F. and Poenitz, W.P. (1967) J. Nucl. Energy 21, 643; ${ }^{235} \mathrm{U}(\mathrm{n}, \mathrm{f})[518] ;{ }^{235} \mathrm{U}(\mathrm{n}, \gamma) /{ }^{197} \mathrm{Au}(\mathrm{n}, \gamma)[519]$

Konks, V.A., et al. (1964) Zh. Eksp. Teor. Fiz. 46, 80; English translation in Sov. Phys. JETP 19, 59; ${ }^{197} \mathrm{Au}(\mathrm{n}, \gamma) /{ }^{10} \mathrm{~B}(\mathrm{n}, \alpha)[265]$

Kononov, V.N., et al. (1977) Yad. Fiz. 26, 947; English translation in Sov. Nucl. Phys. 26, 500; ${ }^{197} \mathrm{Au}(\mathrm{n}, \gamma){ }^{10} \mathrm{~B}\left(\mathrm{n}, \alpha_{1}\right)$, shape [352]

Koroleva, V.P. and Stavisskii, Yu.Ya. (1966) At. Energy 20, 431; English translation in Sov. J. At. Energy 20, 493; ${ }^{238} \mathrm{U}(\mathrm{n}, \gamma)$ [438]

Kuks, I.M., et al. (1971) At. Energy 30, 55; ${ }^{238} \mathrm{U}(\mathrm{n}, \mathrm{f})$ [877]

Kuks, I.M., et al. (1971) Conf. on Neutron Physics, Kiev 4, 18; ${ }^{235} \mathrm{U}(\mathrm{n}, \mathrm{f})$ [878]

Lamaze, G.P., et al. (1975) Nucl. Sci. Eng. 56, $94 ;{ }^{10} B\left(n, \alpha_{0}\right) /{ }^{10} B\left(n, \alpha_{1}\right)[145 \#]$

Lamaze, G.P., et al. (1978) Nucl. Sci. Eng. 68, $183 ;{ }^{6} \mathrm{Li}(\mathrm{n}, \alpha)$, shape [232\#]

Lampere, R.W. (1956) Phys. Rev. 104, 1654; ${ }^{238} \mathrm{U}(\mathrm{n}, \mathrm{f}){ }^{235} \mathrm{U}(\mathrm{n}, \mathrm{f})$ [821]

Lane, R.O., et al. (1961) Ann. Phys. 12, 135; ${ }^{6} \mathrm{Li}(\mathrm{n}, \mathrm{n})[253-255 \#]$

Lane, R.O., et al. (1971) Phys. Rev. C 4, 380; ${ }^{10} \mathrm{~B}(\mathrm{n}, \mathrm{n})[170 \#]$ 
TABLE 3.1. EXPERIMENTS USED FOR THE SIMULTANEOUS EVALUATION (cont.)

(number of data sets in the GMA database for a particular reaction (or ratio) is given in square brackets)

Lemley, J.R., et al. (1971) Nucl. Sci. Eng. 43, 281; ${ }^{235} \mathrm{U}(\mathrm{n}, \mathrm{f}) /{ }^{6} \mathrm{Li}(\mathrm{n}, \alpha)$, shape [244]

Lehto, W.K. (1970) Nucl. Sci. Eng. 39, 361; $\left.{ }^{239} \mathrm{Pu}(\mathrm{n}, \mathrm{f})\right)^{235} \mathrm{U}(\mathrm{n}, \mathrm{f})$, shape [635]

Le Rigoleur, C., et al. (1975) Proc. Conf. on Nuclear Cross Sections and Technology, Washington DC, NBS Spec. Publ. 425, II, $953 ;{ }^{238} \mathrm{U}(\mathrm{n}, \gamma)[428]$

Le Rigoleur, C., et al. (1976) CEA Saclay Report CEA-R-4788; ${ }^{197} \mathrm{Au}(\mathrm{n}, \gamma)[342-343]$

Li Jingwen, et al. (1982) Proc. Int. Conf. on Nuclear Data for Science and Technology, Antwerp $55 ;{ }^{235} \mathrm{U}(\mathrm{n}, \mathrm{f})[643] ;{ }^{239} \mathrm{Pu}(\mathrm{n}, \mathrm{f})$ [644]

Li Jingwen, et al. (1986) IAEA Report INDC(CPR)-009; ${ }^{235} \mathrm{U}(\mathrm{n}, \mathrm{f})[645] ;{ }^{238} \mathrm{U}(\mathrm{n}, \mathrm{f}){ }^{235} \mathrm{U}(\mathrm{n}, \mathrm{f})[646]$

Lindner, M., et al. (1976) Nucl. Sci. Eng. 59, 381; ${ }^{197} \mathrm{Au}(\mathrm{n}, \gamma){ }^{235} \mathrm{U}(\mathrm{n}, \mathrm{f})[302] ;{ }^{238} \mathrm{U}(\mathrm{n}, \gamma){ }^{235} \mathrm{U}(\mathrm{n}, \mathrm{f})[410]$

Linenberger, G.A., et al. (1944) Los Alamos National Laboratory Report LA-179; ${ }^{238} \mathrm{U}(\mathrm{n}, \gamma){ }^{235} \mathrm{U}(\mathrm{n}, \mathrm{f})$, shape [425]

Macklin, R.L. (1981) Nucl. Sci. Eng. 79, 265; ${ }^{197} \mathrm{Au}(\mathrm{n}, \gamma) /{ }^{235} \mathrm{U}(\mathrm{n}, \mathrm{f})[314] ;{ }^{197} \mathrm{Au}(\mathrm{n}, \gamma) /{ }^{6} \mathrm{Li}(\mathrm{n}, \alpha)[313]$

Macklin, R.L. and Gibbons, J.H. (1965) Phys. Rev. 140, B324; ${ }^{10} \mathrm{~B}\left(\mathrm{n}, \mathrm{\alpha}_{0}\right) /{ }^{10} \mathrm{~B}\left(\mathrm{n}, \mathrm{\alpha}_{1}\right)[149 \#]$

Macklin, R.L. and Gibbons, J.H. (1968) Phys. Rev. 165, 1147; ${ }^{10} \mathrm{~B}\left(\mathrm{n}, \alpha_{0}\right) /{ }^{10} \mathrm{~B}\left(\mathrm{n}, \alpha_{1}\right)[125 \#] ;{ }^{10} \mathrm{~B}\left(\mathrm{n}, \alpha_{0}\right)[126 \#]$

Macklin, R.L., et al. (1975) Phys. Rev. C 11, $1270 ;{ }^{197} \mathrm{Au}(\mathrm{n}, \gamma) /{ }^{6} \mathrm{Li}(\mathrm{n}, \alpha)[312]$

Macklin, R.L., et al. (1979) Nucl. Sci. Eng. 71, 205; ${ }^{6} \operatorname{Li}(\mathrm{n}, \alpha)^{235} \mathrm{U}(\mathrm{n}, \mathrm{f})$, shape [200]

Mahdavi, M., et al. (1982) Proc. Int. Conf. on Nuclear Data for Science and Technology, Antwerp 58; ${ }^{239} \mathrm{Pu}(\mathrm{n}, \mathrm{f}){ }^{235} \mathrm{U}(\mathrm{n}, \mathrm{f})[637]$

Manabe, M., et al. (1986) Tohoku University Report NETU-47, 61; $\left.{ }^{238} \mathrm{U}(\mathrm{n}, \mathrm{f})\right)^{235} \mathrm{U}(\mathrm{n}, \mathrm{f})[856]$

Mangialajo, M., et al. (1963) Nucl. Phys. 43, 124; ${ }^{238} \mathrm{U}(\mathrm{n}, \mathrm{f})$, shape [881]

Meadows, J.W. (1970) Neutron Standards and Flux Normalization, Argonne National Laboratory Report 257, 129; ${ }^{6} \mathrm{Li}(\mathrm{n}, \alpha)$ $[707 \#] ;{ }^{10} \mathrm{~B}(\mathrm{n}, \alpha)[703 \#]$

Meadows, J.W. (1983) Argonne National Laboratory Report ANL-NDM-83; ${ }^{238} \mathrm{U}(\mathrm{n}, \mathrm{f}){ }^{235} \mathrm{U}(\mathrm{n}, \mathrm{f})[803] ;{ }^{239} \mathrm{Pu}(\mathrm{n}, \mathrm{f}){ }^{235} \mathrm{U}(\mathrm{n}, \mathrm{f})$ [602]

Meadows, J.W. (1988) Ann. Nucl. Energy 15, 421; Argonne National Laboratory Report ANL/NDM-97 (1986); ${ }^{238} \mathrm{U}(\mathrm{n}, \mathrm{f}) /$ ${ }^{235} \mathrm{U}(\mathrm{n}, \mathrm{f})[865] ;{ }^{239} \mathrm{Pu}(\mathrm{n}, \mathrm{f}) /{ }^{235} \mathrm{U}(\mathrm{n}, \mathrm{f})[685]$

Meadows, J.W. and Whalen, J.F. (1972) Nucl. Sci. Eng. 48, 221; ${ }^{6} \mathrm{Li}($ tot) [229\#]

Menlove, H.O. and Poenitz, W.P. (1968) Nucl. Sci. Eng. 33, 24; ${ }^{238} \mathrm{U}(\mathrm{n}, \gamma) /{ }^{197} \mathrm{Au}(\mathrm{n}, \gamma)[419] ;{ }^{238} \mathrm{U}(\mathrm{n}, \gamma)[420] ;{ }^{238} \mathrm{U}(\mathrm{n}, \gamma)$, shape [421]

Michaudon, A., et al. (1960) J. de Phys. 21, 429; $\left.{ }^{235} \mathrm{U}(\mathrm{n}, \mathrm{f})\right)^{10} \mathrm{~B}(\mathrm{n}, \alpha)$, shape [728]

Moat, A. (1958) personal communication in 1958, see references in J. Nucl. Energy A/B $14(1961) 85 ;{ }^{238} \mathrm{U}(\mathrm{n}, \mathrm{f})[\mathrm{[} 61], ;{ }^{235} \mathrm{U}(\mathrm{n}, \mathrm{f})$ [584]; ${ }^{239} \mathrm{Pu}(\mathrm{n}, \mathrm{f})[657]$

Mooring, F.P., et al. (1966) Nucl. Phys. 82, $16 ;{ }^{10} \mathrm{~B}$ (tot) $[187 \#] ;{ }^{10} \mathrm{~B}(\mathrm{n}, \mathrm{n})[167 \#]$

Mostovaya, T.A., et al. (1980) Conf. on Neutron Physics, $\operatorname{Kiev} 3,30 ;{ }^{235} \mathrm{U}(\mathrm{n}, \mathrm{f}){ }^{10} \mathrm{~B}(\mathrm{n}, \alpha)$, shape [530]

Moxon, M.C. (1969) Harwell Report AERE-R6074; ${ }^{238} \mathrm{U}(\mathrm{n}, \gamma) /{ }^{10} \mathrm{~B}\left(\mathrm{n}, \alpha_{1}\right)[450]$

Muradyan, H.W., et al. (1977) Conf. on Neutron Physics, $\operatorname{Kiev} 3,119 ;{ }^{235} \mathrm{U}(\mathrm{n}, \mathrm{f}) /{ }^{10} \mathrm{~B}\left(\mathrm{n}, \alpha_{1}\right)$, shape [538]

Murzin, A.V., et al. (1980) Conf. on Neutron Physics, Kiev 2, 257; ${ }^{235} \mathrm{U}(\mathrm{n}, \mathrm{f}) /{ }^{10} \mathrm{~B}\left(\mathrm{n}, \alpha_{1}\right)[540]$

Nellis, D.O., et al. (1970) Phys. Rev. C 1, 847; ${ }^{10} \mathrm{~B}\left(\mathrm{n}, \alpha_{1}\right)$ [107\#]

Nereson, N.G. (1954) Los Alamos National Laboratory Report LA-1655; ${ }^{10} \mathrm{~B}(\mathrm{tot})[181 \#]$

Nordborg, C., et al. (1976) Fast Neutron Fission Cross Sections of ${ }^{233} \mathrm{U},{ }^{235} \mathrm{U},{ }^{238} \mathrm{U}$ and ${ }^{239} \mathrm{Pu}$, Argonne National Laboratory Report ANL-76-90, 128; ${ }^{238} \mathrm{U}(\mathrm{n}, \mathrm{f}) \mathrm{P}^{235} \mathrm{U}(\mathrm{n}, \mathrm{f})[830]$

Olson, M.D. and Kavanagh, R.W. (1984) Phys. Rev. C 30, 1375; ${ }^{10} \mathrm{~B}\left(\mathrm{n}, \mathrm{\alpha}_{0}\right)[118 \#]$

Overley, J.C., et al. (1974) Nucl. Phys. A 221, 573; ${ }^{6} \mathrm{Li}(\mathrm{n}, \alpha)$ [285\#]

Panitkin, Yu.G., et al. (1971) Nuclear Data for Reactors, Helsinki, STI/PUB/259 2, 57; also Conf. on Neutron Physics, Kiev 1, $321 ;{ }^{238} \mathrm{U}(\mathrm{n}, \gamma){ }^{235} \mathrm{U}(\mathrm{n}, \mathrm{f})$, shape [466]

Panitkin, Yu.G. and Tolstikov, V.A. (1972) At. Energy 33, 782; English translation in Sov. J. At. Energy 33, 893; ${ }^{238} \mathrm{U}(\mathrm{n}, \gamma) /$

${ }^{235} \mathrm{U}(\mathrm{n}, \mathrm{f})$, shape [465]

Panitkin, Yu.G. and Sherman, L.E. (1975) At. Energy 39, 17; English translation in Sov. J. At. Energy 39, 591; $238 \mathrm{U}(\mathrm{n}, \gamma)$ [464] 
TABLE 3.1. EXPERIMENTS USED FOR THE SIMULTANEOUS EVALUATION (cont.)

(number of data sets in the GMA database for a particular reaction (or ratio) is given in square brackets)

Paulsen, A., et al. (1975) Atomkern 26, 80; ${ }^{197} \mathrm{Au}(\mathrm{n}, \gamma)[337,338]$

Perez, R.B., et al. (1973) Nucl. Sci. Eng. 52, 46; ${ }^{235} \mathrm{U}(\mathrm{n}, \mathrm{f}) /{ }^{10} \mathrm{~B}(\mathrm{n}, \alpha)$, shape [514]

Perez, R.B., et al. (1974) Nucl. Sci. Eng. 55, 203; ${ }^{235} \mathrm{U}(\mathrm{n}, \mathrm{f}) /{ }^{10} \mathrm{~B}(\mathrm{n}, \alpha)$, shape [513]

Perkin, J.L., et al. (1965) J. Nucl. Energy A/B 19, 423; ${ }^{235} \mathrm{U}(\mathrm{n}, \mathrm{f})[725] ;{ }^{239} \mathrm{Pu}(\mathrm{n}, \mathrm{f})[619]$

Petree, B., et al. (1951) Phys. Rev. 83, 1148; ${ }^{10} \mathrm{~B}\left(\mathrm{n}, \alpha_{0}\right) /{ }^{10} \mathrm{~B}\left(\mathrm{n}, \alpha_{1}\right)[162 \#, 163 \#]$

Pfletschinger, E. and Käppeler, F. (1970) Nucl. Sci. Eng. 40, 375; ${ }^{239} \mathrm{Pu}(\mathrm{n}, \mathrm{f}) /{ }^{235} \mathrm{U}(\mathrm{n}, \mathrm{f})[605]$

Poenitz, W.P. (1970) Nucl. Sci. Eng. 40, 383; ${ }^{238} \mathrm{U}(\mathrm{n}, \gamma){ }^{235} \mathrm{U}(\mathrm{n}, \mathrm{f})$, shape [405]; ${ }^{238} \mathrm{U}(\mathrm{n}, \gamma){ }^{235} \mathrm{U}(\mathrm{n}, \mathrm{f})[406] ;{ }^{238} \mathrm{U}(\mathrm{n}, \gamma) /{ }^{239} \mathrm{Pu}(\mathrm{n}, \mathrm{f})[407]$;

${ }^{239} \mathrm{Pu}(\mathrm{n}, \mathrm{f}) /{ }^{235} \mathrm{U}(\mathrm{n}, \mathrm{f})[626]$

Poenitz, W.P. (1974) Nucl. Sci. Eng. 53, 370; ${ }^{235} \mathrm{U}(\mathrm{n}, \mathrm{f})$, shape $[556,559] ;{ }^{235} \mathrm{U}(\mathrm{n}, \mathrm{f})[557,558,560,561] ;{ }^{235} \mathrm{U}(\mathrm{n}, \mathrm{f}) /{ }^{6} \mathrm{Li}(\mathrm{n}, \alpha)$, shape [562]

Poenitz, W.P. (1975) Nucl. Sci. Eng. 57, 300; ${ }^{197} \mathrm{Au}(\mathrm{n}, \gamma)$, shape $[310] ;{ }^{197} \mathrm{Au}(\mathrm{n}, \gamma)[311] ;{ }^{238} \mathrm{U}(\mathrm{n}, \gamma) /{ }^{197} \mathrm{Au}(\mathrm{n}, \gamma)[412]$

Poenitz, W.P. (1977) Nucl. Sci. Eng. 64, 894; ${ }^{235} U(\mathrm{n}, \mathrm{f})$, shape [553]; ${ }^{235} \mathrm{U}(\mathrm{n}, \mathrm{f})[554,555]$

Poenitz, W.P. (1984) Pre-evaluation at thermal energy; ${ }^{10} \mathrm{~B}\left(\mathrm{n}, \alpha_{0}\right) /{ }^{10} \mathrm{~B}\left(\mathrm{n}, \alpha_{1}\right)[706 \#] ;{ }^{238} \mathrm{U}(\mathrm{n}, \gamma)[705]$

Poenitz, W.P. and Armani, R.J. (1972) J. Nucl. Energy 26, 483; ${ }^{238} \mathrm{U}(\mathrm{n}, \mathrm{f}) / 235 \mathrm{U}(\mathrm{n}, \mathrm{f})[816-818] ;{ }^{238} \mathrm{U}(\mathrm{n}, \mathrm{f}) / 235 \mathrm{U}(\mathrm{n}, \mathrm{f})$, shape [819]

Poenitz, W.P. (1985) ${ }^{6} \mathrm{Li}(\mathrm{n}, \alpha)$ [702\#]: Additional data was added to the evaluation at thermal energy undertaken by

Holden, N.E. (1981) Brookhaven National Laboratory Report BNL-NCS-51388

Poenitz, W.P. and Meadows, J.W. (1974) Neutron Standard Reference Data, Vienna, STI/PUB/371, 95; ${ }^{6} \operatorname{Li}(\mathrm{n}, \alpha)[241 \#]$

Poenitz, W.P. and Meadows, J.W. (1976) unpublished, ${ }^{6} \mathrm{Li}(\mathrm{n}, \alpha){ }^{235} \mathrm{U}(\mathrm{n}, \mathrm{f})$, shape [250]

Poenitz, W.P., et al. (1966) J. Nucl. Energy A/B 20, 825; ${ }^{197} \mathrm{Au}(\mathrm{n}, \gamma)[358-359]$

Poenitz, W.P., et al. (1968) J. Nucl. Energy 22, 505; ${ }^{197} \mathrm{Au}(\mathrm{n}, \gamma)$, shape [360]

Poenitz, W.P., et al. (1981) Nucl. Sci. Eng. 78, 239; ${ }^{238} \mathrm{U}(\mathrm{n}, \gamma) /{ }^{235} \mathrm{U}(\mathrm{n}, \mathrm{f})[460] ;{ }^{238} \mathrm{U}(\mathrm{n}, \gamma) /{ }^{197} \mathrm{Au}(\mathrm{n}, \gamma)[461]$

Pankratov, V.M., et al. (1960) At. Energy 9, 399; English translation in Sov. J. At. Energy 9, 939 (1961): also J. Nucl. Energy A/B 16, $494(1962) ;{ }^{235} \mathrm{U}(\mathrm{n}, \mathrm{f})$, shape [721]; ${ }^{238} \mathrm{U}(\mathrm{n}, \mathrm{f})$, shape [873]

Pankratov, V.M., et al. (1964) At. Energy 14, 177; English translation in Sov. J. At. Energy 14, 167; ${ }^{235} \mathrm{U}(\mathrm{n}, \mathrm{f})$, shape [722];

${ }^{238} \mathrm{U}(\mathrm{n}, \mathrm{f})$, shape [874]

Quan, B.L. and Block, R.C. (1976) Chicago Operations Office, AEC Report COO-2479-14 ${ }^{238} \mathrm{U}(\mathrm{n}, \gamma) /{ }^{10} \mathrm{~B}\left(\mathrm{n}, \alpha_{1}\right)[471]$

Renner, C. (1978) PhD thesis, Universidade de São Paulo, Brazil, ${ }^{6} \operatorname{Li}(n, \alpha)$, shape [202\#]

Rimawi, K. and Chrien, R.E. (1975) Proc. Conf. on Neutron Cross Sections and Technology, Washington DC, NBS Spec. Publ. 425, II, 920; ${ }^{196} \mathrm{Au}(\mathrm{n}, \gamma) /{ }^{10} \mathrm{~B}\left(\mathrm{n}, \alpha_{1}\right)[380] ;{ }^{238} \mathrm{U}(\mathrm{n}, \gamma) /{ }^{10} \mathrm{~B}\left(\mathrm{n}, \alpha_{1}\right)[440] ;{ }^{238} \mathrm{U}(\mathrm{n}, \gamma) /{ }^{197} \mathrm{Au}(\mathrm{n}, \gamma)[441]$

Robertson, J.C., et al. (1971) J. Nucl. Energy 23, 205; ${ }^{197} \mathrm{Au}(\mathrm{n}, \gamma)$ [367]

Rohrer, W. (1960) personal communication to authors, Ann. Phys. 10, 455; ${ }^{10} \mathrm{~B}$ (tot) [186\#]

Ryabov, Yu.V. (1971) At. Energy 46, 154; English translation in Sov. J. At. Energy 46, 178; ${ }^{239} \mathrm{Pu}(\mathrm{n}, \mathrm{f}) /{ }^{10} \mathrm{~B}(\mathrm{n}, \alpha)$, shape [660-663]

Ryves, T.B., et al. (1969) J. Nucl. Energy 23, 205; Ryves, T.B. and Robertson, J.C. (1971) J. Nucl. Energy 25, 557; ${ }^{197} \mathrm{Au}(\mathrm{n}, \gamma)$ [367]

Ryves, T.B., et al. (1973) J. Nucl. Energy 27, 519; ${ }^{238} \mathrm{U}(\mathrm{n}, \gamma)$, shape [455]

Safford, G.J., et al. (1960) Phys. Rev. 119, 1291; ${ }^{10}$ B(tot) [188\#]

Sato, O., et al. (1983) Tohoku University Report NETU-41, 33; ${ }^{238} \mathrm{U}(\mathrm{n}, \mathrm{f}) /{ }^{235} \mathrm{U}(\mathrm{n}, \mathrm{f})[859]$

Schagrov, E.A., et al. (1980) Conf. on Neutron Physics, Kiev 3, 45; ${ }^{235} \mathrm{U}(\mathrm{n}, \mathrm{f})$ [525]

Schomberg, M., et al. (1970) Nuclear Data for Reactors, Helsinki, STI/PUB/259, I, 315; ${ }^{239} \mathrm{Pu}(\mathrm{n}, \mathrm{f}) /{ }^{10} \mathrm{~B}(\mathrm{n}, \alpha)$, shape [680]

Schrack, R.A., et al. (1978) Nucl. Sci. Eng. 68, 189; ${ }^{10} \mathrm{~B}\left(\mathrm{n}, \mathrm{\alpha}_{1}\right)$, shape [105\#]

Schmitt, H.W., et al. (1960) Nucl. Phys. 17, 109; ${ }^{10} \mathrm{~B}$ (tot) [189\#]

Schmitt, H.W. and Cook, C.W. (1960) Nucl. Phys. 20, 202; ${ }^{197} \mathrm{Au}(\mathrm{n}, \gamma)[330]$

Schroeder, I.G., et al. (1984) National Bureau of Standards, Gaithersburg, USA, personal communication; also Nuclear Standard Reference Data, Geel, IAEA-TECDOC-335, 320, ${ }^{235} \mathrm{U}(\mathrm{n}, \mathrm{f}), \mathrm{Cf}-\mathrm{AV}$ [517]; ${ }^{239} \mathrm{Pu}(\mathrm{n}, \mathrm{f}), \mathrm{Cf}-\mathrm{AV}$ [614] 
TABLE 3.1. EXPERIMENTS USED FOR THE SIMULTANEOUS EVALUATION (cont.)

(number of data sets in the GMA database for a particular reaction (or ratio) is given in square brackets)

Sealock, R.M. and Overlay, J.C. (1976) Phys. Rev. C 13, 2149; ${ }^{10} \mathrm{~B}\left(\mathrm{n}, \mathrm{\alpha}_{0}\right)[110 \#] ;{ }^{10} \mathrm{~B}\left(\mathrm{n}, \alpha_{1}\right)[111 \#]$

Sealock, R.M., et al. (1981) Nucl. Phys. A 357, 279; ${ }^{10} \mathrm{~B}\left(\mathrm{n}, \alpha_{0}\right)$ inverse reaction [112\#]

Shengyun, et al. (1984) Chin. J. Nucl. Phys. 6, $1 ;{ }^{197} \mathrm{Au}(\mathrm{n}, \gamma)[372]$

Smith, A.B., et al. (1977) Argonne National Laboratory Report ANL/NDM-29; ${ }^{6} \mathrm{Li}($ tot) [218\#,219\#]

Smith, A.B., et al. (1982) Nucl. Phys. A 373, 305; ${ }^{6} \mathrm{Li}(\mathrm{n}, \mathrm{n})$ [223\#]

Smith, R.K., et al. (1975) personal communication to G. Hanson; ${ }^{235} \mathrm{U}(\mathrm{n}, \mathrm{f})$ [567]; ${ }^{238} \mathrm{U}(\mathrm{n}, \mathrm{f})$ [648]; Sowerby, M.G. (1966) J. Nucl. Energy A/B 20, $135 ;{ }^{10} \mathrm{~B}\left(\mathrm{n}, \alpha_{0}\right){ }^{10} \mathrm{~B}\left(\mathrm{n}, \alpha_{1}\right),[140 \#] ;{ }^{10} \mathrm{~B}\left(\mathrm{n}, \alpha_{0}\right) /{ }^{10} \mathrm{~B}\left(\mathrm{n}, \alpha_{1}\right)$, shape [141\#]

Sowerby, M.G., et al. (1970) J. Nucl. Energy 24, 323; ${ }^{6} \mathrm{Li}(\mathrm{n}, \alpha) /{ }^{10} \mathrm{~B}(\mathrm{n}, \alpha),[131] ;{ }^{6} \mathrm{Li}(\mathrm{n}, \alpha) /{ }^{10} \mathrm{~B}\left(\mathrm{n}, \alpha_{1}\right)$, shape [132]; Spencer, R.R. and Käppeler, F. (1975) Proc. Conf. on Nuclear Cross Sections and Technology, Washington, DC, NBS Spec. Publ. 425, II, $620 ;{ }^{238} \mathrm{U}(\mathrm{n}, \gamma) /{ }^{197} \mathrm{Au}(\mathrm{n}, \gamma)$, shape [457]; ${ }^{238} \mathrm{U}(\mathrm{n}, \gamma){ }^{235} \mathrm{U}(\mathrm{n}, \mathrm{f})$, shape [458]; Stavisskii, Yu. Ya., et al. (1966) At. Energy 20, 431; ${ }^{238} \mathrm{U}(\mathrm{n}, \gamma)[438]$

Stavisskii, Yu.Ya., et al. (1971) Nucl. Constants, Issue 7, 218; English translation in IAEA Report INDC(CCP)-43/L, 225; ${ }^{238} \mathrm{U}(\mathrm{n}, \gamma) /{ }^{10} \mathrm{~B}(\mathrm{n}, \alpha)$ [475]; Stein, W.E., et al. (1968) Nuclear Cross-Sections and Technology, Washington DC, NBS Spec. Publ. 299, 1, 627; ${ }^{238} \mathrm{U}(\mathrm{n}, \mathrm{f}) \mathrm{f}^{235} \mathrm{U}(\mathrm{n}, \mathrm{f})$ [822]; Stelts, M.L., et al. (1979) Phys. Rev. C 19, 1159; ${ }^{10} \mathrm{~B}\left(\mathrm{n}, \alpha_{0}\right) /{ }^{10} \mathrm{~B}\left(\mathrm{n}, \alpha_{1}\right)$ [142\#]; Szabo, I., et al. (1970) Neutron Standards and Flux Normalization, Argonne National Laboratory Report 257, 208; revised in Fast Neutron Fission Cross Sections of ${ }^{233} \mathrm{U},{ }^{235} \mathrm{U},{ }^{238} \mathrm{U}$ and ${ }^{239} \mathrm{Pu}$, Argonne National Laboratory Report ANL-76-90, 208; ${ }^{235} \mathrm{U}(\mathrm{n}, \mathrm{f})[503] ;{ }^{239} \mathrm{Pu}(\mathrm{n}, \mathrm{f})[620]$

Szabo, I., et al. (1971) Neutron Cross-Sections and Technology, University of Tennessee, Knoxville, CONF-710301, 573; revised in Fast Neutron Fission Cross Sections of ${ }^{233} \mathrm{U},{ }^{235} \mathrm{U},{ }^{238} \mathrm{U}$ and ${ }^{239} \mathrm{Pu}$, Argonne National Laboratory Report ANL-7690, 208; ${ }^{235} \mathrm{U}(\mathrm{n}, \mathrm{f})[504] ;{ }^{239} \mathrm{Pu}(\mathrm{n}, \mathrm{f})[621]$

Szabo, I., et al. (1973) Conf. on Neutron Physics, Kiev 3, 27; revised in Fast Neutron Fission Cross Sections of ${ }^{233} \mathrm{U},{ }^{235} \mathrm{U},{ }^{238} \mathrm{U}$ and ${ }^{239} \mathrm{Pu}$, Argonne National Laboratory Report ANL-76-90, 208; ${ }^{235} \mathrm{U}(\mathrm{n}, \mathrm{f})[505] ;{ }^{239} \mathrm{Pu}(\mathrm{n}, \mathrm{f})[622]$

Szabo, I., et al. (1976) Fast Neutron Fission Cross Sections of ${ }^{233} \mathrm{U},{ }^{235} \mathrm{U},{ }^{238} \mathrm{U}$ and ${ }^{239} \mathrm{Pu}$, Argonne National Laboratory Report ANL-76-90, 208; ${ }^{235} \mathrm{U}(\mathrm{n}, \mathrm{f})[506] ;{ }^{239} \mathrm{Pu}(\mathrm{n}, \mathrm{f})[623]$

Tsukada, K. and Tanaka, O. (1963) unpublished; ${ }^{10} \mathrm{~B}($ tot $)$ [191]

Uttley, C.A. and Phillips, J.A. (1956) Harwell Report AERE NP/R1996; ${ }^{238} \mathrm{U}(\mathrm{n}, \mathrm{f})[869] ;{ }^{235} \mathrm{U}(\mathrm{n}, \mathrm{f})[526] ;{ }^{239} \mathrm{Pu}(\mathrm{n}, \mathrm{f})[628]$

Uttley, C.A., et al. (1970) Neutron Standards and Flux Normalization, Argonne National Laboratory Report 257, 80; ${ }^{6} \mathrm{Li}($ tot) [235\#]

Van Shi-Di, et al. (1965) Physics and Chemistry of Fission, Salzburg I, 287; ${ }^{235} \mathrm{U}(\mathrm{n}, \mathrm{f}) /^{10} \mathrm{~B}(\mathrm{n}, \alpha)$, shape [727]

Varnagy, M. and Csikai, J. (1982) Nucl. Instrum. Meth. 196, 465; ${ }^{238} \mathrm{U}(\mathrm{n}, \mathrm{f}){ }^{235} \mathrm{U}(\mathrm{n}, \mathrm{f})[848] ;{ }^{239} \mathrm{Pu}(\mathrm{n}, \mathrm{f}){ }^{235} \mathrm{U}(\mathrm{n}, \mathrm{f})[666]$

Viesti, G. and Liskien, H. (1979) Ann. Nucl. Energy 6, 13; ${ }^{10} \mathrm{~B}\left(\mathrm{n}, \alpha_{1}\right)$, shape [135\#, 136\#, 137\#]

Vorotnikov, P.E., et al. (1975) Yad. Fiz., Issue 20, 9; English translation in IAEA Report INDC(CCP)-66, 6; ${ }^{238} \mathrm{U}(\mathrm{n}$,f), shape [839]

Wagemans, C. and Deruytter, A.J. (1976) Ann. Nucl. Energy 3, 437; ${ }^{235} \mathrm{U}(\mathrm{n}, \mathrm{f}) /{ }^{10} \mathrm{~B}(\mathrm{n}, \alpha)$, shape [544]

Wagemans, C. and Deruytter, A.J. (1984) Nuclear Standard Reference Data, IAEA-TECDOC-335, $156 ;{ }^{235} \mathrm{U}(\mathrm{n}, \mathrm{f}) /{ }^{10} \mathrm{~B}(\mathrm{n}, \alpha)$, shape [545-546]

Wagemans, C., et al. (1980) Nuclear Cross Sections for Technology, Knoxville, October 1979, NBS Spec. Publ. 594, 961; ${ }^{235} \mathrm{U}(\mathrm{n}, \mathrm{f}) /{ }^{10} \mathrm{~B}(\mathrm{n}, \alpha)$, shape [541, 543]; ${ }^{235} \mathrm{U}(\mathrm{n}, \mathrm{f}) /{ }^{6} \mathrm{Li}(\mathrm{n}, \alpha)$, shape [542]

Wagemans, C., et al. (1980) Ann. Nucl. Energy 7, $495 ;{ }^{239} \mathrm{Pu}(\mathrm{n}, \mathrm{f}) /{ }^{6} \mathrm{Li}(\mathrm{n}, \alpha)$, shape $[547] ;{ }^{239} \mathrm{Pu}(\mathrm{n}, \mathrm{f}){ }^{10} \mathrm{~B}(\mathrm{n}, \alpha)$, shape [548]; ${ }^{239} \mathrm{Pu}(\mathrm{n}, \mathrm{f}){ }^{235} \mathrm{U}(\mathrm{n}, \mathrm{f})$, shape [549]

Wasson, O.A., et al. (1982) Nucl. Sci. Eng. 80, 282; ${ }^{235} \mathrm{U}(\mathrm{n}, \mathrm{f})[599]$

Wasson, O.A., et al. (1982) Nucl. Sci. Eng. 81, 196; ${ }^{235} \mathrm{U}(\mathrm{n}, \mathrm{f}) / 6 \mathrm{Li}(\mathrm{n}, \alpha)$, shape [585]; ${ }^{235} \mathrm{U}(\mathrm{n}, \mathrm{f})$, shape [586]; ${ }^{235} \mathrm{U}(\mathrm{n}, \mathrm{f})[570]$

Weston, L.W. and Lyon, W.S. (1961) Phys. Rev. 123, 948; ${ }^{197} \mathrm{Au}(\mathrm{n}, \gamma)$ [335]

Weston, L.W. and Todd, J.H. (1972) Oak Ridge National Laboratory, personal communication to R. Chrien; ${ }^{239} \mathrm{Pu}(\mathrm{n}, \mathrm{f}) /$

${ }^{10} \mathrm{~B}(\mathrm{n}, \alpha)$, shape [672]

Weston, L.W. and Todd, J.H. (1983) Nucl. Sci. Eng. 84, 248; ${ }^{239} \mathrm{Pu}(\mathrm{n}, \mathrm{f}){ }^{235} \mathrm{U}(\mathrm{n}, \mathrm{f})$, shape [536] 
TABLE 3.1. EXPERIMENTS USED FOR THE SIMULTANEOUS EVALUATION (cont.)

(number of data sets in the GMA database for a particular reaction (or ratio) is given in square brackets)

Weston, L.W. and Todd, J.H. (1984) Nucl. Sci. Eng. 88, 567; ${ }^{235} \mathrm{U}(\mathrm{n}, \mathrm{f}) /{ }^{10} \mathrm{~B}(\mathrm{n}, \alpha)$, shape [532]; ${ }^{235} \mathrm{U}(\mathrm{n}, \mathrm{f}) /{ }^{6} \mathrm{Li}(\mathrm{n}, \alpha)$, shape [533];

$\left.{ }^{239} \mathrm{Pu}(\mathrm{n}, \mathrm{f})\right|^{10} \mathrm{~B}(\mathrm{n}, \alpha)$, shape [534]; ${ }^{239} \mathrm{Pu}(\mathrm{n}, \mathrm{f}) /{ }^{6} \mathrm{Li}(\mathrm{n}, \alpha)$, shape [535]

White, P.H. (1965) J. Nucl. Energy A/B 19, 325; ${ }^{235} \mathrm{U}(\mathrm{n}, \mathrm{f})$ [499-502]

White, P.H., et al. (1965) Physics and Chemistry of Fission, Salzburg II, 219; ${ }^{239} \mathrm{Pu}(\mathrm{n}, \mathrm{f}) \mathrm{P}^{235} \mathrm{U}(\mathrm{n}, \mathrm{f})[608]$

White, P.H. and Warner, G.P. (1967) J. Nucl. Energy 21, 671; ${ }^{239} \mathrm{Pu}(\mathrm{n}, \mathrm{f}){ }^{235} \mathrm{U}(\mathrm{n}, \mathrm{f})[609] ;{ }^{238} \mathrm{U}(\mathrm{n}, \mathrm{f}){ }^{235} \mathrm{U}(\mathrm{n}, \mathrm{f})[815]$

Willard, H.B., et al. (1955) Phys. Rev. 98, 669; ${ }^{10} \mathrm{~B}(\mathrm{n}, \mathrm{n})[175]$

Wisshak, K. and Käppeler, F. (1978) Nucl. Sci. Eng. 66, 363; ${ }^{238} \mathrm{U}(\mathrm{n}, \gamma){ }^{197} \mathrm{Au}(\mathrm{n}, \gamma)[430,431]$

Wu Jingxia, et al. (1983) Chin. J. Nucl. Phys. 5, 158; ${ }^{238} \mathrm{U}(\mathrm{n}, \mathrm{f})[850]$

Yamamuro, N., et al. (1978) J. Nucl. Sci. Technol. 15, 637; ${ }^{238} \mathrm{U}(\mathrm{n}, \gamma){ }^{10} \mathrm{~B}(\mathrm{n}, \alpha)[423]$

Yamamuro, N., et al. (1980) J. Nucl. Sci. Technol. 17, $582 ;{ }^{238} \mathrm{U}(\mathrm{n}, \gamma) /{ }^{10} \mathrm{~B}\left(\mathrm{n}, \alpha_{1}\right)$, shape [422]

Yamamuro, N., et al. (1983) J. Nucl. Sci. Technol. 20, 797; ${ }^{197} \mathrm{Au}(\mathrm{n}, \gamma) /{ }^{10} \mathrm{~B}\left(\mathrm{n}, \alpha_{1}\right)[340] ;{ }^{197} \mathrm{Au}(\mathrm{n}, \gamma){ }^{10} \mathrm{~B}\left(\mathrm{n}, \alpha_{1}\right)$, shape [341]

Yan Wuguang, et al. (1975) At. Energy Sci. Technol. 9, 133; ${ }^{235} \mathrm{U}(\mathrm{n}, \mathrm{f})$ [738]

Yoshida, K., et al. (1983) Tohoku University Report NETU-44, 30; ${ }^{235} \mathrm{U}(\mathrm{n}, \mathrm{f})[528] ;{ }^{238} \mathrm{U}(\mathrm{n}, \mathrm{f})[857]$

Zhuravlev, K.D., et al. (1977) At. Energy 42, 56; English translation in Sov. J. At. Energy 42, $62 ;{ }^{235} \mathrm{U}(\mathrm{n}, \mathrm{f}) /{ }^{10} \mathrm{~B}(\mathrm{n}, \alpha)$, shape $[515] ;{ }^{239} \mathrm{Pu}(\mathrm{n}, \mathrm{f}) /{ }^{10} \mathrm{~B}(\mathrm{n}, \alpha)$, shape [630]; ${ }^{239} \mathrm{Pu}(\mathrm{n}, \mathrm{f}) /{ }^{10} \mathrm{~B}(\mathrm{n}, \alpha)[631]$

\# These data sets were excluded from the simultaneous evaluation so that they would be available for use in the $\mathrm{R}$ matrix analyses. 
${ }^{7} \mathrm{Li}$ system data

Bartle, C.M. (1980) Nucl. Instrum. Meth. 176, 503; ${ }^{6} \mathrm{Li}(\mathrm{n}, \mathrm{t})^{4} \mathrm{He}, \sigma(\theta), E_{\mathrm{n}}=2.2-3.9 \mathrm{MeV}$

Brown, R.E., et al. (1977) Phys. Rev. C 16, 513; ${ }^{6} \mathrm{Li}(\mathrm{n}, \mathrm{t})^{4} \mathrm{He}, \sigma(\theta), E_{\mathrm{n}}=87-398 \mathrm{keV}$

Condé, H., et al. (1982) Proc. Int. Conf. on Nuclear Data for Science and Technology, Antwerp, pp. 447; ${ }^{6} \mathrm{Li}(\mathrm{n}, \mathrm{t})^{4} \mathrm{He}, \sigma(\theta)$, $E_{\mathrm{n}}=1.3-3.5 \mathrm{MeV}$

Drigo, L. and Tornielli, G. (1982) Nuovo Cimento 70A, 402; ${ }^{6} \mathrm{Li}(\mathrm{n}, \mathrm{n})^{6} \mathrm{Li}, \mathrm{A}_{\mathrm{y}}(\theta), E_{\mathrm{n}}=1.5-4.0 \mathrm{MeV}$

Drosg, M., et al. (1982) Los Alamos National Laboratory Report LA-9129-MS; ${ }^{4} \mathrm{He}(\mathrm{t}, \mathrm{n}){ }^{6} \mathrm{Li}, \sigma(\theta), E_{\mathrm{t}}=8.5-12.9 \mathrm{MeV}$

Drosg, M., et al. (1982) Los Alamos National Laboratory Report LA-9129-MS; ${ }^{4} \mathrm{He}\left(\mathrm{t}, \mathrm{n}_{1}\right)^{6} \mathrm{Li}^{*}, \sigma(\theta), E_{\mathrm{t}}=12.9 \mathrm{MeV}$

Hardekopf, R.A., et al. (1977) Los Alamos National Laboratory Report LA-6188; ${ }^{4} \mathrm{He}(\mathrm{t}, \mathrm{t})^{4} \mathrm{He}, \sigma(\theta), \mathrm{A}_{\mathrm{y}}(\theta), E_{\mathrm{t}}=7-14 \mathrm{MeV}$

Harvey, J.A. and Hill, N.W. (1975) Proc. Conf. on Nuclear Cross Sections and Technology, NBS Spec. Pub. 425, 244, and personal communication from J. Harvey; ${ }^{6} \mathrm{Li}(\mathrm{n}, \mathrm{n})^{6} \mathrm{Li}, \sigma_{\mathrm{T}}(E), E_{\mathrm{n}}=10 \mathrm{eV}-4 \mathrm{MeV}$

Ivanovich, M., Young, P.G. and Ohlsen, G.G. (1968) Nucl. Phys. A 110, 441; ${ }^{4} \mathrm{He}(\mathrm{t}, \mathrm{t})^{4} \mathrm{He}, \sigma(\theta), E_{\mathrm{t}}=1-7 \mathrm{MeV}$

Jarmie, N., et al. (1980) Los Alamos National Laboratory Report LA-8492; ${ }^{4} \mathrm{He}(\mathrm{t}, \mathrm{t})^{4} \mathrm{He}, \sigma(\theta), \mathrm{A}_{\mathrm{y}}(\theta), E_{\mathrm{t}}=6-17 \mathrm{MeV}$

Knitter, H.H., et al. (1983) Nucl. Sci. Eng. 83, 229; ${ }^{6} \mathrm{Li}(\mathrm{n}, \mathrm{t})^{4} \mathrm{He}, \sigma(\theta), E_{\mathrm{n}}=0.035-325 \mathrm{keV}$ (relative data)

Knox, H.D., et al. (1982) Bull. Am. Phys. Soc. 27, 723, and personal communication from H.D. Knox (1985); ${ }^{6} \mathrm{Li}(\mathrm{n}, \mathrm{t})^{4} \mathrm{He}, \sigma(\theta)$, $E_{\mathrm{n}}=2-3.5 \mathrm{MeV}$

Lane, R.O. (1961) Ann. Phys. 12, $135 ;{ }^{6} \mathrm{Li}(\mathrm{n}, \mathrm{n})^{6} \mathrm{Li}, \sigma(\theta), E_{\mathrm{n}}=0.05-1.44 \mathrm{MeV}$

Lane, R.O. (1964) Phys. Rev. 136, B1710; ${ }^{6} \mathrm{Li}(\mathrm{n}, \mathrm{n})^{6} \mathrm{Li}, \mathrm{A}_{\mathrm{y}}(\theta), E_{\mathrm{n}}=0.2-1.7 \mathrm{MeV}$

Meadows, J.W. (1971) Neutron Standards and Flux Normalizations (AEC 23), $129 ;{ }^{6} \mathrm{Li}(\mathrm{n}, \mathrm{t})^{4} \mathrm{He}, \sigma\left(E_{\text {therm }}\right)$

Overley, J.C., et al. (1974) Nucl. Phys. A 221, 573; ${ }^{6} \mathrm{Li}(\mathrm{n}, \mathrm{t})^{4} \mathrm{He}, \sigma(\theta), E_{\mathrm{n}}=0.1-1.9 \mathrm{MeV}$

Renner, C., et al. (1978) Bull. Am. Phys. Soc. 23, 526, and personal communication from J. Harvey; ${ }^{6} \mathrm{Li}(\mathrm{n}, \mathrm{t})^{4} \mathrm{He}, \sigma(E)$, $E_{\mathrm{n}}=82-467 \mathrm{keV}$ (renormalized $-5 \%$ )

Smith, A.B., et al. (1982) Nucl. Phys. A 373, 305; ${ }^{6} \mathrm{Li}(\mathrm{n}, \mathrm{n})^{6} \mathrm{Li}, \sigma(\theta), E_{\mathrm{n}}=1.5-3.7 \mathrm{MeV}$

Spiger, R.J. and Tombrello, T.A. (1967) Phys. Rev. 163, 964; ${ }^{4} \mathrm{He}(\mathrm{t}, \mathrm{t})^{4} \mathrm{He}, \sigma_{\mathrm{T}}(E), E \alpha=12-18 \mathrm{MeV}$

Stelts, M.L., et al. (1979) Phys. Rev. C 19, 1159; ${ }^{6} \mathrm{Li}(\mathrm{n}, \mathrm{t})^{4} \mathrm{He}$ relative $\sigma(\theta), E_{\mathrm{n}}=2,24 \mathrm{keV}$

${ }^{11} \mathrm{~B}$ system data

Bockelman, C.K., et al. (1951) Phys. Rev. 84, 69; ${ }^{10} \mathrm{~B}(\mathrm{n}, \mathrm{n})^{10} \mathrm{~B}, \sigma_{\mathrm{T}}(E), E_{\mathrm{n}}=0.02-1.01 \mathrm{MeV}$

Cusson, R.Y. (1966) Nucl. Phys. 86, 481; also PhD thesis, Cal. Tech. (1965); ${ }^{7} \mathrm{Li}(\alpha, \alpha)^{7} \mathrm{Li}, \sigma(\theta), E \alpha=3-6 \mathrm{MeV}$

Cusson, R.Y. (1966) Nucl. Phys. 86, 481; also PhD thesis, Cal. Tech. (1965); ${ }^{7} \mathrm{Li}\left(\alpha, \alpha_{1}\right)^{7} \mathrm{Li}^{*}, \sigma(\theta) \sigma(E), E \alpha=3-6 \mathrm{MeV}$

Diment, K.M. (1967) Harwell Report AERE-R-5224; $\sigma_{\mathrm{T}}(E), E_{\mathrm{n}}=0.076 \mathrm{keV}-1 \mathrm{MeV}$

Kavanagh, R.W. and Marcley, R.G. (1987) Phys. Rev. C 36, 1194; ${ }^{10} \mathrm{~B}(\mathrm{n}, \mathrm{t}) 2 \alpha, \sigma\left(E_{\text {therm }}\right)$

Lane, R.O., et al. (1971) Phys. Rev. C 4, 380; ${ }^{10} \mathrm{~B}(\mathrm{n}, \mathrm{n}){ }^{10} \mathrm{~B}, \sigma(\theta), \mathrm{A}_{\mathrm{y}}(\theta), E_{\mathrm{n}}=0.1-1.0 \mathrm{MeV}$

Olson, M.D. and Kavanagh, R.W. (1984) Phys. Rev. C 30, $1375 ;{ }^{7} \operatorname{Li}(\alpha, \mathrm{n})^{10} \mathrm{~B}, \sigma(E) E \alpha=4.4-5.5 \mathrm{MeV}$

Sealock, R.M. and Overley, J.C. (1976) Phys. Rev. C 13, 2149; ${ }^{10} \mathrm{~B}\left(\mathrm{n}, \alpha_{1}\right)^{7} \mathrm{Li}^{*}, \sigma(\theta) E_{\mathrm{n}}=0.2-1.0 \mathrm{MeV}$

Spencer, R.R., et al. (1973) Report EANDC(E) 147, A1; ${ }^{10} \mathrm{~B}(\mathrm{n}, \mathrm{n}){ }^{10} \mathrm{~B}, \sigma_{\mathrm{T}}(E), E_{\mathrm{n}}=94-411 \mathrm{keV}$

Van der Zwaan, L. and Geiger, K.W. (1972) Nucl. Phys. A 180, 615; ${ }^{10} \mathrm{~B}(\mathrm{n}, \alpha){ }^{7} \mathrm{Li}, \sigma(\theta) E_{\mathrm{n}}=0.28-0.77 \mathrm{MeV}$

Viesti, G. and Liskien, H. (1979) Ann. Nucl. Energy 6, $13 ;{ }^{10} \mathrm{~B}\left(\mathrm{n}, \alpha_{1}\right)$, shape, $E_{\mathrm{n}}=0.1-2.2 \mathrm{MeV}$ 


\title{
4. MICROSCOPIC NUCLEAR MODELS AND LIGHT ELEMENT STANDARD CROSS-SECTIONS
}

\author{
H.M. Hofmann, G.M. Hale
}

The resonating group model (RGM), especially in the refined version (RRGM), allows the calculation of complete $\mathrm{S}$ matrices in light nuclear systems with many coupled channels on a microscopic basis using nucleon-nucleon potentials expanded in terms of Gaussians. The mass range that can be covered depends on the complexity of the system (i.e. the number of nucleons, number of open channels and potentials used). Whereas for softcore effective nucleon-nucleon potentials, mass number $A=10$ [4.1] and beyond is easily accessible on modern computers, mass number $A=4$ is already a challenge for parameter-free calculations using realistic nucleon-nucleon and three-nucleon potentials $[4.2,4.3]$, and $A=5$ represents the limit even on the massively parallel computers of today. Hence, for the standard cross-section ${ }^{3} \mathrm{He}+\mathrm{n}$ data, $\mathrm{R}$ matrix analysis can be directly compared to $\mathrm{ab}$ initio calculations, and deviations can only be blamed on errors of the experimental database or on the inadequacy of the potentials. However, in the ${ }^{6} \mathrm{Li}+\mathrm{n}$ system, model potentials have to be used with parameters to be determined from conflicting results. Since the two systems are so different, we discuss the lighter one first, especially because this system allows for less freedom in the interpretations.
For the ${ }^{4} \mathrm{He}$ compound system we used the Argonne V18 [4.4] NN and the Urbana IX [4.5] NNN potentials and allowed for the physical ${ }^{3} \mathrm{H}+\mathrm{p}$, ${ }^{3} \mathrm{He}+\mathrm{n}$ and ${ }^{2} \mathrm{H}+\mathrm{d}$ channels, together with a very large number of distortion channels, which have no asymptotic part but which are necessary to give the RRGM scattering wave function enough freedom in the interaction region. The details of the calculation are given in Ref. [4.6]. A comparison of the calculated scattering phase shifts for the physical channels with those extracted from the $\mathrm{R}$ matrix analysis for all partial waves necessary to describe the data gives perfect agreement for some partial waves. Slight differences occurred for others, and only for very few partial waves did qualitative differences occur. The comparison of a large variety of differential observables calculated with the data and R matrix analysis produced clear differences for some polarizations, but the effects on cross-sections are minor [4.6].

The results relevant for the neutron standards have been published together with the spin dependent neutron scattering lengths on ${ }^{3} \mathrm{He}$ [4.7]. As can be seen from Fig. 4.1, the agreement between the full calculation employing $\mathrm{NN}$ and NNN potentials and the ENDF data is good (within the error bars or slightly below), whereas the NN

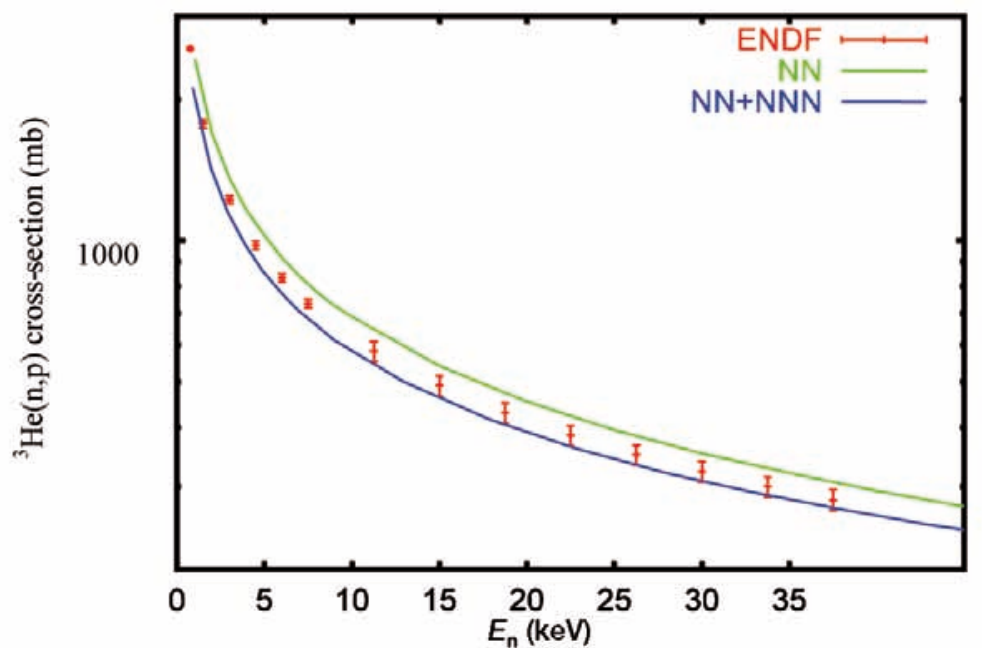

FIG. 4.1. Comparison of the standard neutron cross-section of ${ }^{3} H e$ in ENDF/B-VI [4.8], and calculations using Argonne V18 alone (NN) and Argonne V18 and Urbana IX together $(N N+N N N)$. 
potential alone is consistently above the data outside the error bars. We consider these results well suited for further determinations of the structure of the NNN force.

The calculated result for the coherent $n-{ }^{3} \mathrm{He}$ scattering length also agrees with a recent measurement of the real part of this quantity. Since the calculation was undertaken separately for $J=0$ and $J=1$ and the calculated incoherent scattering length does not agree with the recent datum, we consider the agreement for the coherent scattering length to be fortuitous.

The main aim of the studies was to determine how microscopic calculations could facilitate the $\mathrm{R}$ matrix analyses, including when the calculation does not come close to the precision of the analysis. Ambiguities in the $\mathrm{R}$ matrix parameterizations due to wide and distant poles were the main issue. A comparison of $\mathrm{S}$ matrix poles at complex energy was carried out to assess the physical relevance. Since the original RRGM model used standing wave boundary conditions for real energies [4.9], the code was rewritten to allow for in- and outgoing waves of complex wave numbers, so that we could determine the complex energy plane and quantify the S matrix. The search for complex energy $\mathrm{S}$ matrix poles led in some partial waves to many more poles than shown in the $\mathrm{R}$ matrix analysis. Whereas the low lying poles usually agreed reasonably well in both approaches, the calculation produced many high lying poles of rather weak 'strength' that had no counterpart in the $\mathrm{R}$ matrix analysis (see the discussion of non-Breit-Wigner poles in the appendix associated with the introduction of Ref. [4.10]).

Therefore, we undertook a direct calculation of the R matrix poles within the RRGM approach. A prescription is given in Ref. [4.11] of how to calculate the $\mathrm{R}$ matrix elements from the matrix elements calculated already in the RRGM approach and corrected in terms of the contribution from the external region. These elements can be calculated analytically if anti-symmetrization can be safely neglected (see appendix of Ref. [4.11]). The poles of the $\mathrm{R}$ matrix correspond to the eigenvalues of eq. (10) of Ref. [4.11]. These studies also revealed that the radii necessary to neglect anti-symmetrization are usually larger than typically used in an R matrix analysis, and the parameters of the Gaussians had to be chosen in such a way that the wave functions inside the channel radius were sufficiently different to avoid numerical dependencies. Since the scattering phase shifts in the ${ }^{4} \mathrm{He}$ system agree so well in both approaches and the use of realistic potentials was not feasible beyond this mass number, we studied how to calculate $\mathrm{R}$ matrix poles in the ${ }^{7} \mathrm{Li}$ compound system.

The ${ }^{7} \mathrm{Li}$ compound system has already been studied [4.12] using an effective NN force (as given in the appendix of Ref. [4.13]) that is tailored to bind deuteron, triton and the alpha particle with pure $\mathrm{S}$ waves. This potential allowed the reproduction of the ${ }^{6} \mathrm{Li}+\mathrm{n}$ threshold relative to that of the $\alpha+$ triton, but not the higher ones (see fig. 2 in Ref. [4.12] for the charge conjugate case). Furthermore, the level structure was quite well reproduced and additional resonances were predicted. Some structure in the various elastic scattering phase shifts was well explained, although the exact energy was missed. Thus the ${ }^{7} \mathrm{Li}$ compound system was the ideal example to study the direct calculation of $\mathrm{R}$ matrix poles. However, the charge radii of these nuclei were not well reproduced. These deficiencies were reduced by adopting NN forces developed from those cited, which reproduced the total binding energy of the nuclei much better without being able to reproduce all the relative thresholds together with the charge radii. The results for all the potentials adopted were similar, no qualitative differences occurred, and therefore we do not give any specific results.

First calculations in the ${ }^{7} \mathrm{Li}$ compound system using only ${ }^{4} \mathrm{He}-{ }^{3} \mathrm{H}$ and ${ }^{6} \mathrm{Li}-\mathrm{n}$ channels yielded low lying poles in good agreement with known results. Adding more channels in order to come close to the calculation of Ref. [4.12] resulted in $\mathrm{R}$ matrix poles accumulating just above all thresholds. The same behaviour occurred for the ${ }^{11} \mathrm{~B}$ compound system. Slightly changing the parameters of the calculations (such as channel radii or width parameters) yielded small changes for the low lying poles that are already known, and huge changes for the poles above thresholds. We found no reliable way to combine these many poles to a few resonances of the analysis. Therefore, this approach was judged to be not particularly useful for further analyses, and did not merit further study.

When the cross-section for the ${ }^{6} \mathrm{Li}(\mathrm{n}, \mathrm{t})^{4} \mathrm{He}$ reaction became available from the $\mathrm{R}$ matrix analysis as individual partial waves, we carried out calculations for various effective NN potentials. These calculations showed qualitative agreement for the ${ }^{7} \mathrm{Li}$ system and explained interference patterns found in an $\mathrm{R}$ matrix analysis. New structures were proposed for the ${ }^{11} \mathrm{~B}$ system at energies above the standards region. 
Microscopic cross-section calculations using realistic NN and NNN forces are of similar quality to R matrix analyses for systems with $A=4$. It is hoped that this statement can be extended to $A=5$ in the near future, with calculations for $\alpha+\mathrm{n}$ and ${ }^{3} \mathrm{H}$ $+\mathrm{d}$ under way.

Only effective forces are feasible for heavier systems. Therefore, only rather limited qualitative agreement would appear to be possible because the thresholds of the various coupled channels and the sizes of the reacting nuclei cannot be reproduced satisfactorily by existing effective $\mathrm{NN}$ potentials.

\section{REFERENCES TO SECTION 4}

[4.1] WURZER, J., HOFMANN, H.M., Microscopic multi-channel calculations for the ${ }^{10} \mathrm{Li}$ System, Z. Phys. A 354 (1996) 135-142.

[4.2] HOFMAnN, H.M., HALE, G.M., Microscopic calculation of the ${ }^{4} \mathrm{He}$ system, Nucl. Phys. A $\mathbf{6 1 3}$ (1997) 69-106.

[4.3] PFITZINGER, B., HOFMANN, H.M., HALE, G.M., Elastic $p-{ }^{3} \mathrm{He}$ and $n-{ }^{3} \mathrm{H}$ scattering with twoand three-body forces, Phys. Rev. C 64 (2001) 044003/1-6.

[4.4] WIRINGA, R.B., STOKES, V.G.J., SCHIAVILLA, R., Accurate nucleon-nucleon potential with charge-independence breaking, Phys. Rev. C 51 (1995) 38-51.

[4.5] PUDLINER, B.S., PANDHARIPANDE, V.R., CARLSON, J., PIEPER, S.C., WIRINGA, R.B., Quantum Monte Carlo calculations of nuclei with A = 7, Phys. Rev. C 56 (1997) 1720-1750.
[4.6] HOFMAnN, H.M., HAlE, G.M., Can the ${ }^{4} \mathrm{He}$ Experiments Serve as a Database for Determining the Three-nucleon Force?, http://arxiv.org/abs/ nucl-th/0512065

[4.7] HOFMANN, H.M., HALE, G.M., Microscopic calculation of the spin-dependent neutron scattering lengths on ${ }^{3} \mathrm{He}$, Phys. Rev. C 68 (2003) 021002/1-6.

[4.8] CARLSON, A.D., et al., ENDF/B-VI Neutron Cross Section Measurement Standards, Rep. NISTIR-5177, National Institute of Standards and Technology, Gaithersburg, MD (1993); also ENDF/B-VI Neutron Cross Section Measurement Standards, Rep. ENDF-351, Brookhaven Natl Lab., Upton, NY (1993).

[4.9] HOFMANN, H.M., "Resonating group calculations in light nuclear systems", Models and Methods in Few-body Physics, Lisbon (Proc. 8th Autumn School, Lisbon, 1986), Lecture Notes in Physics, Vol. 273 (FERREIRA, L.S., FONSECA, A.C., STREIT, L., Eds), Springer, Berlin (1987) 243.

[4.10] TILlEY, D.R., WELlER, H.R., HALE, G.M., Energy levels of light nuclei $A=4$, Nucl. Phys. A 541 (1992) 1-104.

[4.11] FUJIMURA, K., BAYE, D., DESCOUVEMONT, P., SUZUKI, Y., VARGA, K., Low-energy $\alpha+{ }^{6} \mathrm{He}$ elastic scattering with the resonatinggroup method, Phys. Rev. C 59 (1999) 817-825.

[4.12] HOFMANN, H.M., MERTELMEIER, T., ZAHN, W., The nuclear systems ${ }^{7} \mathrm{Li}$ and ${ }^{7} \mathrm{Be}$ in a resonating group model, Nucl. Phys. A 410 (1983) 208-236.

[4.13] MERTELMEIER, T., HOFMANN, H.M., Consistent cluster model description of the electromagnetic properties of lithium and beryllium nuclei, Nucl. Phys. A 459 (1986) 387-416. 


\title{
5. R MATRIX THEORY AND LIGHT ELEMENT STANDARDS EVALUATION
}

\author{
G.M. Hale, Chen Zhenpeng, N.M. Larson, S.A. Badikov, V.G. Pronyaev
}

\subsection{INTRODUCTION}

$\mathrm{R}$ matrix theory was used for the evaluation of the standard cross-sections for the neutron induced reactions ${ }^{6} \mathrm{Li}(\mathrm{n}, \mathrm{t}),{ }^{10} \mathrm{~B}\left(\mathrm{n}, \alpha_{1} \gamma\right)$ and ${ }^{10} \mathrm{~B}(\mathrm{n}, \alpha)$. Use of this model is justified because the $\mathrm{R}$ matrix theory of Wigner [5.1] gives an accurate parameterization of the multichannel-multilevel nuclear reaction cross-sections in the resonance region, reproducing the shape of the cross-sections even in the presence of strong interference effects. The influence of the three-body breakup channel on the standard reactions can be accommodated by the inclusion of a pseudo-channel. All observable quantities for which measured data exist can be calculated by $\mathrm{R}$ matrix theory, and therefore may be included in the fitting procedure. The list of such observables in the evaluation of standard reaction cross-sections includes all non-negligible partial reaction crosssections, the total cross-section, angular distributions of secondary particles and polarizations. Data for all reactions that form the ${ }^{7} \mathrm{Li}$ and ${ }^{11} \mathrm{~B}$ systems were analysed, including inverse and charged particle induced reactions.

\subsection{R MATRIX EVALUATIONS}

The $\mathrm{R}$ matrix model is physical, and therefore the fundamental physical conservation laws and symmetries impose limitations on the cross-section values. If general non-model (non-parametric) fits or relatively crude approximations such as multi- or single level Breit-Wigner theory were used in place of R matrix theory, the shape of the standard crosssections could be distorted.

Two R matrix codes, EDA [5.2] and RAC [5.3], were used in the evaluation of the standard cross-sections for light elements. Brief descriptions and intercomparisons of the results of the data fits for specific test cases are given in Section 2. Unfortunately, fits of the same selected data (crosssections with their uncertainties) with these two codes lead to somewhat different results. The differences are even greater when these codes are applied to the fit of a large number of data sets, as in the case of the evaluations for the ${ }^{7} \mathrm{Li}$ and ${ }^{11} \mathrm{~B}$ systems. Three features of the codes combine to produce these discrepancies, as discussed below: (a) different techniques are used to calculate the sensitivity coefficients; (b) systematic uncertainties relevant to the experimental data are treated in different ways in the two codes; (c) details of the fitting procedures themselves are different.

\subsubsection{Sensitivity coefficients}

One difference between the RAC and EDA codes is the method used to generate sensitivity coefficients of the observables relative to the parameters (i.e. partial derivatives of the crosssections with respect to the resonance parameters). These coefficients are calculated analytically in EDA, while RAC uses a seven point finite difference method with variations of step size for higher reliability and stability. No direct comparison of the EDA and RAC sensitivity coefficients was undertaken in these studies, although there are indications that they give comparable results.

\subsubsection{Systematic uncertainties}

The EDA code fits the data by minimizing $\chi^{2}$ in two steps: determining resonance parameter values while holding the normalization fixed for each data set, and then holding resonance parameters fixed while fitting the normalizations. These two steps are then repeated until convergence is reached. The expression for $\chi^{2}$ in EDA may be written as:

$$
\chi_{\mathrm{EDA}}^{2}=\sum_{d}\left\{\sum_{i}\left[\frac{n_{d} X_{i d}(\bar{p})-R_{i d}}{\Delta R_{i d}}\right]^{2}+\left[\frac{n_{d} S_{d}-1}{\Delta S_{d} / S_{d}}\right]^{2}\right\}
$$

where $R_{i d}$ is the experimental value (observable) at point $i$ in data set $d, S_{d}$ is the scale for the $d$ th set of measured data and $n_{d}$ is an adjustable normalization parameter associated with the experimental scale $S_{d}$. Experimental values are normally given at $S_{d}=1$. The quantity $X_{i d}(\bar{p})$ represents the theoretical value of the observable at point $i$, and is calculated via $\mathrm{R}$ matrix theory from the vector of parameters $\bar{p}$. This form of the $\chi^{2}$ expression utilizes 
only the statistical (short energy range correlation (SERC)) uncertainty on the measurement and the systematic (long energy range correlation (LERC)) uncertainty in the normalizations. No other type of uncertainty can be defined within EDA.

Data fitting in the RAC code also proceeds by minimization of $\chi^{2}$. However, the $\chi^{2}$ expression used in RAC is both more general and less exact than that used in EDA. The normalization parameters in EDA are treated on an equal footing with the resonance parameters, and the data covariance matrix (DCM) includes only statistical uncertainties (DCM is diagonal). Normalization and statistical uncertainties (in addition to medium energy range correlation (MERC) uncertainties) are combined in RAC to create explicit off-diagonal DCMs for each data set. These DCMs are used in the definition of $\chi^{2}$ :

$$
\begin{aligned}
\chi_{\mathrm{RAC}}^{2}= & \sum_{d}\left\{\sum_{i, j}\left(X_{i d}(\bar{p})-M_{i d}\right)\right. \\
& \left.\left(\bar{V}_{M}^{d}\right)_{i j}^{-1}\left(X_{j d}(\bar{p})-M_{j d}\right)\right\}
\end{aligned}
$$

in which $M_{i d}=R_{i d} S_{d}, \bar{V}_{M}^{d}$ represents the associated DCM for data set $d$, and other quantities have been defined above. Each DCM is calculated external to RAC and is part of the input to the code.

A general form for the DCM is:

$$
\left(\bar{V}_{M}^{d}\right)_{i j}=v_{i}^{d} \delta_{i j}+\sum_{r} g_{r i}^{d}\left(\Delta^{2} q_{r}^{d}\right) g_{r j}^{d}
$$

where the index $d$ refers to the particular data set, $v_{i}^{d}$ is the square of the statistical uncertainty for data point $i, \Delta q_{r}^{d}$ is the uncertainty of the $r$ th parameter used during the data reduction process and $g_{r i}^{d}$ is the sensitivity of the data to that parameter. Only one type of data reduction parameter in this inter-code comparison contributes to the summation over $r$ in Eq. (5.3) - the scale factor $S_{d}$. Hence, the DCM $\bar{V}_{M}^{d}$ used by RAC in Eq. (5.2) is:

$$
\left(\bar{V}_{M}^{d}\right)_{i j}=\left(S_{d} \Delta R_{i d}\right)^{2} \delta_{i j}+R_{i d}\left(\Delta^{2} S_{d}\right) R_{j d}
$$

A third R matrix code, SAMMY [5.4], was also used in these studies. While RAC and EDA consider all reactions going to the same compound nucleus, SAMMY was created for applications in which the sample often contains more than one nuclide. EDA and RAC are able to treat direct and inverse channels simultaneously, but must have 'pure' data without contamination from impurities, chemical compounds or multiple isotopes. Conversely, SAMMY does not yet possess the capability for both direct and inverse channels, and therefore could not be used in the evaluation of the standard reactions. However, SAMMY has more flexibility with respect to the treatment of uncertainties than either RAC or EDA, and is able to use the RAC method involving an explicit DCM, can treat normalizations in a similar manner to that used by EDA and has other options as well.

A series of comparison tests was devised, involving experimental data that needed only those $\mathrm{R}$ matrix features that all three codes could handle. The SAMMY calculations used all available methods of treating the experimental uncertainties in order to facilitate understanding of the differences between the EDA and RAC methods. Conclusions from these comparison tests include the following:

(a) When all data sets are consistent with each other, and the starting values for resonance parameters are close enough to the final results that non-linearity is not an issue, there is very little difference between the methods. Differences between the EDA and the RAC $\chi^{2}$ values are minimal, and the two methods give similar results.

(b) The EDA method is most similar to the propagated uncertainty method of SAMMY, which has been shown [5.5] to give more reasonable results in the case of discrepant data than the explicit covariance method (RAC method). A solution that is essentially free from Peelle's pertinent puzzle (PPP) effects is obtained by means of the EDA method (PUP method of SAMMY) - see Section 6 for a discussion of PPP.

(c) The RAC method defines and generates experimental uncertainties that are relative to the measured experimental values. Redefinition of the experimental uncertainties relative to the calculated (evaluated) values would result in a solution that is also essentially free from PPP - see Section 6, Chiba-Smith option. 


\subsubsection{Fitting procedure}

As well as treating systematic uncertainties differently, RAC and EDA also differ in the details of their fitting procedures. For angle integrated cross-sections, RAC with implementation of the full error propagation law uses the complete covariance matrices, including LERC, MERC and SERC components; fits with $\chi^{2}$ values that are 'too high' return back to an analysis of the experimental data and determination of the outliers in order to increase the statistical uncertainties on the outliers. EDA gives greater freedom to the normalization and energy shift of the experimental data to obtain an appropriate $\chi^{2}$ value.

Most experimental data on angular distributions are considered as shape type data without accounting for possible cross-energy correlations for angular distributions measured at different incident energies in one experiment. This neglect of the cross-correlations may lead to a significant reduction of the uncertainty in the fit.

\subsection{COMPARISON OF RESULTS}

Comparisons of the results of evaluations obtained with the EDA and RAC R matrix fits for the ${ }^{6} \mathrm{Li}(\mathrm{n}, \mathrm{t}),{ }^{10} \mathrm{~B}\left(\mathrm{n}, \alpha_{0}\right),{ }^{10} \mathrm{~B}\left(\mathrm{n}, \alpha_{1}\right)$ and ${ }^{10} \mathrm{~B}(\mathrm{n}, \alpha)$ reactions are shown in Figs 5.1-5.4 as ratios to the 1987 GMA combined fit used to obtain the ENDF/B-VI standards. The different procedures in the codes led to discrepancies between evaluations in some energy ranges that are larger than the uncertainties of the

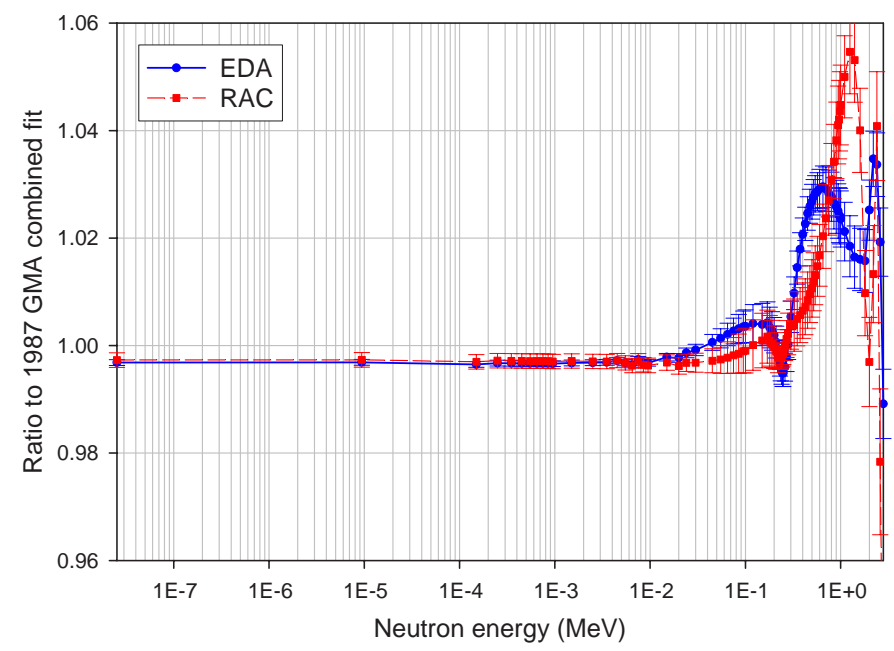

FIG. 5.1. Comparison of EDA and RAC evaluations for the ${ }^{6} \mathrm{Li}(n, t)$ reaction.

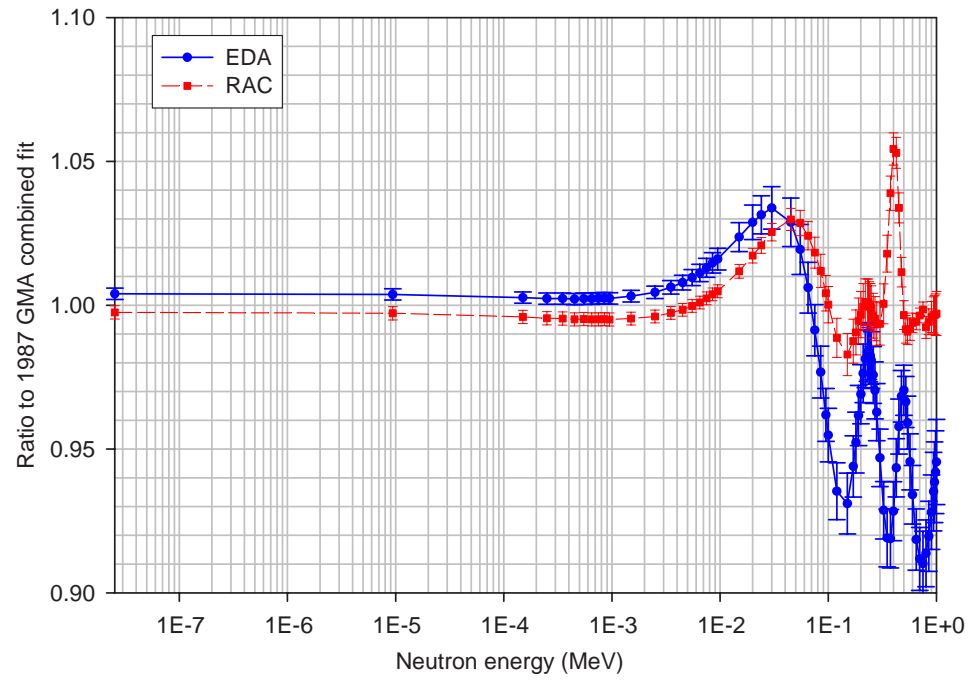

FIG. 5.2. Comparison of EDA and RAC evaluations for the ${ }^{10} B\left(n, \alpha_{0}\right)$ reaction. 


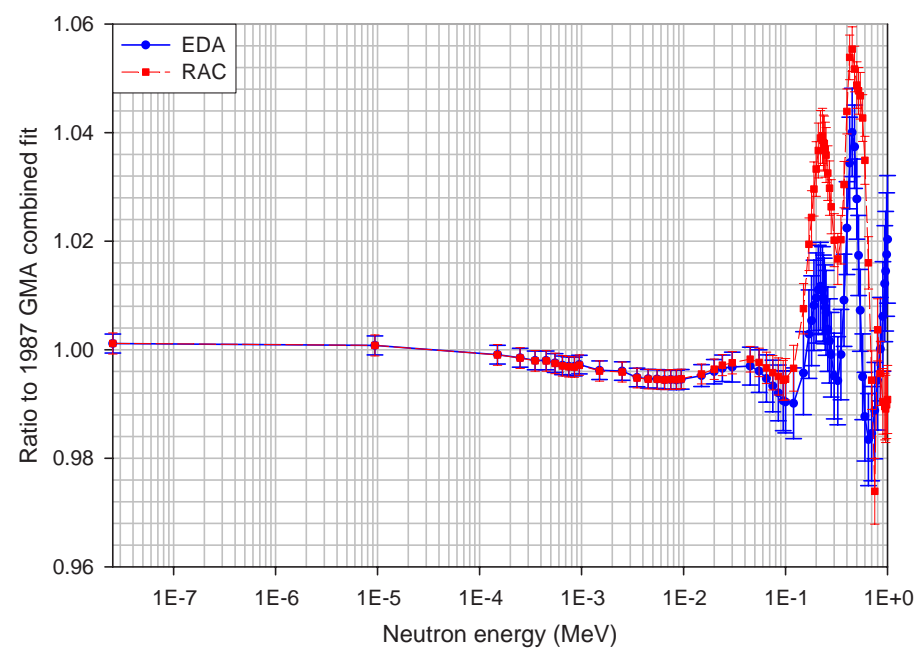

FIG. 5.3. Comparison of EDA and RAC evaluations for the ${ }^{10} B\left(n, \alpha_{1}\right)$ reaction.

evaluated data. Fortunately, these discrepancies generally occur in an energy range higher than that for which the cross-sections are used as standards. Uncertainties of the evaluated data obtained with EDA are lower in most cases than those estimated with RAC. Figures 5.1-5.4 demonstrate clearly the same trends in the new EDA and RAC fits when compared with the 1987 fits obtained using EDA, and reveal the larger differences in the $\mathrm{R}$ matrix evaluations for these standard reactions. Such differences cannot be removed by further analysis, or by improving the consistency of the procedures used in EDA and RAC. The difference between the two fits can be related to the uncertainty of the evaluation method; consequently an additional component of the uncertainty equal to half the difference between the two fits was added to the components of the total uncertainty of the R matrix evaluation.

\subsection{PRACTICAL COMPUTATIONAL CONSIDERATIONS}

The primary results of the $\mathrm{R}$ matrix evaluation are a set of evaluated parameters and the covariance matrix associated with these parameters. Using these parameter values and the covariance matrix, the evaluated cross-sections and the covariance matrix for the cross-sections are calculated at the nodes of the energy grid. If the number of parameters is smaller than the number of nodes in which the cross-sections and covariances

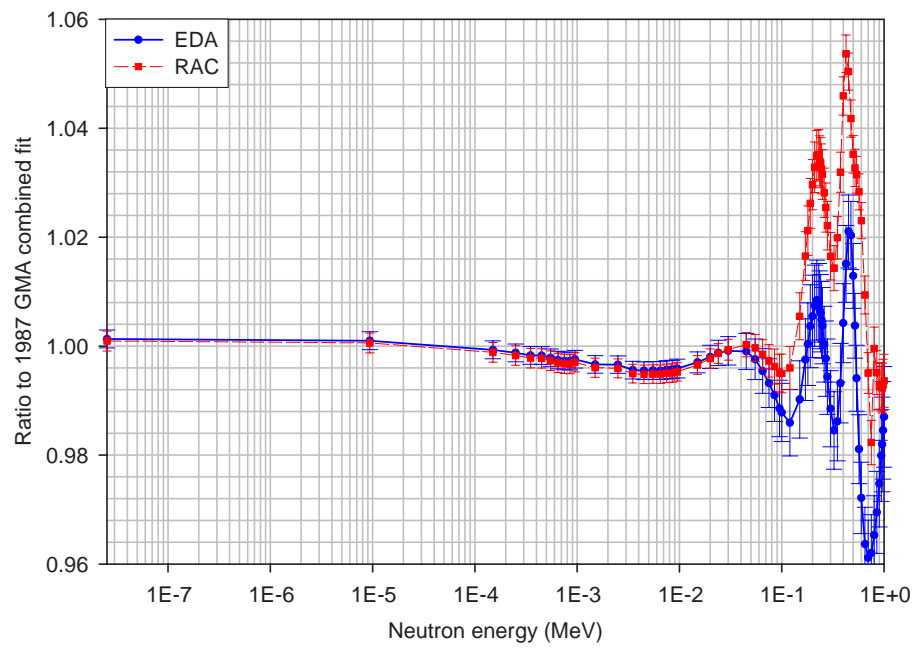

FIG. 5.4. Comparison of EDA and RAC evaluations for the ${ }^{10} B(n, \alpha)$ reaction. 
are reconstructed, the covariance matrix for the evaluated cross-section becomes positive semidefinite. The number of positive eigenvalues will be equal to the number of parameters; other eigenvalues should be zero. Studies with positive semidefinite matrices require some caution strictly speaking, they cannot be used in any calculations requiring matrix inversion, such as in the evaluation of $\chi^{2}$ in Eq. (5.2).

Problems arising from the use of semidefinite matrices can be avoided by directly using the parameters, the parameter covariance matrix and the $\mathrm{R}$ matrix model sensitivity coefficients in the final fit that combines the standard cross-sections for light and heavy elements. However, attempts to adopt this approach have failed because of the absence of convergence when sensitivity coefficients are large and depend strongly on the parameter values.

Any computer calculations impose machine limits on the accuracy with which calculations of eigenvalues and inversion of matrices can be carried out. Evaluation of the standards was undertaken on a 64 bit machine with double precision to provide good accuracy for inversion of the positive definite matrices, with eigenvalues differing by up to 24 orders of magnitude. Under normal circumstances, the formal inversion of positive semidefinite matrices does not cause practical problems because the machine zero is much less than the accuracy of the calculations. Zero eigenvalues of a positive semidefinite matrix are not precisely zero, although machine noise of a positive or negative sign limits the accuracy of the calculations for the absolute values. Formally, with some minimal corrections that have no practical implications, this non-positive definite matrix can be converted into a positive definite matrix.

Fortunately, all non-positive definite matrices obtained in the $\mathrm{R}$ matrix fit with a number of eigenvalues producing numerical noise can be used without any visible practical problems in the combined fit with data for the heavy elements. All covariance matrices obtained in the combined final fit are positive definite matrices. The analyses of covariance matrices obtained in the GMA fit of standards for heavy elements, in the R matrix fit of standards for light elements and in the final combined fit of standards for light and heavy elements have shown that there are no peculiarities in the final evaluated data and their covariance matrices that could have been caused by the adoption of non-positive definite matrices in the evaluation process. All positive eigenvalues of such matrices have much larger absolute values than the non-positive 'zero' eigenvalues that represent numerical noise.

Similar problems with the non-positive nature of the matrices arise when elements of the covariance matrices are rounded off for insertion in ENDF-6 files. The ENDF-6 format requires storage of evaluated data as numbers in a maximum of 11 columns, which translates to six digits in the standard Fortran E format (although this could be increased if more creative formats were used). Thus the evaluated values and covariances that have been calculated with single and double accuracy must be rounded off. Independent truncation of the evaluated values and covariances in this manner may lead to problems such as a loss of positive character in the covariance matrices. In particular, the scatter ellipsoid can be transformed into a hyperboloid or ellipsoid of smaller dimensions, and average values may erroneously become distorted. An estimate can be deduced of the minimal number $k_{\mathrm{cr}}$ of decimal digits in the presentation of correlation coefficients that preserve the positive character of the matrix after independent truncation [5.6]:

$$
k \geq k_{\mathrm{cr}}=\log _{10}\left(\frac{n-1}{2 \alpha_{\min }}\right)
$$

where $n$ is a dimension and $\alpha_{\text {min }}$ is the minimal eigenvalue of the correlation matrix of the uncertainties. Further independent truncation can lead to non-positive definite correlation matrices. Such a loss of positive definiteness (due to negative eigenvalues with absolute values comparable with the accuracy of calculations) can retain the results of some practical calculations; for example, an estimate can be made of the error $\Delta$ in the calculation of the variance of an arbitrary function from a cross-section caused by the negative eigenvalues of the correlation matrix for the uncertainty of the cross-sections [5.7]:

$$
\Delta=\delta^{2} \sum_{k}\left|\lambda_{k}\right| \sum_{m=1}^{M} r_{m} u_{m k}
$$

where $\lambda_{k}$ are the negative eigenvalues of the correlation matrix of averaged cross-sections, $\delta^{2}$ is the mean variance of the averaged cross-sections, $r_{m}$ are the sensitivity coefficients of the function to the averaged cross-sections and $u_{m k}$ are the elements of 
the eigenvector corresponding to eigenvalue $\lambda_{k}$. Values of $\left|\lambda_{k}\right|$ comparable with the accuracy of calculations lead to negligible values of $\Delta$ (in agreement with the findings reported in Ref. [5.6]).

The following rather formal procedure can be used to convert a non-positive definite covariance matrix to positive definite with minimal changes of their elements in the case of a six decimal digits presentation of the covariance matrix:

(a) Singular decomposition of the non-positive definite correlation matrix $U$ of the crosssections (derived from the given covariance matrix):

$U=R^{\mathrm{T}} U^{\prime} R$

where $R$ is an orthogonal matrix and the superscript T indicates transpose, and $U^{\prime}$ is a matrix with eigenvalues on the diagonal;

(b) Correction of the matrix $U^{\prime}$ (i.e. the eigenvalues with absolute values smaller than $\alpha_{\mathrm{cr}} \approx(n-1) / 10^{6}$ must be taken equal to $\left.\alpha_{\mathrm{cr}}\right)$ to construct a matrix $\bar{U}^{\prime}$;

(c) Calculation of a slightly modified correlation matrix $\bar{U}$ of the cross-sections as $\bar{U}=R^{T} \bar{U}^{\prime} R$ and the corresponding covariance matrix.

This procedure changes the elements of the covariance matrix by values comparable with the accuracy of the calculations, and ensures that the matrix is positive definite.

\section{REFERENCES TO SECTION 5}

[5.1] LANE, A.M., THOMAS, G.R., R-matrix theory of nuclear reactions, Rev. Mod. Phys. 30 (1958) 257-353.

[5.2] HALE, G.M., "Use of R-matrix methods for light element evaluations", Nuclear Data Evaluation Methods and Procedures (Proc. Workshop, Upton, NY, 1980), Rep. BNL-NCS51363, Vol. I, Brookhaven Natl Lab., Upton, NY (1981) 509-531.

[5.3] CHEN, Z.P., SUN, Y.Y., ZHANG, R., LIU, T.J., Covariance propagation in R-matrix model fitting, High Energy Phys. Nucl. Phys. 28 (2004) 42-47.

[5.4] LARSON, N.M., Updated Users' Guide For Sammy: Multilevel R-Matrix Fits To Neutron Data Using Bayes' Equations, Reps ORNL/TM9179/R7 and ENDF-364/R1, Oak Ridge Natl Lab., TN (2006).

[5.5] LARSON, N.M., "Treatment of data uncertainties", Nuclear Data for Science and Technology (Proc. Int. Conf. Santa Fe, NM, 2004), American Institute of Physics Conf. Proc. 769, Part 1 (HAIGHT, R.C., CHADWICK, M.B., KAWANO, T., TALOU, P., Eds), American Institute of Physics, New York (2005) 374-377; also LARSON, N.M., "On the efficient treatment of data covariance matrices", 71st Ann. Mtg of the Southeastern Section of the American Physics Society, Oak Ridge Natl Lab., TN (2004).

[5.6] SIVER, A.S., EZHELA, V.V., On the CODATA recommended values of the fundamental physical constants: V3.2 (1998) \& V4.0 (2002), Preprint IHEP 2003-34, Protvino, 2003.

[5.7] BADIKOV, S.A., Statistical analysis of correlated experimental data and the evaluation of neutron cross sections, At. Energy 84 (1998) 426-434. 


\title{
6. PERSPECTIVES ON PEELLE'S PERTINENT PUZZLE
}

\author{
D.L. Smith, S.A. Badikov, E.V. Gai, Soo-Youl Oh, T. Kawano, N.M. Larson, V.G. Pronyaev
}

\subsection{INTRODUCTION}

When modern methods of nuclear data analysis and evaluation based on ordinary and generalized least squares formalisms began to be applied fairly widely within the applied nuclear science community during the middle to late 1970s, there was much scepticism. However, many nuclear scientists and engineers viewed these techniques as the long sought after means of achieving true objectivity [6.1]. Poenitz, in a landmark paper, referred to the situation as emerging from the "Age of Darkness" into an "Age of Enlightenment" [6.2]. Those individuals in the nuclear science community who believed strongly in these newly rediscovered methods (for they had been known and used by statisticians for a long time) were convinced that all that was needed to apply them properly was to ensure that the information being evaluated was complete and truly representative of the experiments that produced the data being evaluated, and as free from biases (i.e. discrepancies) as possible. These practitioners never imagined that there could be inherent flaws in the methodologies themselves. Rather, when somewhat suspicious results were observed, they were usually attributed to shortcomings of the database (i.e. the input information), and not to the methods themselves. Indeed, this viewpoint is supported by the fact that the data to be evaluated are frequently discrepant.

One of these 'suspicious' features was the observation that the evaluation solutions obtained by least squares often appeared to be somewhat low compared with the majority of the experimental data being evaluated. However, the effect was usually fairly small - normally of the order of a few per cent at most - and was generally overlooked [6.3]. The consequences were minimal in many instances (i.e. the effect was smaller than or of the order of the experimental data uncertainties). Therefore the least squares method was heavily used in preparing the ENDF/B-VI neutron crosssection standards that were completed in 1987 [6.4]. Although observant individuals noted a tendency towards rather low values, and the implications were potentially significant given the precision demanded of these standards, the main objection to the ENDF/B-VI standards for nearly two decades has been that the uncertainties predicted by these evaluations seemed unrealistically small. Nevertheless, there were no convincing technical arguments offered to suggest that they should be otherwise. Data evaluators tended to accept the notion that since rigorous methods of evaluation had been applied, the methodology should not be questioned even if the results that were produced in some cases appeared to defy common sense. The user community tended to be unimpressed by this reasoning, and so the issue has remained at an impasse for many years.

By the late 1990s the neutron standards needed revision. New experimental data produced since the late 1980s were available for consideration. Also, evaluators came to accept the idea that the evaluation methods themselves were in need of some fine tuning, if not a major overhaul, for example for reasons that include the issues mentioned above. Therefore the IAEA coordinated research project (CRP) that led to the generation of the current set of neutron cross-section standards documented in this report devoted considerable attention to improving the evaluation methodology, as well as to updating and modifying the experimental database and theoretical foundations of the evaluation effort.

The issue of 'too low' values, a phenomenon that has come to be known to the nuclear data community as Peelle's pertinent puzzle (PPP), is discussed below. This debate also includes examination of the nature and origins of PPP from several different perspectives, as offered by members of the IAEA CRP on neutron crosssection standards. Conditions that lead to the onset of PPP are explored and some approximate technical fixes that have been suggested for minimizing the effects of PPP, if not eliminating the phenomenon completely from nuclear data evaluations, are introduced, with the aim of enhancing the credibility of the present neutron standards evaluations relative to their predecessors. The predictions of these various methods for given test data sets to be evaluated are compared here, and the principal conclusions reached from the research carried out in this area under the auspices of the IAEA CRP on neutron cross-section standards are 
summarized. Two distinct approaches that have been used to produce the present standards evaluation methods are clearly identified. Since contributions to this section were provided by several authors, their names are indicated under the appropriate section headings. The notation used in the equations provided by the original authors, as well as their original figures, is also preserved.

\subsection{BACKGROUND AND SOME CHARACTERISTICS OF THE PEELLE'S PERTINENT PUZZLE EFFECT}

D.L. Smith

Several independent investigations were carried out by CRP participants during the course of their work for the project. Inevitably these studies led to different perspectives on the issue of PPP. In order to assemble these various views into a reasonably coherent presentation, an overview of the essential features of modern nuclear data evaluation was required to discuss the advantages and problems associated with commonly used methodologies, and to explain how certain policy decisions were made concerning the choice of specific methodologies that were applied to produce the final standard cross-section results during the course of this CRP. Citations of several documents that would enable the reader to explore these matters in greater depth than is practicable in the present exposition appear in the reference list.

\subsubsection{Probabilistic data evaluation}

The behaviour of specific random variables is governed by probability distribution functions. Measured data values and (under some circumstances) computed or evaluated values are examples of specific numbers associated with these random variables. Statisticians approach the evaluation of random variables in a variety of ways. Modern nuclear data evaluation practices are generally based on Bayesian probabilistic theory. Why is this particular approach employed? Simply because in nuclear science one often needs to merge objective (experimental) and subjective (theoretical) information, and must reach decisions about the 'best' values for certain physical parameters (random variables) based on rather limited (and often discrepant) information. The Bayesian approach is ideally suited to this task [6.5].

\subsubsection{Probability density functions and their moments}

The mathematical framework for Bayesian analysis is discussed in references that are too numerous to credit completely (e.g. Refs [6.5-6.7]). Knowledge of a collection of $i$ parameters $\mathbf{p}$ (in this case evaluated cross-sections) is assumed to be embodied in a multivariate probability density function $p(\mathbf{p} ; \mathrm{D})$. This function is explicitly influenced by the experimental database $\mathrm{D}$ that is being evaluated. The best values of these parameters are generally defined as expected values that are obtained symbolically from the formula:

$$
<\mathrm{p}_{\mathrm{i}}>=\int p\left(\mathbf{p}^{\prime} ; \mathrm{D}\right) \mathrm{p}_{\mathrm{i}}^{\prime} \mathrm{d} \mathbf{p}^{\prime}(\mathrm{i}=1, \mathrm{n})
$$

This multivariate integration covers the entire range of possibilities for these parameters (i.e. the domain of the probability function $p$ ). Similarly, elements of the covariance matrix $\mathrm{V}_{\mathrm{ij}}$ are given by the formula:

$$
\mathrm{V}_{\mathrm{ij}}=\int p\left(\mathbf{p}^{\prime} ; \mathrm{D}\right)\left(\mathrm{p}_{\mathrm{i}}^{\prime}-<\mathrm{p}_{\mathrm{i}}>\right)\left(\mathrm{p}_{\mathrm{j}}^{\prime}-<\mathrm{p}_{\mathrm{j}}>\right) \mathrm{d} \mathbf{p}^{\prime}(\mathrm{i}, \mathrm{j}=1, \mathrm{n})
$$

Application of Bayes' theorem, along with the principle of maximum entropy, as formulated by Shannon [6.8] and Jaynes [6.9], leads to the following expression for the function $p$ :

$$
p(\mathbf{p} ; \mathrm{D})=\mathrm{C}_{1} \exp \left\{(-1 / 2)[\mathbf{y}-\mathbf{f}(\mathbf{p})]^{+} \mathbf{V}_{\mathrm{y}}^{-1}[\mathbf{y}-\mathbf{f}(\mathbf{p})]\right\} p_{\mathrm{a}}(\mathbf{p})
$$

where $\mathbf{y}$ represents the experimental data points symbolized above by $\mathrm{D}$ and $\mathbf{V}_{\mathrm{y}}$ is their covariance matrix. The evaluated parameters $\mathbf{p}$ relate to the data values $\mathbf{y}$ via the functional relationships symbolized by $\mathbf{f}$. $\mathrm{C}_{1}$ is a normalization constant and $p_{\mathrm{a}}(\mathbf{p})$ is the prior probability distribution that describes our knowledge of parameters $\mathbf{p}$ before the inclusion of the new experimental data set $\mathrm{D}$, in accordance with the Bayesian concept. If there is no knowledge about these parameters other than what is provided by the data set $\mathrm{D}$, then $p_{\mathrm{a}}(\mathbf{p})$ equals unity (the non-informative prior). However, if there is prior knowledge of these parameters, as well as uncertainty estimates, and the principle of maximum entropy is invoked once again, then one obtains:

$p_{\mathrm{a}}(\mathbf{p})=\mathrm{C}_{2} \exp \left[(-1 / 2)\left(\mathbf{p}-\mathbf{p}_{\mathrm{a}}\right)^{+} \mathbf{V}_{\mathrm{a}}^{-1}\left(\mathbf{p}-\mathbf{p}_{\mathrm{a}}\right)\right]$ 
where $\mathbf{p}_{\mathrm{a}}$ represents the prior best values, $\mathbf{V}_{\mathrm{a}}$ is the corresponding covariance matrix and $\mathrm{C}_{2}$ is a normalization constant. The boldface symbols represent vectors and matrices, while superscript + signifies matrix transposition and superscript -1 indicates matrix inversion.

Equations (6.2.1)-(6.2.4) provide a framework for modern nuclear data evaluation. One can evaluate the best values and their covariance matrix by performing the indicated multivariate integrations. At least to the extent that one accepts the Bayesian approach and the principle of maximum entropy, this approach should lead to correct and unbiased results. The problem is that it is impractical to perform these integrations explicitly - even with a high speed computer - when the number of parameters exceeds just a few and the number of experimental data points is significant, as is the case for the present standards evaluation. Therefore several approximations have to be made, and these lead to the least squares formalism described below.

\subsubsection{Ordinary and generalized least squares methods}

The distinction between the ordinary least squares method and the generalized least squares method lies in the choice of the prior probability distribution function $p_{\mathrm{a}}$. While the ordinary least squares procedure follows from the assumption of a non-informative prior, the generalized least squares procedure is based on the use of Eq. (6.2.4) for the prior. One further step is required in order to derive the actual formulas used for both these least squares procedures. The solution values of $\mathbf{p}$ are obtained by assuming that the arguments of the exponential functions that appear in both cases are selected to correspond to the maximum of the probability density function. Thus a maximum likelihood condition is introduced that implies a minimum for the argument of the exponential function, since these arguments are quadratic forms and the probability functions appear superficially to be symmetric Gaussians.

This line of reasoning for the ordinary least squares method leads to the requirement:

$$
[\mathbf{y}-\mathbf{f}(\mathbf{p})]^{+} \mathbf{V}_{\mathrm{y}}^{-1}[\mathbf{y}-\mathbf{f}(\mathbf{p})]=\text { minimum }
$$

while the corresponding requirement for the generalized least squares is:

$$
\begin{aligned}
& \left.[\mathbf{y}-\mathbf{f}(\mathbf{p})]^{+} \mathbf{V}_{\mathrm{y}}^{-1}[\mathbf{y}-\mathbf{f}(\mathbf{p})]+\left(\mathbf{p}-\mathbf{p}_{\mathrm{a}}\right)\right]^{+} \mathbf{V}_{\mathrm{a}}^{-1}\left(\mathbf{p}-\mathbf{p}_{\mathrm{a}}\right) \\
& =\text { minimum }
\end{aligned}
$$

These equations represent the well known least squares conditions for several correlated random variables.

\subsubsection{Issues associated with least squares data evaluation}

There are several critical assumptions involved in deriving the well known least squares conditions from the basic probabilistic formulas for Bayesian data evaluation. Furthermore, another approximation is required to facilitate the solution of least squares problems: linearization of the relationships between the parameters $\mathbf{p}$ and the experimental data $\mathbf{y}$ if they are not already linear. The assumption for non-linear relationships, in particular, is defined as:

$$
\mathbf{y}-\mathbf{f}\left(\mathbf{p}_{\mathrm{a}}\right) \approx \mathbf{A}\left(\mathbf{p}-\mathbf{p}_{\mathrm{a}}\right)
$$

A is a matrix of partial derivatives, as described by Smith [6.7]. This approximation is usually justified as long as the probability distribution function is reasonably well localized to the vicinity of $\mathbf{p}_{\mathrm{a}}$. The formula used to calculate the solutions to the minimization problems indicated in Eqs (6.2.5) and (6.2.6) are reproduced here from Ref. [6.7]. The following three matrix equations are involved in ordinary least squares analyses:

$$
\begin{aligned}
& \mathbf{p}=\mathbf{V}_{\mathrm{p}} \mathbf{A}^{+} \mathbf{V}_{\mathrm{y}}{ }^{-1} \mathbf{y} \\
& \mathbf{V}_{\mathrm{p}}=\left(\mathbf{A}^{+} \mathbf{V}_{\mathrm{y}}^{1} \mathbf{A}\right)^{-1} \\
& \chi_{\text {min }}^{2}=(\mathbf{y}-\mathbf{A} \mathbf{p})^{+} \mathbf{V}_{\mathrm{y}}^{-1}(\mathbf{y}-\mathbf{A p})
\end{aligned}
$$

The following four formulas are used for the generalized least squares case:

$$
\begin{aligned}
& \mathbf{p}=\mathbf{p}_{\mathrm{a}}+\mathbf{V}_{\mathrm{a}} \mathbf{A}^{+}\left(\mathbf{Q}+\mathbf{V}_{\mathrm{y}}\right)^{-1}\left(\mathbf{y}-\mathbf{y}_{\mathrm{a}}\right) \\
& \mathbf{Q}=\mathbf{A} \mathbf{V}_{\mathrm{a}} \mathbf{A}^{+} \\
& \mathbf{V}_{\mathrm{p}}=\mathbf{V}_{\mathrm{a}}-\mathbf{V}_{\mathrm{a}} \mathbf{A}^{+}\left(\mathbf{Q}+\mathbf{V}_{\mathrm{y}}\right)^{-1} \mathbf{A} \mathbf{V}_{\mathrm{a}} \\
& \chi_{\text {min }}^{2}=\left(\mathbf{y}-\mathbf{y}_{\mathrm{a}}\right)^{+}\left(\mathbf{Q}+\mathbf{V}_{\mathrm{y}}\right)^{-1}\left(\mathbf{y}-\mathbf{y}_{\mathrm{a}}\right)
\end{aligned}
$$

The scalar quantity $\chi_{\text {min }}^{2}$ provides a measure of the quality of the least squares solution (i.e. the 
extent to which the evaluated data are consistent with the experimental values in comparison with the experimental uncertainties). An optimal fit is said to be obtained when $\chi_{\text {min }}^{2}$ equals the degrees of freedom of the problem, as discussed by Smith [6.7].

Considering the number of assumptions and approximations involved in deriving both the ordinary and generalized least squares procedures, some problems can emerge in their application, especially in situations where relatively large uncertainties, strong correlations and discrepant data are encountered. Before performing any evaluation, including one based on a statistical analysis, as many discrepancies as possible should be eliminated. The only sensible approach to achieving this aim would be to refer to the original documentation of the experimental data (where available). If the uncertainties reported by the authors are unrealistic (because of scatter and other considerations), the magnitude of the PPP effect is likely to be aggravated. Thus the evaluator needs to examine the reported uncertainties critically and, in some cases, introduce additional error components that may have been overlooked or unstated by the original authors. There are limits to how far an evaluator can proceed in attempting to introduce realistic and valid uncertainties for the reported experimental data in the absence of specific guidance from the documentation provided by the original authors. Consequently, the PPP problem cannot be avoided entirely by evaluator adjustments to the experimental database.

\subsubsection{The dilemma posed by Peelle's specific problem}

The original problem posed by Peelle (Oak Ridge National Laboratory) is presented in order to convince the reader of the seriousness of the PPP issue [6.10]. Peelle considered the determination of a single parameter based on a least squares analysis of two direct measurements of this parameter with partially correlated errors. Consider measured values of $\mathrm{y}_{1}=1.5$ and $\mathrm{y}_{2}=1.0$; for each measurement there is a $20 \%$ fully correlated error and a $10 \%$ independent error. From this information (no further details are provided) one is led to generate the absolute covariance matrix elements $\mathrm{V}_{\mathrm{y} 11}=$ $0.1125, \mathrm{~V}_{\mathrm{y} 12}=\mathrm{V}_{\mathrm{y} 21}=0.06$, and $\mathrm{V}_{\mathrm{y} 22}=0.05$, and the correlation coefficient is $\mathrm{C}_{\mathrm{y} 12}=0.8$. Equations (6.2.8)-(6.2.10) for ordinary least squares analysis can be applied to this problem. The result obtained for the evaluated value is $\mathrm{y}=0.88$ with an uncertainty of $E_{y}=0.22$. This solution falls below both data points and is truly non-intuitive, leading Peelle to pose the following question: "Under what conditions is this a reasonable result that we sought to achieve by the use of an advanced data reduction technique?" A thorough review of all attempts to address this question during the past 18 years could easily form the contents of a book. No attempt is made here to trace all the arguments that have been presented; they are varied and often contradictory, ranging from contentions that the phenomenon does not exist to proclamations that statistical evaluation of nuclear data is so fundamentally flawed that it cannot be rescued. The truth may lie somewhere in between. Here, we focus on the various ways in which the problem can be approached in a pragmatic manner so that the standards evaluation can be carried out in a reasonable manner. These deliberations by members of the CRP led ultimately to some viable procedures that have enabled a reliable evaluation of the neutron standards to be performed within the framework of modern statistical data evaluation and using the existing database of experimental information.

\subsubsection{Mini-PPP and maxi-PPP}

Useful insight into the nature of the PPP problem can be gained by analysing the mathematical structure of Peelle's specific problem in somewhat greater detail. First, note that Eqs (6.2.8) and (6.2.9) take the forms of the following two equations for the special case of two measured data points $\mathrm{y}_{1}$ and $\mathrm{y}_{2}$ with partially correlated absolute errors $E_{\mathrm{y} 1}$ and $\mathrm{E}_{\mathrm{y} 2}$, respectively. A single evaluated result $p$ (with error $E_{p}$ ) is sought that explicitly represents these data quantities:

$$
\begin{gathered}
\mathrm{p}= \\
{\left[\left(\mathrm{E}_{\mathrm{y} 1}{ }^{-2}-\mathrm{C}_{\mathrm{y} 12} \mathrm{E}_{\mathrm{y} 1}{ }^{-1} \mathrm{E}_{\mathrm{y} 2}{ }^{-1}\right) \mathrm{y}_{1}+\left(\mathrm{E}_{\mathrm{y} 2}{ }^{-2}-\mathrm{C}_{\mathrm{y} 12} \mathrm{E}_{\mathrm{y} 1}{ }^{-1} \mathrm{E}_{\mathrm{y} 2}{ }^{-1}\right) \mathrm{y}_{2}\right] /} \\
{\left[\left(\mathrm{E}_{\mathrm{y} 1}{ }^{-2}-\mathrm{C}_{\mathrm{y} 12} \mathrm{E}_{\mathrm{y} 1}{ }^{-1} \mathrm{E}_{\mathrm{y} 2}{ }^{-1}\right)+\left(\mathrm{E}_{\mathrm{y} 2}{ }^{-2}-\mathrm{C}_{\mathrm{y} 12} \mathrm{E}_{\mathrm{y} 1}{ }^{-1} \mathrm{E}_{\mathrm{y} 2}{ }^{-1}\right)\right]}
\end{gathered}
$$

$\mathrm{E}_{\mathrm{p}}^{-2}=\left(\mathrm{E}_{\mathrm{y} 1}{ }^{-2}+\mathrm{E}_{\mathrm{y} 2}{ }^{-2}-2 \mathrm{C}_{\mathrm{y} 12} \mathrm{E}_{\mathrm{y} 1}{ }^{-1} \mathrm{E}_{\mathrm{y} 2}{ }^{-1}\right) /\left(1-\mathrm{C}_{\mathrm{y} 12}{ }^{2}\right)$

$\mathrm{C}_{\mathrm{y} 12}$ is the correlation parameter for the two measured data points; note that $\mathrm{C}_{\mathrm{y} 12}=\mathrm{C}_{\mathrm{y} 21}$ and $\mathrm{C}_{11}=\mathrm{C}_{22}=1$. Also:

$$
\mathrm{E}_{\mathrm{y} 1}^{2}=\left(0.1 \mathrm{y}_{1}\right)^{2}+\left(0.2 \mathrm{y}_{1}\right)^{2}
$$




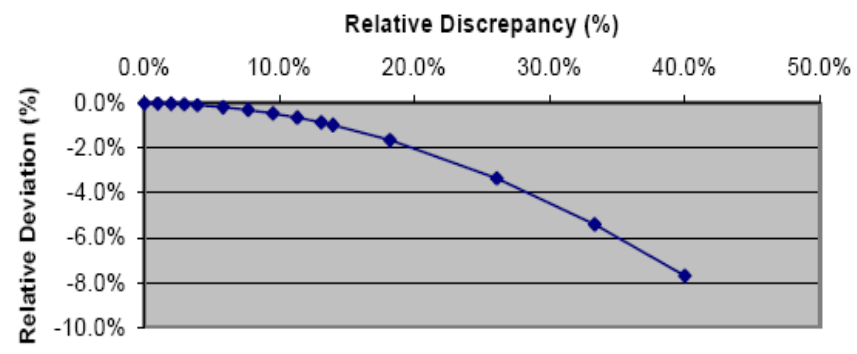

FIG. 6.2.1. Demonstration of the mini-PPP effect using values of Peelle's puzzle.

$$
\begin{gathered}
\mathrm{E}_{\mathrm{y} 2}^{2}=\left(0.1 \mathrm{y}_{2}\right)^{2}+\left(0.2 \mathrm{y}_{2}\right)^{2} \\
\mathrm{C}=\mathrm{C}_{\mathrm{y} 12}=\mathrm{C}_{\mathrm{y} 21}=\left(0.2 \mathrm{y}_{1}\right)\left(0.2 \mathrm{y}_{2}\right) /\left(\mathrm{E}_{\mathrm{y} 1} \mathrm{E}_{\mathrm{y} 2}\right)
\end{gathered}
$$

for the specific problem posed by Peelle in which the random error component is assumed to be $10 \%$ and the correlated error component is taken to be $20 \%$ for each data point. These formulas lead to the result $\mathrm{p}=0.88$ and $\mathrm{E}_{\mathrm{p}}=0.22$ first obtained by Peelle, and mentioned in Section 6.2.5.

Referring to Eqs (6.2.15) and (6.2.16), the parameters $\mathrm{y}_{1}, \mathrm{y}_{2}, \mathrm{E}_{\mathrm{y} 1}, \mathrm{E}_{\mathrm{y} 2}$ and $\mathrm{C}$ can be artificially varied to see what effect is produced. The calculations indicated in Eqs (6.2.15)-(6.2.19) can be performed quite easily using a spreadsheet program. First, let $\mathrm{C}=0$ (uncorrelated errors) and vary the discrepancy (difference between $\mathrm{y}_{1}$ and $\mathrm{y}_{2}$ ) while maintaining fixed percentage errors for each point. The result is shown in Fig. 6.2.1. When the data points are very close in value, the evaluated solution approaches the unweighted average of the two. However, when a significant discrepancy exists, the evaluated solution decreases and tends to favour the lower value noticeably because the weighting factor is the inverse square of the absolute error. Thus when each data point has the same percentage error, the lower value tends to be weighted more heavily. For convenience, the choice is made here to label this phenomenon the 'miniPPP effect'. A $40 \%$ discrepancy leads to a relative deviation of $8 \%$, as shown in Fig. 6.2.1 (as for Peelle's specific problem). Therefore the effect of PPP can never be eliminated completely because corresponding data values inevitably are discrepant to some extent, even if these discrepancies fall within the respective error bars. The lower values will still tend to dominate the evaluation as long as absolute errors are used to determine weighting factors.

Nevertheless, the evaluated solution is never lower than either data point under these circumstances $(\mathrm{C}=0)$, even when the data are very discrepant. Consequently, the unusual effect seen by Peelle must come about from another cause the influence of non-zero error correlations. The correlation parameter $\mathrm{C}$ was artificially varied from 0 to 0.8 (actual value corresponding to Peelle's problem) and even beyond to $\mathrm{C}=1$ to demonstrate this effect. The results are shown in Fig. 6.2.2.

The mini-PPP effect is seen when $\mathrm{C}=0$ (about $8 \%$ ), as indicated above. However, the deviation of the solution from a simple average becomes very pronounced with the onset of strong correlations as well as discrepant data (approaching 20\% when $\mathrm{C}=0.8$ ), and this can lead to evaluated results lower than either data point when the correlation is sufficiently strong. The bias introduced by the combination of discrepant data and data error correlations is labelled the 'maxi-PPP effect'. While the mini-PPP effect alone can be observed, the

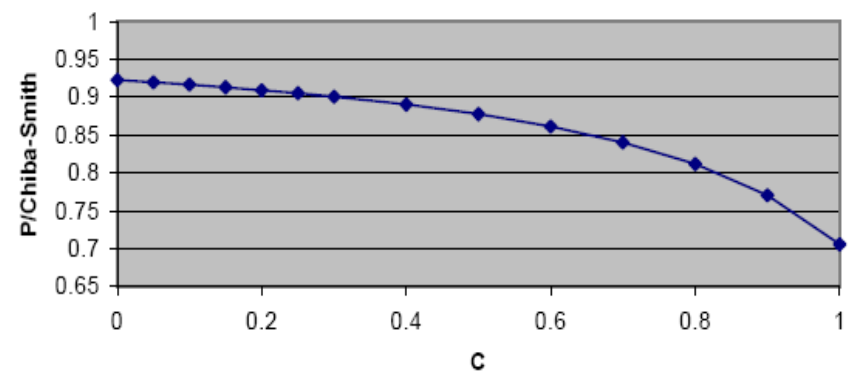

FIG. 6.2.2. Demonstration of the total-PPP effect (mini-PPP plus maxi-PPP) using values of Peelle's puzzle. 
maxi-PPP effect by itself can never be observed. The maxi-PPP effect appears only in connection with the mini-PPP effect via what is labelled the 'total-PPP effect' in Fig. 6.2.2. At what level of correlation strength can one expect to see an evaluated solution lower than either data point? The answer can be found by examining Eq. (6.2.15). The conditions are that $\mathrm{E}_{\mathrm{y} 1}{ }^{-2}-\mathrm{C}_{\mathrm{y} 12} \mathrm{E}_{\mathrm{y} 1}{ }^{-1} \mathrm{E}_{\mathrm{y} 2}{ }^{-1}<0$ or $\mathrm{E}_{\mathrm{y} 2}{ }^{-2}-\mathrm{C}_{\mathrm{y} 12} \mathrm{E}_{\mathrm{y} 1}{ }^{-1} \mathrm{E}_{\mathrm{y} 2}{ }^{-1}<0$ (i.e. when one or the other of the weighting factors becomes negative). Applicable conditions are $\mathrm{V}_{11}<\mathrm{V}_{12}$ or $\mathrm{V}_{22}<\mathrm{V}_{12}$ (recall that $\mathrm{V}_{12}=\mathrm{V}_{21}$ ) when expressed in terms of the actual covariance matrix elements.

Naturally, the mathematics becomes far more complex when several data points are involved, and the provision of explicit formulas becomes impractical for the conditions that lead to PPP; for example, in the standards evaluation hundreds of data points are considered. However, the basic effects are the same: modest PPP biases are seen due to discrepant but uncorrelated data, while considerably larger PPP effects emerge when strong correlations as well as discrepancies are encountered. This fact has been demonstrated in studies of test data sets taken from the archives of experimental data for the neutron standards (see Sections 2 and 6.9).

\subsubsection{Earlier discussions on the Peelle's pertinent puzzle issue}

Considerable activity aimed at resolving Peelle's specific problem emerged shortly after the puzzle was first circulated within the nuclear science community in the late 1980s. A growing body of literature on PPP emerged that is too extensive to document here. However, the reader is referred to the work of Chiba and Smith [6.11], the monograph of Smith [6.6] and the proceedings of a conference on data evaluation methodology that was held at Brookhaven National Laboratory in 1992 [6.12] for the thinking about PPP that was taking place in this time frame. One is led to the conclusion that the disagreements that existed at that time were not particularly related to the validity of the fundamental evaluation approach based on Bayesian statistics, but rather involved different interpretations of the physical problem (parameters to be evaluated and the sources of their uncertainty). This theme appears to persist to this day, as evidenced by the various perspectives on PPP that appear in this publication.

\subsubsection{An independent examination of Peelle's pertinent puzzle}

Hanson and co-workers at the Los Alamos National Laboratory recently took a fresh look at the PPP issue [6.13]. While Hanson is a statistician with experience in pattern recognition technologies, and has little experience of nuclear science, his coauthors (Kawano and Talou) are both nuclear physicists. Consequently, this important examination of the PPP issue is not strongly influenced by the extensive and somewhat incestuous literature on PPP that has been generated entirely within the nuclear community. Furthermore, Hanson and Talou were not involved in the present CRP activity. The approach taken by Hanson et al. is also based on the Bayesian statistical model, and is generally consistent with the concepts discussed by others (e.g. Refs [6.5, 6.6, 6.14]). The difference in this work lies in the details of their exploration of the various possibilities for interpreting Peelle's original problem, including formulations that might even justify the answer Peelle obtained using simple least squares analysis. Hanson et al. concluded that the confusion associated with PPP arises primarily because the original problem is inadequately posed (i.e. both the nature and origin of the uncertainty components given in Peelle's problem are incompletely specified).

Hanson et al. [6.13] noted that in the original statement of the puzzle by Peelle no indication had been given as to whether the correlated uncertainty component of $20 \%$ influences the measurements in either an additive manner (e.g. due to uncertainty in correcting raw counting data for background counts) or a multiplicative manner (e.g. from an uncertain normalization factor). According to these authors, "a precisely-stated uncertainty model clarifies the probabilistic approach that needs to be taken". These authors agree with many others that probabilistic treatments of data uncertainties must begin with consideration of all the fundamental variables - both explicit and implicit - and that analysis becomes relatively straightforward when these variables are explicitly stated and uncorrelated. For example, in Peelle's original problem the correlation arises because of an implicit (hidden) variable. Peelle assumes that there are only two measured values and one parameter to be evaluated. Rather, there are three measured quantities: two independent raw data counts that contribute the random component and a common 
error that might be due to the subtraction of background (possibly variable with time) or could originate from a common normalization factor such as detector efficiency. As long as the probabilistic analysis considers all three fundamental variables separately, and their individual natures are clearly understood in the context of the experiment in question, the probabilistic approach should yield a proper result. However, confusion arises when the evaluator does not clearly understand all the details of the experiment because of inexperience, inadequate documentation of the measurement procedures (very common) or other issues. Hanson et al. [6.13] suggested that one should construct probability distributions corresponding to each possible interpretation of the experiment and, in the absence of any other means for deciding which is the best, average the corresponding probability distributions and base the final evaluation and associated uncertainty on moments of this average distribution. Clearly this is not feasible in such a massive undertaking as the current standards evaluation. Hanson et al. concede that there is a need for approximations such as those that are described in this section. The present standards evaluation is based on the results obtained from an analysis that uses the Chiba-Smith approach (GMAP). An additional uncertainty can be added to account for differences between the solutions obtained by different methods of PPP minimization. However, these differences, as well as the estimated uncertainty in the PPP effect observed in the fit of all data from the GMA database, are rather small compared with the uncertainty of the evaluation and need not be taken into account.

\subsubsection{Practical approximate methods to minimize the Peelle's pertinent puzzle effect}

Several diverse approaches to handling the PPP effect for the standards evaluation are discussed in Sections 6.3-6.8, each with its own mathematical nomenclature and perspective on how to interpret PPP and to address the issue. A discussion of the codes used in the present work and comparisons of the performance of these various methods in dealing with test sets of neutron standards data are presented in Sections 6.9 and 6.10. The choice of approaches to be employed in the final standards evaluation was ultimately dictated by the ease with which they could be implemented in handling large data sets. In particular, these methods (also described as 'technical fixes' or simply 'fixes' to deal with PPP) had to be readily amenable to application in the available production computer codes that were found to be adequate for the task of performing the standards evaluation following minor code alterations. This included the ability to handle the existing GMA database format. These issues are explored in some detail in Sections 6.8 and 6.9. Interesting and worthwhile comparisons could be made by switching on or off any adopted 'fix' intended to minimize PPP, particularly if the 'fix' is implemented as a simple transformation to the input data rather than resorting to extensive changes in the computational algorithms found within the code that performs the least squares analysis.

\subsection{PEELLE'S PERTINENT PUZZLE VIEWED FROM THE PERSPECTIVE OF SUFFICIENT STATISTICS}

\section{S.A. Badikov}

Some thoughts are given in this section as to why the result from an evaluation based on the least squares method should differ from what one might expect from an examination of the raw data. The approach is based on the concept of sufficient statistics.

\subsubsection{Sufficient statistics and Peelle's pertinent puzzle}

In 1987 Peelle drew the attention of nuclear scientists to the problem of the apparent inconsistency between parameters estimated by the least squares method on the basis of raw or reduced experimental data [6.10]. As an example of this effect, values of the parameter and the associated uncertainty $(0.88 \pm 0.22)$ were estimated on the basis of reduced experimental data. This derived valued is distinctly lower than the results $(1.25 \pm$ 0.30) calculated from only the raw data. This problem came to be known within the nuclear science community as PPP.

PPP is explained by examining the impact of three different factors:

(a) Determining percentage uncertainties from experimental (not from estimated) data (miniPPP [6.15]); 
(b) A loss of information after transformation from raw to reduced experimental data;

(c) Non-linear effects [6.14].

This section is devoted to a description of the impact of the second 'non-removable' factor, particularly the loss of information concerning the parameters to be estimated after transformation from raw to reduced experimental data. The methods of sufficient statistics are used as a tool for this analysis.

\subsubsection{Information matrix and sufficient statistics}

Matrix $I_{\vec{y}}(\vec{\theta})=\left(I_{i j}\right)$ of information contained in observations $\vec{y}=\left(y_{1}, \ldots y_{n}\right)^{\mathrm{T}}$ on a vector of parameters $\vec{\theta}=\left(\theta_{1}, \ldots \theta_{L}\right)^{\mathrm{T}}$ is defined as [6.16]:

$$
I_{i j}=-\int \frac{\partial^{2} \ln \rho(\vec{y}, \vec{\theta})}{\partial \theta_{i} \partial \theta_{j}} \rho(\vec{y}, \vec{\theta}) d \vec{y}
$$

where $\rho(\vec{y}, \vec{\theta})$ is the probability density function for vector $\vec{y}$. The observations $\vec{y}=\left(y_{1}, \ldots y_{n}\right)^{\mathrm{T}}$ contain more information on vector $\vec{\theta}$ than the observations $\vec{z}=\left(z_{1}, \ldots z_{n}\right)^{\mathrm{T}}$ if:

$$
\operatorname{det}\left[I_{\vec{y}}(\vec{\theta})\right]>\operatorname{det}\left[I_{\vec{z}}(\vec{\theta})\right]
$$

Any function of observations $y_{1}, \ldots y_{n}$ is defined as a statistic. A vector $\vec{t}=\left(t_{1}\left(y_{1}, \ldots y_{n}\right), \ldots t_{s}\right.$ $\left.\left(y_{1}, \ldots y_{n}\right)\right)$ contains $s$ 'sufficient' statistics if and only if the likelihood function $\left.L\left(y_{1}, \ldots y_{n}\right) \mid \vec{\theta}\right)$ can be represented as follows [6.17]:

$$
L\left(y_{1}, \ldots y_{n} \mid \vec{\theta}\right)=g(\vec{t} \vec{\theta}) h\left(y_{1}, \ldots y_{n}\right)
$$

where the function $h\left(y_{1}, \ldots y_{n}\right)$ does not depend on $\vec{\theta}$.

The most important property of the sufficient statistics approach is that information on the parameters as preserved after transformation of random variables:

$$
I_{t(\vec{y})}(\vec{\theta})=I_{\vec{y}}(\vec{\theta})
$$

\subsubsection{Analysis of Peelle's pertinent puzzle on the basis of sufficient statistics}

When analysing PPP, the raw data are interpreted as two measurements $y_{1}$ and $y_{2}$ (with uncertainties $\sigma_{1}$ and $\sigma_{2}$ ) of the number of counts $a$ in an activation experiment and one measurement $x$ (with uncertainty $\sigma_{x}$ ) of the mass $c$ of the foil. All these measurements are independent. Two unknown parameters ( $a$ and $c$ ) are related by three equations:

$$
\begin{aligned}
& y_{1}=f_{1}(a, c)+\varepsilon_{1} \\
& y_{2}=f_{2}(a, c)+\varepsilon_{2} \\
& x=f_{3}(a, c)+\xi
\end{aligned}
$$

where $f_{1}(a, c)=f_{2}(a, c)=a, f_{3}(a, c)=c, \operatorname{cov}\left(\varepsilon_{i}, \varepsilon_{j}\right)$ $=\delta_{i j} \sigma_{i}^{2}, E \varepsilon_{i}=0, \operatorname{cov}\left(\varepsilon_{i}, \xi\right)=0(i=1,2)$, and $\mathrm{E} \xi=0$. Assuming that random values $\varepsilon_{1}, \varepsilon_{2}, \xi$ are distributed according to the normal law, the likelihood function has the form:

$$
\begin{aligned}
& L\left(y_{1}, y_{2}, x \mid a, c\right)=\frac{1}{\sqrt{2 \pi} \sigma_{1}} \exp \left\{-\frac{\left(y_{1}-a\right)^{2}}{2 \sigma_{1}^{2}}\right\} \frac{1}{\sqrt{2 \pi} \sigma_{2}} \\
& \times \exp \left\{-\frac{\left(y_{2}-a\right)^{2}}{2 \sigma_{2}^{2}}\right\} \frac{1}{\sqrt{2 \pi} \sigma_{x}} \exp \left\{-\frac{(x-c)^{2}}{2 \sigma_{x}^{2}}\right\} \\
& =\frac{1}{(2 \pi)^{3 / 2} \sigma_{1} \sigma_{2} \sigma_{x}} \exp \left\{-\frac{1}{2}\left(\frac{y_{1}^{2}}{\sigma_{1}^{2}}+\frac{y_{2}^{2}}{\sigma_{2}^{2}}+\frac{x^{2}}{\sigma_{x}^{2}}\right)\right\} \\
& \times \exp \left\{a \sum_{i=1}^{2} \frac{y_{i}}{\sigma_{i}^{2}}+c \frac{x}{\sigma_{x}^{2}}-\frac{a^{2}}{2} \sum_{i=1}^{2} \frac{1}{\sigma_{i}^{2}}-\frac{c^{2}}{2 \sigma_{x}^{2}}\right\} \\
& =g\left(t_{1}, t_{2} \mid a, c\right) h\left(y_{1}, y_{2}, x\right)
\end{aligned}
$$

where

$g\left(t_{1}, t_{2} \mid a, c\right)=\exp \left\{a \sum_{i=1}^{2} \frac{y_{i}}{\sigma_{i}^{2}}+c \frac{x}{\sigma_{x}^{2}}-\frac{a^{2}}{2} \sum_{i=1}^{2} \frac{1}{\sigma_{i}^{2}}-\frac{c^{2}}{2 \sigma_{x}^{2}}\right\}$

$t_{1}=\sum_{i=1}^{2} \frac{y_{i}}{\sigma_{i}^{2}}, t_{2}=\frac{x}{\sigma_{x}^{2}}$

$h\left(y_{1}, y_{2}, x\right)=\frac{1}{(2 \pi)^{3 / 2} \sigma_{1} \sigma_{2} \sigma_{x}} \exp \left\{-\frac{1}{2}\left(\frac{y_{1}^{2}}{\sigma_{1}^{2}}+\frac{y_{2}^{2}}{\sigma_{2}^{2}}+\frac{x^{2}}{\sigma_{x}^{2}}\right)\right\}$

Equation (6.3.6) implies that sufficient statistics $t_{1}$ and $t_{2}$ do not include the cross-terms $y_{i} x$ or $y_{i} / x$ that are used in the transformation from raw to reduced data. Thus the statistics that realize the transformation from raw to reduced data are not sufficient, and consequently the information on parameters $a$ and $c$ must decrease after the transformation; this assumption can be checked by direct calculations. Multiplication of $y_{i}$ and $x$ can be used as the transformation from raw to reduced data, since such an approach admits an 'exact' calculation 
of the covariance matrix for the new random variables:

$$
\left\{z_{1}=y_{1} x, z_{2}=y_{2} x, z_{3}=x\right\}
$$

The new variables are related to the parameters $a$ and $c$ that are to be estimated by the equations:

$$
\begin{aligned}
& z_{1}=q_{1}(a, c)+\eta_{1} \\
& z_{2}=q_{2}(a, c)+\eta_{2} \\
& z_{3}=q_{3}(a, c)+\eta_{3}
\end{aligned}
$$

where $q_{1}(a, c)=q_{2}(a, c)=a c$ and $q_{3}(a, c)=c$. The covariance matrix $V$ for variables $z_{1}, z_{2}, z_{3}$ has the form:

$$
V=\left(\begin{array}{ccc}
\sigma_{1}^{2} \sigma_{3}^{2}+\sigma_{1}^{2} c^{2}+a^{2} \sigma_{3}^{2} & a^{2} \sigma_{3}^{2} & a \sigma_{3}^{2} \\
a^{2} \sigma_{3}^{2} & \sigma_{2}^{2} \sigma_{3}^{2}+\sigma_{2}^{2} c^{2}+a^{2} \sigma_{3}^{2} & a \sigma_{3}^{2} \\
a \sigma_{3}^{2} & a \sigma_{3}^{2} & \sigma_{3}^{2}
\end{array}\right)
$$

Consider a normal distribution for the observations $\vec{y}=\left(y_{1}, \ldots, y_{n}\right)^{\mathrm{T}}$. Equation (6.3.1) for the information matrix can be reduced to the form:

$$
I_{i j}=\sum_{k} \sum_{l}\left(Q^{T}\right)_{i k}\left(V^{-1}\right)_{k l} Q_{l j}
$$

where $Q$ is a matrix of sensitivities of the response functions relative to the parameters. As defined for Eq. (6.3.7):

$$
Q_{i j}=\frac{\partial q_{i}\left(\theta_{1}, \theta_{2}\right)}{\partial \theta_{j}}, \quad \theta_{1}=a, \theta_{2}=c
$$

After the calculations, an estimate is obtained of the information contained in the variables $z_{1}, z_{2}$, $z_{3}$ and based on the parameters $a$ and $c$ :

$$
\begin{gathered}
I_{\overrightarrow{\mathrm{Z}}}(a, c)=\left(\begin{array}{cc}
\frac{c^{2}}{\sigma_{3}^{2}+c^{2}}\left[\frac{1}{\sigma_{1}^{2}}+\frac{1}{\sigma_{2}^{2}}\right] & 0 \\
0 & \frac{1}{\sigma_{3}^{2}}
\end{array}\right) \\
\operatorname{det}\left[I_{\overrightarrow{\mathrm{z}}}(a, c)\right]=\frac{c^{2}}{\sigma_{3}^{2}+c^{2}}\left[\frac{1}{\sigma_{1}^{2}}+\frac{1}{\sigma_{2}^{2}}\right] \frac{1}{\sigma_{3}^{2}}
\end{gathered}
$$

Thus:

$$
\begin{gathered}
I_{\overrightarrow{\mathrm{y}}}(a, c)=\left(\begin{array}{cc}
\frac{1}{\sigma_{1}^{2}}+\frac{1}{\sigma_{2}^{2}} & 0 \\
0 & \frac{1}{\sigma_{3}^{2}}
\end{array}\right) \\
\operatorname{det}\left[I_{\overrightarrow{\mathrm{y}}}(a, c)\right]=\left[\frac{1}{\sigma_{1}^{2}}+\frac{1}{\sigma_{2}^{2}}\right] \frac{1}{\sigma_{3}^{2}}
\end{gathered}
$$

The set of variables $\left\{y_{1}, y_{2}, x\right\}$ in Eq. (6.3.12) is obtained from Eq. (6.3.5) and denoted by $\vec{y}$. A loss of information after transformation from the raw values $\left\{y_{1}, y_{2}, x\right\}$ to the reduced data $\left\{z_{1}, z_{2}, z_{3}\right\}$ is estimated as:

$$
\begin{aligned}
& \operatorname{det}\left[I_{\overrightarrow{\mathrm{y}}}(a, c)\right]-\operatorname{det}\left[I_{\overrightarrow{\mathrm{z}}}(a, c)\right] \\
& =\frac{\sigma_{3}^{2}}{\sigma_{3}^{2}+c^{2}}\left[\frac{1}{\sigma_{1}^{2}}+\frac{1}{\sigma_{2}^{2}}\right] \frac{1}{\sigma_{3}^{2}}>0
\end{aligned}
$$

Noteworthy points include the following:

(a) The consideration given below can be generalized to cases when a dependence of a measured number of counts on neutron energy has a complicated structure (e.g. a polynomial).

(b) For other forms of the response functions in Eqs (6.3.5) and (6.3.7) (i.e. $f_{1}(a, c)=f_{2}(a, c)$ $=a / c, f_{3}(a, c)=c, q_{1}(a, c)=q_{2}(a, c)=a$ and $\left.q_{3}(a, c)=c\right)$, one obtains an expression for the loss of information that is similar to Eq. (6.3.13):

$$
\begin{aligned}
& \operatorname{det}\left[I_{\overrightarrow{\mathrm{y}}}(a, c)\right]-\operatorname{det}\left[I_{\overrightarrow{\mathrm{z}}}(a, c)\right] \\
& =\frac{\sigma_{3}^{2}}{c^{2}\left(\sigma_{3}^{2}+c^{2}\right)}\left[\frac{1}{\sigma_{1}^{2}}+\frac{1}{\sigma_{2}^{2}}\right] \frac{1}{\sigma_{3}^{2}}
\end{aligned}
$$

\subsubsection{Concluding remarks}

Information on parameters to be estimated is lost after the $y_{1}, \ldots y_{n}$ transformation from raw to reduced experimental data because the statistics realizing the transformation are not sufficient. Such a loss of information is non-removable, and is inherent (to a greater or lesser degree) in the results of any modern measurements because experimentalists report reduced data. As a consequence, the PPP issue can be resolved only approximately in the statistical processing of reduced experimental data. 
Thus the PPP effect can be classified as one of a category of ill-posed problems.

\subsection{PEELLE'S PERTINENT PUZZLE \\ CAUSE AND EFFECT \\ AND SMALL UNCERTAINTY PARADOX}

\section{E.V. Gai}

The onset of true PPP (i.e. the effect that is not caused by misinterpretation of incompletely documented experimental data) is considered in this section. PPP is shown to be accompanied by an unexpectedly low uncertainty associated with the least squares method estimate. This phenomenon is denoted the small uncertainty paradox (SUP). Two measurements are used to demonstrate that the occurrence of PPP and SUP is conditioned by the presence of large values of the experimental systematic errors and by the significant deviation of their shape from the shape of the assumed regression (model) function. An investigation is made of the dependence of PPP and SUP on the value of the covariance for the experimental errors. SUP can occur in nuclear data evaluation without the manifestation of PPP. Covariance (correlation) limitation is proposed as a radical way of preventing these paradoxes. An estimate of the systematic error is considered as a possible benefit if these paradoxes are true. The work is based on the classical least squares method; the Bayesian approach is not used.

\subsubsection{Background comments}

PPP can be viewed in another way: for some values of variances and covariances of the uncertainties of two measurements, the least squares method estimate of the unknown constant exceeds the measurement range. This behaviour of the estimate conflicts with acceptance of the well established practice of applying the least squares method in problems with uncorrelated uncertainties of measurements. Thus observance of PPP has been interpreted as an indication that in the case of correlated uncertainties the least squares method needs some improvement. PPP and suggested methods of elimination are considered in many recent studies (e.g. an exhaustive survey can be found in Ref. [6.6]), but the problem of decrease of the uncertainty in the estimate with an increase of distance from the measurement range is not normally discussed in these treatises. Our practice of nuclear database evaluation on the basis of statistical processing of thousands of experimental points from tens of studies shows that SUP is often observed even without the estimate exceeding the measurement range, for the same reason as PPP.

Seven approaches to the original PPP problem are thoroughly investigated in the work of Smith [6.6]. Such ambiguity results from incomplete documentation of the experimental errors. Consideration is given below to only the unambiguous situation when the occurrence of PPP and SUP is indeed conditioned by observed experimental errors (i.e. 'the plausible experimental scenario' as stated by Hanson et al. [6.13]). The questions to be answered are as follows:

(a) What values for the experimental uncertainties, after correct re-analysis of the input data, lead to PPP and SUP?

(b) Why do the estimate and associated uncertainty in these cases display such a strange dependence on the covariance (or correlation)?

(c) What is the nature of PPP, and how can this phenomenon be exploited to achieve a better understanding of this issue?

Most of the mathematical expressions given below are elementary and well known, but nevertheless such detailed derivation is considered worthwhile for understanding the nature of the paradoxes.

\subsubsection{Formulation of the problem in the case of two measurements}

The original puzzle stated by Peelle [6.10] involves two data points, and therefore the present treatment involves this same level of complexity.

\subsubsection{Notation}

The term 'error' is defined as the difference (or a component of this difference) between the measurement result and the true value of a measured quantity; 'uncertainty' is the dispersion of this error.

The results of measurements of an unknown physical constant can be written as:

$$
Y_{i}=y+\delta_{i}+\mu_{i}
$$


where $i$ is the measurement number, $Y_{i}$ is the measurement result, $y$ is the unknown true value and $\delta_{i}$ and $\mu_{i}$ are the sample (i.e. corresponding to the given measurement) values of the statistical and systematic errors, respectively. 'Statistical error' is the uncorrelated random error, the sample value of which for one measurement (one energy point) is not correlated with the sample value for another measurement:

$$
\bar{\delta}_{i}=<\delta_{i}>=\overline{\delta_{i} \delta_{k}}=<\delta_{i} \delta_{k}>=0
$$

A bar above a quantity (-) denotes an averaging of the statistical errors at the given sample value of the systematic error (i.e. in the context of one study or one set of measurements), and angular brackets $<>$ denote averaging in the distribution of the statistical and systematic errors for many sets of measurements. The mean square statistical uncertainty of measurement is denoted by $\varepsilon^{2}$ :

$$
\overline{\delta_{i}^{2}}=<\delta_{i}^{2}>\equiv \varepsilon_{i}^{2}
$$

By definition, the systematic error in every set of measurements (sample value) is such that for any one point the systematic component is in rigid connection with the systematic component for any other point in the same set:

$$
\bar{\mu}_{i}=\mu_{i}, \overline{\mu_{i} \mu_{k}}=\mu_{i} \mu_{k}
$$

Consider two measurements in which the following notation is used for the systematic errors, their variances and their covariances:

$$
\begin{aligned}
& \mu_{1}=\mu, \quad \mu_{2}=\alpha \mu, \quad<\mu_{1}^{2}>=s^{2} \\
& <\mu_{2}^{2}>=\alpha^{2} s^{2}, \quad<\mu_{1} \mu_{2}>=\alpha s^{2} \equiv v^{2}
\end{aligned}
$$

where $\alpha$ defines the 'distortion' parameter of the systematic error; $\alpha=1$ corresponds to the systematic error without distortion. This parameter is a distinctive feature of the present approach and plays a key role in elucidating the reason for the occurrence of PPP and SUP. The total mean square uncertainty of measurement is denoted by $\sigma^{2}$ :

$$
\sigma_{i}^{2}=<\left(\delta_{i}+\mu_{i}\right)^{2}>=\varepsilon_{i}^{2}+<\mu_{i}^{2}>
$$

Covariances of the experimental uncertainties are determined by the systematic errors only: $v_{i k}^{2}=<\left(\delta_{i}+\mu_{i}\right)\left(\delta_{k}+\mu_{k}\right)>=<\mu_{i} \mu_{k}>$

For two measurements, $v_{12}^{2}=v^{2}=\alpha s^{2}$. Reference to a correlation coefficient $\rho$ is explicitly avoided because the intent is to emphasize that the value of covariance depends directly and solely on the systematic error uncertainties and distortions, and therefore the customary expression for the covariance $v_{12}^{2}=\rho \sigma_{1} \sigma_{2}$ is rather misleading.

The covariance matrix of the experimental uncertainties $\mathbf{R}$ and inverse $\mathbf{R}^{-1}$ are specified as follows:

$$
\begin{aligned}
\mathbf{R}=\left(\begin{array}{cc}
\varepsilon_{1}^{2}+s^{2} & \alpha s^{2} \\
\alpha s^{2} & \varepsilon_{2}^{2}+\alpha^{2} s^{2}
\end{array}\right)=\left(\begin{array}{cc}
\sigma_{1}^{2} & v^{2} \\
v^{2} & \sigma_{2}^{2}
\end{array}\right) \\
\mathbf{R}^{-1}=\frac{1}{\operatorname{det} \mathbf{R}}\left(\begin{array}{cc}
\varepsilon_{2}^{2}+\alpha^{2} s & -\alpha s^{2} \\
-\alpha s^{2} & \varepsilon_{1}^{2}+s^{2}
\end{array}\right) \\
=\frac{1}{\sigma_{1}^{2} \sigma_{2}^{2}-v^{4}}\left(\begin{array}{cc}
\sigma_{2}^{2} & -v^{2} \\
-v^{2} & \sigma_{1}^{2}
\end{array}\right)
\end{aligned}
$$

$\operatorname{det} \mathbf{R}=\varepsilon_{1}^{2} \varepsilon_{2}^{2}+\alpha^{2} s^{2} \varepsilon_{1}^{2}+s^{2} \varepsilon_{2}^{2}=\sigma_{1}^{2} \sigma_{2}^{2}-v^{4}$

For simplicity, consider the case with conditions:

$$
\sigma_{1}^{2} \leq \sigma_{2}^{2} \text { and } Y_{1} \leq Y_{2}
$$

\subsubsection{Case of uncorrelated errors}

A simple case is examined when there are no systematic errors and the experimental errors are independent, and therefore $v^{2}=0$. The least squares method expression ( $\chi^{2}$ expression) is given by the following equation:

$$
S_{s t}=\frac{1}{2}\left(\frac{\left(Y_{1}-y\right)^{2}}{\varepsilon_{1}^{2}}+\frac{\left(Y_{2}-y\right)^{2}}{\varepsilon_{2}^{2}}\right)
$$

The least squares method solution corresponding to Eq. (6.4.12) is:

$$
Y_{1} \leq \tilde{y}_{s t}=\frac{Y_{1} \varepsilon_{2}^{2}+Y_{2} \varepsilon_{1}^{2}}{\varepsilon_{1}^{2}+\varepsilon_{2}^{2}} \leq Y_{2}
$$

for all non-negative $\varepsilon_{1}^{2}, \varepsilon_{2}^{2}$, and can be found within the range of experimental data $Y_{1} \leq Y_{2}$. Note that 
the least squares method solution is only an estimate with a mean square uncertainty:

$$
<\Delta \tilde{y}_{s t}^{2}>=\frac{\varepsilon_{1}^{2} \varepsilon_{2}^{2}}{\varepsilon_{1}^{2}+\varepsilon_{2}^{2}}
$$

but the true value could actually be outside the range of experimental data.

The probability that the true value is outside the uncertainty band $\pm \sqrt{<\Delta \tilde{y}_{s t}^{2}}$ is $33 \%$, and if the results of the two measurements are close and have large uncertainties, the uncertainty band is essentially wider than the experimental data range (see Fig. 6.4.1). Thus an estimate falling within the range of the experimental data does not offer an incontestable advantage because the true value could lie significantly outside this range in the case of comparatively large measurement uncertainties.

\subsubsection{Case of correlated errors}

Mean square statistical and systematic uncertainties for each of the measurements are usually listed separately; however, in the least squares method only the total variances and covariances are used, as generated from these uncertainties by means of Eqs (6.4.6) and (6.4.7). The least squares method expression in the case of correlated errors is given by:

$$
\begin{aligned}
& S_{o}=\frac{1}{2}\left(\Delta \mathbf{y} \mathbf{R}^{-1} \Delta \mathbf{y}^{T}\right) \\
& =\frac{1}{2} \frac{\left(Y_{1}-y\right)^{2} \sigma_{2}^{2}-2 v^{2}\left(Y_{1}-y\right)\left(Y_{2}-y\right)+\left(Y_{2}-y\right)^{2} \sigma_{1}^{2}}{\sigma_{1}^{2} \sigma_{2}^{2}-v^{4}}
\end{aligned}
$$

while the least squares method estimate is defined as:

$$
\tilde{y}=\frac{Y_{1}\left(\sigma_{2}^{2}-v^{2}\right)+Y_{2}\left(\sigma_{1}^{2}-v^{2}\right)}{\sigma_{1}^{2}+\sigma_{2}^{2}-2 v^{2}} \equiv \frac{Y_{1} \beta_{2}^{2}+Y_{2} \beta_{1}^{2}}{\beta_{1}^{2}+\beta_{2}^{2}}
$$

with $\beta_{i}^{2}=\sigma_{i}^{2}-v^{2}$. This solution coincides in general form with the solution given by Eq. (6.4.13) for the problem without correlations, because Eq. (6.4.15) can be rewritten as:

$$
\begin{aligned}
S_{o}= & \frac{1}{2} \frac{\left(\sigma_{1}^{2}-v^{2}\right)\left(\sigma_{2}^{2}-v^{2}\right)}{\sigma_{1}^{2} \sigma_{2}^{2}-v^{4}} \\
& \times\left(\frac{\left(Y_{1}-y\right)^{2}}{\sigma_{1}^{2}-v^{2}}+\frac{\left(Y_{2}-y\right)^{2}}{\sigma_{2}^{2}-v^{2}}+\frac{v^{2}\left(Y_{1}-Y_{2}\right)^{2}}{\left(\sigma_{1}^{2}-v^{2}\right)\left(\sigma_{2}^{2}-v^{2}\right)}\right)
\end{aligned}
$$

and the least squares method formulas in Eqs (6.4.13) and (6.4.17) coincide if the effective statistical uncertainty (ESU) $\beta_{i}^{2}=\sigma_{i}^{2}-v^{2}$ substitution is adopted instead of the statistical uncertainty $\varepsilon_{i}^{2}$.

Following from Eqs (6.4.5) and (6.4.6) for the case of $\alpha=1$ when the systematic errors are the same for both measurements, $\beta_{i}^{2}=\varepsilon_{i}$ and the ESU coincides with the proper statistical uncertainty. Furthermore, the least squares method estimate of Eq. (6.4.16) coincides with the estimate given in Eq. (6.4.13) for the problem that accounts only for the statistical uncertainties:

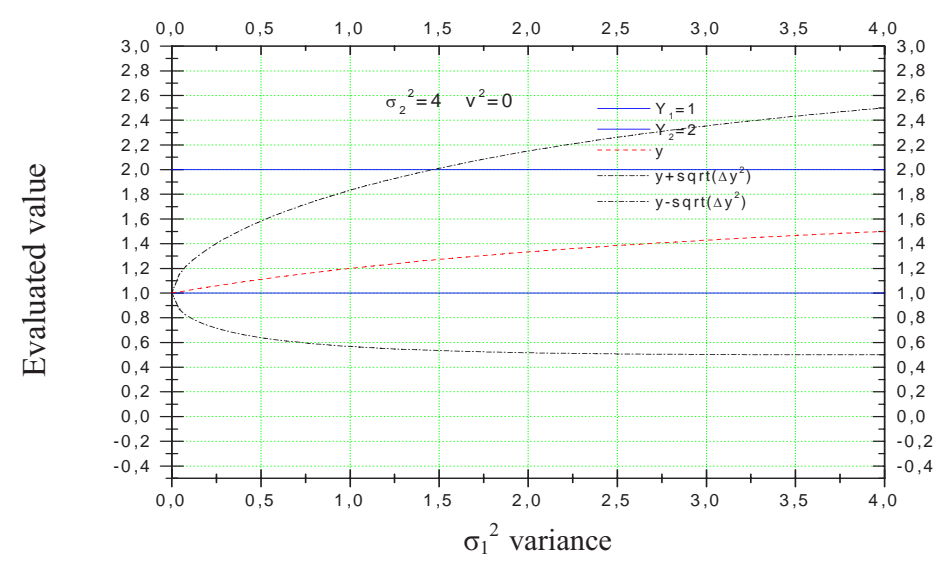

FIG. 6.4.1. Least squares method solution and uncertainty band for $v^{2}=0$. 
$\tilde{y}_{(\alpha=1)}=\tilde{y}_{s t}=\frac{Y_{1} \varepsilon_{2}^{2}+Y_{2} \varepsilon_{1}^{2}}{\varepsilon_{1}^{2}+\varepsilon_{2}^{2}}=y+\mu+\frac{\delta_{1} \varepsilon_{2}^{2}+\delta_{2} \varepsilon_{1}^{2}}{\varepsilon_{1}^{2}+\varepsilon_{2}^{2}}$

The least squares method solution is written not only as a function of the observables but also expresses explicitly the dependence on the unknown sample values of the errors. Analysis of Eq. (6.4.18) leads to the following conclusions:

(a) PPP does not occur in the absence of distortion.

(b) Under such circumstances the least squares method estimate positioned within the experimental data range differs from the true value by the sample value of the systematic error and by the weighted average of the sample values of the statistical errors.

The covariance matrix of the uncertainties of the estimated parameters for common cases is given by inversion of Fisher's information matrix [6.16]. Note that this technique is more general than the use of the error propagation law because such an approach is applicable to cases involving non-linear regression functions. For the single parameter case, one has the expressions:

$$
\begin{gathered}
\mathbf{I}_{o}=\sum_{i, k} R_{i, k}^{-1}=\frac{\sigma_{1}^{2}+\sigma_{2}^{2}-2 v^{2}}{\sigma_{1}^{2} \sigma_{2}^{2}-v^{4}} \\
<\Delta \tilde{y}^{2}>=\mathbf{I}_{o}^{-1}=\frac{\sigma_{1}^{2} \sigma_{2}^{2}-v^{4}}{\sigma_{1}^{2}+\sigma_{2}^{2}-2 v^{2}}=\frac{\beta_{1}^{2} \beta_{2}^{2}}{\beta_{1}^{2}+\beta_{2}^{2}}+v^{2}
\end{gathered}
$$

The last of the equalities of Eq. (6.4.20) shows that, even in the absence of distortion, the presence of the systematic error (i.e. non-zero value of covariance) leads to a corresponding increase in the estimated uncertainty in comparison with the case of $v^{2}=0$ (substitute $\beta_{i}^{2}=\varepsilon_{i}^{2}$ in Eq. (6.4.20) and resembling the result from Eq. (6.4.14)) despite the coincidence of the solutions of Eqs (6.4.18) and (6.4.13).

Thus if the systematic error has the shape of a constant shift, the PPP effect does not occur even in the case of correlated errors of the measurements. The estimate is positioned within the experimental data range, but includes the systematic error as a component. Since the uncertainty band of the estimate is wider than in the absence of the systematic error, the probability that the true value is outside the experimental data range is correspondingly higher.

\subsubsection{Peelle's pertinent puzzle in the case of correlated errors}

The ESUs $\beta_{i}^{2}=\sigma_{i}^{2}-v^{2}$ are always positive for negative covariances $v^{2}$. Under these circumstances, the estimate from Eq. (6.4.16) is positioned within the experimental data range, and PPP does not occur. Thus only non-negative covariances and nonnegative distortion parameters are considered. The positive definiteness of the covariance matrix is a necessary condition for applicability of the statistical methods of data processing, leading to the next limitation on the covariance value:

$$
\left|v^{2}\right|<\sqrt{\sigma_{1}^{2} \sigma_{2}^{2}}
$$

If $\sigma_{1}^{2}<\sigma_{2}^{2}$, the covariance values in the range:

$$
\sigma_{1}^{2}<v^{2}<\sqrt{\sigma_{1}^{2} \sigma_{2}^{2}}
$$

correspond to negative values of the mean square ESU $\beta_{1}^{2}$, and the solution in Eq. (6.4.16) falls below both experimental values. The estimate for the common case lies outside the experimental data range on the side of the more accurate measurement; for our situation, the estimate is $Y_{1}$, which implies that PPP takes place (see Fig. 6.4.2). The estimated uncertainty given by Eq. (6.4.20) for the fixed values of the total experimental uncertainties has a non-monotonic dependence on the covariance, has a maximum at $v^{2}=\sigma_{1}^{2}$, and decreases with further increase of $v^{2}$ to zero (an

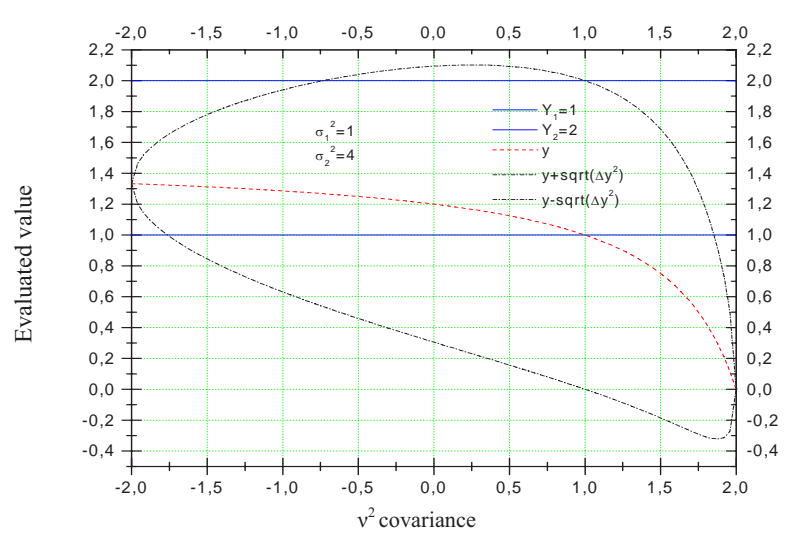

FIG. 6.4.2. Dependence on the covariance of the least squares method solution and the estimated uncertainty band. 
exact estimate!) when the covariance achieves the maximum possible value $v^{2}=\sqrt{\sigma_{1}^{2} \sigma_{2}^{2}}$ (see Fig 6.4.3). This behaviour is a manifestation of SUP.

The condition of non-negativity of the mean square statistical uncertainties $\varepsilon_{i}^{2}$ creates the next limitation on possible values of the distortion parameter for the systematic errors:

$$
\frac{\left|v^{2}\right|}{\sigma_{1}^{2}} \leq|\alpha| \leq \frac{\sigma_{2}^{2}}{\left|v^{2}\right|}
$$

Following from Eqs (6.4.22) and (6.4.23), PPP corresponds to distortion parameter values $\alpha>1$. The lower and upper boundaries of the possible values of the distortion parameter depend on the covariance for the cases $\sigma_{1}^{2}=1, \sigma_{2}^{2}=4$ and $\sigma_{2}^{2}=1$, and are given in Fig. 6.4.4.

Information about the statistical and systematic components of experimental uncertainties in the classical least squares method is in some sense lost because elements of the covariance matrix of the experimental uncertainties are only variances (total uncertainties) and covariances. However, the occurrence of PPP indicates that systematic errors are large and have different values for different measurements.

\subsubsection{Least squares method problem with an explicit account of the systematic error}

Consider the least squares method problem in the presence of a systematic error, which is the situation of specific concern in the present context.

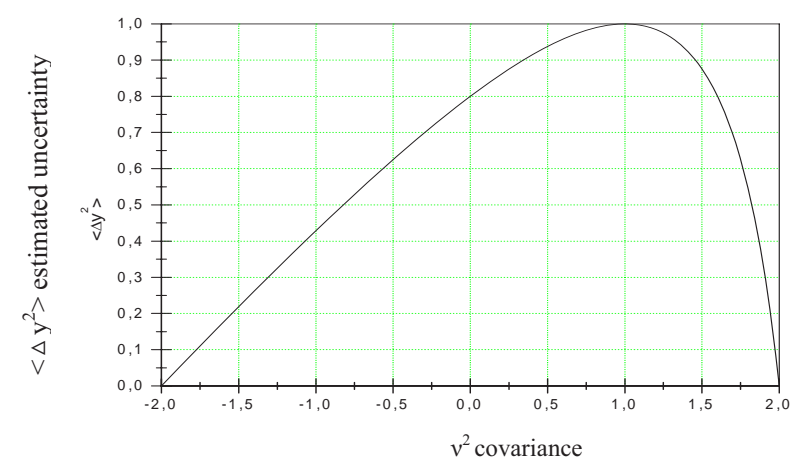

FIG. 6.4.3. Dependence on the covariance of the estimated uncertainty in the case $\sigma_{1}^{2}=1, \sigma_{2}^{2}=4$.

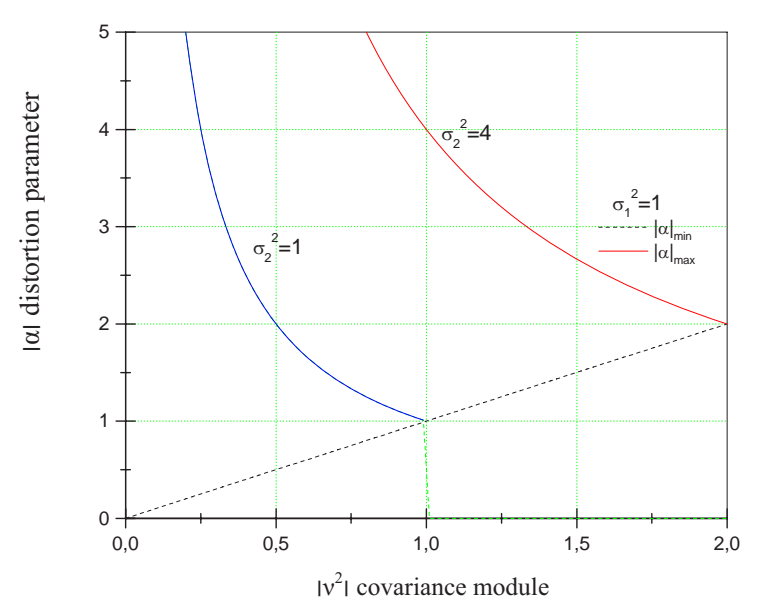

FIG. 6.4.4. Boundaries of the possible values of the distortion parameter for $\sigma_{1}^{2}=1, \sigma_{2}^{2}=4$ and $\sigma_{2}^{2}=1$.

\subsubsection{Statement of the problem, its solution and its connection with the classical approach}

The problems considered above led to the conclusion that PPP and SUP are associated with the value and shape of the systematic errors of the experimental data. Partitioning errors into statistical and systematic (sometimes more than one systematic component) reflects the real experimental situation and is at the foundation of covariance matrix generation. Consider the case with only one component of systematic error, whereby the errors of $N$ measurements can be expressed by $2 N$ quantities (statistical and systematic errors for each measurement). Covariance matrices of experimental uncertainties used in the least squares method can have $N(N+1) / 2$ distinct elements in the common case. With two measurements, there are three such independent elements, but the uncertainties are described by four quantities (see Eq. (6.4.8)). In contrast, for more than three measurements the number $N(N+1) / 2$ of distinct elements of the covariance matrix is larger than the number $2 N$ of individual statistical and systematic uncertainties. This situation means that in the case of two measurements not all the experimental information about the errors is used, and therefore for large numbers of measurements the covariance matrix elements are not independent. Consequently, it may be possible to simplify the least squares method problem.

The least squares method problem can be formulated in such a way that the minimized 
functional relationship contains exactly the number of parameters necessary and sufficient for the description of all the experimental error components. This method takes the mean square statistical uncertainties for each point, the mean square systematic uncertainty for one of the points, and the values of the distortion parameter for the other points. Use is made of a formulation of the problem according to which the sample values of the systematic errors for the various points are rigidly interconnected. Thus $\mu(x)=g(x) \mu\left(x_{1}\right)$ in a common case, where $g(x)$ is a known function. The appropriate equation for two measurements is defined as:

$$
S_{f}=\frac{1}{2}\left(\frac{\left(Y_{1}-y-\mu\right)^{2}}{\varepsilon_{1}^{2}}+\frac{\left(Y_{2}-y-\alpha \mu\right)^{2}}{\varepsilon_{2}^{2}}+\frac{\mu^{2}}{s^{2}}\right)
$$

where $\varepsilon_{1}^{2}, \varepsilon_{2}^{2}, \alpha$ and $s^{2}$ are the known quantities, while the values of $y$ and $\mu$ are estimated, and the set of least squares method equations is given by:

$$
\begin{array}{r}
\frac{\partial S_{f}}{\partial \mu}=\frac{\mu}{s^{2}}-\frac{Y_{1}-y-\mu}{\varepsilon_{1}^{2}}-\alpha \frac{Y_{2}-y-\alpha \mu}{\varepsilon_{2}^{2}}=0 \\
\frac{\partial S_{f}}{\partial y}=-\frac{Y_{1}-y-\mu}{\varepsilon_{1}^{2}}-\frac{Y_{2}-y-\alpha \mu}{\varepsilon_{2}^{2}}=0
\end{array}
$$

Therefore the solution of the least squares method problem is given by the equations:

$$
\begin{gathered}
\tilde{\mu}=\frac{s^{2}(1-\alpha)\left(Y_{1}-Y_{2}\right)}{\varepsilon_{1}^{2}+\varepsilon_{2}^{2}+s^{2}(1-\alpha)^{2}}=\frac{v^{2}(1-\alpha)\left(Y_{1}-Y_{2}\right)}{\alpha\left(\sigma_{1}^{2}+\sigma_{2}^{2}-2 v^{2}\right)} \\
\tilde{y}=\frac{Y_{1} \varepsilon_{2}^{2}+Y_{2} \varepsilon_{1}^{2}}{\varepsilon_{1}^{2}+\varepsilon_{2}^{2}}-\tilde{\mu} \frac{\left(\alpha \varepsilon_{1}^{2}+\varepsilon_{2}^{2}\right)}{\varepsilon_{1}^{2}+\varepsilon_{2}^{2}} \\
=\frac{Y_{1}\left(\sigma_{2}^{2}-v^{2}\right)+Y_{2}\left(\sigma_{1}^{2}-v^{2}\right)}{\sigma_{1}^{2}+\sigma_{2}^{2}-2 v^{2}}
\end{gathered}
$$

The Fisher matrix is:

$$
\begin{aligned}
& \mathbf{I}_{f}=\left(\begin{array}{cc}
<\left(\frac{\partial S_{f}}{\partial y}\right)^{2}> & <\frac{\partial S_{f}}{\partial y} \frac{\partial S_{f}}{\partial \mu}> \\
\frac{\partial S_{f}}{\partial y} \frac{\partial S_{f}}{\partial \mu}> & <\left(\frac{\partial S_{f}}{\partial \mu}\right)^{2}>
\end{array}\right) \\
& =\frac{1}{s^{2} \varepsilon_{1}^{2} \varepsilon_{2}^{2}}\left(\begin{array}{cc}
s^{2}\left(\varepsilon_{1}^{2}+\varepsilon_{2}^{2}\right) & s^{2}\left(\alpha \varepsilon_{1}^{2}+\varepsilon_{2}^{2}\right) \\
s^{2}\left(\alpha \varepsilon_{1}^{2}+\varepsilon_{2}^{2}\right) & \varepsilon_{1}^{2} \varepsilon_{2}^{2}+s^{2}\left(\alpha \varepsilon_{1}^{2}+\varepsilon_{2}^{2}\right)
\end{array}\right)
\end{aligned}
$$

The uncertainties of the estimates are determined by the inverse of this matrix:

$$
\begin{aligned}
& \mathbf{I}_{f}^{-1}=\left(\begin{array}{cc}
<\Delta \tilde{y}^{2}> & <\Delta \tilde{y} \Delta \tilde{\mu}> \\
<\Delta \tilde{y} \Delta \tilde{\mu}> & <\Delta \tilde{\mu}^{2}>
\end{array}\right) \\
& =\frac{1}{\sigma_{1}^{2}+\sigma_{2}^{2}-2 v^{2}}\left(\begin{array}{cc}
\sigma_{1}^{2} \sigma_{2}^{2}-v^{4} & -s^{2}\left(\alpha \varepsilon_{1}^{2}+\varepsilon_{2}^{2}\right) \\
-s^{2}\left(\alpha \varepsilon_{1}^{2}+\varepsilon_{2}^{2}\right) & s^{2}\left(\varepsilon_{1}^{2}+\varepsilon_{2}^{2}\right)
\end{array}\right)
\end{aligned}
$$

These results produce a curious equality in which only statistical uncertainties appear on the right hand side (see below):

$$
<\left(\Delta \tilde{y}+\Delta \tilde{\mu} \frac{\alpha \varepsilon_{1}^{2}+\varepsilon_{2}^{2}}{\varepsilon_{1}^{2}+\varepsilon_{2}^{2}}\right)^{2}>=\frac{\varepsilon_{1}^{2} \varepsilon_{2}^{2}}{\varepsilon_{1}^{2}+\varepsilon_{2}^{2}}
$$

Inserting the expression for $\mu(y)$ that can be obtained from Eq. (6.4.25) into Eq. (6.4.24) produces the classical expression appearing in Eq. (6.4.15) for the least squares method functional relationship. This insertion is equivalent to integrating over the 'nuisance' parameter, as expressed by Froehner [6.14]. Note that this approach is based on the use of the systematic errors concept, and is realized in the work of Gai for an arbitrary number of measurements [6.18]. An expression for the least squares method functional relationship is given that allows one to circumvent the problem of inverting the covariance matrix of the experimental uncertainties, and leads to the above simplification of the least squares method problem. An analogous procedure in the Bayesian approach is called the implicit data covariance method, and has been implemented in the SAMMY code [6.19].

\subsubsection{Uncertainty of the systematic error estimate}

Inserting into Eq. (6.4.24) the expression for $v(\mu)$ that follows from Eq. (6.4.26) gives the following least squares method equation for the sample value of the systematic error:

$$
S_{s}=\frac{1}{2}\left(\frac{\mu^{2}}{s^{2}}+\frac{\left(Y_{1}-Y_{2}-(1-\alpha) \mu\right)^{2}}{\varepsilon_{1}^{2}+\varepsilon_{2}^{2}}\right)
$$

Information about the distortion parameter $\alpha$ is not used in the classical least squares method, and therefore an estimate of the systematic error cannot 
be made. The systematic error in one particular experiment has a definite sample value $\mu$ (unknown, but constant in this set of measurements). Equation (6.4.27) provides a biased estimate (solution of the least squares method problem for Eq. (6.4.32)) because the expectation value for this set (i.e. estimate averaged over the statistical errors of the experiment) does not coincide with the sample value:

$$
\overline{\tilde{\mu}}=\frac{(1-\alpha)^{2} \mu s^{2}}{\sigma_{1}^{2}+\sigma_{2}^{2}-2 v^{2}}
$$

The estimated variance of $\tilde{\mu}$ does not depend on the sample value:

$$
\overline{\tilde{\mu}^{2}}-\overline{\tilde{\mu}}^{2}=\frac{(1-\alpha)^{2} s^{4}\left(\varepsilon_{1}^{2}+\varepsilon_{2}^{2}\right)}{\left(\sigma_{1}^{2}+\sigma_{2}^{2}-2 v^{2}\right)^{2}}
$$

By taking into account the bias, the mean square uncertainty of the estimate in this set of measurements is given by the equation:

$$
\begin{aligned}
\overline{(\tilde{\mu}-\mu)^{2}} & =\overline{\tilde{\mu}^{2}}-\overline{\tilde{\mu}}^{2}+(\overline{\tilde{\mu}}-\mu)^{2} \\
& =\frac{\left((1-\alpha)^{2} s^{4}+\mu^{2}\left(\varepsilon_{1}^{2}+\varepsilon_{2}^{2}\right)\right)\left(\varepsilon_{1}^{2}+\varepsilon_{2}^{2}\right)}{\left(\sigma_{1}^{2}+\sigma_{2}^{2}-2 v^{2}\right)^{2}}
\end{aligned}
$$

Averaging the expression in Eq. (6.4.35) with respect to the sample value $\mu$ (remember that $\left.\left\langle\mu^{2}\right\rangle=s^{2}\right)$ gives the same expression for the total uncertainty $<\Delta \tilde{\mu}^{2}>$ of the systematic error of an ensemble of the experimental results contained in the matrix expression of Eq. (6.4.30). This expression can also be obtained from Fisher's matrix for Eq. (6.4.32):

$$
\begin{gathered}
\mathbf{I}_{s}=<\left(\frac{\partial S_{s}}{\partial \mu}\right)^{2}>=\frac{(1-\alpha)^{2}}{\varepsilon_{1}^{2}+\varepsilon_{2}^{2}}+\frac{1}{s^{2}} \\
<(\Delta \tilde{\mu})^{2}>=\frac{s^{2}\left(\varepsilon_{1}^{2}+\varepsilon_{2}^{2}\right)}{\varepsilon_{1}^{2}+\varepsilon_{2}^{2}+(1-\alpha)^{2} s^{2}}=\frac{s^{2}\left(\varepsilon_{1}^{2}+\varepsilon_{2}^{2}\right)}{\sigma_{1}^{2}+\sigma_{2}^{2}-2 v^{2}}
\end{gathered}
$$

\subsubsection{Estimation of the regression function}

On the basis of the connection between the generalized and the classical expressions in Eqs (6.4.24) and (6.4.15), the estimate given by Eq.
(6.4.28) for the $\tilde{y}$ value coincides with the estimate in Eq. (6.4.15). The estimate of the systematic error $\tilde{\mu}$ plays the role of a hidden parameter in the estimate for $\tilde{y}$ and does not appear in the final expression. However, the introduction of this parameter is helpful for the analysis of the PPP situation. The first equality of Eq. (6.4.28) with this hidden parameter shows that the estimate $\tilde{y}$ from Eq. (6.4.28) is biased with respect to the solution of the problem with no correlated experimental uncertainties $\tilde{y}_{\text {stat}}$, as given by Eq. (6.4.18), which is always positioned within the range of the measurements. This bias is equal to the weighted estimate of the systematic errors:

$$
\tilde{\mu} \frac{\left(\alpha \varepsilon_{1}^{2}+\varepsilon_{2}^{2}\right)}{\varepsilon_{1}^{2}+\varepsilon_{2}^{2}}=\frac{\frac{\tilde{\mu}}{\varepsilon_{1}^{2}}+\frac{\alpha \tilde{\mu}}{\varepsilon_{2}^{2}}}{\frac{\tilde{\mu}}{\varepsilon_{1}^{2}}+\frac{\alpha \tilde{\mu}}{\varepsilon_{2}^{2}}}
$$

After substituting Eqs (6.4.27) and (6.4.1) into the formula for the estimate provided by Eq. (6.4.28), one obtains:

$$
\begin{aligned}
\tilde{y} & =y+\frac{\delta_{1} \varepsilon_{2}^{2}+\delta_{2} \varepsilon_{1}^{2}}{\varepsilon_{1}^{2}+\varepsilon_{2}^{2}}-(\tilde{\mu}-\mu) \frac{\left(\alpha \varepsilon_{1}^{2}+\varepsilon_{2}^{2}\right)}{\left(\varepsilon_{1}^{2}+\varepsilon_{2}^{2}\right)} \\
& =y+\frac{\delta_{1} \varepsilon_{2}^{2}+\delta_{2} \varepsilon_{1}^{2}}{\varepsilon_{1}^{2}+\varepsilon_{2}^{2}} \\
& +\frac{\left(\alpha \varepsilon_{1}^{2}+\varepsilon_{2}^{2}\right)\left(\left(\varepsilon_{1}^{2}+\varepsilon_{2}^{2}\right) \mu-(1-\alpha) s^{2}\left(\delta_{1}-\delta_{2}\right)\right)}{\left(\varepsilon_{1}^{2}+\varepsilon_{2}^{2}\right)\left(\varepsilon_{1}^{2}+\varepsilon_{2}^{2}+(1-\alpha)^{2} s^{2}\right)}
\end{aligned}
$$

This expression can be transformed to the formulation:

$$
\Delta \tilde{y}+\Delta \tilde{\mu} \frac{\left(\alpha \varepsilon_{1}^{2}+\varepsilon_{2}^{2}\right)}{\left(\varepsilon_{1}^{2}+\varepsilon_{2}^{2}\right)}=\frac{\delta_{1} \varepsilon_{2}^{2}+\delta_{2} \varepsilon_{1}^{2}}{\varepsilon_{1}^{2}+\varepsilon_{2}^{2}}
$$

which explains the sense of the equality in Eq. (6.4.31). The third item on the right hand side of the first equality of Eq. (6.4.39) is the weighted difference of the systematic error sample value and the estimate $\tilde{\mu}-\mu$. As follows from Eq. (6.4.33), $\overline{\tilde{\mu}}$ and $\mu$ always have the same sign, and $0 \leq|\overline{\tilde{\mu}}| \leq|\mu|$. Thus for $\alpha \neq 1$ when there is distortion of the systematic errors and PPP can occur, the above mentioned bias of Eq. (6.4.38) partially compensates for the sample value of the systematic error contained in the expression for $\tilde{y}_{\text {stat }}$ in 
Eq. (6.4.18); that is, it improves the estimate (see Fig. 6.4.5). This compensation does not occur in the absence of distortion because $\tilde{\mu}=0$ under such conditions.

By analysing the last of the equalities of Eq. (6.4.39), the second and third items are deduced to be uncorrelated. Therefore the uncertainty of the estimate $\tilde{y}$ can be expressed as a sum of a component with a purely statistical origin and a more complicated term that depends on the systematic uncertainty:

$$
\begin{aligned}
& <(\Delta \tilde{y})^{2}>=<\left(\frac{\delta_{1} \varepsilon_{2}^{2}+\delta_{2} \varepsilon_{1}^{2}}{\varepsilon_{1}^{2}+\varepsilon_{2}^{2}}\right)^{2}>+<(\mu-\tilde{\mu})^{2}>\left(\frac{\left(\alpha \varepsilon_{1}^{2}+\varepsilon_{2}^{2}\right)}{\left(\varepsilon_{1}^{2}+\varepsilon_{2}^{2}\right)}\right)^{2} \\
& =\frac{\varepsilon_{1}^{2} \varepsilon_{2}^{2}}{\varepsilon_{1}^{2}+\varepsilon_{2}^{2}}+\frac{s^{2}}{\varepsilon_{1}^{2}+\varepsilon_{2}^{2}+(1-\alpha)^{2} s^{2}} \frac{\left(\alpha \varepsilon_{1}^{2}+\varepsilon_{2}^{2}\right)^{2}}{\varepsilon_{1}^{2}+\varepsilon_{2}^{2}} \\
& =\frac{\sigma_{1}^{2} \sigma_{2}^{2}-v^{4}}{\sigma_{1}^{2}+\sigma_{2}^{2}-2 v^{2}}
\end{aligned}
$$

The estimated uncertainty is plotted as a function of systematic uncertainty $s^{2}$ at $\varepsilon_{1}^{2}=0.5$ and $\varepsilon_{2}^{2}=3.5$ in Fig. 6.4.6. This figure shows that, for fixed statistical uncertainties and a distortion parameter distinct from unity, the uncertainty of the estimates becomes smaller with an increase of the systematic uncertainty than for the case without distortion, and approaches a plateau.

\subsubsection{The difference approach}

Consider different values of the systematic errors for two measurements. Simple estimates of

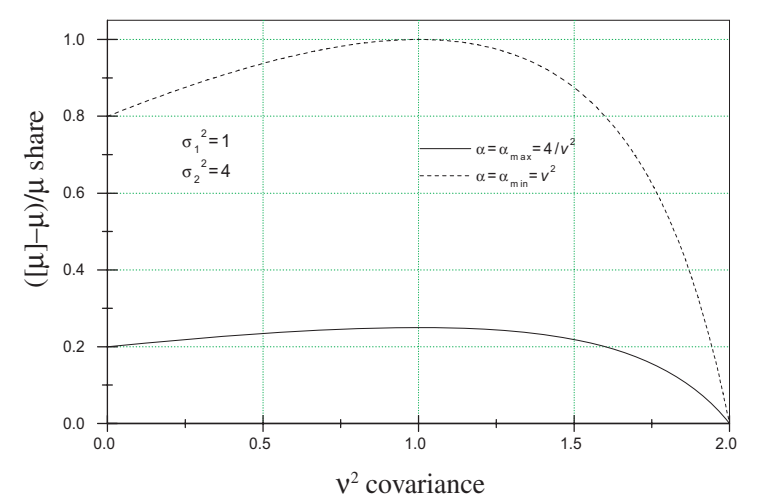

FIG. 6.4.5. Dependence of the share of the uncompensated systematic error for extreme values of the distortion parameter $\alpha$ on the covariance $v^{2}$.

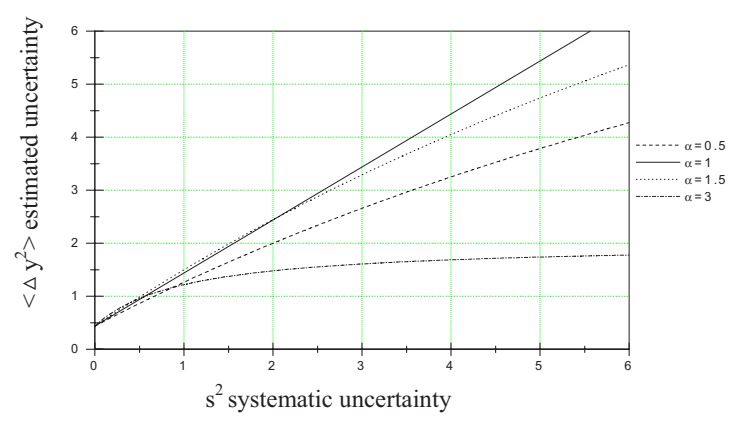

FIG. 6.4.6. Estimated uncertainty $<\Delta y^{2}>$ as a function of the systematic uncertainty $s^{2}$ for the different distortion parameter values.

the unknown constant $y$ and of the sample value of the systematic error $\mu$ can be derived as follows from Eq. (6.4.1), in which the quantities:

$$
\begin{aligned}
& \left(\alpha Y_{1}-Y_{2}\right)-(\alpha-1) y=\alpha \delta_{1}-\delta_{2} \\
& \left(Y_{1}-Y_{2}\right)-(1-\alpha) \mu=\delta_{1}-\delta_{2}
\end{aligned}
$$

are distributed with variances $\alpha^{2} \varepsilon_{1}^{2}+\varepsilon_{2}^{2}$ and $\varepsilon_{1}^{2}+\varepsilon_{2}^{2}$, respectively. From Eqs (6.4.42) and (6.4.43), one obtains the following estimates:

$$
\begin{aligned}
& \tilde{\tilde{y}}=\frac{\alpha Y_{1}-Y_{2}}{\alpha-1}=y+\frac{\alpha \delta_{1}-\delta_{2}}{\alpha-1} \\
& \tilde{\tilde{\mu}}=\frac{Y_{1}-Y_{2}}{1-\alpha}=\mu+\frac{\delta_{1}-\delta_{2}}{1-\alpha}
\end{aligned}
$$

Note that in this approach for the positive correlation of the experimental uncertainties $(\alpha>0)$, the estimate $\tilde{\tilde{y}}$ is always outside the experimental data range because the differences:

$$
\begin{aligned}
& Y_{1}-\tilde{\tilde{y}}=\frac{Y_{1}-Y_{2}}{1-\alpha} \\
& Y_{2}-\tilde{\tilde{y}}=\frac{\alpha\left(Y_{1}-Y_{2}\right)}{1-\alpha}
\end{aligned}
$$

always have the same sign. Thus the PPP effect is always observed.

Compare uncertainties of the estimates of Eqs (6.4.44) and (6.4.45) with the uncertainties of the generalized least squares method problem obtained earlier: 


$$
\begin{aligned}
\overline{(\Delta \tilde{\tilde{y}})^{2}} & =\frac{\alpha^{2} \varepsilon_{1}^{2}+\varepsilon_{2}^{2}}{(1-\alpha)^{2}} \\
& =<(\Delta \tilde{y})^{2}>+\frac{\left(\alpha \varepsilon_{1}^{2}+\varepsilon_{2}^{2}\right)^{2}}{(1-\alpha)^{2}\left(\varepsilon_{1}^{2}+\varepsilon_{2}^{2}+(1-\alpha)^{2} s^{2}\right)}
\end{aligned}
$$

$$
\begin{aligned}
\overline{(\Delta \tilde{\tilde{\mu}})^{2}} & =\frac{\varepsilon_{1}^{2}+\varepsilon_{2}^{2}}{(1-\alpha)^{2}} \\
& =<(\Delta \tilde{\mu})^{2}>+\frac{\varepsilon_{1}^{2}+\varepsilon_{2}^{2}}{(1-\alpha)^{2}\left(\varepsilon_{1}^{2}+\varepsilon_{2}^{2}+(1-\alpha)^{2} s^{2}\right)}
\end{aligned}
$$

The estimates do not take into account the variance of the systematic error (i.e. not all available information is used). Therefore the uncertainties of the estimates are only determined by the statistical uncertainties of the experiment and the distortion parameter $\alpha$, and are higher than for the least squares method problem (corresponding to Eqs (6.4.15), (6.4.24) and (6.4.32)).

\subsubsection{The inverse problem}

The various proposed methods of PPP exclusion are aimed at placing the estimate within the range of experimental data. However, in all the problems considered above, the 'paradox' estimate was found to be closer to the true datum than the more widely accepted non-paradoxical values. Consider an 'inverse' problem - what nature of correction to the experimental data is required so that the unchanged (paradox) estimate falls within the range of these corrected data? Comparing Eqs (6.4.13) and (6.4.28) this can be achieved by solving the evaluation problems without assuming the correlation of the errors, but with the measurement results corrected by the sample value of the systematic error estimate $\tilde{\mu}$ of Eq. (6.4.27) (i.e. $\left.Y_{1}^{c}=Y_{1}-\tilde{\mu}, Y_{2}^{c}=Y_{2}-\alpha \tilde{\mu}\right)$. Indeed, the solution of this problem with uncorrelated errors:

$Y_{1}^{c} \leq \tilde{y}_{s t}^{c}=\frac{\left(Y_{1}-\tilde{\mu}\right) \varepsilon_{2}^{2}+\left(Y_{2}-\alpha \tilde{\mu}\right) \varepsilon_{1}^{2}}{\varepsilon_{1}^{2}+\varepsilon_{2}^{2}} \leq Y_{2}^{c}$

coincides with the solution of Eq. (6.4.28) for the problem with correlated errors.

This result can also be formulated in the following way: for any value of the distortion $\alpha$ in the range of Eq. (6.4.23), the solution of the least squares method problem of Eq. (6.4.12) with noncorrelated uncertainties of measurements (but with corrected measurement results) that depends on the distortion value:

$$
\begin{aligned}
& Y_{1}^{c}=Y_{1}-\frac{v^{2}(1-\alpha)\left(Y_{1}-Y_{2}\right)}{\alpha\left(\sigma_{1}^{2}+\sigma_{2}^{2}-2 v^{2}\right)} \\
& Y_{2}^{c}=Y_{2}-\frac{v^{2}(1-\alpha)\left(Y_{1}-Y_{2}\right)}{\left(\sigma_{1}^{2}+\sigma_{2}^{2}-2 v^{2}\right)}
\end{aligned}
$$

coincides with the solution of Eq. (6.4.28) that does not depend on $\alpha$. However, the estimated uncertainty in this 'inverse' problem for the fixed values of total variances and covariance does depend on $\alpha$, because the statistical uncertainties are dependent on this parameter:

$\overline{\left(\Delta \tilde{y}_{s t}\right)^{2}}=\frac{\varepsilon_{1}^{2} \varepsilon_{2}^{2}}{\varepsilon_{1}^{2}+\varepsilon_{2}^{2}}=\frac{\left(\sigma_{1}^{2}-v^{2} / \alpha\right)\left(\sigma_{2}^{2}-\alpha v^{2}\right)}{\sigma_{1}^{2}-v^{2} / \alpha+\sigma_{2}^{2}-\alpha v^{2}}$

\subsubsection{The case of relative experimental uncertainties}

As a rule, relative uncertainties are the most commonly encountered in experimental studies in which such data are covering a wide range of values. At the same time, the covariance matrix in the least squares method problem depends on absolute uncertainties. Transformation from these relative values to absolute data is simple in concept (i.e. multiply the relative uncertainties by the true values of the function), but this function is unknown and the least squares method is used to derive an estimate.

The usual solution consists of carrying out a relative to absolute transformation by using the experimental values instead of the unknown true values of the function. However, in this approach the experimental values that are downwardly divergent from the true values of the function enter into the least squares method expression with larger weight than those values that are upwardly divergent. Thus the evaluated estimate is drawn downwards even if there is no evidence of PPP. Furthermore, this process increases the possibility of observing PPP because within the relative to absolute transformation the variances $\sigma_{i}^{2}$ depend on the square of $Y_{i}$ but the covariance $v^{2}$ depends only on $Y_{i}$. As a result, the threshold $\sigma_{1}^{2}<v^{2}$ corresponding to Eq. (6.4.22) for the onset of PPP is reduced, and the PPP estimate is directed 
downwards whenever $\sigma_{1}^{2}<\sigma_{2}^{2}$ for $Y_{1}<Y_{2}$ (i.e. if the lesser total uncertainty corresponds to the lesser experimental value). This mini-PPP effect (Section 6.2.6) [6.6] can be eliminated after a few least squares method iterations by using the previously obtained iteration estimate in the subsequent iteration of the relative to absolute transformation.

Usually the least squares method expression, with the covariance matrix depending on the unknown estimated function, is not considered because of the strong non-linearity of the problem. Note that the use of the maximum likelihood method (MLM), which also takes into account the dependence of the pre-exponential factor on the unknown function, may be more appropriate. One of the ways of solving non-linear problems in the usual case is to minimize the least squares method expression by the discrete optimization method (e.g. Ref. [6.20]). The non-linear least squares method and MLM problems can be solved analytically with two measurements, and the estimate for the least squares method problem is:

$$
\tilde{y}_{r}=\frac{Y_{1}^{2} \gamma_{2}^{2}-2 Y_{1} Y_{2} w^{2}+Y_{2}^{2} \gamma_{1}^{2}}{Y_{1} \gamma_{2}^{2}-\left(Y_{1}+Y_{2}\right) w^{2}+Y_{2} \gamma_{1}^{2}}
$$

where $\gamma_{i}^{2}$ denotes the relative variances and $w^{2}$ represents the relative covariance. Instead of Eq. (6.4.22), the following condition applies for PPP occurrence:

$$
\sqrt{\gamma_{1}^{2} \gamma_{2}^{2}}>w^{2}>\gamma_{1}^{2} \frac{Y_{2}}{Y_{1}}
$$

Recall that the first measurement is more accurate in the present case.

Figure 6.4.7 illustrates the main features of the problem. The non-linearity of the problem in the

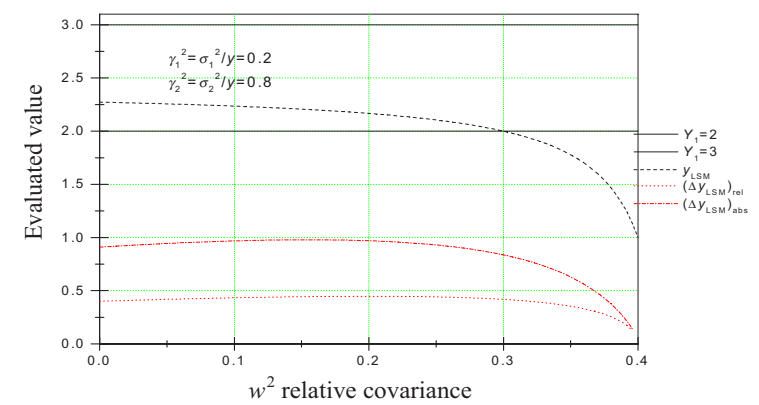

FIG. 6.4.7. PPP example for the least squares method problem with relative experimental uncertainties. estimate and of the estimate in the measurement results makes mathematically correct determination of the estimate uncertainty very difficult. By analogy with the case of the known absolute uncertainty, one uses the following definition of the relative uncertainty of the estimate in Fig. 6.4.7:

$$
<\left(\Delta \tilde{y}_{r}^{2}\right)_{\text {rel }}>=\frac{\gamma_{1}^{2} \gamma_{2}^{2}-w^{4}}{\gamma_{1}^{2}+\gamma_{2}^{2}-2 w^{2}}
$$

Consider the following three points in Fig. 6.4.7:

(a) Point where the estimate exits from the range of the experimental data;

(b) Point of the maximum of the estimate absolute uncertainty;

(c) Point of the maximum of the estimate relative uncertainty.

Figure 6.4.7 confirms the following general conclusions:

(a) For known relative experimental uncertainties, the abscissa of the first point depends not only on the relationship of variances and covariance, but also on the measurement results;

(b) The value of the covariance, corresponding to a maximum of the absolute error of the estimate, also depends on the measurement results - these two points will be moved to some degree for MLM;

(c) Only one characteristic point that depends exclusively on variances and covariance (and not on experimental values) is the point of the maximum relative uncertainty of the estimate - this is achieved at $w^{2}=\gamma_{1}^{2}$, and after the relative to absolute transformation that is equivalent to the condition $v^{2}=\sigma_{1}^{2}$ for the problem with given absolute uncertainties.

This behaviour suggests that non-coincidence of the three characteristic point abscissas in an investigation of the cause and effect of PPP for data evaluation requires consideration of the position of the estimate and the associated uncertainty. Thus at $0.2<w^{2}<0.3$ in Fig. 6.4.7, PPP as classically defined is not observed, the estimate is still within the experimental data range and the uncertainty decreases with an increase of the covariance. 


\subsubsection{Concluding remarks and recommendations}

Some results of PPP and SUP investigations have been described for the case of two measurements. Theoretical investigations and the practice of simultaneous processing of the large experimental sets from many experimental investigations have shown that the cause and effect of PPP and SUP are the same for any number of measurements, and only the concept of systematic error distortion needs to be generalized.

PPP in the classical definition means that the estimate goes outside the range of the experimental data. This behaviour is observed in the case of unequal uncertainties of the measurements whenever their covariance exceeds the minimal variance (see Eq. (6.4.22) and Fig. 6.4.2). If such an effect occurs because the experimental data are used for the relative to absolute transformation (mini-PPP case), the estimate and associated uncertainty are understated. The most logical method for the removal of mini-PPP is the elimination of its origin (e.g. by the use of the iterative least squares method in the relative to absolute transformation [6.11]). However, the removal of mini-PPP is not sufficient for the complete elimination of PPP and SUP [6.21]; large covariance and distorted systematic errors can exist for other reasons than an incorrect relative to absolute transformation.

At fixed values of total uncertainties for the measurements, an increase of covariance beyond some threshold is accompanied by a decrease of the estimated uncertainty. A zero value of this uncertainty (absolutely accurate estimate) is achieved at the highest possible value of the covariance (see Eq. (6.4.21) and Fig. 6.4.3). If PPP is defined in terms of the behaviour of the least squares method estimate, contradictory to custom, the decrease of the estimated uncertainty with an increase of the covariance (SUP) is a more robust and dangerous feature of PPP than the simple matter of the estimate falling outside the range of the experimental data (see Fig. 6.4.7). After removal of the mini-PPP effect for many measurements from different experiments, the estimate can become located within the range of experimental data, despite the large covariances and the distortion of the systematic errors, because PPP 'down' and PPP 'up' for the different experiments tend to compensate. However, the SUP effect continues in full measure.
PPP and SUP are caused by the values of the covariance matrix elements, and they can occur at both large and small scatter of the data. Therefore, the $\chi^{2}$ criterion for the least squares method problem with the expression from Eq. (6.4.15) is:

$$
\tilde{\chi}^{2}=\frac{\left(Y_{1}-Y_{2}\right)^{2}}{\sigma_{1}^{2}+\sigma_{2}^{2}-2 v^{2}}, \quad<\tilde{\chi}^{2}>=1
$$

and does not reflect the relationship between statistical and systematic errors. Furthermore, the value obtained for $\tilde{\chi}^{2}$ gives no information regarding PPP and SUP. Therefore SUP is more dangerous than the more understandable decrease of the estimated uncertainty caused by the underestimation of systematic errors. The latter underestimation can be discovered easily by applying the criterion of a large value for $\tilde{\chi}^{2}$. This situation can be improved by assessing sample values of the real systematic errors and their distribution by means of an analysis of the results of the measurements $[6.22,6.23]$.

A simple explanation of the PPP and SUP effects can be obtained by means of the systematic error concept. Although systematic errors are not explicitly present in the least squares method, the large covariances that are accompanied by PPP and SUP imply that the systematic error is large and that the distortion parameter is greater than unity (see Eq. (6.4.24) and Fig. 6.4.4). Essentially, the sample value of the systematic error in the least squares method estimate is partly compensated by an estimate at any value of the distortion parameter different from unity and compatible with the experimental variances and covariance (see Eq. (6.4.39) and Fig. 6.4.5). Thus the fact that the estimate appears outside the range of experimental data for true PPP is not detrimental to the evaluation. On the contrary, this behaviour brings the result closer to the true value and decreases the uncertainty.

The covariance matrix of the experimental uncertainties used in the least squares method is constructed on the basis of the statistical and systematic errors given by an experimenter for every measurement of the set to be evaluated. If the systematic errors for the different measurements are really different from those obtained with the use of information on the distortion parameter, an estimate of the systematic error sample value can be derived. This estimate is even more accurate than that obtained from the difference method (see Sections 6.4.3.2 and 6.4.4). There is no need to 
remove the PPP and SUP effects since they reflect the real situation. Unfortunately, information about the error components is usually lost in the transformation from the measurement uncertainties to the covariance matrix.

The systematic uncertainties of one set of measurements can only be determined through the assessment of an expert who is able to distinguish them from statistical uncertainties. The overstating of systematic error for the measurements (pessimistic estimate that is often done to increase the uncertainty of the final estimate) sometimes leads to the opposite result (i.e. directly to PPP and SUP). Under these circumstances PPP and SUP must be eliminated, and this is best achieved by analysis and correction of the systematic errors [6.22, 6.23]. If this approach is impossible (e.g. if the original information about the error components is lost and there is only the covariance matrix), all pair covariances can be limited to minimal variances in order to prevent occurrence of the PPP and SUP effects. Thus the following conditions can be imposed on the covariance matrix elements: $\left|v_{i k}\right|=$ $\min \left(\sigma_{i}^{2}, \sigma_{k}^{2}\right)$ [6.24]. These conditions for the covariances were proposed earlier by Tagesen [6.25]. While this approach cannot be justified as a common rule, this procedure ensures the most conservative estimate (with the maximum uncertainty) and appears more logical than the use, for example, of the logarithmic or Box-Cox transformations. As shown by $\mathrm{Oh}$ [6.26] and Kawano (in Section 6.7), these transformations allow one to diminish the influence of the large covariance, remove the PPP effect and (to a lesser degree) minimize the SUP effect. If the elimination of PPP and SUP is necessary, limitation of the covariance at the least squares method input would appear to be simpler and more effective than solving this problem by a formal transformation that is difficult to control.

\subsection{CHIBA-SMITH METHOD TO MINIMIZE PEELLE'S PERTINENT PUZZLE}

\section{D.L. Smith}

\subsubsection{Method and rationale}

Chiba and Smith [6.11] were motivated to address the issue of PPP because of their conviction that the solution obtained by Peelle was unreasonable when the conventional least squares formulas were used (i.e. Eqs (6.2.8-6.2.10) and the requisite covariance matrix was constructed according to a conventional understanding of the role of uncorrelated and correlated absolute data uncertainties in the formalism). This procedure suggested that some changes might be needed in the conventional least squares approach to data evaluation. Chiba and Smith explored the idea of working explicitly with probability density functions based on Bayesian statistics (e.g. see Section 6.2.8), but they soon concluded that this approach would be impractical. They decided that a reasonable approximation lay in preserving the formalism embodied in Eqs (6.2.8-6.2.10) but altering the manner in which the data covariance matrix (DCM) was constructed. When two data values have the same percentage error (e.g. 10\% error), they should essentially be weighted the same in an evaluation. The lower of two discrepant values should not be more heavily weighted, as would be the case if the absolute errors based on the experimental data were used for calculating weighting factors. Their objectives were accomplished if all error specifications can be expressed as relative (or fractional) errors, and computation of the effective DCM can be based on absolute errors calculated using the solution values and the given fractional errors rather than the original data. Obviously, since the solution values are unknown a priori, implementation of this method required an iterative approach in which prior estimates for the evaluated values are first introduced. Chiba and Smith found this approach to be quite robust when dealing with realistic data, and convergence could be achieved for all practical purposes with just a few iterations (perhaps two or three at most). Furthermore, the evaluation solutions appeared to be much more representative of the data upon which they were based when this method was used than when the conventional method was adopted (i.e. no correction for PPP effects). This earlier observation has been verified by more recent experience acquired during the present standards evaluation (see Section 9).

\subsubsection{Implementation of the Chiba-Smith approach}

Chiba incorporated the Chiba-Smith 'technical fix' for the PPP effect into a version of the DATGMA code, which is used to prepare input for the original GMA code. Eventually, this approach evolved into a production code labelled GMAJ, 
which has been used by various researchers for nuclear data evaluations performed during the past decade. Unfortunately, this code did not incorporate a data input routine that could handle the large GMA database as assembled originally by Poenitz and others for the ENDF/B-VI standards evaluation [6.4]. Consequently, the method adopted for the present evaluation was to implement the Chiba-Smith 'technical fix' in the original GMA program package (after correcting some existing coding errors missed by the original author of GMA [6.2]). Since GMA has absolute data errors as input data, and a prior estimate of the evaluation (used mainly for transformation of original data from arbitrary energies to specified energy grid points), fractional errors can easily be calculated and thus a covariance matrix is generated on the basis of these fractional errors and prior evaluated values rather than using the original reported data values. Iteration is correspondingly straightforward. This modification of GMA led to the GMAP code (which can also function as the original GMA when the PPP 'fix' is turned off). GMAP has been used extensively for the present standards evaluation to evaluate non-model information and also to merge non-model data and results generated from $\mathrm{R}$ matrix model analyses.

\subsection{BOX-COX TRANSFORMATION TO MINIMIZE PEELLE'S PERTINENT PUZZLE}

\section{Soo-Youl Oh}

The PPP effect is interpreted in this section as resulting from the use of the least squares method as a linear estimator for a data set that is best estimated by means of a non-linear estimator. A deviation from the normality of the errors of the quantity to be fitted is considered as the source of the anomaly. This deviation can lead to an anomaly not only in applying the least squares method but also in any other fitting and parameter estimation methods, including the Bayesian method, as far as they too assume data normality. In order to resolve this anomaly, a method is proposed that utilizes the Box-Cox transformation [6.27] of the raw data to force the least squares estimator to be the best unbiased estimator (BUE) that is free from the linearity limitation. Thus the Box-Cox transformation is applied as a tool to make non-normally distributed data resemble normally distributed data.
The procedure is reasonably straightforward for computing the estimates, and does not become involved with the true meaning of the given data. Nevertheless, the result of the method applied to the PPP situation suggests adopting a log-normal probability density function instead of the usual normal distribution. This proposal is consistent with some of the other approaches used to explain the nature of PPP, as discussed below. Moreover, the Box-Cox method is robust and provides a generality that transcends the logarithmic transformation, since the log-normal probability density function cannot always be justified for all kinds of quantities.

\subsubsection{Reminder: least squares method}

Given a sample of $T$ observations, the multivariate linear regression specification can be expressed as:

$$
\mathbf{y}=\mathbf{X} \boldsymbol{\beta}+\boldsymbol{\varepsilon}
$$

where $\boldsymbol{\beta}=\left(\beta_{1} \beta_{2} \cdots \beta_{k}\right)^{t}$ is the vector of unknown parameters, while $\mathbf{y}$ and $\mathbf{X}$ contain all the observations of the dependent and explanatory variables:

$$
\mathbf{y}=\left[\begin{array}{c}
y_{1} \\
y_{2} \\
\vdots \\
y_{T}
\end{array}\right], \mathbf{X}=\left[\begin{array}{cccc}
x_{11} & x_{12} & \cdots & x_{1 k} \\
x_{21} & x_{22} & \cdots & x_{2 k} \\
\vdots & \vdots & \ddots & \vdots \\
x_{T 1} & x_{T 2} & \cdots & x_{T k}
\end{array}\right]
$$

Each column of $\mathbf{X}$ contains $T$ observations of an explanatory variable, and $\boldsymbol{\varepsilon}$ is the vector of errors.

The ordinary least squares estimator for the linear model of Eq. (6.6.1) is given by:

$$
\begin{aligned}
& \hat{\boldsymbol{\beta}}_{O L S}=\left(\mathbf{X}^{t} \mathbf{X}\right)^{-1} \mathbf{X}^{t} \mathbf{y} \\
& \operatorname{var}\left(\hat{\boldsymbol{\beta}}_{O L S}\right)=\sigma_{0}^{2}\left(\mathbf{X}^{t} \mathbf{X}\right)^{-1}
\end{aligned}
$$

and the generalized least squares (GLS) estimator is given by:

$$
\begin{aligned}
& \hat{\boldsymbol{\beta}}_{G L S}=\left(\mathbf{X}^{t} \mathbf{V}_{\mathbf{y}}^{-1} \mathbf{X}\right)^{-1} \mathbf{X}^{t} \mathbf{V}_{\mathbf{y}}^{-1} \mathbf{y} \\
& \operatorname{var}\left(\hat{\boldsymbol{\beta}}_{G L S}\right)=\left(\mathbf{X}^{t} \mathbf{V}_{\mathbf{y}}^{-1} \mathbf{X}\right)^{-1}
\end{aligned}
$$

where $\mathbf{V}_{\mathbf{y}}$ is the covariance matrix of $\mathbf{y}$. 
On the other hand, the Gauss-Markov conditions characterize the random data vector $\mathbf{y}$ such that:

$$
\begin{aligned}
& \mathbf{E}(\mathbf{y})=\mathbf{X} \boldsymbol{\beta}_{0} \text { for some } \boldsymbol{\beta}_{0} \\
& \mathbf{V}_{\mathbf{y}}=\sigma_{0}^{2} \mathbf{I}_{T} \text { for some } \sigma_{0}^{2}>0
\end{aligned}
$$

The condition of Eq. (6.6.7) implies that the mean value of the error is zero for any $i$. Equation (6.6.8) implies two conditions: the homoscedasticity of errors (i.e. $V\left(\varepsilon_{i}\right)=\sigma_{0}^{2}=$ constant for any $i$ ) and no correlations between errors (i.e. $\left.\operatorname{cov}\left(\varepsilon_{i}, \varepsilon_{j}\right)=0, i \neq j\right)$.

Gauss-Markov theorem: given the linear specification of Eq. (6.6.1), suppose that the GaussMarkov conditions of Eqs (6.6.7) and (6.6.8) hold. Then the ordinary least squares estimator of Eq. (6.6.3) is the best linear unbiased estimator (BLUE) for $\boldsymbol{\beta}_{0}$.

Aitken theorem: given the linear specification of Eq. (6.6.1), suppose that the condition of Eq. (6.6.7) holds and $\mathbf{V}_{\mathbf{y}}$ is a positive definite matrix. Then the generalized least squares estimator of Eq. (6.6.5) is the BLUE for $\boldsymbol{\beta}_{0}$. The term 'linear' in BLUE means that the estimator $\hat{\beta}$ is a linear function of $\mathbf{y}$, as in Eqs (6.6.3) or (6.6.5), and not that $\mathbf{y}$ is a linear function of $\boldsymbol{\beta}$.

Moreover, given the specification of Eq. (6.6.1), suppose that the normality condition holds such that:

$$
\mathbf{y} \sim N\left(\mathbf{X} \boldsymbol{\beta}_{0}, \mathbf{V}_{\mathbf{y}}\right)
$$

Then the generalized least squares estimator of Eq. (6.6.5) is the BUE for $\boldsymbol{\beta}_{0}$ and:

$$
\hat{\boldsymbol{\beta}}_{G L S} \sim N\left(\boldsymbol{\beta}_{0},\left(\mathbf{X}^{t} \mathbf{V}_{\mathbf{y}}^{-1} \mathbf{X}\right)^{-1}\right)
$$

The Gauss-Markov and Aitken theorems do not involve any distributional assumptions, but the resulting estimators are limited to a narrow class of estimators (i.e. 'linear' estimators). Under the normality condition, the generalized least squares estimator is BUE among both the linear and nonlinear estimators. Furthermore, on the basis of the assumption that the parameter vector obeys the normality condition as given in Eq. (6.6.10) and the linearity specification as in Eq. (6.6.1), the estimate of $\mathbf{y}$ also follows the normal distribution. Thus some tests such as the $F$ test and $\chi^{2}$ test, as well as an analysis of the confidence interval, are justified. Meanwhile, recall that when the conditions of homoscedasticity and zero correlation are not fulfilled, the ordinary least squares estimator is not BLUE any more. However, BLUE is derived with the 'transformed' data of $\mathbf{y}$ :

$$
\mathbf{w}=\mathbf{P}^{-1} \mathbf{y}
$$

where $\mathbf{P}$ is a unique non-singular symmetric matrix such that $\mathbf{P} \mathbf{P}^{\mathbf{t}}=\mathbf{V}_{\mathbf{y}}$ for a positive definite $\mathbf{V}_{\mathbf{y}}$ Such a transformation makes the covariance matrix $\mathbf{V}_{\mathbf{w}}$ satisfy the homoscedasticity and zero correlation conditions, causing the ordinary least squares solution for $\mathbf{w}$ (not $\mathbf{y}$ ) to be BLUE.

The following example is presented to show that a data transformation of sorts occurs in applying the generalized least squares method. This procedure is well documented in textbooks on regression analysis, but an explicit example shows how the transformation works. The covariance matrix of the raw data does not satisfy the condition of Eq. (6.6.8) in the PPP situation (i.e. homoscedasticity and zero correlation between the data). The model of PPP is given by the equation:

$$
\mathbf{y}=\mathbf{X} \boldsymbol{\beta}+\boldsymbol{\varepsilon}=\left(\begin{array}{l}
1.0 \\
1.0
\end{array}\right) \beta+\left(\begin{array}{l}
\varepsilon_{1} \\
\varepsilon_{2}
\end{array}\right)
$$

and the raw data are:

$$
\mathbf{y}=\left(\begin{array}{l}
1.5 \\
1.0
\end{array}\right) \text { and } \mathbf{V}_{\mathbf{y}}=\left(\begin{array}{cc}
0.1125 & 0.06 \\
0.06 & 0.05
\end{array}\right)
$$

With a non-singular symmetric matrix:

$\mathbf{P}=\left(\begin{array}{ll}0.3134 & 0.1194 \\ 0.1194 & 0.1891\end{array}\right)$ or $\mathbf{P}^{-1}=\left(\begin{array}{rr}4.201 & -2.653 \\ -2.653 & 6.965\end{array}\right)$

such that $\mathbf{V}_{\mathbf{y}}=\mathbf{P} \mathbf{P}^{\mathrm{t}}$, the model is transformed as:

$\mathbf{P}^{-1} \mathbf{y}=\mathbf{P}^{-1} \mathbf{X} \beta+\mathbf{P}^{-1}\left(\begin{array}{l}\varepsilon_{1} \\ \varepsilon_{2}\end{array}\right)=\left(\begin{array}{l}1.548 \\ 4.312\end{array}\right) \beta+\left(\begin{array}{l}e_{1} \\ e_{2}\end{array}\right)$

Along with the transformation of the raw data vector such that:

$$
\mathbf{w}=\mathbf{P}^{-1} \mathbf{y}=\left(\begin{array}{l}
3.649 \\
2.985
\end{array}\right)
$$


the corresponding covariance matrix is calculated to be:

$$
\mathbf{V}_{\mathbf{w}}=\mathbf{P}^{-1} \mathbf{V}_{\mathbf{y}} \mathbf{P}^{-1}=\left(\begin{array}{ll}
1.0 & 0.0 \\
0.0 & 1.0
\end{array}\right)
$$

since we intend to force the covariance of the data to meet the condition of Eq. (6.6.8). The ordinary least squares solution to the linear model defined by Eq. (6.6.14), with the data of Eqs (6.6.15) and (6.6.16), is calculated as $\hat{\beta}_{O L S}=0.882 \pm 0.218$, which is the generalized least squares solution to Eq. (6.6.12) with data of Eq. (6.6.13). The estimate of $\mathbf{y}$ is obtained by the inverse transformation of estimated $\mathbf{w}$ :

$$
\begin{aligned}
\hat{\mathbf{y}} & =\mathbf{P} \hat{\mathbf{w}}=\mathbf{P}\left(\mathbf{P}^{-1} \mathbf{X} \hat{\beta}_{O L S}\right)=\mathbf{X} \hat{\beta}_{O L S} \\
& =\left(\begin{array}{l}
1.0 \\
1.0
\end{array}\right) \times 0.882=\left(\begin{array}{l}
0.882 \\
0.882
\end{array}\right)
\end{aligned}
$$

\subsubsection{Box-Cox transformation}

The strange estimate of 0.88 for PPP given above is understood to be the consequence of the limited applicability of the least squares method. Without the normality condition for the errors, there can be a non-linear estimator that yields a smaller variance than that obtained by the least squares estimator. The PPP effect can be perceived from the biased residuals (i.e. the differences between the raw data and the fitted values). Resulting residuals have the same sign in the PPP situation, so that the estimate of 0.88 appears to be biased. For a problem with more data points, as in the TEST1 case [6.26, 6.28], such a biased residual distribution is observed more clearly because almost all residuals are below zero, as can be seen in Fig. 6.6.1.

The residual distribution shown in Fig. 6.6.1 suggests that neither the condition of zero mean of the errors (i.e. the condition of Eq. (6.6.7)) nor the condition of normality for BUE are satisfied by the generalized least squares estimator for $\beta$. There are many factors causing the non-normality of residuals: an inappropriate model that includes the presence of omitted variables, heteroscedasticity and autocorrelation that can be handled with the generalized least squares, the presence of outliers (clearly discrepant experimental values), etc.

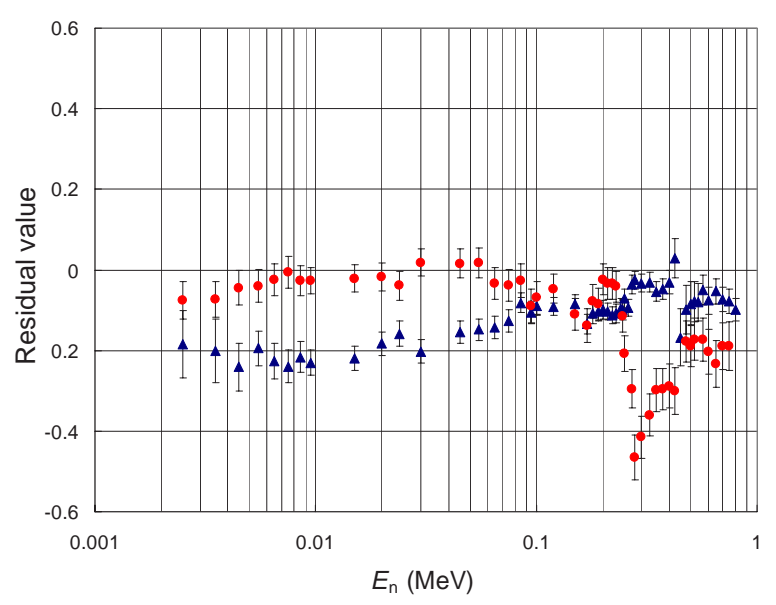

FIG. 6.6.1. Relative residual distribution obtained in TEST1: residual $=(1-$ measured/fitted $)$. Triangles and circles represent the residuals of the Lamaze and Friesenhahn data, respectively, from the fitted values obtained by the GMA code, while the error bar is the total uncertainty of the measured data divided by the GMA value (residuals of other measurements are not shown for brevity).

Three options can be invoked for dealing with non-normally distributed residuals: re-interpret the measurement, transform the 'independent' variable (i.e. the model parameter) or transform the 'dependent' variable to be a suitable type for the model. Despite the importance of thoroughly understanding the nature of the raw data provided by the experimentalist, the issue of how to interpret the raw data or experiment is another topic that is dealt with elsewhere. The second option is equivalent to a revision of the model. While keeping the original model, the last option is the approach proposed and discussed below.

The key issue of the present proposal is the concept of dealing with 'transformed' data in curve fitting or in any evaluation of the model parameters. By applying the transformation, the characteristics of the data set can be made to satisfy the conditions that the particular fitting method assumes. The Box-Cox transformation is utilized as the tool for making non-normally distributed data resemble normally distributed data. Note as an analogy that the generalized least squares method is the same as the ordinary least squares method, but deals with transformed values to meet the homoscedasticity and zero correlation conditions that the GaussMarkov theorem requires.

The proposed fitting procedure is outlined as follows: 
Step 1: transform the measured data and associated covariance matrix.

Step 2: fit the transformed data using a conventional method.

Step 3: inverse transform the estimates and associated covariances into the space of the original data.

The generalized least squares method can be used as a tool for the curve fitting. However, the concept can be incorporated not only into a least squares method but also into any other method, for example the usual Bayesian approach or the MLM. Note that the issue of PPP is perceived because the data are discrepant and strongly correlated with each other; the PPP effect does not arise because of a flaw in fitting formulas themselves, but is due to the characteristics of the data that a fitting methodology assumes. Even the Bayesian approach is not free from the PPP effect for non-normal errors if a normal distribution of the observables is assumed in the formulation. Furthermore, the assumed linearity of the measured quantities with respect to the model parameters makes the Bayesian method (with non-informative priors) identical to the least squares method [6.29]. This provides another justification for the incorporation of a variable transformation in a Bayesian method.

Box and Cox [6.27] proposed a transformation of the dependent (response) variable $y$ to $w$ by:

$w_{i}(\lambda)=\left\{\begin{array}{c}\left(y_{i}^{\lambda}-1\right) / \lambda, \lambda \neq 0 \\ \ln y_{i}, \lambda=0\end{array}, i=1, \ldots, N\right.$

which makes the probability density function of $w$ appear to be rather close to the normal distribution, even if such a transformation does not guarantee the normality of transformed data. The transformation is performed for all $N$ data points of a vector $\mathbf{y}=\left(\begin{array}{llll}y_{1} & y_{2} & \ldots & y_{\mathrm{N}}\end{array}\right)^{t}$ in order to form the vector $\mathbf{w}$, and the transformation parameter $\lambda$ is chosen to maximize the log-likelihood function:

$\ln L(\lambda)=-\frac{N}{2} \ln \left[\frac{1}{N} \sum_{i=1}^{N}\left(\hat{w}_{i}-w_{i}\right)^{2}\right]+(\lambda-1) \sum_{i=1}^{N} \ln y_{i}$

where $\hat{w}_{i}$ is the estimate of $w_{i}$. A numerical algorithm is used to determine $\lambda$, since $L(\lambda)$ in Eq. (6.6.18) is a recursive function of $w$. An optimum value of $\lambda$ is usually sought within the range of $[-2,2]$, while $\lambda=1$ implies no transformation at all.

$\mathbf{V}_{\mathrm{y}}$ is the covariance matrix associated with and provided along with $\mathbf{y}$, and is transformed to $\mathbf{V}_{\mathrm{w}}$ with the aid of the law of error propagation:

$\mathbf{V}_{\mathbf{w}}=\mathbf{S} \mathbf{V}_{\mathbf{y}} \mathbf{S}^{t}$

where $\mathbf{S}$ is a diagonal sensitivity matrix whose $(i, i)$ element is computed as:

$$
S_{i, i}=\frac{\partial w_{i}}{\partial y_{i}}=y_{i}^{\lambda-1}
$$

Then, a curve fitting method (i.e. generalized weighted least squares method (GLSM) as indicated here) yields the estimate $\hat{\mathbf{w}}$ and its associated covariance matrix $\mathbf{V}_{\hat{\mathbf{w}}}$. The estimate $\hat{\mathbf{w}}$ is easily inverse transformed into $\hat{\mathbf{y}}$ by means of:

$$
\hat{y}_{i}=\left\{\begin{array}{c}
\left(\hat{w}_{i} \lambda+1\right)^{1 / \lambda}, \lambda \neq 0 \\
\exp \left(\hat{w}_{i}\right), \lambda=0
\end{array}\right.
$$

The inverse transformation of $\mathbf{V}_{\hat{\mathbf{w}}}$ to $\mathbf{V}_{\hat{\mathbf{y}}}$ is performed similarly to Eq. (6.6.19) according to the equation:

$$
\mathbf{V}_{\hat{\mathbf{y}}}=\mathbf{T} \mathbf{V}_{\hat{\mathbf{w}}} \mathbf{T}^{t}
$$

where the $(i, i)$ th element of the diagonal matrix $\mathbf{T}$ is computed as the derivative $\partial \hat{y}_{i} / \partial \hat{w}_{i}$.

\subsubsection{Solution to Peelle's pertinent puzzle}

Let the Box-Cox solution signify the GLSM solution with the Box-Cox transformation. The PPP problem is modelled as:

$$
\mathbf{y}=\left(\begin{array}{l}
1 \\
1
\end{array}\right) \beta_{y}+\varepsilon_{\mathbf{y}}
$$

The optimum value of the transformation parameter $\lambda$, which maximizes the log-likelihood function of Eq. (6.6.18), is found to be zero from the values of $\ln L(\lambda)$ obtained by varying $\lambda$ over the range $[-1,1]$, as shown in Fig. 6.6.2. With this choice of $\lambda=0$, the data $\mathbf{y}$ and $\mathbf{V}_{\mathbf{y}}$ are transformed to $\mathbf{w}$ and $\mathbf{V}_{\mathbf{w}}$ as follows:

$\mathbf{w}=\left(\begin{array}{l}\ln y_{1} \\ \ln y_{2}\end{array}\right)=\left(\begin{array}{c}0.405 \\ 0.0\end{array}\right)$ 


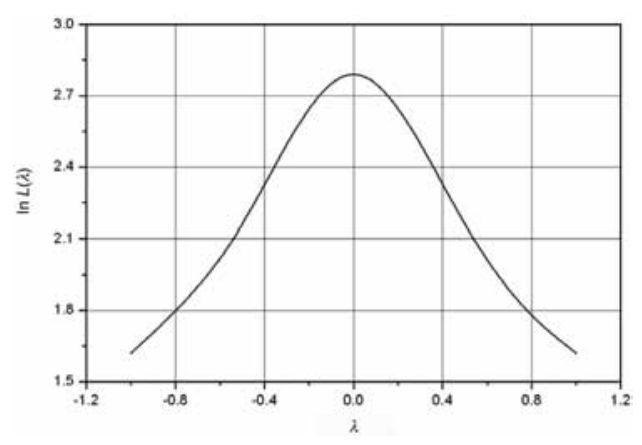

FIG. 6.6.2. Variation of log-likelihood function with $\lambda$ for Peelle's specific problem.

$$
\begin{aligned}
\mathbf{V}_{\mathbf{w}} & =\left(\begin{array}{cc}
1 / y_{1} & 0 \\
0 & 1 / y_{2}
\end{array}\right)\left(\begin{array}{cc}
0.1125 & 0.06 \\
0.06 & 0.05
\end{array}\right)\left(\begin{array}{cc}
1 / y_{1} & 0 \\
0 & 1 / y_{2}
\end{array}\right) \\
& =\left(\begin{array}{cc}
0.05 & 0.04 \\
0.04 & 0.05
\end{array}\right)
\end{aligned}
$$

The specification of Eq. (6.6.23) is correspondingly designated as:

$$
\mathbf{w}=\left(\begin{array}{l}
1 \\
1
\end{array}\right) \beta_{w}+\varepsilon_{\mathbf{w}}
$$

where $\boldsymbol{\varepsilon}_{\mathrm{w}}$ is expected to be normally distributed with a mean value of zero.

The generalized least squares estimator as defined by Eqs (6.6.5) and (6.6.6), with $\mathbf{w}$ and $\mathbf{V}_{\mathbf{w}}$ as given above, yields the model parameter $\hat{\beta}_{w}=0.203$ \pm 0.212 , so that:

$$
\hat{\mathbf{w}}=\left(\begin{array}{l}
0.203 \\
0.203
\end{array}\right) \text { and } \mathbf{V}_{\hat{\mathbf{w}}}=\left(\begin{array}{ll}
0.212^{2} & 0.212^{2} \\
0.212^{2} & 0.212^{2}
\end{array}\right)
$$

Then the inverse transformed final estimate is determined to be:

$\hat{\mathbf{y}}=\left(\begin{array}{l}e^{0.203} \\ e^{0.203}\end{array}\right)=\left(\begin{array}{l}1.225 \\ 1.225\end{array}\right)$ and $\mathbf{V}_{\hat{\mathbf{y}}}=\left(\begin{array}{ll}0.260^{2} & 0.260^{2} \\ 0.260^{2} & 0.260^{2}\end{array}\right)$

or $\hat{\beta}_{y}=1.225 \pm 0.260$ in terms of the model parameter. The estimate of $y=1.225$ with an uncertainty of 0.260 looks reasonable.

Table 6.6.1 presents solutions from three methods applied to the same $y$ values, but with different uncertainties. Scaling both the statistical and systematic uncertainties up or down together does not alter the GLSM solution. The estimate by the Chiba-Smith procedure does not change at all, regardless of the magnitude of the uncertainties. With $\lambda=0$, the estimate from the present procedure also does not change with the uncertainties.

\subsubsection{Justification for the logarithmic transformation}

How do we justify applying the logarithmic transformation to PPP? The transformation parameter $\lambda=0$ signifies a logarithmic transformation, and so several arguments should be considered to justify this situation.

The first justification stems from the perceived non-linearity of a derived variable, most likely caused by the implicit normalization factor. Non-linearity is regarded as the origin of PPP in several relevant studies [6.6, 6.30]; thus taking a logarithm and thereby eliminating the non-normality caused by the quotient (or multi-

\begin{tabular}{|c|c|c|c|c|}
\hline \multicolumn{2}{|c|}{ Uncertainty (\%) } & \multirow{2}{*}{$\begin{array}{l}\text { Generalized least } \\
\text { squares method } \\
\text { (GMA method) }\end{array}$} & \multirow{2}{*}{ Chiba-Smith procedure } & \multirow{2}{*}{ Present procedure } \\
\hline Systematic & Statistical & & & \\
\hline 20 & 20 & $1.071 \pm 0.278$ & $1.250 \pm 0.306$ & $1.225 \pm 0.300$ \\
\hline $20^{b}$ & $10^{b}$ & $0.882 \pm 0.218$ & $1.250 \pm 0.265$ & $1.225 \pm 0.260$ \\
\hline 10 & 10 & $1.071 \pm 0.139$ & $1.250 \pm 0.153$ & $1.225 \pm 0.150$ \\
\hline 10 & 20 & $1.132 \pm 0.202$ & $1.250 \pm 0.217$ & $1.225 \pm 0.212$ \\
\hline 10 & 5 & $0.882 \pm 0.109$ & $1.250 \pm 0.133$ & $1.225 \pm 0.130$ \\
\hline 2 & 1 & $0.882 \pm 0.022$ & $1.250 \pm 0.027$ & $1.225 \pm 0.026$ \\
\hline
\end{tabular}
plicative) form of primary variables seems to be a

TABLE 6.6.1. SOLUTIONS TO PEELLE'S PERTINENT PUZZLE WITH DIFFERENT DATA UNCERTAINTIES

a Optimum $\lambda$ for Box-Cox transformation is zero for all cases.

b Uncertainties in the original PPP. 
reasonable and promising approach. This proposal may be extended to the more general situation. The product of a large number of random variables is known to have a log-normal distribution, and this statement is a different version of the central limit theorem, which states that the sum of a large number of independent errors will tend to be normally distributed. Therefore a normal distribution belongs to an additive world, and a log-normal to a multiplicative world [6.31]. Consequently, if the real world is assumed to be multiplicative, the central limit theorem suggests that uncertainties of real world quantities will be log-normally distributed.

The second justification originates from the contention that a physical quantity under estimation can only take positive values. Thus the maximum entropy (MaxEnt) probability density function for a positive variable should be the log-normal distribution, even though no rigorous derivation was found during the course of this work. Similarly, Smith proposed using a log-normal distribution in cases of large errors and under severe conditions [6.32].

The third justification is found in the work of Sivia [6.33], in which the log-normal distribution is discussed in terms of the MaxEnt likelihood function with relative uncertainties. This argument appears to provide a basis for the Chiba-Smith procedure, as well as Larson's approach.

The Box-Cox transformation approach certainly provides one of the justifications for the logarithmic transformation. As given in Table 6.6.1, the optimum $\lambda$ was always zero for PPP, given the various combinations of systematic and statistical uncertainties in both magnitude and ratio. With respect to the TEST1 case, the Box-Cox transformation method resulted in an optimum $\lambda$ of -0.07 for five pseudo-measurement sets and 0.002 for the other test case with only two data sets [6.26]. Both these numbers can be regarded as essentially equal to zero, and so the discussion here should focus on the logarithmic transformation.

Recall that given the moment constraint:

$$
\int \mathbf{h}(x) p(x) \mathrm{d} x=\mathbf{c}
$$

where $\mathbf{h}$ is a vector valued function of $x$, the MaxEnt density $p(x)$ is of the form:

$$
p(x)=\exp \left(\lambda_{0}+\lambda^{t} \mathbf{h}(x)\right)
$$

The Lagrange multipliers $\lambda_{0}$ and $\lambda$ are chosen so that $p(x)$ is normalized and satisfies the constraint (e.g. Ref. [6.34]). Parameter $\lambda_{0}$ comes from $h_{0}=1$ and $c_{0}=1$. For known mean and variance such that $h_{1}=x, c_{1}=\mu, h_{2}=(x-\mu)^{2}$ and $c_{2}=\sigma$, the probability density function $p(x)$ is the Gaussian distribution. The principle of MaxEnt suggests that the most objective probability density function of $w$ for PPP is the Gaussian distribution:

$$
p(w) \propto \exp \left(-\frac{1}{2} \frac{(w-\hat{w})^{2}}{\sigma_{w}^{2}}\right)
$$

where $\hat{w}$ and $\sigma_{w}$ are known as the least squares solution to the transformed data. This analysis can result in negative values for $w$. Consider the transformation parameter $\lambda=0$, whereby the probability density function of $y$ is derived from a relationship $p(y) \mathrm{d} y=p(w) \mathrm{d} w$ as:

$$
p(y) \propto \frac{1}{y} \exp \left(-\frac{1}{2} \frac{(\ln y-\hat{w})^{2}}{\sigma_{w}^{2}}\right)
$$

i.e. the log-normal distribution.

When the Box-Cox transformation is directly applied to PPP and the TEST1 case, the log-normal distribution is seen to be the governing probability density function for the quantity under estimation, based only on the numbers given and without any other interpretation being imposed on the raw data (although this does not mean that a thorough understanding or interpretation of the raw data provided by the experimentalist is not important). Nevertheless, as indicated above, the use of the logarithmic transformation is judged to be a reasonable approach from this application of the BoxCox method. Moreover, the Box-Cox method is robust and offers greater generality than the logarithmic transformation alone. Consider a non-zero transformation parameter, whereby the probability density function of $y$ is derived from Eq. (6.6.27) to be:

$$
p(y) \propto y^{\lambda-1} \exp \left(-\left(\frac{y^{\lambda}-1}{\lambda}-\hat{w}\right)^{2} / 2 \sigma_{w}^{2}\right)
$$

Figure 6.6.3 shows the probability density function values for different $\lambda$, including both the normal $(\lambda=1)$ and log-normal $(\lambda=0)$ distributions for PPP data. Pairs of $\hat{w}$ and $\sigma_{w}$ are $(0.412,0.146)$ for 


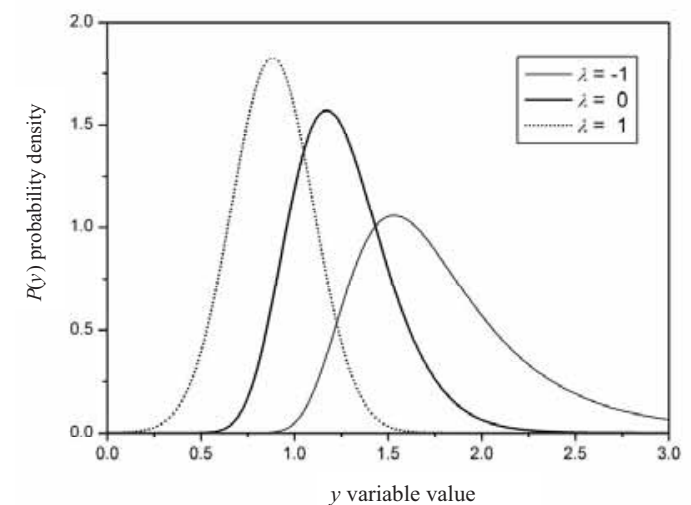

FIG. 6.6.3. Probability density function of y at different $\lambda$ s for PPP.

$\lambda=-1,(0.203,0.212)$ for $\lambda=0$ and $(-0.118,0.218)$ for $\lambda=1$. Even if $\hat{y}$ is readily estimated by Eq. (6.6.21) without the aid of such a probability density function, this plot gives some indication of the characteristics of the probability density function, such as symmetry, skewness and sharpness, as well as the location of the mean or median value.

The Gaussian distribution can be deduced as the MaxEnt probability density function if we are given only the least squares solution $\hat{y}=0.88 \pm 0.22$ to PPP. However, analysis would appear to be less probable in sampling 1.5 and 1.0 from the probability density function for $\lambda=1$ (dotted line) than for sampling the same data from the probability density function for $\lambda=0$ (thick solid line). Nevertheless, when a derived quantity is well defined as a function of independent variables, a Monte Carlo method can be applied to construct the probability density function of the quantity (e.g. see Refs [6.35, 6.36]). When no clear relationship exists, as is the case for a regression analysis of truly measured data, this Box-Cox method can be applied to the analysis (this method does not assume probability density functions of any independent variables).

\subsubsection{Inverse transformation}

Equation (6.6.21) defines how to calculate the estimate of the original quantity from the estimate of the transformed data. However, for $\lambda=0$, the inverse transformed estimate differs from the 'mean' value weighted according to the probability density function of Eq. (6.6.28), as indicated in Table 6.6.2.

The estimate $\hat{y}=\exp (\hat{w})$ corresponds to the 'median' of the log-normal probability density function. When we assign a log-normal distribution for $y$, a question arises: should we report a mean or median value as the nominal 'best' value?

Slob wrote that "there are both theoretical and practical reasons for choosing the median as the measure of central tendency in a log-normal distribution" [6.31]. On the other hand, Smith and Naberejnev state that "if the decision is made to use the median value to characterize a physical quantity conceptually, there remains the question of how to specify its uncertainty" [6.37].

The Box-Cox method proposed here supports the use of the median value because the covariance matrix of $\hat{y}$ is calculated from Eq. (6.6.22). However, this issue has to be left as an open question for further discussion because the variance obtained from Eq. (6.6.22) has a meaning that differs from the standard deviation of a normal distribution.

\subsection{LOGARITHM TRANSFORMATION TO MINIMIZE PEELLE'S PERTINENT PUZZLE}

\section{T. Kawano}

The least squares SOK code applies a logarithm transformation to experimental data. A basic aim of this approach is to transform a ratio measurement (data A/data B) into a linear form (i.e. $(\log ($ data A $)-\log ($ data B $)))$, so that the

TABLE 6.6.2. INVERSE TRANSFORMED AND PROBABILITY DENSITY FUNCTION WEIGHTED ESTIMATES FOR LOG-NORMAL DISTRIBUTION

\begin{tabular}{lcc}
\hline & Inverse transformed & Probability density function weighted \\
\hline Estimate of $y$ & $\hat{y}=\exp (\hat{w})$ & $<y>=\exp \left(\hat{w}+\sigma_{w}^{2} / 2\right)$ \\
Variance & $\sigma_{y}^{2}=\exp (2 \hat{w}) \sigma_{w}^{2}$ & $S^{2}=\exp \left(2 \hat{w}+\sigma_{w}^{2}\right)\left(\exp \left(\sigma_{w}^{2}\right)-1\right)$ \\
\hline
\end{tabular}

$\sigma_{w}$ has null dimension in PPP. 
linearized least squares technique can be applied without having to rely on using a Taylor series expansion or iterative procedure for handling nonlinear equations.

Another advantage of the logarithm transformation is that the data can be scaled. A data space in which experimental and/or calculated data are distributed across wide ranges of energy and crosssection can be effectively transformed into a uniformly distributed space; for example, a time of flight measurement often covers an energy range from $\mathrm{eV}$ to $\mathrm{MeV}$, and the lower energies have a greater density of data points. The transformation from the real energy domain into log-energy domain gives us an equidistant picture of the measurement (similar to the use of lethargy units in reactor physics).

Uncertainties in experimental data are often reported in terms of relative numbers for the measured cross-sections, due mainly to the presence of a strong systematic component in the experiments. However, such relative errors sometimes cause a problem when the measured values vary across a wide range. For example, consider two measured points (e.g. $1 \mathrm{~b}$ and $1 \mathrm{mb}$ ) at two different energies, with reported uncertainties of $1 \%$ : the absolute uncertainty for the first data point is $10 \mathrm{mb}$, while the absolute uncertainty for the second point is only $0.01 \mathrm{mb}$. Consequently, the lower data point will carry a heavier weight in the least squares fitting procedure that can only be balanced by the occurrence of correspondingly smaller differences between the least squares solution and the experimental value. On the other hand, with the logarithm transformation, the uncertainties are transformed into relative values, so that those two points now have the same weight in the least squares analysis. Thus the logarithmic transformation does not give exactly the same answer as would be obtained in the original data space. This situation arises because we assume that the data distribution is Gaussian in the $\log$ space but is not Gaussian in the original space.

\subsection{THE PROPAGATED UNCERTAINTY PARAMETER METHOD}

\section{N.M. Larson}

The propagated uncertainty parameter (PUP) method described in this section was first reported at the International Conference on Nuclear Data for Science and Technology in 2004 [6.38].
Derivation of this method begins with the assumption that there is no ambiguity in fitting uncorrelated data. Algebraic manipulation of Bayes' equations (or least squares equations) for uncorrelated data, coupled with transformations of data via such processes as normalization, produces equivalent equations appropriate for correlated data. The PUP technique has been implemented in the SAMMY R matrix code [6.39].

\subsubsection{Derivation of propagated uncertainty parameter equations}

Bayes' equations are assumed to be appropriate for the determination of those parameter values that give the best fit of theory to data. This assumption can be challenged because of the reliance on the dual hypotheses that all quantities obey Gaussian distributions and that the theory is linear with respect to the varied parameters. Neither hypothesis is strictly true. Nevertheless, both are sufficiently close to true that Bayes' equations are almost correct. Therefore these complications will be ignored in the remainder of this discussion.

Bayes' equations can be written in the form:

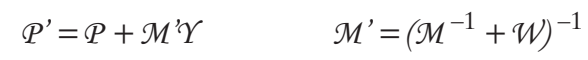

$$
\begin{aligned}
& \Upsilon=G^{t} \mathcal{V}^{-1}(\mathcal{D}-\mathcal{T}) \quad W=G^{t} \mathcal{V}^{-1} G
\end{aligned}
$$

where $P$ represents all parameters, $M$ the full covariance matrix for all parameters, $D$ the measured data, $T$ the corresponding theoretical calculation, $G$ the partial derivative of $T$ with respect to $P$ and $V$ the DCM. The quantities $Y$ and $W$ are defined by the expressions in Eq. (6.8.1). Primes represent updated values for $P$ and $M$, and superscript $t$ indicates the transpose. Substituting zero in place of $M^{-1}$ reduces Eq. (6.8.1) to the more familiar least squares equations.

Consider the case of fitting raw uncorrelated data, for example counts per time channel as measured in a time of flight experiment. While it is seldom practical to calculate directly the quantities measured in a time of flight experiment, nevertheless Bayes' equations can be formally expressed in this manner. Furthermore, because raw data are uncorrelated, there is little ambiguity or argument regarding the treatment of the diagonal DCM.

Bayes' equations can be written in terms of two distinct types of parameter: $P$ are those parameters related to the theory (e.g. $\mathrm{R}$ matrix 
parameters) and $p$ are those related to the measurement conditions (e.g. normalizations, backgrounds and other corrections required to convert raw to reduced data, collectively denoted the 'data reduction parameters'). The prior covariance matrices $M$ and $m$ (for $P$ and $p$, respectively) are not correlated with each other.

If $d$ denotes the raw data, $v$ the associated diagonal DCM and $t$ the corresponding theoretical calculation, the components of Eq. (6.8.1) can be written in terms of these quantities as follows:

$$
\begin{aligned}
& {\left[\begin{array}{l}
P^{\prime} \\
p^{\prime}
\end{array}\right]=\left[\begin{array}{l}
P \\
p
\end{array}\right]+M^{\prime} Y \quad M=\left(\left[\begin{array}{cc}
M & 0 \\
0 & m
\end{array}\right]^{-1}+W\right)^{-1}} \\
& Y=\left[\begin{array}{l}
G^{t} \\
g^{t}
\end{array}\right] v^{-1}(d-t) \quad W=\left[\begin{array}{l}
G^{t} \\
g^{t}
\end{array}\right] v^{-1}\left[\begin{array}{ll}
G & g
\end{array}\right]
\end{aligned}
$$

where $G$ represents the partial derivatives of $t$ with respect to the theory parameters and $g$ the partial derivatives of $t$ with respect to the data related parameters.

Experimentalists transform the raw data $d$ into reduced data $\tilde{d}$ by a series of operations involving the data reduction parameters $p$. This transformation (T) also takes the theory $t$ into $\tilde{t}$ and (applied twice) $v$ into $\tilde{v}$ (which is not the covariance matrix for the reduced data, but represents only the diagonal 'statistical' portion thereof). Similarly, $\tilde{G}$ and $\tilde{g}$ indicate partial derivatives of $\tilde{t}$ with respect to $P$ and $p$, respectively. The quantity $T T^{-1}=1$ can be inserted as needed into Eq. (6.8.2), with the goal of expressing Bayes' equations entirely in terms of reduced rather than raw data. After many pages of algebra (available from Larson upon request), the transformed equations reduce to the form:

$$
\begin{array}{ll}
P^{\prime}=P+M^{\prime} Y & M^{\prime}=\left(M^{-1}+W\right)^{-1} \\
Y=\tilde{G}^{t} V^{-1}(\tilde{d}-\tilde{t}) & W=\tilde{G}^{t} V^{-1} \tilde{G}
\end{array}
$$

where $V$ (entire off-diagonal covariance matrix for the reduced data) is given by:

$$
V=\tilde{v}+\tilde{g} m \tilde{g}^{t}
$$

Equations (6.8.3) and (6.8.4) represent only those portions of the transformed equations that apply to the theory parameters $P$. Similar equations can be derived for the data reduction parameters $p$, along with equations for the covariance matrix elements connecting $P$ and $p$.

Use of Eq. (6.8.3) produces results for $P^{\prime}$ and $M^{\prime}$ (updated parameter and covariance matrix) that are exactly equivalent to those produced if raw data could be fitted directly. This assertion has been verified by studies of simple cases and by computer simulations, as described in Ref. [6.38]. Exact equivalence is only assured for those cases in which the assumption of linearity is valid. Nevertheless, approximate equivalence is found for cases in which the assumption of linearity is approximately valid.

\subsubsection{Comparison with methods in common use}

An examination of Eqs (6.8.3) and (6.8.4) shows that those equations are identical to the general equations used for analysing reduced (correlated) data, with one notable exception: the definition of $\tilde{g}$ in Eq. (6.8.4) is different. The usual definition involves the derivative of the reduced data (and not of the theoretical data) with respect to the parameters $p$. This difference is a subtle distinction, often unnoticeable with high quality data. However, when data discrepancies exist, this small difference can lead to seemingly paradoxical results, as true for PPP [6.10].

\subsubsection{Application to Peelle's pertinent puzzle}

Peelle postulated two data points $D_{1}$ and $D_{2}$ with values 1.5 and 1.0. Both had statistical uncertainties of $10 \%(0.1)$ and a normalization uncertainty of $20 \%(0.2)$. Hence, the DCM was defined as:

$$
\begin{aligned}
V & =\left[\begin{array}{cc}
0.15^{2}+1.5^{2} 0.2^{2} & 0.15 \times 1.0 \times 0.2^{2} \\
0.15 \times 1.0 \times 0.2^{2} & 0.10^{2}+1.0^{2} 0.2^{2}
\end{array}\right] \\
& =\left[\begin{array}{cc}
0.1125 & 0.006 \\
0.006 & 0.05
\end{array}\right]
\end{aligned}
$$

Applying Bayes' Eq. (6.8.3) (with one parameter and two data points) and assuming $M^{-1}=0$ and $G=1$, the unacceptable solution $P^{\prime}=15 / 17 \approx 0.88$ and $\Delta P^{\prime} \approx 0.22$ is obtained. However, if one uses the appropriate version of Eq. (6.8.4):

$$
V=\left[\begin{array}{cc}
0.15^{2}+P^{2} \times 0.2^{2} & P^{2} \times 0.2^{2} \\
P^{2} \times 0.2^{2} & 0.10^{2}+P^{2} \times 0.2^{2}
\end{array}\right]
$$


rather than Eq. (6.8.5) for the DCM, then the far more reasonable solution $P^{\prime}=15 / 13 \approx 1.15$ with $\Delta P^{\prime}$ 0.25 is derived. An identical result would be obtained if the 'hidden' normalization factor were included as a fitting parameter (equivalent to 'fitting the raw data').

\subsubsection{Implementation in the SAMMY code}

The form of Bayes' equations found in Eq. (6.8.3) has been implemented in the multilevel multichannel R matrix SAMMY code [6.39, 6.40], and is available for use with any parameter for which SAMMY is able to calculate partial derivatives. Thus any parameter permitted to be varied (treated as a search parameter) can be used in the calculation of the data covariance matrix. Parameters used in this fashion are designated propogated uncertainty parameters (PUPs).

The PUP option is useful when the analyst has reason to believe that the input value of the parameter is the 'best' and therefore should not be modified by the analysis of the current data set; nevertheless, there is uncertainty associated with the parameter value. Designating this parameter as a PUP allows the associated uncertainty to be propagated through the analysis process and be reflected in the final results.

\subsubsection{Implicit data covariance method for solving Bayes' equations}

$V$ can be generated directly from Eq. (6.8.4) and then inverted for use in Eq. (6.8.3). However, this method is both costly (in terms of computer time and memory) and inefficient. Instead, the matrix $V$ can be inverted by matrix manipulation of the components:

$$
V^{-1}=v^{-1}-v^{-1} g Z^{-1} g^{t} v^{-1}
$$

in which the tildes have been omitted for simplicity and $Z$ is defined as:

$$
Z=m^{-1}+g^{t} v^{-1} g
$$

Even $V^{-1}$ need never be stored. Instead, Eq. (6.8.7) can be inserted directly into the final two equations of Eq. (6.7.3) to give:

$Y=G^{t} v^{-1}(d-t)-G^{t} v^{-1} g Z^{-1} g^{t} v^{-1}(d-t)$

and

$$
W=G^{t} v^{-1} G-G^{t} v^{-1} g Z^{-1} g^{t} v^{-1} G
$$

Although the equations look more complex in this form, and indeed they are more difficult to program, the substantial savings in computer time and memory make the effort well worth while. Detailed examples illustrating these savings are available from the author. PUPs and other types of data covariance matrices in SAMMY are treated in this fashion, which is denoted the implicit data covariance method.

\subsection{MINIMIZATION OF PEELLE'S PERTINENT PUZZLE IN THE STANDARDS EVALUATION}

\section{V.G. Pronyaev}

Since the last standards evaluation exercise in the mid-1980s, a number of codes have been developed or updated to minimize or exclude PPP. These codes include model and non-model least squares fitting codes using the GMA database to generate covariances of experimental data for input or to prepare independent covariance matrices of uncertainties in the experimental data or even the measured raw data such as number of counts per channel. The act of fitting in the space of the primary observables that have diagonal covariance matrices of uncertainties will generally produce the minimum PPP effect. Other approaches serve to reduce the PPP effect, but no method completely excludes this phenomenon.

A version of the GMA code labelled GMAJ was written by Chiba [6.11], and uses the ChibaSmith approach to minimize PPP. The format of input data in GMAJ is different from that used in the GMA code, and so GMAJ cannot be used directly with the GMA database. Smith and Pronyaev [6.15] have also implemented the ChibaSmith option in the original Poenitz GMA code (labelled GMAP), while preserving the structure of the input data, as have Tagesen and Vonach in the GLUCS code [6.41]. This form of PPP minimization requires the use of an iterative procedure in the evaluation. GMAJ and the modified GLUCS codes were only used for the tests of the GMAP code with the TEST1 data set (see Section 2) and in a comparison of the various proposed approaches for minimizing the PPP effect.

The SOK code uses the logarithmic transformation of the experimental data to minimize the 
PPP effect. Kawano produced a conversion code to transform the experimental data in the GMA format to the SOK input format in order to fit the data from the GMA database. The SOK code was used to compare the logarithmic transformation option of PPP minimization with the Chiba-Smith approach using the full GMA database.

Badikov and Gai updated the PADE2 code, which uses the technique of analytical expansions, with the inclusion of options to minimize the PPP effect:

(a) An inequality establishes the upper physical limits of the covariances of the experimental data, and was used to check and correct the covariance matrices [6.24];

(b) A method of experimental data analysis assigns to each set of data certain unrecognized systematical uncertainties and reduces the PPP effect [6.22].

The PADE2 code was not adopted for computations involving the full GMA database but was used to study the PPP effect and to influence any reduction of uncertainties associated with the evaluation process.

A code developed by Oh [6.26] that implements the Box-Cox transformation was used in a comparison of different options of PPP minimization with the TEST1 data set (see Section 2).

The $\mathrm{R}$ matrix fitting EDA code minimizes the reduced $\chi^{2}$ expression in the evaluation process. As shown by Hale [6.42], this approach should lead to the same values as would be achieved in the minimization of a full $\chi^{2}$ expression with implementation of the Chiba-Smith option. EDA was used in comparisons of the $\mathrm{R}$ matrix model codes for the TEST2 data set and evaluations of crosssections for the neutron standard reactions with ${ }^{1} \mathrm{H},{ }^{6} \mathrm{Li}$ and ${ }^{10} \mathrm{~B}$.

The R matrix SAMMY code was updated by Larson [6.19] to include various options for preparation of the experimental data and parameter fitting. This code also allows searching for optimal $\mathrm{R}$ matrix parameters when fitting raw experimental data that have diagonal covariance matrices of uncertainties, and thereby an evaluation can be achieved with minimal impact from PPP effects.

\subsection{COMPARISON OF TECHNICAL APPROACHES TO PEELLE'S PERTINENT PUZZLE MINIMIZATION}

\section{V.G. Pronyaev}

The role of the PPP phenomenon in the standards evaluation and an intercomparison of different technical options for PPP minimization were addressed in the evaluation of five realistic TEST1 data sets (Section 2, Fig. 2.1) for the ${ }^{6} \mathrm{Li}(\mathrm{n}, \mathrm{t})$ reaction, which exhibits a strong energy dependence. Evaluations from standard formulations of the $\mathrm{R}$ matrix model and non-model least squares methods exhibited large and clearly observable PPP biases (Section 2, Fig. 2.2). The standard formulation of the evaluation process is understood to be that based on the application of the error propagation law for derived quantities (cross-sections) and covariance matrices of uncertainties estimated independently for each set of data. The TEST1 data were employed in the various evaluation fits without any alterations to the original data. No values were adjusted, no errors were enhanced and no correlations were corrected.

Detailed comparisons of the evaluated data obtained with these different approaches to the minimization of PPP are shown in Fig. 6.10.1. The results labelled GMAP were obtained by means of three computational steps involving the ChibaSmith approach to exclude the PPP effect:

(a) The first pass was obtained using the assumed prior data (ENDF/B-VI);

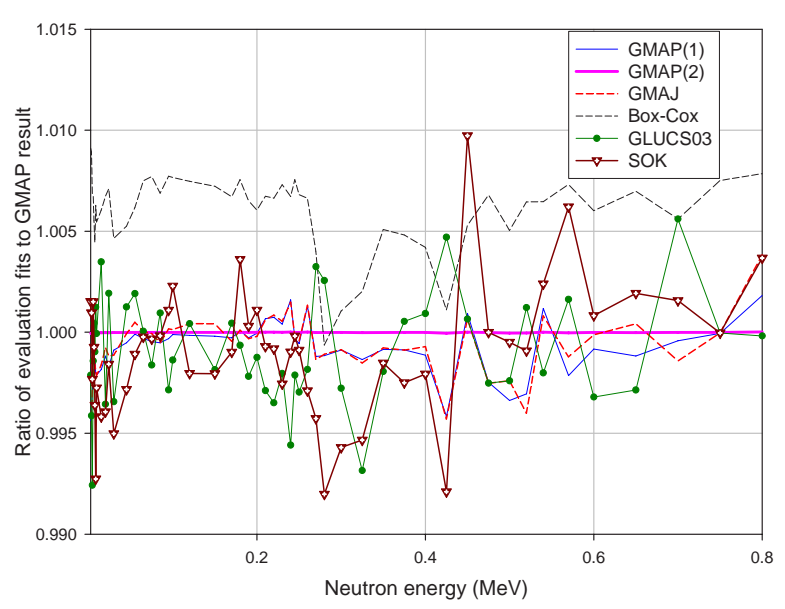

FIG. 6.10.1. Ratios of evaluation fits of ${ }^{6} \mathrm{Li}(n, t)$ crosssections with different options for minimizing PPP to the GMAP(2) iterative fit (Chiba-Smith option) for TEST1 data. 
(b) GMAP(1) is the result after one iteration;

(c) GMAP(2) is the result after two iterations.

GMA results without any technical fixes applied to exclude PPP are about $10 \%$ below the indicated curves (see Section 2, Fig. 2.2), and are not shown in Fig. 6.10.1. Therefore this test case exhibits the full extent of the PPP bias.

The GLUCS03 data in Fig. 6.10.1 are the results obtained by Tagesen and Vonach [6.41] with the inclusion of the Chiba-Smith option. GMAJ are the results obtained by $\mathrm{Oh}$ [6.26] when using the GMAJ code with only a single iteration. The impact of excluding the PPP effect by means of the BoxCox transformation is also shown and was taken from the study by $\mathrm{Oh}$ [6.26]. SOK shows the results of an evaluated fit by Kawano using a logarithmic transformation of the data. PADE2 [6.15] and RAC $\mathrm{R}$ matrix fits were performed without any technical fix to exclude PPP; both these fits were affected by PPP (see Section 2, Fig. 2.2), but to a lesser extent than in the non-model fits.

An inspection of the results of these different approaches to minimizing the PPP effect for the TEST1 data set shows that all these methods lead to results that are relatively close to each other (Fig. 6.10.1). Taking into account that the uncertainty of the evaluated values varies between $1.4 \%$ and $5 \%$, an average observed difference of $0.5 \%$ obtained with the different technical fixes to minimize PPP can be considered as relatively small. The Box-Cox approach gives slightly higher values of the evaluated cross-sections, while the logarithmic transformation and Chiba-Smith methods give closely agreeing values. Any attempt to determine the 'best' result from an inspection of the plot is difficult because the true values to which these real data should correspond are not known. The GMAP (linear least squares) and GLUCS03 (Bayesian generalized least squares) fits are based on the same technical fix to exclude PPP (Chiba-Smith approach), and the small differences between them $(\sim 0.3 \%)$ can be explained in terms of the precision of the numerical solutions of the various equations. Thus any claim that one approach is better than the other would seem unreasonable when the observed differences are at the level of the observed numerical precision. The Chiba-Smith option was implemented in the GMA code because this choice required only minimal changes to the code and no changes to the format of the GMA database.

As was seen in Section 6.2.6, two distinct effects (mini- and maxi-PPP) lead to the presence of
PPP biases in data evaluated by the least squares method, and can be minimized by means of the Chiba-Smith option. Their contributions to the total-PPP effect for TEST1 data can be seen in Fig. 6.10.2. The bias due to the combined mini- and maxi-PPP effects is depicted by the thick solid line as the ratio of the GMA to the GMAP fits. When all correlations between experimental data points are excluded, the observed bias can be explained only by the mini-PPP effect, which is shown in Fig. 6.10.2 as the ratio of $\operatorname{GMA}(\mathrm{nc})$ to $\operatorname{GMAP}(\mathrm{nc})$, where nc means no correlations. The effect of maxi-PPP leads to a further shift of the evaluation, as shown by the ratio of GMA to GMAP.

The presence of the PPP effect, along with use of various options to minimize PPP, contribute an additional uncertainty to the standards evaluation. Results of the fit with all data from the GMA database and using both the logarithmic transformation (SOK) and Chiba-Smith (GMAP) options for minimization of PPP are shown in Figs 6.10.36.10.14. The GMA database also included the pseudo-experimental data set corresponding to the results of the RAC R matrix model fit for the ${ }^{6} \mathrm{Li}(\mathrm{n}, \mathrm{t})$ reaction. Ordinary least squares fits with GMA are shown in these figures to show the magnitude of the PPP effect for the GMA database. Kawano transformed the data from the GMA database to the input format required in order to run the SOK code, although integral data corresponding to the californium fission spectrum

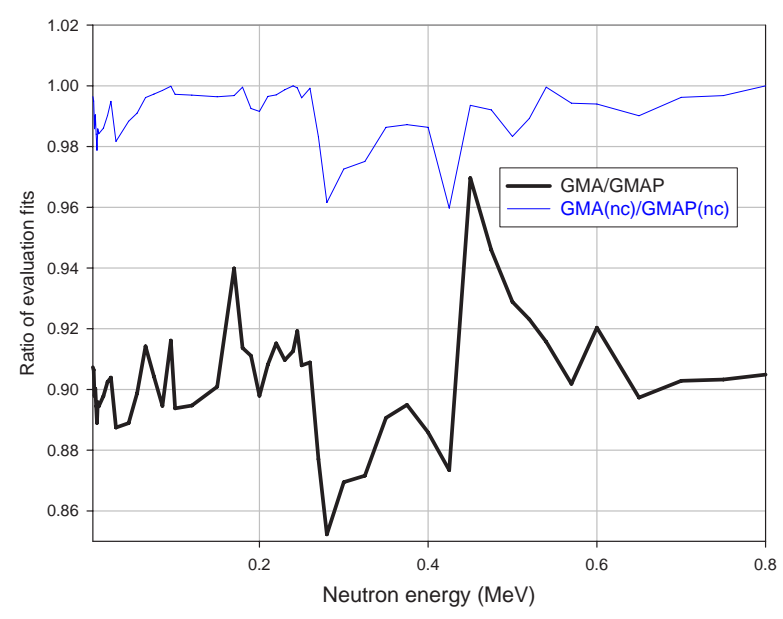

FIG. 6.10.2. Ratios of different evaluation fits of ${ }^{6} \mathrm{Li}(n, t)$ cross-sections demonstrate the effect of mini- and maxiPPP for the Chiba-Smith option for minimizing PPP using TEST1 data. The thick solid line shows a bias due to a combined effect of mini- and maxi-PPP (total-PPP), while the thin solid line shows only the effect of mini-PPP. 


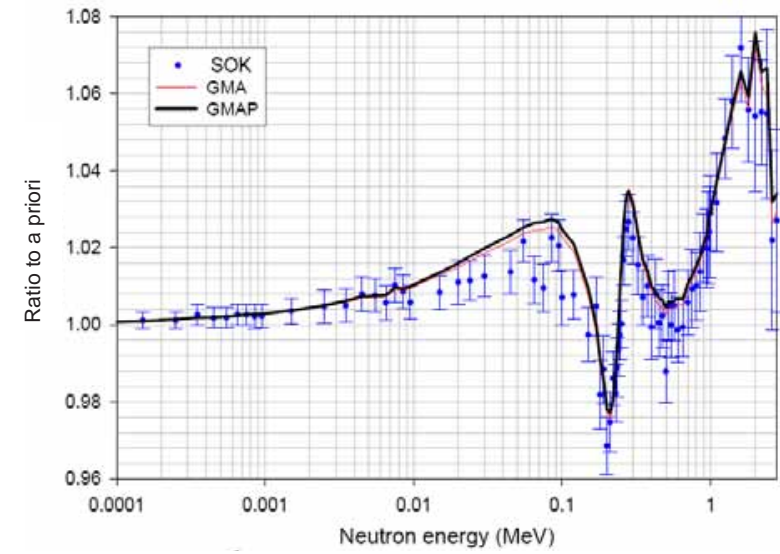

FIG. 6.10.3. Ratio of the ${ }^{6} \mathrm{Li}(n, t)$ cross-section evaluated by a fit of data from the GMA database to a priori evaluation (previous ENDF/B-VI standard). Results were also obtained with the code SOK, using a logarithmic transformation, and code GMAP, using the Chiba-Smith option to minimize PPP; the GMA curve corresponds to the results of the usual fit without any technical fix to minimize PPP.

averaged cross-sections were not used. By comparing the GMAP and GMA results in Figs 6.10.3-6.10.14, one can generally conclude that the effect of PPP for the GMA database is much less than the uncertainty of the evaluated data. Differences in the fits with SOK and GMA in the energy range from a few tens of $\mathrm{keV}$ to a few $\mathrm{MeV}$ for the fission cross-sections and those strongly coupled ${ }^{6} \mathrm{Li}(\mathrm{n}, \mathrm{t})$ cross-sections can be partially explained by the influence of the integral data

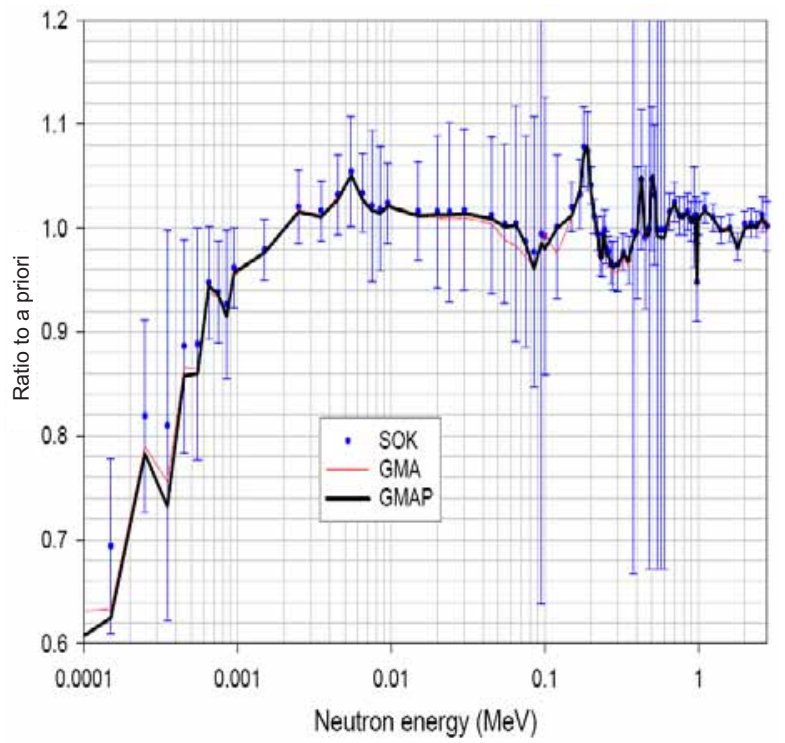

FIG. 6.10.4. Same information as appears in the caption to Fig. 6.10.3, but for the ${ }^{6} \mathrm{Li}(n, n)$ cross-section.

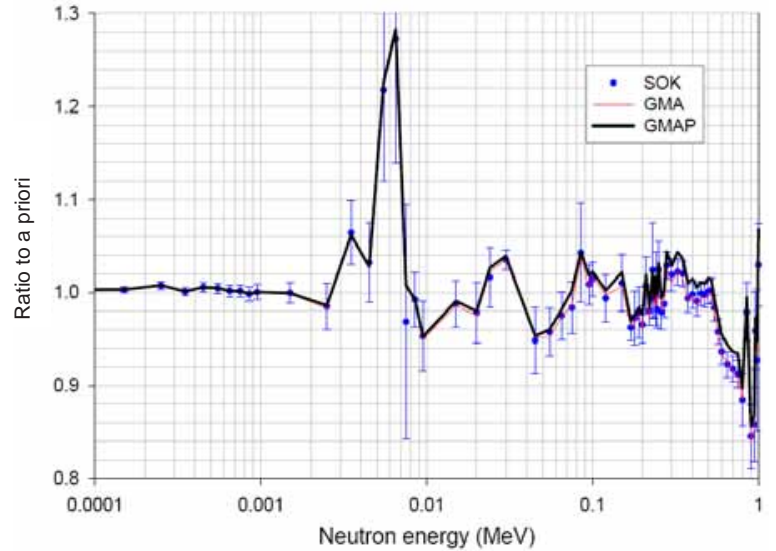

FIG. 6.10.5. Same information as appears in the caption to Fig. 6.10.3, but for the ${ }^{10} B\left(n, \alpha_{0}\right)$ cross-section.

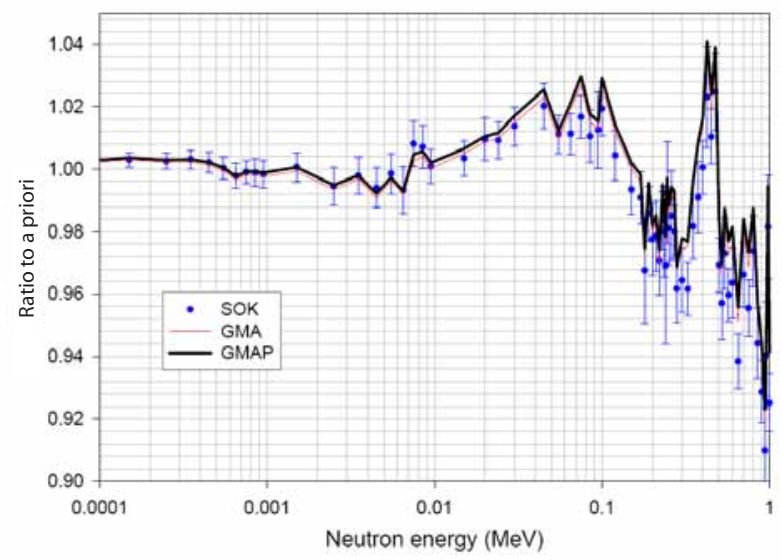

FIG. 6.10.6. Same information as appears in the caption to Fig. 6.10.3, but for the ${ }^{10} B\left(n, \alpha_{1}\right)$ cross-section.

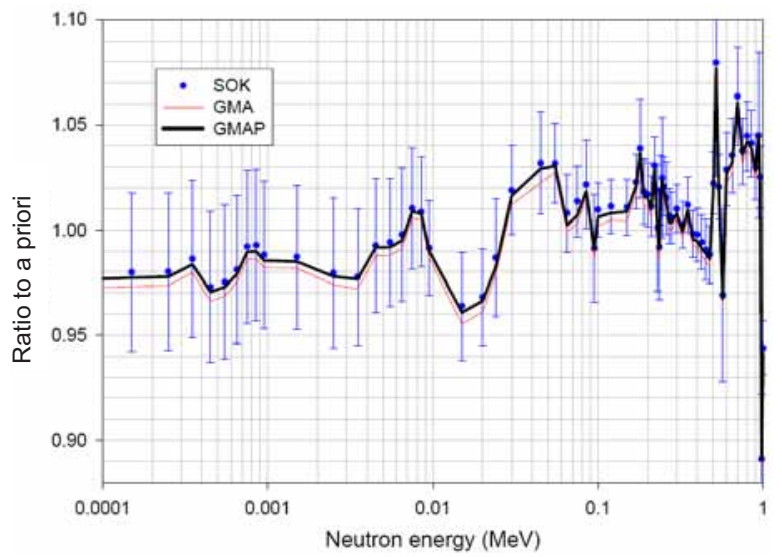

FIG. 6.10.7. Same information as appears in the caption to Fig. 6.10.3, but for the ${ }^{10} B(n, n)$ cross-section. 


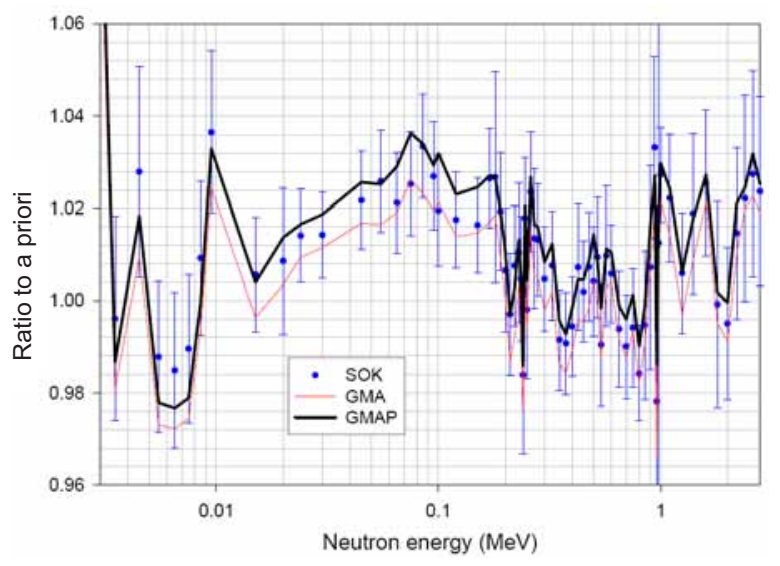

FIG. 6.10.8. Same information as appears in the caption to Fig. 6.10.3, but for the $\mathrm{Au}(n, \gamma)$ cross-section.

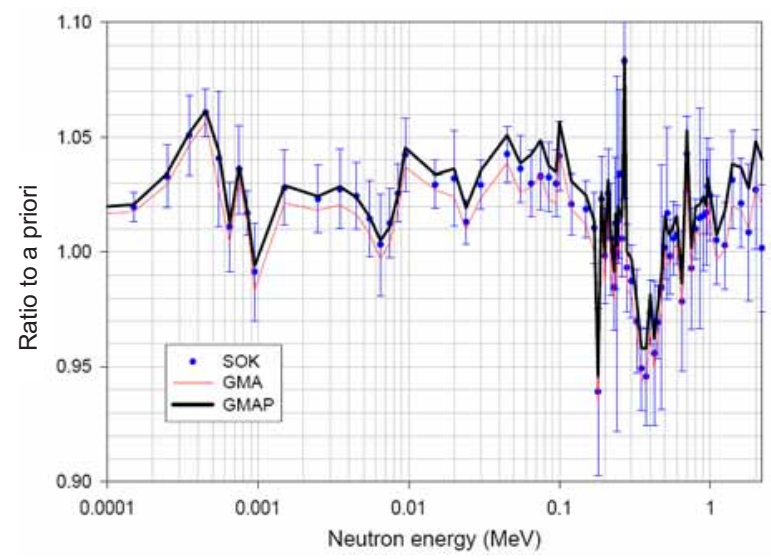

FIG. 6.10.9. Same information as appears in the caption to Fig. 6.10.3, but for the ${ }^{238} U(n, \gamma)$ cross-section.

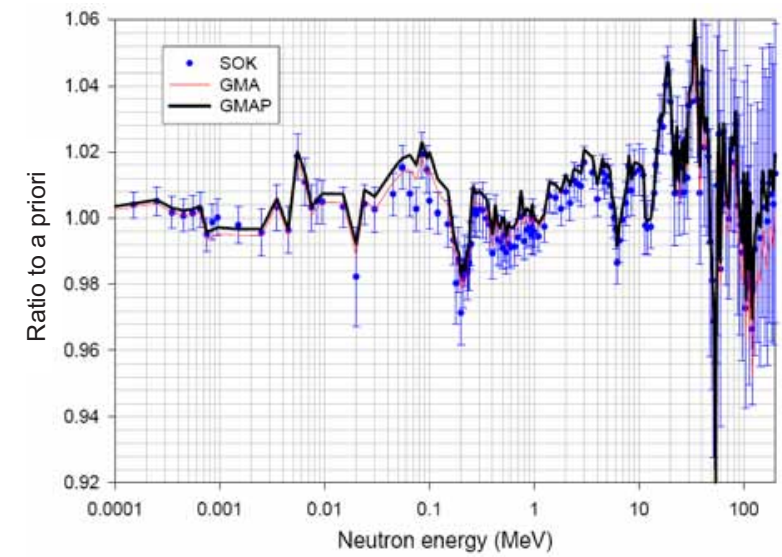

FIG. 6.10.10. Same information as appears in the caption to Fig. 6.10.3, but for the ${ }^{235} U(n, f)$ cross-section.

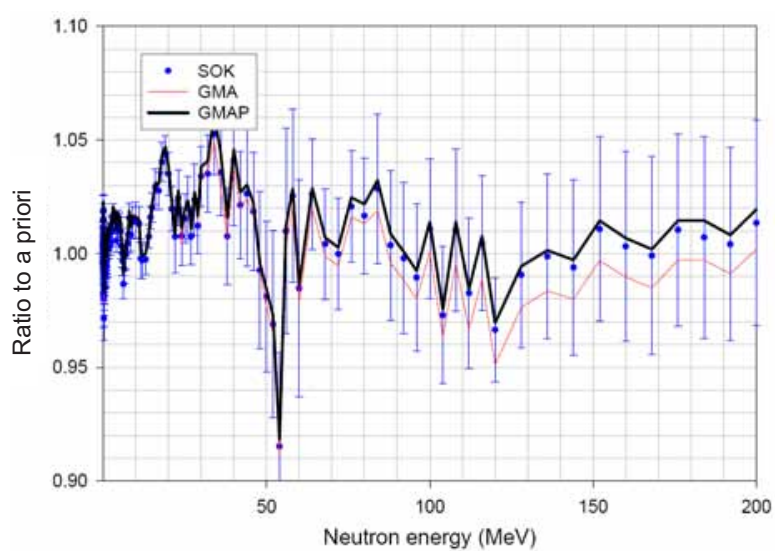

FIG. 6.10.11. Same information as appears in the caption to Fig. 6.10.3, but for the ${ }^{235} U(n, f)$ cross-section.

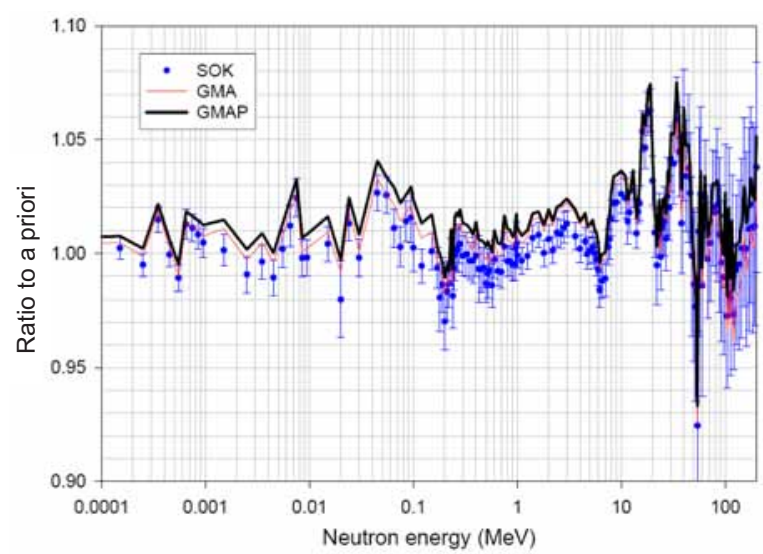

FIG. 6.10.12. Same information as appears in the caption to Fig. 6.10.3, but for the ${ }^{239} \mathrm{Pu}(n, f)$ cross-section.

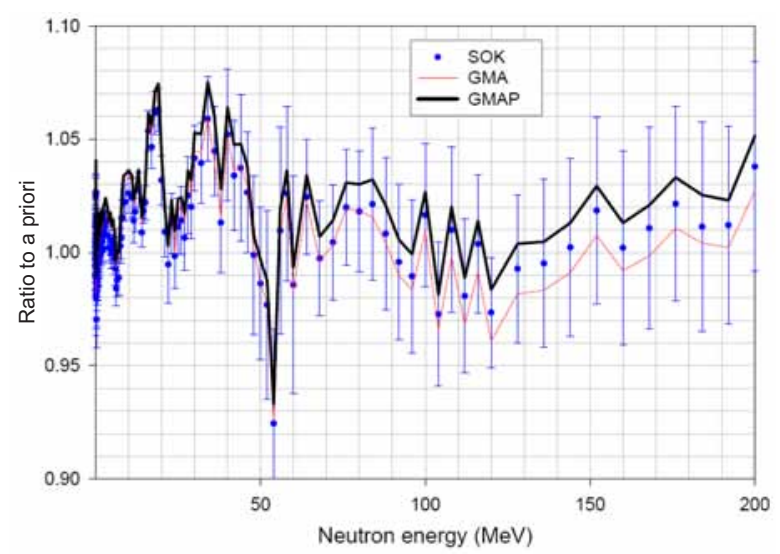

FIG. 6.10.13. Same information as appears in the caption to Fig. 6.10.3, but for the ${ }^{239} \mathrm{Pu}(n, f)$ cross-section. 


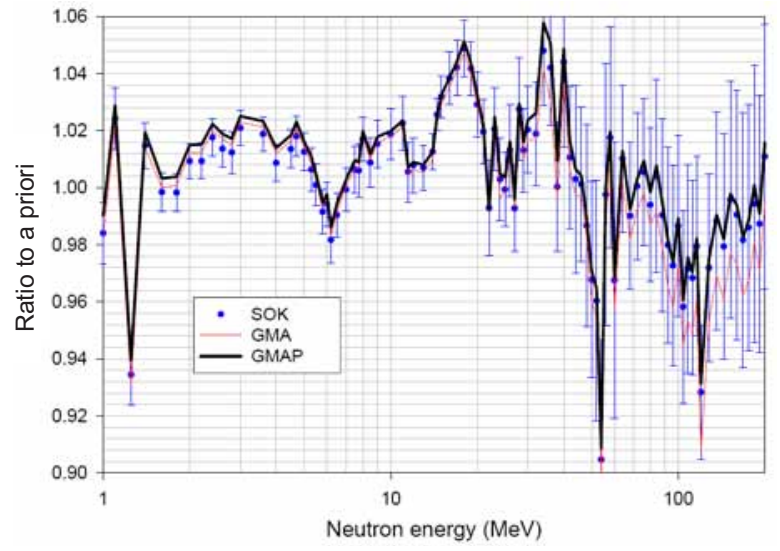

FIG. 6.10.14. Same information as appears in the caption to Fig. 6.10.3, but for the ${ }^{238} U(n, f)$ cross-section.

accounted for within the GMA fit but not in the SOK fit (leading to an increase of these evaluated cross-sections in this energy range). The average uncertainty obtained from the different codes and options used to minimize PPP can be estimated conservatively as $0.5 \%$ and should be incorporated into the final estimate of the uncertainties of the evaluated data at all energy points excluding the thermal value. This exclusion is appropriate because the thermal cross-sections are rather strongly decoupled from all other experimental data in the GMA database.

\subsection{SUMMARY}

There is a general consensus among the contributors to this section and all members of the CRP that the phenomenon known as PPP does appear in nuclear data evaluations carried out using least squares techniques and can be a significant problem that has to be dealt with in the evaluation of cross-sections. Furthermore, there is agreement that a Bayesian approach based on probability distributions that reflect the nature of the data to be evaluated is the rigorously correct way to proceed, as described in the work of Hanson et al. [6.13]. However, this approach is currently impractical in the handling of large data sets, and so approximate methods ('technical fixes') need to be applied in order to produce a reasonable set of evaluated neutron cross-section standards. All the contributors to this section agree that every effort should be made when performing such an evaluation to identify sources of significant discrepancy in the experimental data sets, to make adjustments where possible and (in some cases) to enhance certain uncertainties to cover effects that appear not to have been considered by the original authors. However, the documentation available for individual data sets is also recognized to be inadequate in most cases, leaving the evaluator with the difficult and rather arbitrary task of applying the best judgement possible as to how individual data sets (and points) should be adjusted and handled in an evaluation.

A description of the Bayesian approach to probabilistic data evaluation appears in Section 6.2, along with a discussion of some practical issues that needed to be resolved by the CRP in order to forge ahead with the standards evaluation. The manner in which the PPP phenomenon emerges for the simple example provided by Peelle is discussed in great detail in the contributions to this section from several different perspectives. These discussions include an examination of the impact of information loss during data analysis, as viewed on the basis of sufficient statistics, and the nature and impact of the SUP as related to PPP. The terms 'mini-PPP' and 'maxi-PPP' have been introduced to label two distinct effects that contribute to PPP, as demonstrated in the context of Peelle's original problem. A 'technical fix' (Chiba-Smith) is described in Section 6.5 that enables the usual least squares formulas to be used without alteration of the experimental data (other than the adjustments mentioned above). The approach employs relative total uncertainties rather than absolute total uncertainties in the usual least squares analysis, and iterates until the solution converges. Section 6.8 describes a similar method of analysis in which the systematic and random errors are treated somewhat differently. Sections 6.6 and 6.7 contain descriptions of other approaches in which the experimental data are first transformed prior to performing the usual least squares analysis in order to minimize the effects of non-linearity and to establish conditions in which the transformed data are near normally distributed. The natural logarithm transformation does tend to minimize the PPP effect and is shown to be the most suitable procedure to use in most cases. Note that if absolute errors are given for the actual cross-sections, the corresponding uncertainties for the natural logarithms will be equal to the relative errors of the original values. This fact establishes a link between the various 'fixes' described in Sections 6.5-6.8. 
Sections 6.9 and 6.10 are devoted to comparing the results of evaluations on actual standards data sets by means of the methods described in Sections 6.5-6.7. The Chiba-Smith and logarithmic transformation approaches were judged to be the only methods of analysis that could be implemented practically in the standards evaluation project, considering the time and resources available to undertake the job. Their predictions were found to differ by only modest amounts, even in the worst cases. The GMAP code was used to provide all the non-model evaluations of the standards reactions since the entire GMA experimental database could be utilized with minimal modifications to the coding. The uncertainty in this method of minimizing the PPP effect does contribute an additional uncertainty to the standards evaluation; however, compared with the other uncertainties, the effect is generally quite small and has negligible impact on the total uncertainty.

\section{REFERENCES TO SECTION 6}

[6.1] SMITH, D.L., "Examination of various roles for covariance matrices in the development, evaluation and application of nuclear data", Nuclear Data for Science and Technology (Proc. Int. Conf. Mito, Japan, 1988) (IGARASI, S., Ed.), Saikon, Tokyo (1988) 425-433.

[6.2] POENITZ, W.P., Data interpretation, objective evaluation procedures and mathematical techniques for the evaluation of energy-dependent ratio, shape and cross section data, Nuclear Data Evaluation Methods and Procedures (Proc. Conf. Upton, NY, 1980) (MAGURNO, B.A., PEARLSTEIN, S., Eds), Rep. BNL-NCS-51363, Vol. 1, Brookhaven Natl Lab., Upton, NY (1981) 249-289.

[6.3] EVAIN, B.P., SMITH, D.L., LUCCHESE, P., Compilation and Evaluation of 14-MeV Neutronactivation Cross Sections for Nuclear Technology Applications: Set I, Rep. ANL/NDM-89, Argonne Natl Lab., IL (1985).

[6.4] CARLSON, A.D., et al., ENDF/B-VI Neutron Cross Section Measurement Standards, Rep. NISTIR-5177, National Institute of Standards and Technology, Gaithersburg, MD (1993); also ENDF/B-VI Neutron Cross Section Measurement Standards, Rep. ENDF-351, Brookhaven Natl Lab., Upton, NY (1993).

[6.5] D'AGOSTINI, G., Bayesian Reasoning in Data Analysis: A Critical Introduction, World Scientific, Hackensack, NJ (2003).

[6.6] SMITH, D.L., Probability, Statistics, and Data Uncertainties in Nuclear Science and Technology,
American Nuclear Society, La Grange Park, IL (1991).

[6.7] SMITH, D.L., A Least-squares Computational Tool Kit, Rep. ANL/NDM-128, Argonne Natl Lab., IL (1993).

[6.8] SHANNON, C.E., Bell System Tech. J. 27 (1948) 379, 623.

[6.9] JAYNES, E.T., "Where do we stand on maximum entropy?", The Maximum Entropy Formalism (LEGINE, R.D., TRIBUS, M., Eds), MIT University Press, Cambridge, MA (1978) 15-118.

[6.10] PEELLE, R.W., Oak Ridge Natl Lab., TN, Peelle's Pertinent Puzzle, memorandum, 13 October 1987.

[6.11] CHIBA, S., SMITH, D.L., A Suggested Procedure for Resolving an Anomaly in Least-squares Data Analysis Known as Peelle's Pertinent Puzzle and the General Implications for Nuclear Data Evaluation, Rep. ANL/NDM-121, Argonne Natl Lab., IL (1991).

[6.12] DUNFORD, C. (Ed.), Nuclear Data Evaluation Methodology (Proc. Int. Symp. Upton, NY, 1992), World Scientific, Singapore (1993).

[6.13] HANSON, K.M., KAWANO, T., TALOU, P., "Probabilistic interpretation of Peelle's pertinent puzzle and its resolution", Nuclear Data for Science and Technology (Proc. Int. Conf. Santa Fe, NM, 2004), American Institute of Physics Conf. Proc. 769, Part 1 (HAIGHT, R.C., CHADWICK, M.B., KAWANO, T., TALOU, P., Eds), American Institute of Physics, New York (2005) 304-307.

[6.14] FROEHNER, F.H., Evaluation of Data with Systematic Errors, Nucl. Sci. Eng. 145 (2003) 342-353.

[6.15] SMITH, D.L., PRONYAEV, V.G., "Update of GMA code to solve the PPP problem (technically)", Summary Report of the Second Research Co-ordination Meeting on Improvement of the Standard Cross Sections for Light Elements, Rep. INDC(NDS)-453, IAEA, Vienna (2004) 333-342.

[6.16] COX, D.R, HINKLEY, D.V., Theoretical Statistics, Chapman and Hall, London (1974).

[6.17] KENDALL, M.G., STUART, A., The Advanced Theory of Statistics, 2nd edn, Vol. 2, Charles Griffin, London (1964).

[6.18] GAI, E.V., "The least square method formulation with account of systematic errors", Summary Report of the Second Research Coordination Meeting on Improvement of the Standard Cross Sections for Light Elements, Rep. INDC(NDS)453, IAEA, Vienna (2004) 359-361.

[6.19] LARSON, N.M., "Some thoughts on the data analysis process", Summary Report of the Second Research Coordination Meeting on Improvement of the Standard Cross Sections for Light Elements, Rep. INDC(NDS)-453, IAEA, Vienna (2004) 47-96.

[6.20] VINOGRADOV, V.N., GAI, E.V., RABOTNOV, N.S., Data's Analytical Approximation in Nuclear and Neutron Physics, Energoatomizdat, Moscow (1987) (in Russian). 
[6.21] GAI, E.V., "On the explanation of Peelle's pertinent puzzle", Nuclear Data for Science and Technology (Proc. Int. Conf. Gatlinburg, TN, 1994) (DICKENS, J.K., Ed.), American Nuclear Society, La Grange Park, IL (1994) 511-513.

[6.22] BADIKOV, S.A., GAI, E.V., "Some sources of the underestimation of evaluated cross section uncertainties", Summary Report of the First Research Coordination Meeting on Improvement of the Standard Cross Sections for Light Elements, Rep. INDC(NDS)-438, IAEA, Vienna (2003) 117-129.

[6.23] BADIKOV, S.A., GAI, E.V., Uncertainties of neutron reaction cross sections, Atomnaya Energiya 1 (2005) 3.

[6.24] GAI, E.V., BADIKOV, S.A., "Once again on the Peelle's puzzle", Summary Report of the Second Research Co-ordination Meeting on Improvement of the Standard Cross Sections for Light Elements, Rep. INDC(NDS)-453, IAEA, Vienna (2004) 139-142.

[6.25] TAGESEN, S., "Aspects of internal consistency of covariance data", Evaluation and Processing of Covariance Data (Proc. Specialists Mtg, Oak Ridge, TN, 1992), OECD, Paris (1993) 213-220.

[6.26] OH, S., "Box-Cox transformation for resolving Peelle's pertinent puzzle in curve fitting", Summary Report of the First Research Coordination Meeting on Improvement of the Standard Cross Sections for Light Elements, Rep. INDC(NDS)438, IAEA, Vienna (2003) 146-158; also OH, S., SEO, C., "Box-Cox transformation for resolving Peelle's pertinent puzzle in curve fitting", paper presented at PHYSOR-2004: The Physics of Fuel Cycles and Advanced Nuclear Systems: Global Development, Chicago, IL, 2004.

[6.27] BOX, G.E.P., COX, D.R., An analysis of transformations, J. Royal Statistical Soc., Series B 26 (1964) 211.

[6.28] PRONYAEV, V.G., "Test and inter-comparisons of data fitting with general least squares code GMA versus Bayesian code GLUCS”, Summary Report of the First Research Coordination Meeting on Improvement of the Standard Cross Sections for Light Elements, Rep. INDC(NDS)-438, IAEA, Vienna (2003) 159-171.

[6.29] LARSON, N.M., "Proof that Bayes and least squares give exactly equivalent results for arbitrary number of data sets assuming linearity", Summary Report of the First Research Coordination Meeting on Improvement of the Standard
Cross Sections for Light Elements, Rep. INDC(NDS)-438, IAEA, Vienna (2003) 91-95.

[6.30] FROEHNER, F.H., Assigning uncertainties to scientific data, Nucl. Sci. Eng. 126 (1997) 1-18.

[6.31] SLOB, W., Uncertainty analysis in multiplicative models, Risk Anal. 14 (4) (1994) 571.

[6.32] SMITH, D.L., NABEREJNEV, D.G., VAN WORMER, L.A., Large errors and severe conditions, Nucl. Instrum. Meth. Phys. Res. A 488 (2002) 342; also SIVIA, D.S., Data Analysis: A Bayesian Tutorial, 2nd edn, Oxford University Press, Oxford (2006).

[6.33] SIVIA, D.S., "Data analysis - a dialogue with the data", paper presented at the VII Conf. on Advanced Mathematical and Computational Tools in Metrology, Caparica, Portugal, 2005.

[6.34] VAN CAMPENHOUT, J.M., COVER, T.M., Maximum entropy and conditional probability, IEEE Trans. Inf. Theory IT-27 (1981) 483.

[6.35] OH, S., "Monte Carlo method for the estimates in a model calculation", paper presented at the Korean Nuclear Society Autumn Mtg, Yongpyung, Republic of Korea, 2004.

[6.36] KONING, A., "Generating covariance data with nuclear models", paper presented at the Int. Workshop on Nuclear Data Needs for Generation IV Nuclear Energy Systems, Antwerp, 2005.

[6.37] SMITH, D.L., NABEREJNEV, D.G., Confidence intervals for the lognormal probability distribution, Nucl. Instrum. Meth. Phys. Res. A 518 (2004) 754.

[6.38] LARSON, N.M., "On the efficient treatment of data covariance matrices", paper presented at the 71st Ann. Mtg of the Southeastern Section of the American Physics Society, Oak Ridge, TN, 2004.

[6.39] LARSON, N.M., Updated Users' Guide for SAMMY, Rep. ORNL/TM-9179/R6, Oak Ridge Natl Lab., TN (2003).

[6.40] LARSON, N.M., Introduction to the Theory and Analysis of Resolved (and Unresolved) Neutron Resonances via SAMMY, Rep. ORNL/M-6576, Oak Ridge Natl Lab., TN (1998).

[6.41] TAGESEN, S., VONACH, H., Institut für Isotopenforschung und Kernphysik, Austria, unpublished memorandum, 2003.

[6.42] HALE, G., Los Alamos Natl Lab., NM, Some Thoughts on Chi-square Expressions, unpublished memorandum, 2004. 


\title{
7. RESULTS OF THE EVALUATION: COMPARISONS WITH PREVIOUS STANDARDS AND EXPERIMENTAL DATA
}

\author{
V.G. Pronyaev, S.A. Badikov, A.D. Carlson, Chen Zhenpeng, E.V. Gai, G.M. Hale, F.-J. Hambsch, \\ H.M. Hofmann, T. Kawano, N.M. Larson, D.L. Smith, Soo-Youl Oh, S. Tagesen, H. Vonach
}

\subsection{INTRODUCTION}

The procedure for evaluating the standards can be divided into two stages.

(a) Independent evaluation of ${ }^{6} \mathrm{Li}(\mathrm{n}, \alpha),{ }^{10} \mathrm{~B}\left(\mathrm{n}, \alpha_{0}\right)$ and ${ }^{10} \mathrm{~B}\left(\mathrm{n}, \alpha_{1}\right)$ reactions using the $\mathrm{R}$ matrix model and experimental data available for all reactions that create ${ }^{7} \mathrm{Li}$ and ${ }^{11} \mathrm{~B}$ compound systems. These data include various observables for all neutron and charged particle induced reactions (integral and differential cross-sections, and polarizations). Use of different $\mathrm{R}$ matrix codes to fit the same data followed by analysis and minimization of the observed differences between the fits increases the reliability of the evaluation. Any differences in fits that cannot be eliminated by this analysis are accommodated when the $\mathrm{R}$ matrix results are combined with the remaining data in a least squares fit to produce the standards for the light and heavy nuclides.

(b) Cross-sections for the ${ }^{6} \mathrm{Li}(\mathrm{n}, \alpha),{ }^{6} \mathrm{Li}(\mathrm{n}, \mathrm{n})$, ${ }^{10} \mathrm{~B}(\mathrm{n}, \mathrm{n}),{ }^{10} \mathrm{~B}\left(\mathrm{n}, \mathrm{\alpha}_{0}\right)$ and ${ }^{10} \mathrm{~B}\left(\mathrm{n}, \mathrm{\alpha}_{1}\right)$ reactions and their covariance matrices (including crossreaction covariances) obtained in the $\mathrm{R}$ matrix evaluation were used in the combined least squares fit with all other data from the GMA database. These data include reactions with heavy nuclides and ratios between light and heavy nuclide cross-sections. Finally, the outlying experimental data were analysed and additional components of uncertainty were added to these data points to restore consistency and to bring the general $\chi^{2}$ per degree of freedom close to unity.

Figures 7.1-7.123 show the results of the GMA fits described above (labelled 'combined final') to the experimental data for the reaction cross-sections and their ratios over various energy ranges. The combined final fits are shown by thick solid lines, with evaluated uncertainties given at the nodes. The results of a previous set of evaluations $[7.1,7.2]$ used as non-informative priors in the GMA fits are shown by thin dashed lines (these evaluations only included data up to $20 \mathrm{MeV}$ ). 'Prior', 'prior, old standard' and 'W. Poenitz, 1987' in the figure legends refer to the ENDF/B-VI evaluations for energies below $20 \mathrm{MeV}$. The present evaluation expands the energy range for fission reactions up to $200 \mathrm{MeV}$. Earlier ${ }^{235} \mathrm{U}(\mathrm{n}, \mathrm{f})$ and ${ }^{238} \mathrm{U}(\mathrm{n}, \mathrm{f})$ high energy standards evaluated independently from the standards below $20 \mathrm{MeV}$ [7.3] and high energy evaluations for ${ }^{239} \mathrm{Pu}(\mathrm{n}, \mathrm{f})$ were used as a non-informative a priori, and are labelled 'prior' in the legends of the figures.

The experimental data shown in the figures are taken directly from the GMA database. The data set number, the name of the first author and the year of publication are given in the legend. The references for each data set are given in Tables 7.1 and 7.2. Data are reduced to the original form in which they were obtained by the experimentalists: absolute cross-sections, non-normalized (shape) cross-sections, absolute ratio of cross-sections and non-normalized (shape) ratio of cross-sections. Absolute cross-sections normalized using the hydrogen scattering standard were renormalized to the new standard [7.4]. Data sets with shape crosssections and shape cross-section ratios were renormalized with coefficients that give the best $\chi^{2}$ values relative to the final evaluation. The uncertainties in the experimental data shown in the figures are the original uncertainties assigned by the authors in virtually all cases. Expanded uncertainties for the outlying experimental data used in the final combined fit are not shown. However, they can easily be envisaged as error bars that restore consistency with the final evaluation. The GMA database also includes covariance matrices of the uncertainties of the experimental data generated from partial components of the uncertainties and their correlative properties. Many data sets obtained at the same laboratory, or with the same sample or detector, are combined in data blocks that account for correlations between sets.

Tables 7.3 and 7.4 show the number of data sets in the GMA database for given reactions and types of data. Twenty-five thermal constants evaluated by Axton [7.5] were used as preevaluated values in the GMA final combined fit. 
TABLE 7.1. EXPERIMENTAL DATA SETS FROM THE GMA DATABASE USED IN THE FINAL COMBINED FIT

\begin{tabular}{|c|c|c|c|c|}
\hline $\begin{array}{l}\text { Data set } \\
\text { number }\end{array}$ & Reaction & Data type & First author(s) & Reference \\
\hline 120 & ${ }^{6} \operatorname{Li}(\mathrm{n}, \alpha) /{ }^{10} \mathrm{~B}(\mathrm{n}, \alpha)$ & Shape & J.B. Czirr, A.D. Carlson & 79Knoxville (1979) 84 \\
\hline 131 & ${ }^{6} \operatorname{Li}(\mathrm{n}, \alpha) /{ }^{10} \mathrm{~B}(\mathrm{n}, \alpha)$ & Shape & M.J. Sowerby et al. & J. Nucl. Energy 24 (1970) 328 \\
\hline 132 & ${ }^{6} \mathrm{Li}(\mathrm{n}, \alpha) /{ }^{10} \mathrm{~B}\left(\mathrm{n}, \alpha_{1}\right)$ & Shape & M.J. Sowerby et al. & J. Nucl. Energy 24 (1970) 328 \\
\hline 160 & ${ }^{6} \mathrm{Li}(\mathrm{n}, \alpha) /{ }^{10} \mathrm{~B}(\mathrm{n}, \alpha)$ & Shape & A.A. Bergman et al. & J. Exp. Theor. Phys. (1958) 6 \\
\hline 200 & ${ }^{6} \mathrm{Li}(\mathrm{n}, \alpha) / 235 \mathrm{U}(\mathrm{n}, \mathrm{f})$ & Shape & R.L. Macklin et al. & Nucl. Sci. Eng. 71 (1979) 205 \\
\hline 244 & ${ }^{235} \mathrm{U}(\mathrm{n}, \mathrm{f}) /{ }^{6} \mathrm{Li}(\mathrm{n}, \alpha)$ & Shape & J.R. Lemley et al. & Nucl. Sci. Eng. 43 (1971) 281 \\
\hline 250 & ${ }^{6} \mathrm{Li}(\mathrm{n}, \alpha) /{ }^{235} \mathrm{U}(\mathrm{n}, \mathrm{f})$ & Shape & W.P. Poenitz, J.W. Meadows & ERDA-NDC-3 (1976) 28 \\
\hline 261 & ${ }^{6} \operatorname{Li}(\mathrm{n}, \alpha) / 235 \mathrm{U}(\mathrm{n}, \mathrm{f})$ & Shape & D.B. Gayther & Ann. Nucl. Energy 4 (1977) 515 \\
\hline 265 & $\mathrm{Au}(\mathrm{n}, \gamma) /{ }^{10} \mathrm{~B}(\mathrm{n}, \alpha)$ & Absolute & V.A. Konks et al. & J. Exp. Theor. Phys. 19 (1964) 59 \\
\hline 270 & ${ }^{6} \mathrm{Li}(\mathrm{n}, \alpha) / 235 \mathrm{U}(\mathrm{n}, \mathrm{f})$ & Shape & J.B. Czirr, G.S. Sidhu & Nucl. Sci. Eng. 60 (1976) 383 \\
\hline 271 & ${ }^{235} \mathrm{U}(\mathrm{n}, \mathrm{f}) /{ }^{6} \operatorname{Li}(\mathrm{n}, \alpha)$ & Shape & J.B. Czirr, G.W. Carlson & Nucl. Sci. Eng. 64 (1977) 892 \\
\hline 272 & ${ }^{235} \mathrm{U}(\mathrm{n}, \mathrm{f}) /{ }^{6} \mathrm{Li}(\mathrm{n}, \alpha)$ & Shape & J.B. Czirr, G.W. Carlson & Nucl. Sci. Eng. 64 (1977) 892 \\
\hline 282 & ${ }^{6} \mathrm{Li}(\mathrm{n}, \alpha) /{ }^{238} \mathrm{U}(\mathrm{n}, \mathrm{f})$ & Shape & P.J. Clements, I.C. Rickard & $\begin{array}{l}\text { AERE-R7075 (1972); personal } \\
\text { communication }\end{array}$ \\
\hline 288 & ${ }^{6} \mathrm{Li}(\mathrm{n}, \alpha) /{ }^{235} \mathrm{U}(\mathrm{n}, \mathrm{f})$ & Shape & J.F. Barry & 66Washington, vol. 2 (1966) 763 \\
\hline 297 & ${ }^{6} \operatorname{Li}(\mathrm{n}, \alpha) /{ }^{10} \mathrm{~B}(\mathrm{n}, \alpha)$ & Shape & C. Bastian, H. Riemenschneider & IAEA-TECDOC-335 (1984) 118 \\
\hline 300 & $\mathrm{Au}(\mathrm{n}, \gamma) /{ }^{10} \mathrm{~B}(\mathrm{n}, \alpha)$ & Absolute & M.P. Fricke et al. & 70Helsinki, vol. 2 (1970) 256 \\
\hline 301 & $\mathrm{Au}(\mathrm{n}, \gamma)$ & Shape & M.P. Fricke et al. & 70Helsinki, vol. 2 (1970) 256 \\
\hline 302 & $\mathrm{Au}(\mathrm{n}, \gamma){ }^{235} \mathrm{U}(\mathrm{n}, \mathrm{f})$ & Absolute & W. Lindner et al. & Nucl. Sci. Eng. 59 (1976) 381 \\
\hline 304 & $\mathrm{Au}(\mathrm{n}, \gamma) /{ }^{10} \mathrm{~B}(\mathrm{n}, \alpha)$ & Absolute & R. Gwin et al. & Nucl. Sci. Eng. 59 (1976) 79 \\
\hline 305 & $\mathrm{Au}(\mathrm{n}, \gamma) /{ }^{10} \mathrm{~B}(\mathrm{n}, \alpha)$ & Absolute & R. Gwin et al. & Nucl. Sci. Eng. 59 (1976) 79 \\
\hline 310 & $\mathrm{Au}(\mathrm{n}, \gamma)$ & Shape & W.P. Poenitz & Nucl. Sci. Eng. 57 (1975) 300 \\
\hline 311 & $\mathrm{Au}(\mathrm{n}, \gamma)$ & Absolute & W.P. Poenitz & Nucl. Sci. Eng. 57 (1975) 300 \\
\hline 312 & $\operatorname{Au}(\mathrm{n}, \gamma){ }^{6} \operatorname{Li}(\mathrm{n}, \alpha)$ & Absolute & R.L. Macklin et al. & Phys. Rev. C11 (1975) 1270 \\
\hline 313 & $\operatorname{Au}(\mathrm{n}, \gamma) /{ }^{6} \operatorname{Li}(\mathrm{n}, \alpha)$ & Absolute & R.L. Macklin et al. & Nucl. Sci. Eng. 79 (1981) 265 \\
\hline 314 & $\mathrm{Au}(\mathrm{n}, \gamma){ }^{235} \mathrm{U}(\mathrm{n}, \mathrm{f})$ & Absolute & R.L. Macklin et al. & Nucl. Sci. Eng. 79 (1981) 265 \\
\hline 315 & $\mathrm{Au}(\mathrm{n}, \gamma)$ & Absolute & H.A. Hussain, S.E. Hunt & Int. J. Appl. Radiat. Isot. 34 (1983) 731 \\
\hline 320 & $\operatorname{Au}(\mathrm{n}, \gamma){ }^{235} \mathrm{U}(\mathrm{n}, \mathrm{f})$ & Absolute & J.F. Barry et al. & J. Nucl. Energy A/B18 (1964) 491 \\
\hline 325 & $\mathrm{Au}(\mathrm{n}, \gamma){ }^{235} \mathrm{U}(\mathrm{n}, \mathrm{f})$ & Shape & A.E. Johnsrud et al. & Phys. Rev. 116 (1959) 927 \\
\hline 330 & $\mathrm{Au}(\mathrm{n}, \gamma)$ & Absolute & H.W. Schmitt & Nucl. Phys. 20 (1960) 202 \\
\hline 331 & $\mathrm{Au}(\mathrm{n}, \gamma){ }^{235} \mathrm{U}(\mathrm{n}, \mathrm{f})$ & Absolute & H.A. Grench et al. & $\begin{array}{l}\text { EANDC(US)-79 (1965) 72; personal } \\
\text { communication }\end{array}$ \\
\hline 332 & $\mathrm{Au}(\mathrm{n}, \gamma)$ & Absolute & K.K. Harris et al. & Nucl. Phys. 69 (1965) 37 \\
\hline 335 & $\mathrm{Au}(\mathrm{n}, \gamma)$ & Absolute & L.W. Weston, W.S. Lyon & Phys. Rev. 123 (1961) 948 \\
\hline 337 & $\mathrm{Au}(\mathrm{n}, \gamma)$ & Shape & A. Paulsen et al. & Atomkernenergie 26 (1975) 80 \\
\hline 338 & $\mathrm{Au}(\mathrm{n}, \gamma)$ & Absolute & A. Paulsen et al. & Atomkernenergie $\mathbf{2 6}$ (1975) 80 \\
\hline 340 & $\mathrm{Au}(\mathrm{n}, \gamma) /{ }^{10} \mathrm{~B}\left(\mathrm{n}, \alpha_{1}\right)$ & Absolute & N. Yamamuro et al. & J. Nucl. Sci. Technol. 20 (1983) 797 \\
\hline 340 & $\mathrm{Au}(\mathrm{n}, \gamma) /{ }^{10} \mathrm{~B}\left(\mathrm{n}, \alpha_{1}\right)$ & Absolute & N. Yamamuro et al. & J. Nucl. Sci. Technol. 20 (1983) 797 \\
\hline 341 & $\mathrm{Au}(\mathrm{n}, \gamma) /{ }^{10} \mathrm{~B}\left(\mathrm{n}, \alpha_{1}\right)$ & Shape & N. Yamamuro et al. & J. Nucl. Sci. Technol. 20 (1983) 797 \\
\hline 342 & $\mathrm{Au}(\mathrm{n}, \gamma)$ & Absolute & C. Le Rigoleur et al. & CEA-R-4788 (1976) \\
\hline 343 & $\operatorname{Au}(n, \gamma)$ & Absolute & C. Le Rigoleur et al. & CEA-R-4788 (1976) \\
\hline 344 & $\operatorname{Au}(n, \gamma)$ & Absolute & S. Joly et al. & Nucl. Sci. Eng. 70 (1979) 53 \\
\hline
\end{tabular}


TABLE 7.1. EXPERIMENTAL DATA SETS FROM THE GMA DATABASE USED IN THE FINAL COMBINED FIT (cont.)

\begin{tabular}{|c|c|c|c|c|}
\hline $\begin{array}{l}\text { Data set } \\
\text { number }\end{array}$ & Reaction & Data type & First author(s) & Reference \\
\hline 345 & $\operatorname{Au}(n, \gamma)$ & Absolute & E. Fort, C. Le Rigoleur & 75Washington (1975) 953 \\
\hline 346 & ${ }^{238} \mathrm{U}(\mathrm{n}, \gamma) / \mathrm{Au}(\mathrm{n}, \gamma)$ & Absolute & L.E. Kazakov et al. & Yad. Konst. 3 (1986) 37 \\
\hline 347 & $\operatorname{Au}(\mathrm{n}, \gamma)$ & Absolute & A.N. Davletshin et al. & Sov. J. At. Energy 65 (1988) 91 \\
\hline 348 & $\operatorname{Au}(\mathrm{n}, \gamma)$ & Absolute & A.N. Davletshin et al. & Sov. J. At. Energy 65 (1988) 91 \\
\hline 349 & $\mathrm{Au}(\mathrm{n}, \gamma){ }^{235} \mathrm{U}(\mathrm{n}, \mathrm{f})$ & Absolute & A.N. Davletshin et al. & Sov. J. At. Energy 65 (1988) 91 \\
\hline 350 & $\operatorname{Au}(\mathrm{n}, \gamma)$ & Absolute & A.N. Davletshin et al. & At. Energy 48 (1980) 87 \\
\hline 352 & $\mathrm{Au}(\mathrm{n}, \gamma) /{ }^{10} \mathrm{~B}\left(\mathrm{n}, \alpha_{1}\right)$ & Shape & V.N. Kononov et al. & Yad. Fiz. 27 (1978) 10 \\
\hline 355 & $\mathrm{Au}(\mathrm{n}, \gamma)$ & Shape & A.T.G. Ferguson, E.B. Paul & J. Nucl. Energy A10 (1959) 19 \\
\hline 358 & $\operatorname{Au}(\mathrm{n}, \gamma)$ & Absolute & W.P. Poenitz & J. Nucl. Energy A/B20 (1967) 825 \\
\hline 359 & $\operatorname{Au}(n, \gamma)$ & Absolute & W.P. Poenitz & J. Nucl. Energy A/B20 (1967) 825 \\
\hline 360 & $\operatorname{Au}(n, \gamma)$ & Shape & W.P. Poenitz et al. & J. Nucl. Energy 22 (1968) 505 \\
\hline 363 & $\mathrm{Au}(\mathrm{n}, \gamma){ }^{235} \mathrm{U}(\mathrm{n}, \mathrm{f})$ & Absolute & P. Andersson, D.L. Smith & Nucl. Phys. A443 (1985) 404 \\
\hline 367 & $\operatorname{Au}(n, \gamma)$ & Absolute & T.B. Ryves et al. & J. Nucl. Energy 23 (1971) 205; 25 (1971) 557 \\
\hline 370 & $\operatorname{Au}(\mathrm{n}, \gamma)$ & Absolute & Chen Ying et al. & 82Antwerp (1982) 462 \\
\hline 371 & $\mathrm{Au}(\mathrm{n}, \gamma)$ & Shape & Chen Ying et al. & 82Antwerp (1982) 462 \\
\hline 372 & $\operatorname{Au}(n, \gamma)$ & Absolute & Shengyun et al. & Chin. J. Nucl. Phys. 6 (1984) 1 \\
\hline 378 & $\mathrm{Au}(\mathrm{n}, \gamma){ }^{235} \mathrm{U}(\mathrm{n}, \mathrm{f})$ & Shape & J.B. Czirr, M.L. Stelts & Nucl. Sci. Eng. 52 (1973) 299 \\
\hline 380 & $\mathrm{Au}(\mathrm{n}, \gamma) /{ }^{10} \mathrm{~B}\left(\mathrm{n}, \alpha_{1}\right)$ & Absolute & K. Rimawi, R.E. Chrien & 75Washington (1975) 920 \\
\hline 400 & ${ }^{238} \mathrm{U}(\mathrm{n}, \gamma) /{ }^{10} \mathrm{~B}(\mathrm{n}, \alpha)$ & Absolute & M.P. Fricke et al. & 71Knoxville, vol. 1 (1971) 252 \\
\hline 401 & ${ }^{238} \mathrm{U}(\mathrm{n}, \gamma)$ & Shape & M.P. Fricke et al. & 71Knoxville, vol. 1 (1971) 252 \\
\hline 403 & ${ }^{239} \mathrm{Pu}(\mathrm{n}, \mathrm{f}) /{ }^{10} \mathrm{~B}(\mathrm{n}, \alpha)$ & Shape & L.W. Weston et al. & Nucl. Sci. Eng. 115 (1993) 164 \\
\hline 405 & ${ }^{238} \mathrm{U}(\mathrm{n}, \gamma){ }^{235} \mathrm{U}(\mathrm{n}, \mathrm{f})$ & Shape & W.P. Poenitz & Nucl. Sci. Eng. 40 (1970) 383 \\
\hline 406 & ${ }^{238} \mathrm{U}(\mathrm{n}, \gamma) /{ }^{235} \mathrm{U}(\mathrm{n}, \mathrm{f})$ & Absolute & W.P. Poenitz & Nucl. Sci. Eng. 40 (1970) 383 \\
\hline 407 & ${ }^{238} \mathrm{U}(\mathrm{n}, \gamma) /{ }^{239} \mathrm{Pu}(\mathrm{n}, \mathrm{f})$ & Absolute & W.P. Poenitz & Nucl. Sci. Eng. 40 (1970) 383 \\
\hline 408 & ${ }^{238} \mathrm{U}(\mathrm{n}, \gamma) /{ }^{10} \mathrm{~B}(\mathrm{n}, \alpha)$ & Absolute & G. Desaussure et al. & Nucl. Sci. Eng. 51 (1973) 385 \\
\hline 410 & ${ }^{238} \mathrm{U}(\mathrm{n}, \gamma){ }^{235} \mathrm{U}(\mathrm{n}, \mathrm{f})$ & Absolute & W. Lindner et al. & Nucl. Sci. Eng. 59 (1976) 381 \\
\hline 412 & ${ }^{238} \mathrm{U}(\mathrm{n}, \gamma) / \mathrm{Au}(\mathrm{n}, \gamma)$ & Absolute & W.P. Poenitz & Nucl. Sci. Eng. 57 (1975) 300 \\
\hline 415 & ${ }^{238} \mathrm{U}(\mathrm{n}, \gamma){ }^{235} \mathrm{U}(\mathrm{n}, \mathrm{f})$ & Absolute & J.F. Barry et al. & J. Nucl. Energy A/B18 (1964) 481 \\
\hline 419 & ${ }^{238} \mathrm{U}(\mathrm{n}, \gamma) / \mathrm{Au}(\mathrm{n}, \gamma)$ & Absolute & H.O. Menlove, W.P. Poenitz & Nucl. Sci. Eng. 33 (1968) 24 \\
\hline 420 & ${ }^{238} \mathrm{U}(\mathrm{n}, \gamma)$ & Absolute & H.O. Menlove, W.P. Poenitz & Nucl. Sci. Eng. 33 (1968) 24 \\
\hline 421 & ${ }^{238} \mathrm{U}(\mathrm{n}, \gamma)$ & Shape & H.O. Menlove, W.P. Poenitz & Nucl. Sci. Eng. 33 (1968) 24 \\
\hline 422 & ${ }^{238} \mathrm{U}(\mathrm{n}, \gamma) /{ }^{10} \mathrm{~B}\left(\mathrm{n}, \alpha_{1}\right)$ & Shape & N. Yamamuro et al. & J. Nucl. Sci. Technol. 17 (1980) 582 \\
\hline 423 & ${ }^{238} \mathrm{U}(\mathrm{n}, \gamma) /{ }^{10} \mathrm{~B}(\mathrm{n}, \alpha)$ & Absolute & N. Yamamuro et al. & J. Nucl. Sci. Technol. 15 (1978) 637 \\
\hline 425 & ${ }^{238} \mathrm{U}(\mathrm{n}, \gamma){ }^{235} \mathrm{U}(\mathrm{n}, \mathrm{f})$ & Shape & G.A. Linenberger et al. & LA-179 (1944) \\
\hline 428 & ${ }^{238} \mathrm{U}(\mathrm{n}, \gamma)$ & Absolute & C. Le Rigoleur et al. & 75Washington (1975) 953 \\
\hline 430 & ${ }^{238} \mathrm{U}(\mathrm{n}, \gamma) / \mathrm{Au}(\mathrm{n}, \gamma)$ & Absolute & K. Wisshak, F. Kaeppeler & Nucl. Sci. Eng. 66 (1978) 363 \\
\hline 431 & ${ }^{238} \mathrm{U}(\mathrm{n}, \gamma) / \mathrm{Au}(\mathrm{n}, \gamma)$ & Absolute & K. Wisshak, F. Kaeppeler & Nucl. Sci. Eng. 66 (1978) 363 \\
\hline 432 & ${ }^{238} \mathrm{U}(\mathrm{n}, \gamma)$ & Absolute & K. Dietze & ZFK-341 (1977) \\
\hline 435 & ${ }^{238} \mathrm{U}(\mathrm{n}, \gamma)$ & Absolute & T.S. Belanova et al. & J. Nucl. Energy A/B20 (1966) 411 \\
\hline 436 & ${ }^{238} \mathrm{U}(\mathrm{n}, \gamma)$ & Absolute & A.N. Davletshin et al. & At. Energy 48 (1980) 87 \\
\hline 437 & ${ }^{238} \mathrm{U}(\mathrm{n}, \gamma) / \mathrm{Au}(\mathrm{n}, \gamma)$ & Absolute & N.N. Buleeva et al. & Sov. J. At. Energy 65 (1988) 92 \\
\hline
\end{tabular}


TABLE 7.1. EXPERIMENTAL DATA SETS FROM THE GMA DATABASE USED IN THE FINAL COMBINED FIT (cont.)

\begin{tabular}{|c|c|c|c|c|}
\hline $\begin{array}{l}\text { Data set } \\
\text { number }\end{array}$ & Reaction & Data type & First author(s) & Reference \\
\hline 438 & ${ }^{238} \mathrm{U}(\mathrm{n}, \gamma)$ & Absolute & Yu.Ya. Stavisskii, V.P. Koroleva & At. Energy 20 (1966) 431 \\
\hline 440 & ${ }^{238} \mathrm{U}(\mathrm{n}, \gamma) /{ }^{10} \mathrm{~B}\left(\mathrm{n}, \alpha_{1}\right)$ & Absolute & K. Rimawi, R.E. Chrien & 75Washington (1975) 920 \\
\hline 441 & ${ }^{238} \mathrm{U}(\mathrm{n}, \gamma) / \mathrm{Au}(\mathrm{n}, \gamma)$ & Absolute & K. Rimawi, R.E. Chrien & 75Washington (1975) 920 \\
\hline 443 & ${ }^{238} \mathrm{U}(\mathrm{n}, \gamma){ }^{235} \mathrm{U}(\mathrm{n}, \mathrm{f})$ & Absolute & N.N. Buleeva et al. & Sov. J. At. Energy 65 (1988) 92 \\
\hline 445 & ${ }^{238} \mathrm{U}(\mathrm{n}, \gamma) /{ }^{10} \mathrm{~B}\left(\mathrm{n}, \alpha_{1}\right)$ & Absolute & Yu.V. Adamchuk et al. & 77Kiev, vol. 2 (1977) 192 \\
\hline 446 & ${ }^{238} \mathrm{U}(\mathrm{n}, \gamma) /{ }^{10} \mathrm{~B}\left(\mathrm{n}, \alpha_{1}\right)$ & Absolute & Yu.V. Adamchuk et al. & Sov. J. At. Energy 65 (1988) 356 \\
\hline 448 & ${ }^{238} \mathrm{U}(\mathrm{n}, \gamma) /{ }^{10} \mathrm{~B}\left(\mathrm{n}, \alpha_{1}\right)$ & Shape & K. Kobayashi et al. & 91Jülich (1991) 65 \\
\hline 450 & ${ }^{238} \mathrm{U}(\mathrm{n}, \gamma) /{ }^{10} \mathrm{~B}\left(\mathrm{n}, \alpha_{1}\right)$ & Absolute & M.C. Moxon & AERE-R6074 (1971) \\
\hline 452 & $\operatorname{Au}(n, \gamma)$ & Absolute & S. Sakamoto et al. & Nucl. Sci. Eng. 109 (1991) 215 \\
\hline 453 & ${ }^{238} \mathrm{U}(\mathrm{n}, \gamma)$ & Absolute & E. Quang, G. Knoll & Nucl. Sci. Eng. 110 (1992) 282 \\
\hline 455 & ${ }^{238} \mathrm{U}(\mathrm{n}, \gamma)$ & Shape & T.B. Ryves et al. & J. Nucl. Energy 27 (1973) 519 \\
\hline 457 & ${ }^{238} \mathrm{U}(\mathrm{n}, \gamma) / \mathrm{Au}(\mathrm{n}, \gamma)$ & Shape & R.R. Spencer, F. Kaeppeler & 75Washington, vol. 2 (1975) 620 \\
\hline 458 & $\left.{ }^{238} \mathrm{U}(\mathrm{n}, \gamma)\right)^{235} \mathrm{U}(\mathrm{n}, \mathrm{f})$ & Shape & R.R. Spencer, F. Kaeppeler & 75Washington, vol. 2 (1975) 620 \\
\hline 460 & ${ }^{238} \mathrm{U}(\mathrm{n}, \gamma){ }^{235} \mathrm{U}(\mathrm{n}, \mathrm{f})$ & Absolute & W.P. Poenitz et al. & Nucl. Sci. Eng. 78 (1981) 239 \\
\hline 461 & ${ }^{238} \mathrm{U}(\mathrm{n}, \gamma) / \mathrm{Au}(\mathrm{n}, \gamma)$ & Absolute & W.P. Poenitz et al. & Nucl. Sci. Eng. 78 (1981) 239 \\
\hline 464 & ${ }^{238} \mathrm{U}(\mathrm{n}, \gamma)$ & Absolute & Yu.G. Panitkin, L.E. Sherman & At. Energy 39 (1975) 17 \\
\hline 465 & ${ }^{238} \mathrm{U}(\mathrm{n}, \gamma){ }^{235} \mathrm{U}(\mathrm{n}, \mathrm{f})$ & Shape & Yu.G. Panitkin, V.A. Tolstikov & At. Energy 33 (1972) 825 \\
\hline 466 & ${ }^{238} \mathrm{U}(\mathrm{n}, \gamma){ }^{235} \mathrm{U}(\mathrm{n}, \mathrm{f})$ & Shape & Yu.G. Panitkin et al. & 71Helsinki, vol. 2 (1971) 57 \\
\hline 470 & ${ }^{238} \mathrm{U}(\mathrm{n}, \gamma) / \mathrm{Au}(\mathrm{n}, \gamma)$ & Absolute & R.C. Block et al. & 72Kiamesha (1972) 1107 \\
\hline 471 & ${ }^{238} \mathrm{U}(\mathrm{n}, \gamma) /{ }^{10} \mathrm{~B}\left(\mathrm{n}, \alpha_{1}\right)$ & Absolute & B.L. Quan, R.C. Block & COO-2479-14 (1976) \\
\hline 475 & ${ }^{238} \mathrm{U}(\mathrm{n}, \gamma) /{ }^{10} \mathrm{~B}(\mathrm{n}, \alpha)$ & Absolute & Yu.Ya. Stavisskii et al. & INDC(CCP)-43 (1972) \\
\hline 478 & $\left.{ }^{238} \mathrm{U}(\mathrm{n}, \gamma)\right)^{235} \mathrm{U}(\mathrm{n}, \mathrm{f})$ & Absolute & G. Desaussure, L. Weston & ORNL-3360 (1963) \\
\hline 480 & ${ }^{238} \mathrm{U}(\mathrm{n}, \gamma)$ & Absolute & G. Desaussure et al. & ORNL/TM-6152 (1978) \\
\hline 482 & ${ }^{238} \mathrm{U}(\mathrm{n}, \gamma) /{ }^{6} \operatorname{Li}(\mathrm{n}, \alpha)$ & Absolute & L.E. Kazakov et al. & Yad. Konst. 2 (1986) 44; 3 (1986) 37 \\
\hline 483 & ${ }^{238} \mathrm{U}(\mathrm{n}, \gamma) /{ }^{6} \operatorname{Li}(\mathrm{n}, \alpha)$ & Absolute & L.E. Kazakov et al. & Yad. Konst. 2 (1986) 44; 3 (1986) 37 \\
\hline 484 & ${ }^{238} \mathrm{U}(\mathrm{n}, \gamma) /{ }^{10} \mathrm{~B}\left(\mathrm{n}, \alpha_{1}\right)$ & Shape & L.E. Kazakov et al. & Yad. Konst. 2 (1986) 44; 3 (1986) 37 \\
\hline 485 & ${ }^{238} \mathrm{U}(\mathrm{n}, \gamma) /{ }^{10} \mathrm{~B}\left(\mathrm{n}, \alpha_{1}\right)$ & Shape & L.E. Kazakov et al. & Yad. Konst. 2 (1986) 44; 3 (1986) 37 \\
\hline 499 & ${ }^{235} \mathrm{U}(\mathrm{n}, \mathrm{f})$ & Absolute & P.H. White & J. Nucl. Energy A/B19 (1965) 325 \\
\hline 500 & ${ }^{235} \mathrm{U}(\mathrm{n}, \mathrm{f})$ & Absolute & P.H. White & J. Nucl. Energy A/B19 (1965) 325 \\
\hline 501 & ${ }^{235} \mathrm{U}(\mathrm{n}, \mathrm{f})$ & Absolute & P.H. White & J. Nucl. Energy A/B19 (1965) 325 \\
\hline 502 & ${ }^{235} \mathrm{U}(\mathrm{n}, \mathrm{f})$ & Absolute & P.H. White & J. Nucl. Energy A/B19 (1965) 325 \\
\hline 503 & ${ }^{235} \mathrm{U}(\mathrm{n}, \mathrm{f})$ & Absolute & I. Szabo et al. & 70ANL (1970) 257; 76ANL (1976) 208 \\
\hline 503 & ${ }^{235} \mathrm{U}(\mathrm{n}, \mathrm{f})$ & Absolute & I. Szabo et al. & 70ANL (1970) 257; 76ANL (1976) 208 \\
\hline 504 & ${ }^{235} \mathrm{U}(\mathrm{n}, \mathrm{f})$ & Absolute & I. Szabo et al. & 71Knoxville, 2 (1970) 573; 76ANL (1976) 208 \\
\hline 505 & ${ }^{235} \mathrm{U}(\mathrm{n}, \mathrm{f})$ & Absolute & I. Szabo et al. & 73Kiev, 3 (1973) 27; 76ANL (1976) 208 \\
\hline 506 & ${ }^{235} \mathrm{U}(\mathrm{n}, \mathrm{f})$ & Absolute & I. Szabo et al. & 76ANL (1976) 208 \\
\hline 508 & ${ }^{235} \mathrm{U}(\mathrm{n}, \mathrm{f})$ & Shape & A.D. Carlson, B.H. Patrick & 78Harwell (1978) 880 \\
\hline 509 & ${ }^{235} \mathrm{U}(\mathrm{n}, \mathrm{f})$ & Shape & A.D. Carlson, B.H. Patrick & 78Harwell (1978) 880 \\
\hline 510 & ${ }^{238} \mathrm{U}(\mathrm{n}, \mathrm{f})$ & Shape & J.B. Czirr, G.S. Sidhu & Nucl. Sci. Eng. 57 (1975) 18 \\
\hline 511 & ${ }^{235} \mathrm{U}(\mathrm{n}, \mathrm{f})$ & Shape & J.B. Czirr, G.S. Sidhu & Nucl. Sci. Eng. 58 (1975) 371 \\
\hline 513 & ${ }^{235} \mathrm{U}(\mathrm{n}, \mathrm{f}) /{ }^{10} \mathrm{~B}(\mathrm{n}, \alpha)$ & Shape & R.B. Perez et al. & Nucl. Sci. Eng. 55 (1974) 203 \\
\hline
\end{tabular}


TABLE 7.1. EXPERIMENTAL DATA SETS FROM THE GMA DATABASE USED IN THE FINAL COMBINED FIT (cont.)

\begin{tabular}{|c|c|c|c|c|}
\hline $\begin{array}{l}\text { Data set } \\
\text { number }\end{array}$ & Reaction & Data type & First author(s) & Reference \\
\hline 514 & ${ }^{235} \mathrm{U}(\mathrm{n}, \mathrm{f}) /{ }^{10} \mathrm{~B}(\mathrm{n}, \alpha)$ & Shape & R.B. Perez et al. & Nucl. Sci. Eng. 52 (1973) 46 \\
\hline 515 & ${ }^{235} \mathrm{U}(\mathrm{n}, \mathrm{f}) /{ }^{10} \mathrm{~B}(\mathrm{n}, \alpha)$ & Shape & K.D. Zhuravlev et al. & At. Energy 42 (1977) 56 \\
\hline 517 & $\begin{array}{l}{ }^{235} \mathrm{U}(\mathrm{n}, \mathrm{f}) \text { Cf fiss. sp. } \\
\text { av. }\end{array}$ & Absolute & I.G. Schroeder et al. & $\begin{array}{l}\text { IAEA-335 (1984) 320; personal } \\
\text { communication }\end{array}$ \\
\hline 518 & ${ }^{235} \mathrm{U}(\mathrm{n}, \mathrm{f})$ & Absolute & G.F. Knoll, W.P. Poenitz & J. Nucl. Energy 21 (1967) 643 \\
\hline 519 & ${ }^{235} \mathrm{U}(\mathrm{n}, \mathrm{f}) / \mathrm{Au}(\mathrm{n}, \gamma)$ & Absolute & G.F. Knoll, W.P. Poenitz & J. Nucl. Energy 21 (1967) 643 \\
\hline 520 & ${ }^{235} \mathrm{U}(\mathrm{n}, \mathrm{f})$ & Shape & K. Kari & KFK-2673 (1978) \\
\hline 521 & ${ }^{239} \mathrm{Pu}(\mathrm{n}, \mathrm{f})$ & Shape & K. Kari & KFK-2673 (1978) \\
\hline 522 & ${ }^{235} \mathrm{U}(\mathrm{n}, \mathrm{f})$ & Absolute & N.N. Buleeva et al. & Sov. J. At. Energy 65 (1988) 92 \\
\hline 523 & ${ }^{235} \mathrm{U}(\mathrm{n}, \mathrm{f})$ & Absolute & A.D. Carlson et al. & $\begin{array}{l}\text { IAEA-335 (1984) 162; personal } \\
\text { communication }\end{array}$ \\
\hline 524 & ${ }^{235} \mathrm{U}(\mathrm{n}, \mathrm{f})$ & Shape & A.D. Carlson et al. & 91Jülich (1991) 518 \\
\hline 525 & ${ }^{235} \mathrm{U}(\mathrm{n}, \mathrm{f})$ & Absolute & E.A. Schagrov et al. & 80Kiev, vol. 3 (1980) 45 \\
\hline 526 & ${ }^{235} \mathrm{U}(\mathrm{n}, \mathrm{f})$ & Absolute & C.A. Uttley, J.A. Phillips & AERE-NP/R1996 (1956) \\
\hline 527 & ${ }^{235} \mathrm{U}(\mathrm{n}, \mathrm{f}) /{ }^{6} \mathrm{Li}(\mathrm{n}, \alpha)$ & Shape & F. Corvi & Personal communication (1983) \\
\hline 528 & ${ }^{235} \mathrm{U}(\mathrm{n}, \mathrm{f})$ & Absolute & K. Yoshida et al. & NETU-44(TOHOKU) (1983) \\
\hline 530 & ${ }^{235} \mathrm{U}(\mathrm{n}, \mathrm{f}) /{ }^{10} \mathrm{~B}(\mathrm{n}, \alpha)$ & Shape & T.A. Mostovaya et al. & 80Kiev, vol. 3 (1980) 30 \\
\hline 531 & ${ }^{235} \mathrm{U}(\mathrm{n}, \mathrm{f}) /{ }^{6} \operatorname{Li}(\mathrm{n}, \alpha)$ & Shape & F. Corvi & Personal communication (1983) \\
\hline 532 & ${ }^{235} \mathrm{U}(\mathrm{n}, \mathrm{f}) /{ }^{10} \mathrm{~B}(\mathrm{n}, \alpha)$ & Shape & L.W. Weston, J.H. Todd & Nucl. Sci. Eng. 88 (1984) 567 \\
\hline 533 & ${ }^{235} \mathrm{U}(\mathrm{n}, \mathrm{f}) /{ }^{6} \operatorname{Li}(\mathrm{n}, \alpha)$ & Shape & L.W. Weston, J.H. Todd & Nucl. Sci. Eng. 88 (1984) 567 \\
\hline 534 & ${ }^{239} \mathrm{Pu}(\mathrm{n}, \mathrm{f}) /{ }^{10} \mathrm{~B}(\mathrm{n}, \alpha)$ & Shape & L.W. Weston, J.H. Todd & Nucl. Sci. Eng. 88 (1984) 567 \\
\hline 535 & ${ }^{239} \mathrm{Pu}(\mathrm{n}, \mathrm{f}) /{ }^{6} \operatorname{Li}(\mathrm{n}, \alpha)$ & Shape & L.W. Weston, J.H. Todd & Nucl. Sci. Eng. 88 (1984) 567 \\
\hline 536 & ${ }^{239} \mathrm{Pu}(\mathrm{n}, \mathrm{f}){ }^{235} \mathrm{U}(\mathrm{n}, \mathrm{f})$ & Shape & L.W. Weston, J.H. Todd & Nucl. Sci. Eng. 84 (1983) 248 \\
\hline 538 & ${ }^{235} \mathrm{U}(\mathrm{n}, \mathrm{f}) /{ }^{10} \mathrm{~B}\left(\mathrm{n}, \alpha_{1}\right)$ & Shape & G.W. Muradian et al. & 77Kiev, vol. 3 (1977) 119 \\
\hline 540 & ${ }^{235} \mathrm{U}(\mathrm{n}, \mathrm{f}) /{ }^{10} \mathrm{~B}\left(\mathrm{n}, \alpha_{1}\right)$ & Absolute & A.V. Murzin et al. & 80Kiev, vol. 2 (1980) 257 \\
\hline 541 & ${ }^{235} \mathrm{U}(\mathrm{n}, \mathrm{f}) /{ }^{10} \mathrm{~B}(\mathrm{n}, \alpha)$ & Shape & C. Wagemans et al. & 79Knoxville (1979) 961 \\
\hline 542 & ${ }^{235} \mathrm{U}(\mathrm{n}, \mathrm{f}) /{ }^{6} \operatorname{Li}(\mathrm{n}, \alpha)$ & Shape & C. Wagemans et al. & 79Knoxville (1979) 961 \\
\hline 543 & ${ }^{235} \mathrm{U}(\mathrm{n}, \mathrm{f}) /{ }^{10} \mathrm{~B}(\mathrm{n}, \alpha)$ & Shape & C. Wagemans et al. & 79Knoxville (1979) 961 \\
\hline 544 & ${ }^{235} \mathrm{U}(\mathrm{n}, \mathrm{f}) /{ }^{10} \mathrm{~B}(\mathrm{n}, \alpha)$ & Shape & C. Wagemans, A.J. Deruytter & Ann. Nucl. Energy 3 (1976) 437 \\
\hline 545 & ${ }^{235} \mathrm{U}(\mathrm{n}, \mathrm{f}) /{ }^{10} \mathrm{~B}(\mathrm{n}, \alpha)$ & Shape & C. Wagemans, A.J. Deruytter & 84Geel (1984); IAEA-335 (1984) 156 \\
\hline 546 & ${ }^{235} \mathrm{U}(\mathrm{n}, \mathrm{f}) /{ }^{10} \mathrm{~B}(\mathrm{n}, \alpha)$ & Shape & C. Wagemans, A.J. Deruytter & 84Geel (1984); IAEA-335 (1984) 156 \\
\hline 547 & ${ }^{239} \mathrm{Pu}(\mathrm{n}, \mathrm{f}) /{ }^{6} \operatorname{Li}(\mathrm{n}, \alpha)$ & Shape & C. Wagemans et al. & Ann. Nucl. Energy 7 (1980) 495 \\
\hline 548 & ${ }^{239} \mathrm{Pu}(\mathrm{n}, \mathrm{f}) /{ }^{10} \mathrm{~B}(\mathrm{n}, \alpha)$ & Shape & C. Wagemans et al. & Ann. Nucl. Energy 7 (1980) 495 \\
\hline 549 & ${ }^{239} \mathrm{Pu}(\mathrm{n}, \mathrm{f}){ }^{235} \mathrm{U}(\mathrm{n}, \mathrm{f})$ & Shape & C. Wagemans et al. & Ann. Nucl. Energy 7 (1980) 495 \\
\hline 550 & ${ }^{235} \mathrm{U}(\mathrm{n}, \mathrm{f}) /{ }^{10} \mathrm{~B}(\mathrm{n}, \alpha)$ & Shape & A.A. Bergman et al. & 80Kiev, vol. 3 (1980) 49 \\
\hline 551 & ${ }^{239} \mathrm{Pu}(\mathrm{n}, \mathrm{f}) /{ }^{10} \mathrm{~B}(\mathrm{n}, \alpha)$ & Shape & A.A. Bergman et al. & 80Kiev, vol. 3 (1980) 49 \\
\hline 552 & ${ }^{235} \mathrm{U}(\mathrm{n}, \mathrm{f}) /{ }^{10} \mathrm{~B}(\mathrm{n}, \alpha)$ & Shape & A.A. Bergman et al. & Cited in 80Kiev, vol. 3 (1980) 49 \\
\hline 553 & ${ }^{235} \mathrm{U}(\mathrm{n}, \mathrm{f})$ & Shape & W.P. Poenitz & Nucl. Sci. Eng. 64 (1977) 894 \\
\hline 554 & ${ }^{235} \mathrm{U}(\mathrm{n}, \mathrm{f})$ & Absolute & W.P. Poenitz & Nucl. Sci. Eng. 64 (1977) 894 \\
\hline 555 & ${ }^{235} \mathrm{U}(\mathrm{n}, \mathrm{f})$ & Absolute & W.P. Poenitz & Nucl. Sci. Eng. 64 (1977) 894 \\
\hline 556 & ${ }^{235} \mathrm{U}(\mathrm{n}, \mathrm{f})$ & Shape & W.P. Poenitz & Nucl. Sci. Eng. 53 (1974) 370 \\
\hline 557 & ${ }^{235} \mathrm{U}(\mathrm{n}, \mathrm{f})$ & Absolute & W.P. Poenitz & Nucl. Sci. Eng. 53 (1974) 370 \\
\hline
\end{tabular}


TABLE 7.1. EXPERIMENTAL DATA SETS FROM THE GMA DATABASE USED IN THE FINAL COMBINED FIT (cont.)

\begin{tabular}{|c|c|c|c|c|}
\hline $\begin{array}{l}\text { Data set } \\
\text { number }\end{array}$ & Reaction & Data type & First author(s) & Reference \\
\hline 558 & ${ }^{235} \mathrm{U}(\mathrm{n}, \mathrm{f})$ & Absolute & W.P. Poenitz & Nucl. Sci. Eng. 53 (1974) 370 \\
\hline 559 & ${ }^{235} \mathrm{U}(\mathrm{n}, \mathrm{f})$ & Shape & W.P. Poenitz & Nucl. Sci. Eng. 53 (1974) 370 \\
\hline 560 & ${ }^{235} \mathrm{U}(\mathrm{n}, \mathrm{f})$ & Absolute & W.P. Poenitz & Nucl. Sci. Eng. 53 (1974) 370 \\
\hline 561 & ${ }^{235} \mathrm{U}(\mathrm{n}, \mathrm{f})$ & Absolute & W.P. Poenitz & Nucl. Sci. Eng. 53 (1974) 370 \\
\hline 562 & ${ }^{235} \mathrm{U}(\mathrm{n}, \mathrm{f}) /{ }^{6} \mathrm{Li}(\mathrm{n}, \alpha)$ & Shape & W.P. Poenitz & Nucl. Sci. Eng. 53 (1974) 370 \\
\hline 564 & ${ }^{235} \mathrm{U}(\mathrm{n}, \mathrm{f})$ & Absolute & M.C. Davis et al. & Ann. Nucl. Energy 5 (1978) 569 \\
\hline 565 & $\begin{array}{l}{ }^{235} \mathrm{U}(\mathrm{n}, \mathrm{f}) \text { Cf fiss. sp. } \\
\text { av. }\end{array}$ & Absolute & M.C. Davis et al. & Ann. Nucl. Energy 5 (1978) 583 \\
\hline 567 & ${ }^{235} \mathrm{U}(\mathrm{n}, \mathrm{f})$ & Absolute & R.K. Smith et al. (1956) & Personal communication, G. Hanson (1975) \\
\hline 568 & ${ }^{235} \mathrm{U}(\mathrm{n}, \mathrm{f})$ & Shape & W.D. Allen, A.T.G. Ferguson & Proc. Phys. Soc. 70 (1957) 573 \\
\hline 570 & ${ }^{235} \mathrm{U}(\mathrm{n}, \mathrm{f})$ & Absolute & O.A. Wasson et al. & Nucl. Sci. Eng. 81 (1982) 196 \\
\hline 572 & ${ }^{235} \mathrm{U}(\mathrm{n}, \mathrm{f})$ & Shape & B.C. Diven & Phys. Rev. 105 (1957) 1350 \\
\hline 573 & ${ }^{235} \mathrm{U}(\mathrm{n}, \mathrm{f})$ & Absolute & B.C. Diven & Phys. Rev. 105 (1957) 1350 \\
\hline 575 & $\begin{array}{l}{ }^{235} \mathrm{U}(\mathrm{n}, \mathrm{f}) \text { Cf fiss. sp. } \\
\text { av. }\end{array}$ & Absolute & V.M. Adamov et al. & INDC(CCP)-180 (1982) \\
\hline 576 & $\begin{array}{l}{ }^{235} \mathrm{U}(\mathrm{n}, \mathrm{f}) \text { Cf fiss. sp. } \\
\text { av. }\end{array}$ & Absolute & H.T. Heaton et al. & Memo, J. Grundle (1982) \\
\hline 578 & ${ }^{235} \mathrm{U}(\mathrm{n}, \mathrm{f}) /{ }^{10} \mathrm{~B}(\mathrm{n}, \alpha)$ & Shape & G. Desaussure et al. & 66Paris, vol. 2 (1966) 233 \\
\hline 580 & ${ }^{235} \mathrm{U}(\mathrm{n}, \mathrm{f})$ & Absolute & D.M. Barton et al. & Nucl. Sci. Eng. 60 (1976) 369 \\
\hline 581 & ${ }^{235} \mathrm{U}(\mathrm{n}, \mathrm{f})$ & Absolute & F. Kaeppeler & KFK-1772 (1973) \\
\hline 582 & ${ }^{235} \mathrm{U}(\mathrm{n}, \mathrm{f})$ & Shape & F. Kaeppeler & KFK-1772 (1973) \\
\hline 584 & ${ }^{235} \mathrm{U}(\mathrm{n}, \mathrm{f})$ & Absolute & A. Moat & $\begin{array}{l}\text { J. Nucl. Energy A/B14 (1958) 85; personal } \\
\text { communication }\end{array}$ \\
\hline 585 & ${ }^{235} \mathrm{U}(\mathrm{n}, \mathrm{f}) /{ }^{6} \operatorname{Li}(\mathrm{n}, \alpha)$ & Shape & O.A. Wasson & Nucl. Sci. Eng. 81 (1982) 196 \\
\hline 586 & ${ }^{235} \mathrm{U}(\mathrm{n}, \mathrm{f})$ & Shape & O.A. Wasson & Nucl. Sci. Eng. 81 (1982) 196 \\
\hline 587 & ${ }^{235} \mathrm{U}(\mathrm{n}, \mathrm{f})$ & Absolute & TUD/KRI collaboration & $\begin{array}{l}\text { INDC(GDR)-35 (1985), INDC(GDR)-37 } \\
(1985)\end{array}$ \\
\hline 588 & ${ }^{235} \mathrm{U}(\mathrm{n}, \mathrm{f})$ & Shape & D.B. Gayther & 75Washington, vol. 2 (1975) 564 \\
\hline 589 & ${ }^{239} \mathrm{Pu}(\mathrm{n}, \mathrm{f})$ & Shape & D.B. Gayther & 75Washington, vol. 2 (1975) 564 \\
\hline 590 & ${ }^{235} \mathrm{U}(\mathrm{n}, \mathrm{f})$ & Absolute & TUD/KRI collaboration & IAEA-335 (1985) 174; 84Geel (1984) \\
\hline 591 & ${ }^{235} \mathrm{U}(\mathrm{n}, \mathrm{f})$ & Absolute & TUD/KRI collaboration & 83Smolenice (1983) 53 \\
\hline 592 & ${ }^{235} \mathrm{U}(\mathrm{n}, \mathrm{f})$ & Absolute & TUD/KRI collaboration & 83Smolenice (1983) 53 \\
\hline 593 & ${ }^{235} \mathrm{U}(\mathrm{n}, \mathrm{f})$ & Absolute & TUD/KRI collaboration & 83Smolenice (1983) 53 \\
\hline 596 & ${ }^{235} \mathrm{U}(\mathrm{n}, \mathrm{f})$ & Absolute & M. Cance, G. Grenier & Nucl. Sci. Eng. 68 (1978) 197 \\
\hline 597 & ${ }^{235} \mathrm{U}(\mathrm{n}, \mathrm{f})$ & Absolute & M. Cance, G. Grenier & CEA-N-2194 (1983) \\
\hline 598 & ${ }^{235} \mathrm{U}(\mathrm{n}, \mathrm{f})$ & Absolute & M. Cance, G. Grenier & Personal communication (1983) \\
\hline 599 & ${ }^{235} \mathrm{U}(\mathrm{n}, \mathrm{f})$ & Absolute & O.A. Wasson et al. & Nucl. Sci. Eng. 80 (1982) 282 \\
\hline 600 & ${ }^{239} \mathrm{Pu}(\mathrm{n}, \mathrm{f}){ }^{235} \mathrm{U}(\mathrm{n}, \mathrm{f})$ & Absolute & G.W. Carlson, J.W. Behrens & J. Nucl. Energy 66 (1978) 205 \\
\hline 602 & ${ }^{239} \mathrm{Pu}(\mathrm{n}, \mathrm{f}){ }^{235} \mathrm{U}(\mathrm{n}, \mathrm{f})$ & Absolute & J.W. Meadows & ANL/NDM-83 (1983) \\
\hline 605 & ${ }^{239} \mathrm{Pu}(\mathrm{n}, \mathrm{f}){ }^{235} \mathrm{U}(\mathrm{n}, \mathrm{f})$ & Absolute & E. Pfletschinger, F. Kaeppeler & Nucl. Sci. Eng. 40 (1970) 375 \\
\hline 608 & ${ }^{239} \mathrm{Pu}(\mathrm{n}, \mathrm{f}){ }^{235} \mathrm{U}(\mathrm{n}, \mathrm{f})$ & Absolute & P.H. White et al. & 65Salzburg, vol. 1 (1965) 219 \\
\hline 609 & ${ }^{239} \mathrm{Pu}(\mathrm{n}, \mathrm{f}){ }^{235} \mathrm{U}(\mathrm{n}, \mathrm{f})$ & Absolute & P.H. White, G.P. Warner & J. Nucl. Energy 21 (1967) 671 \\
\hline
\end{tabular}


TABLE 7.1. EXPERIMENTAL DATA SETS FROM THE GMA DATABASE USED IN THE FINAL COMBINED FIT (cont.)

\begin{tabular}{|c|c|c|c|c|}
\hline $\begin{array}{l}\text { Data set } \\
\text { number }\end{array}$ & Reaction & Data type & First author(s) & Reference \\
\hline 611 & ${ }^{239} \mathrm{Pu}(\mathrm{n}, \mathrm{f})$ & Absolute & TUD/KRI collaboration & 83Smolenice (1983) 53 \\
\hline 612 & ${ }^{239} \mathrm{Pu}(\mathrm{n}, \mathrm{f})$ & Absolute & M. Cance, G. Grenier & Nucl. Sci. Eng. 68 (1978) 197 \\
\hline 614 & $\begin{array}{l}{ }^{239} \mathrm{Pu}(\mathrm{n}, \mathrm{f}) \mathrm{Cf} \text { fiss. sp. } \\
\text { av. }\end{array}$ & Absolute & I.G. Schroeder et al. & DOE-NDC-38 (1986) 124 \\
\hline 615 & ${ }^{239} \mathrm{Pu}(\mathrm{n}, \mathrm{f})$ & Absolute & TUD/KRI collaboration & $\begin{array}{l}\text { INDC(GDR)-35 (1985), INDC(GDR)-37 } \\
\text { (1985) }\end{array}$ \\
\hline 616 & ${ }^{239} \mathrm{Pu}(\mathrm{n}, \mathrm{f})$ & Absolute & TUD/KRI collaboration & $\begin{array}{l}\text { INDC(GDR)-35 (1985), INDC(GDR)-37 } \\
(1985)\end{array}$ \\
\hline 617 & ${ }^{239} \mathrm{Pu}(\mathrm{n}, \mathrm{f})$ & Absolute & TUD/KRI collaboration & INDC(GDR)-35 (1983) \\
\hline 619 & ${ }^{239} \mathrm{Pu}(\mathrm{n}, \mathrm{f})$ & Absolute & J.L. Perkin et al. & J. Nucl. Energy A/B19 (1965) 423 \\
\hline 620 & ${ }^{239} \mathrm{Pu}(\mathrm{n}, \mathrm{f})$ & Absolute & I. Szabo et al. & 70ANL (1970) 257; 76ANL (1976) 208 \\
\hline 621 & ${ }^{239} \mathrm{Pu}(\mathrm{n}, \mathrm{f})$ & Absolute & I. Szabo et al. & 71Knoxville (1971) 573; 76ANL (1976) 208 \\
\hline 622 & ${ }^{239} \mathrm{Pu}(\mathrm{n}, \mathrm{f})$ & Absolute & I. Szabo et al. & 73Kiev, 3 (1973) 27; 76ANL (1976) 208 \\
\hline 623 & ${ }^{239} \mathrm{Pu}(\mathrm{n}, \mathrm{f})$ & Absolute & I. Szabo et al. & 76ANL (1976) 208 \\
\hline 626 & ${ }^{239} \mathrm{Pu}(\mathrm{n}, \mathrm{f}){ }^{235} \mathrm{U}(\mathrm{n}, \mathrm{f})$ & Absolute & W.P. Poenitz & Nucl. Sci. Eng. 40 (1970) 383 \\
\hline 628 & ${ }^{239} \mathrm{Pu}(\mathrm{n}, \mathrm{f})$ & Absolute & C.A. Uttley, J.A. Phillips & AERE-NP/R1996 (1956) \\
\hline 630 & ${ }^{239} \mathrm{Pu}(\mathrm{n}, \mathrm{f}) /{ }^{10} \mathrm{~B}(\mathrm{n}, \alpha)$ & Shape & K.D. Zhuravlev et al. & At. Energy 42 (1977) 56 \\
\hline 631 & ${ }^{239} \mathrm{Pu}(\mathrm{n}, \mathrm{f}) /{ }^{235} \mathrm{U}(\mathrm{n}, \mathrm{f})$ & Absolute & K.D. Zhuravlev et al. & At. Energy 42 (1977) 56 \\
\hline 633 & ${ }^{239} \mathrm{Pu}(\mathrm{n}, \mathrm{f}) /{ }^{235} \mathrm{U}(\mathrm{n}, \mathrm{f})$ & Absolute & I. Garlea et al. & INDC(ROM)-15 (1983) \\
\hline 635 & ${ }^{239} \mathrm{Pu}(\mathrm{n}, \mathrm{f}) /{ }^{235} \mathrm{U}(\mathrm{n}, \mathrm{f})$ & Shape & W.K. Lehto & Nucl. Sci. Eng. 39 (1970) 361 \\
\hline 637 & ${ }^{239} \mathrm{Pu}(\mathrm{n}, \mathrm{f}){ }^{235} \mathrm{U}(\mathrm{n}, \mathrm{f})$ & Absolute & M. Mahdavi et al. & 82Antwerp (1982) 58 \\
\hline 640 & ${ }^{239} \mathrm{Pu}(\mathrm{n}, \mathrm{f})$ & Absolute & M.C. Davis et al. & Ann. Nucl. Energy 5 (1978) 569 \\
\hline 641 & $\begin{array}{l}{ }^{239} \mathrm{Pu}(\mathrm{n}, \mathrm{f}) \mathrm{Cf} \text { fiss. sp. } \\
\text { av. }\end{array}$ & Absolute & M.C. Davis et al. & Ann. Nucl. Energy 5 (1978) 583 \\
\hline 643 & ${ }^{235} \mathrm{U}(\mathrm{n}, \mathrm{f})$ & Absolute & Li Jingwen et al. & 82Antwerpen (1982) 55 \\
\hline 644 & ${ }^{239} \mathrm{Pu}(\mathrm{n}, \mathrm{f})$ & Absolute & Li Jingwen et al. & 82Antwerpen (1982) 55 \\
\hline 645 & ${ }^{235} \mathrm{U}(\mathrm{n}, \mathrm{f})$ & Absolute & Li Jingwen et al. & INDC(CPR)-009 (1986) 3 \\
\hline 646 & ${ }^{238} \mathrm{U}(\mathrm{n}, \mathrm{f}) /{ }^{235} \mathrm{U}(\mathrm{n}, \mathrm{f})$ & Absolute & Li Jingwen et al. & INDC(CPR)-009 (1986) 7 \\
\hline 648 & ${ }^{238} \mathrm{U}(\mathrm{n}, \mathrm{f})$ & Absolute & R.K. Smith et al. (1956) & Personal communication, G. Hanson (1975) \\
\hline 653 & ${ }^{239} \mathrm{Pu}(\mathrm{n}, \mathrm{f}){ }^{235} \mathrm{U}(\mathrm{n}, \mathrm{f})$ & Absolute & B.I. Fursov et al. & At. Energy 43 (1977) 261 \\
\hline 654 & ${ }^{239} \mathrm{Pu}(\mathrm{n}, \mathrm{f}){ }^{235} \mathrm{U}(\mathrm{n}, \mathrm{f})$ & Absolute & B.I. Fursov et al. & At. Energy 43 (1977) 261 \\
\hline 657 & ${ }^{239} \mathrm{Pu}(\mathrm{n}, \mathrm{f})$ & Absolute & A. Moat & $\begin{array}{l}\text { J. Nucl. Energy A/B14 (1958) 85; personal } \\
\text { communication }\end{array}$ \\
\hline 660 & ${ }^{239} \mathrm{Pu}(\mathrm{n}, \mathrm{f}) /{ }^{10} \mathrm{~B}(\mathrm{n}, \alpha)$ & Shape & Yu.V. Ryabov & At. Energy 46 (1979) 154 \\
\hline 661 & ${ }^{239} \mathrm{Pu}(\mathrm{n}, \mathrm{f}) /{ }^{10} \mathrm{~B}(\mathrm{n}, \alpha)$ & Shape & Yu.V. Ryabov & At. Energy 46 (1979) 154 \\
\hline 662 & ${ }^{239} \mathrm{Pu}(\mathrm{n}, \mathrm{f}) /{ }^{10} \mathrm{~B}(\mathrm{n}, \alpha)$ & Shape & Yu.V. Ryabov & At. Energy 46 (1979) 154 \\
\hline 663 & ${ }^{239} \mathrm{Pu}(\mathrm{n}, \mathrm{f}) /{ }^{/ 10} \mathrm{~B}(\mathrm{n}, \alpha)$ & Shape & Yu.V. Ryabov & At. Energy 46 (1979) 154 \\
\hline 666 & ${ }^{239} \mathrm{Pu}(\mathrm{n}, \mathrm{f}) /{ }^{235} \mathrm{U}(\mathrm{n}, \mathrm{f})$ & Absolute & M. Varnagy, J. Csikai & Nucl. Instrum. Meth. Phys. Res. 196 (1982) 465 \\
\hline 668 & ${ }^{239} \mathrm{Pu}(\mathrm{n}, \mathrm{f}){ }^{238} \mathrm{U}(\mathrm{n}, \mathrm{f})$ & Absolute & R.H. Iyer et al. & 69Roorkee 2 (1969) 289 \\
\hline 671 & ${ }^{239} \mathrm{Pu}(\mathrm{n}, \mathrm{f})$ & Shape & W.D. Allen, A.T.G. Ferguson & Proc. Phys. Soc. A70 (1957) 573 \\
\hline 672 & ${ }^{239} \mathrm{Pu}(\mathrm{n}, \mathrm{f})$ & Absolute & W.D. Allen, A.T.G. Ferguson & Proc. Phys. Soc. A70 (1957) 573 \\
\hline
\end{tabular}


TABLE 7.1. EXPERIMENTAL DATA SETS FROM THE GMA DATABASE USED IN THE FINAL COMBINED FIT (cont.)

\begin{tabular}{|c|c|c|c|c|}
\hline $\begin{array}{l}\text { Data set } \\
\text { number }\end{array}$ & Reaction & Data type & First author(s) & Reference \\
\hline 674 & $\begin{array}{l}{ }^{239} \mathrm{Pu}(\mathrm{n}, \mathrm{f}) \mathrm{Cf} \text { fiss. sp. } \\
\text { av. }\end{array}$ & Absolute & H.T. Heaton et al. & ANS 44-533 DLE (1983) \\
\hline 676 & ${ }^{239} \mathrm{Pu}(\mathrm{n}, \mathrm{f}) /{ }^{10} \mathrm{~B}(\mathrm{n}, \alpha)$ & Shape & R. Gwin et al. & Nucl. Sci. Eng. 61 (1976) 116 \\
\hline 677 & ${ }^{239} \mathrm{Pu}(\mathrm{n}, \mathrm{f}) /{ }^{10} \mathrm{~B}(\mathrm{n}, \alpha)$ & Shape & L.W. Weston, J.H. Todd & Personal communication to Chrien (1972) \\
\hline 678 & ${ }^{239} \mathrm{Pu}(\mathrm{n}, \mathrm{f}) /{ }^{10} \mathrm{~B}(\mathrm{n}, \alpha)$ & Shape & L. Bollinger et al. & 58Geneva, vol. 15 (1958) 127 \\
\hline 679 & ${ }^{239} \mathrm{Pu}(\mathrm{n}, \mathrm{f}) /{ }^{10} \mathrm{~B}(\mathrm{n}, \alpha)$ & Shape & G.D. James & 70Helsinki, vol. 1 (1970) 267 \\
\hline 680 & ${ }^{239} \mathrm{Pu}(\mathrm{n}, \mathrm{f}) /{ }^{10} \mathrm{~B}(\mathrm{n}, \alpha)$ & Shape & M. Schomberg et al. & 70Helsinki, vol. 1 (1970) 289 \\
\hline 681 & ${ }^{239} \mathrm{Pu}(\mathrm{n}, \mathrm{f}) /{ }^{10} \mathrm{~B}(\mathrm{n}, \alpha)$ & Shape & R. Gwin et al. & Nucl. Sci. Eng. 45 (1971) 25 \\
\hline 682 & ${ }^{239} \mathrm{Pu}(\mathrm{n}, \mathrm{f}) /{ }^{10} \mathrm{~B}(\mathrm{n}, \alpha)$ & Shape & R. Gwin et al. & Nucl. Sci. Eng. 45 (1971) 25 \\
\hline 685 & ${ }^{239} \mathrm{Pu}(\mathrm{n}, \mathrm{f}) /{ }^{235} \mathrm{U}(\mathrm{n}, \mathrm{f})$ & Absolute & J.W. Meadows & ANL/NDM-97 (1986) \\
\hline 704 & $\operatorname{Au}(\mathrm{n}, \gamma)$ & Absolute & N.E. Holden & BNL-NCS-51320 (1981) \\
\hline 705 & $\begin{array}{l}{ }^{238} \mathrm{U}(\mathrm{n}, \gamma) \text {, therm. } \\
\text { pre-eval. }\end{array}$ & Absolute & A. Trkov et al. & Nucl. Sci. Eng. 150 (2005) 336 \\
\hline 710 & ${ }^{235} \mathrm{U}(\mathrm{n}, \mathrm{f}) /{ }^{10} \mathrm{~B}(\mathrm{n}, \alpha)$ & Shape & R. Gwin et al. & Nucl. Sci. Eng. 88 (1984) 37 \\
\hline 711 & ${ }^{235} \mathrm{U}(\mathrm{n}, \mathrm{f}) /{ }^{10} \mathrm{~B}(\mathrm{n}, \alpha)$ & Shape & R. Gwin et al. & Nucl. Sci. Eng. 88 (1984) 37 \\
\hline 712 & ${ }^{235} \mathrm{U}(\mathrm{n}, \mathrm{f}) /{ }^{10} \mathrm{~B}(\mathrm{n}, \alpha)$ & Shape & R. Gwin et al. & Nucl. Sci. Eng. 88 (1984) 37 \\
\hline 713 & ${ }^{235} \mathrm{U}(\mathrm{n}, \mathrm{f}) /{ }^{10} \mathrm{~B}(\mathrm{n}, \alpha)$ & Shape & R. Gwin et al. & Nucl. Sci. Eng. 88 (1984) 37 \\
\hline 714 & ${ }^{235} \mathrm{U}(\mathrm{n}, \mathrm{f}) /{ }^{10} \mathrm{~B}(\mathrm{n}, \alpha)$ & Shape & R. Gwin et al. & Nucl. Sci. Eng. 88 (1984) 37 \\
\hline 718 & ${ }^{235} \mathrm{U}(\mathrm{n}, \mathrm{f}) /{ }^{10} \mathrm{~B}(\mathrm{n}, \alpha)$ & Shape & J. Blons & Nucl. Sci. Eng. 51 (1973) 130 \\
\hline 719 & ${ }^{239} \mathrm{Pu}(\mathrm{n}, \mathrm{f}) /{ }^{10} \mathrm{~B}(\mathrm{n}, \alpha)$ & Shape & J. Blons & Nucl. Sci. Eng. 51 (1973) 130 \\
\hline 721 & ${ }^{235} \mathrm{U}(\mathrm{n}, \mathrm{f})$ & Shape & V.M. Pankratov et al. & J. Nucl. Energy 16 (1962) 494 \\
\hline 722 & ${ }^{235} \mathrm{U}(\mathrm{n}, \mathrm{f})$ & Shape & V.M. Pankratov et al. & Sov. J. At. Energy 14 (1964) 167 \\
\hline 725 & ${ }^{235} \mathrm{U}(\mathrm{n}, \mathrm{f})$ & Absolute & J.L. Perkin et al. & J. Nucl. Energy A/B19 (1965) 423 \\
\hline 727 & ${ }^{235} \mathrm{U}(\mathrm{n}, \mathrm{f}) /{ }^{10} \mathrm{~B}(\mathrm{n}, \alpha)$ & Shape & Van Shi-di et al. & 65Salzburg, vol. 1 (1965) 287 \\
\hline 728 & ${ }^{235} \mathrm{U}(\mathrm{n}, \mathrm{f}) /{ }^{10} \mathrm{~B}(\mathrm{n}, \alpha)$ & Shape & A. Michaudon et al. & J. de Phys. 21 (1960) 429 \\
\hline 730 & ${ }^{235} \mathrm{U}(\mathrm{n}, \mathrm{f}) /{ }^{10} \mathrm{~B}(\mathrm{n}, \alpha)$ & Shape & G. Desaussure et al. & 66Paris, vol. 2 (1966) 233 \\
\hline 731 & ${ }^{235} \mathrm{U}(\mathrm{n}, \mathrm{f}) /{ }^{10} \mathrm{~B}(\mathrm{n}, \alpha)$ & Shape & A.J. Deruytter, C. Wagemans & J. Nucl. Energy 25 (1971) 263 \\
\hline 732 & ${ }^{235} \mathrm{U}(\mathrm{n}, \mathrm{f}) /{ }^{10} \mathrm{~B}(\mathrm{n}, \alpha)$ & Shape & C.D. Bowman & Phys. Rev. 130 (1963) 1482 \\
\hline 735 & ${ }^{235} \mathrm{U}(\mathrm{n}, \mathrm{f})$ & Shape & W.D. Allen, A.T.G. Ferguson & Proc. Phys. Soc. A70 (1957) 573 \\
\hline 738 & ${ }^{235} \mathrm{U}(\mathrm{n}, \mathrm{f})$ & Absolute & Yan Wuguang et al. & At. Energy Sci. Technol. 9 (1975) 133 \\
\hline 803 & ${ }^{238} \mathrm{U}(\mathrm{n}, \mathrm{f}) /{ }^{235} \mathrm{U}(\mathrm{n}, \mathrm{f})$ & Absolute & J.W. Meadows & ANL/NDM-83 (1983) \\
\hline 805 & ${ }^{238} \mathrm{U}(\mathrm{n}, \mathrm{f}) / 235 \mathrm{U}(\mathrm{n}, \mathrm{f})$ & Absolute & J.W. Behrens, G.W. Carlson & J. Nucl. Energy 63 (1977) 250 \\
\hline 808 & ${ }^{238} \mathrm{U}(\mathrm{n}, \mathrm{f}) /{ }^{235} \mathrm{U}(\mathrm{n}, \mathrm{f})$ & Absolute & F.C. Defilippo et al. & Nucl. Sci. Eng. 68 (1978) 43 \\
\hline 809 & ${ }^{238} \mathrm{U}(\mathrm{n}, \mathrm{f})$ & Absolute & G. Winkler et al. & 91Jülich (1991) 514 \\
\hline 810 & ${ }^{238} \mathrm{U}(\mathrm{n}, \mathrm{f})$ & Absolute & K. Merla et al. & 91Jülich (1991) 510 \\
\hline 811 & ${ }^{238} \mathrm{U}(\mathrm{n}, \mathrm{f})$ & Absolute & TUD/KRI collaboration & 83Smolenice (1983) 53 \\
\hline 812 & ${ }^{238} \mathrm{U}(\mathrm{n}, \mathrm{f})$ & Absolute & M. Cance, G. Grenier & Nucl. Sci. Eng. 68 (1978) 197 \\
\hline 815 & ${ }^{238} \mathrm{U}(\mathrm{n}, \mathrm{f}) / 235 \mathrm{U}(\mathrm{n}, \mathrm{f})$ & Absolute & P.H. White, G.P. Warner & J. Nucl. Energy 21 (1967) 671 \\
\hline 816 & ${ }^{238} \mathrm{U}(\mathrm{n}, \mathrm{f}) /{ }^{235} \mathrm{U}(\mathrm{n}, \mathrm{f})$ & Absolute & W.P. Poenitz, R.J. Armani & J. Nucl. Energy 26 (1972) 483 \\
\hline 817 & ${ }^{238} \mathrm{U}(\mathrm{n}, \mathrm{f}){ }^{235} \mathrm{U}(\mathrm{n}, \mathrm{f})$ & Absolute & W.P. Poenitz, R.J. Armani & J. Nucl. Energy 26 (1972) 483 \\
\hline 818 & ${ }^{238} \mathrm{U}(\mathrm{n}, \mathrm{f}) /{ }^{235} \mathrm{U}(\mathrm{n}, \mathrm{f})$ & Absolute & W.P. Poenitz, R.J. Armani & J. Nucl. Energy 26 (1972) 483 \\
\hline 819 & ${ }^{238} \mathrm{U}(\mathrm{n}, \mathrm{f}){ }^{235} \mathrm{U}(\mathrm{n}, \mathrm{f})$ & Absolute & W.P. Poenitz, R.J. Armani & J. Nucl. Energy 26 (1972) 483 \\
\hline
\end{tabular}


TABLE 7.1. EXPERIMENTAL DATA SETS FROM THE GMA DATABASE USED IN THE FINAL COMBINED FIT (cont.)

\begin{tabular}{|c|c|c|c|c|}
\hline $\begin{array}{l}\text { Data set } \\
\text { number }\end{array}$ & Reaction & Data type & First author(s) & Reference \\
\hline 821 & ${ }^{238} \mathrm{U}(\mathrm{n}, \mathrm{f}) /{ }^{235} \mathrm{U}(\mathrm{n}, \mathrm{f})$ & Absolute & R.W. Lamphere & Phys. Rev. 104 (1956) 1654 \\
\hline 822 & ${ }^{238} \mathrm{U}(\mathrm{n}, \mathrm{f}) /{ }^{235} \mathrm{U}(\mathrm{n}, \mathrm{f})$ & Absolute & W.E. Stein et al. & 68Washington, vol. 1 (1968) 627 \\
\hline 824 & ${ }^{238} \mathrm{U}(\mathrm{n}, \mathrm{f}){ }^{235} \mathrm{U}(\mathrm{n}, \mathrm{f})$ & Shape & S. Cierjacks et al. & 76ANL (1976) 94 \\
\hline 826 & ${ }^{238} \mathrm{U}(\mathrm{n}, \mathrm{f}){ }^{235} \mathrm{U}(\mathrm{n}, \mathrm{f})$ & Shape & M.S. Coates et al. & $\begin{array}{l}\text { 75Washington, personal communication } \\
\text { (1975) }\end{array}$ \\
\hline 828 & ${ }^{238} \mathrm{U}(\mathrm{n}, \mathrm{f}){ }^{235} \mathrm{U}(\mathrm{n}, \mathrm{f})$ & Shape & W. Blons et al. & $\begin{array}{l}\text { Personal communication by Blons to NEA } \\
\text { (1977) }\end{array}$ \\
\hline 830 & ${ }^{238} \mathrm{U}(\mathrm{n}, \mathrm{f}){ }^{235} \mathrm{U}(\mathrm{n}, \mathrm{f})$ & Absolute & C. Nordborg et al. & 76ANL (1976) 128 \\
\hline 832 & ${ }^{238} \mathrm{U}(\mathrm{n}, \mathrm{f}){ }^{235} \mathrm{U}(\mathrm{n}, \mathrm{f})$ & Absolute & M. Cance, G. Grenier & 76ANL (1976) 141 \\
\hline 835 & ${ }^{238} \mathrm{U}(\mathrm{n}, \mathrm{f})$ & Shape & B. Adams et al. & J. Nucl. Energy 14 (1961) 85 \\
\hline 836 & ${ }^{235} \mathrm{U}(\mathrm{n}, \mathrm{f}) /{ }^{238} \mathrm{U}(\mathrm{n}, \mathrm{f})$ & Shape & B. Adams et al. & J. Nucl. Energy 14 (1961) 85 \\
\hline 837 & ${ }^{239} \mathrm{Pu}(\mathrm{n}, \mathrm{f}){ }^{238} \mathrm{U}(\mathrm{n}, \mathrm{f})$ & Shape & B. Adams et al. & J. Nucl. Energy 14 (1961) 85 \\
\hline 839 & ${ }^{238} \mathrm{U}(\mathrm{n}, \mathrm{f})$ & Shape & P.E. Vorotnikov et al. & INDC(CCP)-66 (1975) 6 \\
\hline 844 & ${ }^{238} \mathrm{U}(\mathrm{n}, \mathrm{f}){ }^{235} \mathrm{U}(\mathrm{n}, \mathrm{f})$ & Absolute & B.I. Fursov et al. & At. Energy 43 (1977) 181 \\
\hline 845 & ${ }^{238} \mathrm{U}(\mathrm{n}, \mathrm{f}){ }^{235} \mathrm{U}(\mathrm{n}, \mathrm{f})$ & Absolute & B.I. Fursov et al. & At. Energy 43 (1977) 181 \\
\hline 848 & ${ }^{238} \mathrm{U}(\mathrm{n}, \mathrm{f}) /{ }^{235} \mathrm{U}(\mathrm{n}, \mathrm{f})$ & Absolute & M. Varnagy, J. Csikai & Nucl. Instrum. Meth. Phys. Res. 196 (1982) 465 \\
\hline 850 & ${ }^{238} \mathrm{U}(\mathrm{n}, \mathrm{f})$ & Absolute & Wu Jingxia et al. & Chin. J. Nucl. Phys. 150 (1983) 158 \\
\hline 853 & ${ }^{238} \mathrm{U}(\mathrm{n}, \mathrm{f}){ }^{235} \mathrm{U}(\mathrm{n}, \mathrm{f})$ & Absolute & A.A. Goverdovskii et al. & 83Kiev (1983) 159 \\
\hline 854 & ${ }^{238} \mathrm{U}(\mathrm{n}, \mathrm{f}){ }^{235} \mathrm{U}(\mathrm{n}, \mathrm{f})$ & Absolute & A.A. Goverdovskii et al. & Sov. J. At. Energy 56 (1984) 173 \\
\hline 855 & ${ }^{238} \mathrm{U}(\mathrm{n}, \mathrm{f}) /{ }^{235} \mathrm{U}(\mathrm{n}, \mathrm{f})$ & Absolute & G.A. Jarvis et al. & LA-1571 (1953) \\
\hline 856 & ${ }^{238} \mathrm{U}(\mathrm{n}, \mathrm{f}){ }^{235} \mathrm{U}(\mathrm{n}, \mathrm{f})$ & Absolute & F. Manabe et al. & NETU-47(TOHOKU) (1986) 61 \\
\hline 857 & ${ }^{238} \mathrm{U}(\mathrm{n}, \mathrm{f})$ & Absolute & K. Yoshida et al. & NETU-44(TOHOKU) (1983) \\
\hline 859 & ${ }^{238} \mathrm{U}(\mathrm{n}, \mathrm{f}){ }^{235} \mathrm{U}(\mathrm{n}, \mathrm{f})$ & Absolute & O. Sato et al. & NETU-TOHUKU Univ. (1982) \\
\hline 860 & ${ }^{238} \mathrm{U}(\mathrm{n}, \mathrm{f})$ & Absolute & N.N. Flerov et al. & At. Energy 5 (1958) 657 \\
\hline 861 & ${ }^{238} \mathrm{U}(\mathrm{n}, \mathrm{f})$ & Absolute & A. Moat & $\begin{array}{l}\text { J. Nucl. Energy A/B14 (1958) 85; personal } \\
\text { communication }\end{array}$ \\
\hline 863 & ${ }^{238} \mathrm{U}(\mathrm{n}, \mathrm{f}){ }^{235} \mathrm{U}(\mathrm{n}, \mathrm{f})$ & Absolute & I. Garlea et al. & INDC(ROM)-15 (1983) \\
\hline 865 & ${ }^{238} \mathrm{U}(\mathrm{n}, \mathrm{f}){ }^{235} \mathrm{U}(\mathrm{n}, \mathrm{f})$ & Absolute & J.W. Meadows & ANL/NDM-97 (1986) \\
\hline 869 & ${ }^{238} \mathrm{U}(\mathrm{n}, \mathrm{f})$ & Absolute & C.A. Uttley, J.A. Phillips & AERE-NP/R1996 (1956) \\
\hline 870 & ${ }^{235} \mathrm{U}(\mathrm{n}, \mathrm{f}){ }^{238} \mathrm{U}(\mathrm{n}, \mathrm{f})$ & Absolute & A.A. Berezin et al. & At. Energy 5 (1958) 659 \\
\hline 871 & ${ }^{235} \mathrm{U}(\mathrm{n}, \mathrm{f}){ }^{238} \mathrm{U}(\mathrm{n}, \mathrm{f})$ & Absolute & R.H. Iyer et al. & 69Roorkee, 2 (1969) 289 \\
\hline 873 & ${ }^{238} \mathrm{U}(\mathrm{n}, \mathrm{f})$ & Shape & V.M. Pankratov et al. & J. Nucl. Energy 16 (1962) 494 \\
\hline 874 & ${ }^{238} \mathrm{U}(\mathrm{n}, \mathrm{f})$ & Shape & V.M. Pankratov et al. & Sov. J. At. Energy 14 (1964) 167 \\
\hline 875 & ${ }^{238} \mathrm{U}(\mathrm{n}, \mathrm{f})$ & Shape & P. Kalinin, V.M. Pankratov & 58Geneva, vol. 16 (1962) 136 \\
\hline 877 & ${ }^{238} \mathrm{U}(\mathrm{n}, \mathrm{f})$ & Absolute & I.M. Kuks et al. & At. Energy 30 (1971) 55 \\
\hline 878 & ${ }^{235} \mathrm{U}(\mathrm{n}, \mathrm{f})$ & Absolute & I.M. Kuks et al. & 73Kiev, vol. 4 (1973) 18 \\
\hline 881 & ${ }^{238} \mathrm{U}(\mathrm{n}, \mathrm{f})$ & Shape & M. Mangialajo et al. & Nucl. Phys. 43 (1963) 124 \\
\hline 1010 & ${ }^{6} \operatorname{Li}(\mathrm{n}, \alpha) /{ }^{238} \mathrm{U}(\mathrm{n}, \mathrm{f})$ & Absolute & Guohui Zhang et al. & Nucl. Sci. Eng. 143 (2003) 86 \\
\hline 1012 & ${ }^{239} \mathrm{Pu}(\mathrm{n}, \mathrm{f}) /{ }^{235} \mathrm{U}(\mathrm{n}, \mathrm{f})$ & Absolute & O. Shcherbakov et al. & JINR-E3-2001-192 (2001) \\
\hline 1013 & $\left.{ }^{238} \mathrm{U}(\mathrm{n}, \mathrm{f})\right)^{235} \mathrm{U}(\mathrm{n}, \mathrm{f})$ & Absolute & O. Shcherbakov et al. & JINR-E3-2001-192 (2001) \\
\hline 1014 & ${ }^{239} \mathrm{Pu}(\mathrm{n}, \mathrm{f}){ }^{235} \mathrm{U}(\mathrm{n}, \mathrm{f})$ & Absolute & P. Staples, K. Moorley & Nucl. Sci. Eng. 129 (1998) 149 \\
\hline
\end{tabular}


TABLE 7.1. EXPERIMENTAL DATA SETS FROM THE GMA DATABASE USED IN THE FINAL COMBINED FIT (cont.)

\begin{tabular}{|c|c|c|c|c|}
\hline $\begin{array}{l}\text { Data set } \\
\text { number }\end{array}$ & Reaction & Data type & First author(s) & Reference \\
\hline 1016 & $\operatorname{Au}(\mathrm{n}, \gamma)$ & Absolute & J. Voigner et al. & Nucl. Sci. Eng. 93 (1986) 43 \\
\hline 1017 & ${ }^{238} \mathrm{U}(\mathrm{n}, \gamma)$ & Absolute & J. Voigner et al. & Nucl. Sci. Eng. 93 (1986) 43 \\
\hline 1018 & $\mathrm{Au}(\mathrm{n}, \gamma){ }^{235} \mathrm{U}(\mathrm{n}, \mathrm{f})$ & Absolute & A.N. Davletshin et al. & Yad. Konst. 1 (1992) 41 \\
\hline 1019 & $\mathrm{Au}(\mathrm{n}, \gamma){ }^{235} \mathrm{U}(\mathrm{n}, \mathrm{f})$ & Absolute & A.N. Davletshin et al. & Yad. Konst. 1 (1993) 13 \\
\hline 1020 & $\mathrm{Au}(\mathrm{n}, \gamma){ }^{235} \mathrm{U}(\mathrm{n}, \mathrm{f})$ & Absolute & V.A. Tolstikov & Yad. Konst. 4 (1994) 46 \\
\hline 1021 & $\operatorname{Au}(\mathrm{n}, \gamma) /^{6} \operatorname{Li}(\mathrm{n}, \alpha)$ & Absolute & L.E. Kazakov et al. & Yad. Konst. 2 (1985) 44 \\
\hline 1022 & $\mathrm{Au}(\mathrm{n}, \gamma) /{ }^{10} \mathrm{~B}\left(\mathrm{n}, \alpha_{1}\right)$ & Shape & L.E. Kazakov et al. & Yad. Konst. 2 (1985) 44 \\
\hline 1023 & ${ }^{235} \mathrm{U}(\mathrm{n}, \mathrm{f}) /{ }^{10} \mathrm{~B}(\mathrm{n}, \alpha)$ & Shape & L.W. Weston, J.H. Todd & Nucl. Sci. Eng. 111 (1992) 415 \\
\hline 1024 & ${ }^{239} \mathrm{Pu}(\mathrm{n}, \mathrm{f}) /{ }^{10} \mathrm{~B}(\mathrm{n}, \alpha)$ & Shape & L.W. Weston, J.H. Todd & Nucl. Sci. Eng. 111 (1992) 415 \\
\hline 1025 & ${ }^{235} \mathrm{U}(\mathrm{n}, \mathrm{f})$ & Absolute & A.D. Carlson et al. & Personal communication (1991) \\
\hline 1026 & ${ }^{235} \mathrm{U}(\mathrm{n}, \mathrm{f})$ & Absolute & V.A. Kalinin et al. & At. Energy 71 (1991) 18 \\
\hline 1027 & ${ }^{235} \mathrm{U}(\mathrm{n}, \mathrm{f})$ & Absolute & T. Iwasaki et al. & 88Mito (1988) 87 \\
\hline 1028 & ${ }^{235} \mathrm{U}(\mathrm{n}, \mathrm{f})$ & Shape & P.W. Lisowski et al. & Personal communication (1991) \\
\hline 1029 & ${ }^{239} \mathrm{Pu}(\mathrm{n}, \mathrm{f}) /{ }^{235} \mathrm{U}(\mathrm{n}, \mathrm{f})$ & Shape & P.W. Lisowski et al. & Personal communication (1991) \\
\hline 1030 & ${ }^{238} \mathrm{U}(\mathrm{n}, \mathrm{f}) /{ }^{235} \mathrm{U}(\mathrm{n}, \mathrm{f})$ & Shape & P.W. Lisowski et al. & Personal communication (1991) \\
\hline 1035 & ${ }^{238} \mathrm{U}(\mathrm{n}, \mathrm{f}) /{ }^{235} \mathrm{U}(\mathrm{n}, \mathrm{f})$ & Absolute & M. Baba et al. & J. Nucl. Sci. Technol. 26 (1989) 11 \\
\hline 1036 & ${ }^{235} \mathrm{U}(\mathrm{n}, \mathrm{f})$ & Absolute & R. Nolte & Personal communication, preliminary (2003) \\
\hline 1037 & ${ }^{235} \mathrm{U}(\mathrm{n}, \mathrm{f}) /{ }^{38} \mathrm{U}(\mathrm{n}, \mathrm{f})$ & Absolute & R. Nolte & Personal communication, preliminary (2003) \\
\hline 1038 & ${ }^{239} \mathrm{Pu}(\mathrm{n}, \mathrm{f})$ & Absolute & Zhou Xian-Jian & 82Antwerp (1982) 36 \\
\hline 1915 & $\begin{array}{l}{ }^{233} \mathrm{U}(\mathrm{nu}-\mathrm{bar}) \\
\text { thermal }\end{array}$ & Absolute & R.L. Reed et al. & COO-3058, 29 (1972) 3 \\
\hline 1918 & ${ }^{235} \mathrm{U}(\mathrm{n}, \mathrm{n})$, thermal & Absolute & M. Arif et al. & Phys. Rev. A35 (1987) 2810 \\
\hline 1921 & $\begin{array}{l}{ }^{235} \mathrm{U}(\mathrm{nu}-\mathrm{bar}) \text {, } \\
\text { thermal }\end{array}$ & Absolute & R.L. Reed et al. & COO-3058 29 (1972) 3 \\
\hline 910-934 & $\begin{array}{l}25 \text { thermal } \\
\text { constants }\end{array}$ & Absolute & E.J. Axton & Personal communication (1986) \\
\hline
\end{tabular}

\subsection{REACTION CROSS-SECTION STANDARDS}

The results for the ${ }^{6} \operatorname{Li}(\mathrm{n}, \alpha)$ integral reaction cross-section (same as ${ }^{6} \mathrm{Li}(\mathrm{n}, \mathrm{t})$ ) are shown in Figs 7.1 and 7.3, and the ratio of the combined final evaluation to the previous standard is shown in Figs 7.2 and 7.4. This cross-section is recommended as a standard for neutron energies below $1 \mathrm{MeV}$. The evaluated cross-section at a neutron energy of $0.0253 \mathrm{eV}$ is $938.467 \pm 1.267 \mathrm{~b}$. The small uncertainty of the evaluated thermal cross-section and the cross-section in the $1 / v$ region is predetermined by the small uncertainty of the experimental data at the thermal point, which extends into the $1 / v$ region because of the strong model correlations. This behaviour only occurs if the model is adequate and compares well with the experimental data. Comparison of the final combined evaluation with the experimental data for the neutron elastic scattering cross-section is shown in Figs 7.5 and 7.7, and the ratio of the combined final evaluation to the previous GMA combined fit is shown in Figs 7.6 and 7.8. In both cases there are differences between the results of the present and previous evaluations that exceed the uncertainty of the newly evaluated data. The main reason for this significant discrepancy is the inclusion in the R matrix fit of new experimental data that were not used in the previous analysis. The influence of Peelle's 
TABLE 7.2. EXPERIMENTAL DATA FROM GMA DATABASE USED IN R MATRIX MODEL FIT AND EXCLUDED FROM FINAL COMBINED FIT TO AVOID DOUBLE COUNTING

\begin{tabular}{|c|c|c|c|c|}
\hline $\begin{array}{l}\text { Data set } \\
\text { number }\end{array}$ & Reaction & Data type & First author(s) & Reference \\
\hline 100 & ${ }^{10} \mathrm{~B}(\mathrm{n}, \alpha)$ & Shape & S.J. Friesehnahn et al. & INTERL-RT-7011-001 (1974) \\
\hline 103 & ${ }^{10} \mathrm{~B}\left(\mathrm{n}, \mathrm{\alpha}_{1}\right)$ & Shape & S.J. Friesehnahn et al. & INTERL-RT-7011-001 (1974) \\
\hline 104 & ${ }^{10} \mathrm{~B}\left(\mathrm{n}, \mathrm{\alpha}_{0}\right) /{ }^{10} \mathrm{~B}\left(\mathrm{n}, \alpha_{1}\right)$ & Absolute & L.W. Weston, J.H. Todd & Nucl. Sci. Eng. 109 (1991) 113 \\
\hline 105 & ${ }^{10} \mathrm{~B}\left(\mathrm{n}, \mathrm{\alpha}_{1}\right)$ & Shape & R.A. Schrack et al. & Nucl. Sci. Eng. 68 (1978) 189 \\
\hline 107 & ${ }^{10} \mathrm{~B}\left(\mathrm{n}, \mathrm{\alpha}_{1}\right)$ & Absolute & D.O. Nellis et al. & Phys. Rev. C1 (1970) 847 \\
\hline 110 & ${ }^{10} \mathrm{~B}\left(\mathrm{n}, \mathrm{\alpha}_{0}\right)$ & Absolute & R.M. Sealock, J.C. Overlay & Phys. Rev. C13 (1976) 2149 \\
\hline 111 & ${ }^{10} \mathrm{~B}\left(\mathrm{n}, \alpha_{1}\right)$ & Absolute & R.M. Sealock, J.C. Overlay & Phys. Rev. C13 (1976) 2149 \\
\hline 112 & ${ }^{10} \mathrm{~B}\left(\mathrm{n}, \mathrm{\alpha}_{0}\right)$ & Absolute & R.M. Sealock et al. & Nucl. Phys. A357 (1981) 279 \\
\hline 113 & ${ }^{10} \mathrm{~B}\left(\mathrm{n}, \mathrm{\alpha}_{1}\right)$ & Shape & R.A. Schrack et al. & Nucl. Sci. Eng. 114 (1978) 352 \\
\hline 114 & ${ }^{10} \mathrm{~B}\left(\mathrm{n}, \mathrm{\alpha}_{0}\right)$ & Absolute & J.H. Gibbons, R.L. Macklin & Phys. Rev. 114 (1959) 571 \\
\hline 115 & ${ }^{10} \mathrm{~B}(\mathrm{n}, \alpha)$ & Absolute & S.A. Cox, F.R. Pontet & J. Nucl. Energy 21 (1967) 271 \\
\hline 118 & ${ }^{10} \mathrm{~B}\left(\mathrm{n}, \mathrm{\alpha}_{0}\right)$ & Absolute & M.D. Olson, R.W. Kawanagh & Phys. Rev. C30 (1984) 1375 \\
\hline 121 & ${ }^{10} \mathrm{~B}(\mathrm{n}, \alpha)$ & Absolute & E.A. Davis et al. & Nucl. Phys. 27 (1961) 448 \\
\hline 122 & ${ }^{10} \mathrm{~B}\left(\mathrm{n}, \mathrm{\alpha}_{0}\right) /{ }^{10} \mathrm{~B}\left(\mathrm{n}, \mathrm{\alpha}_{1}\right)$ & Absolute & E.A. Davis et al. & Nucl. Phys. 27 (1961) 448 \\
\hline 124 & ${ }^{10} \mathrm{~B}(\mathrm{n}, \alpha)$ & Shape & H. Bichsel, T.W. Bonner & Phys. Rev. 108 (1957) 1025 \\
\hline 125 & ${ }^{10} \mathrm{~B}\left(\mathrm{n}, \alpha_{0}\right) /{ }^{10} \mathrm{~B}\left(\mathrm{n}, \alpha_{1}\right)$ & Absolute & R.L. Macklin, J.H. Gibbons & Phys. Rev. 65 (1968) 1147 \\
\hline 126 & ${ }^{10} \mathrm{~B}\left(\mathrm{n}, \mathrm{\alpha}_{0}\right)$ & Shape & R.L. Macklin, J.H. Gibbons & Phys. Rev. 65 (1968) 1147 \\
\hline 128 & ${ }^{10} \mathrm{~B}\left(\mathrm{n}, \alpha_{1}\right)$ & Shape & M.S. Coates et al. & 72Vienna (1972) 129 \\
\hline 130 & ${ }^{10} \mathrm{~B}(\mathrm{n}, \alpha)$ & Shape & D. Bogart, L.L. Nichols & Nucl. Phys. A125 (1969) 463 \\
\hline 135 & ${ }^{10} \mathrm{~B}\left(\mathrm{n}, \alpha_{1}\right)$ & Shape & G. Vesti, H. Liskien & Ann. Nucl. Energy 6 (1979) 13 \\
\hline 136 & ${ }^{10} \mathrm{~B}\left(\mathrm{n}, \alpha_{1}\right)$ & Shape & G. Vesti, H. Liskien & Ann. Nucl. Energy 6 (1979) 13 \\
\hline 137 & ${ }^{10} \mathrm{~B}\left(\mathrm{n}, \alpha_{1}\right)$ & Shape & G. Vesti, H. Liskien & Ann. Nucl. Energy 6 (1979) 13 \\
\hline 140 & ${ }^{10} \mathrm{~B}\left(\mathrm{n}, \mathrm{\alpha}_{0}\right) /{ }^{10} \mathrm{~B}\left(\mathrm{n}, \alpha_{1}\right)$ & Shape & M.G. Sowerby & J. Nucl. Energy 20 (1966) 135 \\
\hline 141 & ${ }^{10} \mathrm{~B}\left(\mathrm{n}, \mathrm{\alpha}_{0}\right) /{ }^{10} \mathrm{~B}\left(\mathrm{n}, \mathrm{\alpha}_{1}\right)$ & Shape & M.G. Sowerby & J. Nucl. Energy 20 (1966) 135 \\
\hline 142 & ${ }^{10} \mathrm{~B}\left(\mathrm{n}, \mathrm{\alpha}_{0}\right) /{ }^{10} \mathrm{~B}\left(\mathrm{n}, \alpha_{1}\right)$ & Absolute & M.L. Stelts et al. & Phys. Rev. C19 (1979) 1159 \\
\hline 145 & ${ }^{10} \mathrm{~B}\left(\mathrm{n}, \mathrm{\alpha}_{0}\right) /{ }^{10} \mathrm{~B}\left(\mathrm{n}, \mathrm{\alpha}_{1}\right)$ & Absolute & G.P. Lamaze et al. & Nucl. Sci. Eng. 56 (1975) 94 \\
\hline 149 & ${ }^{10} \mathrm{~B}\left(\mathrm{n}, \mathrm{\alpha}_{0}\right) /{ }^{10} \mathrm{~B}\left(\mathrm{n}, \alpha_{1}\right)$ & Absolute & R.L. Macklin, J.H. Gibbons & Phys. Rev. 140 (1965) B324 \\
\hline 162 & ${ }^{10} \mathrm{~B}\left(\mathrm{n}, \mathrm{\alpha}_{0}\right) /{ }^{10} \mathrm{~B}\left(\mathrm{n}, \alpha_{1}\right)$ & Absolute & B. Petree et al. & Phys. Rev. 83 (1951) 1148 \\
\hline 163 & ${ }^{10} \mathrm{~B}\left(\mathrm{n}, \mathrm{\alpha}_{0}\right) /{ }^{10} \mathrm{~B}\left(\mathrm{n}, \mathrm{\alpha}_{1}\right)$ & Absolute & B. Petree et al. & Phys. Rev. 83 (1951) 1148 \\
\hline 167 & ${ }^{10} \mathrm{~B}(\mathrm{n}, \mathrm{n})$ & Absolute & F.P. Mooring et al. & Nucl. Phys. 82 (1966) 16 \\
\hline 170 & ${ }^{10} \mathrm{~B}(\mathrm{n}, \mathrm{n})$ & Absolute & R.O. Lane et al. & Phys. Rev. C4 (1971) 380 \\
\hline 175 & ${ }^{10} \mathrm{~B}(\mathrm{n}, \mathrm{n})$ & Absolute & H.B. Willard et al. & Phys. Rev. 98 (1955) 669 \\
\hline 178 & ${ }^{10} \mathrm{~B}(\mathrm{n}, \mathrm{n})$ & Absolute & A. Asami, M.C. Moxon & AERE-R-5980 (1969) \\
\hline 180 & ${ }^{10} \mathrm{~B}(\mathrm{n}, \mathrm{tot})$ & Absolute & G.F. Auchampaugh et al. & Nucl. Sci. Eng. 69 (1979) 30 \\
\hline 181 & ${ }^{10} \mathrm{~B}(\mathrm{n}, \mathrm{tot})$ & Absolute & N.G. Nereson & LA-1655 (1954) \\
\hline 182 & ${ }^{10} \mathrm{~B}(\mathrm{n}$, tot $)$ & Absolute & C.K. Bockelman et al. & Phys. Rev. 84 (1951) 69 \\
\hline 183 & ${ }^{10} \mathrm{~B}(\mathrm{n}$, tot $)$ & Absolute & J.H. Coon et al. & Phys. Rev. 88 (1952) 562 \\
\hline 185 & ${ }^{10} \mathrm{~B}(\mathrm{n}$, tot $)$ & Absolute & R.L. Becker, H.H. Barschal & Phys. Rev. 102 (1956) 1384 \\
\hline 185 & ${ }^{10} \mathrm{~B}$ (n,tot) & Absolute & W. Rohrer & Ann. Phys. 10 (1960) 455 \\
\hline 187 & ${ }^{10} \mathrm{~B}(\mathrm{n}, \mathrm{tot})$ & Absolute & F.P. Mooring et al. & Nucl. Phys. 82 (1966) 16 \\
\hline 188 & ${ }^{10} \mathrm{~B}(\mathrm{n}, \mathrm{tot})$ & Absolute & G.J. Saffort et al. & Phys. Rev. 119 (1960) 1291 \\
\hline
\end{tabular}


TABLE 7.2. EXPERIMENTAL DATA FROM GMA DATABASE USED IN R MATRIX MODEL FIT AND EXCLUDED FROM FINAL COMBINED FIT TO AVOID DOUBLE COUNTING (cont.)

\begin{tabular}{|c|c|c|c|c|}
\hline $\begin{array}{l}\text { Data set } \\
\text { number }\end{array}$ & Reaction & Data type & First author(s) & Reference \\
\hline 189 & ${ }^{10} \mathrm{~B}(\mathrm{n}$, tot $)$ & Absolute & H.W. Schmitt et al. & Nucl. Phys. 17 (1960) 109 \\
\hline 190 & ${ }^{10} \mathrm{~B}$ (n,tot) & Absolute & D.J. Huges et al. & WASH-745 (1958) 9 \\
\hline 191 & ${ }^{10} \mathrm{~B}(\mathrm{n}, \mathrm{tot})$ & Absolute & K. Tsukuda, O. Tanaka & Personal communication (1963) \\
\hline 192 & ${ }^{10} \mathrm{~B}(\mathrm{n}$, tot $)$ & Absolute & R.R. Spencer et al. & Nucl. Sci. Eng. 70 (1979) 98 \\
\hline 193 & ${ }^{10} \mathrm{~B}(\mathrm{n}, \mathrm{tot})$ & Absolute & R.R. Spencer et al. & Nucl. Sci. Eng. 70 (1979) 98 \\
\hline 194 & ${ }^{10} \mathrm{~B}(\mathrm{n}, \mathrm{tot})$ & Absolute & K.M. Diment & AERE-R-5224 (1967) \\
\hline 195 & ${ }^{10} \mathrm{~B}(\mathrm{n}, \mathrm{tot})$ & Absolute & K.M. Diment & AERE-R-5224 (1967) \\
\hline 196 & ${ }^{10} \mathrm{~B}(\mathrm{n}$, tot $)$ & Absolute & K.M. Diment & AERE-R-5224 (1967) \\
\hline 198 & ${ }^{6} \operatorname{Li}(\mathrm{n}, \alpha)$ & Absolute & H. Conde et al. & Arkiv Fysik 29 (1965) 45 \\
\hline 202 & ${ }^{6} \operatorname{Li}(\mathrm{n}, \alpha)$ & Shape & C. Renner & DOE-NDC-12 (1978) 233; thesis (1978) \\
\hline 205 & ${ }^{6} \operatorname{Li}(\mathrm{n}, \alpha)$ & Shape & M.S. Coates et al. & 72Vienna (1972) 105 \\
\hline 208 & ${ }^{6} \operatorname{Li}(\mathrm{n}, \mathrm{n})$ & Absolute & A. Asami, M.C. Moxon & 70Helsinki, vol. 1 (1970) 153 \\
\hline 210 & ${ }^{6} \operatorname{Li}(n, n)$ & Absolute & V.P. Alfimenkov et al. & 82Antwerp (1982) 353 \\
\hline 212 & ${ }^{6} \mathrm{Li}(\mathrm{n}, \mathrm{n})$ & Absolute & H. Knitter, M. Coppola & EUR-3454E (1967) \\
\hline 214 & ${ }^{6} \mathrm{Li}(\mathrm{n}, \mathrm{tot})$ & Absolute & H.H. Knitter et al. & EUR-5726E (1977) \\
\hline 214 & ${ }^{6} \mathrm{Li}(\mathrm{n}, \mathrm{n})$ & Absolute & H.H. Knitter et al. & EUR-5726E (1977) \\
\hline 218 & ${ }^{6} \mathrm{Li}(\mathrm{n}, \mathrm{tot})$ & Absolute & A.B. Smith et al. & ANL/NDM-29 (1977) \\
\hline 219 & ${ }^{6} \mathrm{Li}(\mathrm{n}, \mathrm{tot})$ & Absolute & A.B. Smith et al. & ANL/NDM-29 (1977) \\
\hline 220 & ${ }^{6} \mathrm{Li}(\mathrm{n}, \mathrm{tot})$ & Absolute & P. Guenter et al. & ANL/NDM-52 (1980) \\
\hline 221 & ${ }^{6} \mathrm{Li}(\mathrm{n}, \mathrm{tot})$ & Absolute & P. Guenter et al. & ANL/NDM-52 (1980) \\
\hline 222 & ${ }^{6} \mathrm{Li}(\mathrm{n}, \mathrm{tot})$ & Absolute & P. Guenter et al. & ANL/NDM-52 (1980) \\
\hline 223 & ${ }^{6} \operatorname{Li}(\mathrm{n}, \mathrm{n})$ & Absolute & A.B. Smith et al. & Nucl. Phys. A373 (1982) 305 \\
\hline 226 & ${ }^{6} \operatorname{Li}(\mathrm{n}, \alpha)$ & Shape & H. Conde et al. & 82Antwerp (1982) 447 \\
\hline 229 & ${ }^{6} \mathrm{Li}(\mathrm{n}, \mathrm{tot})$ & Absolute & J.W. Meadows, J.F. Whalen & Nucl. Sci. Eng. 48 (1975) 221 \\
\hline 232 & ${ }^{6} \operatorname{Li}(n, \alpha)$ & Shape & G.P. Lamaze et al. & Nucl. Sci. Eng. 68 (1978) 183 \\
\hline 235 & ${ }^{6} \mathrm{Li}(\mathrm{n}, \mathrm{tot})$ & Absolute & C.A. Uttley et al. & 70ANL (1970) 80 \\
\hline 238 & ${ }^{6} \operatorname{Li}(\mathrm{n}, \alpha)$ & Absolute & C.M. Bartle & Nucl. Phys. A330 (1979) 1 \\
\hline 241 & ${ }^{6} \operatorname{Li}(\mathrm{n}, \alpha)$ & Absolute & W.P. Poenitz, J.W. Meadows & 72Vienna (1972) 95 \\
\hline 246 & ${ }^{6} \operatorname{Li}(n, \alpha)$ & Shape & S.J. Friesehnahn et al. & INTERL-RT-7011-001 (1974) \\
\hline 253 & ${ }^{6} \operatorname{Li}(\mathrm{n}, \mathrm{n})$ & Absolute & R.O. Lane & Ann. Phys. 12 (1961) 135 \\
\hline 254 & ${ }^{6} \operatorname{Li}(\mathrm{n}, \mathrm{n})$ & Absolute & R.O. Lane & Ann. Phys. 12 (1961) 135 \\
\hline 255 & ${ }^{6} \mathrm{Li}(\mathrm{n}, \mathrm{n})$ & Absolute & R.O. Lane & Ann. Phys. 12 (1961) 135 \\
\hline 257 & ${ }^{6} \mathrm{Li}(\mathrm{n}, \mathrm{tot})$ & Absolute & C.A. Goulding et al. & USNDC-3 (1972) 161 \\
\hline 274 & ${ }^{6} \mathrm{Li}(\mathrm{n}, \mathrm{tot})$ & Absolute & J. Harvey, N. Hill & $\begin{array}{l}\text { 75Washington }(1975) 244 \text {; personal } \\
\text { communication }(1976,1981)\end{array}$ \\
\hline 275 & ${ }^{6} \mathrm{Li}(\mathrm{n}, \mathrm{tot})$ & Absolute & J. Harvey, N. Hill & $\begin{array}{l}\text { 75Washington }(1975) \text { 244; personal } \\
\text { communication }(1976,1981)\end{array}$ \\
\hline 276 & ${ }^{6} \mathrm{Li}(\mathrm{n}, \mathrm{tot})$ & Absolute & J. Harvey, N. Hill & $\begin{array}{l}\text { 75Washington }(1975) 244 ; \text { personal } \\
\text { communication }(1976,1981)\end{array}$ \\
\hline 277 & ${ }^{6} \mathrm{Li}(\mathrm{n}, \mathrm{tot})$ & Absolute & J. Harvey, N. Hill & $\begin{array}{l}\text { 75Washington }(1975) 244 ; \text { personal } \\
\text { communication }(1976,1981)\end{array}$ \\
\hline 280 & ${ }^{6} \operatorname{Li}(\mathrm{n}, \alpha)$ & Shape & P.J. Clements, I.C. Ricard & AERE-R7075 (1972) \\
\hline
\end{tabular}


TABLE 7.2. EXPERIMENTAL DATA FROM GMA DATABASE USED IN R MATRIX MODEL FIT AND EXCLUDED FROM FINAL COMBINED FIT TO AVOID DOUBLE COUNTING (cont.)

\begin{tabular}{|c|c|c|c|c|}
\hline $\begin{array}{l}\text { Data set } \\
\text { number }\end{array}$ & Reaction & Data type & First author(s) & Reference \\
\hline 281 & ${ }^{6} \operatorname{Li}(\mathrm{n}, \alpha)$ & Shape & P.J. Clements, I.C. Ricard & AERE-R7075 (1972) \\
\hline 285 & ${ }^{6} \operatorname{Li}(\mathrm{n}, \alpha)$ & Absolute & J.W. Overley & Personal communication (1976) \\
\hline 290 & ${ }^{6} \operatorname{Li}(\mathrm{n}, \alpha)$ & Shape & E. Fort, J.P. Marquette & EANDC(E)-148 (1972) \\
\hline 291 & ${ }^{6} \operatorname{Li}(\mathrm{n}, \alpha)$ & Shape & E. Fort, J.P. Marquette & EANDC(E)-148 (1972) \\
\hline 292 & ${ }^{6} \operatorname{Li}(\mathrm{n}, \alpha)$ & Shape & E. Fort, J.P. Marquette & EANDC(E)-148 (1972) \\
\hline 294 & ${ }^{6} \operatorname{Li}(\mathrm{n}, \alpha)$ & Shape & E. Fort & 70Helsinki, vol. 1 (1970) 253 \\
\hline 702 & ${ }^{6} \operatorname{Li}(\mathrm{n}, \alpha)$ & Absolute & W.P. Poenitz, N.E. Holden & BNL-NCS-51388 (1981) \\
\hline 703 & 10Bi(n,a) & Absolute & J.W. Meadows & 70ANL (1971) 129 \\
\hline 706 & ${ }^{10} \mathrm{~B}\left(\mathrm{n}, \mathrm{\alpha}_{0}\right) /{ }^{10} \mathrm{~B}\left(\mathrm{n}, \alpha_{1}\right)$ & Absolute & W.P. Poenitz & $\begin{array}{l}\text { Personal communication, pre-evaluation } \\
\text { (1984) }\end{array}$ \\
\hline 707 & ${ }^{6} \operatorname{Li}(\mathrm{n}, \alpha)$ & Absolute & J.W. Meadows & 70ANL (1971) 129 \\
\hline 708 & ${ }^{10} \mathrm{~B}(\mathrm{n}, \alpha)$ & Absolute & G.H. Debus et al. & J. Nucl. Energy 21 (1967) 37 \\
\hline 1011 & ${ }^{6} \operatorname{Li}(\mathrm{n}, \alpha)$ & Absolute & M. Drosg et al. & $\begin{array}{l}\text { Nucl. Instrum. Meth. Phys. Res. B94 (1994) } \\
319\end{array}$ \\
\hline 1015 & ${ }^{10} \mathrm{~B}\left(\mathrm{n}, \alpha_{0}\right) /{ }^{10} \mathrm{~B}\left(\mathrm{n}, \alpha_{1}\right)$ & Absolute & F.-J. Hambsch et al. & Personal communication (2004) \\
\hline 1033 & ${ }^{10} \mathrm{~B}\left(\mathrm{n}, \alpha_{1}\right)$ & Shape & R.A. Schrack et al. & Personal communication (2003) \\
\hline 1034 & ${ }^{10} \mathrm{~B}\left(\mathrm{n}, \alpha_{1}\right)$ & Shape & R.A. Schrack et al. & 94Gatlinburg, vol. 1 (1994) 43 \\
\hline 1039 & ${ }^{10} \mathrm{~B}(\mathrm{n}$, tot $)$ & Absolute & O.A. Wasson et al. & 94Gatlinburg, vol. 1 (1994) 50 \\
\hline 1040 & ${ }^{10} \mathrm{~B}$ (n,tot) & Absolute & O.A. Wasson et al. & 94Gatlinburg, vol. 1 (1994) 50 \\
\hline
\end{tabular}

TABLE 7.3. TOTAL NUMBER OF DATA SETS FOR REACTIONS (VALUES SHOWN AT THE DIAGONAL) AND THEIR RATIOS (OFF-DIAGONAL VALUES) IN THE GMA DATABASE

(values in brackets are the number of data sets with absolute cross-sections)

\begin{tabular}{|c|c|c|c|c|c|c|c|c|c|}
\hline & ${ }^{6} \operatorname{Li}(\mathrm{n}, \alpha)$ & ${ }^{10} \mathrm{~B}\left(\mathrm{n}, \mathrm{\alpha}_{0}\right)$ & ${ }^{10} \mathrm{~B}\left(\mathrm{n}, \alpha_{1}\right)$ & ${ }^{10} \mathrm{~B}(\mathrm{n}, \alpha)$ & $\mathrm{Au}(\mathrm{n}, \gamma)$ & ${ }^{238} \mathrm{U}(\mathrm{n}, \gamma)$ & ${ }^{235} \mathrm{U}(\mathrm{n}, \mathrm{f})$ & ${ }^{239} \mathrm{Pu}(\mathrm{n}, \mathrm{f})$ & ${ }^{238} \mathrm{U}(\mathrm{n}, \mathrm{f})$ \\
\hline${ }^{6} \operatorname{Li}(\mathrm{n}, \alpha)$ & $18(7)$ & & & & & & & & \\
\hline${ }^{10} \mathrm{~B}\left(\mathrm{n}, \mathrm{\alpha}_{0}\right)$ & 0 & $5(4)$ & & & & & & & \\
\hline${ }^{10} \mathrm{~B}\left(\mathrm{n}, \alpha_{1}\right)$ & $1(0)$ & $12(10)$ & $11(2)$ & & & & & & \\
\hline${ }^{10} \mathrm{~B}(\mathrm{n}, \alpha)$ & $4(0)$ & 0 & 0 & $5(2)$ & & & & & \\
\hline $\mathrm{Au}(\mathrm{n}, \gamma)$ & $3(3)$ & 0 & $6(3)$ & $4(4)$ & $27(21)$ & & & & \\
\hline${ }^{238} \mathrm{U}(\mathrm{n}, \gamma)$ & $2(2)$ & 0 & $9(5)$ & $4(4)$ & $10(9)$ & $14(11)$ & & & \\
\hline${ }^{235} \mathrm{U}(\mathrm{n}, \mathrm{f})$ & $14(0)$ & 0 & $2(1)$ & $25(0)$ & $12(10)$ & $12(6)$ & $68(52)$ & & \\
\hline${ }^{239} \mathrm{Pu}(\mathrm{n}, \mathrm{f})$ & $2(0)$ & 0 & 0 & $19(0)$ & 0 & $1(0)$ & $19(14)$ & 22 (19) & \\
\hline${ }^{238} \mathrm{U}(\mathrm{n}, \mathrm{f})$ & $2(1)$ & 0 & 0 & 0 & 0 & 0 & 34 (29) & $3(1)$ & $18(11)$ \\
\hline
\end{tabular}

TABLE 7.4. TOTAL NUMBER OF DATA SETS WITH ABSOLUTE CROSS-SECTIONS IN THE GMA DATABASE FOR REACTIONS THAT CAN BE USED AS CONSTRAINTS

\begin{tabular}{lccc}
\hline${ }^{6} \mathrm{Li}(\mathrm{n}, \mathrm{n})$ & ${ }^{6} \mathrm{Li}(\mathrm{n}$, tot $)$ & ${ }^{10} \mathrm{~B}(\mathrm{n}, \mathrm{n})$ & ${ }^{10} \mathrm{~B}(\mathrm{n}$, tot $)$ \\
\hline 8 & 13 & 4 & 18 \\
\hline
\end{tabular}


pertinent puzzle (PPP) (see Section 6) also cannot be excluded. Finally, independent studies with two $\mathrm{R}$ matrix codes (EDA and RAC) and analyses of these results reduced previous ambiguities and resulted in a more reliable evaluation.

Results for the ${ }^{10} \mathrm{~B}\left(\mathrm{n}, \alpha_{1}\right)$ and ${ }^{10} \mathrm{~B}\left(\mathrm{n}, \alpha_{0}\right)$ reaction cross-sections and their ratios, together with the ratios of the present to the previous evaluations, are shown in Figs 7.9-7.26. The following values were obtained at $0.0253 \mathrm{eV}: 241.693 \pm 0.596 \mathrm{~b}$ for the ${ }^{10} \mathrm{~B}\left(\mathrm{n}, \alpha_{0}\right)$ reaction, and $3600.86 \pm 2.96 \mathrm{~b}$ for the ${ }^{10} \mathrm{~B}\left(\mathrm{n}, \alpha_{1}\right)$ reaction. These values give a ${ }^{10} \mathrm{~B}\left(\mathrm{n}, \alpha_{0}\right)$ to ${ }^{10} \mathrm{~B}\left(\mathrm{n}, \alpha_{1}\right)$ branching ratio of $0.06712 \pm 0.00022$. As is the case for the ${ }^{6} \mathrm{Li}(\mathrm{n}, \alpha)$ reaction, the large differences (greater than the evaluated uncertainties) compared with the results of the previous evaluation are due to an analysis in which the ambiguity of the $\mathrm{R}$ matrix fit was reduced. Furthermore, a more realistic account of the uncertainties in the experimental data and inclusion of new data obtained with the Frisch gridded ionization chamber (FGIC) gave more accurate evaluations free from distortion due to particle leakage [7.6]. The upper energy for both the ${ }^{10} \mathrm{~B}\left(\mathrm{n}, \alpha_{1}\right)$ and ${ }^{10} \mathrm{~B}(\mathrm{n}, \alpha)$ standard reactions should be extended up to $1 \mathrm{MeV}$. Comparison of the newly evaluated neutron elastic scattering cross-sections with the previous evaluation and with the experimental data is shown in Figs 7.27 and 7.28. Although all the experimental data shown in Figs 7.1-7.28 are part of the GMA database, to avoid double counting they were not used in the combined fit because they had been included in the $\mathrm{R}$ matrix analysis.

Comparison of the newly evaluated $\mathrm{Au}(\mathrm{n}, \gamma)$ cross-sections with the previous evaluation and the experimental data is shown in Figs 7.29-7.34. Note that ' $\mathrm{Au}$ ' is equivalent to ${ }^{197} \mathrm{Au}$ ', since this element is mono-isotopic. The evaluated cross-section at a neutron energy of $0.0253 \mathrm{eV}$ is $98.66 \pm 0.14 \mathrm{~b}$. Generally, the newly recommended cross-sections are slightly higher than those of the previous evaluation. The uncertainties for this standard $\mathrm{Au}(\mathrm{n}, \gamma)$ reaction are higher than for the neutron reactions with ${ }^{6} \mathrm{Li}$ and ${ }^{10} \mathrm{~B}$, but show greater consistency with the previous evaluation. The ratio of the two evaluations is not smooth because, owing to the bug in the old GMA code, not all experimental data sets were accounted for in the old evaluation and the new evaluation gives smoothed values for some energy regions. It is recommended that the cross-sections in the energy range $0.2-2.5 \mathrm{MeV}$ and the thermal value be considered as standards.
Figures $7.35-7.40$ compare the newly evaluated ${ }^{238} \mathrm{U}(\mathrm{n}, \gamma)$ reaction cross-sections with the previous evaluation and the experimental data. The evaluated cross-section at a neutron energy of $0.0253 \mathrm{eV}$ is $2.6771 \pm 0.0123 \mathrm{~b}$, and is strongly influenced by the value of $2.683 \pm 0.013 \mathrm{~b}$ used in the combined final fit [7.7]. Differences occur between these data and the earlier evaluation for the same reasons as discussed for the $\mathrm{Au}(\mathrm{n}, \gamma)$ reaction.

The largest amount of experimental data in the GMA database is for the ${ }^{235} \mathrm{U}(\mathrm{n}, \mathrm{f})$ reaction. Figures 7.41-7.47 compare the newly evaluated cross-sections with the previous GMA evaluation (ENDF/B-VI) below $20 \mathrm{MeV}$ [7.2] and with the previous high energy standard [7.3]. Overall, the new evaluation is consistent with the previous data except in the energy ranges $1.2-5.4 \mathrm{MeV}$ and $14-36 \mathrm{MeV}$, where the new data are higher. Comparisons of the new cross-section evaluation with experimental data and the ratio of this evaluation to the earlier one are shown in Figs 7.487.62. There is some fine structure in the fission cross-section near $1 \mathrm{MeV}$, which has a physical meaning and is supported by the combined fit of all cross-sections and their ratios. Most of the experimental data are consistent with the evaluation, particularly the most recent highly precise measurements. Discrepant outlying data are mainly old measurements with low uncertainties. Increasing the uncertainties of these data reduces the $\chi^{2}$ per degree of freedom to close to unity without significantly increasing the evaluated uncertainties of the recommended cross-section standards. This crosssection is recommended as a standard from 0.15 to $200 \mathrm{MeV}$ and at thermal neutron energies.

Figures 7.63-7.72 compare the newly evaluated data for the ${ }^{239} \mathrm{Pu}(\mathrm{n}, \mathrm{f})$ reaction crosssections with the previous evaluation and the experimental data. Although not used as a standard, this reaction is included in the GMA fit because of the large amount of experimental data and measured ratios relative to the ${ }^{235} \mathrm{U}(\mathrm{n}, \mathrm{f})$ and other reactions. The new cross-section evaluation is higher than the previous one at virtually all energies, reaching a maximum difference of $6-8 \%$ at $14-20 \mathrm{MeV}$. As a consequence of the simultaneous fitting of many coupled reactions, the uncertainty in the evaluated data is close to the uncertainty obtained for the standard ${ }^{235} \mathrm{U}(\mathrm{n}, \mathrm{f})$ reaction.

Figures 7.73-7.80 compare the newly evaluated data for the standard ${ }^{238} \mathrm{U}(\mathrm{n}, \mathrm{f})$ reaction with the previous evaluation for energies below $20 \mathrm{MeV}$ and the previous high energy standard for 
energies above $20 \mathrm{MeV}$, and with the experimental data. The same trends are observed as for the other fission reactions discussed above. The recommended neutron energy range for this particular fission standard is 2-200 MeV. Strong near threshold energy dependence and the small number of nodes used in the evaluation prevent its use at neutron energies below $2 \mathrm{MeV}$.

\subsection{CROSS-SECTION RATIOS}

The cross-section ratios that contribute substantially to the evaluation are shown in Figs 7.81-7.123. There are still large differences between the results of the ratio measurements of fission cross-sections at high energies that need to be explained in order to decrease the uncertainties of the evaluations. New high precision absolute crosssection measurements are necessary in this energy region to reduce the uncertainty of the standards for energies above $14 \mathrm{MeV}$. The evaluated cross-section ratio for ${ }^{238} \mathrm{U}(\mathrm{n}, \gamma) / \mathrm{Au}(\mathrm{n}, \gamma)$ is systematically higher for virtually all experimental data at neutron energies below $0.4 \mathrm{MeV}$. The reason for the discrepancy between the absolute cross-sections and ratio measurements for these two reactions is unclear. Some ratio measurements may be biased because of the difficulties in detecting all the gamma rays emitted by the ${ }^{238} \mathrm{U}(\mathrm{n}, \gamma)$ and $\mathrm{Au}(\mathrm{n}, \gamma)$ reactions.

\subsection{THERMAL CONSTANTS}

The thermal constants for the most important uranium and plutonium isotopes were taken from the Axton evaluation [7.5]. The GMA database was updated with the new high precision value of the thermal scattering cross-section determined by Arif et al. [7.8] and greater weighting was assigned to the fission neutron yield microscopic measurements by Gwin et al. [7.9]. The results of the evaluation of the thermal constants are compared with previous values in Table 7.5, for which the following abbreviations have been adopted [7.5]:

GA-U3: $g$ factor for the absorption (capture and fission) cross-section in ${ }^{233} \mathrm{U}$.

GF-U3: $g$ factor for the fission cross-section of ${ }^{233} \mathrm{U}$.

SS-U3: elastic scattering cross-section of ${ }^{233} \mathrm{U}$.
SF-U3: fission cross-section of ${ }^{233} \mathrm{U}$.

SG-U3: capture cross-section of ${ }^{233} \mathrm{U}$.

NU-U3: total fission neutron yield of ${ }^{233} \mathrm{U}$.

GA-U5: $g$ factor for the absorption (capture and fission) cross-section of ${ }^{235} \mathrm{U}$.

GF-U5: $\mathrm{g}$ factor for the fission cross-section of ${ }^{235} \mathrm{U}$.

SS-U5: elastic scattering cross-section of ${ }^{235} \mathrm{U}$.

SF-U5: fission cross-section of ${ }^{235} \mathrm{U}$.

SG-U5: capture cross-section of ${ }^{235} \mathrm{U}$.

NU-U5: total fission neutron yield of ${ }^{235} \mathrm{U}$.

GA-PU9: $g$ factor for the absorption (capture and fission) cross-section of ${ }^{239} \mathrm{Pu}$.

GF-PU9: $\mathrm{g}$ factor for the fission cross-section of ${ }^{239} \mathrm{Pu}$.

SS-PU9: elastic scattering cross-section of ${ }^{239} \mathrm{Pu}$.

SF-PU9: fission cross-section of ${ }^{239} \mathrm{Pu}$.

SG-PU9: capture cross-section of ${ }^{239} \mathrm{Pu}$.

NU-PU9: total fission neutron yield of ${ }^{239} \mathrm{Pu}$.

GA-PU1: $\mathrm{g}$ factor for the absorption (capture and fission) cross-section of ${ }^{241} \mathrm{Pu}$.

GF-PU1: $\mathrm{g}$ factor for the fission cross-section of ${ }^{241} \mathrm{Pu}$.

SS-PU1: elastic scattering cross-section of ${ }^{241} \mathrm{Pu}$.

SF-PU1: fission cross-section of ${ }^{241} \mathrm{Pu}$.

SG-PU1: capture cross-section of ${ }^{241} \mathrm{Pu}$.

NU-PU1: total fission neutron yield of ${ }^{241} \mathrm{Pu}$.

NU-CF2: total fission neutron yield of ${ }^{252} \mathrm{Cf}$.

The largest changes from the earlier evaluations are observed for the thermal neutron elastic scattering and fission cross-sections. The 
TABLE 7.5. COMPARISON OF THE THERMAL CONSTANTS (NEUTRON ENERGY OF 0.0253 eV) OBTAINED FROM THE COMBINED FIT OF THE STANDARD CROSS-SECTIONS WITH THE AXTON VALUES [7.5]

\begin{tabular}{|c|c|c|c|c|c|}
\hline & Constant & New evaluation ${ }^{a}$ & $\begin{array}{c}\text { Uncertainty of } \\
\text { new evaluation }\end{array}$ & Axton value ${ }^{a}$ & $\begin{array}{c}\text { Ratio of new to } \\
\text { previous evaluation }\end{array}$ \\
\hline 1 & GA-U3 & 0.99959 & 0.00110 & 0.9995 & 1.0001 \\
\hline 2 & GF-U3 & 0.99563 & 0.00139 & 0.9955 & 1.0001 \\
\hline 3 & SS-U3 & $12.11 b$ & $0.66 \mathrm{~b}$ & $12.19 \mathrm{~b}$ & 0.9934 \\
\hline 4 & SF-U3 & $531.22 \mathrm{~b}$ & $1.31 \mathrm{~b}$ & $530.7 \mathrm{~b}$ & 1.0010 \\
\hline 5 & SG-U3 & $45.558 \mathrm{~b}$ & $0.682 \mathrm{~b}$ & $45.52 \mathrm{~b}$ & 1.0008 \\
\hline 6 & NU-U3 & 2.4968 & 0.0035 & 2.495 & 1.0007 \\
\hline 7 & GA-U5 & 0.97881 & 0.00078 & 0.9789 & 0.9999 \\
\hline 8 & GF-U5 & 0.97729 & 0.00078 & 0.9774 & 0.9999 \\
\hline 9 & SS-U5 & $14.087 \mathrm{~b}$ & $0.2197 \mathrm{~b}$ & $15.98 \mathrm{~b}$ & 0.8815 \\
\hline 10 & SF-U5 & $584.33 \mathrm{~b}$ & $1.02 \mathrm{~b}$ & $582.8 \mathrm{~b}$ & 1.0026 \\
\hline 11 & SG-U5 & $99.401 \mathrm{~b}$ & $0.719 \mathrm{~b}$ & $99.05 \mathrm{~b}$ & 1.0035 \\
\hline 12 & NU-U5 & 2.4355 & 0.0023 & 2.433 & 1.0010 \\
\hline 13 & GA-PU9 & 1.0780 & 0.0024 & 1.078 & 1.0000 \\
\hline 14 & GF-PU9 & 1.0554 & 0.0022 & 1.056 & 0.9994 \\
\hline 15 & SS-PU9 & $7.8000 \mathrm{~b}$ & $0.9592 \mathrm{~b}$ & $7.897 \mathrm{~b}$ & 0.9877 \\
\hline 16 & SF-PU9 & $750.00 \mathrm{~b}$ & $1.83 \mathrm{~b}$ & $747.6 \mathrm{~b}$ & 1.0032 \\
\hline 17 & SG-PU9 & $271.50 \mathrm{~b}$ & $2.14 \mathrm{~b}$ & $271.3 \mathrm{~b}$ & 1.0007 \\
\hline 18 & NU-PU9 & 2.8836 & 0.0047 & 2.882 & 1.0006 \\
\hline 19 & GA-PU1 & 1.0440 & 0.0020 & 1.044 & 1.0000 \\
\hline 20 & GF-PU1 & 1.0454 & 0.0055 & 1.045 & 1.0004 \\
\hline 21 & SS-PU1 & $12.13 \mathrm{~b}$ & $2.61 \mathrm{~b}$ & $12.19 \mathrm{~b}$ & 0.9951 \\
\hline 22 & SF-PU1 & $1013.96 \mathrm{~b}$ & $6.56 \mathrm{~b}$ & 1012 b & 1.0019 \\
\hline 23 & SG-PU1 & $361.79 \mathrm{~b}$ & $4.95 \mathrm{~b}$ & $361.3 \mathrm{~b}$ & 1.0014 \\
\hline 24 & NU-PU1 & 2.9479 & 0.0054 & 2.946 & 1.0006 \\
\hline 25 & NU-CF2 & 3.7692 & 0.0047 & 3.768 & 1.0003 \\
\hline
\end{tabular}

a factors and fission yields are dimensionless; cross-sections are expressed in barns (b).

correlation matrix of the thermal constants obtained in the final combined fit with GMA is shown in Table 7.6; little change occurred compared with the values of Axton [7.5].

\subsection{ADDITIONAL REMARKS}

Further improvements in the standards evaluation would require a more realistic consideration of the uncertainties of the experimental data in the $\mathrm{R}$ matrix fit, in particular accounting for cross-angular and cross-energy correlations in the experimental angular distributions. Reduction of discrepancies between different types of data (e.g. between ${ }^{238} \mathrm{U}(\mathrm{n}, \gamma), \mathrm{Au}(\mathrm{n}, \gamma)$ and $\left.{ }^{238} \mathrm{U}(\mathrm{n}, \gamma) / \mathrm{Au}(\mathrm{n}, \gamma)\right)$ will decrease the uncertainty of the evaluations and hence increase their reliability. Improvements in the experimental database, particularly for the boron cross-sections and the fission cross-sections at high neutron energies, should also be made. 


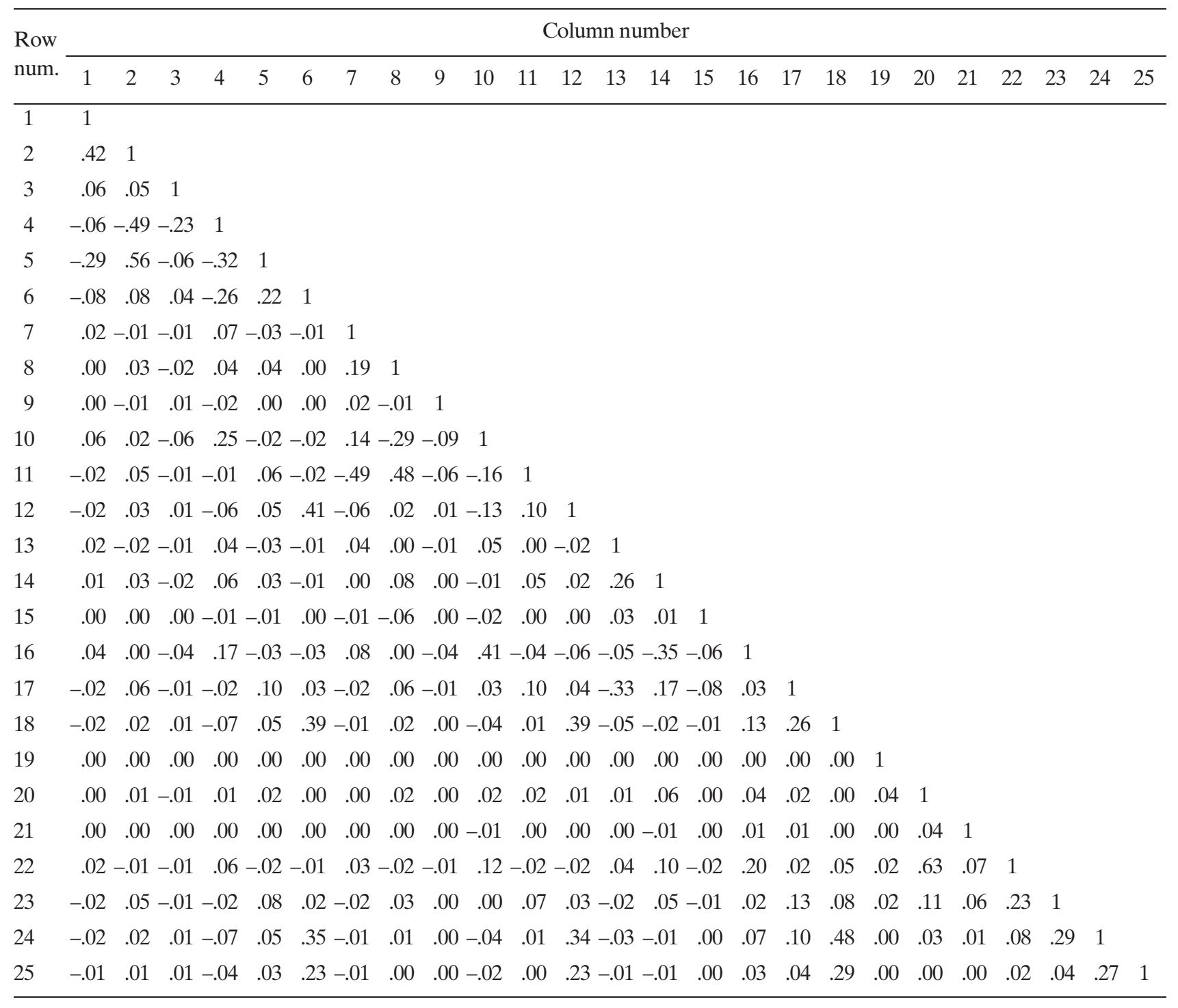




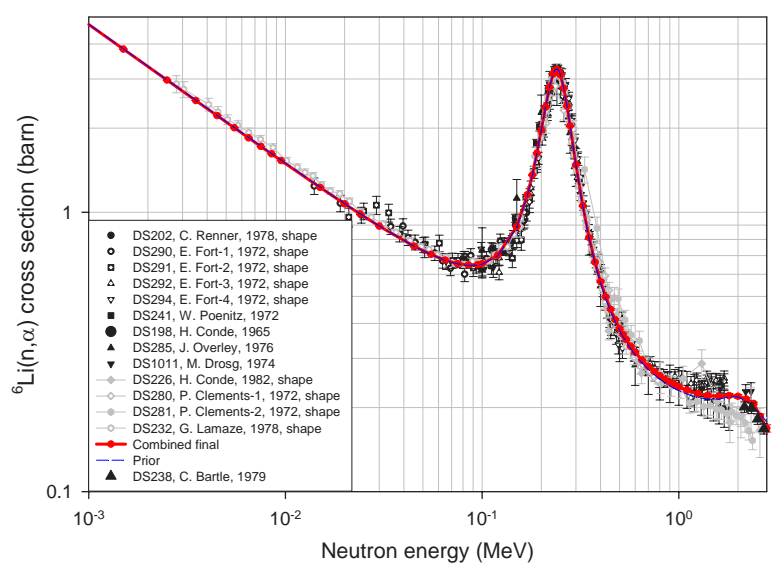

FIG. 7.1. Comparison of present and prior evaluations, together with experimental data for the ${ }^{6} \mathrm{Li}(n, \alpha)$ reaction.

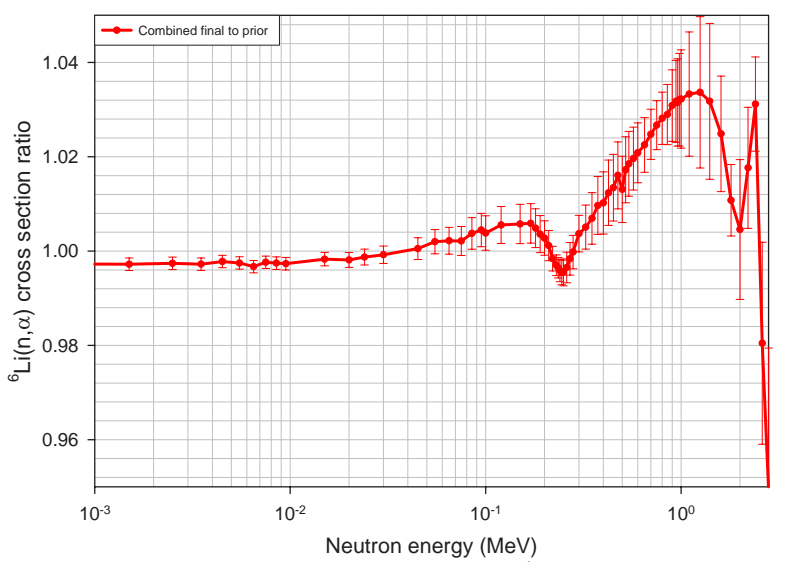

FIG. 7.2. Ratio of present to prior evaluations for the ${ }^{6} \mathrm{Li}(n, \alpha)$ reaction.

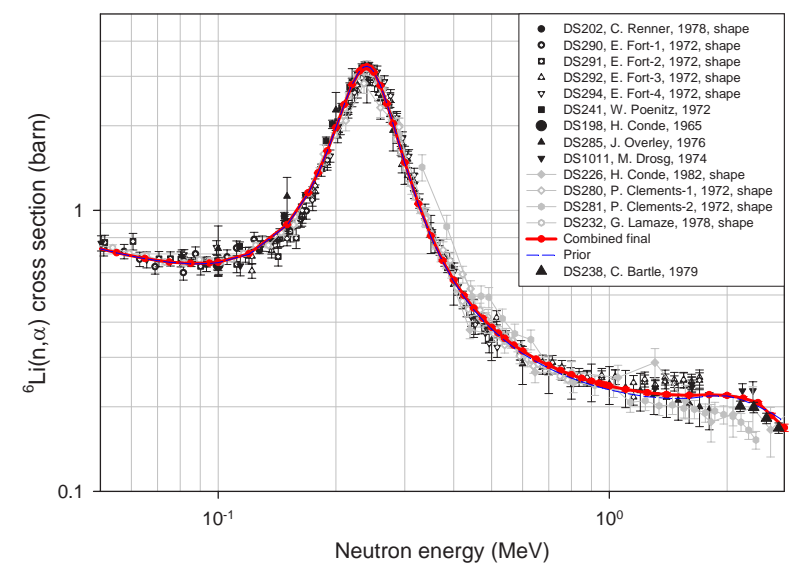

FIG. 7.3. Expanded view of data in Fig. 7.1 for the energy range $0.05-2.8 \mathrm{MeV}$.

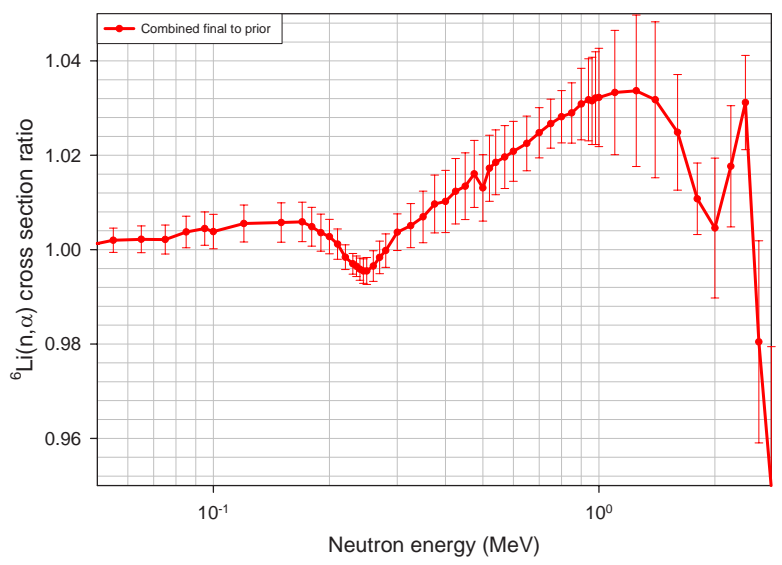

FIG. 7.4. Expanded view of data in Fig. 7.2 for the energy range $0.05-2.8 \mathrm{MeV}$.

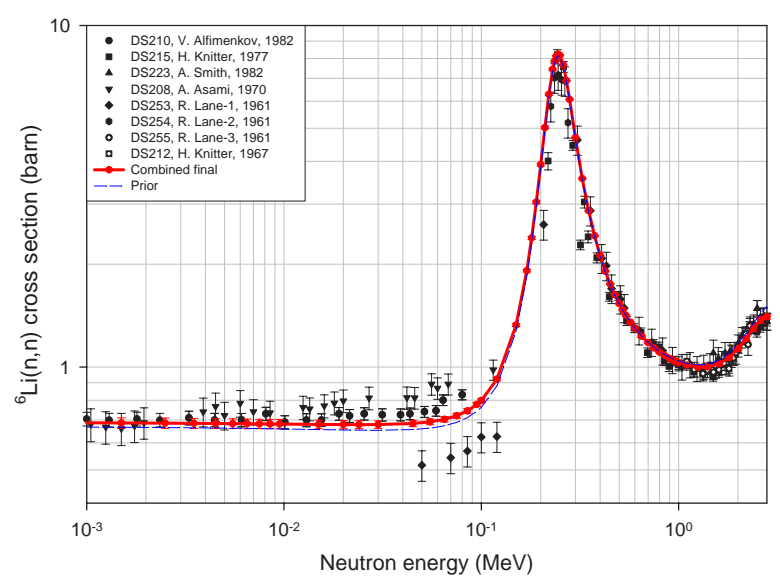

FIG. 7.5. Comparison of present and prior evaluations, together with experimental data for the ${ }^{6} \mathrm{Li}(n, n)$ reaction.

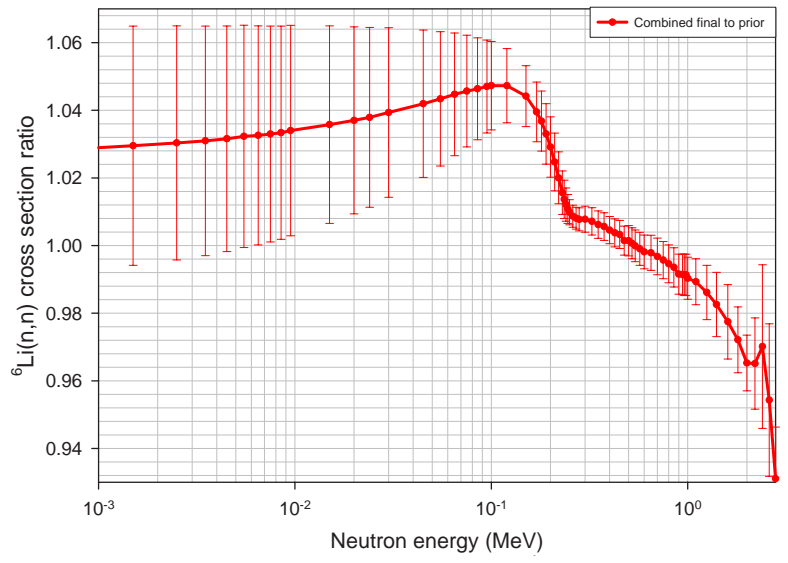

FIG. 7.6. Ratio of present to prior evaluations for the ${ }^{6} \mathrm{Li}(n, n)$ reaction. 


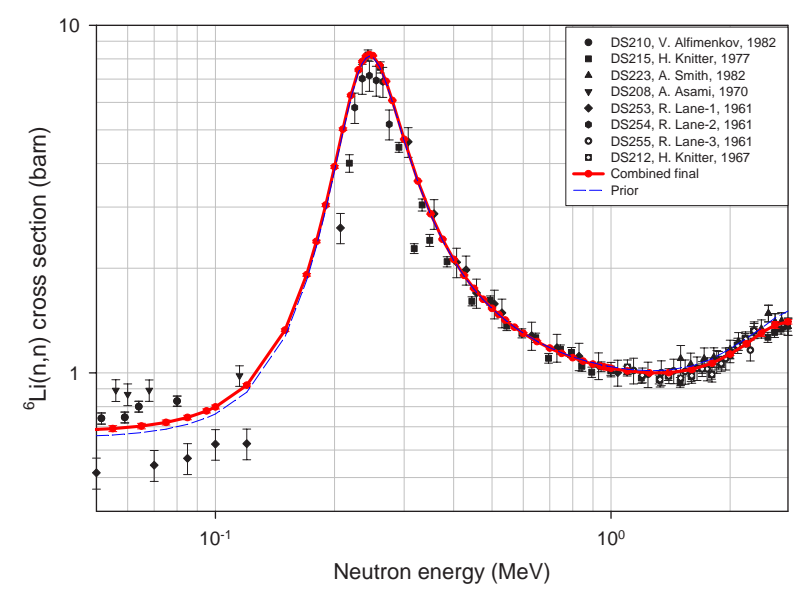

FIG. 7.7. Expanded view of data in Fig. 7.5 for the energy range $0.05-2.8 \mathrm{MeV}$.

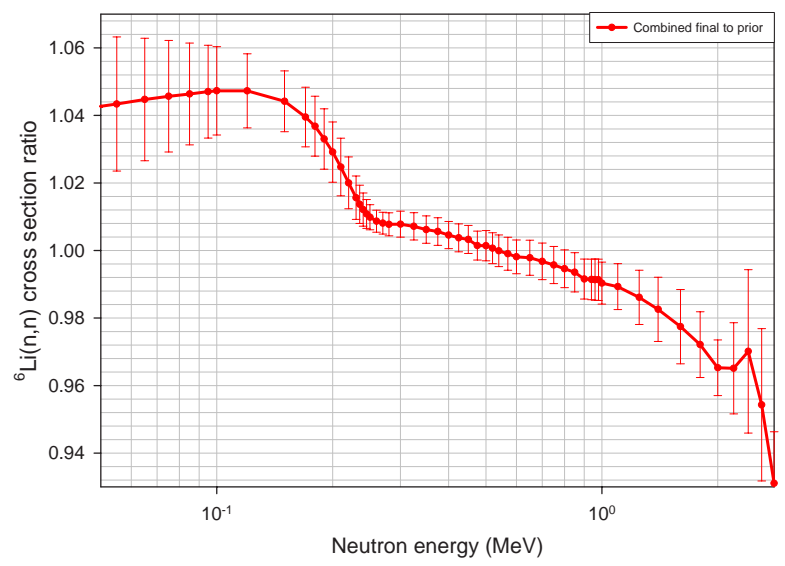

FIG. 7.8. Expanded view of data in Fig. 7.6 for the energy range $0.05-2.8 \mathrm{MeV}$.

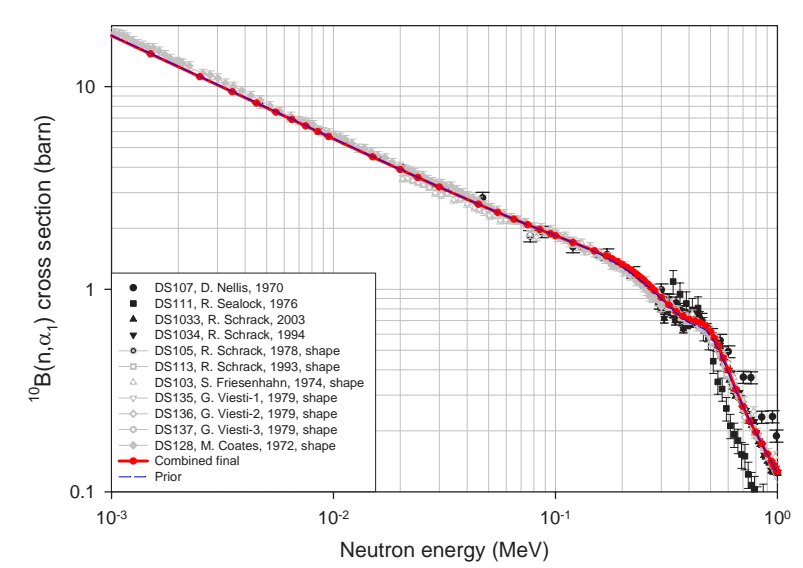

FIG. 7.9. Comparison of present and prior evaluations, together with experimental data for the ${ }^{10} B\left(n, \alpha_{1}\right)$ reaction.

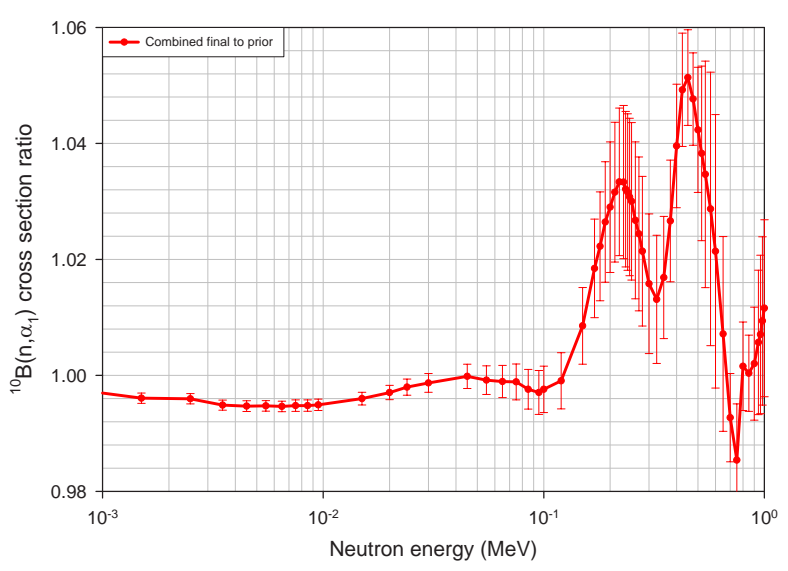

FIG. 7.10. Ratio of present to prior evaluations for the ${ }^{10} B\left(n, \alpha_{1}\right)$ reaction.

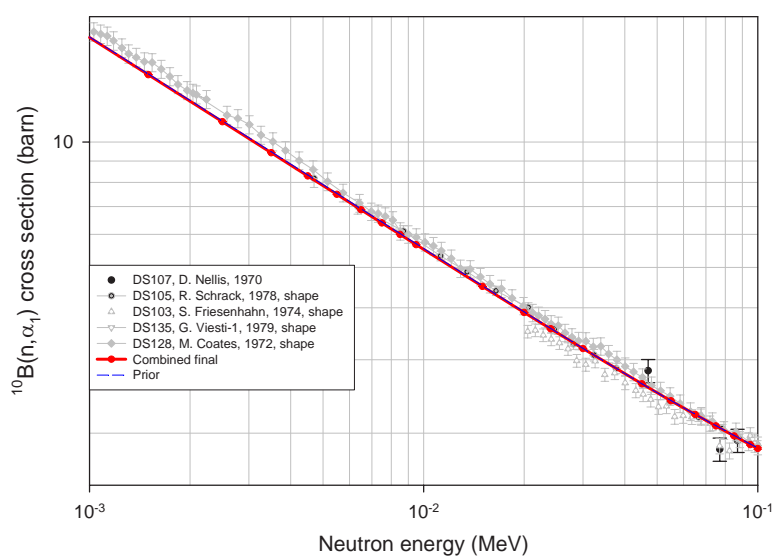

FIG. 7.11. Expanded view of data in Fig. 7.9 for the energy range $0.001-0.1 \mathrm{MeV}$.

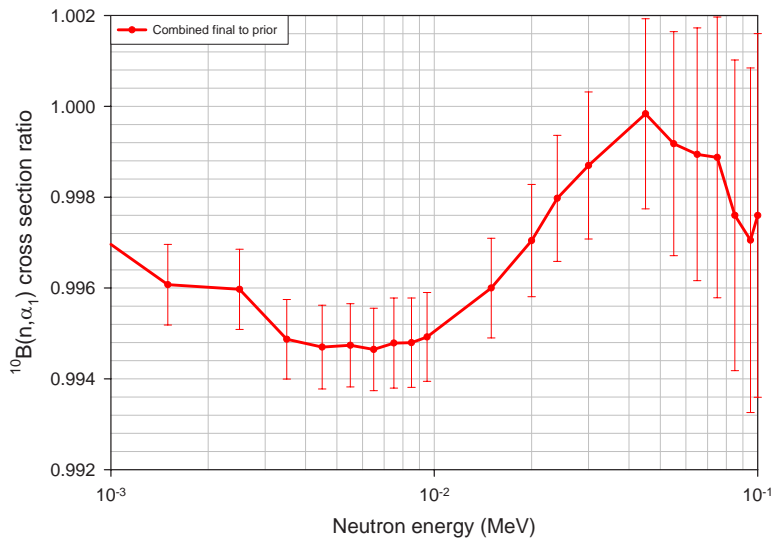

FIG. 7.12. Expanded view of data in Fig. 7.10 for the energy range 0.001-0.1 MeV. 


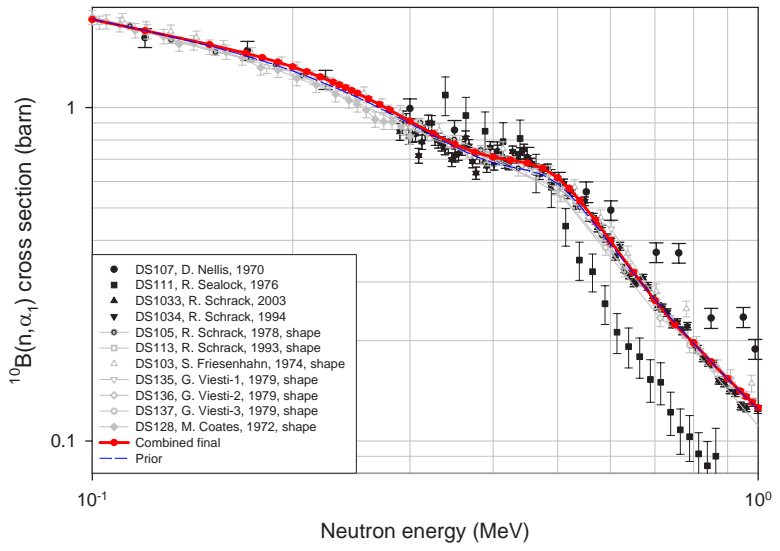

FIG. 7.13. Expanded view of data in Fig. 7.9 for the energy range 0.1-1 $\mathrm{MeV}$.

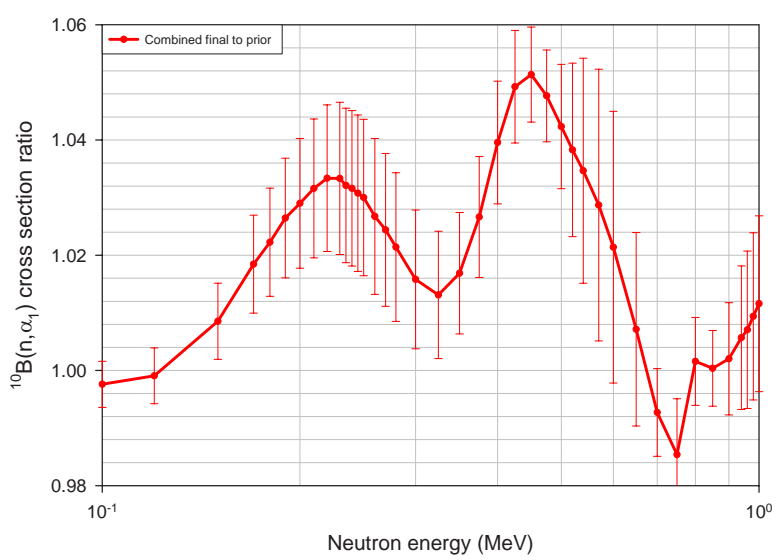

FIG. 7.14. Expanded view of data in Fig. 7.10 for the energy range $0.1-1 \mathrm{MeV}$.

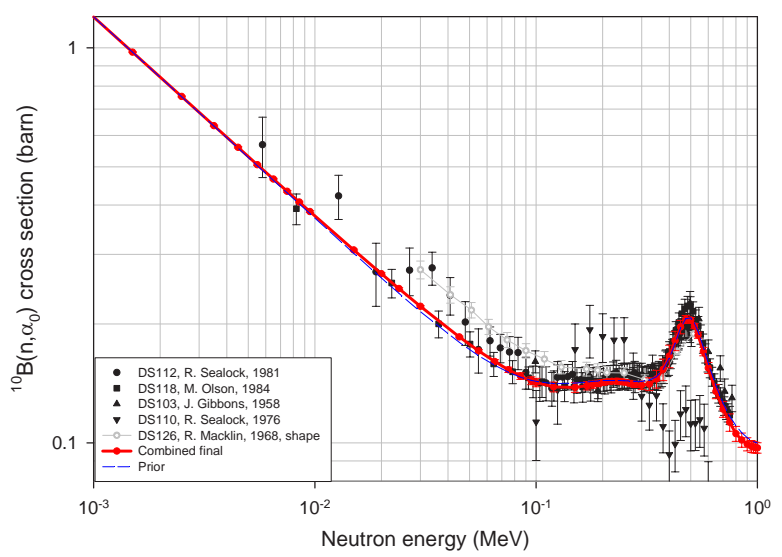

FIG. 7.15. Comparison of present and prior evaluations, together with experimental data for the ${ }^{10} B\left(n, \alpha_{0}\right)$ reaction.

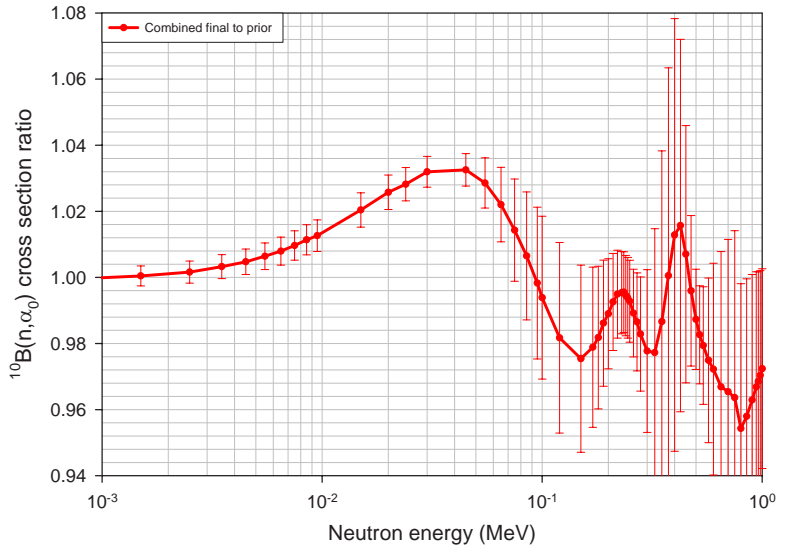

FIG. 7.16. Ratio of present to prior evaluations for the ${ }^{10} B\left(n, \alpha_{0}\right)$ reaction.

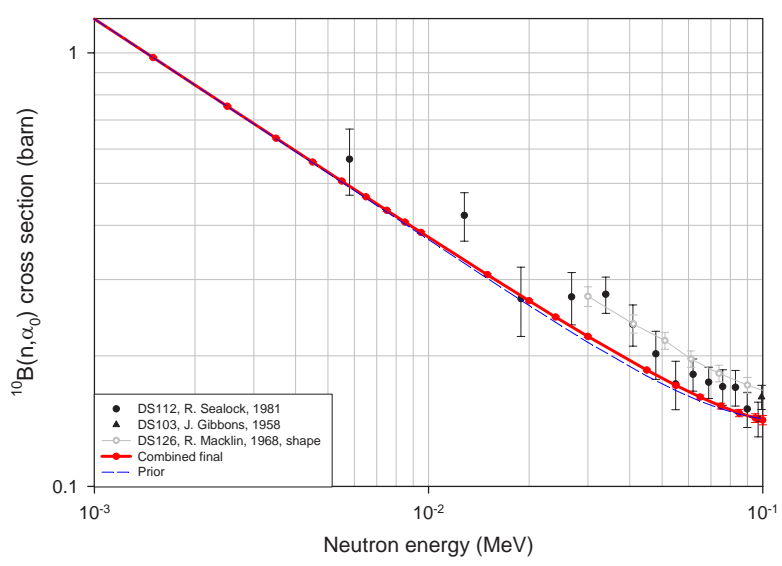

FIG. 7.17. Expanded view of data in Fig. 7.15 for the energy range 0.001-0.1 MeV.

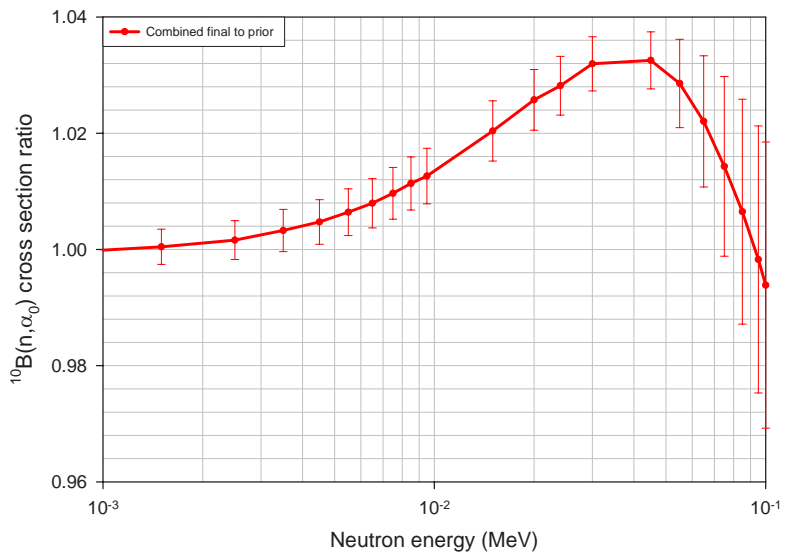

FIG. 7.18. Expanded view of data in Fig. 7.16 for the energy range 0.001-0.1 MeV. 


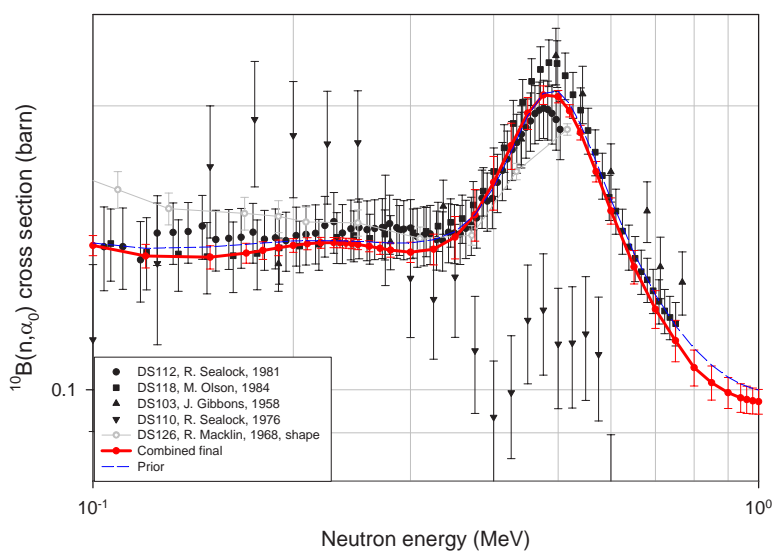

FIG. 7.19. Expanded view of data in Fig. 7.15 for the energy range 0.1-1 $\mathrm{MeV}$.

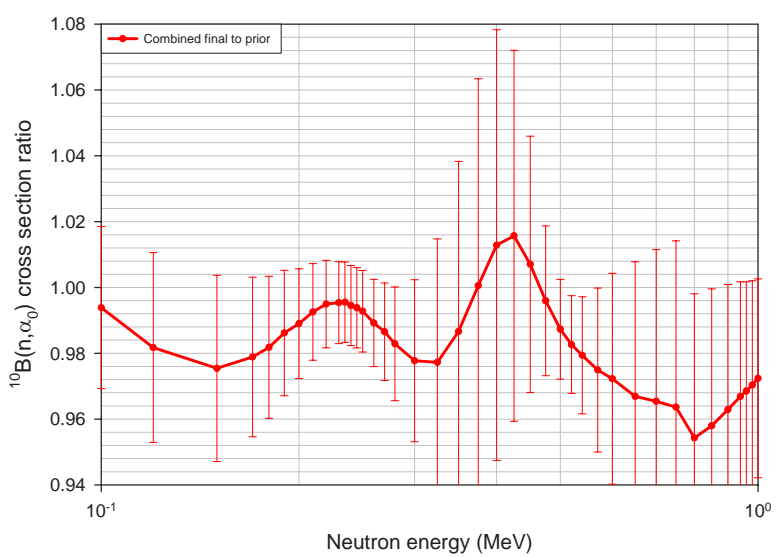

FIG. 7.20. Expanded view of data in Fig. 7.16 for the energy range $0.1-1 \mathrm{MeV}$.

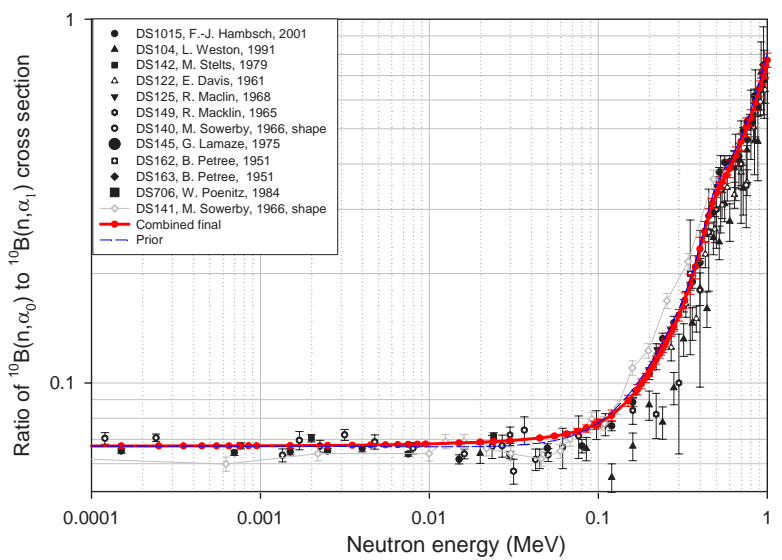

FIG. 7.21. Comparison of present and prior evaluations, together with experimental data for the branching ratio ${ }^{10} B\left(n, \alpha_{0}\right) /{ }^{10} B\left(n, \alpha_{1}\right)$.

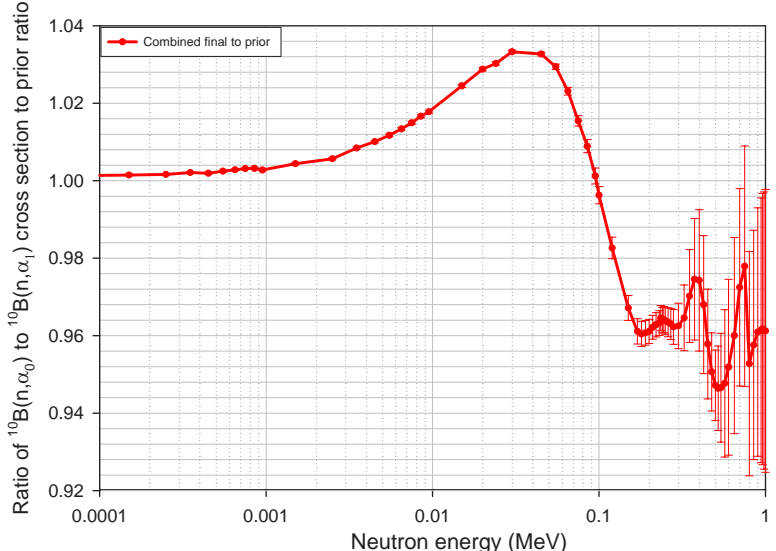

FIG. 7.22. Ratio of present to prior evaluations for the branching ${ }^{10} B\left(n, \alpha_{0}\right) /{ }^{10} B\left(n, \alpha_{1}\right)$.

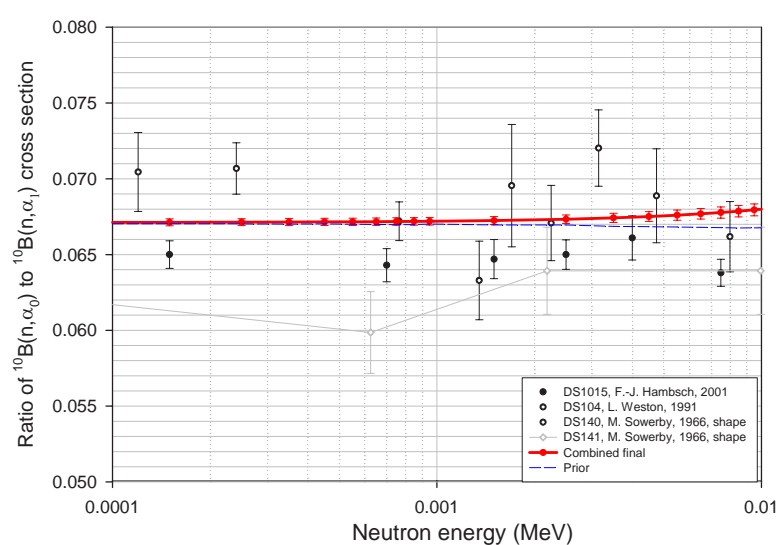

FIG. 7.23. Expanded view of data in Fig. 7.20 for the energy range 0.0001-0.01 MeV.

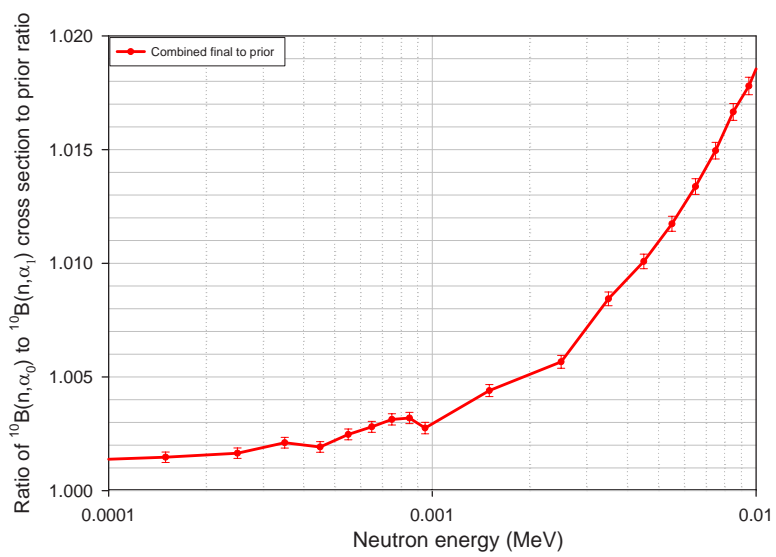

FIG. 7.24. Expanded view of data in Fig. 7.21 for the energy range 0.0001-0.01 $\mathrm{MeV}$. 


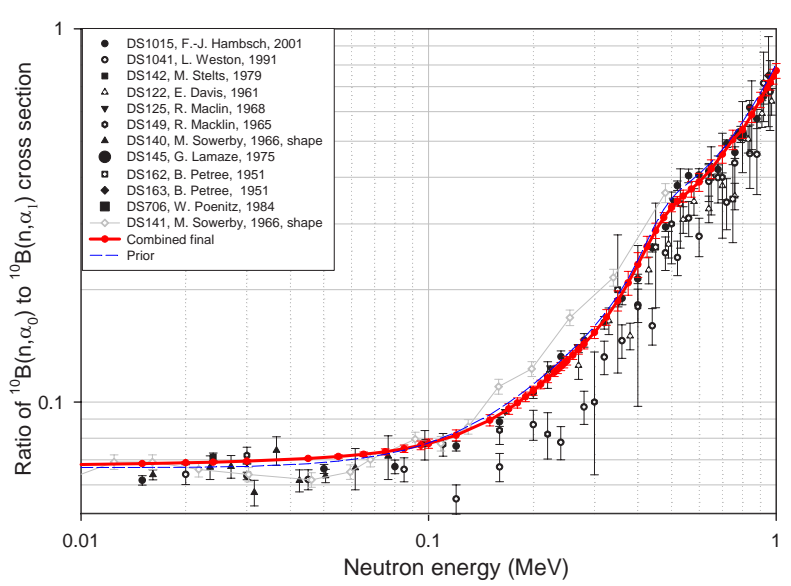

FIG. 7.25. Expanded view of data in Fig. 7.21 for the energy range 0.01-1 $\mathrm{MeV}$.

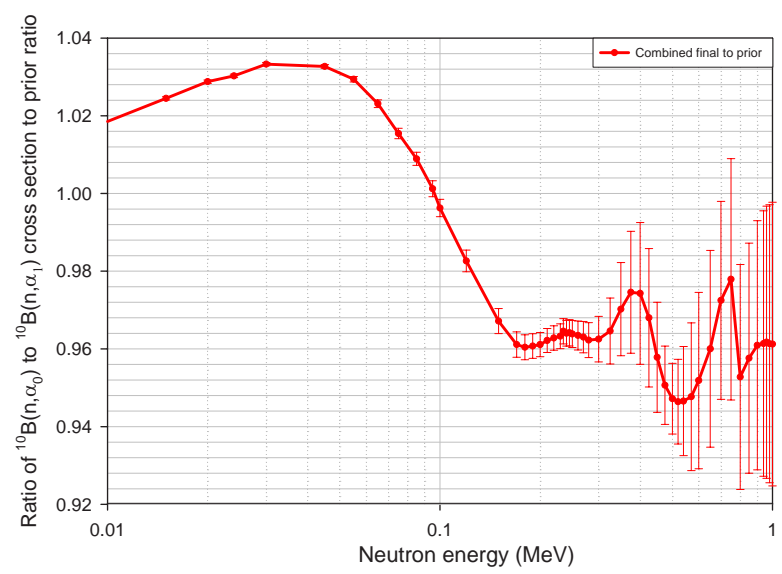

FIG. 7.26. Expanded view of data in Fig. 7.22 for the energy range 0.01-1 $\mathrm{MeV}$.

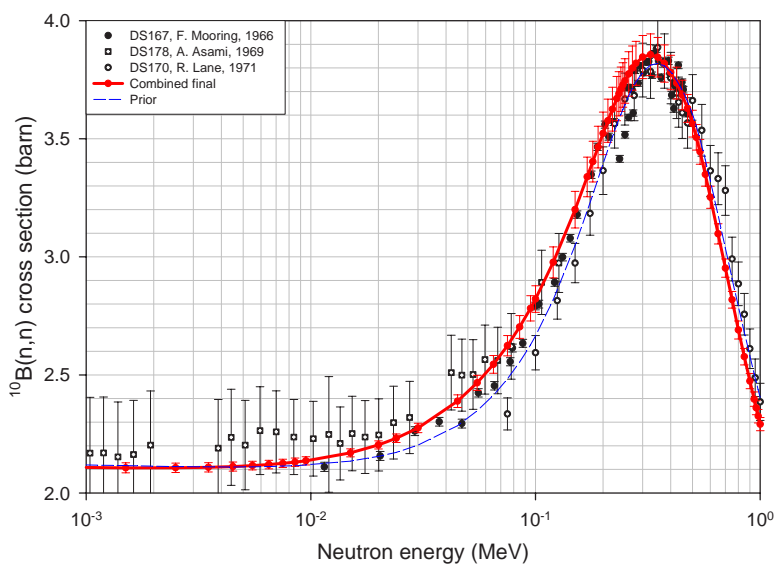

FIG. 7.27. Comparison of present and prior evaluations, together with experimental data for the ${ }^{10} B(n, n)$ reaction.

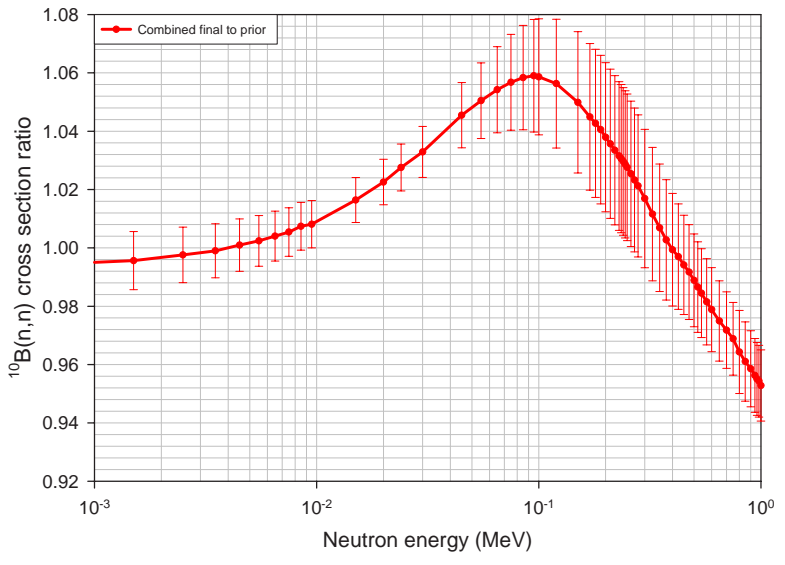

FIG. 7.28. Ratio of present to prior evaluations for the ${ }^{10} B(n, n)$ reaction.

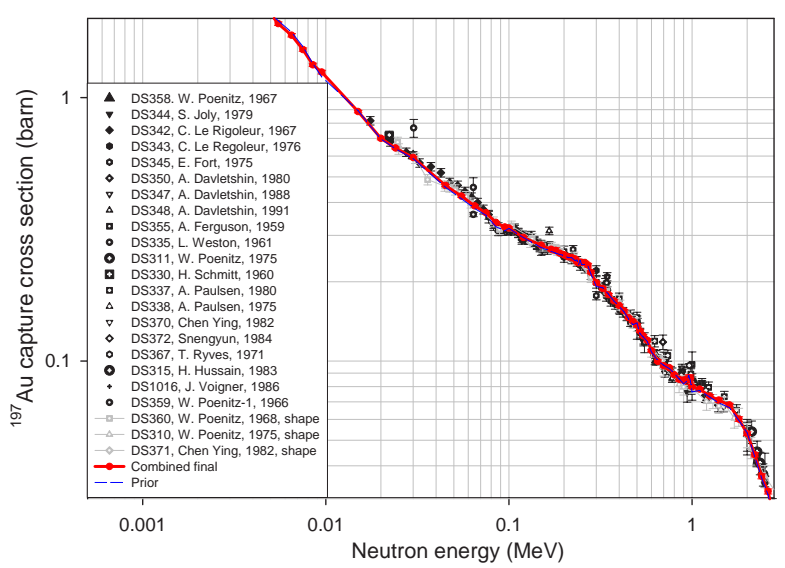

FIG. 7.29. Comparison of present and prior evaluations, together with experimental data for the $A u(n, \gamma)$ reaction.

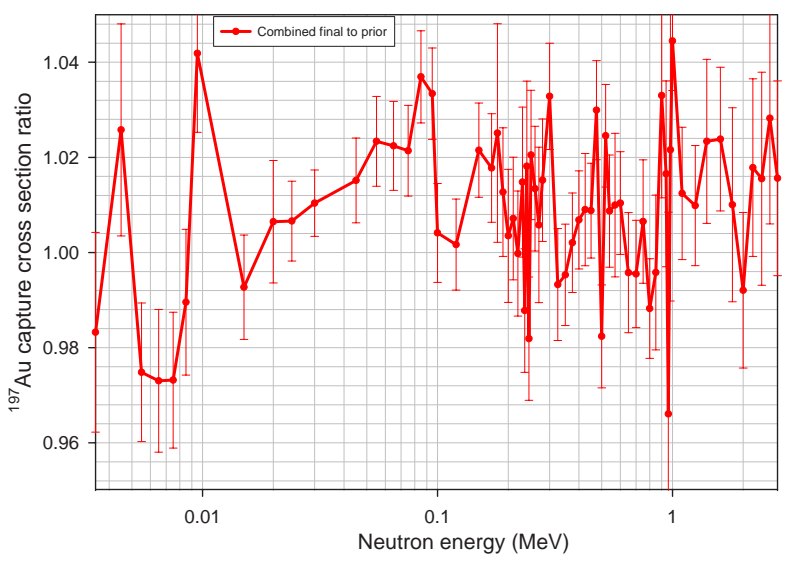

FIG. 7.30. Ratio of present to prior evaluations for the $A u(n, \gamma)$ reaction. 


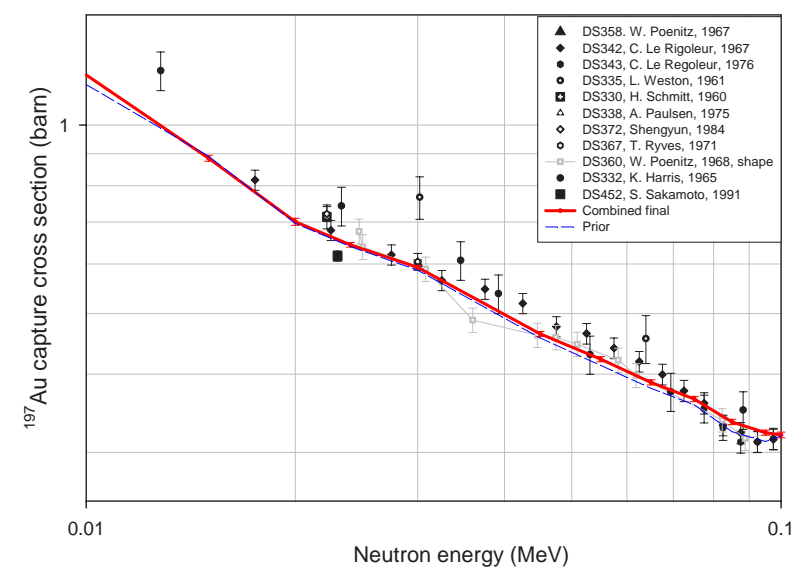

FIG. 7.31. Expanded view of data in Fig. 7.29 for the energy range 0.01-0.1 $\mathrm{MeV}$.

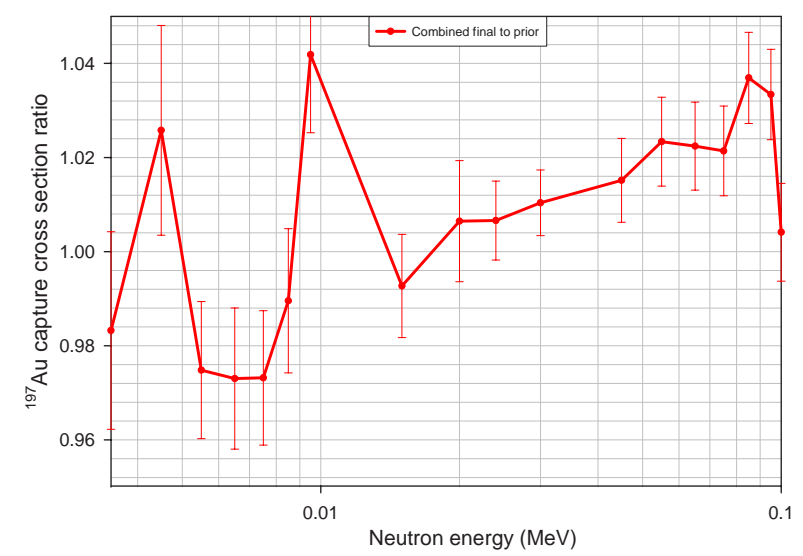

FIG. 7.32. Expanded view of data in Fig. 7.30 for the energy range 0.0035-0.1 MeV.

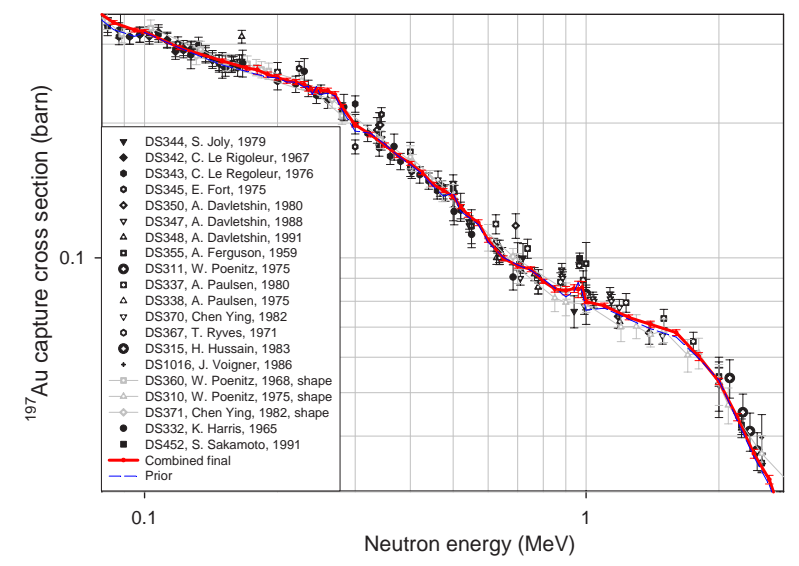

FIG. 7.33. Expanded view of data in Fig. 7.29 for the energy range $0.08-2.8 \mathrm{MeV}$.

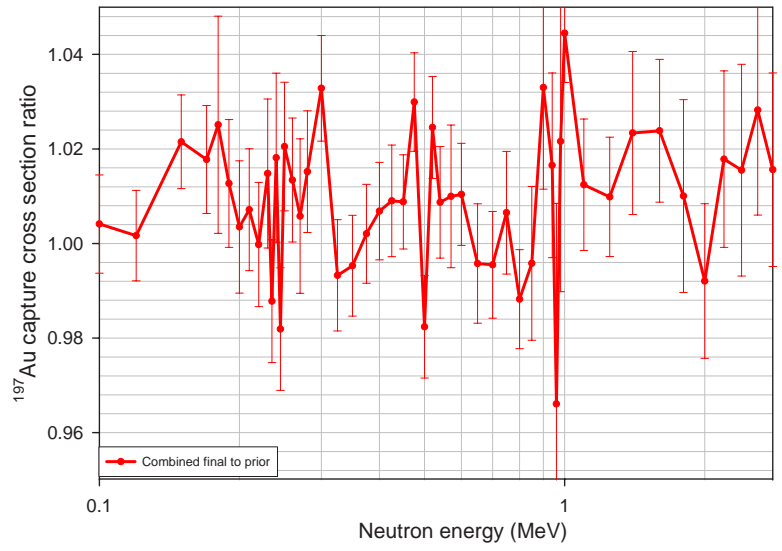

FIG. 7.34. Expanded view of data in Fig. 7.30 for the energy range 0.01-2.8 $\mathrm{MeV}$.

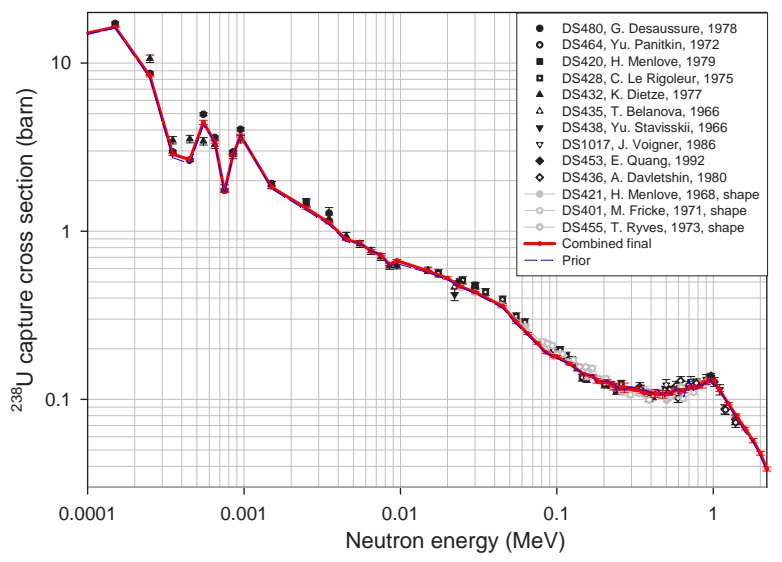

FIG. 7.35. Comparison of present and prior evaluations, together with experimental data for the ${ }^{238} U(n, \gamma)$ reaction.

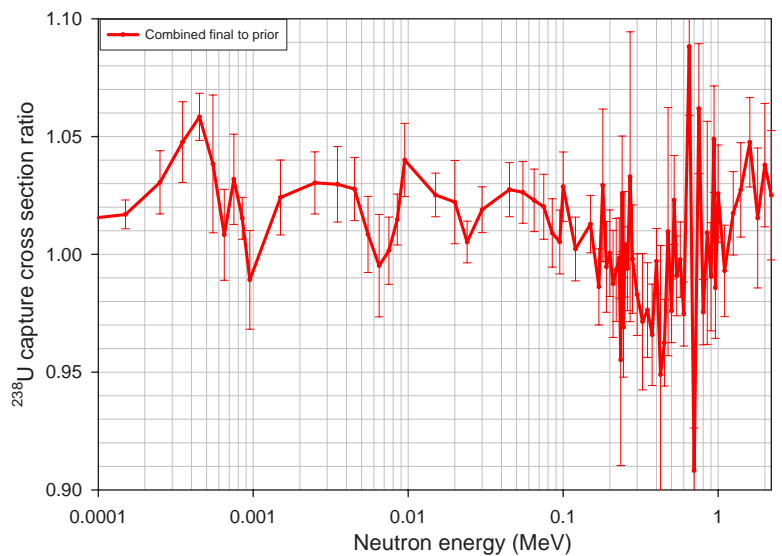

FIG. 7.36. Ratio of present to prior evaluations for the ${ }^{238} U(n, \gamma)$ reaction. 


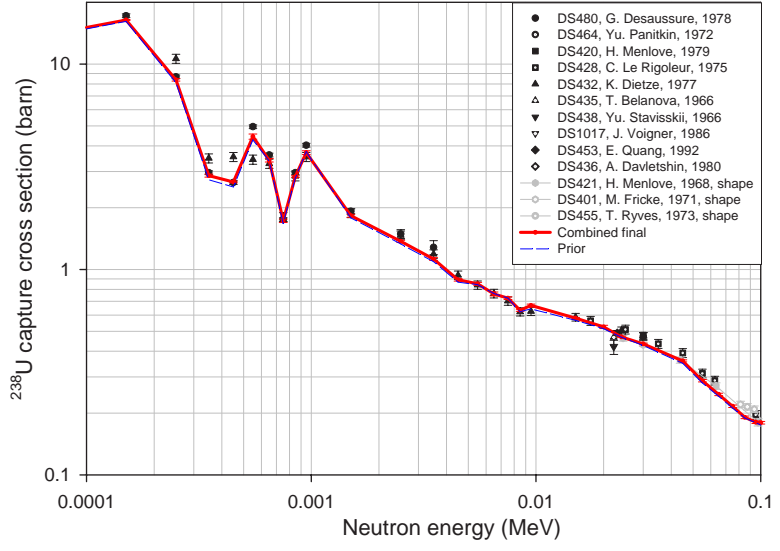

FIG. 7.37. Expanded view of data in Fig. 7.35 for the energy range 0.0001-0.1 MeV.

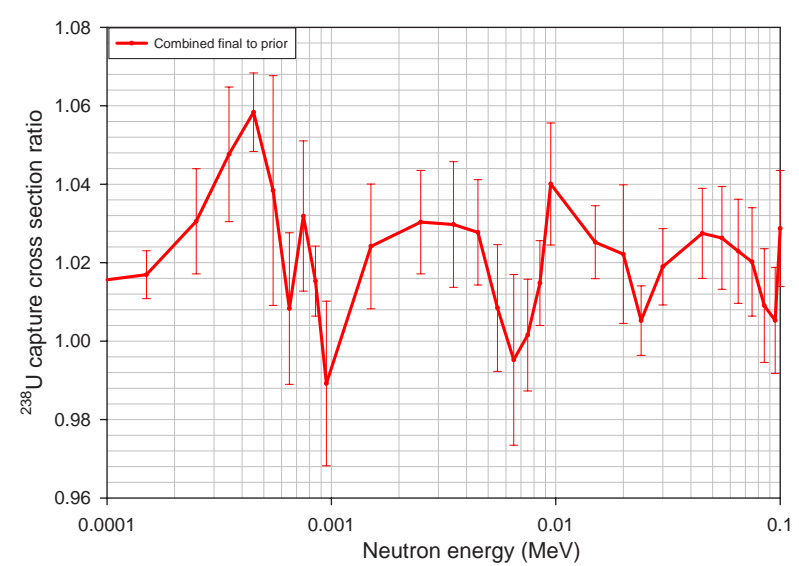

FIG. 7.38. Expanded view of data in Fig. 7.36 for the energy range 0.0001-0.1 $\mathrm{MeV}$.

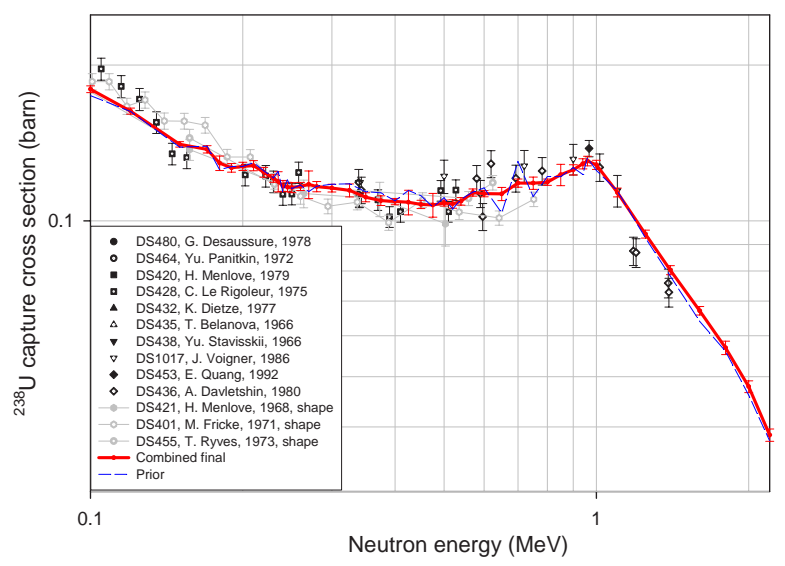

FIG. 7.39. Expanded view of data in Fig. 7.35 for the energy range 0.1-2.2 $\mathrm{MeV}$.

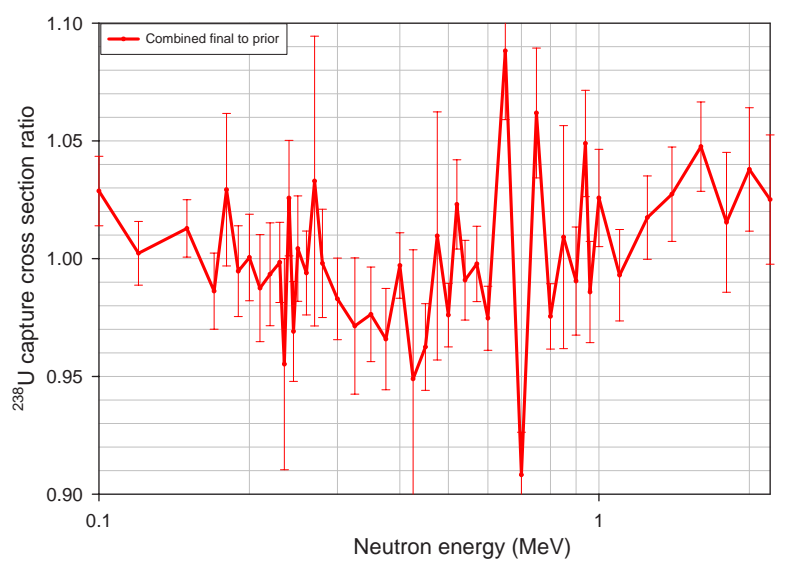

FIG. 7.40. Expanded view of data in Fig. 7.36 for the energy range 0.1-2.2 $\mathrm{MeV}$.

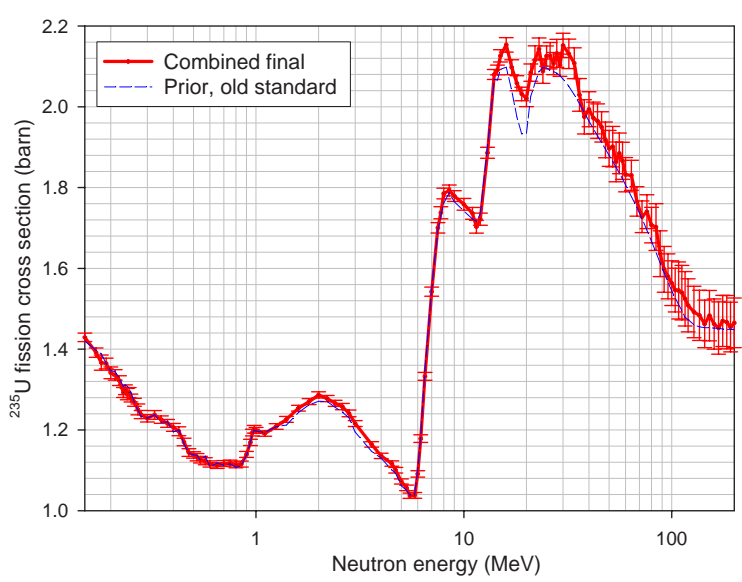

FIG. 7.41. Comparison of present and prior evaluations for the ${ }^{235} U(n, f)$ reaction.

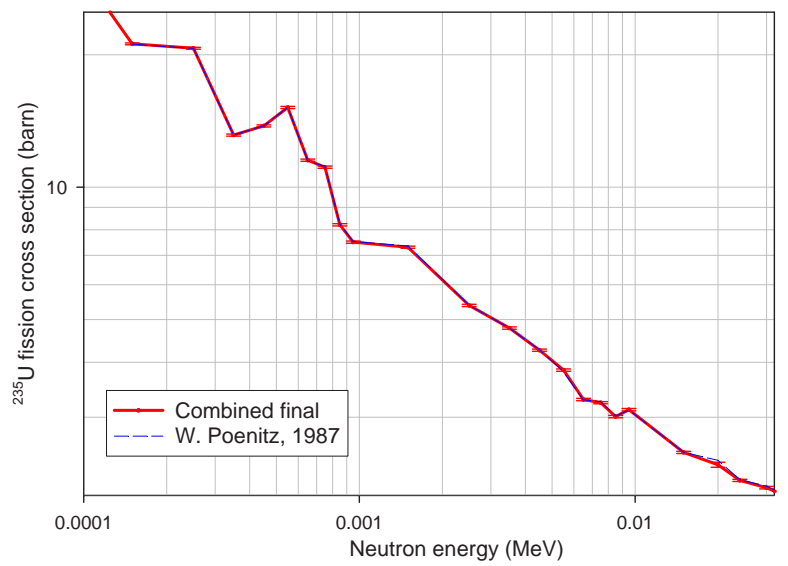

FIG. 7.42. Expanded view of data in Fig. 7.41 for the energy range $0.0001-0.0325 \mathrm{MeV}$. 


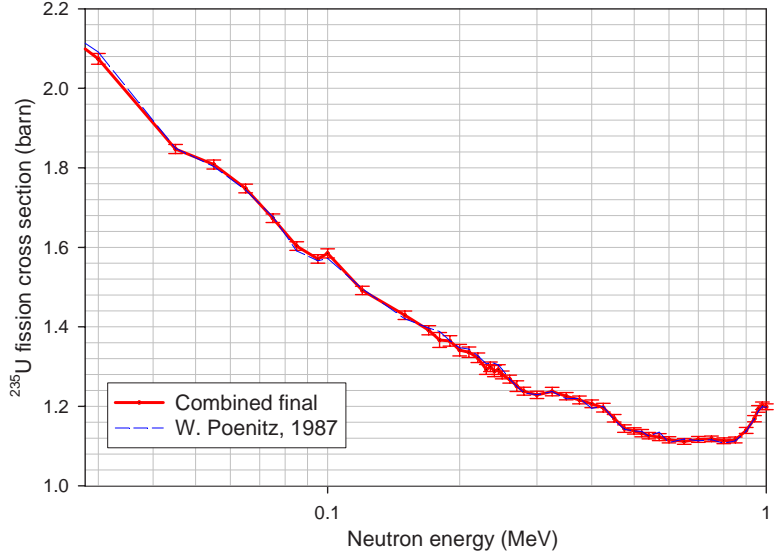

FIG. 7.43. Expanded view of data in Fig. 7.41 for the energy range 0.028-0.1 $\mathrm{MeV}$.

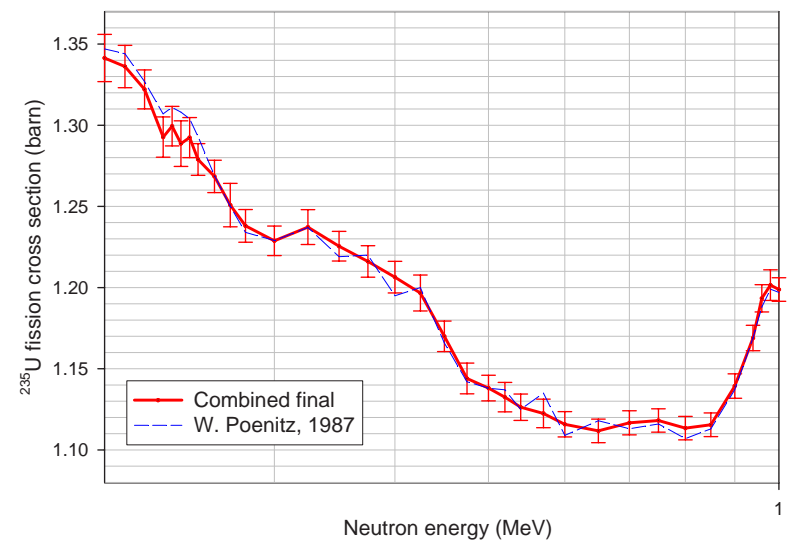

FIG. 7.44. Expanded view of data in Fig. 7.41 for the energy range 0.01-1 $\mathrm{MeV}$.

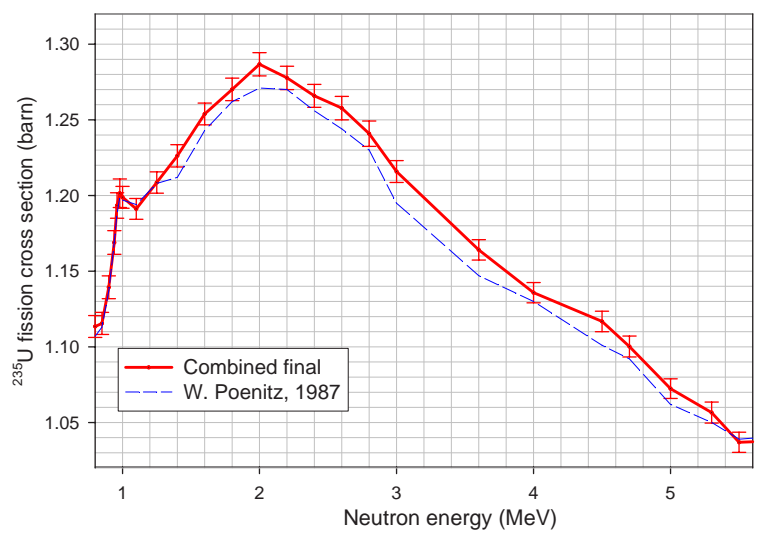

FIG. 7.45. Expanded view of data in Fig. 7.41 for the energy range 0.8-5.6 $\mathrm{MeV}$.

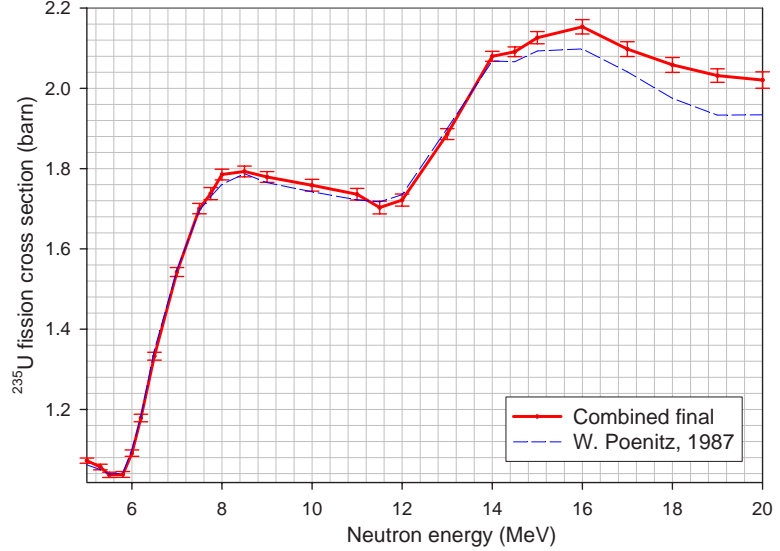

FIG. 7.46. Expanded view of data in Fig. 7.41 for the energy range 5.5-20 MeV.

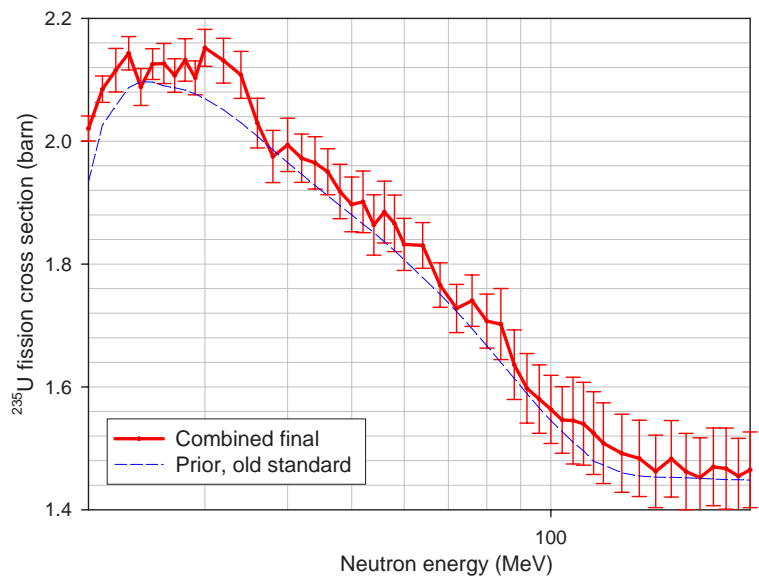

FIG. 7.47. Expanded view of data in Fig. 7.41 for the energy range 20-200 $\mathrm{MeV}$.

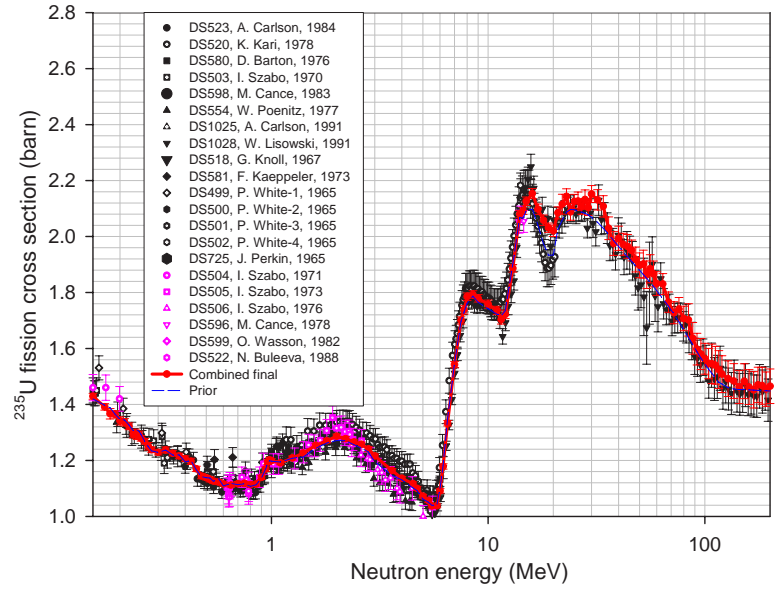

FIG. 7.48. Comparison of present and prior evaluations, together with experimental data for the ${ }^{235} U(n, f)$ reaction. 


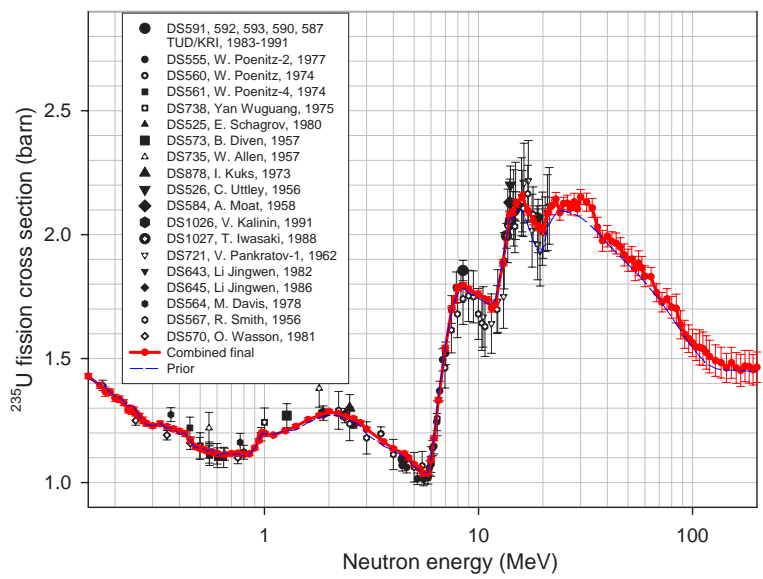

FIG. 7.49. Same as Fig. 7.48 with other experimental data.

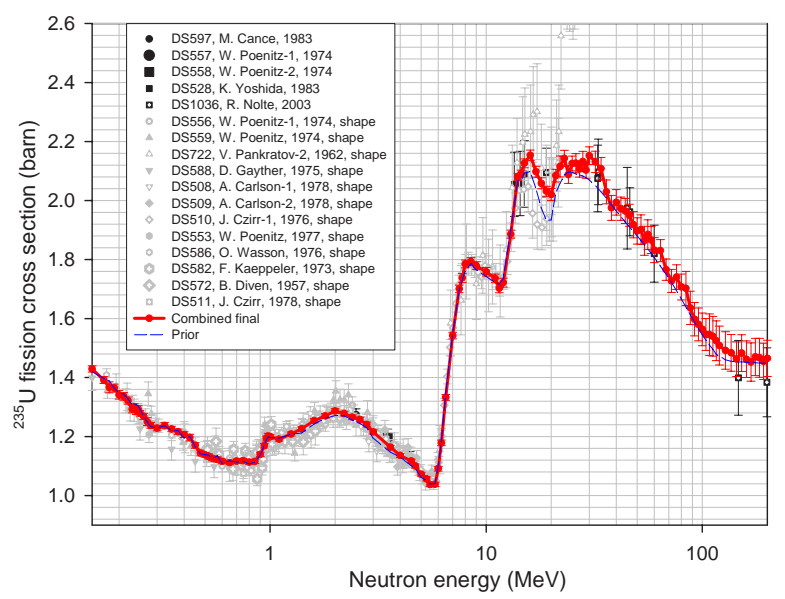

FIG. 7.50. Same as Fig. 7.48 with other experimental data.

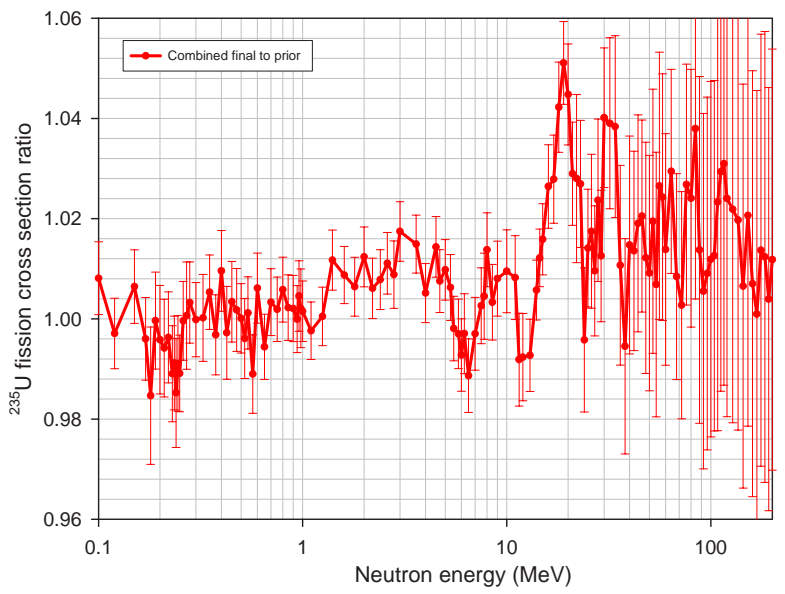

FIG. 7.51. Ratio of present to prior evaluations for the ${ }^{235} U(n, f)$ reaction.

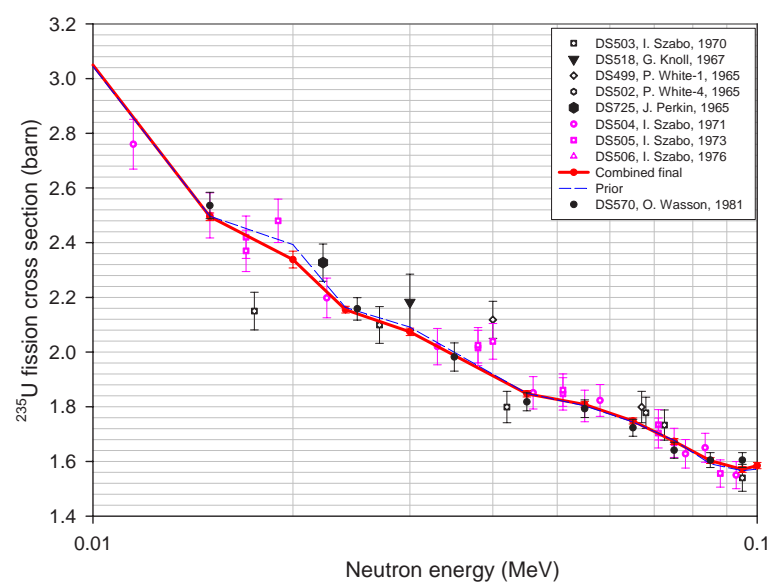

FIG. 7.52. Comparison of present and prior evaluations, together with experimental data for the ${ }^{235} U(n, f)$ reaction in the energy range $0.01-0.1 \mathrm{MeV}$.

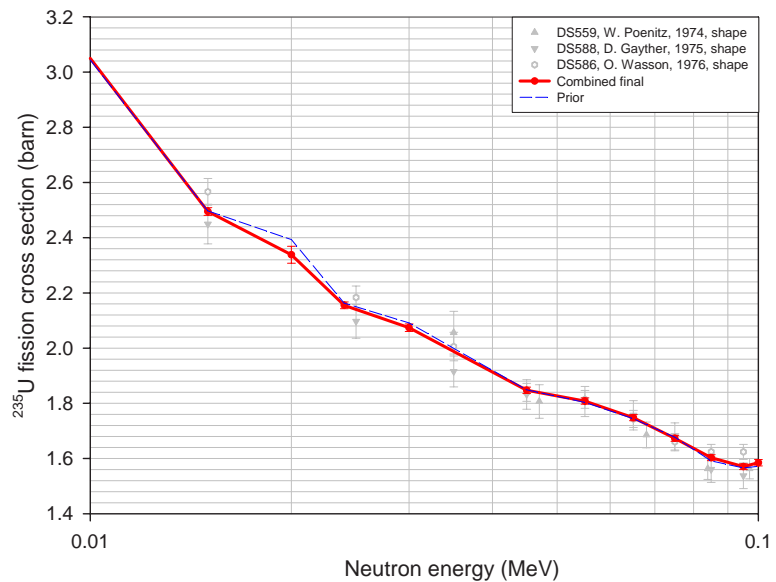

FIG. 7.53. Same as Fig. 7.52 with other experimental data.

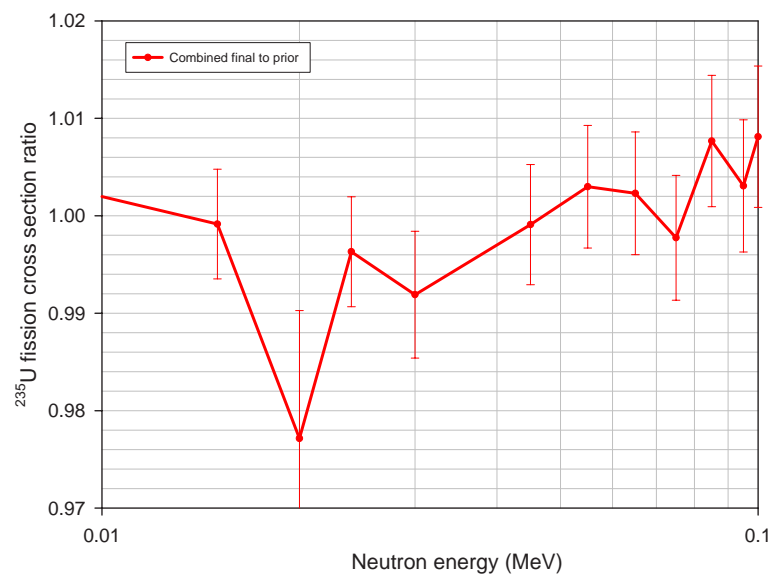

FIG. 7.54. Ratio of present to prior evaluations for the ${ }^{235} \mathrm{U}(n, f)$ reaction in the energy range $0.01-0.1 \mathrm{MeV}$. 


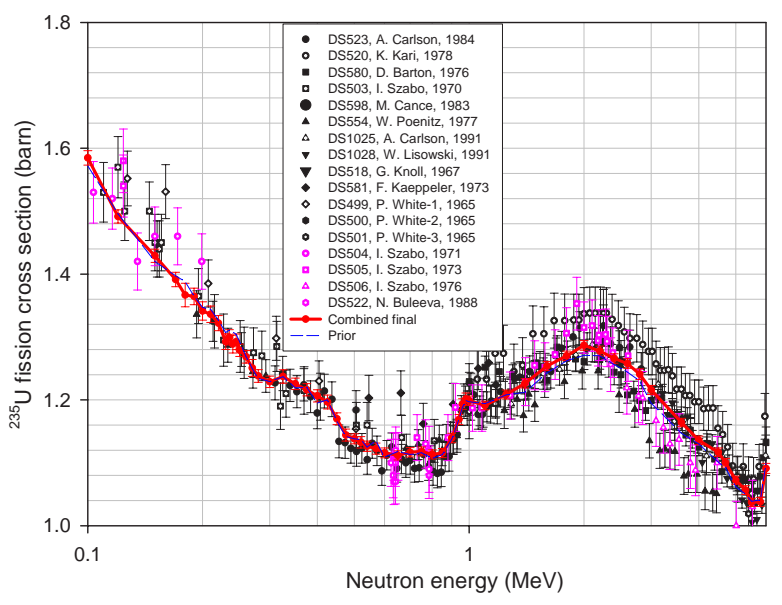

FIG. 7.55. Comparison of present and prior evaluations, together with experimental data for the ${ }^{235} U(n, f)$ reaction in the energy range $0.1-6 \mathrm{MeV}$.

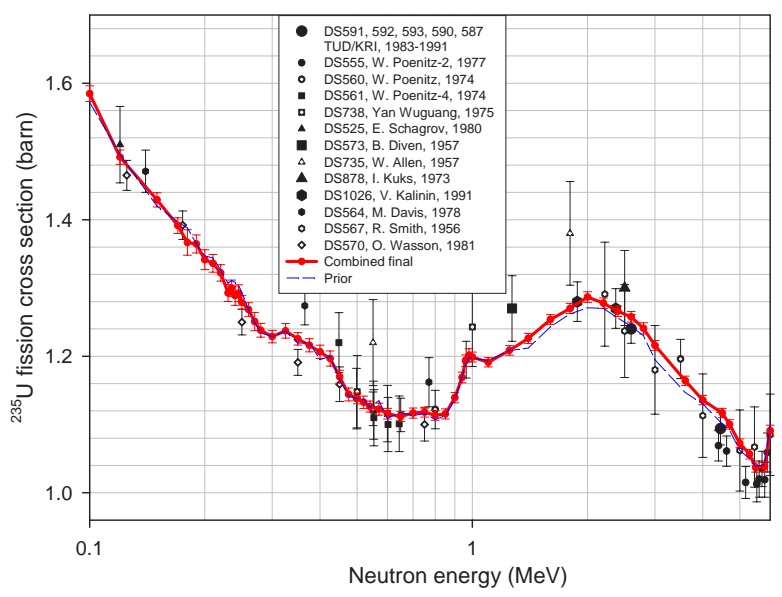

FIG. 7.56. Same as Fig. 7.55 with other experimental data.

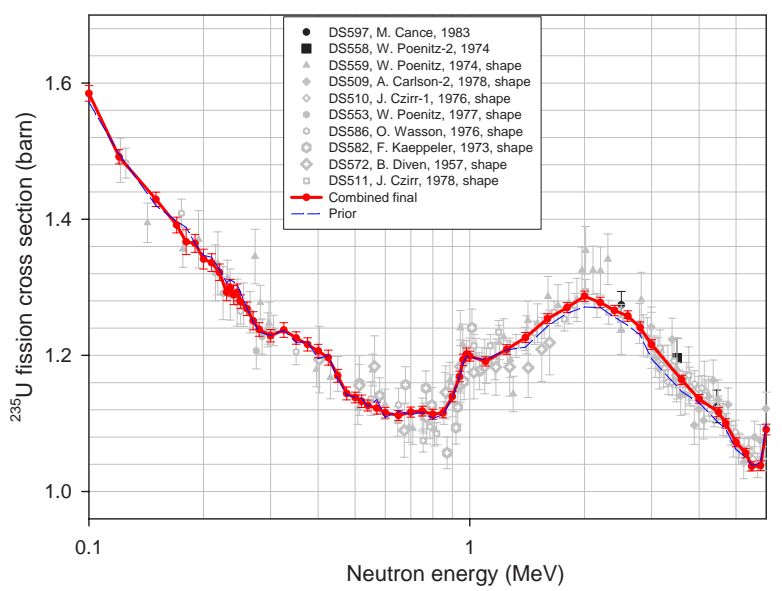

FIG. 7.57. Same as Fig. 7.55 with other experimental data.

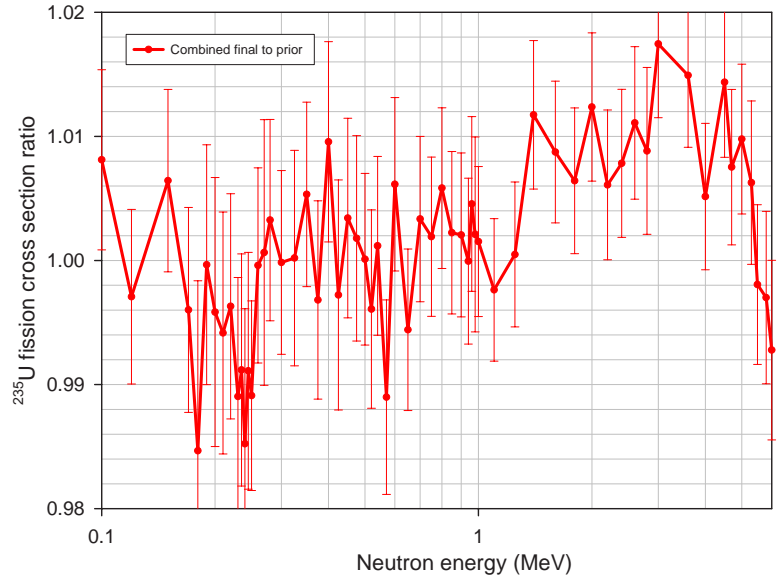

FIG. 7.58. Ratio of present to prior evaluations for the ${ }^{235} \mathrm{U}(n, f)$ reaction in the energy range 0.1-6 $\mathrm{MeV}$.

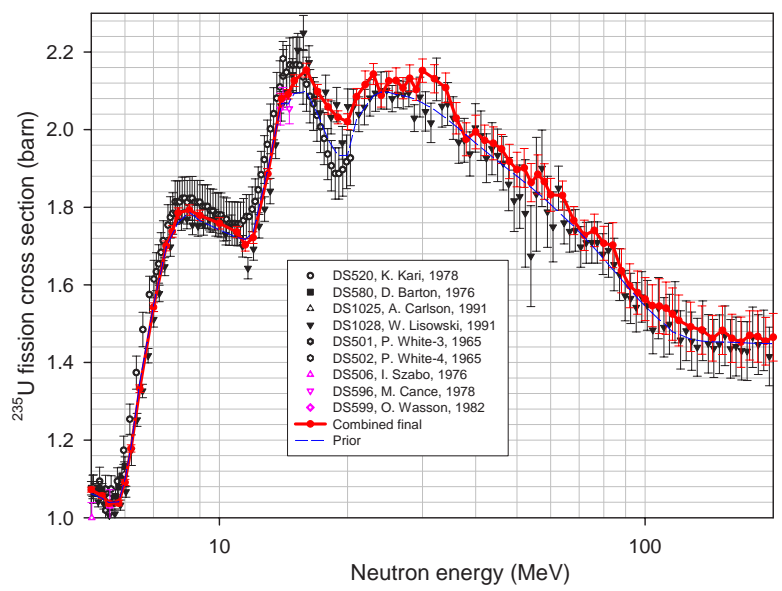

FIG. 7.59. Comparison of present and prior evaluations, together with experimental data for the ${ }^{235} U(n, f)$ reaction in the energy range 5-200 $\mathrm{MeV}$.

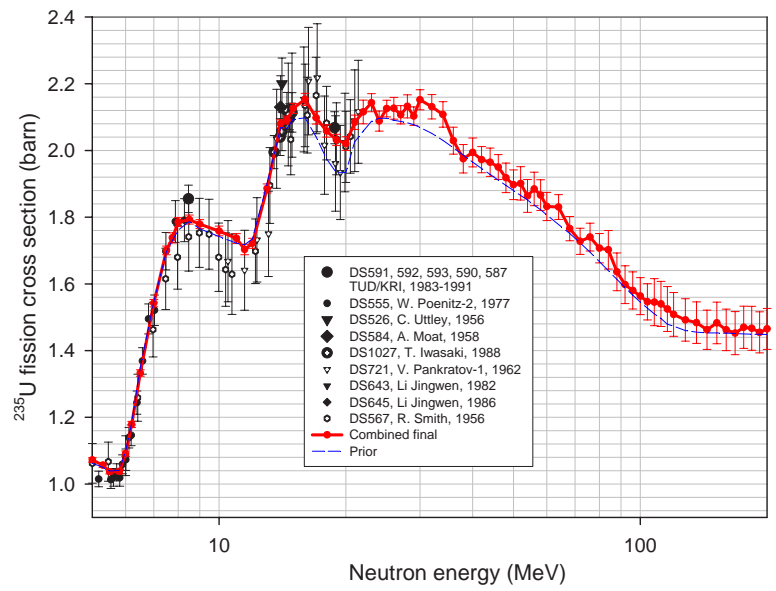

FIG. 7.60. Same as Fig. 7.59 with other experimental data. 


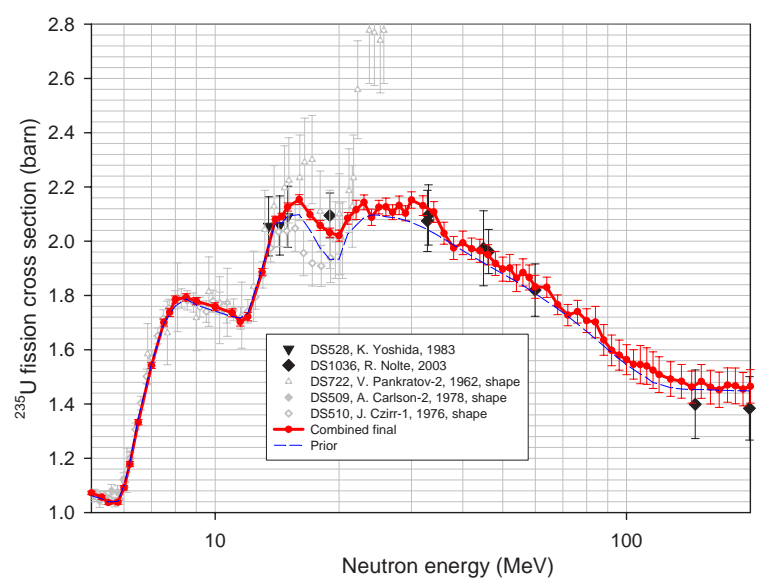

FIG. 7.61. Same as Fig. 7.59 with other experimental data.

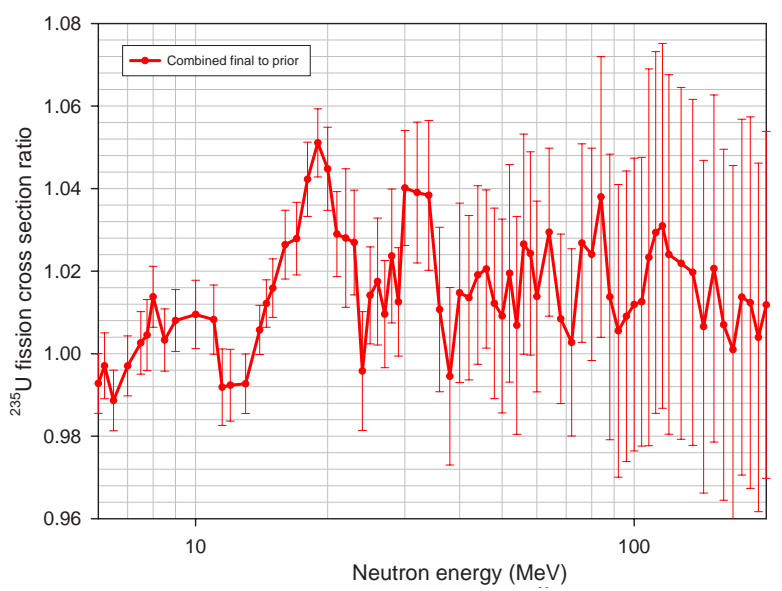

FIG. 7.62. Ratio of present to prior evaluations for the ${ }^{235} \mathrm{U}(n, f)$ reaction in the energy range 6-200 $\mathrm{MeV}$.

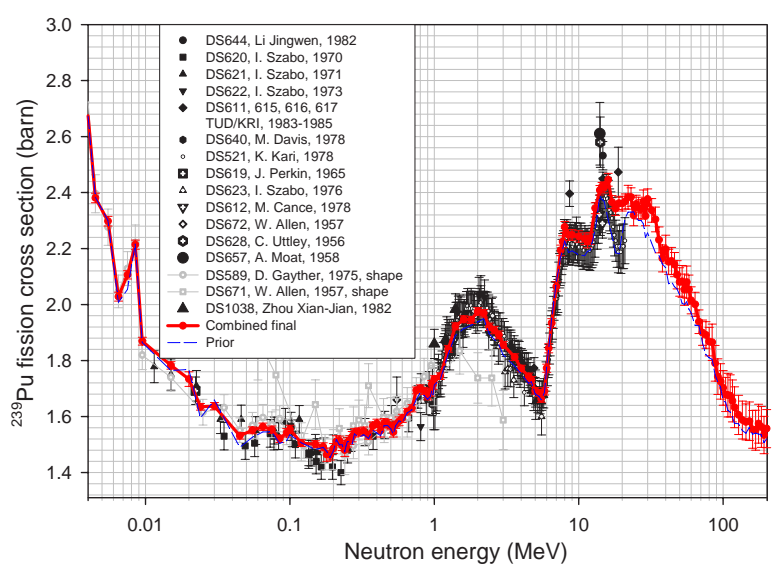

FIG. 7.63. Comparison of present and prior evaluations, together with experimental data for the ${ }^{239} \mathrm{Pu}(n, f)$ reaction.

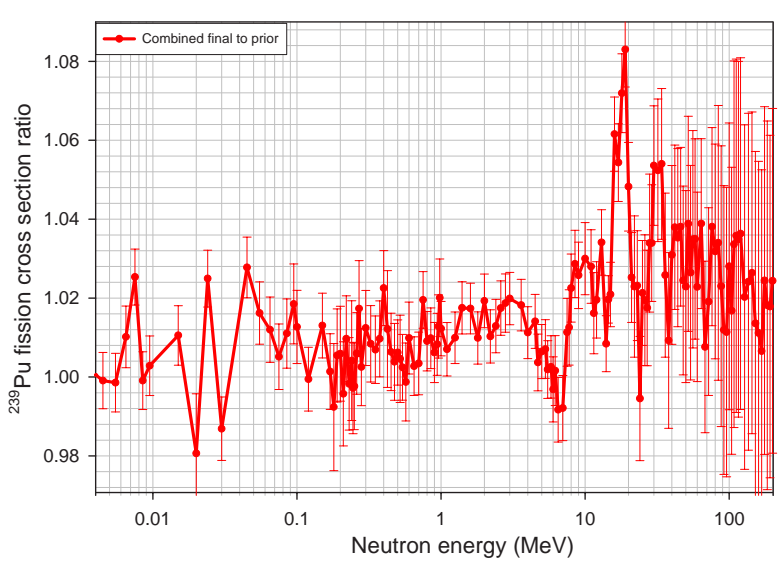

FIG. 7.64. Ratio of present to prior evaluations for the ${ }^{239} \mathrm{Pu}(n, f)$ reaction.

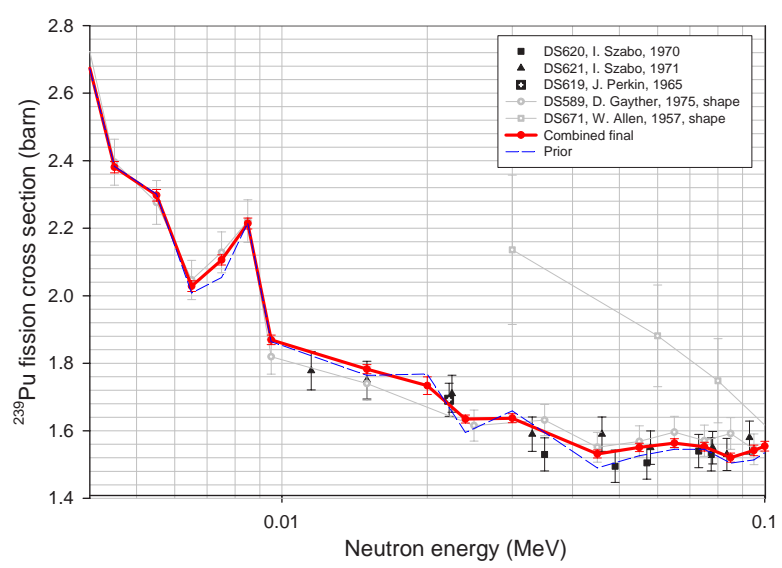

FIG. 7.65. Comparison of present and prior evaluations, together with experimental data for the ${ }^{239} \mathrm{Pu}(n, f)$ reaction in the energy range 0.04-0.1 MeV.

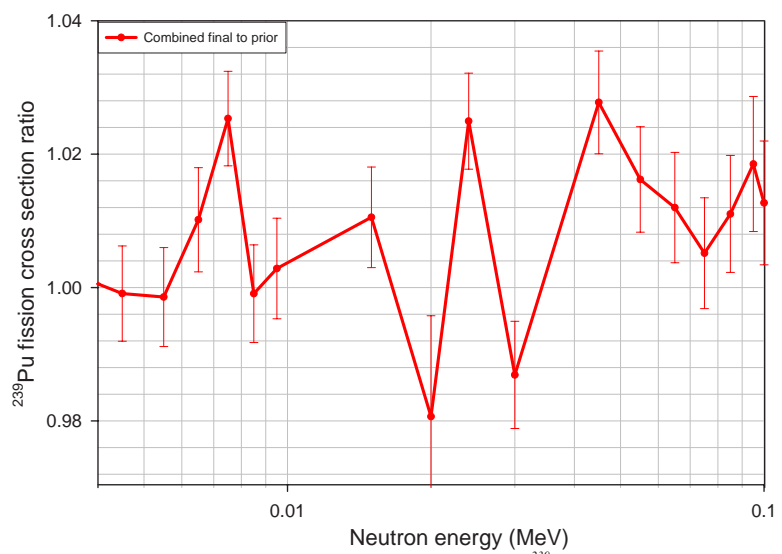

FIG. 7.66. Ratio of present to prior evaluations for the ${ }^{239} \mathrm{Pu}(n, f)$ reaction in the energy range 0.04-0.1 MeV. 


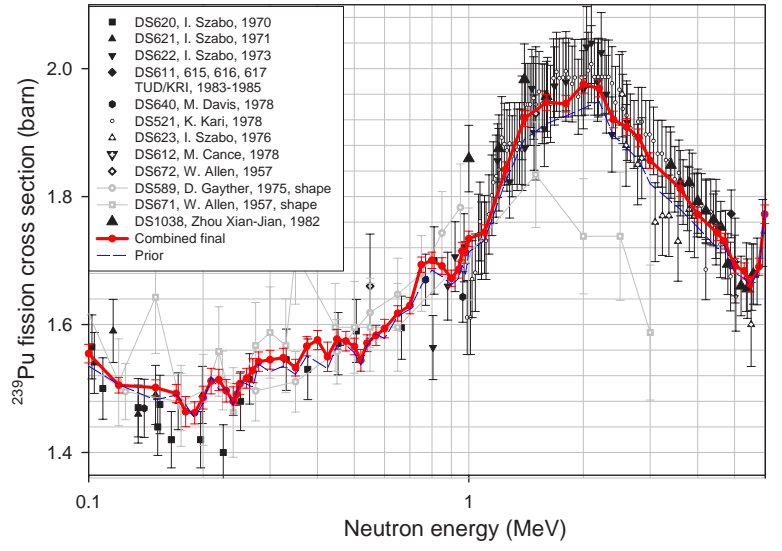

FIG. 7.67. Comparison of present and prior evaluations, together with experimental data for the ${ }^{239} \mathrm{Pu}(n, f)$ reaction in the energy range $0.1-6 \mathrm{MeV}$.

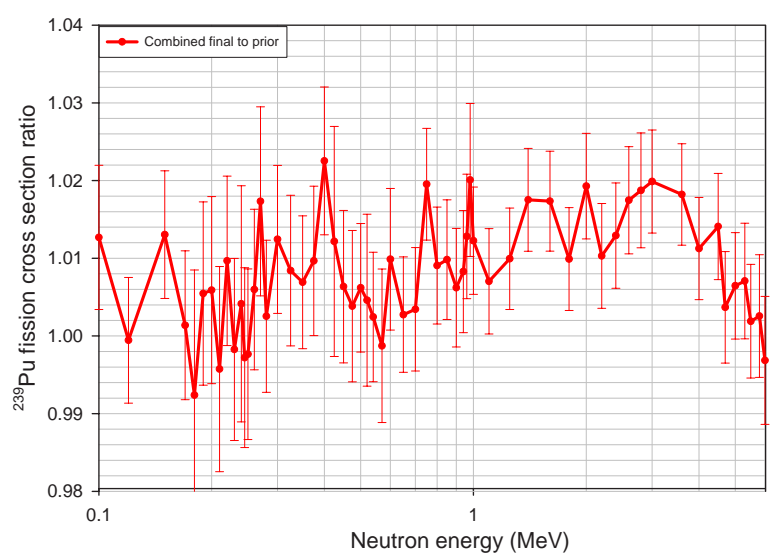

FIG. 7.68. Ratio of present to prior evaluations for the ${ }^{239} \mathrm{Pu}(n, f)$ reaction in the energy range $0.1-6 \mathrm{MeV}$.

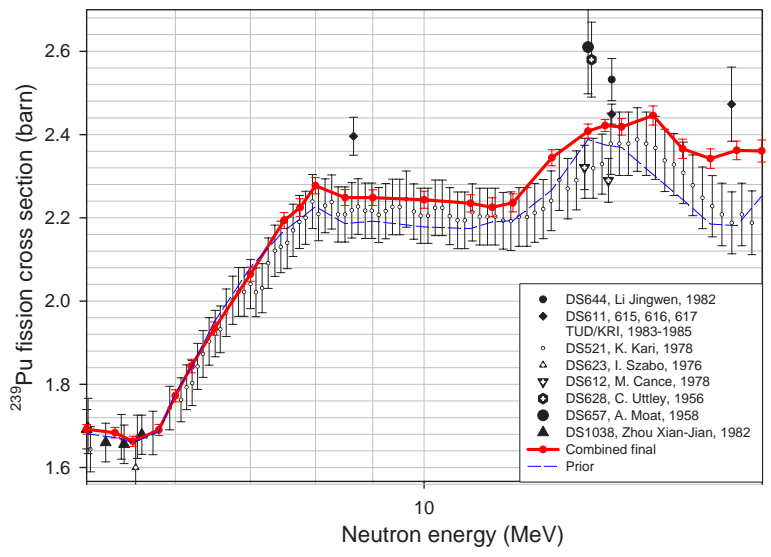

FIG. 7.69. Comparison of present and prior evaluations, together with experimental data for the ${ }^{239} \mathrm{Pu}(n, f)$ reaction in the energy range 5-20 MeV.

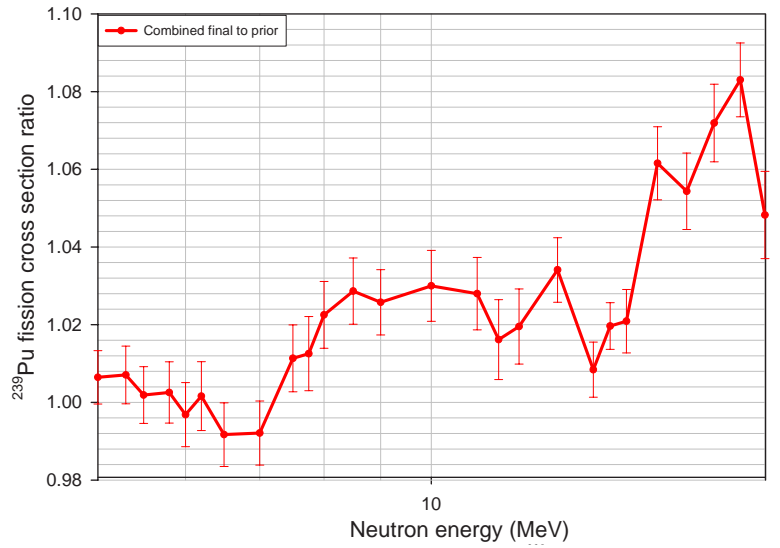

FIG. 7.70. Ratio of present to prior evaluations for the ${ }^{239} \mathrm{Pu}(n, f)$ reaction in the energy range 5-20 MeV.

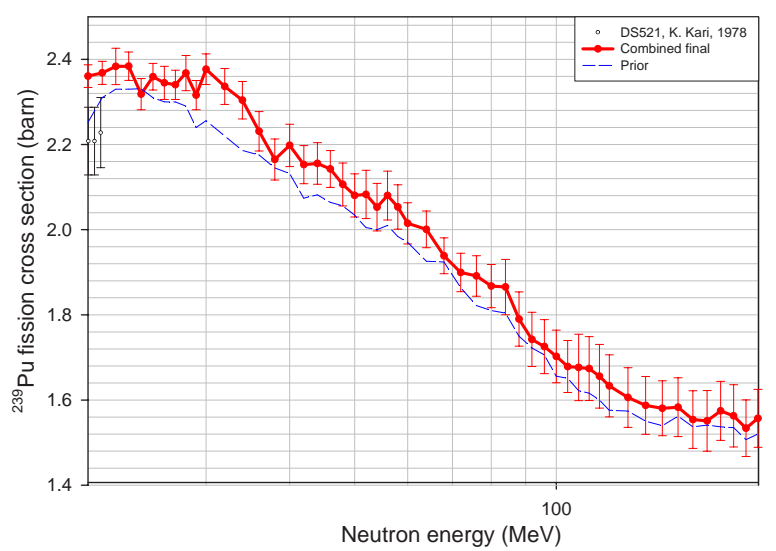

FIG. 7.71. Comparison of present and prior evaluations, together with experimental data for the ${ }^{239} \mathrm{Pu}(n, f)$ reaction in the energy range 20-200 MeV.

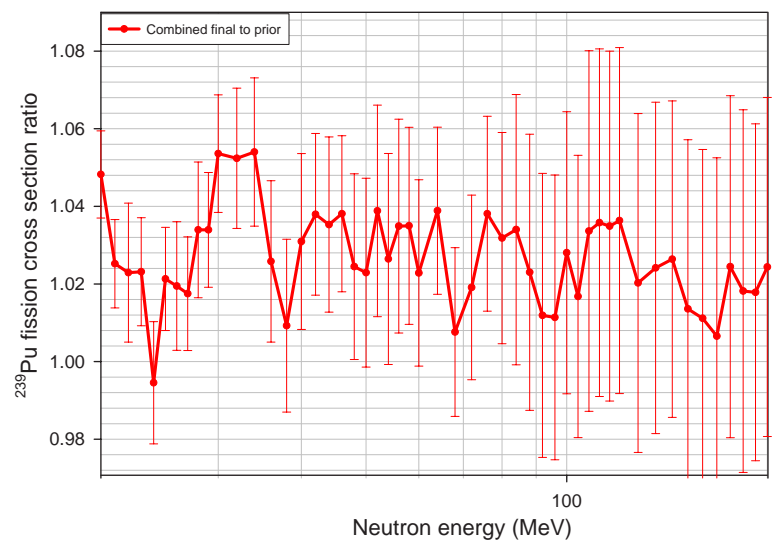

FIG. 7.72. Ratio of present to prior evaluations for the ${ }^{239} \mathrm{Pu}(n, f)$ reaction in the energy range $20-200 \mathrm{MeV}$. 


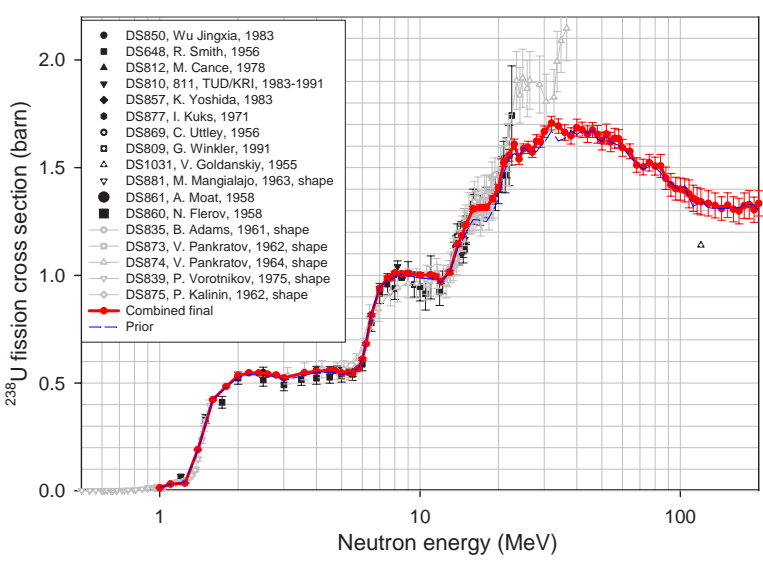

FIG. 7.73. Comparison of present and prior evaluations, together with experimental data for the ${ }^{238} U(n, f)$ reaction.

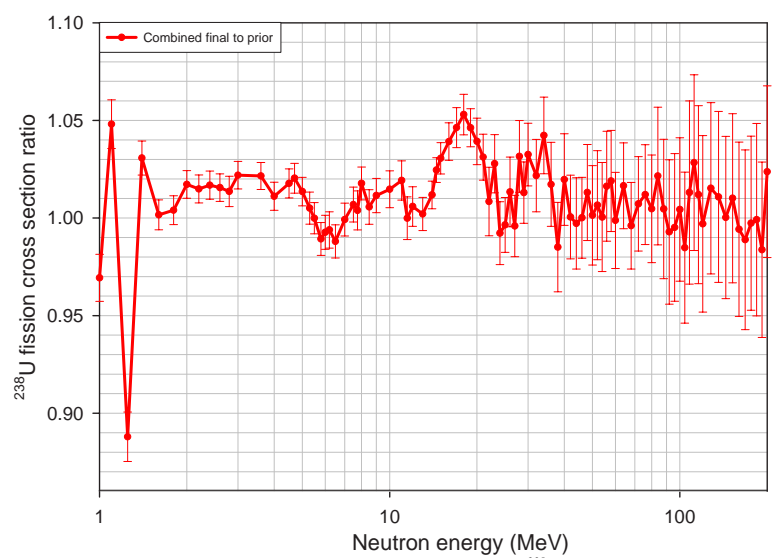

FIG. 7.74. Ratio of present to prior evaluations for the ${ }^{238} U(n, f)$ reaction.

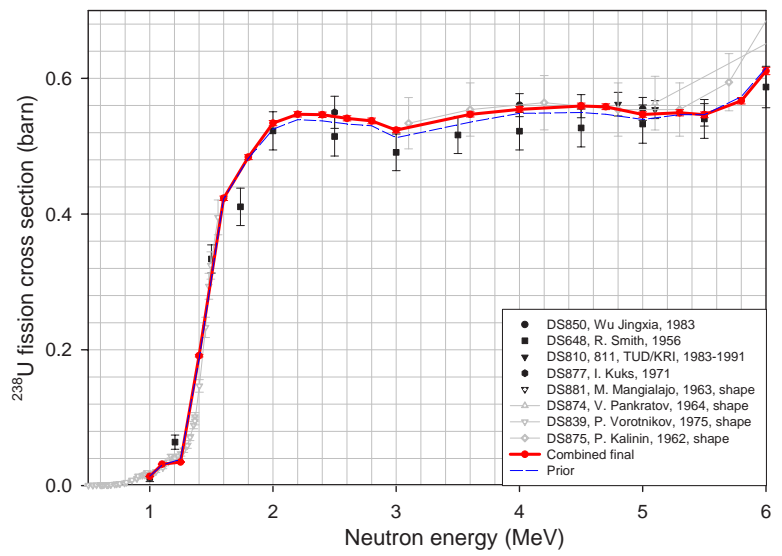

FIG. 7.75. Comparison of present and prior evaluations, together with experimental data for the ${ }^{238} U(n, f)$ reaction in the energy range 1-6 $\mathrm{MeV}$.

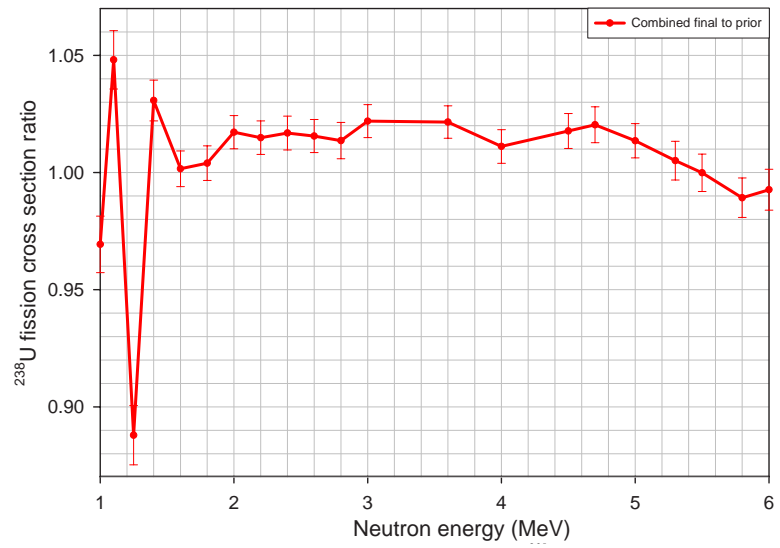

FIG. 7.76. Ratio of present to prior evaluations for the ${ }^{238} \mathrm{U}(n, f)$ reaction in the energy range $1-6 \mathrm{MeV}$.

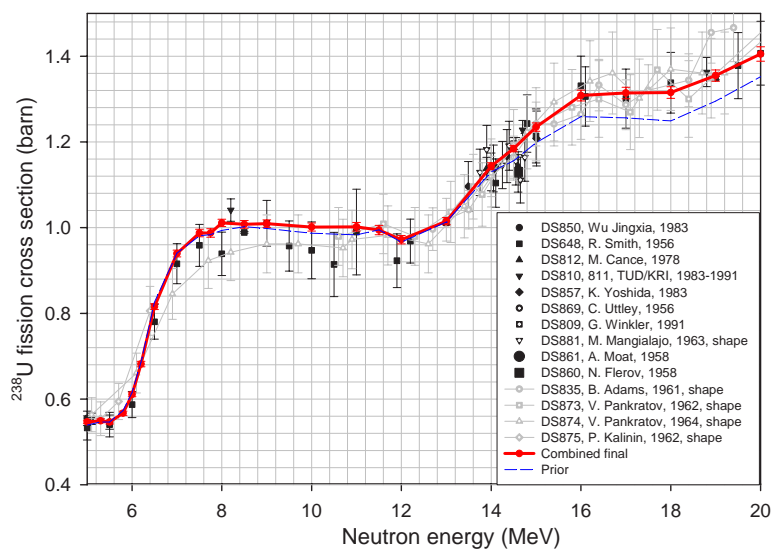

FIG. 7.77. Comparison of present and prior evaluations, together with experimental data for the ${ }^{238} U(n, f)$ reaction in the energy range 5-20 $\mathrm{MeV}$.

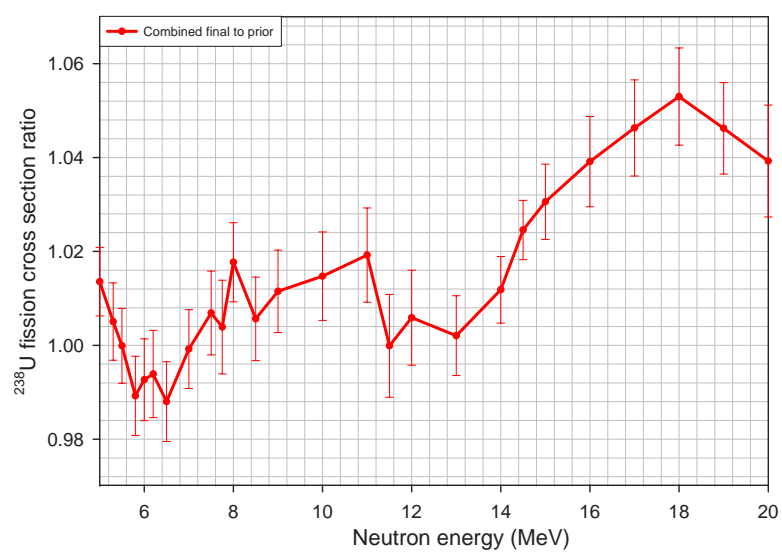

FIG. 7.78. Ratio of present to prior evaluations for the ${ }^{238} \mathrm{U}(n, f)$ reaction in the energy range 5-20 MeV. 


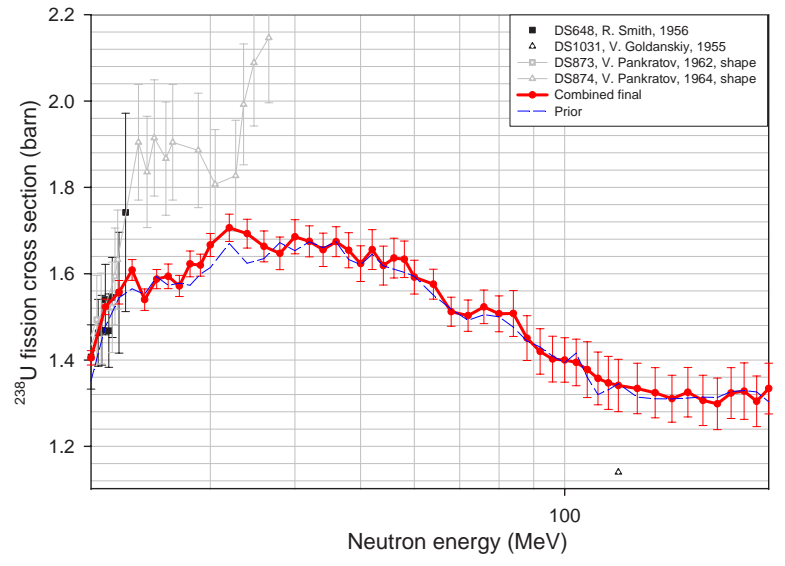

FIG. 7.79. Comparison of present and prior evaluations, together with experimental data for the ${ }^{238} U(n, f)$ reaction in the energy range 20-200 $\mathrm{MeV}$.

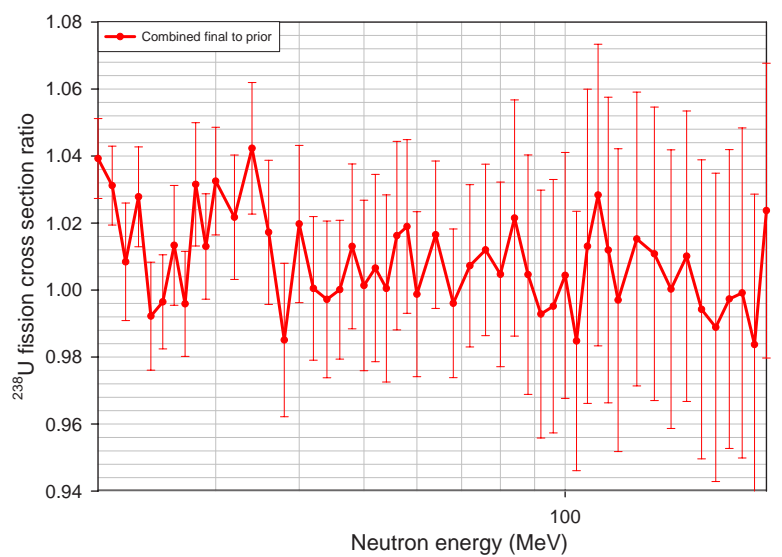

FIG. 7.80. Ratio of present to prior evaluations for the ${ }^{238} \mathrm{U}(n, f)$ reaction in the energy range $20-200 \mathrm{MeV}$.

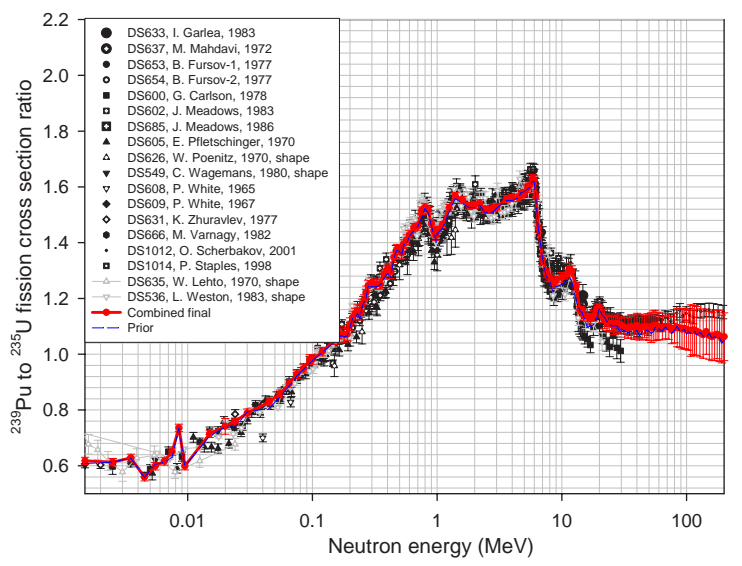

FIG. 7.81. Comparison of present and prior evaluations, together with experimental data for the ${ }^{239} \mathrm{Pu}(n, f){ }^{235} \mathrm{U}(n, f)$ reaction cross-section ratio.

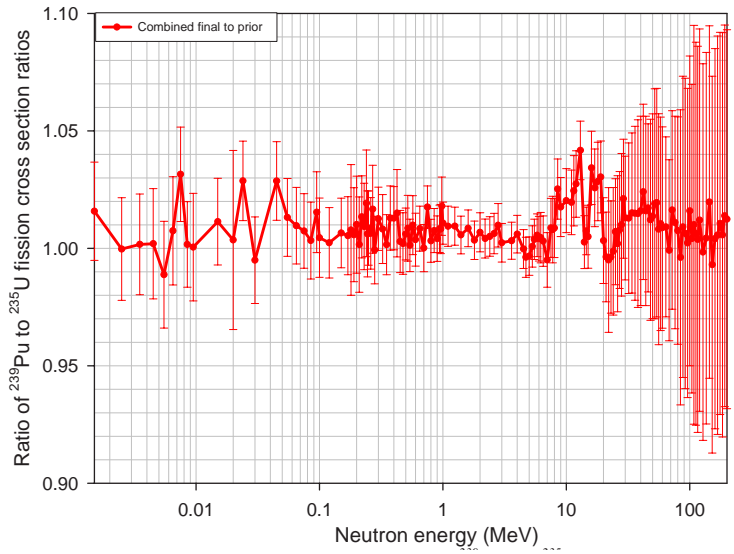

FIG. 7.82. Ratio of present to prior evaluations for the $\left.{ }^{239} \mathrm{Pu}(n, f)\right)^{235} U(n, f)$ reaction cross-section ratio.

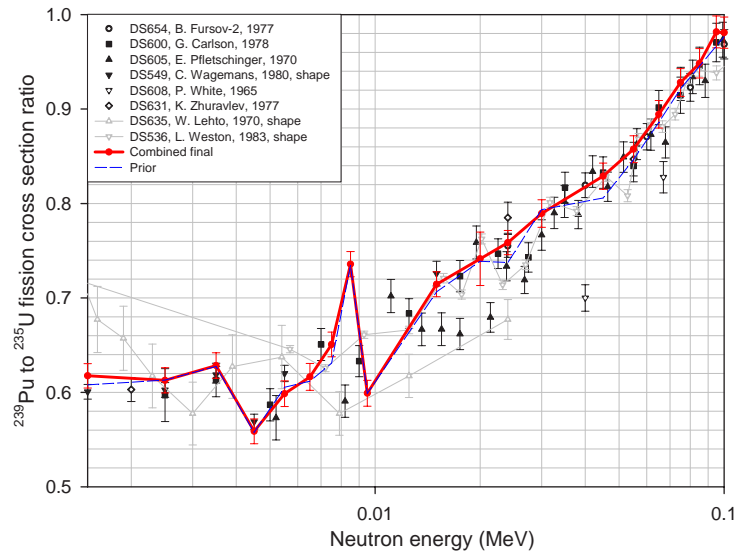

FIG. 7.83. Comparison of present and prior evaluations, together with experimental data for the ${ }^{239} \mathrm{Pu}(n, f)$ / ${ }^{235} U(n, f)$ reaction cross-section ratio in the energy range 0.0015-0.1 MeV

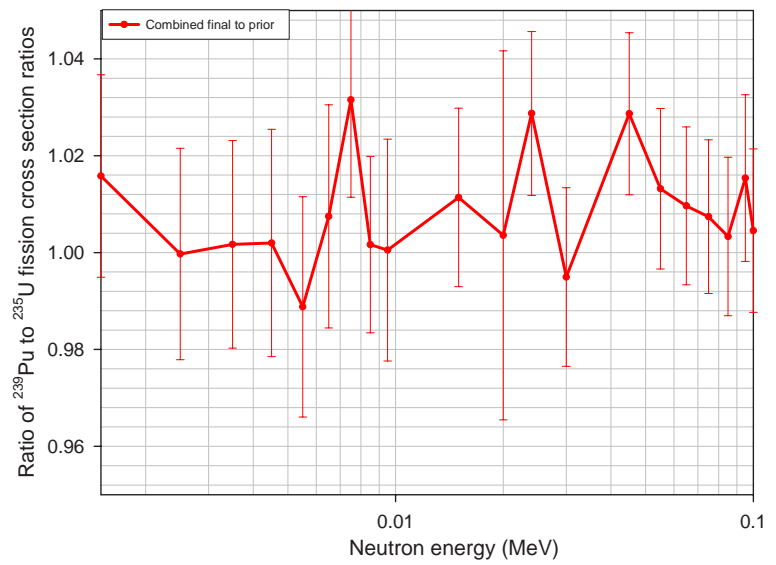

FIG. 7.84. Ratio of present to prior evaluations for the ${ }^{239} \mathrm{Pu}(n, f){ }^{235} \mathrm{U}(n, f)$ reaction cross-section ratio in the energy range 0.0015-0.1 $\mathrm{MeV}$. 


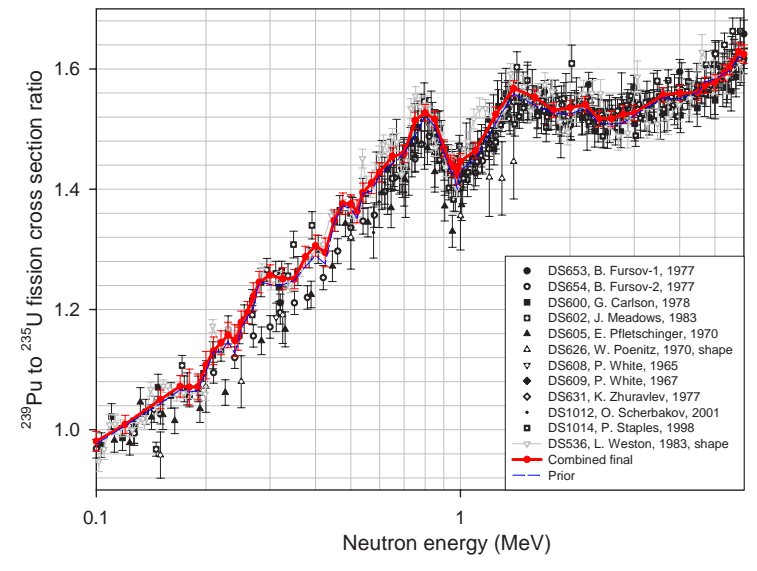

FIG. 7.85. Comparison of present and prior evaluations, together with experimental data for the ${ }^{239} \mathrm{Pu}(n, f) \rho^{235} U(n, f)$ reaction cross-section ratio in the energy range $0.1-6 \mathrm{MeV}$.

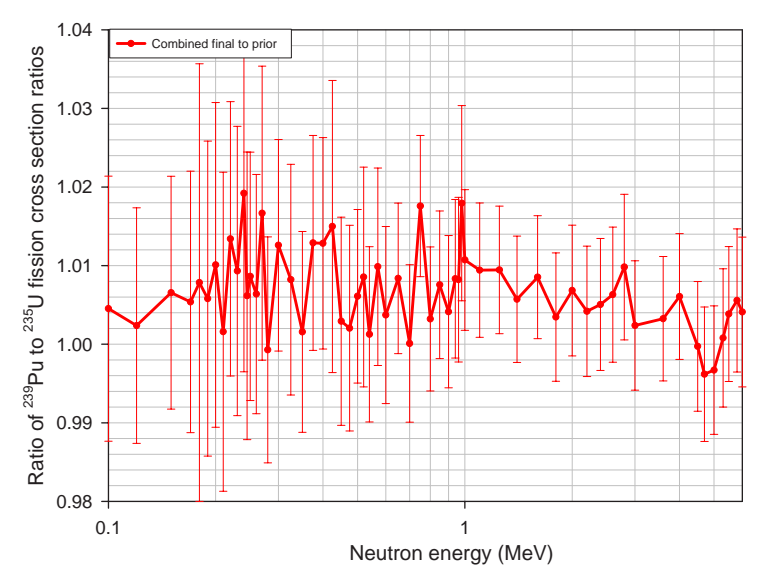

FIG. 7.86. Ratio of present to prior evaluations for the ${ }^{239} \mathrm{Pu}(n, f){ }^{235} U(n, f)$ reaction cross-section ratio in the energy range $0.1-6 \mathrm{MeV}$.

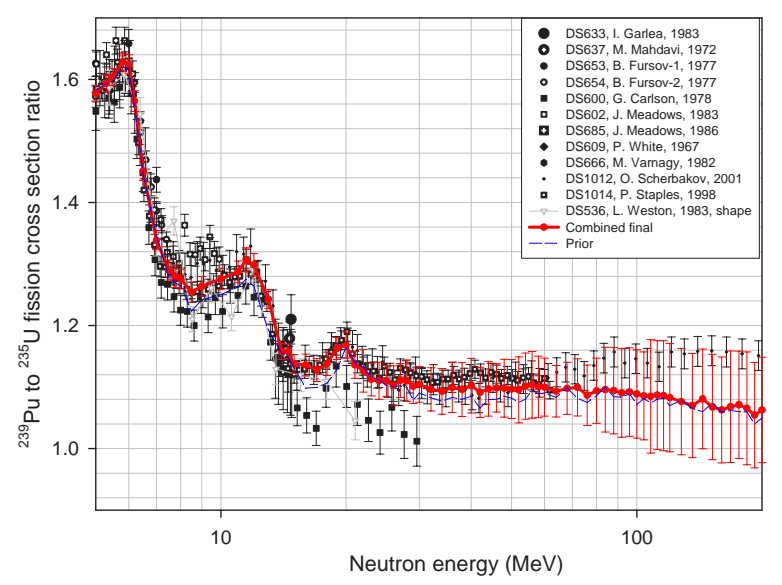

FIG. 7.87. Comparison of present and prior evaluations, together with experimental data for the ${ }^{239} \mathrm{Pu}(n, f) f^{235} U(n, f)$ reaction cross-section ratio in the energy range 5-200 $\mathrm{MeV}$.

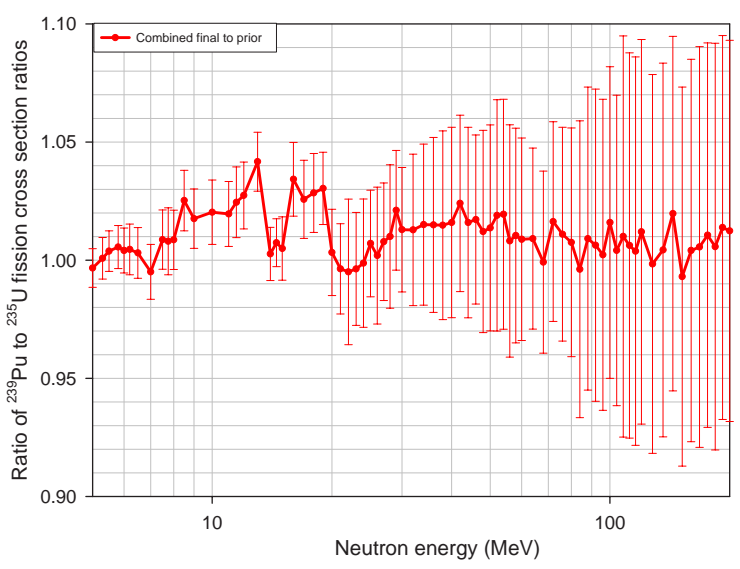

FIG. 7.88. Ratio of present to prior evaluations for the ${ }^{239} \mathrm{Pu}(n, f){ }^{235} \mathrm{U}(n, f)$ reaction cross-section ratio in the energy range 5-200 $\mathrm{MeV}$.

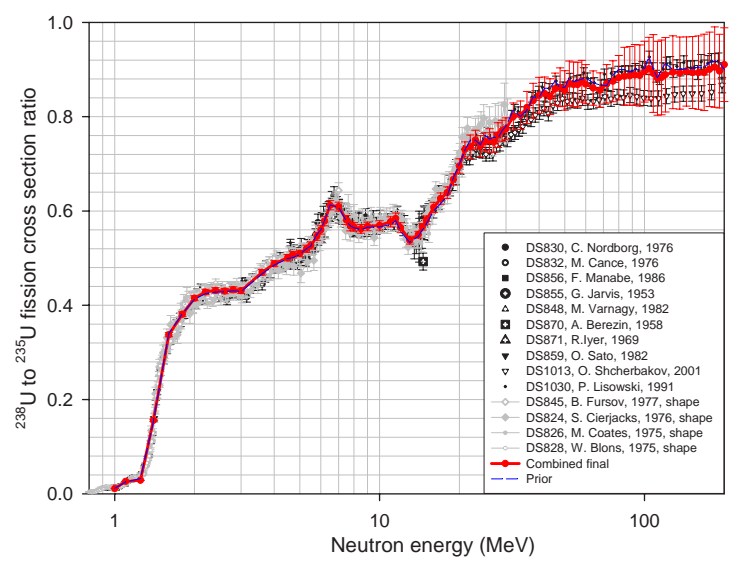

FIG. 7.89. Comparison of present and prior evaluations, together with experimental data for the ${ }^{238} U(n, f) f^{235} U(n, f)$ reaction cross-section ratio.

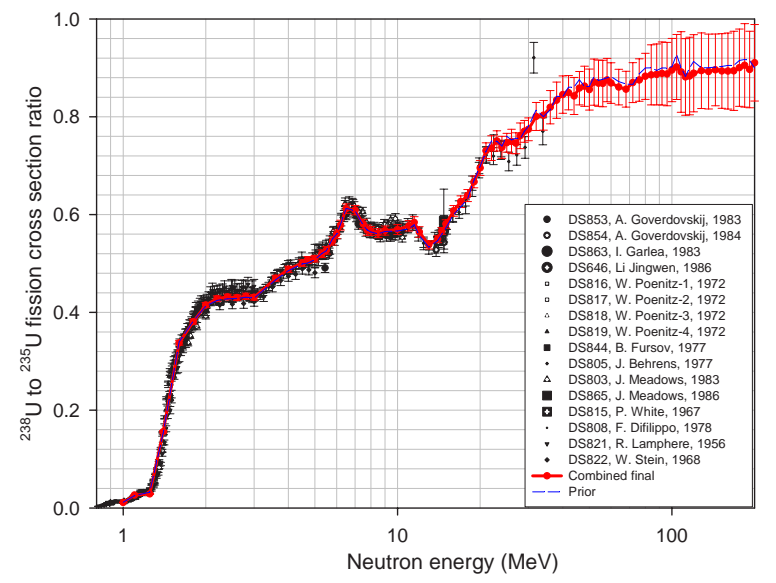

FIG. 7.90. Same as Fig. 7.89 with other experimental data. 


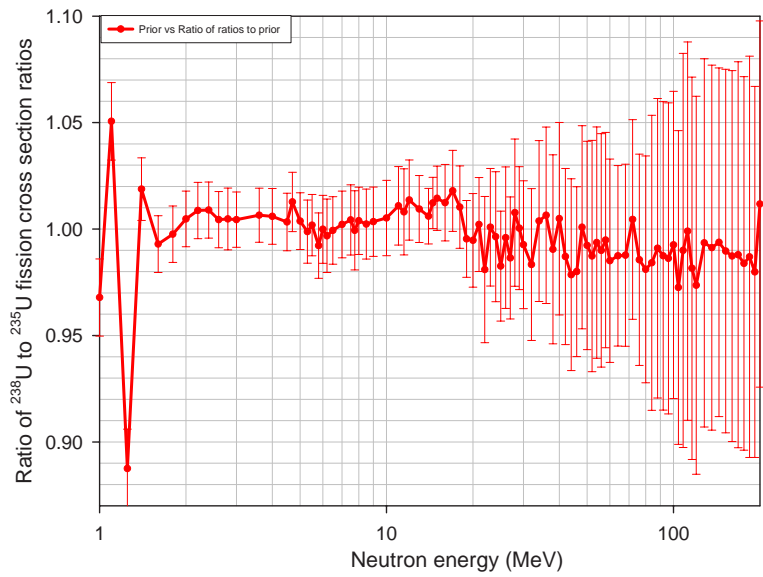

FIG. 7.91. Ratio of present to prior evaluations for the ${ }^{238} U(n, f){ }^{235} U(n, f)$ reaction cross-section ratio.

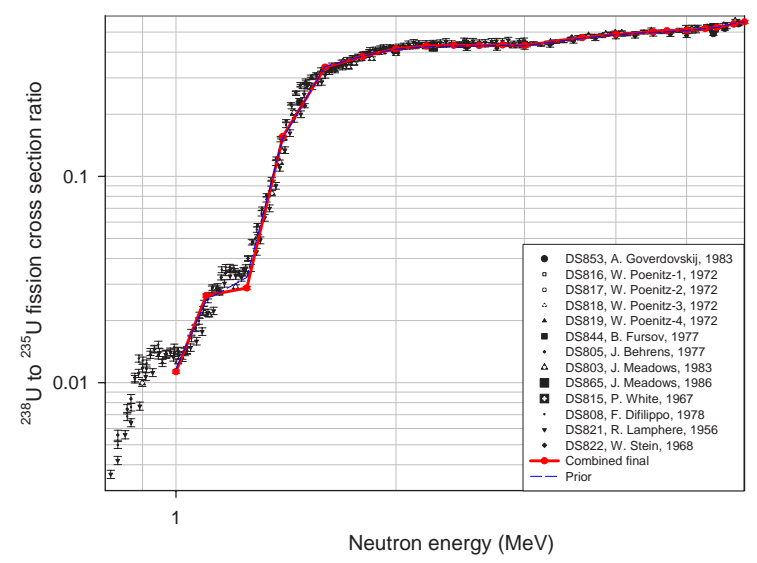

FIG. 7.92. Comparison of present and prior evaluations, together with experimental data for the ${ }^{238} U(n, f) \rho^{235} U(n, f)$ reaction cross-section ratio in the energy range 1-6 $\mathrm{MeV}$.

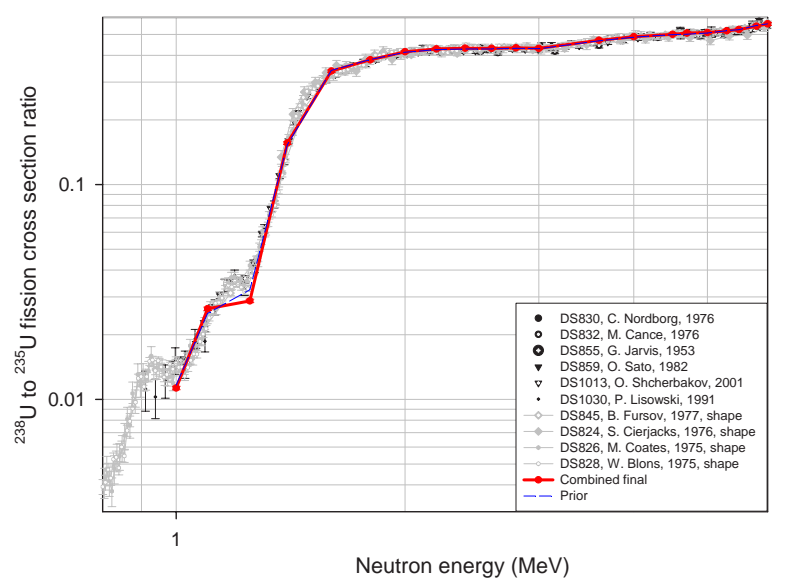

FIG. 7.93. Same as Fig. 7.92 with other experimental data.

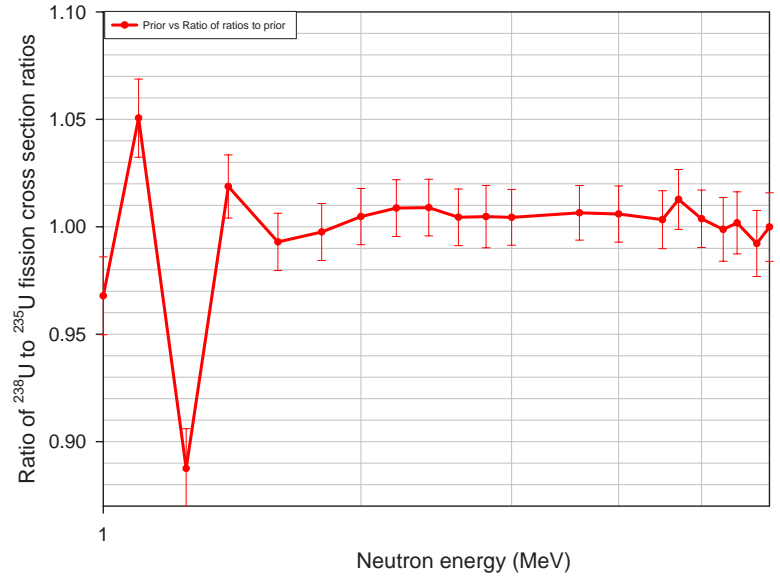

FIG. 7.94. Ratio of present to prior evaluations for the ${ }^{238} U(n, f){ }^{235} U(n, f)$ reaction cross-section ratio in the energy range 1-6 $\mathrm{MeV}$.

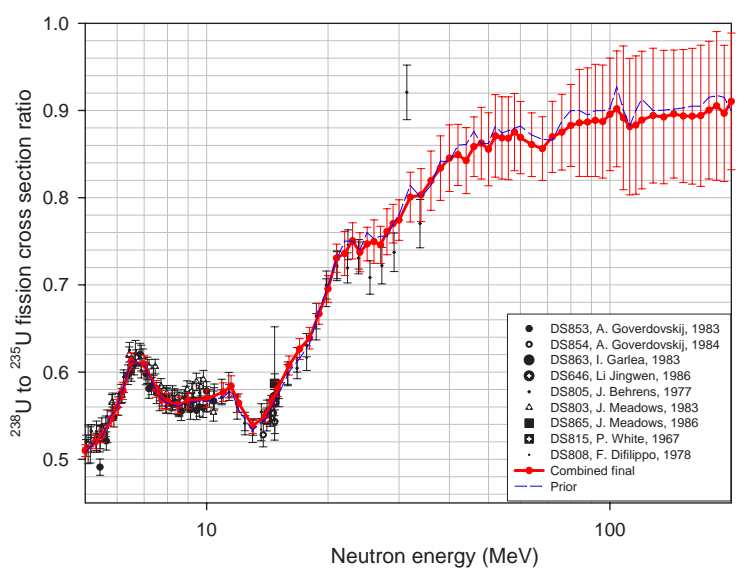

FIG. 7.95. Comparison of present and prior evaluations, together with experimental data for the ${ }^{238} U(n, f) f^{235} U(n, f)$ reaction cross-section ratio in the energy range 5-200 MeV.

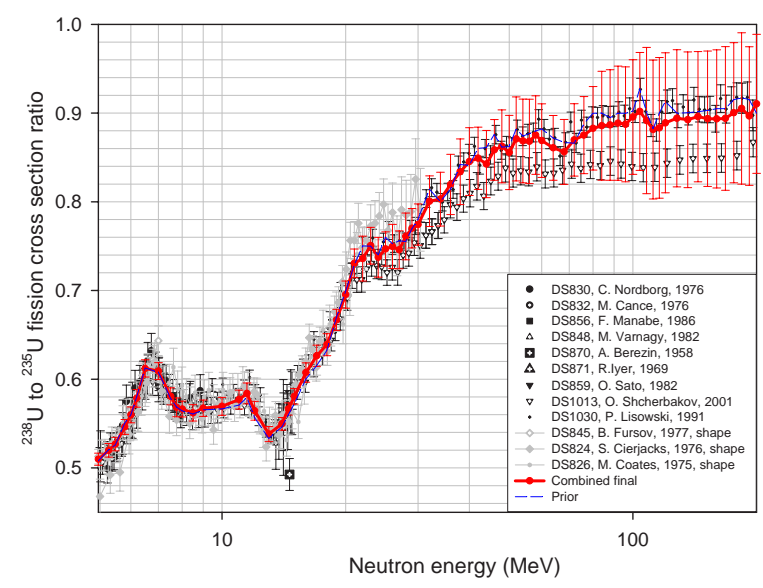

FIG. 7.96. Same as Fig. 7.95 with other experimental data. 


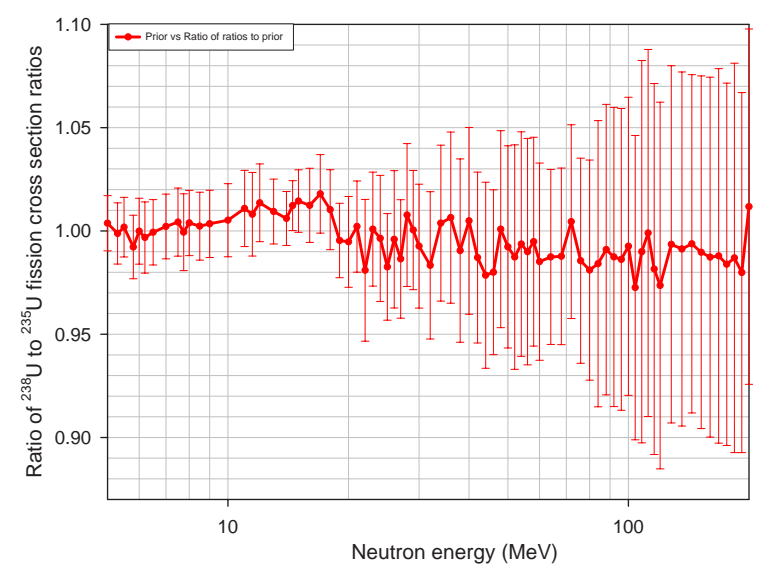

FIG. 7.97. Ratio of present to prior evaluations for the ${ }^{238} U(n, f){ }^{235} U(n, f)$ reaction cross-section ratio in the energy range 5-200 $\mathrm{MeV}$.

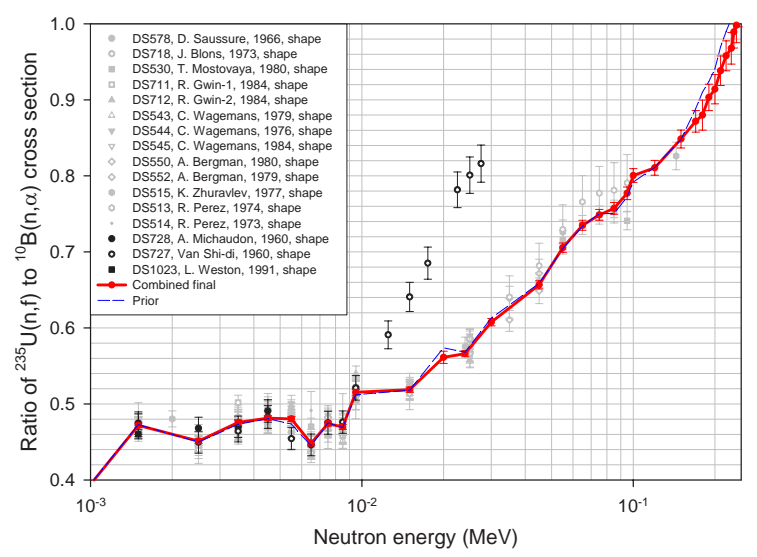

FIG. 7.98. Comparison of present and prior evaluations, together with experimental data for the ${ }^{235} U(n, f) /{ }^{10} B(n, \alpha)$ reaction cross-section ratio.

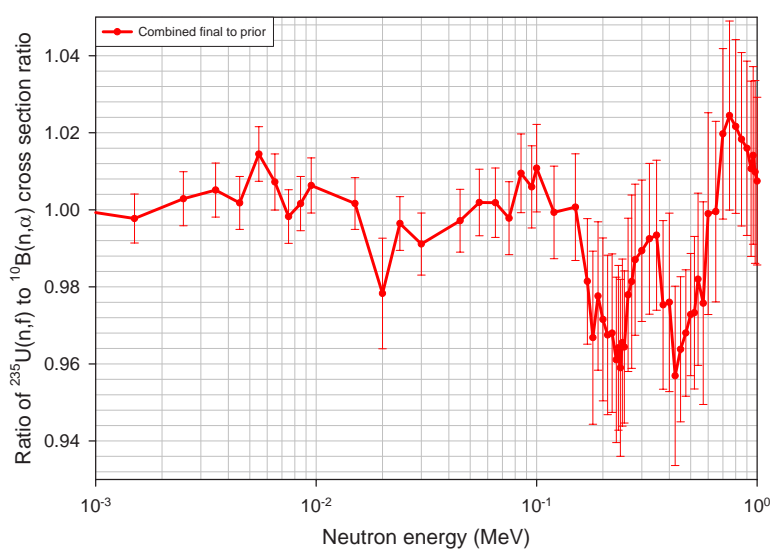

FIG. 7.99. Ratio of present to prior evaluations for the ${ }^{235} U(n, f) /{ }^{10} B(n, \alpha)$ reaction cross-section ratio.

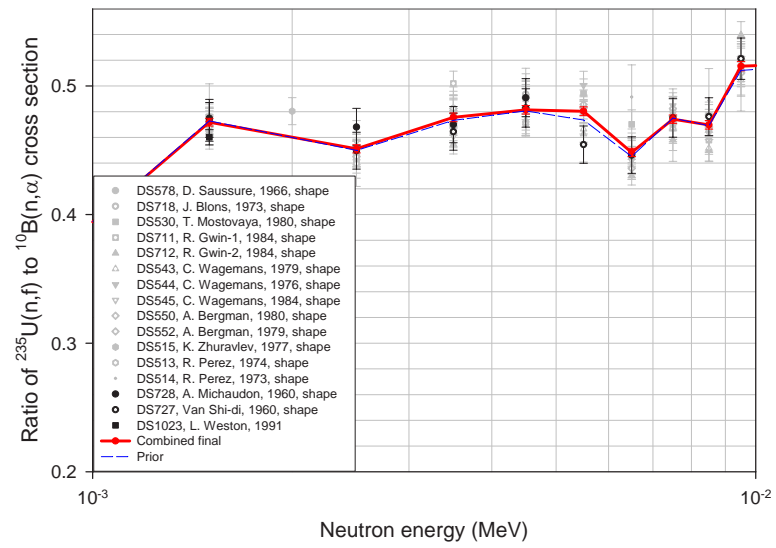

FIG. 7.100. Comparison of present and prior evaluations, together with experimental data for the ${ }^{235} U(n, f) /{ }^{10} B(n, \alpha)$ reaction cross-section ratio in the energy range 0.001-0.01 MeV.

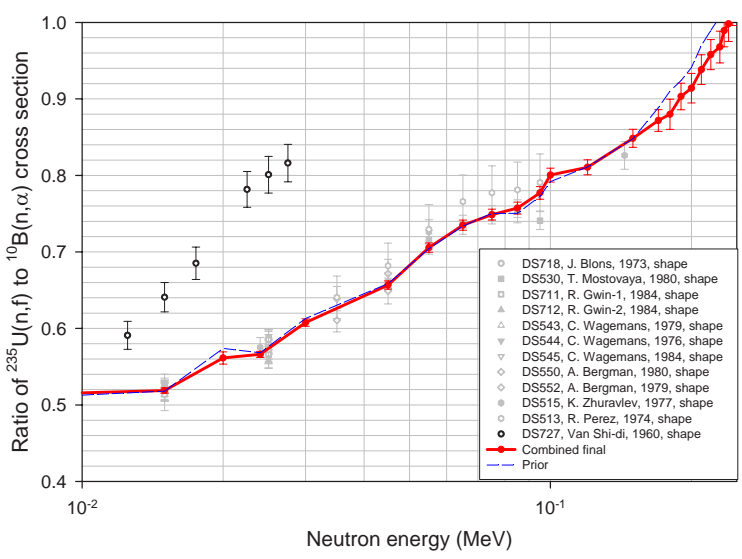

FIG. 7.101. Comparison of present and prior evaluations, together with experimental data for the ${ }^{235} U(n, f) /{ }^{10} B(n, \alpha)$ reaction cross-section ratio in the energy range $0.01-0.25 \mathrm{MeV}$.

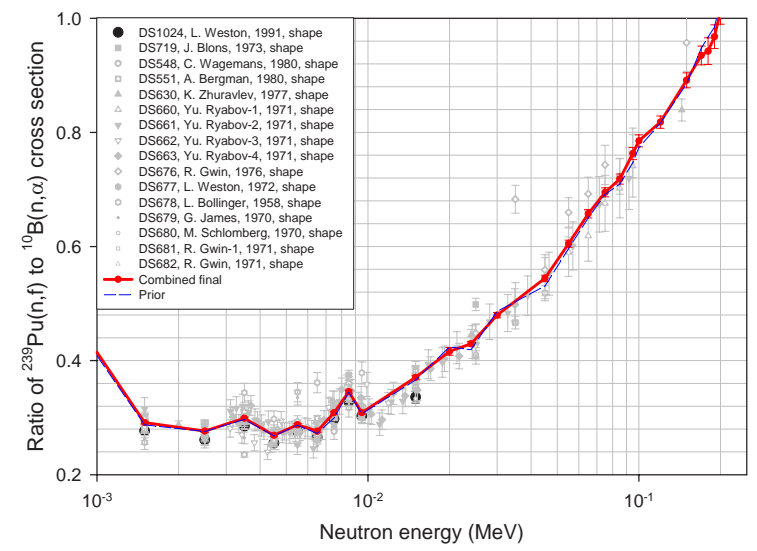

FIG. 7.102. Comparison of present and prior evaluations, together with experimental data for the ${ }^{239} \mathrm{Pu}(n, f) /{ }^{10} \mathrm{~B}(n, \alpha)$ reaction cross-section ratio. 


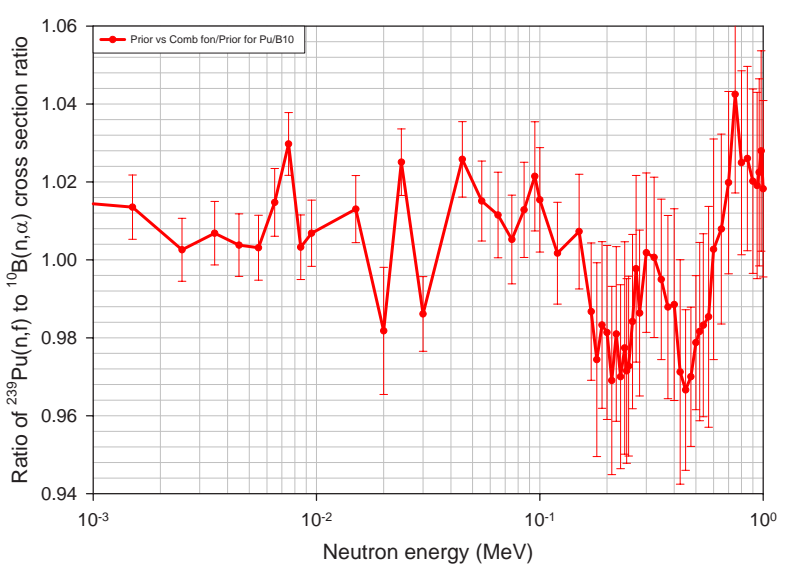

FIG. 7.103. Ratio of present to prior evaluations for the ${ }^{239} \mathrm{Pu}(n, f){ }^{10} \mathrm{~B}(n, \alpha)$ reaction cross-section ratio.

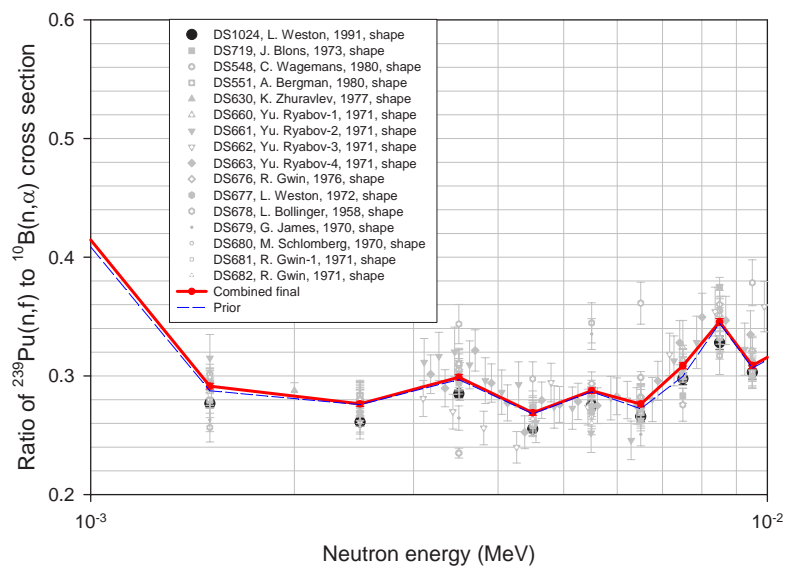

FIG. 7.104. Comparison of present and prior evaluations, together with experimental data for the ${ }^{239} \mathrm{Pu}(n, f){ }^{10} \mathrm{~B}(n, \alpha)$ reaction cross-section ratio in the energy range 0.001-0.01 MeV.

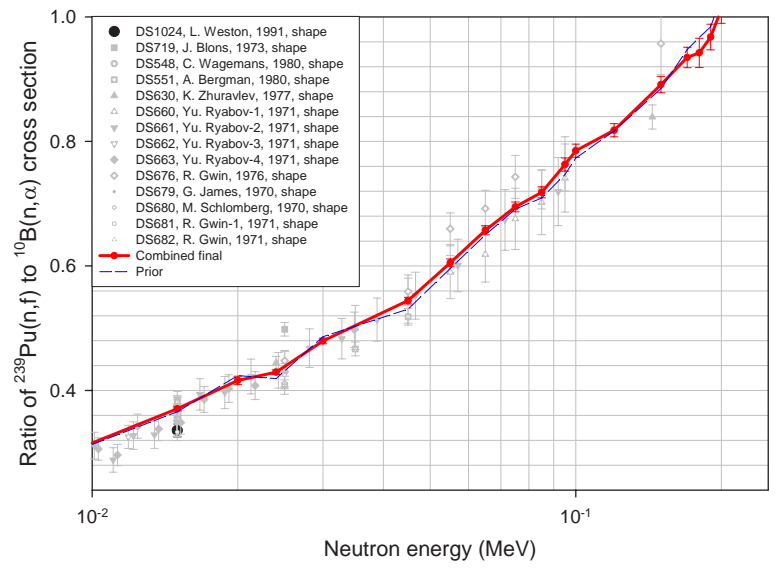

FIG. 7.105. Comparison of present and prior evaluations, together with experimental data for the ${ }^{239} \mathrm{Pu}(n, f){ }^{10} \mathrm{~B}(\mathrm{n}, \alpha)$ reaction cross-section ratio in the energy range 0.01-0.25 MeV.

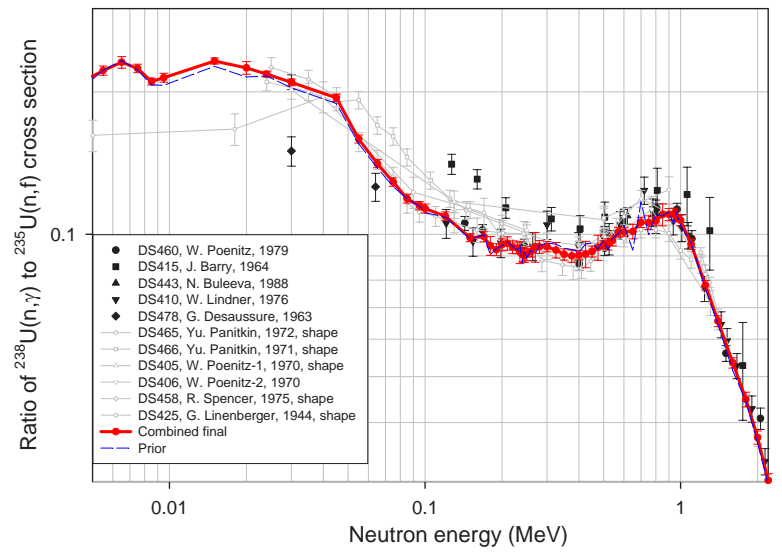

FIG. 7.106. Comparison of present and prior evaluations, together with experimental data for the ${ }^{238} U(n, \gamma){ }^{235} U(n, f)$ reaction cross-section ratio.

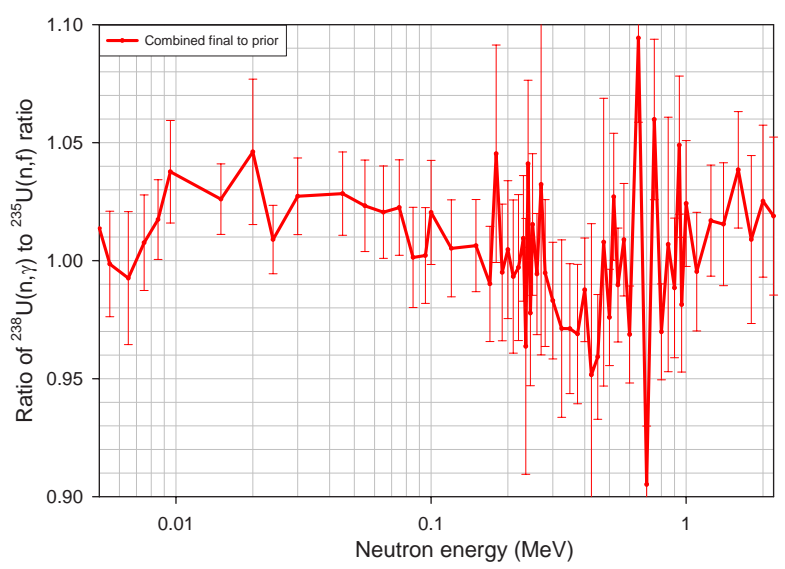

FIG. 7.107. Ratio of present to prior evaluations for the ${ }^{238} U(n, \gamma){ }^{235} U(n, f)$ reaction cross-section ratio.

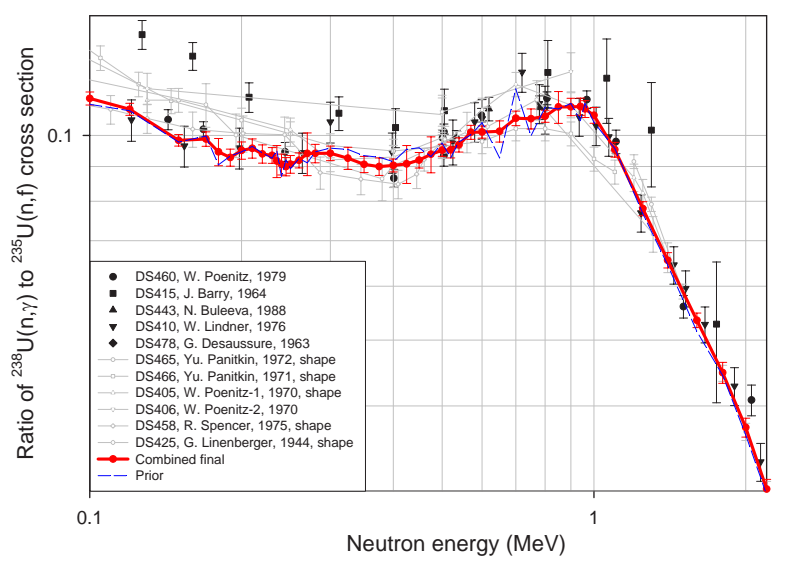

FIG. 7.108. Comparison of present and prior evaluations, together with experimental data for the ${ }^{238} U(n, \gamma){ }^{235} U(n, f)$ reaction cross-section ratio in the energy range 0.1-2.2 MeV. 


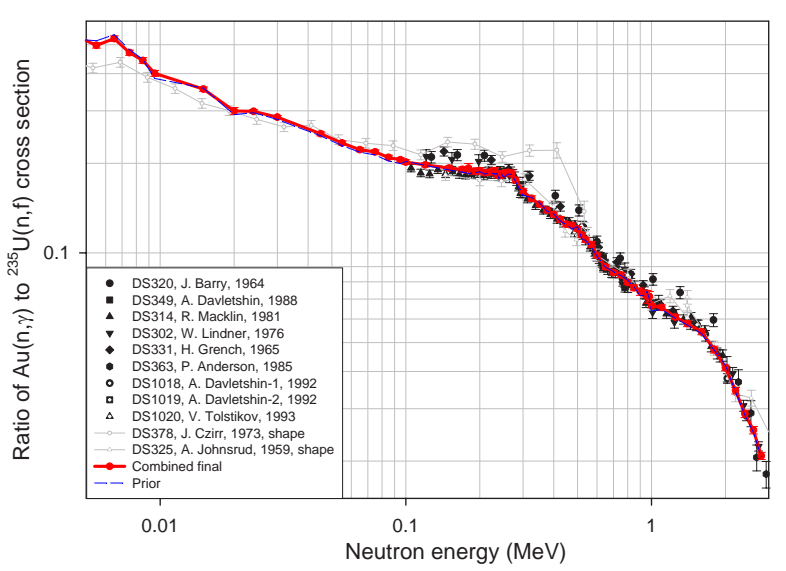

FIG. 7.109. Comparison of present and prior evaluations, together with experimental data for the $A u(n, \gamma) f^{235} U(n, f)$ reaction cross-section ratio.

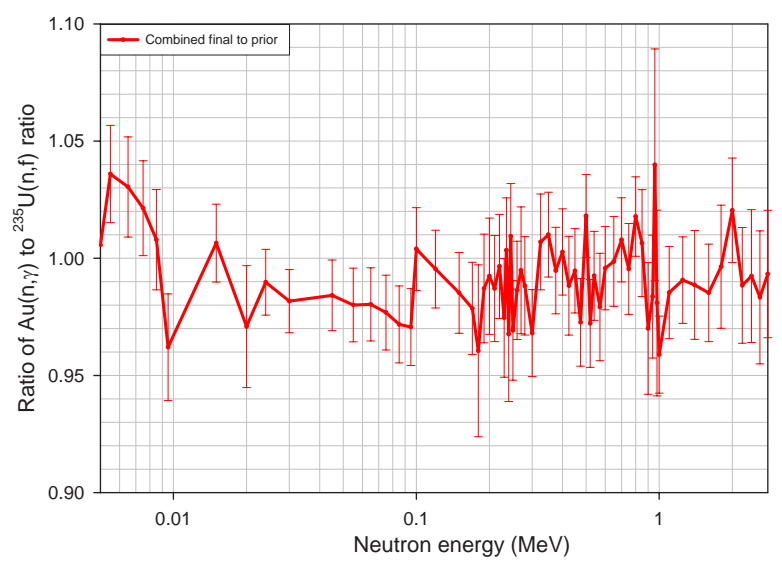

FIG. 7.110. Ratio of present to prior evaluations for the $A u(n, \gamma))^{235} U(n, f)$ reaction cross-section ratio.

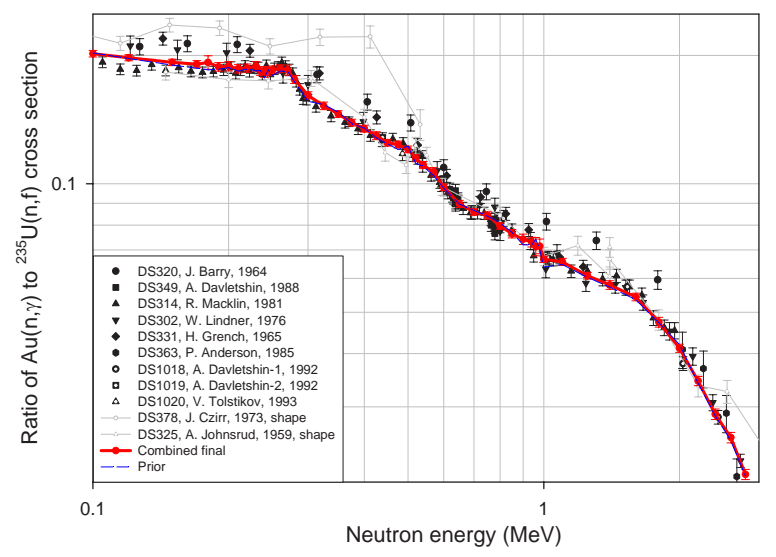

FIG. 7.111. Comparison of present and prior evaluations, together with experimental data for the $A u(n, \gamma) f^{235} U(n, f)$ reaction cross-section ratio in the energy range $0.1-2.8 \mathrm{MeV}$.

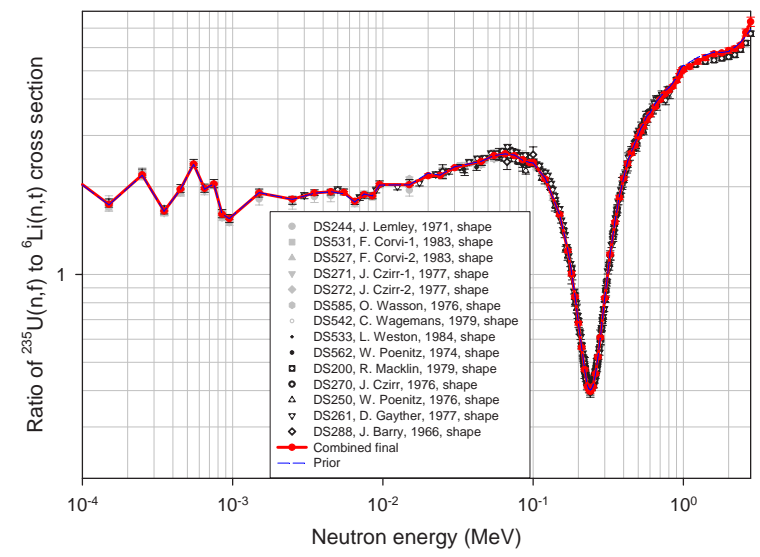

FIG. 7.112. Comparison of present and prior evaluations, together with experimental data for the ${ }^{235} U(n, f){ }^{6} \mathrm{Li}(n, \alpha)$ reaction cross-section ratio.

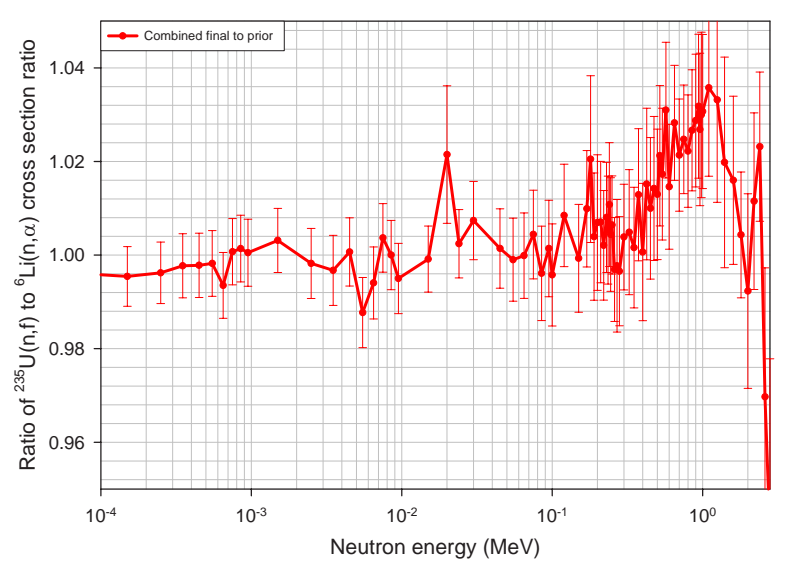

FIG. 7.113. Ratio of present to prior evaluations for the ${ }^{235} U(n, f) /{ }^{6} \mathrm{Li}(n, \alpha)$ reaction cross-section ratio.

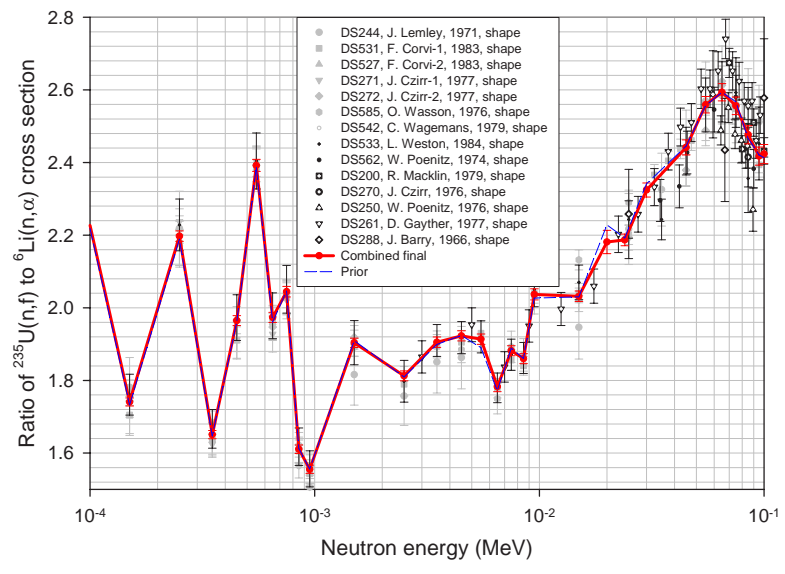

FIG. 7.114. Comparison of present and prior evaluations, together with experimental data for the ${ }^{235} U(n, f){ }^{6} \mathrm{Li}(n, \alpha)$ reaction cross-section ratio in the energy range 0.0001-0.1 MeV. 


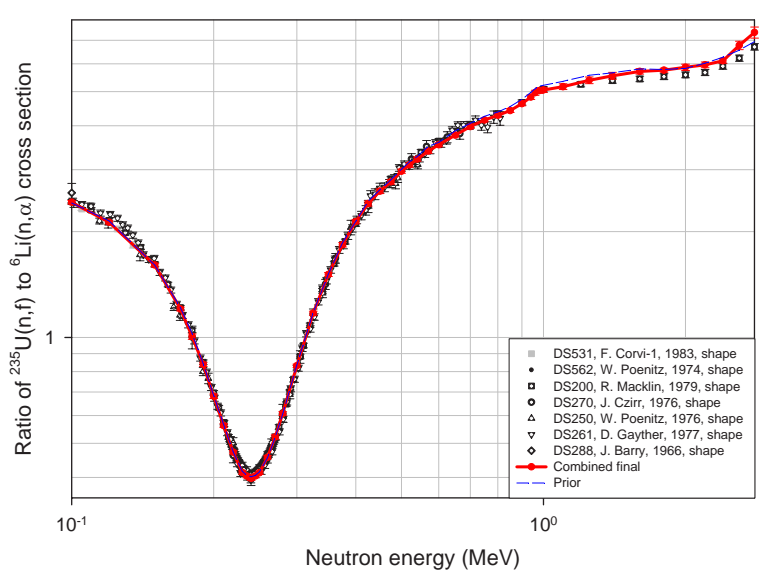

FIG. 7.115. Comparison of present and prior evaluations, together with experimental data for the ${ }^{235} U(n, f) / 6 i(n, \alpha)$ reaction cross-section ratio in the energy range $0.1-2.8 \mathrm{MeV}$.

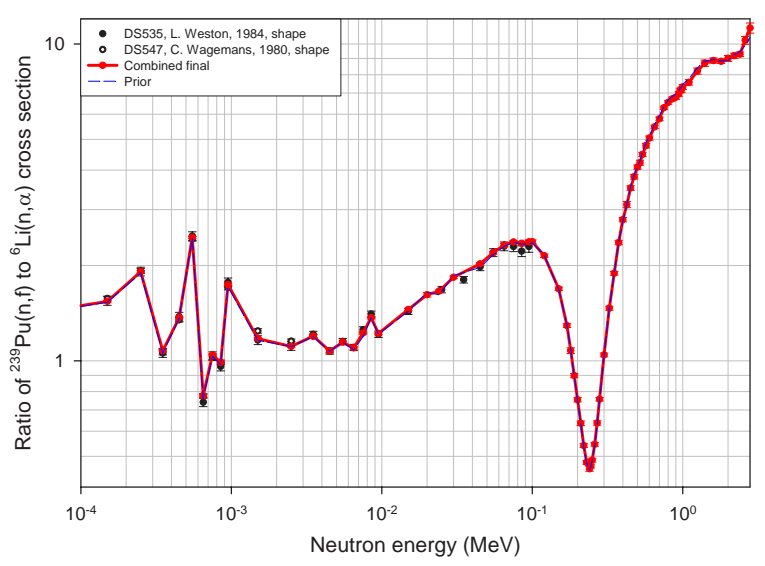

FIG. 7.116. Comparison of present and prior evaluations, together with experimental data for the ${ }^{239} \mathrm{Pu}(n, f){ }^{\circ} \mathrm{Li}(n, \alpha)$ reaction cross-section ratio.

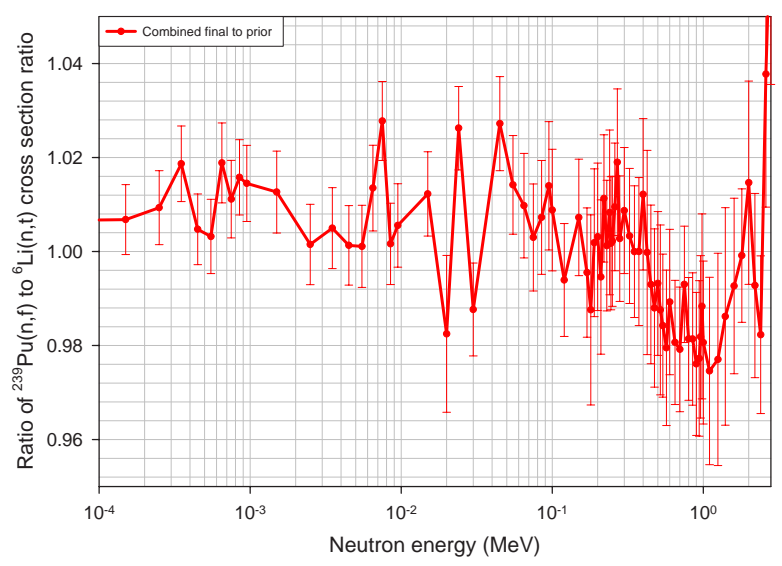

FIG. 7.117. Ratio of present to prior evaluations for the ${ }^{239} \mathrm{Pu}(n, f){ }^{\circ} \mathrm{Li}(n, \alpha)$ reaction cross-section ratio.

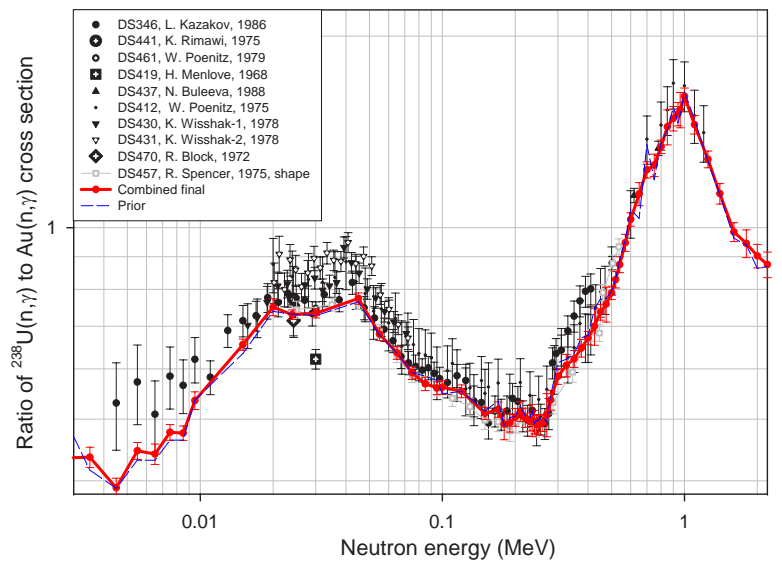

FIG. 7.118. Comparison of present and prior evaluations, together with experimental data for the ${ }^{238} U(n, \gamma) / A u(n, \gamma)$ reaction cross-section ratio.

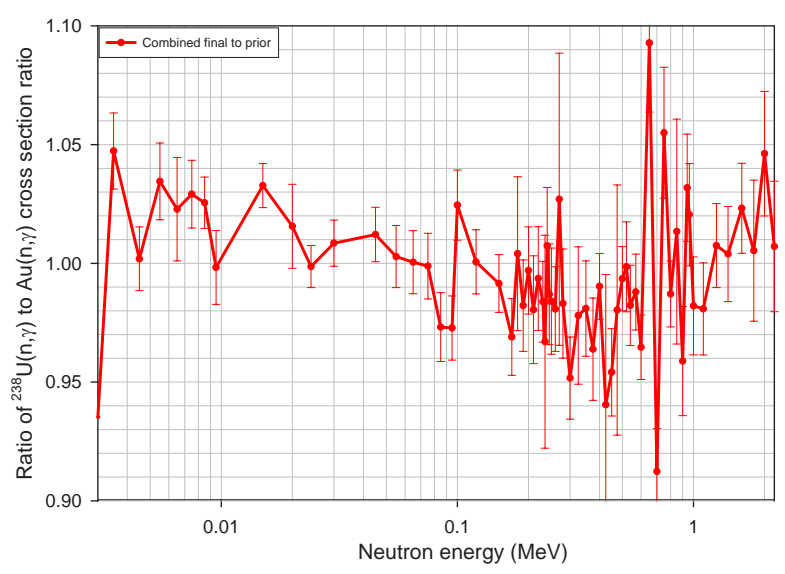

FIG. 7.119. Ratio of present to prior evaluations for the ${ }^{238} U(n, \gamma) / A u(n, \gamma)$ reaction cross-section ratio.

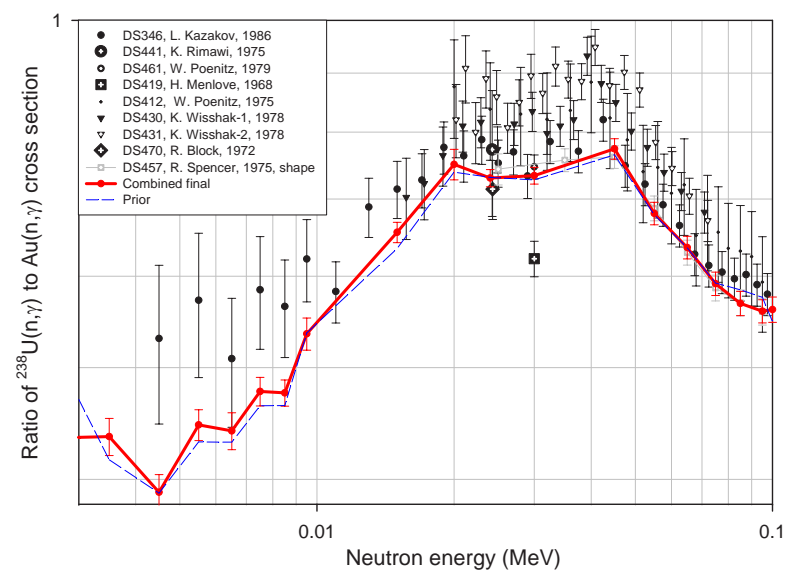

FIG. 7.120. Comparison of present and prior evaluations, together with experimental data for the ${ }^{238} U(n, \gamma) / A u(n, \gamma)$ reaction cross-section ratio in the energy range 0.0001-0.1 MeV. 


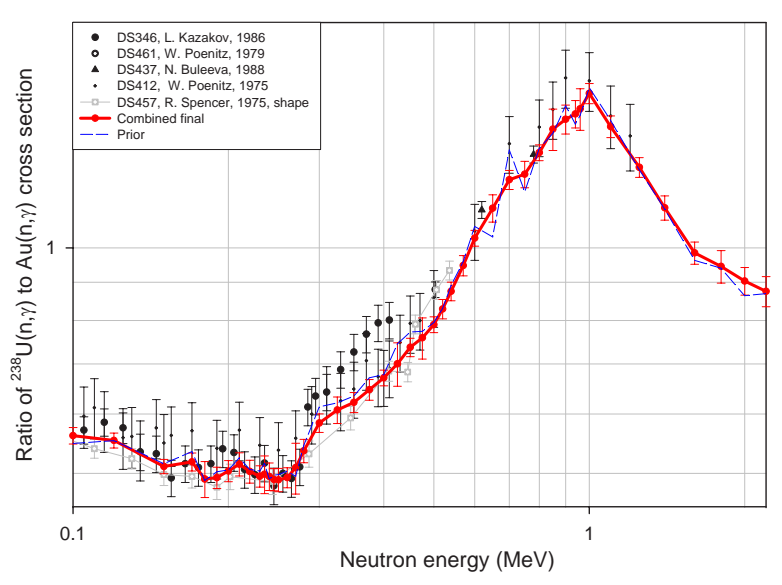

FIG. 7.121. Comparison of present and prior evaluations, together with experimental data for the ${ }^{238} U(n, \gamma) / A u(n, \gamma)$ reaction cross-section ratio in the energy range 0.1-2.2 MeV.

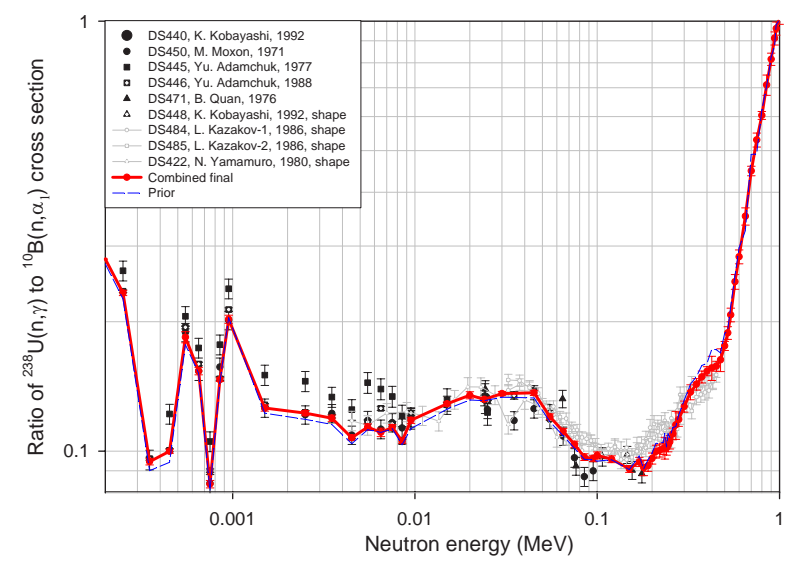

FIG. 7.122. Comparison of present and prior evaluations, together with experimental data for the ${ }^{238} U(n, \gamma){ }^{10} B\left(n, \alpha_{1}\right)$ reaction cross-section ratio.

\section{REFERENCES TO SECTION 7}

[7.1] CONDÉ, H. (Ed.), Nuclear Data Standards for Nuclear Measurements, 1991 NEANDC/INDC Nuclear Standards File, Rep. NEANDC-311, INDC(SEC)-101, OECD, Paris (1992).

[7.2] CARLSON, A.D., et al., ENDF/B-VI Neutron Cross Section Measurement Standards, Rep. NISTIR-5177, National Institute of Standards and Technology, Gaithersburg, MD (1993); also ENDF/B-VI Neutron Cross Section Measurement Standards, Rep. ENDF-351, Brookhaven Natl Lab., Upton, NY (1993).

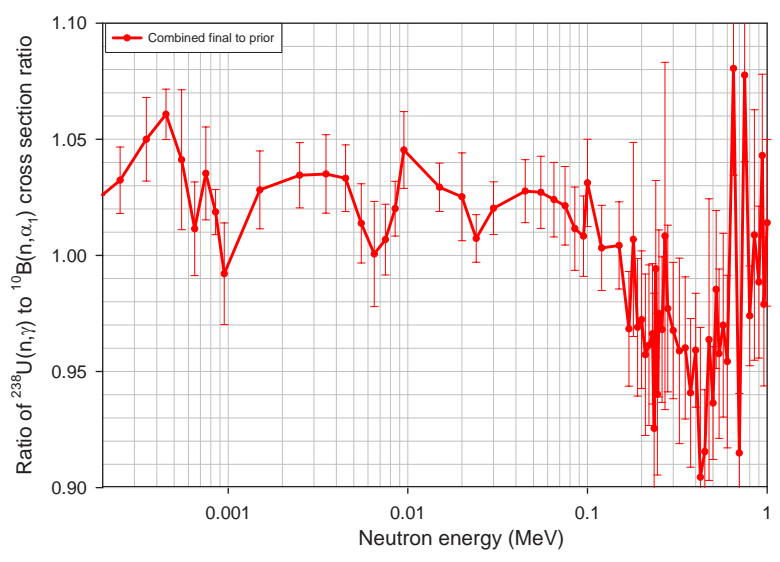

FIG. 7.123. Ratio of present to prior evaluations for the ${ }^{238} U(n, \gamma){ }^{10} B\left(n, \alpha_{1}\right)$ reaction cross-section ratio.

[7.3] CARLSON, A.D., CHIBA, S., HAMBSCH, F.-J., OLSSON, N., SMIRNOV, A.N., "Update to nuclear data standards for nuclear measurements", Nuclear Data for Science and Technology (Proc. Int. Conf. Trieste, 1997), Vol. 59, Part II (REFFO, G., VENTURA, A., GRANDI, C., Eds), Italian Physics Society, Bologna (1997) 1223-1229.

[7.4] HALE, G.M., File MAT=125, ENDF/B-VII beta1 version, June 2005.

[7.5] AXTON, E.J., Evaluation of Thermal Constants of ${ }^{233} \mathrm{U},{ }^{235} \mathrm{U},{ }^{239} \mathrm{Pu}$ and ${ }^{241} \mathrm{Pu}$ and the Fission Neutron Yield of ${ }^{252} \mathrm{Cf}$, Rep. GE/PH/01/86, Commission of the European Communities, Joint Research Centre, Geel (1986).

[7.6] GIORGINIS, G., KHRYACHKOV, V., "Particle leaking, cross-section ratio ${ }^{10} \mathrm{~B}\left(\mathrm{n}, \alpha_{0}\right) /$ ${ }^{238} \mathrm{U}$ (n,fission), and excitation function of the reaction $\left.{ }^{10} \mathrm{~B}(\mathrm{n}, \alpha)\right)^{7} \mathrm{Li}$ at $1 \mathrm{MeV}$ Energies", Nuclear Data for Science and Technology (Proc. Int. Conf. Santa Fe, NM, 2004), American Institute of Physics Conf. Proc. 769, Part 1 (HAIGHT, R.C., CHADWICK, M.B., KAWANO, T., TALOU, P., Eds), American Institute of Physics, New York (2005) 816-819.

[7.7] TRKOV, A., et al., Revisiting the ${ }^{238} \mathrm{U}$ thermal capture cross section and gamma-ray emission probabilities from ${ }^{239} \mathrm{~Np}$ decay, Nucl. Sci. Eng. 150 (2005) 336-348.

[7.8] ARIF, M., KAISER, H., WERNER, S.A., WILLIS, J.O., Precision measurements of the bound coherent neutron scattering length of ${ }^{235} \mathrm{U}$, Phys. Rev. A 35 (1987) 2810-2814.

[7.9] GWIN, R., SPENCER, R.R., INGLE，R.W., Measurements of the energy dependence of prompt neutron emission from ${ }^{233} \mathrm{U},{ }^{235} \mathrm{U}$ and ${ }^{239} \mathrm{Pu}$ for $\mathrm{E}=0.005$ to $10 \mathrm{eV}$ relative to emission from spontaneous fission of ${ }^{252} \mathrm{Cf}$, Nucl. Sci. Eng. 87 (1984) 381-404. 


\title{
8. RESULTING STANDARDS DATA
}

\author{
V.G. Pronyaev, S.A. Badikov, A.D. Carlson, Chen Zhenpeng, E.V. Gai, G.M. Hale, F.-J. Hambsch, \\ H.M. Hofmann, T. Kawano, N.M. Larson, D.L. Smith, Soo-Youl Oh, S. Tagesen, H. Vonach
}

Nuclear models and experimental data used in the evaluation of the standards introduce not only cross-energy correlations but also cross-reaction and cross-material correlations. Thus the full set of evaluated standard reactions should include the set of all coupled reactions used in the evaluation and the full covariance matrix of uncertainty with all cross-reaction and cross-material covariances. Under these circumstances, the presentation of the uncertainties of any data measured relative to the standard reaction and reduced to absolute values will require the full covariance matrix of the uncertainties for the standard reactions. If the correlations between some reactions obtained in the evaluation can be considered as negligible, the blocks of the full covariance matrix that describe such correlations do not need to be used. However, adding new data to the evaluation will require the use of the full covariance matrix of such data, since the earlier recommendations represent the results of a previous evaluation based on the Bayesian approach.

The most direct way to include the results of $\mathrm{R}$ matrix analyses in the combined fit of the standards is through the use of evaluated parameters, the covariance matrix of the uncertainties of these parameters and the sensitivity coefficients of the cross-section to the parameters. An attempt to use this procedure was undertaken in the ENDF/B-VI evaluation of the standards, but proved to be unsuccessful. The cross-sections for ${ }^{6} \mathrm{Li}(\mathrm{n}, \mathrm{n}),{ }^{6} \mathrm{Li}(\mathrm{n}, \mathrm{t})$, ${ }^{10} \mathrm{~B}(\mathrm{n}, \mathrm{n}),{ }^{10} \mathrm{~B}\left(\mathrm{n}, \alpha_{0}\right)$ and ${ }^{10} \mathrm{~B}\left(\mathrm{n}, \alpha_{1}\right)$ as well as the covariance matrices of uncertainties for these reactions (including the blocks describing the crossreaction calculations) were reconstructed from $\mathrm{R}$ matrix evaluated parameters and their covariance matrix for the ${ }^{6} \mathrm{Li}+\mathrm{n}$ and ${ }^{10} \mathrm{~B}+\mathrm{n}$ systems and used as pseudo-experimental data in the final combined fit. This method may underestimate the correlations and gives more freedom to the variation of the cross-sections taken from the $\mathrm{R}$ matrix analysis in the combined GMA fit. However, such an approach reduces the complexity and non-uniformity of the presentation of information on the uncertainties of the standards.

Some users may prefer the evaluated covariance matrix of the uncertainties to have only cross-energy correlations between data points for a given standard reaction (lower triangle of the square covariance matrix). While other users prefer an even simpler approach in which only the diagonal values of the covariance matrix (variances) or percentage uncertainties are employed. Clearly some caution is required in the use of such uncertainties, especially when the standards are applied in the evaluation of the uncertainties of the crosssections measured relative to the standard crosssections, or in the evaluation of the uncertainty of an integral quantity obtained by means of this standard.

Standard cross-sections (central values) evaluated with the non-parametric least squares GMA code may need to be smoothed. The crosssections for the neutron reactions with ${ }^{6} \mathrm{Li}$ and ${ }^{10} \mathrm{~B}$ were evaluated on the basis of $\mathrm{R}$ matrix model fitting, and continue to be very smooth after being combined in the GMA fit with other data due to the dominance of the $\mathrm{R}$ matrix data. However, the evaluated capture and fission cross-sections for the standards and other reactions for the heavy isotopes may sometimes exhibit a non-smooth energy dependence at energies where no physical justification can be given for such behaviour. These discontinuities in the cross-section values at neighbouring points are usually within the defined uncertainties, but they should be smoothed for the tabulation of the standard values. A simple three point smoothing scheme was applied to the crosssections in limited regions where the non-smooth behaviour was most significant. Smoothing was not applied in the regions where the structure and variation in the cross-sections could be physically justified or supported by other data such as crosssection ratios.

The results of the evaluation of the neutron cross-section standards and other important crosssections obtained in the standards evaluation process are given in Tables 8.1-8.9. Both the evaluated cross-sections and their uncertainties are listed. The cross-sections are point values at all energies for ${ }^{6} \mathrm{Li}$ and ${ }^{10} \mathrm{~B}$, while the cross-sections are point values at thermal and above $20 \mathrm{keV}$ for the heavy elements. Average heavy element crosssections are given from $0.1-0.2 \mathrm{keV}$ (labelled 
$0.15 \mathrm{keV}$ ) to $10-20 \mathrm{keV}$ (labelled $15 \mathrm{keV}$ ). The value at $9.4 \mathrm{eV}$ for the ${ }^{235} \mathrm{U}(\mathrm{n}, \mathrm{f})$ cross-section represents the integral (barn-eV) from 7.8 to $11 \mathrm{eV}$, which is often used to normalize some crosssections. Covariance (correlation) matrices are not given because of their size, although they have been included in two different sets of evaluated data files in ENDF-6 format. One of these sets of files contains covariance matrices with only cross-energy and cross-reaction covariances included for the given material. The second file also includes blocks of cross-material covariances and gives the most complete presentation of the uncertainties of the standards. Only blocks describing cross-material covariances are included in the files that contain at least one correlation coefficient with an absolute value higher than 0.2. All other cross-material correlations have been judged to be unimportant and are not included.

The standards evaluation also contains the thermal constants for the main fissile materials: ${ }^{233} \mathrm{U},{ }^{235} \mathrm{U},{ }^{239} \mathrm{Pu}$ and ${ }^{241} \mathrm{Pu}$. These data include $0.0253 \mathrm{eV}$ fission cross-sections, capture and elastic scattering cross-sections, $\mathrm{g}$ factors for absorption and fission and the average neutron yield per fission. Furthermore, the average neutron yield per fission for ${ }^{252} \mathrm{Cf}$ is specified. The evaluated thermal constants and the covariance matrix of their uncertainties are given in Section 7, along with plots comparing the new and old standards with experimental data.

Data tables for the ${ }^{1} \mathrm{H}(\mathrm{n}, \mathrm{n}),{ }^{3} \mathrm{He}(\mathrm{n}, \mathrm{p})$ and $\mathrm{C}(\mathrm{n}, \mathrm{n})$ cross-section standards are included for completeness (Tables 8.10, 8.12 and 8.13), even though they are not products of the present evaluation efforts. The ${ }^{1} \mathrm{H}(\mathrm{n}, \mathrm{n})$ evaluation is a new hydrogen standard prepared by Hale that includes all the latest experimental data. The evaluations undertaken in the 1980 s for ${ }^{3} \mathrm{He}(\mathrm{n}, \mathrm{p})$ and $\mathrm{C}(\mathrm{n}, \mathrm{n})$ reactions were judged to be essentially suitable for re-adoption. Legendre polynomial coefficients for the angular distribution of protons from the ${ }^{3} \mathrm{He}(\mathrm{n}, \mathrm{p})$ reaction and neutrons from the $\mathrm{C}(\mathrm{n}, \mathrm{n})$ reaction are given in Tables 8.11 and 8.14 , because the differential cross-sections for these two reactions are also standards (taken from the standards files of the ENDF/B-VII library).

TABLE 8.1. ${ }^{6} \mathrm{Li}(\mathrm{n}, \mathrm{t})\left(\mathrm{OR}{ }^{6} \mathrm{Li}(\mathrm{n}, \alpha)\right)$ CROSS-SECTION RECOMMENDED FOR USE AS A STANDARD IN THE INCIDENT NEUTRON ENERGY RANGE $0.0253 \mathrm{eV}-1 \mathrm{MeV}$

\begin{tabular}{|c|c|c|c|}
\hline $\begin{array}{l}\text { Neutron energy } \\
(\mathrm{MeV})\end{array}$ & $\begin{array}{l}\text { Cross-section } \\
\text { (barn) }\end{array}$ & $\begin{array}{c}\text { Cross-section } \\
\text { uncertainty (barn) }\end{array}$ & $\begin{array}{c}\text { Cross-section } \\
\text { uncertainty }(\%)\end{array}$ \\
\hline $0.2530 \mathrm{E}-07$ & 938.46695117 & 1.26713157 & 0.1350 \\
\hline $0.9400 \mathrm{E}-05$ & 48.66048038 & 0.06565630 & 0.1349 \\
\hline $0.1500 \mathrm{E}-03$ & 12.16302873 & 0.01641901 & 0.1350 \\
\hline $0.2500 \mathrm{E}-03$ & 9.41678082 & 0.01270708 & 0.1349 \\
\hline $0.3500 \mathrm{E}-03$ & 7.95665688 & 0.01073788 & 0.1350 \\
\hline $0.4500 \mathrm{E}-03$ & 7.01412166 & 0.00946690 & 0.1350 \\
\hline $0.5500 \mathrm{E}-03$ & 6.34297383 & 0.00849980 & 0.1340 \\
\hline $0.6500 \mathrm{E}-03$ & 5.83410908 & 0.00781842 & 0.1340 \\
\hline $0.7500 \mathrm{E}-03$ & 5.42980902 & 0.00727563 & 0.1340 \\
\hline $0.8500 \mathrm{E}-03$ & 5.09963128 & 0.00683370 & 0.1340 \\
\hline $0.9500 \mathrm{E}-03$ & 4.82363700 & 0.00646264 & 0.1340 \\
\hline $0.1500 \mathrm{E}-02$ & 3.83625493 & 0.00510154 & 0.1330 \\
\hline $0.2500 \mathrm{E}-02$ & 2.97125151 & 0.00392086 & 0.1320 \\
\hline $0.3500 \mathrm{E}-02$ & 2.51100920 & 0.00330983 & 0.1318 \\
\hline $0.4500 \mathrm{E}-02$ & 2.21608258 & 0.00291676 & 0.1316 \\
\hline $0.5500 \mathrm{E}-02$ & 2.00592415 & 0.00263461 & 0.1313 \\
\hline $0.6500 \mathrm{E}-02$ & 1.84589298 & 0.00241907 & 0.1311 \\
\hline $0.7500 \mathrm{E}-02$ & 1.71991388 & 0.00226416 & 0.1316 \\
\hline $0.8500 \mathrm{E}-02$ & 1.61785888 & 0.00215445 & 0.1332 \\
\hline
\end{tabular}


TABLE 8.1. ${ }^{6} \mathrm{Li}(\mathrm{n}, \mathrm{t})\left(\mathrm{OR}^{6} \mathrm{Li}(\mathrm{n}, \alpha)\right)$ CROSS-SECTION RECOMMENDED FOR USE AS A STANDARD IN THE INCIDENT NEUTRON ENERGY RANGE $0.0253 \mathrm{eV}-1 \mathrm{MeV}$ (cont.)

\begin{tabular}{|c|c|c|c|}
\hline $\begin{array}{l}\text { Neutron energy } \\
(\mathrm{MeV})\end{array}$ & $\begin{array}{l}\text { Cross-section } \\
\text { (barn) }\end{array}$ & $\begin{array}{c}\text { Cross-section } \\
\text { uncertainty (barn) }\end{array}$ & $\begin{array}{c}\text { Cross-section } \\
\text { uncertainty }(\%)\end{array}$ \\
\hline $0.9500 \mathrm{E}-02$ & 1.53187494 & 0.00204782 & 0.1337 \\
\hline $0.1500 \mathrm{E}-01$ & 1.22789632 & 0.00175209 & 0.1427 \\
\hline $0.2000 \mathrm{E}-01$ & 1.07198777 & 0.00167649 & 0.1564 \\
\hline $0.2400 \mathrm{E}-01$ & 0.98544602 & 0.00164834 & 0.1673 \\
\hline $0.3000 \mathrm{E}-01$ & 0.89230421 & 0.00164713 & 0.1846 \\
\hline $0.4500 \mathrm{E}-01$ & 0.75659139 & 0.00174804 & 0.2310 \\
\hline $0.5500 \mathrm{E}-01$ & 0.70660619 & 0.00182408 & 0.2581 \\
\hline $0.6500 \mathrm{E}-01$ & 0.67397370 & 0.00191402 & 0.2840 \\
\hline $0.7500 \mathrm{E}-01$ & 0.65459689 & 0.00201092 & 0.3072 \\
\hline $0.8500 \mathrm{E}-01$ & 0.64741305 & 0.00216551 & 0.3345 \\
\hline $0.9500 \mathrm{E}-01$ & 0.64969300 & 0.00229640 & 0.3535 \\
\hline $0.1000 \mathrm{E}+00$ & 0.65399281 & 0.00238588 & 0.3648 \\
\hline $0.1200 \mathrm{E}+00$ & 0.70146284 & 0.00274897 & 0.3919 \\
\hline $0.1500 \mathrm{E}+00$ & 0.88937972 & 0.00371512 & 0.4177 \\
\hline $0.1700 \mathrm{E}+00$ & 1.15474658 & 0.00482280 & 0.4177 \\
\hline $0.1800 \mathrm{E}+00$ & 1.35856757 & 0.00558273 & 0.4109 \\
\hline $0.1900 \mathrm{E}+00$ & 1.62683500 & 0.00638486 & 0.3925 \\
\hline $0.2000 \mathrm{E}+00$ & 1.97042390 & 0.00719134 & 0.3650 \\
\hline $0.2100 \mathrm{E}+00$ & 2.37878217 & 0.00762725 & 0.3206 \\
\hline $0.2200 \mathrm{E}+00$ & 2.80049239 & 0.00736374 & 0.2629 \\
\hline $0.2300 \mathrm{E}+00$ & 3.12958773 & 0.00683999 & 0.2186 \\
\hline $0.2350 \mathrm{E}+00$ & 3.21963141 & 0.00700347 & 0.2175 \\
\hline $0.2400 \mathrm{E}+00$ & 3.24350770 & 0.00759915 & 0.2343 \\
\hline $0.2450 \mathrm{E}+00$ & 3.20139627 & 0.00828457 & 0.2588 \\
\hline $0.2500 \mathrm{E}+00$ & 3.10091680 & 0.00885445 & 0.2855 \\
\hline $0.2600 \mathrm{E}+00$ & 2.78028096 & 0.00902923 & 0.3248 \\
\hline $0.2700 \mathrm{E}+00$ & 2.39905647 & 0.00828212 & 0.3452 \\
\hline $0.2800 \mathrm{E}+00$ & 2.03659526 & 0.00723574 & 0.3553 \\
\hline $0.3000 \mathrm{E}+00$ & 1.47943543 & 0.00575418 & 0.3889 \\
\hline $0.3250 \mathrm{E}+00$ & 1.05533615 & 0.00493904 & 0.4680 \\
\hline $0.3500 \mathrm{E}+00$ & 0.81118808 & 0.00443744 & 0.5470 \\
\hline $0.3750 \mathrm{E}+00$ & 0.66284885 & 0.00406188 & 0.6128 \\
\hline $0.4000 \mathrm{E}+00$ & 0.56481177 & 0.00372619 & 0.6597 \\
\hline $0.4250 \mathrm{E}+00$ & 0.49798239 & 0.00345057 & 0.6929 \\
\hline $0.4500 \mathrm{E}+00$ & 0.44905721 & 0.00317860 & 0.7078 \\
\hline $0.4750 \mathrm{E}+00$ & 0.41302203 & 0.00293387 & 0.7103 \\
\hline $0.5000 \mathrm{E}+00$ & 0.38314886 & 0.00269032 & 0.7022 \\
\hline $0.5200 \mathrm{E}+00$ & 0.36589981 & 0.00256205 & 0.7002 \\
\hline $0.5400 \mathrm{E}+00$ & 0.35046392 & 0.00241023 & 0.6877 \\
\hline $0.5700 \mathrm{E}+00$ & 0.33127651 & 0.00220852 & 0.6667 \\
\hline $0.6000 \mathrm{E}+00$ & 0.31574379 & 0.00200794 & 0.6359 \\
\hline
\end{tabular}


TABLE 8.1. ${ }^{6} \mathrm{Li}(\mathrm{n}, \mathrm{t})\left(\mathrm{OR}^{6} \mathrm{Li}(\mathrm{n}, \alpha)\right)$ CROSS-SECTION RECOMMENDED FOR USE AS A STANDARD IN THE INCIDENT NEUTRON ENERGY RANGE $0.0253 \mathrm{eV}-1 \mathrm{MeV}$ (cont.)

\begin{tabular}{|c|c|c|c|}
\hline $\begin{array}{l}\text { Neutron energy } \\
(\mathrm{MeV})\end{array}$ & $\begin{array}{l}\text { Cross-section } \\
\text { (barn) }\end{array}$ & $\begin{array}{c}\text { Cross-section } \\
\text { uncertainty (barn) }\end{array}$ & $\begin{array}{c}\text { Cross-section } \\
\text { uncertainty }(\%)\end{array}$ \\
\hline $0.6500 \mathrm{E}+00$ & 0.29560913 & 0.00171141 & 0.5789 \\
\hline $0.7000 \mathrm{E}+00$ & 0.28078794 & 0.00149457 & 0.5323 \\
\hline $0.7500 \mathrm{E}+00$ & 0.26930384 & 0.00139712 & 0.5188 \\
\hline $0.8000 \mathrm{E}+00$ & 0.26002423 & 0.00143885 & 0.5534 \\
\hline $0.8500 \mathrm{E}+00$ & 0.25250732 & 0.00161344 & 0.6390 \\
\hline $0.9000 \mathrm{E}+00$ & 0.24647852 & 0.00186787 & 0.7578 \\
\hline $0.9400 \mathrm{E}+00$ & 0.24235958 & 0.00210639 & 0.8691 \\
\hline $0.9600 \mathrm{E}+00$ & 0.24044730 & 0.00222603 & 0.9258 \\
\hline $0.9800 \mathrm{E}+00$ & 0.23872874 & 0.00234751 & 0.9833 \\
\hline $0.1000 \mathrm{E}+01$ & 0.23710787 & 0.00247067 & 1.0420 \\
\hline $0.1100 \mathrm{E}+01$ & 0.23063245 & 0.00303670 & 1.3167 \\
\hline $0.1250 \mathrm{E}+01$ & 0.22440879 & 0.00360184 & 1.6050 \\
\hline $0.1400 \mathrm{E}+01$ & 0.22110695 & 0.00365420 & 1.6527 \\
\hline $0.1600 \mathrm{E}+01$ & 0.21962822 & 0.00269065 & 1.2251 \\
\hline $0.1800 \mathrm{E}+01$ & 0.22075194 & 0.00167198 & 0.7574 \\
\hline $0.2000 \mathrm{E}+01$ & 0.21939993 & 0.00325266 & 1.4825 \\
\hline $0.2200 \mathrm{E}+01$ & 0.21452476 & 0.00275573 & 1.2846 \\
\hline $0.2400 \mathrm{E}+01$ & 0.20685256 & 0.00206502 & 0.9983 \\
\hline $0.2600 \mathrm{E}+01$ & 0.18589324 & 0.00398194 & 2.1421 \\
\hline $0.2800 \mathrm{E}+01$ & 0.16846986 & 0.00501613 & 2.9775 \\
\hline
\end{tabular}

TABLE 8.2. ${ }^{10} \mathrm{~B}\left(\mathrm{n}, \mathrm{\alpha}_{0}\right)$ CROSS-SECTION

\begin{tabular}{|c|c|c|c|}
\hline Neutron energy $(\mathrm{MeV})$ & $\begin{array}{l}\text { Cross-section } \\
\text { (barn) }\end{array}$ & $\begin{array}{c}\text { Cross-section } \\
\text { uncertainty (barn) }\end{array}$ & $\begin{array}{c}\text { Cross-section } \\
\text { uncertainty }(\%)\end{array}$ \\
\hline $0.2530 \mathrm{E}-07$ & 241.69269414 & 0.59600393 & 0.2466 \\
\hline $0.9400 \mathrm{E}-05$ & 12.51771449 & 0.03087241 & 0.2466 \\
\hline $0.1500 \mathrm{E}-03$ & 3.11787973 & 0.00798270 & 0.2560 \\
\hline $0.2500 \mathrm{E}-03$ & 2.41077980 & 0.00617278 & 0.2560 \\
\hline $0.3500 \mathrm{E}-03$ & 2.03468818 & 0.00540081 & 0.2654 \\
\hline $0.4500 \mathrm{E}-03$ & 1.79241436 & 0.00475786 & 0.2654 \\
\hline $0.5500 \mathrm{E}-03$ & 1.61964475 & 0.00445183 & 0.2749 \\
\hline $0.6500 \mathrm{E}-03$ & 1.48853039 & 0.00409146 & 0.2749 \\
\hline $0.7500 \mathrm{E}-03$ & 1.38477662 & 0.00393717 & 0.2843 \\
\hline $0.8500 \mathrm{E}-03$ & 1.29987336 & 0.00369573 & 0.2843 \\
\hline $0.9500 \mathrm{E}-03$ & 1.22877550 & 0.00349347 & 0.2843 \\
\hline $0.1500 \mathrm{E}-02$ & 0.97524352 & 0.00295740 & 0.3032 \\
\hline $0.2500 \mathrm{E}-02$ & 0.75311248 & 0.00251960 & 0.3346 \\
\hline $0.3500 \mathrm{E}-02$ & 0.63536605 & 0.00230546 & 0.3629 \\
\hline $0.4500 \mathrm{E}-02$ & 0.55973420 & 0.00215107 & 0.3843 \\
\hline $0.5500 \mathrm{E}-02$ & 0.50602425 & 0.00203865 & 0.4029 \\
\hline
\end{tabular}


TABLE 8.2. ${ }^{10} \mathrm{~B}\left(\mathrm{n}, \mathrm{\alpha}_{0}\right)$ CROSS-SECTION (cont.)

\begin{tabular}{|c|c|c|c|}
\hline Neutron energy $(\mathrm{MeV})$ & $\begin{array}{l}\text { Cross-section } \\
\text { (barn) }\end{array}$ & $\begin{array}{c}\text { Cross-section } \\
\text { uncertainty (barn) }\end{array}$ & $\begin{array}{c}\text { Cross-section } \\
\text { uncertainty }(\%)\end{array}$ \\
\hline $0.6500 \mathrm{E}-02$ & 0.46537018 & 0.00197371 & 0.4241 \\
\hline $0.7500 \mathrm{E}-02$ & 0.43324609 & 0.00192928 & 0.4453 \\
\hline $0.8500 \mathrm{E}-02$ & 0.40707504 & 0.00186047 & 0.4570 \\
\hline 0.9500E-02 & 0.38520364 & 0.00184205 & 0.4782 \\
\hline $0.1500 \mathrm{E}-01$ & 0.30785273 & 0.00159890 & 0.5194 \\
\hline $0.2000 \mathrm{E}-01$ & 0.26802846 & 0.00139778 & 0.5215 \\
\hline $0.2400 \mathrm{E}-01$ & 0.24573666 & 0.00124170 & 0.5053 \\
\hline 0.3000E-01 & 0.22166285 & 0.00103441 & 0.4667 \\
\hline $0.4500 \mathrm{E}-01$ & 0.18544316 & 0.00091110 & 0.4913 \\
\hline $0.5500 \mathrm{E}-01$ & 0.17094797 & 0.00129997 & 0.7604 \\
\hline $0.6500 \mathrm{E}-01$ & 0.16066291 & 0.00181293 & 1.1284 \\
\hline $0.7500 \mathrm{E}-01$ & 0.15315986 & 0.00236901 & 1.5468 \\
\hline 0.8500E-01 & 0.14765481 & 0.00285828 & 1.9358 \\
\hline $0.9500 \mathrm{E}-01$ & 0.14375173 & 0.00330324 & 2.2979 \\
\hline $0.1000 \mathrm{E}+00$ & 0.14222240 & 0.00350315 & 2.4631 \\
\hline $0.1200 \mathrm{E}+00$ & 0.13862034 & 0.00399694 & 2.8834 \\
\hline $0.1500 \mathrm{E}+00$ & 0.13821547 & 0.00391225 & 2.8305 \\
\hline $0.1700 \mathrm{E}+00$ & 0.13958562 & 0.00338493 & 2.4250 \\
\hline $0.1800 \mathrm{E}+00$ & 0.14049451 & 0.00303110 & 2.1575 \\
\hline $0.1900 \mathrm{E}+00$ & 0.14141373 & 0.00269596 & 1.9064 \\
\hline $0.2000 \mathrm{E}+00$ & 0.14221666 & 0.00236915 & 1.6659 \\
\hline $0.2100 \mathrm{E}+00$ & 0.14282943 & 0.00209519 & 1.4669 \\
\hline $0.2200 \mathrm{E}+00$ & 0.14317072 & 0.00190338 & 1.3294 \\
\hline $0.2300 \mathrm{E}+00$ & 0.14323401 & 0.00178424 & 1.2457 \\
\hline $0.2350 \mathrm{E}+00$ & 0.14315613 & 0.00174849 & 1.2214 \\
\hline $0.2400 \mathrm{E}+00$ & 0.14301024 & 0.00173863 & 1.2157 \\
\hline $0.2450 \mathrm{E}+00$ & 0.14281246 & 0.00174535 & 1.2221 \\
\hline $0.2500 \mathrm{E}+00$ & 0.14256280 & 0.00176748 & 1.2398 \\
\hline $0.2600 \mathrm{E}+00$ & 0.14195172 & 0.00188188 & 1.3257 \\
\hline $0.2700 \mathrm{E}+00$ & 0.14127086 & 0.00209629 & 1.4839 \\
\hline $0.2800 \mathrm{E}+00$ & 0.14064708 & 0.00242841 & 1.7266 \\
\hline $0.3000 \mathrm{E}+00$ & 0.13991337 & 0.00344371 & 2.4613 \\
\hline $0.3250 \mathrm{E}+00$ & 0.14091965 & 0.00528311 & 3.7490 \\
\hline $0.3500 \mathrm{E}+00$ & 0.14513006 & 0.00750057 & 5.1682 \\
\hline $0.3750 \mathrm{E}+00$ & 0.15338337 & 0.00964118 & 6.2857 \\
\hline $0.4000 \mathrm{E}+00$ & 0.16590332 & 0.01085826 & 6.5449 \\
\hline $0.4250 \mathrm{E}+00$ & 0.18150273 & 0.01022742 & 5.6349 \\
\hline $0.4500 \mathrm{E}+00$ & 0.19647102 & 0.00764916 & 3.8933 \\
\hline $0.4750 \mathrm{E}+00$ & 0.20536438 & 0.00467633 & 2.2771 \\
\hline $0.5000 \mathrm{E}+00$ & 0.20456709 & 0.00310048 & 1.5156 \\
\hline $0.5200 \mathrm{E}+00$ & 0.19760966 & 0.00293164 & 1.4836 \\
\hline $0.5400 \mathrm{E}+00$ & 0.18735580 & 0.00333286 & 1.7789 \\
\hline
\end{tabular}


TABLE 8.2. ${ }^{10} \mathrm{~B}\left(\mathrm{n}, \mathrm{\alpha}_{0}\right)$ CROSS-SECTION (cont.)

\begin{tabular}{lccc}
\hline Neutron energy (MeV) & $\begin{array}{c}\text { Cross-section } \\
\text { (barn) }\end{array}$ & $\begin{array}{c}\text { Cross-section } \\
\text { uncertainty (barn) }\end{array}$ & $\begin{array}{c}\text { Cross-section } \\
\text { uncertainty }(\%)\end{array}$ \\
\hline $0.5700 \mathrm{E}+00$ & 0.17031559 & 0.00423982 & 2.4894 \\
$0.6000 \mathrm{E}+00$ & 0.15477952 & 0.00495938 & 3.2042 \\
$0.6500 \mathrm{E}+00$ & 0.13497791 & 0.00552292 & 4.0917 \\
$0.7000 \mathrm{E}+00$ & 0.12173883 & 0.00561140 & 4.6094 \\
$0.7500 \mathrm{E}+00$ & 0.11274452 & 0.00569395 & 5.0503 \\
$0.8000 \mathrm{E}+00$ & 0.10554202 & 0.00462453 & 4.3817 \\
$0.8500 \mathrm{E}+00$ & 0.10173516 & 0.00423125 & 4.1591 \\
$0.9000 \mathrm{E}+00$ & 0.09927345 & 0.00377093 & 3.7985 \\
$0.9400 \mathrm{E}+00$ & 0.09803797 & 0.00341843 & 3.4868 \\
$0.9600 \mathrm{E}+00$ & 0.09762583 & 0.00323986 & 3.3187 \\
$0.9800 \mathrm{E}+00$ & 0.09732674 & 0.00308141 & 3.1660 \\
$0.1000 \mathrm{E}+01$ & 0.09714092 & 0.00293436 & 3.0207 \\
\hline
\end{tabular}

TABLE 8.3. ${ }^{10} \mathrm{~B}\left(\mathrm{n}, \alpha_{1}\right)$ CROSS-SECTION RECOMMENDED FOR USE AS A STANDARD IN THE INCIDENT NEUTRON ENERGY RANGE $0.0253 \mathrm{eV}-1 \mathrm{MeV}$

\begin{tabular}{|c|c|c|c|}
\hline $\begin{array}{l}\text { Neutron energy } \\
(\mathrm{MeV})\end{array}$ & $\begin{array}{l}\text { Cross-section } \\
\text { (barn) }\end{array}$ & $\begin{array}{c}\text { Cross-section } \\
\text { uncertainty (barn) }\end{array}$ & $\begin{array}{c}\text { Cross-section } \\
\text { uncertainty }(\%)\end{array}$ \\
\hline $0.2530 \mathrm{E}-07$ & 3600.86493607 & 2.95752920 & 0.0821 \\
\hline $0.9400 \mathrm{E}-05$ & 186.50081808 & 0.15876691 & 0.0851 \\
\hline $0.1500 \mathrm{E}-03$ & 46.44489008 & 0.03956951 & 0.0852 \\
\hline $0.2500 \mathrm{E}-03$ & 35.90754277 & 0.03059078 & 0.0852 \\
\hline $0.3500 \mathrm{E}-03$ & 30.30145300 & 0.02581393 & 0.0852 \\
\hline $0.4500 \mathrm{E}-03$ & 26.68999724 & 0.02273490 & 0.0852 \\
\hline $0.5500 \mathrm{E}-03$ & 24.11504073 & 0.02053708 & 0.0852 \\
\hline $0.6500 \mathrm{E}-03$ & 22.16075814 & 0.01886842 & 0.0851 \\
\hline $0.7500 \mathrm{E}-03$ & 20.61205403 & 0.01754314 & 0.0851 \\
\hline $0.8500 \mathrm{E}-03$ & 19.34629620 & 0.01646117 & 0.0851 \\
\hline $0.9500 \mathrm{E}-03$ & 18.28631263 & 0.01627765 & 0.0890 \\
\hline $0.1500 \mathrm{E}-02$ & 14.50280973 & 0.01287766 & 0.0888 \\
\hline $0.2500 \mathrm{E}-02$ & 11.18475017 & 0.00987434 & 0.0883 \\
\hline $0.3500 \mathrm{E}-02$ & 9.42341563 & 0.00826183 & 0.0877 \\
\hline $0.4500 \mathrm{E}-02$ & 8.29082372 & 0.00765061 & 0.0923 \\
\hline $0.5500 \mathrm{E}-02$ & 7.48541060 & 0.00685368 & 0.0916 \\
\hline $0.6500 \mathrm{E}-02$ & 6.87499841 & 0.00624630 & 0.0909 \\
\hline $0.7500 \mathrm{E}-02$ & 6.39250598 & 0.00633969 & 0.0992 \\
\hline $0.8500 \mathrm{E}-02$ & 5.99862203 & 0.00590431 & 0.0984 \\
\hline 0.9500E-02 & 5.66906591 & 0.00553892 & 0.0977 \\
\hline 0.1500E-01 & 4.50091829 & 0.00494337 & 0.1098 \\
\hline $0.2000 \mathrm{E}-01$ & 3.89744800 & 0.00482222 & 0.1237 \\
\hline $0.2400 \mathrm{E}-01$ & 3.56077089 & 0.00494642 & 0.1389 \\
\hline 0.3000E-01 & 3.19183954 & 0.00516844 & 0.1619 \\
\hline
\end{tabular}


TABLE 8.3. ${ }^{10} \mathrm{~B}\left(\mathrm{n}, \alpha_{1}\right)$ CROSS-SECTION RECOMMENDED FOR USE AS A STANDARD IN THE INCIDENT NEUTRON ENERGY RANGE $0.0253 \mathrm{eV}-1 \mathrm{MeV}$ (cont.)

\begin{tabular}{|c|c|c|c|}
\hline $\begin{array}{l}\text { Neutron energy } \\
(\mathrm{MeV})\end{array}$ & $\begin{array}{l}\text { Cross-section } \\
\text { (barn) }\end{array}$ & $\begin{array}{c}\text { Cross-section } \\
\text { uncertainty (barn) }\end{array}$ & $\begin{array}{c}\text { Cross-section } \\
\text { uncertainty }(\%)\end{array}$ \\
\hline $0.4500 \mathrm{E}-01$ & 2.62756945 & 0.00550047 & 0.2093 \\
\hline $0.5500 \mathrm{E}-01$ & 2.39202869 & 0.00589872 & 0.2466 \\
\hline $0.6500 \mathrm{E}-01$ & 2.21765467 & 0.00617172 & 0.2783 \\
\hline $0.7500 \mathrm{E}-01$ & 2.08165596 & 0.00643355 & 0.3091 \\
\hline $0.8500 \mathrm{E}-01$ & 1.96926238 & 0.00673832 & 0.3422 \\
\hline $0.9500 \mathrm{E}-01$ & 1.87744821 & 0.00712091 & 0.3793 \\
\hline $0.1000 \mathrm{E}+00$ & 1.83757494 & 0.00735717 & 0.4004 \\
\hline $0.1200 \mathrm{E}+00$ & 1.70141205 & 0.00824589 & 0.4846 \\
\hline $0.1500 \mathrm{E}+00$ & 1.54609267 & 0.01023299 & 0.6619 \\
\hline $0.1700 \mathrm{E}+00$ & 1.45638625 & 0.01237031 & 0.8494 \\
\hline $0.1800 \mathrm{E}+00$ & 1.41275556 & 0.01326320 & 0.9388 \\
\hline $0.1900 \mathrm{E}+00$ & 1.36929130 & 0.01422397 & 1.0388 \\
\hline $0.2000 \mathrm{E}+00$ & 1.32537449 & 0.01492045 & 1.1258 \\
\hline $0.2100 \mathrm{E}+00$ & 1.28123910 & 0.01544592 & 1.2055 \\
\hline $0.2200 \mathrm{E}+00$ & 1.23694874 & 0.01575095 & 1.2734 \\
\hline $0.2300 \mathrm{E}+00$ & 1.19246322 & 0.01576304 & 1.3219 \\
\hline $0.2350 \mathrm{E}+00$ & 1.17041692 & 0.01569390 & 1.3409 \\
\hline $0.2400 \mathrm{E}+00$ & 1.14818264 & 0.01549141 & 1.3492 \\
\hline $0.2450 \mathrm{E}+00$ & 1.12663699 & 0.01529585 & 1.3577 \\
\hline $0.2500 \mathrm{E}+00$ & 1.10520882 & 0.01499778 & 1.3570 \\
\hline $0.2600 \mathrm{E}+00$ & 1.06266935 & 0.01437472 & 1.3527 \\
\hline $0.2700 \mathrm{E}+00$ & 1.02194345 & 0.01356318 & 1.3272 \\
\hline $0.2800 \mathrm{E}+00$ & 0.98289927 & 0.01268457 & 1.2905 \\
\hline $0.3000 \mathrm{E}+00$ & 0.91087353 & 0.01097329 & 1.2047 \\
\hline $0.3250 \mathrm{E}+00$ & 0.83510590 & 0.00923263 & 1.1056 \\
\hline $0.3500 \mathrm{E}+00$ & 0.77649268 & 0.00817790 & 1.0532 \\
\hline $0.3750 \mathrm{E}+00$ & 0.73537992 & 0.00771371 & 1.0489 \\
\hline $0.4000 \mathrm{E}+00$ & 0.71033705 & 0.00756117 & 1.0644 \\
\hline $0.4250 \mathrm{E}+00$ & 0.69607237 & 0.00680584 & 0.9777 \\
\hline $0.4500 \mathrm{E}+00$ & 0.68275273 & 0.00562416 & 0.8237 \\
\hline $0.4750 \mathrm{E}+00$ & 0.65813894 & 0.00523868 & 0.7960 \\
\hline $0.5000 \mathrm{E}+00$ & 0.61602179 & 0.00664939 & 1.0794 \\
\hline $0.5200 \mathrm{E}+00$ & 0.57261407 & 0.00861702 & 1.5049 \\
\hline $0.5400 \mathrm{E}+00$ & 0.52581674 & 0.01027368 & 1.9539 \\
\hline $0.5700 \mathrm{E}+00$ & 0.45798249 & 0.01080564 & 2.3594 \\
\hline $0.6000 \mathrm{E}+00$ & 0.39844904 & 0.00939508 & 2.3579 \\
\hline $0.6500 \mathrm{E}+00$ & 0.32047476 & 0.00538319 & 1.6798 \\
\hline $0.7000 \mathrm{E}+00$ & 0.26396307 & 0.00200948 & 0.7613 \\
\hline $0.7500 \mathrm{E}+00$ & 0.22338844 & 0.00216588 & 0.9696 \\
\hline $0.8000 \mathrm{E}+00$ & 0.19680799 & 0.00150101 & 0.7627 \\
\hline $0.8500 \mathrm{E}+00$ & 0.17276348 & 0.00113435 & 0.6566 \\
\hline
\end{tabular}


TABLE 8.3. ${ }^{10} \mathrm{~B}\left(\mathrm{n}, \alpha_{1}\right)$ CROSS-SECTION RECOMMENDED FOR USE AS A STANDARD IN THE INCIDENT NEUTRON ENERGY RANGE $0.0253 \mathrm{eV}-1 \mathrm{MeV}$ (cont.)

\begin{tabular}{lccc}
\hline $\begin{array}{l}\text { Neutron energy } \\
(\mathrm{MeV})\end{array}$ & $\begin{array}{c}\text { Cross-section } \\
\text { (barn) }\end{array}$ & $\begin{array}{c}\text { Cross-section } \\
\text { uncertainty (barn) }\end{array}$ & $\begin{array}{c}\text { Cross-section } \\
\text { uncertainty }(\%)\end{array}$ \\
\hline $0.9000 \mathrm{E}+00$ & 0.15381109 & 0.00149902 & 0.9746 \\
$0.9400 \mathrm{E}+00$ & 0.14129822 & 0.00176047 & 1.2459 \\
$0.9600 \mathrm{E}+00$ & 0.13575152 & 0.00185349 & 1.3654 \\
$0.9800 \mathrm{E}+00$ & 0.13061541 & 0.00189564 & 1.4513 \\
$0.1000 \mathrm{E}+01$ & 0.12584093 & 0.00192000 & 1.5257 \\
\hline
\end{tabular}

TABLE 8.4. ${ }^{10} \mathrm{~B}(\mathrm{n}, \alpha)$ CROSS-SECTION RECOMMENDED FOR USE AS A STANDARD IN THE INCIDENT NEUTRON ENERGY RANGE $0.0253 \mathrm{eV}-1 \mathrm{MeV}$

\begin{tabular}{|c|c|c|c|}
\hline $\begin{array}{l}\text { Neutron energy } \\
(\mathrm{MeV})\end{array}$ & $\begin{array}{c}\text { Cross-section } \\
\text { (barn) }\end{array}$ & $\begin{array}{c}\text { Cross-section } \\
\text { uncertainty (barn) }\end{array}$ & $\begin{array}{c}\text { Cross-section } \\
\text { uncertainty }(\%)\end{array}$ \\
\hline $0.2530 \mathrm{E}-07$ & $3.8426 \mathrm{E}+03$ & $3.2047 \mathrm{E}+00$ & 0.0834 \\
\hline $0.9400 \mathrm{E}-05$ & $1.9902 \mathrm{E}+02$ & $1.7136 \mathrm{E}-01$ & 0.0861 \\
\hline $0.1500 \mathrm{E}-03$ & $4.9563 \mathrm{E}+01$ & 4.2822E-02 & 0.0864 \\
\hline $0.2500 \mathrm{E}-03$ & $3.8318 \mathrm{E}+01$ & $3.3068 \mathrm{E}-02$ & 0.0863 \\
\hline $0.3500 \mathrm{E}-03$ & $3.2336 \mathrm{E}+01$ & $2.8003 \mathrm{E}-02$ & 0.0866 \\
\hline $0.4500 \mathrm{E}-03$ & $2.8482 \mathrm{E}+01$ & $2.4665 \mathrm{E}-02$ & 0.0866 \\
\hline $0.5500 \mathrm{E}-03$ & $2.5735 \mathrm{E}+01$ & $2.2364 \mathrm{E}-02$ & 0.0869 \\
\hline $0.6500 \mathrm{E}-03$ & $2.3649 \mathrm{E}+01$ & $2.0551 \mathrm{E}-02$ & 0.0869 \\
\hline $0.7500 \mathrm{E}-03$ & $2.1997 \mathrm{E}+01$ & $1.9159 \mathrm{E}-02$ & 0.0871 \\
\hline $0.8500 \mathrm{E}-03$ & $2.0646 \mathrm{E}+01$ & $1.7983 \mathrm{E}-02$ & 0.0871 \\
\hline $0.9500 \mathrm{E}-03$ & $1.9515 \mathrm{E}+01$ & $1.7700 \mathrm{E}-02$ & 0.0907 \\
\hline $0.1500 \mathrm{E}-02$ & $1.5478 \mathrm{E}+01$ & $1.4100 \mathrm{E}-02$ & 0.0911 \\
\hline $0.2500 \mathrm{E}-02$ & $1.1938 \mathrm{E}+01$ & $1.0947 \mathrm{E}-02$ & 0.0917 \\
\hline $0.3500 \mathrm{E}-02$ & $1.0059 \mathrm{E}+01$ & $9.2643 \mathrm{E}-03$ & 0.0921 \\
\hline $0.4500 \mathrm{E}-02$ & $8.8506 \mathrm{E}+00$ & $8.5674 \mathrm{E}-03$ & 0.0968 \\
\hline $0.5500 \mathrm{E}-02$ & 7.9914E+00 & 7.7357E-03 & 0.0968 \\
\hline $0.6500 \mathrm{E}-02$ & 7.3404E+00 & 7.1128E-03 & 0.0969 \\
\hline $0.7500 \mathrm{E}-02$ & $6.8258 \mathrm{E}+00$ & 7.1739E-03 & 0.1051 \\
\hline $0.8500 \mathrm{E}-02$ & $6.4057 \mathrm{E}+00$ & 6.7196E-03 & 0.1049 \\
\hline $0.9500 \mathrm{E}-02$ & $6.0543 \mathrm{E}+00$ & $6.3570 \mathrm{E}-03$ & 0.1050 \\
\hline $0.1500 \mathrm{E}-01$ & $4.8088 \mathrm{E}+00$ & $5.6311 \mathrm{E}-03$ & 0.1171 \\
\hline $0.2000 \mathrm{E}-01$ & $4.1655 \mathrm{E}+00$ & $5.3693 \mathrm{E}-03$ & 0.1289 \\
\hline $0.2400 \mathrm{E}-01$ & $3.8065 \mathrm{E}+00$ & $5.2872 \mathrm{E}-03$ & 0.1389 \\
\hline $0.3000 \mathrm{E}-01$ & $3.4135 \mathrm{E}+00$ & $5.4684 \mathrm{E}-03$ & 0.1602 \\
\hline $0.4500 \mathrm{E}-01$ & $2.8130 \mathrm{E}+00$ & $5.8229 \mathrm{E}-03$ & 0.2070 \\
\hline $0.5500 \mathrm{E}-01$ & $2.5630 \mathrm{E}+00$ & $6.3870 \mathrm{E}-03$ & 0.2492 \\
\hline $0.6500 \mathrm{E}-01$ & $2.3783 \mathrm{E}+00$ & $6.9185 \mathrm{E}-03$ & 0.2909 \\
\hline $0.7500 \mathrm{E}-01$ & $2.2348 \mathrm{E}+00$ & 7.4732E-03 & 0.3344 \\
\hline $0.8500 \mathrm{E}-01$ & $2.1169 \mathrm{E}+00$ & $8.0696 \mathrm{E}-03$ & 0.3812 \\
\hline $0.9500 \mathrm{E}-01$ & $2.0212 \mathrm{E}+00$ & 8.7033E-03 & 0.4306 \\
\hline
\end{tabular}


TABLE 8.4. ${ }^{10} \mathrm{~B}(\mathrm{n}, \alpha)$ CROSS-SECTION RECOMMENDED FOR USE AS A STANDARD IN THE INCIDENT NEUTRON ENERGY RANGE $0.0253 \mathrm{eV}-1 \mathrm{MeV}$ (cont.)

\begin{tabular}{|c|c|c|c|}
\hline $\begin{array}{l}\text { Neutron energy } \\
(\mathrm{MeV})\end{array}$ & $\begin{array}{l}\text { Cross-section } \\
\text { (barn) }\end{array}$ & $\begin{array}{c}\text { Cross-section } \\
\text { uncertainty (barn) }\end{array}$ & $\begin{array}{c}\text { Cross-section } \\
\text { uncertainty }(\%)\end{array}$ \\
\hline $0.1000 \mathrm{E}+00$ & $1.9798 \mathrm{E}+00$ & $9.0477 \mathrm{E}-03$ & 0.4570 \\
\hline $0.1200 \mathrm{E}+00$ & $1.8400 \mathrm{E}+00$ & $1.0186 \mathrm{E}-02$ & 0.5536 \\
\hline $0.1500 \mathrm{E}+00$ & $1.6843 \mathrm{E}+00$ & $1.1935 \mathrm{E}-02$ & 0.7086 \\
\hline $0.1700 \mathrm{E}+00$ & $1.5960 \mathrm{E}+00$ & 1.3710E-02 & 0.8590 \\
\hline $0.1800 \mathrm{E}+00$ & $1.5533 \mathrm{E}+00$ & 1.4382E-02 & 0.9259 \\
\hline $0.1900 \mathrm{E}+00$ & $1.5107 \mathrm{E}+00$ & $1.5151 \mathrm{E}-02$ & 1.0029 \\
\hline $0.2000 \mathrm{E}+00$ & $1.4676 \mathrm{E}+00$ & $1.5681 \mathrm{E}-02$ & 1.0685 \\
\hline $0.2100 \mathrm{E}+00$ & $1.4241 \mathrm{E}+00$ & 1.6078E-02 & 1.1290 \\
\hline $0.2200 \mathrm{E}+00$ & $1.3801 \mathrm{E}+00$ & 1.6293E-02 & 1.1806 \\
\hline $0.2300 \mathrm{E}+00$ & $1.3357 \mathrm{E}+00$ & $1.6266 \mathrm{E}-02$ & 1.2178 \\
\hline $0.2350 \mathrm{E}+00$ & $1.3136 \mathrm{E}+00$ & $1.6186 \mathrm{E}-02$ & 1.2322 \\
\hline $0.2400 \mathrm{E}+00$ & $1.2912 \mathrm{E}+00$ & $1.5981 \mathrm{E}-02$ & 1.2377 \\
\hline $0.2450 \mathrm{E}+00$ & $1.2694 \mathrm{E}+00$ & $1.5789 \mathrm{E}-02$ & 1.2438 \\
\hline $0.2500 \mathrm{E}+00$ & $1.2478 \mathrm{E}+00$ & $1.5500 \mathrm{E}-02$ & 1.2422 \\
\hline $0.2600 \mathrm{E}+00$ & $1.2046 \mathrm{E}+00$ & 1.4938E-02 & 1.2401 \\
\hline $0.2700 \mathrm{E}+00$ & $1.1632 \mathrm{E}+00$ & 1.4213E-02 & 1.2219 \\
\hline $0.2800 \mathrm{E}+00$ & $1.1235 \mathrm{E}+00$ & $1.3498 \mathrm{E}-02$ & 1.2014 \\
\hline $0.3000 \mathrm{E}+00$ & $1.0508 \mathrm{E}+00$ & $1.2295 \mathrm{E}-02$ & 1.1701 \\
\hline $0.3250 \mathrm{E}+00$ & 9.7603E-01 & $1.1686 \mathrm{E}-02$ & 1.1973 \\
\hline $0.3500 \mathrm{E}+00$ & $9.2162 \mathrm{E}-01$ & 1.2303E-02 & 1.3349 \\
\hline $0.3750 \mathrm{E}+00$ & 8.8876Е-01 & $1.3717 \mathrm{E}-02$ & 1.5434 \\
\hline $0.4000 \mathrm{E}+00$ & $8.7624 \mathrm{E}-01$ & 1.4589E-02 & 1.6650 \\
\hline $0.4250 \mathrm{E}+00$ & $8.7758 \mathrm{E}-01$ & $1.3370 \mathrm{E}-02$ & 1.5235 \\
\hline $0.4500 \mathrm{E}+00$ & 8.7922E-01 & 1.0108E-02 & 1.1497 \\
\hline $0.4750 \mathrm{E}+00$ & $8.6350 \mathrm{E}-01$ & 7.2957E-03 & 0.8449 \\
\hline $0.5000 \mathrm{E}+00$ & 8.2059E-01 & $7.5035 \mathrm{E}-03$ & 0.9144 \\
\hline $0.5200 \mathrm{E}+00$ & 7.7022E-01 & 9.2942E-03 & 1.2067 \\
\hline $0.5400 \mathrm{E}+00$ & 7.1317E-01 & $1.1113 \mathrm{E}-02$ & 1.5583 \\
\hline $0.5700 \mathrm{E}+00$ & $6.2830 \mathrm{E}-01$ & 1.2185E-02 & 1.9394 \\
\hline $0.6000 \mathrm{E}+00$ & $5.5323 \mathrm{E}-01$ & $1.1386 \mathrm{E}-02$ & 2.0581 \\
\hline $0.6500 \mathrm{E}+00$ & $4.5545 \mathrm{E}-01$ & $8.4131 \mathrm{E}-03$ & 1.8472 \\
\hline $0.7000 \mathrm{E}+00$ & 3.8570E-01 & $6.2738 \mathrm{E}-03$ & 1.6266 \\
\hline $0.7500 \mathrm{E}+00$ & 3.3613E-01 & $6.3884 \mathrm{E}-03$ & 1.8730 \\
\hline $0.8000 \mathrm{E}+00$ & 3.0235E-01 & 4.9610E-03 & 1.6408 \\
\hline $0.8500 \mathrm{E}+00$ & $2.7450 \mathrm{E}-01$ & 4.4461E-03 & 1.6197 \\
\hline $0.9000 \mathrm{E}+00$ & $2.5308 \mathrm{E}-01$ & 4.1133E-03 & 1.6253 \\
\hline $0.9400 \mathrm{E}+00$ & 2.3934E-01 & 3.8919E-03 & 1.6261 \\
\hline $0.9600 \mathrm{E}+00$ & $2.3338 \mathrm{E}-01$ & 3.7647E-03 & 1.6131 \\
\hline $0.9800 \mathrm{E}+00$ & 2.2794E-01 & $3.6500 \mathrm{E}-03$ & 1.6013 \\
\hline $0.1000 \mathrm{E}+01$ & $2.2298 \mathrm{E}-01$ & $3.5226 \mathrm{E}-03$ & 1.5798 \\
\hline
\end{tabular}


TABLE 8.5. ${ }^{197} \mathrm{Au}(\mathrm{n}, \gamma)$ CROSS-SECTION RECOMMENDED FOR USE AS A STANDARD AT $0.0253 \mathrm{eV}$ AND IN THE INCIDENT NEUTRON ENERGY RANGE 0.2-2.5 MeV

(smoothed values are marked by * and values averaged on the energy groups (@) are expressed in terms of the central energy of that group)

\begin{tabular}{|c|c|c|c|}
\hline $\begin{array}{l}\text { Neutron energy } \\
(\mathrm{MeV})\end{array}$ & $\begin{array}{l}\text { Cross-section } \\
\text { (barn) }\end{array}$ & $\begin{array}{c}\text { Cross-section } \\
\text { uncertainty (barn) }\end{array}$ & $\begin{array}{c}\text { Cross-section } \\
\text { uncertainty ( } \%)\end{array}$ \\
\hline $0.2530 \mathrm{E}-07$ & 98.65931850 & 0.13853593 & 0.1404 \\
\hline $0.2500 \mathrm{E}-02$ & $3.15813647 @$ & 0.56433337 & 17.869 \\
\hline $0.3500 \mathrm{E}-02$ & $2.58099387 @$ & 0.05417321 & 2.0989 \\
\hline $0.4500 \mathrm{E}-02$ & 2.28545555@ & 0.05092097 & 2.2280 \\
\hline $0.5500 \mathrm{E}-02$ & $1.90967660 @$ & 0.02781642 & 1.4566 \\
\hline $0.6500 \mathrm{E}-02$ & 1.72519776@ & 0.02585512 & 1.4987 \\
\hline $0.7500 \mathrm{E}-02$ & $1.52205940 @$ & 0.02173001 & 1.4277 \\
\hline $0.8500 \mathrm{E}-02$ & $1.33195364 @$ & 0.02041558 & 1.5328 \\
\hline $0.9500 \mathrm{E}-02$ & $1.25023425 @$ & 0.02072775 & 1.6579 \\
\hline $0.1500 \mathrm{E}-01$ & 0.88529574@ & 0.00970831 & 1.0966 \\
\hline $0.2000 \mathrm{E}-01$ & 0.70081240 & 0.00902308 & 1.2875 \\
\hline $0.2400 \mathrm{E}-01$ & 0.64382957 & 0.00540716 & 0.8398 \\
\hline 0.3000E-01 & 0.59238902 & 0.00413067 & 0.6973 \\
\hline $0.4500 \mathrm{E}-01$ & 0.46392815 & 0.00413582 & 0.8915 \\
\hline $0.5500 \mathrm{E}-01$ & 0.42275736 & 0.00398988 & 0.9438 \\
\hline 0.6500E-01 & 0.38811248 & 0.00362727 & 0.9346 \\
\hline $0.7500 \mathrm{E}-01$ & 0.36514890 & 0.00348115 & 0.9534 \\
\hline $0.8500 \mathrm{E}-01$ & $0.33554849 *$ & 0.00324783 & 0.9679 \\
\hline 0.9500E-01 & $0.32262758 *$ & 0.00309887 & 0.9605 \\
\hline $0.1000 \mathrm{E}+00$ & $0.31991428 *$ & 0.00332756 & 1.0401 \\
\hline $0.1200 \mathrm{E}+00$ & 0.29459216 & 0.00281541 & 0.9557 \\
\hline $0.1500 \mathrm{E}+00$ & 0.27529696 & 0.00272810 & 0.9910 \\
\hline $0.1700 \mathrm{E}+00$ & 0.26543616 & 0.00302669 & 1.1403 \\
\hline $0.1800 \mathrm{E}+00$ & 0.26314860 & 0.00604501 & 2.2972 \\
\hline $0.1900 \mathrm{E}+00$ & 0.25661976 & 0.00347051 & 1.3524 \\
\hline $0.2000 \mathrm{E}+00$ & 0.25308706 & 0.00354077 & 1.3990 \\
\hline $0.2100 \mathrm{E}+00$ & 0.24866585 & 0.00320738 & 1.2898 \\
\hline $0.2200 \mathrm{E}+00$ & 0.24694665 & 0.00324611 & 1.3145 \\
\hline $0.2300 \mathrm{E}+00$ & 0.24385967 & 0.00384182 & 1.5754 \\
\hline $0.2350 \mathrm{E}+00$ & $0.23884975 *$ & 0.00309955 & 1.2977 \\
\hline $0.2400 \mathrm{E}+00$ & $0.23590450 *$ & 0.00421702 & 1.7876 \\
\hline $0.2450 \mathrm{E}+00$ & $0.23702947 *$ & 0.00307322 & 1.2966 \\
\hline $0.2500 \mathrm{E}+00$ & $0.23665657 *$ & 0.00321681 & 1.3593 \\
\hline $0.2600 \mathrm{E}+00$ & 0.23623140 & 0.00309654 & 1.3108 \\
\hline $0.2700 \mathrm{E}+00$ & 0.23123289 & 0.00377872 & 1.6342 \\
\hline $0.2800 \mathrm{E}+00$ & 0.21735446 & 0.00279851 & 1.2875 \\
\hline $0.3000 \mathrm{E}+00$ & $0.19819990 *$ & 0.00221346 & 1.1168 \\
\hline $0.3250 \mathrm{E}+00$ & $0.18852183 *$ & 0.00221745 & 1.1762 \\
\hline $0.3500 \mathrm{E}+00$ & 0.17865817 & 0.00190327 & 1.0653 \\
\hline
\end{tabular}


TABLE 8.5. ${ }^{197} \mathrm{Au}(\mathrm{n}, \gamma)$ CROSS-SECTION RECOMMENDED FOR USE AS A STANDARD AT $0.0253 \mathrm{eV}$ AND IN THE INCIDENT NEUTRON ENERGY RANGE 0.2-2.5 MeV (cont.)

(smoothed values are marked by * and values averaged on the energy groups (@) are expressed in terms of the central energy of that group)

\begin{tabular}{|c|c|c|c|}
\hline $\begin{array}{l}\text { Neutron energy } \\
(\mathrm{MeV})\end{array}$ & $\begin{array}{l}\text { Cross-section } \\
\quad \text { (barn) }\end{array}$ & $\begin{array}{c}\text { Cross-section } \\
\text { uncertainty (barn) }\end{array}$ & $\begin{array}{c}\text { Cross-section } \\
\text { uncertainty (\%) }\end{array}$ \\
\hline $0.3750 \mathrm{E}+00$ & 0.16924827 & 0.00177038 & 1.0460 \\
\hline $0.4000 \mathrm{E}+00$ & 0.16250629 & 0.00167639 & 1.0316 \\
\hline $0.4250 \mathrm{E}+00$ & 0.15518777 & 0.00183231 & 1.1807 \\
\hline $0.4500 \mathrm{E}+00$ & 0.14607597 & 0.00145481 & 0.9959 \\
\hline $0.4750 \mathrm{E}+00$ & $0.14151087 *$ & 0.00147474 & 1.0421 \\
\hline $0.5000 \mathrm{E}+00$ & $0.13704216 *$ & 0.00148234 & 1.0817 \\
\hline $0.5200 \mathrm{E}+00$ & $0.13011856 *$ & 0.00140243 & 1.0778 \\
\hline $0.5400 \mathrm{E}+00$ & 0.12467839 & 0.00146966 & 1.1788 \\
\hline $0.5700 \mathrm{E}+00$ & 0.11978376 & 0.00180842 & 1.5097 \\
\hline $0.6000 \mathrm{E}+00$ & 0.10952793 & 0.00118278 & 1.0799 \\
\hline $0.6500 \mathrm{E}+00$ & 0.09977657 & 0.00126033 & 1.2632 \\
\hline $0.7000 \mathrm{E}+00$ & 0.09596536 & 0.00108257 & 1.1281 \\
\hline $0.7500 \mathrm{E}+00$ & 0.09431097 & 0.00122320 & 1.2970 \\
\hline $0.8000 \mathrm{E}+00$ & 0.08864401 & 0.00092882 & 1.0478 \\
\hline $0.8500 \mathrm{E}+00$ & 0.08524062 & 0.00138647 & 1.6265 \\
\hline $0.9000 \mathrm{E}+00$ & $0.08449953 *$ & 0.00181715 & 2.1505 \\
\hline $0.9400 \mathrm{E}+00$ & $0.08539009 *$ & 0.00166777 & 1.9531 \\
\hline $0.9600 \mathrm{E}+00$ & 0.08511002 & 0.00361199 & 4.2439 \\
\hline $0.9800 \mathrm{E}+00$ & 0.08581323 & 0.00272686 & 3.1777 \\
\hline $0.1000 \mathrm{E}+01$ & 0.07979908 & 0.00083047 & 1.0407 \\
\hline $0.1100 \mathrm{E}+01$ & 0.07815919 & 0.00108799 & 1.3920 \\
\hline $0.1250 \mathrm{E}+01$ & 0.07361931 & 0.00092932 & 1.2623 \\
\hline $0.1400 \mathrm{E}+01$ & 0.07102221 & 0.00122496 & 1.7248 \\
\hline $0.1600 \mathrm{E}+01$ & 0.06808586 & 0.00102782 & 1.5096 \\
\hline $0.1800 \mathrm{E}+01$ & 0.06019876 & 0.00122788 & 2.0397 \\
\hline $0.2000 \mathrm{E}+01$ & 0.05297658 & 0.00086598 & 1.6346 \\
\hline $0.2200 \mathrm{E}+01$ & 0.04407293 & 0.00082283 & 1.8670 \\
\hline $0.2400 \mathrm{E}+01$ & 0.03650792 & 0.00081764 & 2.2396 \\
\hline $0.2600 \mathrm{E}+01$ & 0.03197786 & 0.00071000 & 2.2203 \\
\hline $0.2800 \mathrm{E}+01$ & 0.02585768 & 0.00052952 & 2.0478 \\
\hline
\end{tabular}


TABLE 8.6. ${ }^{235} \mathrm{U}(\mathrm{n}, \mathrm{f})$ CROSS-SECTION RECOMMENDED FOR USE AS A STANDARD AT $0.0253 \mathrm{eV}$ AND IN THE INCIDENT NEUTRON ENERGY RANGE 0.15-200 MeV

(smoothed values are marked by *, while the $9.4 \mathrm{eV}$ value (\#) is the integral cross-section from 7.8 to $11 \mathrm{eV}$ with units of barn-eV; values averaged on the energy groups (@) are expressed in terms of the central energy of that group)

\begin{tabular}{|c|c|c|c|}
\hline $\begin{array}{l}\text { Neutron energy } \\
(\mathrm{MeV})\end{array}$ & $\begin{array}{l}\text { Cross-section } \\
\text { (barn) }\end{array}$ & $\begin{array}{c}\text { Cross-section } \\
\text { uncertainty (barn) }\end{array}$ & $\begin{array}{c}\text { Cross-section } \\
\text { uncertainty (\%) }\end{array}$ \\
\hline $0.2530 \mathrm{E}-07$ & 584.32585508 & $1.0216 \mathrm{E}+00$ & $1.7483 \mathrm{E}-01$ \\
\hline $0.9400 \mathrm{E}-05$ & 246.39644943 \# & $1.2445 \mathrm{E}+00$ & $5.0507 \mathrm{E}-01$ \\
\hline $0.1500 \mathrm{E}-03$ & 21.17248433@ & $1.0648 \mathrm{E}-01$ & 5.0290E-01 \\
\hline $0.2500 \mathrm{E}-03$ & 20.69082861@ & $1.0803 \mathrm{E}-01$ & $5.2214 \mathrm{E}-01$ \\
\hline $0.3500 \mathrm{E}-03$ & 13.13491211@ & 7.2119E-02 & $5.4906 \mathrm{E}-01$ \\
\hline $0.4500 \mathrm{E}-03$ & 13.78125943@ & $7.6084 \mathrm{E}-02$ & $5.5208 \mathrm{E}-01$ \\
\hline $0.5500 \mathrm{E}-03$ & 15.17390031@ & 8.6133E-02 & $5.6764 \mathrm{E}-01$ \\
\hline $0.6500 \mathrm{E}-03$ & 11.51346038@ & $6.5647 \mathrm{E}-02$ & 5.7018E-01 \\
\hline $0.7500 \mathrm{E}-03$ & 11.10096738@ & $6.3766 \mathrm{E}-02$ & $5.7442 \mathrm{E}-01$ \\
\hline $0.8500 \mathrm{E}-03$ & $8.21339660 @$ & $4.7513 \mathrm{E}-02$ & $5.7848 \mathrm{E}-01$ \\
\hline $0.9500 \mathrm{E}-03$ & $7.50242989 @$ & $4.3677 \mathrm{E}-02$ & $5.8218 \mathrm{E}-01$ \\
\hline $0.1500 \mathrm{E}-02$ & $7.30262413 @$ & $4.0315 \mathrm{E}-02$ & $5.5206 \mathrm{E}-01$ \\
\hline $0.2500 \mathrm{E}-02$ & $5.38560404 @$ & 3.3177E-02 & 6.1603E-01 \\
\hline $0.3500 \mathrm{E}-02$ & $4.78437683 @$ & $2.9500 \mathrm{E}-02$ & $6.1659 \mathrm{E}-01$ \\
\hline $0.4500 \mathrm{E}-02$ & $4.26065443 @$ & $2.5482 \mathrm{E}-02$ & $5.9807 \mathrm{E}-01$ \\
\hline $0.5500 \mathrm{E}-02$ & 3.83856859@ & $2.3779 \mathrm{E}-02$ & 6.1947E-01 \\
\hline $0.6500 \mathrm{E}-02$ & $3.29074885 @$ & $2.1030 \mathrm{E}-02$ & $6.3906 \mathrm{E}-01$ \\
\hline $0.7500 \mathrm{E}-02$ & $3.23639532 @$ & $1.9406 \mathrm{E}-02$ & 5.9962E-01 \\
\hline $0.8500 \mathrm{E}-02$ & 3.00925292@ & $1.8270 \mathrm{E}-02$ & $6.0712 \mathrm{E}-01$ \\
\hline $0.9500 \mathrm{E}-02$ & $3.12023990 @$ & $1.9284 \mathrm{E}-02$ & 6.1803E-01 \\
\hline $0.1500 \mathrm{E}-01$ & 2.49488396@ & $1.4058 \mathrm{E}-02$ & 5.6349E-01 \\
\hline $0.2000 \mathrm{E}-01$ & 2.33832484 & $3.0701 \mathrm{E}-02$ & $1.3130 \mathrm{E}+00$ \\
\hline $0.2400 \mathrm{E}-01$ & 2.15502605 & $1.2148 \mathrm{E}-02$ & $5.6371 \mathrm{E}-01$ \\
\hline $0.3000 \mathrm{E}-01$ & 2.07406856 & $1.3503 \mathrm{E}-02$ & $6.5102 \mathrm{E}-01$ \\
\hline $0.4500 \mathrm{E}-01$ & 1.84733883 & 1.1397E-02 & 6.1695E-01 \\
\hline $0.5500 \mathrm{E}-01$ & 1.80838321 & $1.1384 \mathrm{E}-02$ & $6.2952 \mathrm{E}-01$ \\
\hline $0.6500 \mathrm{E}-01$ & 1.74803254 & $1.1006 \mathrm{E}-02$ & $6.2961 \mathrm{E}-01$ \\
\hline $0.7500 \mathrm{E}-01$ & 1.67322199 & $1.0723 \mathrm{E}-02$ & $6.4083 \mathrm{E}-01$ \\
\hline $0.8500 \mathrm{E}-01$ & 1.60321199 & $1.0810 \mathrm{E}-02$ & $6.7429 \mathrm{E}-01$ \\
\hline 0.9500E-01 & 1.57080970 & 1.0649E-02 & 6.7793E-01 \\
\hline $0.1000 \mathrm{E}+00$ & 1.58475275 & $1.1503 \mathrm{E}-02$ & $7.2585 \mathrm{E}-01$ \\
\hline $0.1200 \mathrm{E}+00$ & 1.49163501 & $1.0494 \mathrm{E}-02$ & $7.0355 \mathrm{E}-01$ \\
\hline $0.1500 \mathrm{E}+00$ & 1.42914089 & $1.0502 \mathrm{E}-02$ & 7.3487E-01 \\
\hline $0.1700 \mathrm{E}+00$ & 1.39143634 & $1.1494 \mathrm{E}-02$ & 8.2604E-01 \\
\hline $0.1800 \mathrm{E}+00$ & 1.36671392 & $1.8731 \mathrm{E}-02$ & $1.3705 \mathrm{E}+00$ \\
\hline $0.1900 \mathrm{E}+00$ & 1.36453421 & 1.3191E-02 & $9.6672 \mathrm{E}-01$ \\
\hline $0.2000 \mathrm{E}+00$ & 1.34139563 & $1.4539 \mathrm{E}-02$ & $1.0960 \mathrm{E}+00$ \\
\hline $0.2100 \mathrm{E}+00$ & 1.33615231 & $1.3030 \mathrm{E}-02$ & $9.6661 \mathrm{E}-01$ \\
\hline $0.2200 \mathrm{E}+00$ & 1.32209584 & $1.2000 \mathrm{E}-02$ & 9.0762E-01 \\
\hline
\end{tabular}


TABLE 8.6. ${ }^{235} \mathrm{U}(\mathrm{n}, \mathrm{f})$ CROSS-SECTION RECOMMENDED FOR USE AS A STANDARD AT $0.0253 \mathrm{eV}$ AND IN THE INCIDENT NEUTRON ENERGY RANGE 0.15-200 MeV (cont.)

(smoothed values are marked by *, while the $9.4 \mathrm{eV}$ value (\#) is the integral cross-section from 7.8 to $11 \mathrm{eV}$ with units of barn-eV; values averaged on the energy groups (@) are expressed in terms of the central energy of that group)

\begin{tabular}{|c|c|c|c|}
\hline $\begin{array}{l}\text { Neutron energy } \\
(\mathrm{MeV})\end{array}$ & $\begin{array}{l}\text { Cross-section } \\
\text { (barn) }\end{array}$ & $\begin{array}{c}\text { Cross-section } \\
\text { uncertainty (barn) }\end{array}$ & $\begin{array}{c}\text { Cross-section } \\
\text { uncertainty }(\%)\end{array}$ \\
\hline $0.2300 \mathrm{E}+00$ & 1.29267825 & $1.2393 \mathrm{E}-02$ & 9.5874E-01 \\
\hline $0.2350 \mathrm{E}+00$ & 1.29943664 & $1.2158 \mathrm{E}-02$ & $9.3562 \mathrm{E}-01$ \\
\hline $0.2400 \mathrm{E}+00$ & 1.28867519 & $1.4035 \mathrm{E}-02$ & $1.0891 \mathrm{E}+00$ \\
\hline $0.2450 \mathrm{E}+00$ & 1.29240688 & $1.2333 \mathrm{E}-02$ & $9.5425 \mathrm{E}-01$ \\
\hline $0.2500 \mathrm{E}+00$ & 1.27891777 & $9.7698 \mathrm{E}-03$ & 7.6391E-01 \\
\hline $0.2600 \mathrm{E}+00$ & 1.26848974 & $9.9747 \mathrm{E}-03$ & 7.8634E-01 \\
\hline $0.2700 \mathrm{E}+00$ & 1.25080297 & $1.3383 \mathrm{E}-02$ & $1.0700 \mathrm{E}+00$ \\
\hline $0.2800 \mathrm{E}+00$ & 1.23801801 & $1.0044 \mathrm{E}-02$ & 8.1133E-01 \\
\hline $0.3000 \mathrm{E}+00$ & 1.22880371 & $9.0987 \mathrm{E}-03$ & 7.4045E-01 \\
\hline $0.3250 \mathrm{E}+00$ & 1.23724233 & $1.0742 \mathrm{E}-02$ & 8.6821E-01 \\
\hline $0.3500 \mathrm{E}+00$ & $1.22549352 *$ & $9.1073 \mathrm{E}-03$ & 7.4315E-01 \\
\hline $0.3750 \mathrm{E}+00$ & $1.21611656 *$ & $9.7194 \mathrm{E}-03$ & $7.9920 \mathrm{E}-01$ \\
\hline $0.4000 \mathrm{E}+00$ & $1.20643068 *$ & $9.7325 \mathrm{E}-03$ & 8.0672E-01 \\
\hline $0.4250 \mathrm{E}+00$ & $1.19666563 *$ & $1.1090 \mathrm{E}-02$ & $9.2674 \mathrm{E}-01$ \\
\hline $0.4500 \mathrm{E}+00$ & $1.16998620 *$ & $9.4090 \mathrm{E}-03$ & $8.0420 \mathrm{E}-01$ \\
\hline $0.4750 \mathrm{E}+00$ & $1.14403862 *$ & $9.4681 \mathrm{E}-03$ & $8.2760 \mathrm{E}-01$ \\
\hline $0.5000 \mathrm{E}+00$ & $1.13811781 *$ & 7.8759E-03 & $6.9201 \mathrm{E}-01$ \\
\hline $0.5200 \mathrm{E}+00$ & $1.13254404 *$ & $9.0561 \mathrm{E}-03$ & 7.9963E-01 \\
\hline $0.5400 \mathrm{E}+00$ & $1.12632570 *$ & 8.1138E-03 & 7.2038E-01 \\
\hline $0.5700 \mathrm{E}+00$ & $1.12249734 *$ & 8.7951E-03 & $7.8353 \mathrm{E}-01$ \\
\hline $0.6000 \mathrm{E}+00$ & $1.11580979 *$ & $7.7928 \mathrm{E}-03$ & $6.9840 \mathrm{E}-01$ \\
\hline $0.6500 \mathrm{E}+00$ & $1.11175441 *$ & $7.2373 \mathrm{E}-03$ & $6.5098 \mathrm{E}-01$ \\
\hline $0.7000 \mathrm{E}+00$ & $1.11671625 *$ & 7.4413E-03 & $6.6635 \mathrm{E}-01$ \\
\hline $0.7500 \mathrm{E}+00$ & $1.11813757 *$ & $7.1765 \mathrm{E}-03$ & $6.4182 \mathrm{E}-01$ \\
\hline $0.8000 \mathrm{E}+00$ & $1.11345655 *$ & $7.2085 \mathrm{E}-03$ & 6.4740E-01 \\
\hline $0.8500 \mathrm{E}+00$ & 1.11548977 & $7.3030 \mathrm{E}-03$ & $6.5469 \mathrm{E}-01$ \\
\hline $0.9000 \mathrm{E}+00$ & 1.13934263 & 7.5207E-03 & 6.6009E-01 \\
\hline $0.9400 \mathrm{E}+00$ & 1.16894021 & $7.8157 \mathrm{E}-03$ & $6.6861 \mathrm{E}-01$ \\
\hline $0.9600 \mathrm{E}+00$ & 1.19340871 & 8.4003E-03 & 7.0389E-01 \\
\hline $0.9800 \mathrm{E}+00$ & 1.20152187 & $9.4355 \mathrm{E}-03$ & 7.8529E-01 \\
\hline $0.1000 \mathrm{E}+01$ & 1.19882730 & $7.2426 \mathrm{E}-03$ & 6.0414E-01 \\
\hline $0.1100 \mathrm{E}+01$ & 1.19117041 & $6.8443 \mathrm{E}-03$ & 5.7459E-01 \\
\hline $0.1250 \mathrm{E}+01$ & 1.20858530 & 7.0609E-03 & 5.8423E-01 \\
\hline $0.1400 \mathrm{E}+01$ & 1.22622254 & 7.3389E-03 & $5.9850 \mathrm{E}-01$ \\
\hline $0.1600 \mathrm{E}+01$ & 1.25386482 & 7.1643E-03 & $5.7138 \mathrm{E}-01$ \\
\hline $0.1800 \mathrm{E}+01$ & 1.27010292 & $7.4577 \mathrm{E}-03$ & $5.8717 \mathrm{E}-01$ \\
\hline $0.2000 \mathrm{E}+01$ & 1.28672157 & $7.6882 \mathrm{E}-03$ & $5.9750 \mathrm{E}-01$ \\
\hline $0.2200 \mathrm{E}+01$ & 1.27773163 & 7.7129E-03 & $6.0364 \mathrm{E}-01$ \\
\hline $0.2400 \mathrm{E}+01$ & 1.26583108 & 7.5488E-03 & $5.9635 \mathrm{E}-01$ \\
\hline
\end{tabular}


TABLE 8.6. ${ }^{235} \mathrm{U}(\mathrm{n}, \mathrm{f})$ CROSS-SECTION RECOMMENDED FOR USE AS A STANDARD AT $0.0253 \mathrm{eV}$ AND IN THE INCIDENT NEUTRON ENERGY RANGE 0.15-200 MeV (cont.)

(smoothed values are marked by *, while the $9.4 \mathrm{eV}$ value (\#) is the integral cross-section from 7.8 to $11 \mathrm{eV}$ with units of barn-eV; values averaged on the energy groups (@) are expressed in terms of the central energy of that group)

\begin{tabular}{|c|c|c|c|}
\hline $\begin{array}{l}\text { Neutron energy } \\
(\mathrm{MeV})\end{array}$ & $\begin{array}{l}\text { Cross-section } \\
\text { (barn) }\end{array}$ & $\begin{array}{c}\text { Cross-section } \\
\text { uncertainty (barn) }\end{array}$ & $\begin{array}{c}\text { Cross-section } \\
\text { uncertainty }(\%)\end{array}$ \\
\hline $0.2600 \mathrm{E}+01$ & 1.25778667 & $7.7308 \mathrm{E}-03$ & 6.1463E-01 \\
\hline $0.2800 \mathrm{E}+01$ & 1.24085775 & 8.3445E-03 & $6.7248 \mathrm{E}-01$ \\
\hline $0.3000 \mathrm{E}+01$ & 1.21585320 & 7.2239E-03 & 5.9415E-01 \\
\hline $0.3600 \mathrm{E}+01$ & 1.16410561 & $6.7422 \mathrm{E}-03$ & 5.7918E-01 \\
\hline $0.4000 \mathrm{E}+01$ & 1.13582059 & 6.7012E-03 & 5.8999E-01 \\
\hline $0.4500 \mathrm{E}+01$ & 1.11681801 & 6.7598E-03 & $6.0527 \mathrm{E}-01$ \\
\hline $0.4700 \mathrm{E}+01$ & 1.10021716 & $6.8926 \mathrm{E}-03$ & $6.2648 \mathrm{E}-01$ \\
\hline $0.5000 \mathrm{E}+01$ & 1.07238656 & $6.4730 \mathrm{E}-03$ & $6.0360 \mathrm{E}-01$ \\
\hline $0.5300 \mathrm{E}+01$ & 1.05658348 & $6.9575 \mathrm{E}-03$ & 6.5849E-01 \\
\hline $0.5500 \mathrm{E}+01$ & 1.03698406 & $6.6729 \mathrm{E}-03$ & $6.4349 \mathrm{E}-01$ \\
\hline $0.5800 \mathrm{E}+01$ & 1.03788504 & $7.2106 \mathrm{E}-03$ & $6.9474 \mathrm{E}-01$ \\
\hline $0.6000 \mathrm{E}+01$ & 1.09106642 & $7.8938 \mathrm{E}-03$ & $7.2350 \mathrm{E}-01$ \\
\hline $0.6200 \mathrm{E}+01$ & 1.17851421 & $9.3984 \mathrm{E}-03$ & $7.9748 \mathrm{E}-01$ \\
\hline $0.6500 \mathrm{E}+01$ & 1.33271633 & $9.7821 \mathrm{E}-03$ & 7.3399E-01 \\
\hline $0.7000 \mathrm{E}+01$ & 1.54240537 & $1.1208 \mathrm{E}-02$ & $7.2668 \mathrm{E}-01$ \\
\hline $0.7500 \mathrm{E}+01$ & 1.70042434 & $1.2882 \mathrm{E}-02$ & $7.5760 \mathrm{E}-01$ \\
\hline $0.7750 \mathrm{E}+01$ & 1.73780711 & $1.4943 \mathrm{E}-02$ & 8.5989E-01 \\
\hline $0.8000 \mathrm{E}+01$ & 1.78526615 & $1.3167 \mathrm{E}-02$ & $7.3752 \mathrm{E}-01$ \\
\hline $0.8500 \mathrm{E}+01$ & 1.79292452 & $1.3548 \mathrm{E}-02$ & $7.5566 \mathrm{E}-01$ \\
\hline $0.9000 \mathrm{E}+01$ & 1.77917369 & $1.3318 \mathrm{E}-02$ & $7.4855 \mathrm{E}-01$ \\
\hline $0.1000 \mathrm{E}+02$ & 1.75854059 & $1.4548 \mathrm{E}-02$ & $8.2729 \mathrm{E}-01$ \\
\hline $0.1100 \mathrm{E}+02$ & 1.73619514 & $1.4550 \mathrm{E}-02$ & 8.3801E-01 \\
\hline $0.1150 \mathrm{E}+02$ & 1.70304747 & $1.5785 \mathrm{E}-02$ & $9.2687 \mathrm{E}-01$ \\
\hline $0.1200 \mathrm{E}+02$ & 1.72173991 & $1.4992 \mathrm{E}-02$ & 8.7074E-01 \\
\hline $0.1300 \mathrm{E}+02$ & 1.88616156 & $1.3598 \mathrm{E}-02$ & 7.2093E-01 \\
\hline $0.1400 \mathrm{E}+02$ & 2.07990047 & $1.2412 \mathrm{E}-02$ & $5.9674 \mathrm{E}-01$ \\
\hline $0.1450 \mathrm{E}+02$ & 2.09111419 & $1.2022 \mathrm{E}-02$ & $5.7490 \mathrm{E}-01$ \\
\hline $0.1500 \mathrm{E}+02$ & 2.12623431 & $1.5082 \mathrm{E}-02$ & 7.0931E-01 \\
\hline $0.1600 \mathrm{E}+02$ & 2.15342507 & $1.7952 \mathrm{E}-02$ & $8.3366 \mathrm{E}-01$ \\
\hline $0.1700 \mathrm{E}+02$ & 2.09788196 & $1.8454 \mathrm{E}-02$ & 8.7965E-01 \\
\hline $0.1800 \mathrm{E}+02$ & 2.05843900 & $1.8534 \mathrm{E}-02$ & $9.0040 \mathrm{E}-01$ \\
\hline $0.1900 \mathrm{E}+02$ & 2.03173076 & 1.6792E-02 & 8.2650E-01 \\
\hline $0.2000 \mathrm{E}+02$ & 2.02063129 & $2.0371 \mathrm{E}-02$ & $1.0082 \mathrm{E}+00$ \\
\hline $0.2100 \mathrm{E}+02$ & 2.08468998 & $2.1485 \mathrm{E}-02$ & $1.0306 \mathrm{E}+00$ \\
\hline $0.2200 \mathrm{E}+02$ & 2.11564076 & $3.5508 \mathrm{E}-02$ & $1.6784 \mathrm{E}+00$ \\
\hline $0.2300 \mathrm{E}+02$ & 2.14320684 & $2.7184 \mathrm{E}-02$ & $1.2684 \mathrm{E}+00$ \\
\hline $0.2400 \mathrm{E}+02$ & 2.08818218 & $3.0054 \mathrm{E}-02$ & $1.4392 \mathrm{E}+00$ \\
\hline $0.2500 \mathrm{E}+02$ & 2.12559479 & 2.4989E-02 & $1.1756 \mathrm{E}+00$ \\
\hline $0.2600 \mathrm{E}+02$ & 2.12652468 & $3.2666 \mathrm{E}-02$ & $1.5361 \mathrm{E}+00$ \\
\hline
\end{tabular}


TABLE 8.6. ${ }^{235} \mathrm{U}(\mathrm{n}, \mathrm{f})$ CROSS-SECTION RECOMMENDED FOR USE AS A STANDARD AT $0.0253 \mathrm{eV}$ AND IN THE INCIDENT NEUTRON ENERGY RANGE 0.15-200 MeV (cont.)

(smoothed values are marked by *, while the $9.4 \mathrm{eV}$ value (\#) is the integral cross-section from 7.8 to $11 \mathrm{eV}$ with units of barn-eV; values averaged on the energy groups (@) are expressed in terms of the central energy of that group)

\begin{tabular}{|c|c|c|c|}
\hline $\begin{array}{l}\text { Neutron energy } \\
(\mathrm{MeV})\end{array}$ & $\begin{array}{l}\text { Cross-section } \\
\text { (barn) }\end{array}$ & $\begin{array}{c}\text { Cross-section } \\
\text { uncertainty (barn) }\end{array}$ & $\begin{array}{c}\text { Cross-section } \\
\text { uncertainty }(\%)\end{array}$ \\
\hline $0.2700 \mathrm{E}+02$ & 2.10699803 & 2.7362E-02 & $1.2986 \mathrm{E}+00$ \\
\hline $0.2800 \mathrm{E}+02$ & 2.13230617 & $3.4575 \mathrm{E}-02$ & $1.6215 \mathrm{E}+00$ \\
\hline $0.2900 \mathrm{E}+02$ & 2.10308383 & 2.7612E-02 & $1.3129 \mathrm{E}+00$ \\
\hline $0.3000 \mathrm{E}+02$ & 2.15207650 & 2.9999E-02 & $1.3940 \mathrm{E}+00$ \\
\hline $0.3200 \mathrm{E}+02$ & 2.13108438 & $3.6387 \mathrm{E}-02$ & $1.7074 \mathrm{E}+00$ \\
\hline $0.3400 \mathrm{E}+02$ & 2.10789535 & $3.8256 \mathrm{E}-02$ & $1.8149 \mathrm{E}+00$ \\
\hline $0.3600 \mathrm{E}+02$ & 2.02949265 & 4.0443E-02 & $1.9927 \mathrm{E}+00$ \\
\hline $0.3800 \mathrm{E}+02$ & 1.97513669 & $4.2458 \mathrm{E}-02$ & $2.1496 \mathrm{E}+00$ \\
\hline $0.4000 \mathrm{E}+02$ & 1.99398306 & $4.3335 \mathrm{E}-02$ & $2.1733 \mathrm{E}+00$ \\
\hline $0.4200 \mathrm{E}+02$ & 1.97239744 & $3.9258 \mathrm{E}-02$ & $1.9904 \mathrm{E}+00$ \\
\hline $0.4400 \mathrm{E}+02$ & 1.96474709 & 4.2531E-02 & $2.1647 \mathrm{E}+00$ \\
\hline $0.4600 \mathrm{E}+02$ & 1.95019739 & $3.7386 \mathrm{E}-02$ & $1.9170 \mathrm{E}+00$ \\
\hline $0.4800 \mathrm{E}+02$ & 1.91809664 & 4.4267E-02 & $2.3079 \mathrm{E}+00$ \\
\hline $0.5000 \mathrm{E}+02$ & 1.89717308 & 4.4567E-02 & $2.3491 \mathrm{E}+00$ \\
\hline $0.5200 \mathrm{E}+02$ & 1.90131561 & $5.0128 \mathrm{E}-02$ & $2.6365 \mathrm{E}+00$ \\
\hline $0.5400 \mathrm{E}+02$ & 1.86370595 & 4.9214E-02 & $2.6406 \mathrm{E}+00$ \\
\hline $0.5600 \mathrm{E}+02$ & 1.88473150 & $5.0288 \mathrm{E}-02$ & $2.6682 \mathrm{E}+00$ \\
\hline $0.5800 \mathrm{E}+02$ & 1.86626261 & $4.5963 \mathrm{E}-02$ & $2.4628 \mathrm{E}+00$ \\
\hline $0.6000 \mathrm{E}+02$ & 1.83204170 & $4.2350 \mathrm{E}-02$ & $2.3116 \mathrm{E}+00$ \\
\hline $0.6400 \mathrm{E}+02$ & 1.83035776 & $3.7275 \mathrm{E}-02$ & $2.0365 \mathrm{E}+00$ \\
\hline $0.6800 \mathrm{E}+02$ & 1.76578329 & $3.6285 \mathrm{E}-02$ & $2.0549 \mathrm{E}+00$ \\
\hline $0.7200 \mathrm{E}+02$ & 1.72770368 & 3.9174E-02 & $2.2674 \mathrm{E}+00$ \\
\hline $0.7600 \mathrm{E}+02$ & 1.74043199 & 4.1848E-02 & $2.4045 \mathrm{E}+00$ \\
\hline $0.8000 \mathrm{E}+02$ & 1.70712225 & 4.3917E-02 & $2.5726 \mathrm{E}+00$ \\
\hline $0.8400 \mathrm{E}+02$ & 1.70227429 & 5.7899E-02 & $3.4012 \mathrm{E}+00$ \\
\hline $0.8800 \mathrm{E}+02$ & 1.63620283 & $5.6616 \mathrm{E}-02$ & $3.4602 \mathrm{E}+00$ \\
\hline $0.9200 \mathrm{E}+02$ & 1.59777499 & $5.6670 \mathrm{E}-02$ & $3.5468 \mathrm{E}+00$ \\
\hline $0.9600 \mathrm{E}+02$ & $1.58019730 *$ & $5.5624 \mathrm{E}-02$ & $3.5201 \mathrm{E}+00$ \\
\hline $0.1000 \mathrm{E}+03$ & $1.56338392 *$ & $5.5444 \mathrm{E}-02$ & $3.5464 \mathrm{E}+00$ \\
\hline $0.1040 \mathrm{E}+03$ & $1.54623508 *$ & 5.4094E-02 & $3.4984 \mathrm{E}+00$ \\
\hline $0.1080 \mathrm{E}+03$ & $1.54524790 *$ & $7.0545 \mathrm{E}-02$ & $4.5653 \mathrm{E}+00$ \\
\hline $0.1120 \mathrm{E}+03$ & $1.53993939 *$ & $6.7475 \mathrm{E}-02$ & $4.3815 \mathrm{E}+00$ \\
\hline $0.1160 \mathrm{E}+03$ & $1.52478950 *$ & $6.7403 \mathrm{E}-02$ & $4.4204 \mathrm{E}+00$ \\
\hline $0.1200 \mathrm{E}+03$ & $1.50839350 *$ & $6.5700 \mathrm{E}-02$ & $4.3556 \mathrm{E}+00$ \\
\hline $0.1280 \mathrm{E}+03$ & 1.49193956 & $6.3591 \mathrm{E}-02$ & $4.2623 \mathrm{E}+00$ \\
\hline $0.1360 \mathrm{E}+03$ & 1.48368137 & $6.2194 \mathrm{E}-02$ & $4.1919 \mathrm{E}+00$ \\
\hline $0.1440 \mathrm{E}+03$ & 1.46250189 & $5.8956 \mathrm{E}-02$ & $4.0312 \mathrm{E}+00$ \\
\hline $0.1520 \mathrm{E}+03$ & 1.48298953 & $6.2356 \mathrm{E}-02$ & $4.2048 \mathrm{E}+00$ \\
\hline $0.1600 \mathrm{E}+03$ & 1.46218146 & $6.2164 \mathrm{E}-02$ & $4.2515 \mathrm{E}+00$ \\
\hline
\end{tabular}


TABLE 8.6. ${ }^{235} \mathrm{U}(\mathrm{n}, \mathrm{f})$ CROSS-SECTION RECOMMENDED FOR USE AS A STANDARD AT $0.0253 \mathrm{eV}$ AND IN THE INCIDENT NEUTRON ENERGY RANGE 0.15-200 MeV (cont.)

(smoothed values are marked by *, while the $9.4 \mathrm{eV}$ value (\#) is the integral cross-section from 7.8 to $11 \mathrm{eV}$ with units of barn-eV; values averaged on the energy groups (@) are expressed in terms of the central energy of that group)

\begin{tabular}{lccc}
\hline $\begin{array}{l}\text { Neutron energy } \\
(\mathrm{MeV})\end{array}$ & $\begin{array}{c}\text { Cross-section } \\
\text { (barn) }\end{array}$ & $\begin{array}{c}\text { Cross-section } \\
\text { uncertainty (barn) }\end{array}$ & $\begin{array}{c}\text { Cross-section } \\
\text { uncertainty }(\%)\end{array}$ \\
\hline $0.1680 \mathrm{E}+03$ & 1.45238992 & $6.4805 \mathrm{E}-02$ & $4.4620 \mathrm{E}+00$ \\
$0.1760 \mathrm{E}+03$ & 1.46986846 & $6.3385 \mathrm{E}-02$ & $4.3123 \mathrm{E}+00$ \\
$0.1840 \mathrm{E}+03$ & 1.46690834 & $6.6009 \mathrm{E}-02$ & $4.4999 \mathrm{E}+00$ \\
$0.1920 \mathrm{E}+03$ & 1.45471578 & $6.1431 \mathrm{E}-02$ & $4.2229 \mathrm{E}+00$ \\
$0.2000 \mathrm{E}+03$ & 1.46511113 & $6.1566 \mathrm{E}-02$ & $4.2022 \mathrm{E}+00$ \\
\hline
\end{tabular}

TABLE 8.7. ${ }^{238} \mathrm{U}(\mathrm{n}, \mathrm{f})$ CROSS-SECTION RECOMMENDED FOR USE AS A STANDARD IN THE INCIDENT NEUTRON ENERGY RANGE 2-200 MeV

(smoothed values are marked by *)

\begin{tabular}{|c|c|c|c|}
\hline $\begin{array}{l}\text { Neutron energy } \\
(\mathrm{MeV})\end{array}$ & $\begin{array}{l}\text { Cross-section } \\
\text { (barn) }\end{array}$ & $\begin{array}{c}\text { Cross-section } \\
\text { uncertainty (barn) }\end{array}$ & $\begin{array}{c}\text { Cross-section } \\
\text { uncertainty }(\%)\end{array}$ \\
\hline $0.1000 \mathrm{E}+01$ & 0.01355137 & $1.6347 \mathrm{E}-04$ & $1.2063 \mathrm{E}+00$ \\
\hline $0.1100 \mathrm{E}+01$ & 0.03148451 & 3.9204E-04 & $1.2452 \mathrm{E}+00$ \\
\hline $0.1250 \mathrm{E}+01$ & 0.03473557 & 4.4022E-04 & $1.2674 \mathrm{E}+00$ \\
\hline $0.1400 \mathrm{E}+01$ & 0.19119852 & 1.6659E-03 & 8.7132E-01 \\
\hline $0.1600 \mathrm{E}+01$ & 0.42328233 & $3.2268 \mathrm{E}-03$ & 7.6233E-01 \\
\hline $0.1800 \mathrm{E}+01$ & 0.48392439 & $3.5725 \mathrm{E}-03$ & 7.3823E-01 \\
\hline $0.2000 \mathrm{E}+01$ & 0.53402727 & 3.7840E-03 & 7.0858E-01 \\
\hline $0.2200 \mathrm{E}+01$ & 0.54711402 & 3.9234E-03 & 7.1710E-01 \\
\hline $0.2400 \mathrm{E}+01$ & 0.54634309 & 3.9448E-03 & 7.2205E-01 \\
\hline $0.2600 \mathrm{E}+01$ & 0.54108868 & 3.8127E-03 & 7.0463E-01 \\
\hline $0.2800 \mathrm{E}+01$ & 0.53721997 & 4.1734E-03 & $7.7686 \mathrm{E}-01$ \\
\hline $0.3000 \mathrm{E}+01$ & 0.52373956 & $3.6927 \mathrm{E}-03$ & 7.0507E-01 \\
\hline $0.3600 \mathrm{E}+01$ & 0.54692267 & 3.7823E-03 & 6.9156E-01 \\
\hline $0.4000 \mathrm{E}+01$ & 0.55440109 & 3.9797E-03 & 7.1784E-01 \\
\hline $0.4500 \mathrm{E}+01$ & 0.55933835 & 4.1670E-03 & 7.4498E-01 \\
\hline $0.4700 \mathrm{E}+01$ & 0.55813689 & $4.2737 \mathrm{E}-03$ & 7.6571E-01 \\
\hline $0.5000 \mathrm{E}+01$ & 0.54671151 & 3.9912E-03 & 7.3003E-01 \\
\hline $0.5300 \mathrm{E}+01$ & 0.54926082 & $4.5288 \mathrm{E}-03$ & $8.2452 \mathrm{E}-01$ \\
\hline $0.5500 \mathrm{E}+01$ & 0.54633789 & 4.3601E-03 & 7.9806E-01 \\
\hline $0.5800 \mathrm{E}+01$ & 0.56693575 & 4.7763E-03 & 8.4247E-01 \\
\hline $0.6000 \mathrm{E}+01$ & 0.61079005 & 5.3197E-03 & 8.7096E-01 \\
\hline $0.6200 \mathrm{E}+01$ & 0.68170787 & $6.3320 \mathrm{E}-03$ & $9.2884 \mathrm{E}-01$ \\
\hline $0.6500 \mathrm{E}+01$ & 0.81579519 & $6.9322 \mathrm{E}-03$ & $8.4975 \mathrm{E}-01$ \\
\hline $0.7000 \mathrm{E}+01$ & 0.93955131 & $7.8828 \mathrm{E}-03$ & 8.3900E-01 \\
\hline $0.7500 \mathrm{E}+01$ & 0.98746213 & 8.8154E-03 & 8.9274E-01 \\
\hline $0.7750 \mathrm{E}+01$ & 0.98763222 & $9.8650 \mathrm{E}-03$ & $9.9885 \mathrm{E}-01$ \\
\hline
\end{tabular}


TABLE 8.7. ${ }^{238} \mathrm{U}(\mathrm{n}, \mathrm{f})$ CROSS-SECTION RECOMMENDED FOR USE AS A STANDARD IN THE INCIDENT NEUTRON ENERGY RANGE 2-200 MeV (cont.)

(smoothed values are marked by *)

\begin{tabular}{|c|c|c|c|}
\hline $\begin{array}{l}\text { Neutron energy } \\
(\mathrm{MeV})\end{array}$ & $\begin{array}{l}\text { Cross-section } \\
\text { (barn) }\end{array}$ & $\begin{array}{c}\text { Cross-section } \\
\text { uncertainty (barn) }\end{array}$ & $\begin{array}{c}\text { Cross-section } \\
\text { uncertainty }(\%)\end{array}$ \\
\hline $0.8000 \mathrm{E}+01$ & 1.01109156 & 8.5129E-03 & 8.4195E-01 \\
\hline $0.8500 \mathrm{E}+01$ & 1.00766137 & 8.9508E-03 & 8.8827E-01 \\
\hline $0.9000 \mathrm{E}+01$ & 1.00937717 & $8.8653 \mathrm{E}-03$ & 8.7829E-01 \\
\hline $0.1000 \mathrm{E}+02$ & 1.00133567 & $9.4376 \mathrm{E}-03$ & $9.4250 \mathrm{E}-01$ \\
\hline $0.1100 \mathrm{E}+02$ & 1.00189688 & $1.0069 \mathrm{E}-02$ & $1.0050 \mathrm{E}+00$ \\
\hline $0.1150 \mathrm{E}+02$ & 0.99448715 & $1.0893 \mathrm{E}-02$ & $1.0953 \mathrm{E}+00$ \\
\hline $0.1200 \mathrm{E}+02$ & 0.97188595 & $9.8296 \mathrm{E}-03$ & $1.0114 \mathrm{E}+00$ \\
\hline $0.1300 \mathrm{E}+02$ & 1.01508870 & $8.6305 \mathrm{E}-03$ & $8.5022 \mathrm{E}-01$ \\
\hline $0.1400 \mathrm{E}+02$ & 1.14337812 & 8.1064E-03 & 7.0899E-01 \\
\hline $0.1450 \mathrm{E}+02$ & 1.18439534 & $7.4802 \mathrm{E}-03$ & $6.3156 \mathrm{E}-01$ \\
\hline $0.1500 \mathrm{E}+02$ & 1.23462382 & $9.8885 \mathrm{E}-03$ & 8.0094E-01 \\
\hline $0.1600 \mathrm{E}+02$ & 1.30827191 & $1.2582 \mathrm{E}-02$ & $9.6175 \mathrm{E}-01$ \\
\hline $0.1700 \mathrm{E}+02$ & 1.31415146 & $1.3445 \mathrm{E}-02$ & $1.0231 \mathrm{E}+00$ \\
\hline $0.1800 \mathrm{E}+02$ & 1.31518690 & $1.3620 \mathrm{E}-02$ & $1.0356 \mathrm{E}+00$ \\
\hline $0.1900 \mathrm{E}+02$ & 1.35485738 & $1.3201 \mathrm{E}-02$ & $9.7435 \mathrm{E}-01$ \\
\hline $0.2000 \mathrm{E}+02$ & 1.40508093 & $1.6740 \mathrm{E}-02$ & $1.1914 \mathrm{E}+00$ \\
\hline $0.2100 \mathrm{E}+02$ & 1.52303967 & $1.7942 \mathrm{E}-02$ & $1.1781 \mathrm{E}+00$ \\
\hline $0.2200 \mathrm{E}+02$ & 1.55700843 & 2.7329E-02 & $1.7552 \mathrm{E}+00$ \\
\hline $0.2300 \mathrm{E}+02$ & 1.60853410 & $2.3972 \mathrm{E}-02$ & $1.4903 \mathrm{E}+00$ \\
\hline $0.2400 \mathrm{E}+02$ & 1.53992995 & $2.4822 \mathrm{E}-02$ & $1.6119 \mathrm{E}+00$ \\
\hline $0.2500 \mathrm{E}+02$ & 1.58738371 & $2.2312 \mathrm{E}-02$ & $1.4056 \mathrm{E}+00$ \\
\hline $0.2600 \mathrm{E}+02$ & 1.59398783 & $2.8481 \mathrm{E}-02$ & $1.7868 \mathrm{E}+00$ \\
\hline $0.2700 \mathrm{E}+02$ & 1.57152519 & $2.4641 \mathrm{E}-02$ & $1.5680 \mathrm{E}+00$ \\
\hline $0.2800 \mathrm{E}+02$ & 1.62263535 & $2.9828 \mathrm{E}-02$ & $1.8382 \mathrm{E}+00$ \\
\hline $0.2900 \mathrm{E}+02$ & 1.61977825 & $2.5477 \mathrm{E}-02$ & $1.5729 \mathrm{E}+00$ \\
\hline $0.3000 \mathrm{E}+02$ & 1.66646769 & $2.6773 \mathrm{E}-02$ & $1.6066 \mathrm{E}+00$ \\
\hline $0.3200 \mathrm{E}+02$ & 1.70629385 & $3.1686 \mathrm{E}-02$ & $1.8570 \mathrm{E}+00$ \\
\hline $0.3400 \mathrm{E}+02$ & 1.69270900 & 3.3224E-02 & $1.9628 \mathrm{E}+00$ \\
\hline $0.3600 \mathrm{E}+02$ & 1.66316121 & $3.5784 \mathrm{E}-02$ & $2.1515 \mathrm{E}+00$ \\
\hline $0.3800 \mathrm{E}+02$ & 1.64705852 & 3.7713E-02 & $2.2897 \mathrm{E}+00$ \\
\hline $0.4000 \mathrm{E}+02$ & 1.68559032 & $3.9563 \mathrm{E}-02$ & $2.3471 \mathrm{E}+00$ \\
\hline $0.4200 \mathrm{E}+02$ & 1.67482055 & $3.5903 \mathrm{E}-02$ & $2.1437 \mathrm{E}+00$ \\
\hline $0.4400 \mathrm{E}+02$ & 1.65536141 & 3.8723E-02 & $2.3392 \mathrm{E}+00$ \\
\hline $0.4600 \mathrm{E}+02$ & 1.67419554 & $3.4671 \mathrm{E}-02$ & $2.0709 \mathrm{E}+00$ \\
\hline $0.4800 \mathrm{E}+02$ & 1.65428673 & $4.0710 \mathrm{E}-02$ & $2.4609 \mathrm{E}+00$ \\
\hline $0.5000 \mathrm{E}+02$ & 1.62322274 & 4.1298E-02 & $2.5442 \mathrm{E}+00$ \\
\hline $0.5200 \mathrm{E}+02$ & 1.65580204 & $4.6284 \mathrm{E}-02$ & $2.7953 \mathrm{E}+00$ \\
\hline $0.5400 \mathrm{E}+02$ & 1.61877514 & $4.5193 \mathrm{E}-02$ & $2.7918 \mathrm{E}+00$ \\
\hline $0.5600 \mathrm{E}+02$ & 1.63615399 & 4.6041E-02 & $2.8140 \mathrm{E}+00$ \\
\hline $0.5800 \mathrm{E}+02$ & 1.63340832 & 4.2344E-02 & $2.5924 \mathrm{E}+00$ \\
\hline
\end{tabular}


TABLE 8.7. ${ }^{238} \mathrm{U}(\mathrm{n}, \mathrm{f})$ CROSS-SECTION RECOMMENDED FOR USE AS A STANDARD IN THE INCIDENT NEUTRON ENERGY RANGE 2-200 MeV (cont.)

(smoothed values are marked by *)

\begin{tabular}{|c|c|c|c|}
\hline $\begin{array}{l}\text { Neutron energy } \\
(\mathrm{MeV})\end{array}$ & $\begin{array}{l}\text { Cross-section } \\
\text { (barn) }\end{array}$ & $\begin{array}{c}\text { Cross-section } \\
\text { uncertainty (barn) }\end{array}$ & $\begin{array}{c}\text { Cross-section } \\
\text { uncertainty }(\%)\end{array}$ \\
\hline $0.6000 \mathrm{E}+02$ & 1.59203041 & $3.9195 \mathrm{E}-02$ & $2.4619 \mathrm{E}+00$ \\
\hline $0.6400 \mathrm{E}+02$ & 1.57558672 & $3.4663 \mathrm{E}-02$ & $2.2000 \mathrm{E}+00$ \\
\hline $0.6800 \mathrm{E}+02$ & 1.51199229 & $3.3580 \mathrm{E}-02$ & $2.2209 \mathrm{E}+00$ \\
\hline $0.7200 \mathrm{E}+02$ & 1.50280613 & $3.6385 \mathrm{E}-02$ & $2.4212 \mathrm{E}+00$ \\
\hline $0.7600 \mathrm{E}+02$ & 1.52304411 & $3.8955 \mathrm{E}-02$ & $2.5577 \mathrm{E}+00$ \\
\hline $0.8000 \mathrm{E}+02$ & 1.50702348 & $4.1528 \mathrm{E}-02$ & $2.7556 \mathrm{E}+00$ \\
\hline $0.8400 \mathrm{E}+02$ & 1.50774895 & 5.3160E-02 & $3.5258 \mathrm{E}+00$ \\
\hline $0.8800 \mathrm{E}+02$ & 1.45066209 & 5.1832E-02 & $3.5730 \mathrm{E}+00$ \\
\hline $0.9200 \mathrm{E}+02$ & 1.41977253 & $5.2522 \mathrm{E}-02$ & $3.6993 \mathrm{E}+00$ \\
\hline $0.9600 \mathrm{E}+02$ & $1.40219671 *$ & 5.3027E-02 & $3.7817 \mathrm{E}+00$ \\
\hline $0.1000 \mathrm{E}+03$ & $1.40008093 *$ & $5.1398 \mathrm{E}-02$ & $3.6711 \mathrm{E}+00$ \\
\hline $0.1040 \mathrm{E}+03$ & $1.39448546 *$ & $5.3965 \mathrm{E}-02$ & $3.8699 \mathrm{E}+00$ \\
\hline $0.1080 \mathrm{E}+03$ & $1.37775279 *$ & 6.4604E-02 & $4.6891 \mathrm{E}+00$ \\
\hline $0.1120 \mathrm{E}+03$ & $1.35742035 *$ & 6.1120E-02 & $4.5027 \mathrm{E}+00$ \\
\hline $0.1160 \mathrm{E}+03$ & $1.34690512 *$ & 6.1431E-02 & $4.5609 \mathrm{E}+00$ \\
\hline $0.1200 \mathrm{E}+03$ & $1.34095378 *$ & 6.0619E-02 & $4.5206 \mathrm{E}+00$ \\
\hline $0.1280 \mathrm{E}+03$ & 1.33401941 & $5.8495 \mathrm{E}-02$ & $4.3849 \mathrm{E}+00$ \\
\hline $0.1360 \mathrm{E}+03$ & 1.32416210 & 5.7989E-02 & $4.3793 \mathrm{E}+00$ \\
\hline $0.1440 \mathrm{E}+03$ & 1.31035094 & $5.4479 \mathrm{E}-02$ & $4.1576 \mathrm{E}+00$ \\
\hline $0.1520 \mathrm{E}+03$ & 1.32526144 & 5.7427E-02 & $4.3333 \mathrm{E}+00$ \\
\hline $0.1600 \mathrm{E}+03$ & 1.30642175 & $5.8296 \mathrm{E}-02$ & $4.4622 \mathrm{E}+00$ \\
\hline $0.1680 \mathrm{E}+03$ & 1.29838942 & $5.9764 \mathrm{E}-02$ & $4.6030 \mathrm{E}+00$ \\
\hline $0.1760 \mathrm{E}+03$ & 1.32345065 & 5.9011E-02 & $4.4589 \mathrm{E}+00$ \\
\hline $0.1840 \mathrm{E}+03$ & 1.32785692 & $6.5401 \mathrm{E}-02$ & $4.9253 \mathrm{E}+00$ \\
\hline $0.1920 \mathrm{E}+03$ & 1.30440723 & $5.8605 \mathrm{E}-02$ & $4.4928 \mathrm{E}+00$ \\
\hline $0.2000 \mathrm{E}+03$ & 1.33389620 & $5.8678 \mathrm{E}-02$ & $4.3990 \mathrm{E}+00$ \\
\hline
\end{tabular}

TABLE 8.8. ${ }^{238} \mathrm{U}(\mathrm{n}, \gamma)$ CROSS-SECTION

(smoothed values are marked by * and values averaged on the energy groups (@) are expressed in terms of the central energy of that group)

\begin{tabular}{|c|c|c|c|}
\hline $\begin{array}{l}\text { Neutron energy } \\
(\mathrm{MeV})\end{array}$ & $\begin{array}{l}\text { Cross-section } \\
\text { (barn) }\end{array}$ & $\begin{array}{c}\text { Cross-section } \\
\text { uncertainty (barn) }\end{array}$ & $\begin{array}{c}\text { Cross-section } \\
\text { uncertainty }(\%)\end{array}$ \\
\hline $0.2530 \mathrm{E}-07$ & 2.67705834 & 0.01227690 & 0.5 \\
\hline $0.1500 \mathrm{E}-03$ & 16.40345905@ & 0.10016508 & 0.6 \\
\hline $0.2500 \mathrm{E}-03$ & $8.38157160 @$ & 0.11242939 & 1.3 \\
\hline $0.3500 \mathrm{E}-03$ & 2.86526321@ & 0.04914795 & 1.7 \\
\hline $0.4500 \mathrm{E}-03$ & 2.66709032@ & 0.02668240 & 1.0 \\
\hline $0.5500 \mathrm{E}-03$ & 4.43917681@ & 0.12993952 & 2.9 \\
\hline
\end{tabular}


TABLE 8.8. ${ }^{238} \mathrm{U}(\mathrm{n}, \gamma)$ CROSS-SECTION (cont.)

(smoothed values are marked by * and values averaged on the energy groups (@) are expressed in terms of the central energy of that group)

\begin{tabular}{|c|c|c|c|}
\hline $\begin{array}{l}\text { Neutron energy } \\
(\mathrm{MeV})\end{array}$ & $\begin{array}{l}\text { Cross-section } \\
\text { (barn) }\end{array}$ & $\begin{array}{c}\text { Cross-section } \\
\text { uncertainty (barn) }\end{array}$ & $\begin{array}{l}\text { Cross-section } \\
\text { uncertainty }(\%)\end{array}$ \\
\hline $0.6500 \mathrm{E}-03$ & 3.40302929@ & 0.06569958 & 1.9 \\
\hline $0.7500 \mathrm{E}-03$ & 1.72738697@ & 0.03307590 & 1.9 \\
\hline $0.8500 \mathrm{E}-03$ & 2.83678450@ & 0.02527669 & 0.9 \\
\hline $0.9500 \mathrm{E}-03$ & 3.70653977@ & 0.07778262 & 2.1 \\
\hline $0.1500 \mathrm{E}-02$ & 1.82709885@ & 0.02905043 & 1.6 \\
\hline $0.2500 \mathrm{E}-02$ & 1.37138213@ & 0.01807938 & 1.3 \\
\hline $0.3500 \mathrm{E}-02$ & 1.12447832@ & 0.01801082 & 1.6 \\
\hline $0.4500 \mathrm{E}-02$ & $0.89115124 @$ & 0.01195889 & 1.3 \\
\hline $0.5500 \mathrm{E}-02$ & 0.85164887@ & 0.01375318 & 1.6 \\
\hline $0.6500 \mathrm{E}-02$ & $0.76025636 @$ & 0.01654485 & 2.2 \\
\hline $0.7500 \mathrm{E}-02$ & $0.72571914 @$ & 0.01033383 & 1.4 \\
\hline $0.8500 \mathrm{E}-02$ & $0.63323845 @$ & 0.00684449 & 1.1 \\
\hline $0.9500 \mathrm{E}-02$ & 0.66876151@ & 0.01039564 & 1.6 \\
\hline $0.1500 \mathrm{E}-01$ & $0.57985893 @$ & 0.00538843 & 0.9 \\
\hline $0.2000 \mathrm{E}-01$ & 0.52571225 & 0.00929082 & 1.8 \\
\hline $0.2400 \mathrm{E}-01$ & 0.46994887 & 0.00415725 & 0.9 \\
\hline 0.3000E-01 & 0.43448746 & 0.00422828 & 1.0 \\
\hline $0.4500 \mathrm{E}-01$ & 0.35900098 & 0.00411795 & 1.1 \\
\hline $0.5500 \mathrm{E}-01$ & 0.28757234 & 0.00376471 & 1.3 \\
\hline $0.6500 \mathrm{E}-01$ & 0.24662623 & 0.00327425 & 1.3 \\
\hline $0.7500 \mathrm{E}-01$ & 0.21587377 & 0.00298115 & 1.4 \\
\hline 0.8500E-01 & 0.19071497 & 0.00276572 & 1.5 \\
\hline 0.9500E-01 & 0.18054793 & 0.00244102 & 1.4 \\
\hline $0.1000 \mathrm{E}+00$ & 0.17961668 & 0.00265317 & 1.5 \\
\hline $0.1200 \mathrm{E}+00$ & 0.16297159 & 0.00220029 & 1.4 \\
\hline $0.1500 \mathrm{E}+00$ & 0.14058370 & 0.00171056 & 1.2 \\
\hline $0.1700 \mathrm{E}+00$ & 0.13747810 & 0.00222319 & 1.6 \\
\hline $0.1800 \mathrm{E}+00$ & $0.12927828^{*}$ & 0.00418640 & 3.3 \\
\hline $0.1900 \mathrm{E}+00$ & $0.12662137 *$ & 0.00243970 & 1.9 \\
\hline $0.2000 \mathrm{E}+00$ & $0.12746494^{*}$ & 0.00234037 & 1.9 \\
\hline $0.2100 \mathrm{E}+00$ & $0.12787819 *$ & 0.00290525 & 2.2 \\
\hline $0.2200 \mathrm{E}+00$ & $0.12417342 *$ & 0.00271294 & 2.2 \\
\hline $0.2300 \mathrm{E}+00$ & $0.12080753^{*}$ & 0.00205540 & 1.7 \\
\hline $0.2350 \mathrm{E}+00$ & $0.11911300 *$ & 0.00534138 & 4.4 \\
\hline $0.2400 \mathrm{E}+00$ & $0.11682643^{*}$ & 0.00286433 & 2.5 \\
\hline $0.2450 \mathrm{E}+00$ & $0.11629365^{*}$ & 0.00246762 & 2.1 \\
\hline $0.2500 \mathrm{E}+00$ & $0.11599478^{*}$ & 0.00259474 & 2.3 \\
\hline $0.2600 \mathrm{E}+00$ & $0.11658732 *$ & 0.00207584 & 1.8 \\
\hline $0.2700 \mathrm{E}+00$ & $0.11765405^{*}$ & 0.00723798 & 6.0 \\
\hline $0.2800 \mathrm{E}+00$ & $0.11646769 *$ & 0.00267776 & 2.3 \\
\hline
\end{tabular}


TABLE 8.8. ${ }^{238} \mathrm{U}(\mathrm{n}, \gamma)$ CROSS-SECTION (cont.)

(smoothed values are marked by* and values averaged on the energy groups (@) are expressed in terms of the central energy of that group)

\begin{tabular}{|c|c|c|c|}
\hline $\begin{array}{l}\text { Neutron energy } \\
(\mathrm{MeV})\end{array}$ & $\begin{array}{l}\text { Cross-section } \\
\text { (barn) }\end{array}$ & $\begin{array}{c}\text { Cross-section } \\
\text { uncertainty (barn) }\end{array}$ & $\begin{array}{c}\text { Cross-section } \\
\text { uncertainty }(\%)\end{array}$ \\
\hline $0.3000 \mathrm{E}+00$ & $0.11568992 *$ & 0.00200258 & 1.7 \\
\hline $0.3250 \mathrm{E}+00$ & $0.11453138 *$ & 0.00331197 & 2.8 \\
\hline $0.3500 \mathrm{E}+00$ & $0.11111003^{*}$ & 0.00223272 & 2.1 \\
\hline $0.3750 \mathrm{E}+00$ & $0.10942991 *$ & 0.00235546 & 2.1 \\
\hline $0.4000 \mathrm{E}+00$ & $0.10898173^{*}$ & 0.00151340 & 1.4 \\
\hline $0.4250 \mathrm{E}+00$ & $0.10865831^{*}$ & 0.00595241 & 5.4 \\
\hline $0.4500 \mathrm{E}+00$ & $0.10760785^{*}$ & 0.00197978 & 1.8 \\
\hline $0.4750 \mathrm{E}+00$ & $0.10732578^{*}$ & 0.00565435 & 5.4 \\
\hline $0.5000 \mathrm{E}+00$ & $0.10824353^{*}$ & 0.00146107 & 1.3 \\
\hline $0.5200 \mathrm{E}+00$ & $0.10782893^{*}$ & 0.00204030 & 1.9 \\
\hline $0.5400 \mathrm{E}+00$ & 0.10909529* & 0.00184566 & 1.7 \\
\hline $0.5700 \mathrm{E}+00$ & $0.11344814 *$ & 0.00181441 & 1.6 \\
\hline $0.6000 \mathrm{E}+00$ & $0.11286867^{*}$ & 0.00153277 & 1.3 \\
\hline $0.6500 \mathrm{E}+00$ & $0.11274003^{*}$ & 0.00328997 & 3.2 \\
\hline $0.7000 \mathrm{E}+00$ & $0.11833885^{*}$ & 0.00213918 & 1.6 \\
\hline $0.7500 \mathrm{E}+00$ & $0.11829182 *$ & 0.00326286 & 2.9 \\
\hline $0.8000 \mathrm{E}+00$ & $0.11881469^{*}$ & 0.00164640 & 1.4 \\
\hline $0.8500 \mathrm{E}+00$ & $0.12281274 *$ & 0.00581637 & 4.8 \\
\hline $0.9000 \mathrm{E}+00$ & $0.12549621^{*}$ & 0.00288284 & 2.3 \\
\hline $0.9400 \mathrm{E}+00$ & $0.12891020^{*}$ & 0.00291052 & 2.3 \\
\hline $0.9600 \mathrm{E}+00$ & $0.13052439 *$ & 0.00280863 & 2.1 \\
\hline $0.1000 \mathrm{E}+01$ & $0.12832436^{*}$ & 0.00264905 & 2.1 \\
\hline $0.1100 \mathrm{E}+01$ & $0.11350049^{*}$ & 0.00220267 & 1.9 \\
\hline $0.1250 \mathrm{E}+01$ & $0.09431692 *$ & 0.00166833 & 1.8 \\
\hline $0.1400 \mathrm{E}+01$ & $0.08034129^{*}$ & 0.00161086 & 2.0 \\
\hline $0.1600 \mathrm{E}+01$ & $0.06704474 *$ & 0.00127148 & 1.9 \\
\hline $0.1800 \mathrm{E}+01$ & $0.05686464 *$ & 0.00168891 & 3.0 \\
\hline $0.2000 \mathrm{E}+01$ & $0.04784651 *$ & 0.00125415 & 2.6 \\
\hline $0.2200 \mathrm{E}+01$ & 0.03856413 & 0.00105892 & 2.7 \\
\hline
\end{tabular}

TABLE 8.9. ${ }^{239} \mathrm{Pu}(\mathrm{n}, \mathrm{f})$ CROSS-SECTION

(smoothed values are marked by*, while values averaged on the energy groups (@) are expressed in terms of the central energy of that group)

\begin{tabular}{lccc}
\hline $\begin{array}{l}\text { Neutron energy } \\
(\mathrm{MeV})\end{array}$ & $\begin{array}{c}\text { Cross-section } \\
(\text { barn })\end{array}$ & $\begin{array}{c}\text { Cross-section } \\
\text { uncertainty (barn) }\end{array}$ & $\begin{array}{c}\text { Cross-section } \\
\text { uncertainty }(\%)\end{array}$ \\
\hline $0.2530 \mathrm{E}-07$ & 750.00158246 & $1.8260 \mathrm{E}+00$ & $2.4347 \mathrm{E}-01$ \\
$0.1500 \mathrm{E}-03$ & $18.73986120 @$ & $1.1420 \mathrm{E}-01$ & $6.0940 \mathrm{E}-01$ \\
$0.2500 \mathrm{E}-03$ & $17.99667498 @$ & $1.1747 \mathrm{E}-01$ & $6.5272 \mathrm{E}-01$ \\
$-\ldots-\ldots-\ldots$
\end{tabular}


TABLE 8.9. ${ }^{239} \mathrm{Pu}(\mathrm{n}, \mathrm{f})$ CROSS-SECTION (cont.)

(smoothed values are marked by*, while values averaged on the energy groups (@) are expressed in terms of the central energy of that group)

\begin{tabular}{|c|c|c|c|}
\hline $\begin{array}{l}\text { Neutron energy } \\
(\mathrm{MeV})\end{array}$ & $\begin{array}{l}\text { Cross-section } \\
\text { (barn) }\end{array}$ & $\begin{array}{c}\text { Cross-section } \\
\text { uncertainty (barn) }\end{array}$ & $\begin{array}{c}\text { Cross-section } \\
\text { uncertainty ( } \%)\end{array}$ \\
\hline $0.3500 \mathrm{E}-03$ & $8.56437463 @$ & $5.7336 \mathrm{E}-02$ & 6.6947E-01 \\
\hline $0.4500 \mathrm{E}-03$ & $9.58807544 @$ & 5.9139E-02 & 6.1679E-01 \\
\hline $0.5500 \mathrm{E}-03$ & 15.56557080@ & $1.0227 \mathrm{E}-01$ & $6.5701 \mathrm{E}-01$ \\
\hline $0.6500 \mathrm{E}-03$ & 4.53074519@ & $3.2451 \mathrm{E}-02$ & 7.1624E-01 \\
\hline $0.7500 \mathrm{E}-03$ & 5.67685896@ & $3.9245 \mathrm{E}-02$ & 6.9131E-01 \\
\hline $0.8500 \mathrm{E}-03$ & $5.04333941 @$ & 3.3607E-02 & 6.6636E-01 \\
\hline $0.9500 \mathrm{E}-03$ & 8.39396888@ & $5.6691 \mathrm{E}-02$ & $6.7537 \mathrm{E}-01$ \\
\hline 0.1500E-02 & $4.50984902 @$ & 3.3320E-02 & 7.3883E-01 \\
\hline $0.2500 \mathrm{E}-02$ & $3.30034184 @$ & $2.3840 \mathrm{E}-02$ & $7.2235 \mathrm{E}-01$ \\
\hline $0.3500 \mathrm{E}-02$ & $3.00658447 @$ & 2.1943E-02 & 7.2984E-01 \\
\hline $0.4500 \mathrm{E}-02$ & 2.38083353@ & 1.6997E-02 & 7.1391E-01 \\
\hline $0.5500 \mathrm{E}-02$ & $2.29771280 @$ & $1.7055 \mathrm{E}-02$ & 7.4225E-01 \\
\hline $0.6500 \mathrm{E}-02$ & $2.02839892 @$ & $1.5838 \mathrm{E}-02$ & 7.8084E-01 \\
\hline 0.7500E-02 & $2.10603311 @$ & $1.4928 \mathrm{E}-02$ & 7.0882E-01 \\
\hline 0.8500E-02 & $2.21394487 @$ & $1.6220 \mathrm{E}-02$ & 7.3262E-01 \\
\hline $0.9500 \mathrm{E}-02$ & 1.86930209@ & 1.4097E-02 & 7.5411E-01 \\
\hline 0.1500E-01 & $1.78256980 @$ & $1.3432 \mathrm{E}-02$ & $7.5350 \mathrm{E}-01$ \\
\hline $0.2000 \mathrm{E}-01$ & 1.73377514 & 2.6209E-02 & $1.5116 \mathrm{E}+00$ \\
\hline $0.2400 \mathrm{E}-01$ & 1.63478051 & $1.1776 \mathrm{E}-02$ & 7.2033E-01 \\
\hline 0.3000E-01 & 1.63725991 & $1.3172 \mathrm{E}-02$ & $8.0450 \mathrm{E}-01$ \\
\hline $0.4500 \mathrm{E}-01$ & 1.53135278 & 1.1789E-02 & 7.6981E-01 \\
\hline 0.5500E-01 & 1.55072473 & $1.2271 \mathrm{E}-02$ & 7.9129E-01 \\
\hline $0.6500 \mathrm{E}-01$ & 1.56351352 & $1.2944 \mathrm{E}-02$ & $8.2790 \mathrm{E}-01$ \\
\hline 0.7500E-01 & 1.55294618 & $1.2912 \mathrm{E}-02$ & 8.3148E-01 \\
\hline 0.8500E-01 & 1.52058511 & $1.3343 \mathrm{E}-02$ & 8.7749E-01 \\
\hline 0.9500E-01 & 1.54202858 & $1.5609 \mathrm{E}-02$ & $1.0122 \mathrm{E}+00$ \\
\hline $0.1000 \mathrm{E}+00$ & 1.55446525 & $1.4433 \mathrm{E}-02$ & $9.2849 \mathrm{E}-01$ \\
\hline $0.1200 \mathrm{E}+00$ & 1.50516261 & $1.2177 \mathrm{E}-02$ & 8.0904E-01 \\
\hline $0.1500 \mathrm{E}+00$ & 1.50132416 & $1.2332 \mathrm{E}-02$ & $8.2143 \mathrm{E}-01$ \\
\hline $0.1700 \mathrm{E}+00$ & 1.49204912 & $1.4289 \mathrm{E}-02$ & $9.5768 \mathrm{E}-01$ \\
\hline $0.1800 \mathrm{E}+00$ & 1.46376257 & $2.3579 \mathrm{E}-02$ & $1.6108 \mathrm{E}+00$ \\
\hline $0.1900 \mathrm{E}+00$ & 1.46194207 & $1.7248 \mathrm{E}-02$ & $1.1798 \mathrm{E}+00$ \\
\hline $0.2000 \mathrm{E}+00$ & $1.48570861 *$ & $1.7883 \mathrm{E}-02$ & $1.2037 \mathrm{E}+00$ \\
\hline $0.2100 \mathrm{E}+00$ & $1.51152891 *$ & $1.9966 \mathrm{E}-02$ & $1.3209 \mathrm{E}+00$ \\
\hline $0.2200 \mathrm{E}+00$ & $1.51349709 *$ & $1.6508 \mathrm{E}-02$ & $1.0907 \mathrm{E}+00$ \\
\hline $0.2300 \mathrm{E}+00$ & $1.49639567 *$ & $1.7530 \mathrm{E}-02$ & $1.1715 \mathrm{E}+00$ \\
\hline $0.2400 \mathrm{E}+00$ & $1.48009971 *$ & 2.2493E-02 & $1.5188 \mathrm{E}+00$ \\
\hline $0.2450 \mathrm{E}+00$ & $1.49083532 *$ & $1.7250 \mathrm{E}-02$ & $1.1571 \mathrm{E}+00$ \\
\hline $0.2500 \mathrm{E}+00$ & $1.50745098 *$ & $1.6560 \mathrm{E}-02$ & $1.0985 \mathrm{E}+00$ \\
\hline $0.2600 \mathrm{E}+00$ & $1.51600309 *$ & $1.5664 \mathrm{E}-02$ & $1.0332 \mathrm{E}+00$ \\
\hline
\end{tabular}


TABLE 8.9. ${ }^{239} \mathrm{Pu}(\mathrm{n}, \mathrm{f})$ CROSS-SECTION (cont.)

(smoothed values are marked by*, while values averaged on the energy groups (@) are expressed in terms of the central energy of that group)

\begin{tabular}{|c|c|c|c|}
\hline $\begin{array}{l}\text { Neutron energy } \\
(\mathrm{MeV})\end{array}$ & $\begin{array}{l}\text { Cross-section } \\
\text { (barn) }\end{array}$ & $\begin{array}{c}\text { Cross-section } \\
\text { uncertainty (barn) }\end{array}$ & $\begin{array}{l}\text { Cross-section } \\
\text { uncertainty }(\%)\end{array}$ \\
\hline $0.2700 \mathrm{E}+00$ & $1.52802249 *$ & $1.8576 \mathrm{E}-02$ & $1.2157 \mathrm{E}+00$ \\
\hline $0.2800 \mathrm{E}+00$ & $1.54190322 *$ & $1.5097 \mathrm{E}-02$ & $9.7912 \mathrm{E}-01$ \\
\hline $0.3000 \mathrm{E}+00$ & $1.54496705 *$ & $1.4707 \mathrm{E}-02$ & 9.5191E-01 \\
\hline $0.3250 \mathrm{E}+00$ & 1.54791357 & 1.4994E-02 & $9.6865 \mathrm{E}-01$ \\
\hline $0.3500 \mathrm{E}+00$ & 1.53251478 & $1.3104 \mathrm{E}-02$ & $8.5507 \mathrm{E}-01$ \\
\hline $0.3750 \mathrm{E}+00$ & 1.56599056 & $1.5058 \mathrm{E}-02$ & $9.6157 \mathrm{E}-01$ \\
\hline $0.4000 \mathrm{E}+00$ & 1.57571600 & 1.4980E-02 & $9.5065 \mathrm{E}-01$ \\
\hline $0.4250 \mathrm{E}+00$ & 1.54961941 & 2.2937E-02 & $1.4802 \mathrm{E}+00$ \\
\hline $0.4500 \mathrm{E}+00$ & 1.57695638 & $1.5466 \mathrm{E}-02$ & 9.8077E-01 \\
\hline $0.4750 \mathrm{E}+00$ & 1.57401518 & $1.5325 \mathrm{E}-02$ & 9.7359E-01 \\
\hline $0.5000 \mathrm{E}+00$ & 1.56565527 & $1.2952 \mathrm{E}-02$ & $8.2726 \mathrm{E}-01$ \\
\hline $0.5200 \mathrm{E}+00$ & 1.54406504 & $1.7087 \mathrm{E}-02$ & $1.1066 \mathrm{E}+00$ \\
\hline $0.5400 \mathrm{E}+00$ & 1.57082816 & $1.3096 \mathrm{E}-02$ & 8.3371E-01 \\
\hline $0.5700 \mathrm{E}+00$ & 1.58299321 & $1.5633 \mathrm{E}-02$ & 9.8759E-01 \\
\hline $0.6000 \mathrm{E}+00$ & 1.59358095 & $1.4516 \mathrm{E}-02$ & $9.1088 \mathrm{E}-01$ \\
\hline $0.6500 \mathrm{E}+00$ & 1.61742622 & 1.2011E-02 & 7.4262E-01 \\
\hline $0.7000 \mathrm{E}+00$ & 1.62957763 & $1.2944 \mathrm{E}-02$ & 7.9430E-01 \\
\hline $0.7500 \mathrm{E}+00$ & 1.69343920 & $1.2176 \mathrm{E}-02$ & 7.1900E-01 \\
\hline $0.8000 \mathrm{E}+00$ & 1.70028264 & $1.2793 \mathrm{E}-02$ & $7.5238 \mathrm{E}-01$ \\
\hline $0.8500 \mathrm{E}+00$ & 1.69144446 & $1.3015 \mathrm{E}-02$ & 7.6949E-01 \\
\hline $0.9000 \mathrm{E}+00$ & 1.67231829 & $1.2753 \mathrm{E}-02$ & 7.6259E-01 \\
\hline $0.9400 \mathrm{E}+00$ & 1.68584529 & $1.3243 \mathrm{E}-02$ & 7.8557E-01 \\
\hline $0.9600 \mathrm{E}+00$ & 1.71468706 & $1.3746 \mathrm{E}-02$ & 8.0164E-01 \\
\hline $0.9800 \mathrm{E}+00$ & 1.71271672 & $1.6862 \mathrm{E}-02$ & 9.8451E-01 \\
\hline $0.1000 \mathrm{E}+01$ & 1.73400586 & 1.1974E-02 & $6.9056 \mathrm{E}-01$ \\
\hline $0.1100 \mathrm{E}+01$ & 1.74418312 & $1.1815 \mathrm{E}-02$ & 6.7737E-01 \\
\hline $0.1250 \mathrm{E}+01$ & 1.84213099 & $1.2033 \mathrm{E}-02$ & 6.5319E-01 \\
\hline $0.1400 \mathrm{E}+01$ & 1.92209008 & $1.2720 \mathrm{E}-02$ & 6.6176E-01 \\
\hline $0.1600 \mathrm{E}+01$ & 1.94719801 & $1.2514 \mathrm{E}-02$ & $6.4268 \mathrm{E}-01$ \\
\hline $0.1800 \mathrm{E}+01$ & 1.94506265 & $1.2879 \mathrm{E}-02$ & 6.6213E-01 \\
\hline $0.2000 \mathrm{E}+01$ & 1.97537185 & $1.3423 \mathrm{E}-02$ & $6.7950 \mathrm{E}-01$ \\
\hline $0.2200 \mathrm{E}+01$ & 1.96907685 & $1.3289 \mathrm{E}-02$ & 6.7490E-01 \\
\hline $0.2400 \mathrm{E}+01$ & 1.92049957 & $1.3023 \mathrm{E}-02$ & 6.7812E-01 \\
\hline $0.2600 \mathrm{E}+01$ & 1.90876018 & $1.3167 \mathrm{E}-02$ & 6.8981E-01 \\
\hline $0.2800 \mathrm{E}+01$ & 1.89178898 & $1.3985 \mathrm{E}-02$ & 7.3925E-01 \\
\hline $0.3000 \mathrm{E}+01$ & 1.85617203 & $1.2314 \mathrm{E}-02$ & 6.6339E-01 \\
\hline $0.3600 \mathrm{E}+01$ & 1.81241026 & $1.1832 \mathrm{E}-02$ & $6.5282 \mathrm{E}-01$ \\
\hline $0.4000 \mathrm{E}+01$ & 1.77170797 & $1.1656 \mathrm{E}-02$ & $6.5790 \mathrm{E}-01$ \\
\hline $0.4500 \mathrm{E}+01$ & 1.74321653 & 1.1917E-02 & $6.8360 \mathrm{E}-01$ \\
\hline $0.4700 \mathrm{E}+01$ & 1.73034888 & $1.2425 \mathrm{E}-02$ & 7.1806E-01 \\
\hline
\end{tabular}


TABLE 8.9. ${ }^{239} \mathrm{Pu}(\mathrm{n}, \mathrm{f})$ CROSS-SECTION (cont.)

(smoothed values are marked by*, while values averaged on the energy groups (@) are expressed in terms of the central energy of that group)

\begin{tabular}{|c|c|c|c|}
\hline $\begin{array}{l}\text { Neutron energy } \\
(\mathrm{MeV})\end{array}$ & $\begin{array}{l}\text { Cross-section } \\
\text { (barn) }\end{array}$ & $\begin{array}{c}\text { Cross-section } \\
\text { uncertainty (barn) }\end{array}$ & $\begin{array}{l}\text { Cross-section } \\
\text { uncertainty }(\%)\end{array}$ \\
\hline $0.5000 \mathrm{E}+01$ & 1.69185026 & 1.1592E-02 & 6.8514E-01 \\
\hline $0.5300 \mathrm{E}+01$ & 1.68382527 & $1.2525 \mathrm{E}-02$ & 7.4384E-01 \\
\hline $0.5500 \mathrm{E}+01$ & 1.66314489 & $1.2166 \mathrm{E}-02$ & 7.3148E-01 \\
\hline $0.5800 \mathrm{E}+01$ & 1.69031523 & 1.3332E-02 & 7.8871E-01 \\
\hline $0.6000 \mathrm{E}+01$ & 1.77240740 & $1.4605 \mathrm{E}-02$ & 8.2401E-01 \\
\hline $0.6200 \mathrm{E}+01$ & 1.84397171 & $1.6334 \mathrm{E}-02$ & 8.8578E-01 \\
\hline $0.6500 \mathrm{E}+01$ & 1.93382163 & $1.5874 \mathrm{E}-02$ & 8.2088E-01 \\
\hline $0.7000 \mathrm{E}+01$ & 2.06459968 & $1.7043 \mathrm{E}-02$ & $8.2551 \mathrm{E}-01$ \\
\hline $0.7500 \mathrm{E}+01$ & 2.19358925 & $1.8854 \mathrm{E}-02$ & 8.5950E-01 \\
\hline $0.7750 \mathrm{E}+01$ & 2.22459085 & $2.1242 \mathrm{E}-02$ & $9.5485 \mathrm{E}-01$ \\
\hline $0.8000 \mathrm{E}+01$ & 2.27717938 & $1.9601 \mathrm{E}-02$ & $8.6075 \mathrm{E}-01$ \\
\hline $0.8500 \mathrm{E}+01$ & 2.24864053 & 1.9181E-02 & 8.5298E-01 \\
\hline $0.9000 \mathrm{E}+01$ & 2.24848219 & $1.8909 \mathrm{E}-02$ & 8.4099E-01 \\
\hline $0.1000 \mathrm{E}+02$ & 2.24333869 & $2.0483 \mathrm{E}-02$ & 9.1307E-01 \\
\hline $0.1100 \mathrm{E}+02$ & 2.23485271 & $2.0845 \mathrm{E}-02$ & $9.3273 \mathrm{E}-01$ \\
\hline $0.1150 \mathrm{E}+02$ & 2.22540467 & 2.2877E-02 & $1.0280 \mathrm{E}+00$ \\
\hline $0.1200 \mathrm{E}+02$ & 2.23585296 & $2.1660 \mathrm{E}-02$ & $9.6875 \mathrm{E}-01$ \\
\hline $0.1300 \mathrm{E}+02$ & 2.34430206 & $1.9448 \mathrm{E}-02$ & 8.2959E-01 \\
\hline $0.1400 \mathrm{E}+02$ & 2.40813691 & $1.7065 \mathrm{E}-02$ & $7.0865 \mathrm{E}-01$ \\
\hline $0.1450 \mathrm{E}+02$ & 2.42169216 & 1.4539E-02 & $6.0038 \mathrm{E}-01$ \\
\hline $0.1500 \mathrm{E}+02$ & 2.41852062 & $1.9758 \mathrm{E}-02$ & 8.1697E-01 \\
\hline $0.1600 \mathrm{E}+02$ & 2.44583771 & $2.3000 \mathrm{E}-02$ & $9.4035 \mathrm{E}-01$ \\
\hline $0.1700 \mathrm{E}+02$ & 2.36594550 & 2.3304E-02 & 9.8498E-01 \\
\hline $0.1800 \mathrm{E}+02$ & 2.34213283 & 2.3409E-02 & 9.9949E-01 \\
\hline $0.1900 \mathrm{E}+02$ & 2.36205034 & $2.2476 \mathrm{E}-02$ & $9.5156 \mathrm{E}-01$ \\
\hline $0.2000 \mathrm{E}+02$ & 2.36061715 & $2.6525 \mathrm{E}-02$ & $1.1237 \mathrm{E}+00$ \\
\hline $0.2100 \mathrm{E}+02$ & 2.36823081 & $2.6960 \mathrm{E}-02$ & $1.1384 \mathrm{E}+00$ \\
\hline $0.2200 \mathrm{E}+02$ & 2.38340818 & 4.2681E-02 & $1.7907 \mathrm{E}+00$ \\
\hline $0.2300 \mathrm{E}+02$ & 2.38392391 & 3.3189E-02 & $1.3922 \mathrm{E}+00$ \\
\hline $0.2400 \mathrm{E}+02$ & 2.31828388 & $3.6516 \mathrm{E}-02$ & $1.5752 \mathrm{E}+00$ \\
\hline $0.2500 \mathrm{E}+02$ & 2.35919844 & 3.1377E-02 & $1.3300 \mathrm{E}+00$ \\
\hline $0.2600 \mathrm{E}+02$ & 2.34478211 & $3.8855 \mathrm{E}-02$ & $1.6571 \mathrm{E}+00$ \\
\hline $0.2700 \mathrm{E}+02$ & 2.34023441 & $3.4283 \mathrm{E}-02$ & $1.4650 \mathrm{E}+00$ \\
\hline $0.2800 \mathrm{E}+02$ & 2.36770490 & 4.1404E-02 & $1.7487 \mathrm{E}+00$ \\
\hline $0.2900 \mathrm{E}+02$ & 2.31603251 & $3.4215 \mathrm{E}-02$ & $1.4773 \mathrm{E}+00$ \\
\hline $0.3000 \mathrm{E}+02$ & 2.37687669 & $3.6009 \mathrm{E}-02$ & $1.5150 \mathrm{E}+00$ \\
\hline $0.3200 \mathrm{E}+02$ & 2.33628777 & $4.2215 \mathrm{E}-02$ & $1.8069 \mathrm{E}+00$ \\
\hline $0.3400 \mathrm{E}+02$ & 2.30406579 & 4.4009E-02 & $1.9101 \mathrm{E}+00$ \\
\hline $0.3600 \mathrm{E}+02$ & 2.23113656 & 4.6339E-02 & $2.0769 \mathrm{E}+00$ \\
\hline $0.3800 \mathrm{E}+02$ & 2.16484920 & 4.8193E-02 & $2.2262 \mathrm{E}+00$ \\
\hline
\end{tabular}


TABLE 8.9. ${ }^{239} \mathrm{Pu}(\mathrm{n}, \mathrm{f})$ CROSS-SECTION (cont.)

(smoothed values are marked by*, while values averaged on the energy groups (@) are expressed in terms of the central energy of that group)

\begin{tabular}{|c|c|c|c|}
\hline $\begin{array}{l}\text { Neutron energy } \\
(\mathrm{MeV})\end{array}$ & $\begin{array}{l}\text { Cross-section } \\
\text { (barn) }\end{array}$ & $\begin{array}{c}\text { Cross-section } \\
\text { uncertainty (barn) }\end{array}$ & $\begin{array}{c}\text { Cross-section } \\
\text { uncertainty }(\%)\end{array}$ \\
\hline $0.4000 \mathrm{E}+02$ & 2.19798293 & 4.9824E-02 & $2.2668 \mathrm{E}+00$ \\
\hline $0.4200 \mathrm{E}+02$ & 2.15270969 & 4.4834E-02 & $2.0827 \mathrm{E}+00$ \\
\hline $0.4400 \mathrm{E}+02$ & 2.15550477 & 4.8672E-02 & $2.2581 \mathrm{E}+00$ \\
\hline $0.4600 \mathrm{E}+02$ & 2.14261721 & $4.3112 \mathrm{E}-02$ & $2.0121 \mathrm{E}+00$ \\
\hline $0.4800 \mathrm{E}+02$ & 2.10631539 & $5.0397 \mathrm{E}-02$ & $2.3927 \mathrm{E}+00$ \\
\hline $0.5000 \mathrm{E}+02$ & 2.08062433 & $5.0623 \mathrm{E}-02$ & $2.4331 \mathrm{E}+00$ \\
\hline $0.5200 \mathrm{E}+02$ & 2.08283022 & $5.6760 \mathrm{E}-02$ & $2.7251 \mathrm{E}+00$ \\
\hline $0.5400 \mathrm{E}+02$ & 2.05290442 & $5.5815 \mathrm{E}-02$ & $2.7188 \mathrm{E}+00$ \\
\hline $0.5600 \mathrm{E}+02$ & 2.08016020 & $5.7316 \mathrm{E}-02$ & $2.7554 \mathrm{E}+00$ \\
\hline $0.5800 \mathrm{E}+02$ & 2.05340808 & $5.2126 \mathrm{E}-02$ & $2.5385 \mathrm{E}+00$ \\
\hline $0.6000 \mathrm{E}+02$ & 2.01499729 & 4.8372E-02 & $2.4006 \mathrm{E}+00$ \\
\hline $0.6400 \mathrm{E}+02$ & 2.00085805 & 4.3068E-02 & $2.1525 \mathrm{E}+00$ \\
\hline $0.6800 \mathrm{E}+02$ & 1.93867754 & $4.2152 \mathrm{E}-02$ & $2.1742 \mathrm{E}+00$ \\
\hline $0.7200 \mathrm{E}+02$ & 1.89961786 & 4.5183E-02 & $2.3785 \mathrm{E}+00$ \\
\hline $0.7600 \mathrm{E}+02$ & 1.89141585 & 4.7497E-02 & $2.5112 \mathrm{E}+00$ \\
\hline $0.8000 \mathrm{E}+02$ & 1.86759165 & $5.0810 \mathrm{E}-02$ & $2.7206 \mathrm{E}+00$ \\
\hline $0.8400 \mathrm{E}+02$ & 1.86534967 & $6.4947 \mathrm{E}-02$ & $3.4818 \mathrm{E}+00$ \\
\hline $0.8800 \mathrm{E}+02$ & 1.79026942 & $6.3664 \mathrm{E}-02$ & $3.5561 \mathrm{E}+00$ \\
\hline $0.9200 \mathrm{E}+02$ & 1.74250200 & $6.3743 \mathrm{E}-02$ & $3.6582 \mathrm{E}+00$ \\
\hline $0.9600 \mathrm{E}+02$ & $1.72542575 *$ & $6.3280 \mathrm{E}-02$ & $3.6675 \mathrm{E}+00$ \\
\hline $0.1000 \mathrm{E}+03$ & $1.70243842 *$ & $6.1880 \mathrm{E}-02$ & $3.6348 \mathrm{E}+00$ \\
\hline $0.1040 \mathrm{E}+03$ & $1.67871057 *$ & $6.1061 \mathrm{E}-02$ & $3.6374 \mathrm{E}+00$ \\
\hline $0.1080 \mathrm{E}+03$ & $1.67656722 *$ & $7.7870 \mathrm{E}-02$ & $4.6446 \mathrm{E}+00$ \\
\hline $0.1120 \mathrm{E}+03$ & $1.67383125 *$ & 7.4950E-02 & $4.4778 \mathrm{E}+00$ \\
\hline $0.1160 \mathrm{E}+03$ & $1.65585962 *$ & $7.4646 \mathrm{E}-02$ & $4.5079 \mathrm{E}+00$ \\
\hline $0.1200 \mathrm{E}+03$ & $1.63324392 *$ & 7.2798E-02 & $4.4574 \mathrm{E}+00$ \\
\hline $0.1280 \mathrm{E}+03$ & $1.60588973 *$ & $7.0123 \mathrm{E}-02$ & $4.3666 \mathrm{E}+00$ \\
\hline $0.1360 \mathrm{E}+03$ & $1.58742691 *$ & $6.7769 \mathrm{E}-02$ & $4.2692 \mathrm{E}+00$ \\
\hline $0.1440 \mathrm{E}+03$ & $1.58064677 *$ & $6.4468 \mathrm{E}-02$ & $4.0786 \mathrm{E}+00$ \\
\hline $0.1520 \mathrm{E}+03$ & $1.58319431 *$ & $6.9016 \mathrm{E}-02$ & $4.3593 \mathrm{E}+00$ \\
\hline $0.1600 \mathrm{E}+03$ & 1.55412996 & $6.7626 \mathrm{E}-02$ & $4.3514 \mathrm{E}+00$ \\
\hline $0.1680 \mathrm{E}+03$ & 1.55110963 & 7.1247E-02 & $4.5933 \mathrm{E}+00$ \\
\hline $0.1760 \mathrm{E}+03$ & 1.57457484 & 6.9347E-02 & $4.4042 \mathrm{E}+00$ \\
\hline $0.1840 \mathrm{E}+03$ & 1.56289577 & 7.3015E-02 & $4.6718 \mathrm{E}+00$ \\
\hline $0.1920 \mathrm{E}+03$ & 1.53388683 & $6.6580 \mathrm{E}-02$ & $4.3406 \mathrm{E}+00$ \\
\hline $0.2000 \mathrm{E}+03$ & 1.55705176 & $6.8023 \mathrm{E}-02$ & $4.3687 \mathrm{E}+00$ \\
\hline
\end{tabular}


TABLE 8.10. ${ }^{1} \mathrm{H}(\mathrm{n}, \mathrm{n})$ CROSS-SECTION (linear interpolation in linear-linear scale is recommended)

\begin{tabular}{|c|c|c|}
\hline $\begin{array}{l}\text { Neutron energy } \\
(\mathrm{MeV})\end{array}$ & $\begin{array}{l}\text { Cross-section } \\
\text { (barn) }\end{array}$ & $\begin{array}{c}\text { Cross-section } \\
\text { uncertainty }(\%)\end{array}$ \\
\hline $1.0000 \mathrm{E}-11$ & 20.436340 & 0.20 \\
\hline $2.0000 \mathrm{E}-11$ & 20.436340 & 0.20 \\
\hline $5.0000 \mathrm{E}-11$ & 20.436340 & 0.20 \\
\hline $1.0000 \mathrm{E}-10$ & 20.436330 & 0.20 \\
\hline $2.0000 \mathrm{E}-10$ & 20.436330 & 0.20 \\
\hline $5.0000 \mathrm{E}-10$ & 20.436330 & 0.20 \\
\hline $1.0000 \mathrm{E}-09$ & 20.436330 & 0.20 \\
\hline $2.0000 \mathrm{E}-09$ & 20.436330 & 0.20 \\
\hline $5.0000 \mathrm{E}-09$ & 20.436330 & 0.20 \\
\hline $1.0000 \mathrm{E}-08$ & 20.436330 & 0.20 \\
\hline $2.5300 \mathrm{E}-08$ & 20.436330 & 0.20 \\
\hline $5.0000 \mathrm{E}-08$ & 20.436330 & 0.20 \\
\hline $1.0000 \mathrm{E}-07$ & 20.436320 & 0.20 \\
\hline $2.0000 \mathrm{E}-07$ & 20.436310 & 0.20 \\
\hline $5.0000 \mathrm{E}-07$ & 20.436270 & 0.20 \\
\hline $1.0000 \mathrm{E}-06$ & 20.436200 & 0.20 \\
\hline $2.0000 \mathrm{E}-06$ & 20.436060 & 0.20 \\
\hline $5.0000 \mathrm{E}-06$ & 20.435660 & 0.20 \\
\hline $1.0000 \mathrm{E}-05$ & 20.434990 & 0.20 \\
\hline $2.0000 \mathrm{E}-05$ & 20.433640 & 0.20 \\
\hline $5.0000 \mathrm{E}-05$ & 20.429600 & 0.20 \\
\hline $1.0000 \mathrm{E}-04$ & 20.422880 & 0.20 \\
\hline $2.0000 \mathrm{E}-04$ & 20.409440 & 0.20 \\
\hline $5.0000 \mathrm{E}-04$ & 20.369260 & 0.20 \\
\hline $1.0000 \mathrm{E}-03$ & 20.302690 & 0.20 \\
\hline $2.0000 \mathrm{E}-03$ & 20.171050 & 0.20 \\
\hline $4.0000 \mathrm{E}-03$ & 19.913520 & 0.20 \\
\hline $6.0000 \mathrm{E}-03$ & 19.663410 & 0.20 \\
\hline $8.0000 \mathrm{E}-03$ & 19.420400 & 0.20 \\
\hline $1.0000 \mathrm{E}-02$ & 19.184180 & 0.20 \\
\hline $1.5000 \mathrm{E}-02$ & 18.621560 & 0.20 \\
\hline $2.0000 \mathrm{E}-02$ & 18.095670 & 0.20 \\
\hline $4.0000 \mathrm{E}-02$ & 16.295540 & 0.20 \\
\hline $6.0000 \mathrm{E}-02$ & 14.867280 & 0.20 \\
\hline $8.0000 \mathrm{E}-02$ & 13.705830 & 0.20 \\
\hline $1.0000 \mathrm{E}-01$ & 12.742290 & 0.20 \\
\hline $1.5000 \mathrm{E}-01$ & 10.923400 & 0.20 \\
\hline $2.0000 \mathrm{E}-01$ & 9.643178 & 0.20 \\
\hline $3.0000 \mathrm{E}-01$ & 7.951949 & 0.20 \\
\hline 4.0000E-01 & 6.876412 & 0.20 \\
\hline
\end{tabular}

TABLE 8.10. ${ }^{1} \mathrm{H}(\mathrm{n}, \mathrm{n})$ CROSS-SECTION (cont.) (linear interpolation in linear-linear scale is recommended)

\begin{tabular}{|c|c|c|}
\hline $\begin{array}{l}\text { Neutron energy } \\
(\mathrm{MeV})\end{array}$ & $\begin{array}{l}\text { Cross-section } \\
\quad \text { (barn) }\end{array}$ & $\begin{array}{c}\text { Cross-section } \\
\text { uncertainty (\%) }\end{array}$ \\
\hline $5.0000 \mathrm{E}-01$ & 6.125445 & 0.20 \\
\hline $6.0000 \mathrm{E}-01$ & 5.566879 & 0.20 \\
\hline $7.0000 \mathrm{E}-01$ & 5.132010 & 0.20 \\
\hline $8.0000 \mathrm{E}-01$ & 4.781570 & 0.20 \\
\hline $9.0000 \mathrm{E}-01$ & 4.491471 & 0.20 \\
\hline $1.0000 \mathrm{E}+00$ & 4.246104 & 0.20 \\
\hline $1.2000 \mathrm{E}+00$ & 3.850454 & 0.20 \\
\hline $1.4000 \mathrm{E}+00$ & 3.541748 & 0.20 \\
\hline $1.6000 \mathrm{E}+00$ & 3.291314 & 0.20 \\
\hline $1.8000 \mathrm{E}+00$ & 3.082187 & 0.20 \\
\hline $2.0000 \mathrm{E}+00$ & 2.903645 & 0.22 \\
\hline $2.2000 \mathrm{E}+00$ & 2.748543 & 0.22 \\
\hline $2.4000 \mathrm{E}+00$ & 2.611918 & 0.22 \\
\hline $2.6000 \mathrm{E}+00$ & 2.490197 & 0.22 \\
\hline $2.8000 \mathrm{E}+00$ & 2.380736 & 0.22 \\
\hline $3.0000 \mathrm{E}+00$ & 2.281521 & 0.22 \\
\hline $3.2000 \mathrm{E}+00$ & 2.190993 & 0.22 \\
\hline $3.4000 \mathrm{E}+00$ & 2.107917 & 0.22 \\
\hline $3.6000 \mathrm{E}+00$ & 2.031301 & 0.22 \\
\hline $3.8000 \mathrm{E}+00$ & 1.960334 & 0.22 \\
\hline $4.0000 \mathrm{E}+00$ & 1.894349 & 0.30 \\
\hline $4.2000 \mathrm{E}+00$ & 1.832787 & 0.30 \\
\hline $4.4000 \mathrm{E}+00$ & 1.775177 & 0.30 \\
\hline $4.6000 \mathrm{E}+00$ & 1.721118 & 0.30 \\
\hline $4.8000 \mathrm{E}+00$ & 1.670264 & 0.30 \\
\hline $5.0000 \mathrm{E}+00$ & 1.622318 & 0.30 \\
\hline $5.5000 \mathrm{E}+00$ & 1.513553 & 0.30 \\
\hline $6.0000 \mathrm{E}+00$ & 1.418157 & 0.36 \\
\hline $6.5000 \mathrm{E}+00$ & 1.333709 & 0.36 \\
\hline $7.0000 \mathrm{E}+00$ & 1.258367 & 0.36 \\
\hline $7.5000 \mathrm{E}+00$ & 1.190697 & 0.36 \\
\hline $8.0000 \mathrm{E}+00$ & 1.129564 & 0.44 \\
\hline $8.5000 \mathrm{E}+00$ & 1.074052 & 0.44 \\
\hline $9.0000 \mathrm{E}+00$ & 1.023415 & 0.44 \\
\hline $9.5000 \mathrm{E}+00$ & 0.977035 & 0.44 \\
\hline $1.0000 \mathrm{E}+01$ & 0.934397 & 0.50 \\
\hline $1.0500 \mathrm{E}+01$ & 0.895069 & 0.50 \\
\hline $1.1000 \mathrm{E}+01$ & 0.858680 & 0.50 \\
\hline $1.1500 \mathrm{E}+01$ & 0.824915 & 0.50 \\
\hline $1.2000 \mathrm{E}+01$ & 0.793504 & 0.49 \\
\hline
\end{tabular}


TABLE 8.10. ${ }^{1} \mathrm{H}(\mathrm{n}, \mathrm{n})$ CROSS-SECTION (cont.) (linear interpolation in linear-linear scale is recommended)

\begin{tabular}{lcc}
\hline $\begin{array}{l}\text { Neutron energy } \\
(\mathrm{MeV})\end{array}$ & $\begin{array}{c}\text { Cross-section } \\
\text { (barn) }\end{array}$ & $\begin{array}{c}\text { Cross-section } \\
\text { uncertainty }(\%)\end{array}$ \\
\hline $1.2500 \mathrm{E}+01$ & 0.764211 & 0.49 \\
$1.3000 \mathrm{E}+01$ & 0.736831 & 0.49 \\
$1.3500 \mathrm{E}+01$ & 0.711185 & 0.49 \\
$1.4000 \mathrm{E}+01$ & 0.687114 & 0.46 \\
$1.4500 \mathrm{E}+01$ & 0.664480 & 0.46 \\
$1.5000 \mathrm{E}+01$ & 0.643159 & 0.46 \\
$1.5500 \mathrm{E}+01$ & 0.623040 & 0.46 \\
$1.6000 \mathrm{E}+01$ & 0.604026 & 0.40 \\
-------------
\end{tabular}

TABLE 8.10. ${ }^{1} \mathrm{H}(\mathrm{n}, \mathrm{n})$ CROSS-SECTION (cont.) (linear interpolation in linear-linear scale is recommended)

\begin{tabular}{lcc}
\hline $\begin{array}{l}\text { Neutron energy } \\
(\mathrm{MeV})\end{array}$ & $\begin{array}{c}\text { Cross-section } \\
\text { (barn) }\end{array}$ & $\begin{array}{c}\text { Cross-section } \\
\text { uncertainty }(\%)\end{array}$ \\
\hline $1.6500 \mathrm{E}+01$ & 0.586029 & 0.40 \\
$1.7000 \mathrm{E}+01$ & 0.568969 & 0.40 \\
$1.7500 \mathrm{E}+01$ & 0.552776 & 0.40 \\
$1.8000 \mathrm{E}+01$ & 0.537384 & 0.35 \\
$1.8500 \mathrm{E}+01$ & 0.522736 & 0.35 \\
$1.9000 \mathrm{E}+01$ & 0.508778 & 0.35 \\
$1.9500 \mathrm{E}+01$ & 0.495463 & 0.35 \\
$2.0000 \mathrm{E}+01$ & 0.482746 & 0.30 \\
\hline
\end{tabular}

TABLE 8.11. LEGENDRE POLYNOMIAL COEFFICIENTS IN THE CENTRE OF MASS SYSTEM FOR THE ANGULAR DISTRIBUTION OF NEUTRONS FROM THE ${ }^{1} \mathrm{H}(\mathrm{n}, \mathrm{n}) \mathrm{REACTION}$

(linear interpolation in linear-linear scale is recommended)

\begin{tabular}{|c|c|c|c|c|c|c|}
\hline $\begin{array}{l}\text { Neutron } \\
\text { energy } \\
(\mathrm{MeV})\end{array}$ & $a_{1}$ & $a_{2}$ & $a_{3}$ & $a_{4}$ & $a_{5}$ & $a_{6}$ \\
\hline $1.0000 \mathrm{E}-11$ & $-1.603 \mathrm{E}-14$ & $5.547 \mathrm{E}-17$ & $2.133 \mathrm{E}-17$ & $2.276 \mathrm{E}-17$ & $-7.758 \mathrm{E}-18$ & $-2.232 \mathrm{E}-17$ \\
\hline $2.0000 \mathrm{E}-11$ & $-3.190 \mathrm{E}-14$ & $4.352 \mathrm{E}-17$ & $9.753 \mathrm{E}-18$ & $2.086 \mathrm{E}-17$ & $-1.396 \mathrm{E}-17$ & $-4.070 \mathrm{E}-17$ \\
\hline $5.0000 \mathrm{E}-11$ & $-7.990 \mathrm{E}-14$ & $4.907 \mathrm{E}-17$ & $3.048 \mathrm{E}-17$ & $1.422 \mathrm{E}-17$ & $6.206 \mathrm{E}-18$ & $-3.545 \mathrm{E}-17$ \\
\hline $1.0000 \mathrm{E}-10$ & $-1.597 \mathrm{E}-13$ & 4.309E-17 & $1.219 \mathrm{E}-17$ & $8.534 \mathrm{E}-18$ & $-1.862 \mathrm{E}-17$ & $-2.757 \mathrm{E}-17$ \\
\hline $2.0000 \mathrm{E}-10$ & $-3.195 \mathrm{E}-13$ & $2.005 \mathrm{E}-17$ & $-7.314 \mathrm{E}-18$ & $8.534 \mathrm{E}-18$ & $-1.086 \mathrm{E}-17$ & $-3.020 \mathrm{E}-17$ \\
\hline $5.0000 \mathrm{E}-10$ & $-7.986 \mathrm{E}-13$ & $2.261 \mathrm{E}-17$ & $2.377 \mathrm{E}-17$ & $2.655 \mathrm{E}-17$ & $-1.552 \mathrm{E}-17$ & $-3.545 \mathrm{E}-17$ \\
\hline $1.0000 \mathrm{E}-09$ & $-1.597 \mathrm{E}-12$ & 4.693E-17 & $3.535 \mathrm{E}-17$ & $2.370 \mathrm{E}-17$ & $-2.017 \mathrm{E}-17$ & $-2.626 \mathrm{E}-17$ \\
\hline $2.0000 \mathrm{E}-09$ & $-3.195 \mathrm{E}-12$ & 6.187E-17 & $2.682 \mathrm{E}-17$ & $1.138 \mathrm{E}-17$ & $-1.241 \mathrm{E}-17$ & $-2.626 \mathrm{E}-17$ \\
\hline $5.0000 \mathrm{E}-09$ & $-7.986 \mathrm{E}-12$ & $6.229 \mathrm{E}-17$ & $4.572 \mathrm{E}-17$ & $1.327 \mathrm{E}-17$ & $-1.552 \mathrm{E}-18$ & $-2.363 \mathrm{E}-17$ \\
\hline $1.0000 \mathrm{E}-08$ & $-1.597 \mathrm{E}-11$ & $7.808 \mathrm{E}-17$ & $1.585 \mathrm{E}-17$ & $2.939 \mathrm{E}-17$ & $-1.086 \mathrm{E}-17$ & $-3.151 \mathrm{E}-17$ \\
\hline $2.5300 \mathrm{E}-08$ & $-4.041 \mathrm{E}-11$ & $5.077 \mathrm{E}-17$ & $-6.705 \mathrm{E}-18$ & $1.517 \mathrm{E}-17$ & $-3.103 \mathrm{E}-18$ & $-2.363 \mathrm{E}-17$ \\
\hline $5.0000 \mathrm{E}-08$ & $-7.986 \mathrm{E}-11$ & $6.016 \mathrm{E}-17$ & $3.048 \mathrm{E}-17$ & $2.845 \mathrm{E}-17$ & $-1.707 \mathrm{E}-17$ & $-1.575 \mathrm{E}-17$ \\
\hline $1.0000 \mathrm{E}-07$ & $-1.597 \mathrm{E}-10$ & 5.333E-17 & $2.316 \mathrm{E}-17$ & $2.750 \mathrm{E}-17$ & $-1.862 \mathrm{E}-17$ & $-3.020 \mathrm{E}-17$ \\
\hline $2.0000 \mathrm{E}-07$ & $-3.194 \mathrm{E}-10$ & $3.243 \mathrm{E}-17$ & $9.753 \mathrm{E}-18$ & $2.560 \mathrm{E}-17$ & $-1.086 \mathrm{E}-17$ & $-2.494 \mathrm{E}-17$ \\
\hline $5.0000 \mathrm{E}-07$ & $-7.986 \mathrm{E}-10$ & $3.243 \mathrm{E}-17$ & $-3.657 \mathrm{E}-18$ & $2.939 \mathrm{E}-17$ & 0.0000 & $-2.757 \mathrm{E}-17$ \\
\hline $1.0000 \mathrm{E}-06$ & $-1.597 \mathrm{E}-09$ & $6.443 \mathrm{E}-17$ & $1.524 \mathrm{E}-17$ & $1.991 \mathrm{E}-17$ & $-1.552 \mathrm{E}-18$ & $-1.838 \mathrm{E}-17$ \\
\hline $2.0000 \mathrm{E}-06$ & $-3.194 \mathrm{E}-09$ & $2.944 \mathrm{E}-17$ & $2.072 \mathrm{E}-17$ & $1.896 \mathrm{E}-17$ & $-1.707 \mathrm{E}-17$ & $-3.807 \mathrm{E}-17$ \\
\hline $5.0000 \mathrm{E}-06$ & $-7.986 \mathrm{E}-09$ & $-3.243 \mathrm{E}-17$ & $6.827 \mathrm{E}-17$ & $1.517 \mathrm{E}-17$ & $-1.086 \mathrm{E}-17$ & $-3.282 \mathrm{E}-17$ \\
\hline $1.0000 \mathrm{E}-05$ & $-1.597 \mathrm{E}-08$ & $-2.035 \mathrm{E}-16$ & $2.134 \mathrm{E}-17$ & $3.698 \mathrm{E}-17$ & $-1.241 \mathrm{E}-17$ & $-3.808 \mathrm{E}-17$ \\
\hline $2.0000 \mathrm{E}-05$ & $-3.194 \mathrm{E}-08$ & $-7.749 \mathrm{E}-16$ & $4.267 \mathrm{E}-17$ & $1.328 \mathrm{E}-17$ & $-6.207 E-18$ & $-3.939 \mathrm{E}-17$ \\
\hline $5.0000 \mathrm{E}-05$ & $-7.986 \mathrm{E}-08$ & $-5.105 \mathrm{E}-15$ & $4.451 \mathrm{E}-17$ & $2.561 \mathrm{E}-17$ & $-3.104 \mathrm{E}-18$ & $-3.677 \mathrm{E}-17$ \\
\hline $1.0000 \mathrm{E}-04$ & $-1.597 \mathrm{E}-07$ & $-2.053 \mathrm{E}-14$ & $5.062 \mathrm{E}-17$ & $5.693 \mathrm{E}-18$ & $9.315 \mathrm{E}-18$ & $-3.941 \mathrm{E}-17$ \\
\hline $2.0000 \mathrm{E}-04$ & $-3.193 \mathrm{E}-07$ & $-8.214 \mathrm{E}-14$ & $8.118 \mathrm{E}-17$ & $2.089 \mathrm{E}-17$ & $2.796 \mathrm{E}-17$ & $-3.681 \mathrm{E}-17$ \\
\hline
\end{tabular}


TABLE 8.11. LEGENDRE POLYNOMIAL COEFFICIENTS IN THE CENTRE OF MASS SYSTEM FOR THE ANGULAR DISTRIBUTION OF NEUTRONS FROM THE ${ }^{1} \mathrm{H}(\mathrm{n}, \mathrm{n})$ REACTION (cont.)

(linear interpolation in linear-linear scale is recommended)

\begin{tabular}{|c|c|c|c|c|c|c|}
\hline $\begin{array}{l}\text { Neutron } \\
\text { energy } \\
(\mathrm{MeV})\end{array}$ & $a_{1}$ & $a_{2}$ & $a_{3}$ & $a_{4}$ & $a_{5}$ & $a_{6}$ \\
\hline $5.0000 \mathrm{E}-04$ & $-7.980 \mathrm{E}-07$ & $-5.168 \mathrm{E}-13$ & $1.229 \mathrm{E}-16$ & $-4.186 \mathrm{E}-17$ & $3.269 \mathrm{E}-17$ & $-5.532 \mathrm{E}-17$ \\
\hline $1.0000 \mathrm{E}-03$ & $-1.595 \mathrm{E}-06$ & $-2.091 \mathrm{E}-12$ & $3.190 \mathrm{E}-17$ & $-9.878 \mathrm{E}-17$ & $1.015 \mathrm{E}-16$ & $-8.854 \mathrm{E}-17$ \\
\hline $2.0000 \mathrm{E}-03$ & $-3.185 \mathrm{E}-06$ & $-8.561 \mathrm{E}-12$ & $-1.095 \mathrm{E}-15$ & $-2.104 \mathrm{E}-16$ & $1.761 \mathrm{E}-16$ & $-1.543 \mathrm{E}-16$ \\
\hline $4.0000 \mathrm{E}-03$ & $-6.350 \mathrm{E}-06$ & $-3.582 \mathrm{E}-11$ & $-1.205 \mathrm{E}-14$ & $-4.277 \mathrm{E}-16$ & $3.535 \mathrm{E}-16$ & $-2.775 \mathrm{E}-16$ \\
\hline $6.0000 \mathrm{E}-03$ & $-9.496 \mathrm{E}-06$ & $-8.412 \mathrm{E}-11$ & $-4.256 \mathrm{E}-14$ & $-6.598 \mathrm{E}-16$ & $5.402 \mathrm{E}-16$ & $-3.998 \mathrm{E}-16$ \\
\hline $8.0000 \mathrm{E}-03$ & $-1.262 \mathrm{E}-05$ & $-1.558 \mathrm{E}-10$ & $-1.025 \mathrm{E}-13$ & $-8.980 \mathrm{E}-16$ & $7.135 \mathrm{E}-16$ & $-5.084 \mathrm{E}-16$ \\
\hline $1.0000 \mathrm{E}-02$ & $-1.573 \mathrm{E}-05$ & $-2.531 \mathrm{E}-10$ & $-2.017 \mathrm{E}-13$ & $-1.102 \mathrm{E}-15$ & $9.107 \mathrm{E}-16$ & $-6.377 \mathrm{E}-16$ \\
\hline $1.5000 \mathrm{E}-02$ & $-2.342 \mathrm{E}-05$ & $-6.236 \mathrm{E}-10$ & $-6.852 \mathrm{E}-13$ & $-1.650 \mathrm{E}-15$ & $1.369 \mathrm{E}-15$ & $-9.207 \mathrm{E}-16$ \\
\hline $2.0000 \mathrm{E}-02$ & $-3.099 \mathrm{E}-05$ & $-1.203 \mathrm{E}-09$ & $-1.627 \mathrm{E}-12$ & $-2.160 \mathrm{E}-15$ & $1.786 \mathrm{E}-15$ & $-1.208 \mathrm{E}-15$ \\
\hline 4.0000E-02 & $-6.018 \mathrm{E}-05$ & $-6.281 E-09$ & $-1.303 \mathrm{E}-11$ & $-2.506 \mathrm{E}-15$ & $3.495 \mathrm{E}-15$ & $-2.302 \mathrm{E}-15$ \\
\hline $6.0000 \mathrm{E}-02$ & $-8.771 \mathrm{E}-05$ & $-1.726 \mathrm{E}-08$ & $-4.391 \mathrm{E}-11$ & $4.091 \mathrm{E}-15$ & $5.109 \mathrm{E}-15$ & $-3.348 \mathrm{E}-15$ \\
\hline 8.0000E-02 & $-1.137 \mathrm{E}-04$ & $-3.597 \mathrm{E}-08$ & $-1.040 \mathrm{E}-10$ & $2.768 \mathrm{E}-14$ & $6.600 \mathrm{E}-15$ & $-4.329 \mathrm{E}-15$ \\
\hline $1.0000 \mathrm{E}-01$ & $-1.384 \mathrm{E}-04$ & $-6.405 \mathrm{E}-08$ & $-2.028 \mathrm{E}-10$ & $8.434 \mathrm{E}-14$ & $8.045 \mathrm{E}-15$ & $-5.253 \mathrm{E}-15$ \\
\hline $1.5000 \mathrm{E}-01$ & $-1.946 \mathrm{E}-04$ & $-1.846 \mathrm{E}-07$ & $-6.827 \mathrm{E}-10$ & $5.419 \mathrm{E}-13$ & $1.114 \mathrm{E}-14$ & $-7.362 \mathrm{E}-15$ \\
\hline $2.0000 \mathrm{E}-01$ & $-2.443 \mathrm{E}-04$ & $-3.918 \mathrm{E}-07$ & $-1.615 \mathrm{E}-09$ & $1.967 \mathrm{E}-12$ & $1.333 \mathrm{E}-14$ & $-9.204 \mathrm{E}-15$ \\
\hline $3.0000 \mathrm{E}-01$ & $-3.291 \mathrm{E}-04$ & $-1.122 \mathrm{E}-06$ & $-5.444 \mathrm{E}-09$ & $1.208 \mathrm{E}-11$ & $1.116 \mathrm{E}-14$ & $-1.224 \mathrm{E}-14$ \\
\hline 4.0000E-01 & $-4.000 \mathrm{E}-04$ & $-2.337 \mathrm{E}-06$ & $-1.291 \mathrm{E}-08$ & $4.393 \mathrm{E}-11$ & $-1.487 \mathrm{E}-14$ & $-1.452 \mathrm{E}-14$ \\
\hline $5.0000 \mathrm{E}-01$ & $-4.622 \mathrm{E}-04$ & $-4.083 \mathrm{E}-06$ & $-2.526 \mathrm{E}-08$ & $1.197 \mathrm{E}-10$ & $-1.022 \mathrm{E}-13$ & $-1.588 \mathrm{E}-14$ \\
\hline $6.0000 \mathrm{E}-01$ & $-5.190 \mathrm{E}-04$ & $-6.382 \mathrm{E}-06$ & $-4.379 \mathrm{E}-08$ & $2.713 \mathrm{E}-10$ & $-3.207 \mathrm{E}-13$ & $-1.566 \mathrm{E}-14$ \\
\hline 7.0000E-01 & $-5.730 \mathrm{E}-04$ & $-9.244 \mathrm{E}-06$ & $-6.982 \mathrm{E}-08$ & $5.416 \mathrm{E}-10$ & $-7.843 \mathrm{E}-13$ & $-1.239 \mathrm{E}-14$ \\
\hline $8.0000 \mathrm{E}-01$ & $-6.259 \mathrm{E}-04$ & $-1.266 \mathrm{E}-05$ & $-1.047 \mathrm{E}-07$ & $9.852 \mathrm{E}-10$ & $-1.666 \mathrm{E}-12$ & $-3.395 \mathrm{E}-15$ \\
\hline $9.0000 \mathrm{E}-01$ & $-6.791 \mathrm{E}-04$ & $-1.663 \mathrm{E}-05$ & $-1.499 \mathrm{E}-07$ & $1.669 \mathrm{E}-09$ & $-3.210 \mathrm{E}-12$ & $1.581 \mathrm{E}-14$ \\
\hline $1.0000 \mathrm{E}+00$ & $-7.334 \mathrm{E}-04$ & $-2.114 \mathrm{E}-05$ & $-2.067 \mathrm{E}-07$ & $2.673 \mathrm{E}-09$ & $-5.752 \mathrm{E}-12$ & $5.209 \mathrm{E}-14$ \\
\hline $1.2000 \mathrm{E}+00$ & $-8.479 \mathrm{E}-04$ & $-3.168 \mathrm{E}-05$ & $-3.615 \mathrm{E}-07$ & $6.032 \mathrm{E}-09$ & $-1.571 \mathrm{E}-11$ & $2.204 \mathrm{E}-13$ \\
\hline $1.4000 \mathrm{E}+00$ & $-9.730 \mathrm{E}-04$ & $-4.412 \mathrm{E}-05$ & $-5.812 \mathrm{E}-07$ & $1.199 \mathrm{E}-08$ & $-3.666 \mathrm{E}-11$ & $6.390 \mathrm{E}-13$ \\
\hline $1.6000 \mathrm{E}+00$ & $-1.110 \mathrm{E}-03$ & $-5.825 \mathrm{E}-05$ & $-8.785 \mathrm{E}-07$ & $2.172 \mathrm{E}-08$ & $-7.631 \mathrm{E}-11$ & $1.550 \mathrm{E}-12$ \\
\hline $1.8000 \mathrm{E}+00$ & $-1.261 \mathrm{E}-03$ & $-7.389 \mathrm{E}-05$ & $-1.267 \mathrm{E}-06$ & $3.666 \mathrm{E}-08$ & $-1.456 \mathrm{E}-10$ & $3.347 \mathrm{E}-12$ \\
\hline $2.0000 \mathrm{E}+00$ & $-1.424 \mathrm{E}-03$ & $-9.081 E-05$ & $-1.759 \mathrm{E}-06$ & $5.851 \mathrm{E}-08$ & $-2.596 \mathrm{E}-10$ & $6.633 \mathrm{E}-12$ \\
\hline $2.2000 \mathrm{E}+00$ & $-1.600 \mathrm{E}-03$ & $-1.088 \mathrm{E}-04$ & $-2.370 \mathrm{E}-06$ & $8.930 \mathrm{E}-08$ & $-4.379 \mathrm{E}-10$ & $1.229 \mathrm{E}-11$ \\
\hline $2.4000 \mathrm{E}+00$ & $-1.787 \mathrm{E}-03$ & $-1.277 \mathrm{E}-04$ & $-3.113 \mathrm{E}-06$ & $1.313 \mathrm{E}-07$ & $-7.058 \mathrm{E}-10$ & $2.156 \mathrm{E}-11$ \\
\hline $2.6000 \mathrm{E}+00$ & $-1.987 \mathrm{E}-03$ & $-1.473 \mathrm{E}-04$ & $-4.003 \mathrm{E}-06$ & $1.871 \mathrm{E}-07$ & $-1.095 \mathrm{E}-09$ & $3.613 \mathrm{E}-11$ \\
\hline $2.8000 \mathrm{E}+00$ & $-2.196 \mathrm{E}-03$ & $-1.673 \mathrm{E}-04$ & $-5.054 \mathrm{E}-06$ & $2.598 \mathrm{E}-07$ & $-1.644 \mathrm{E}-09$ & $5.824 \mathrm{E}-11$ \\
\hline $3.0000 \mathrm{E}+00$ & $-2.416 \mathrm{E}-03$ & $-1.876 \mathrm{E}-04$ & $-6.281 \mathrm{E}-06$ & $3.524 \mathrm{E}-07$ & $-2.401 \mathrm{E}-09$ & $9.083 \mathrm{E}-11$ \\
\hline $3.2000 \mathrm{E}+00$ & $-2.644 \mathrm{E}-03$ & $-2.080 \mathrm{E}-04$ & $-7.699 \mathrm{E}-06$ & $4.686 \mathrm{E}-07$ & $-3.422 \mathrm{E}-09$ & $1.376 \mathrm{E}-10$ \\
\hline $3.4000 \mathrm{E}+00$ & $-2.881 \mathrm{E}-03$ & $-2.284 \mathrm{E}-04$ & $-9.322 \mathrm{E}-06$ & $6.124 \mathrm{E}-07$ & $-4.773 \mathrm{E}-09$ & $2.032 \mathrm{E}-10$ \\
\hline $3.6000 \mathrm{E}+00$ & $-3.125 \mathrm{E}-03$ & $-2.484 \mathrm{E}-04$ & $-1.116 \mathrm{E}-05$ & $7.879 \mathrm{E}-07$ & $-6.532 \mathrm{E}-09$ & $2.934 \mathrm{E}-10$ \\
\hline $3.8000 \mathrm{E}+00$ & $-3.376 \mathrm{E}-03$ & $-2.681 E-04$ & $-1.324 \mathrm{E}-05$ & 9.997E-07 & $-8.788 \mathrm{E}-09$ & $4.152 \mathrm{E}-10$ \\
\hline $4.0000 \mathrm{E}+00$ & $-3.633 \mathrm{E}-03$ & $-2.871 \mathrm{E}-04$ & $-1.557 \mathrm{E}-05$ & $1.253 \mathrm{E}-06$ & $-1.165 \mathrm{E}-08$ & $5.771 \mathrm{E}-10$ \\
\hline $\begin{array}{l}4.2000 \mathrm{E}+00 \\
-\ldots-\ldots\end{array}$ & $-3.895 \mathrm{E}-03$ & $\begin{array}{l}-3.054 \mathrm{E}-04 \\
-\end{array}$ & $\begin{array}{l}-1.816 \mathrm{E}-05 \\
-\end{array}$ & $\begin{array}{l}1.553 \mathrm{E}-06 \\
-\end{array}$ & $\begin{array}{l}-1.522 \mathrm{E}-08 \\
--\ldots---\end{array}$ & $\begin{array}{r}7.891 \mathrm{E}-10 \\
-\end{array}$ \\
\hline
\end{tabular}


TABLE 8.11. LEGENDRE POLYNOMIAL COEFFICIENTS IN THE CENTRE OF MASS SYSTEM FOR THE ANGULAR DISTRIBUTION OF NEUTRONS FROM THE ${ }^{1} \mathrm{H}(\mathrm{n}, \mathrm{n})$ REACTION (cont.)

(linear interpolation in linear-linear scale is recommended)

\begin{tabular}{|c|c|c|c|c|c|c|}
\hline $\begin{array}{l}\text { Neutron } \\
\text { energy } \\
(\mathrm{MeV})\end{array}$ & $a_{1}$ & $a_{2}$ & $a_{3}$ & $a_{4}$ & $a_{5}$ & $a_{6}$ \\
\hline $4.4000 \mathrm{E}+00$ & $-4.161 \mathrm{E}-03$ & $-3.228 \mathrm{E}-04$ & $-2.103 \mathrm{E}-05$ & $1.905 \mathrm{E}-06$ & $-1.965 \mathrm{E}-08$ & $1.063 \mathrm{E}-09$ \\
\hline $4.6000 \mathrm{E}+00$ & $-4.431 \mathrm{E}-03$ & $-3.391 \mathrm{E}-04$ & $-2.419 \mathrm{E}-05$ & $2.315 \mathrm{E}-06$ & $-2.507 \mathrm{E}-08$ & $1.413 \mathrm{E}-09$ \\
\hline $4.8000 \mathrm{E}+00$ & $-4.705 E-03$ & $-3.543 \mathrm{E}-04$ & $-2.765 \mathrm{E}-05$ & $2.789 \mathrm{E}-06$ & $-3.167 \mathrm{E}-08$ & $1.856 \mathrm{E}-09$ \\
\hline $5.0000 \mathrm{E}+00$ & $-4.981 \mathrm{E}-03$ & $-3.680 \mathrm{E}-04$ & $-3.144 \mathrm{E}-05$ & $3.335 \mathrm{E}-06$ & $-3.961 \mathrm{E}-08$ & $2.409 \mathrm{E}-09$ \\
\hline $5.5000 \mathrm{E}+00$ & $-5.680 \mathrm{E}-03$ & $-3.958 \mathrm{E}-04$ & $-4.238 \mathrm{E}-05$ & $5.055 \mathrm{E}-06$ & $-6.677 E-08$ & $4.425 \mathrm{E}-09$ \\
\hline $6.0000 \mathrm{E}+00$ & $-6.384 \mathrm{E}-03$ & $-4.123 \mathrm{E}-04$ & $-5.560 \mathrm{E}-05$ & $7.380 \mathrm{E}-06$ & $-1.075 \mathrm{E}-07$ & $7.696 \mathrm{E}-09$ \\
\hline $6.5000 \mathrm{E}+00$ & $-7.086 \mathrm{E}-03$ & $-4.159 \mathrm{E}-04$ & $-7.127 \mathrm{E}-05$ & $1.044 \mathrm{E}-05$ & $-1.665 \mathrm{E}-07$ & $1.278 \mathrm{E}-08$ \\
\hline $7.0000 \mathrm{E}+00$ & $-7.781 \mathrm{E}-03$ & $-4.048 \mathrm{E}-04$ & $-8.955 \mathrm{E}-05$ & $1.437 \mathrm{E}-05$ & $-2.494 \mathrm{E}-07$ & 2.042E-08 \\
\hline $7.5000 \mathrm{E}+00$ & $-8.462 \mathrm{E}-03$ & $-3.776 \mathrm{E}-04$ & $-1.106 \mathrm{E}-04$ & $1.932 \mathrm{E}-05$ & $-3.629 \mathrm{E}-07$ & 3.152E-08 \\
\hline $8.0000 \mathrm{E}+00$ & $-9.125 \mathrm{E}-03$ & $-3.329 \mathrm{E}-04$ & $-1.345 \mathrm{E}-04$ & $2.545 \mathrm{E}-05$ & $-5.152 \mathrm{E}-07$ & 4.722E-08 \\
\hline $8.5000 \mathrm{E}+00$ & $-9.767 \mathrm{E}-03$ & $-2.695 \mathrm{E}-04$ & $-1.615 \mathrm{E}-04$ & $3.292 \mathrm{E}-05$ & $-7.152 \mathrm{E}-07$ & $6.890 \mathrm{E}-08$ \\
\hline $9.0000 \mathrm{E}+00$ & $-1.038 \mathrm{E}-02$ & $-1.864 \mathrm{E}-04$ & $-1.915 \mathrm{E}-04$ & $4.190 \mathrm{E}-05$ & $-9.736 \mathrm{E}-07$ & $9.820 \mathrm{E}-08$ \\
\hline $9.5000 \mathrm{E}+00$ & $-1.097 \mathrm{E}-02$ & $-8.247 \mathrm{E}-05$ & $-2.246 \mathrm{E}-04$ & 5.257E-05 & $-1.302 \mathrm{E}-06$ & $1.370 \mathrm{E}-07$ \\
\hline $1.0000 \mathrm{E}+01$ & $-1.153 \mathrm{E}-02$ & $4.306 \mathrm{E}-05$ & $-2.609 \mathrm{E}-04$ & $6.509 \mathrm{E}-05$ & $-1.714 \mathrm{E}-06$ & $1.876 \mathrm{E}-07$ \\
\hline $1.0500 \mathrm{E}+01$ & $-1.206 \mathrm{E}-02$ & $1.910 \mathrm{E}-04$ & $-3.004 \mathrm{E}-04$ & 7.965E-05 & $-2.223 \mathrm{E}-06$ & $2.525 \mathrm{E}-07$ \\
\hline $1.1000 \mathrm{E}+01$ & $-1.255 \mathrm{E}-02$ & $3.618 \mathrm{E}-04$ & $-3.431 \mathrm{E}-04$ & $9.642 \mathrm{E}-05$ & $-2.847 \mathrm{E}-06$ & $3.345 \mathrm{E}-07$ \\
\hline $1.1500 \mathrm{E}+01$ & $-1.301 \mathrm{E}-02$ & $5.563 \mathrm{E}-04$ & $-3.888 \mathrm{E}-04$ & $1.156 \mathrm{E}-04$ & $-3.601 E-06$ & $4.366 \mathrm{E}-07$ \\
\hline $1.2000 \mathrm{E}+01$ & $-1.344 \mathrm{E}-02$ & 7.747E-04 & $-4.376 \mathrm{E}-04$ & $1.373 \mathrm{E}-04$ & $-4.505 \mathrm{E}-06$ & $5.624 \mathrm{E}-07$ \\
\hline $1.2500 \mathrm{E}+01$ & $-1.383 \mathrm{E}-02$ & $1.017 \mathrm{E}-03$ & $-4.894 \mathrm{E}-04$ & $1.616 \mathrm{E}-04$ & $-5.579 \mathrm{E}-06$ & $7.154 \mathrm{E}-07$ \\
\hline $1.3000 \mathrm{E}+01$ & $-1.419 \mathrm{E}-02$ & $1.285 \mathrm{E}-03$ & $-5.440 \mathrm{E}-04$ & $1.889 \mathrm{E}-04$ & $-6.843 E-06$ & $8.995 \mathrm{E}-07$ \\
\hline $1.3500 \mathrm{E}+01$ & $-1.451 \mathrm{E}-02$ & $1.577 \mathrm{E}-03$ & $-6.013 \mathrm{E}-04$ & $2.191 \mathrm{E}-04$ & $-8.320 \mathrm{E}-06$ & 1.119E-06 \\
\hline $1.4000 \mathrm{E}+01$ & $-1.480 \mathrm{E}-02$ & $1.893 \mathrm{E}-03$ & $-6.611 \mathrm{E}-04$ & $2.525 \mathrm{E}-04$ & $-1.003 E-05$ & $1.377 \mathrm{E}-06$ \\
\hline $1.4500 \mathrm{E}+01$ & $-1.505 \mathrm{E}-02$ & $2.235 \mathrm{E}-03$ & $-7.232 \mathrm{E}-04$ & $2.891 \mathrm{E}-04$ & $-1.200 \mathrm{E}-05$ & $1.679 \mathrm{E}-06$ \\
\hline $1.5000 \mathrm{E}+01$ & $-1.528 \mathrm{E}-02$ & $2.600 \mathrm{E}-03$ & $-7.874 \mathrm{E}-04$ & $3.290 \mathrm{E}-04$ & $-1.426 \mathrm{E}-05$ & $2.029 \mathrm{E}-06$ \\
\hline $1.5500 \mathrm{E}+01$ & $-1.547 \mathrm{E}-02$ & 2.991E-03 & $-8.534 \mathrm{E}-04$ & $3.723 \mathrm{E}-04$ & $-1.682 \mathrm{E}-05$ & $2.430 \mathrm{E}-06$ \\
\hline $1.6000 \mathrm{E}+01$ & $-1.563 \mathrm{E}-02$ & $3.405 \mathrm{E}-03$ & $-9.209 \mathrm{E}-04$ & 4.190E-04 & $-1.972 \mathrm{E}-05$ & $2.887 \mathrm{E}-06$ \\
\hline $1.6500 \mathrm{E}+01$ & $-1.577 \mathrm{E}-02$ & $3.843 \mathrm{E}-03$ & $-9.896 \mathrm{E}-04$ & 4.693E-04 & $-2.297 \mathrm{E}-05$ & 3.402E-06 \\
\hline $1.7000 \mathrm{E}+01$ & $-1.588 \mathrm{E}-02$ & 4.303E-03 & $-1.059 \mathrm{E}-03$ & $5.231 \mathrm{E}-04$ & $-2.660 \mathrm{E}-05$ & $3.978 \mathrm{E}-06$ \\
\hline $1.7500 \mathrm{E}+01$ & $-1.596 \mathrm{E}-02$ & 4.787E-03 & $-1.129 \mathrm{E}-03$ & $5.804 \mathrm{E}-04$ & $-3.064 \mathrm{E}-05$ & $4.618 \mathrm{E}-06$ \\
\hline $1.8000 \mathrm{E}+01$ & $-1.602 \mathrm{E}-02$ & $5.292 \mathrm{E}-03$ & $-1.199 \mathrm{E}-03$ & $6.411 \mathrm{E}-04$ & $-3.511 \mathrm{E}-05$ & $5.323 \mathrm{E}-06$ \\
\hline $1.8500 \mathrm{E}+01$ & $-1.607 \mathrm{E}-02$ & $5.818 \mathrm{E}-03$ & $-1.268 \mathrm{E}-03$ & $7.052 \mathrm{E}-04$ & $-4.003 \mathrm{E}-05$ & $6.092 \mathrm{E}-06$ \\
\hline $1.9000 \mathrm{E}+01$ & $-1.609 \mathrm{E}-02$ & $6.364 \mathrm{E}-03$ & $-1.337 \mathrm{E}-03$ & 7.727E-04 & $-4.541 \mathrm{E}-05$ & $6.924 \mathrm{E}-06$ \\
\hline $1.9500 \mathrm{E}+01$ & $-1.609 \mathrm{E}-02$ & $6.929 \mathrm{E}-03$ & $-1.404 \mathrm{E}-03$ & $8.433 \mathrm{E}-04$ & $-5.128 \mathrm{E}-05$ & 7.816E-06 \\
\hline $2.0000 \mathrm{E}+01$ & $-1.609 \mathrm{E}-02$ & $7.512 \mathrm{E}-03$ & $-1.468 \mathrm{E}-03$ & $9.169 \mathrm{E}-04$ & $-5.764 \mathrm{E}-05$ & $8.765 \mathrm{E}-06$ \\
\hline
\end{tabular}


TABLE 8.12. ${ }^{3} \mathrm{He}(\mathrm{n}, \mathrm{p})$ CROSS-SECTION (linear interpolation in log-log scale is recommended)

\begin{tabular}{|c|c|c|}
\hline $\begin{array}{l}\text { Neutron } \\
\text { energy } \\
(\mathrm{MeV})\end{array}$ & $\begin{array}{c}\text { Cross-section } \\
\text { (barn) }\end{array}$ & $\begin{array}{c}\text { Cross-section } \\
\text { uncertainty } \\
(\%)\end{array}$ \\
\hline $1.00000 \mathrm{E}-11$ & 267450.0 & 0.3 \\
\hline $1.00000 \mathrm{E}-10$ & 84577.9 & 0.3 \\
\hline $1.00000 \mathrm{E}-09$ & 26744.2 & 0.3 \\
\hline $1.00000 \mathrm{E}-08$ & 8456.17 & 0.3 \\
\hline $2.53000 \mathrm{E}-08$ & 5316.00 & 0.3 \\
\hline $1.00000 \mathrm{E}-07$ & 2673.30 & 0.3 \\
\hline $1.00000 \mathrm{E}-06$ & 844.530 & 0.3 \\
\hline $1.00000 \mathrm{E}-05$ & 266.220 & 0.3 \\
\hline $1.00000 \mathrm{E}-04$ & 83.3570 & 0.7 \\
\hline $2.00000 \mathrm{E}-04$ & 58.5900 & 0.7 \\
\hline 4.00000E-04 & 41.0810 & 0.7 \\
\hline $6.00000 \mathrm{E}-04$ & 33.3260 & 0.7 \\
\hline $8.00000 \mathrm{E}-04$ & 28.7050 & 0.7 \\
\hline $1.00000 \mathrm{E}-03$ & 25.5520 & 2.0 \\
\hline $1.40000 \mathrm{E}-03$ & 21.4149 & 2.0 \\
\hline $2.00000 \mathrm{E}-03$ & 17.7330 & 2.0 \\
\hline $2.40000 \mathrm{E}-03$ & 16.0921 & 2.0 \\
\hline $3.00000 \mathrm{E}-03$ & 14.2755 & 2.0 \\
\hline $4.00000 \mathrm{E}-03$ & 12.2160 & 2.0 \\
\hline $5.00000 \mathrm{E}-03$ & 10.8129 & 2.0 \\
\hline $6.00000 \mathrm{E}-03$ & 9.77790 & 2.0 \\
\hline $7.00000 \mathrm{E}-03$ & 8.97471 & 2.0 \\
\hline $8.00000 \mathrm{E}-03$ & 8.32880 & 2.0 \\
\hline $9.00000 \mathrm{E}-03$ & 7.79443 & 2.0 \\
\hline $1.00000 \mathrm{E}-02$ & 7.34260 & 5.0 \\
\hline $1.20000 \mathrm{E}-02$ & 6.61627 & 5.0 \\
\hline $1.50000 \mathrm{E}-02$ & 5.81630 & 5.0 \\
\hline $1.70000 \mathrm{E}-02$ & 5.40666 & 5.0 \\
\hline $2.00000 \mathrm{E}-02$ & 4.91280 & 5.0 \\
\hline $2.20000 \mathrm{E}-02$ & 4.64236 & 5.0 \\
\hline $2.50000 \mathrm{E}-02$ & 4.30060 & 5.0 \\
\hline $2.70000 \mathrm{E}-02$ & 4.10584 & 5.0 \\
\hline $3.00000 \mathrm{E}-02$ & 3.85200 & 5.0 \\
\hline $3.20000 \mathrm{E}-02$ & 3.70350 & 5.0 \\
\hline $3.50000 \mathrm{E}-02$ & 3.50580 & 5.0 \\
\hline $4.00000 \mathrm{E}-02$ & 3.22880 & 5.0 \\
\hline $4.50000 \mathrm{E}-02$ & 3.00120 & 5.0 \\
\hline $5.00000 \mathrm{E}-02$ & 2.81000 & 5.0 \\
\hline
\end{tabular}

TABLE 8.13. C(n,n) CROSS-SECTION (linear interpolation in linear-linear scale is recommended)

\begin{tabular}{|c|c|c|}
\hline $\begin{array}{l}\text { Neutron } \\
\text { energy } \\
(\mathrm{MeV})\end{array}$ & $\begin{array}{l}\text { Cross-section } \\
\quad \text { (barn) }\end{array}$ & $\begin{array}{c}\text { Cross-section } \\
\text { uncertainty } \\
(\%)\end{array}$ \\
\hline 1.0000E-11 & 4.73918 & 0.20 \\
\hline $1.0000 \mathrm{E}-09$ & 4.73920 & 0.20 \\
\hline $2.5300 \mathrm{E}-08$ & 4.73924 & 0.20 \\
\hline $1.0000 \mathrm{E}-07$ & 4.73919 & 0.20 \\
\hline $1.0000 \mathrm{E}-05$ & 4.73913 & 0.20 \\
\hline $1.0000 \mathrm{E}-03$ & 4.73458 & 0.49 \\
\hline $5.0000 \mathrm{E}-03$ & 4.71609 & 0.48 \\
\hline $1.0000 \mathrm{E}-02$ & 4.69910 & 0.48 \\
\hline $1.5000 \mathrm{E}-02$ & 4.68210 & 0.48 \\
\hline $2.0000 \mathrm{E}-02$ & 4.66530 & 0.48 \\
\hline $2.5000 \mathrm{E}-02$ & 4.64860 & 0.49 \\
\hline $3.0000 \mathrm{E}-02$ & 4.63190 & 0.49 \\
\hline $3.5000 \mathrm{E}-02$ & 4.61540 & 0.49 \\
\hline 4.0000E-02 & 4.59890 & 0.49 \\
\hline $4.5000 \mathrm{E}-02$ & 4.58250 & 0.49 \\
\hline $5.0000 \mathrm{E}-02$ & 4.56620 & 0.46 \\
\hline $7.5000 \mathrm{E}-02$ & 4.48620 & 0.46 \\
\hline $1.0000 \mathrm{E}-01$ & 4.40840 & 0.46 \\
\hline $1.2500 \mathrm{E}-01$ & 4.33010 & 0.49 \\
\hline $1.3000 \mathrm{E}-01$ & 4.31480 & 0.49 \\
\hline $1.3500 \mathrm{E}-01$ & 4.30120 & 0.49 \\
\hline $1.4000 \mathrm{E}-01$ & 4.28910 & 0.52 \\
\hline $1.4250 \mathrm{E}-01$ & 4.28480 & 0.52 \\
\hline $1.4500 \mathrm{E}-01$ & 4.28380 & 0.52 \\
\hline $1.4750 \mathrm{E}-01$ & 4.29240 & 0.58 \\
\hline $1.4875 \mathrm{E}-01$ & 4.30700 & 0.57 \\
\hline $1.5000 \mathrm{E}-01$ & 4.34000 & 0.60 \\
\hline $1.5100 \mathrm{E}-01$ & 4.39370 & 0.60 \\
\hline $1.5200 \mathrm{E}-01$ & 4.47650 & 0.60 \\
\hline $1.5290 \mathrm{E}-01$ & 4.52060 & 0.58 \\
\hline $1.5400 \mathrm{E}-01$ & 4.45450 & 0.59 \\
\hline $1.5500 \mathrm{E}-01$ & 4.37310 & 0.60 \\
\hline $1.5600 \mathrm{E}-01$ & 4.32100 & 0.53 \\
\hline $1.5800 \mathrm{E}-01$ & 4.27100 & 0.53 \\
\hline $1.6000 \mathrm{E}-01$ & 4.24840 & 0.58 \\
\hline $1.6125 \mathrm{E}-01$ & 4.23930 & 0.58 \\
\hline $1.6250 \mathrm{E}-01$ & 4.23200 & 0.52 \\
\hline $1.6500 \mathrm{E}-01$ & 4.22040 & 0.49 \\
\hline $1.7000 \mathrm{E}-01$ & 4.20210 & 0.49 \\
\hline
\end{tabular}


TABLE 8.13. C(n,n) CROSS-SECTION (cont.) (linear interpolation in linear-linear scale is recommended)

\begin{tabular}{|c|c|c|}
\hline $\begin{array}{l}\text { Neutron } \\
\text { energy } \\
(\mathrm{MeV})\end{array}$ & $\begin{array}{l}\text { Cross-section } \\
\text { (barn) }\end{array}$ & $\begin{array}{c}\text { Cross-section } \\
\text { uncertainty } \\
(\%)\end{array}$ \\
\hline $1.7500 \mathrm{E}-01$ & 4.18610 & 0.49 \\
\hline $1.8000 \mathrm{E}-01$ & 4.17120 & 0.47 \\
\hline $2.0000 \mathrm{E}-01$ & 4.11590 & 0.46 \\
\hline $2.2500 \mathrm{E}-01$ & 4.04840 & 0.47 \\
\hline $2.5000 \mathrm{E}-01$ & 3.98280 & 0.46 \\
\hline $2.7500 \mathrm{E}-01$ & 3.91820 & 0.46 \\
\hline $3.0000 \mathrm{E}-01$ & 3.85510 & 0.46 \\
\hline $3.2500 \mathrm{E}-01$ & 3.79370 & 0.46 \\
\hline $3.5000 \mathrm{E}-01$ & 3.73380 & 0.46 \\
\hline $3.7500 \mathrm{E}-01$ & 3.67530 & 0.46 \\
\hline $4.0000 \mathrm{E}-01$ & 3.61820 & 0.46 \\
\hline $4.2500 \mathrm{E}-01$ & 3.56260 & 0.46 \\
\hline $4.5000 \mathrm{E}-01$ & 3.50820 & 0.46 \\
\hline 4.7500E-01 & 3.45510 & 0.46 \\
\hline $5.0000 \mathrm{E}-01$ & 3.40330 & 0.54 \\
\hline $5.2500 \mathrm{E}-01$ & 3.35270 & 0.54 \\
\hline $5.5000 \mathrm{E}-01$ & 3.30320 & 0.54 \\
\hline $5.7500 \mathrm{E}-01$ & 3.25490 & 0.54 \\
\hline $6.0000 \mathrm{E}-01$ & 3.20760 & 0.54 \\
\hline $6.2500 \mathrm{E}-01$ & 3.16150 & 0.54 \\
\hline $6.5000 \mathrm{E}-01$ & 3.11630 & 0.54 \\
\hline $6.7500 \mathrm{E}-01$ & 3.07220 & 0.54 \\
\hline 7.0000E-01 & 3.02900 & 0.54 \\
\hline $7.2500 \mathrm{E}-01$ & 2.98680 & 0.54 \\
\hline $7.5000 \mathrm{E}-01$ & 2.94540 & 0.54 \\
\hline 7.7500E-01 & 2.90500 & 0.54 \\
\hline $8.0000 \mathrm{E}-01$ & 2.86540 & 0.54 \\
\hline $8.2500 \mathrm{E}-01$ & 2.82670 & 0.54 \\
\hline $8.5000 \mathrm{E}-01$ & 2.78880 & 0.54 \\
\hline $8.7500 \mathrm{E}-01$ & 2.75170 & 0.54 \\
\hline $9.0000 \mathrm{E}-01$ & 2.71540 & 0.54 \\
\hline $9.2500 \mathrm{E}-01$ & 2.67980 & 0.54 \\
\hline $9.5000 \mathrm{E}-01$ & 2.64500 & 0.54 \\
\hline $9.7500 \mathrm{E}-01$ & 2.61080 & 0.54 \\
\hline $1.0000 \mathrm{E}+00$ & 2.57740 & 0.68 \\
\hline $1.0250 \mathrm{E}+00$ & 2.54460 & 0.68 \\
\hline $1.0500 \mathrm{E}+00$ & 2.51250 & 0.77 \\
\hline $1.0530 \mathrm{E}+00$ & 2.50870 & 0.68 \\
\hline $1.0750 \mathrm{E}+00$ & 2.48110 & 0.68 \\
\hline
\end{tabular}

TABLE 8.13. C(n,n) CROSS-SECTION (cont.) (linear interpolation in linear-linear scale is recommended)

\begin{tabular}{|c|c|c|}
\hline $\begin{array}{l}\text { Neutron } \\
\text { energy } \\
(\mathrm{MeV})\end{array}$ & $\begin{array}{c}\text { Cross-section } \\
\text { (barn) }\end{array}$ & $\begin{array}{c}\text { Cross-section } \\
\text { uncertainty } \\
(\%)\end{array}$ \\
\hline $1.1000 \mathrm{E}+00$ & 2.45030 & 0.68 \\
\hline $1.1250 \mathrm{E}+00$ & 2.42010 & 0.68 \\
\hline $1.1500 \mathrm{E}+00$ & 2.39050 & 0.68 \\
\hline $1.1750 \mathrm{E}+00$ & 2.36150 & 0.68 \\
\hline $1.2000 \mathrm{E}+00$ & 2.33310 & 0.68 \\
\hline $1.2250 \mathrm{E}+00$ & 2.30520 & 0.68 \\
\hline $1.2500 \mathrm{E}+00$ & 2.27790 & 0.68 \\
\hline $1.2750 \mathrm{E}+00$ & 2.25110 & 0.68 \\
\hline $1.3000 \mathrm{E}+00$ & 2.22490 & 0.68 \\
\hline $1.3250 \mathrm{E}+00$ & 2.19910 & 0.68 \\
\hline $1.3500 \mathrm{E}+00$ & 2.17390 & 0.68 \\
\hline $1.3750 \mathrm{E}+00$ & 2.14920 & 0.68 \\
\hline $1.4000 \mathrm{E}+00$ & 2.12500 & 0.68 \\
\hline $1.4250 \mathrm{E}+00$ & 2.10120 & 0.68 \\
\hline $1.4500 \mathrm{E}+00$ & 2.07800 & 0.68 \\
\hline $1.4750 \mathrm{E}+00$ & 2.05520 & 0.68 \\
\hline $1.5000 \mathrm{E}+00$ & 2.03280 & 0.74 \\
\hline $1.5250 \mathrm{E}+00$ & 2.01050 & 0.74 \\
\hline $1.5500 \mathrm{E}+00$ & 1.98880 & 0.89 \\
\hline $1.5530 \mathrm{E}+00$ & 1.98620 & 0.75 \\
\hline $1.5750 \mathrm{E}+00$ & 1.96740 & 0.75 \\
\hline $1.6000 \mathrm{E}+00$ & 1.94650 & 0.74 \\
\hline $1.6250 \mathrm{E}+00$ & 1.92590 & 0.74 \\
\hline $1.6500 \mathrm{E}+00$ & 1.90590 & 0.75 \\
\hline $1.6750 \mathrm{E}+00$ & 1.88580 & 0.83 \\
\hline $1.6800 \mathrm{E}+00$ & 1.88190 & 0.75 \\
\hline $1.7000 \mathrm{E}+00$ & 1.86550 & 0.78 \\
\hline $1.7100 \mathrm{E}+00$ & 1.85740 & 0.83 \\
\hline $1.7150 \mathrm{E}+00$ & 1.85370 & 0.83 \\
\hline $1.7200 \mathrm{E}+00$ & 1.85070 & 0.83 \\
\hline $1.7250 \mathrm{E}+00$ & 1.85010 & 0.83 \\
\hline $1.7300 \mathrm{E}+00$ & 1.85470 & 0.96 \\
\hline $1.7320 \mathrm{E}+00$ & 1.85830 & 0.96 \\
\hline $1.7340 \mathrm{E}+00$ & 1.86160 & 0.96 \\
\hline $1.7360 \mathrm{E}+00$ & 1.86250 & 0.96 \\
\hline $1.7380 \mathrm{E}+00$ & 1.85980 & 0.96 \\
\hline $1.7400 \mathrm{E}+00$ & 1.85440 & 0.83 \\
\hline $1.7450 \mathrm{E}+00$ & 1.84080 & 0.83 \\
\hline $1.7500 \mathrm{E}+00$ & 1.83270 & 0.83 \\
\hline
\end{tabular}


TABLE 8.13. C(n,n) CROSS-SECTION (cont.) (linear interpolation in linear-linear scale is recommended)

\begin{tabular}{lcc}
\hline $\begin{array}{l}\text { Neutron } \\
\text { energy } \\
(\mathrm{MeV})\end{array}$ & $\begin{array}{c}\text { Cross-section } \\
\text { (barn) }\end{array}$ & $\begin{array}{c}\text { Cross-section } \\
\text { uncertainty } \\
(\%)\end{array}$ \\
\hline $1.7550 \mathrm{E}+00$ & 1.82800 & 0.83 \\
$1.7600 \mathrm{E}+00$ & 1.82440 & 0.78 \\
$1.7700 \mathrm{E}+00$ & 1.81800 & 0.83 \\
$1.7750 \mathrm{E}+00$ & 1.81470 & 0.83 \\
----------------------
\end{tabular}

TABLE 8.13. C(n,n) CROSS-SECTION (cont.) (linear interpolation in linear-linear scale is recommended)

\begin{tabular}{lcc}
\hline $\begin{array}{l}\text { Neutron } \\
\text { energy } \\
(\mathrm{MeV})\end{array}$ & $\begin{array}{c}\text { Cross-section } \\
\text { (barn) }\end{array}$ & $\begin{array}{c}\text { Cross-section } \\
\text { uncertainty } \\
(\%)\end{array}$ \\
\hline $1.7800 \mathrm{E}+00$ & 1.81150 & 0.78 \\
$1.7900 \mathrm{E}+00$ & 1.80480 & 0.78 \\
$1.8000 \mathrm{E}+00$ & 1.79800 & 0.72 \\
\hline
\end{tabular}

TABLE 8.14. LEGENDRE POLYNOMIAL COEFFICIENTS IN THE CENTRE OF MASS SYSTEM FOR THE ANGULAR DISTRIBUTION OF NEUTRONS FROM THE C(n,n) REACTION

(linear interpolation in linear-linear scale is recommended)

\begin{tabular}{|c|c|c|c|c|c|}
\hline $\begin{array}{l}\text { Neutron } \\
\text { energy } \\
(\mathrm{MeV})\end{array}$ & $a_{1}$ & $a_{2}$ & $a_{3}$ & $a_{4}$ & $a_{5}$ \\
\hline $1.0000 \mathrm{E}-11$ & 0.0000 & & & & \\
\hline $1.0000 \mathrm{E}-03$ & $1.401 \mathrm{E}-04$ & & & & \\
\hline $5.0000 \mathrm{E}-03$ & $6.982 \mathrm{E}-04$ & & & & \\
\hline 1.0000E-02 & $1.372 \mathrm{E}-03$ & 0.0000 & & & \\
\hline $5.0000 \mathrm{E}-02$ & 6.603E-03 & 7.423E-05 & & & \\
\hline $1.0000 \mathrm{E}-01$ & $1.246 \mathrm{E}-02$ & $2.801 \mathrm{E}-04$ & & & \\
\hline $1.1000 \mathrm{E}-01$ & $1.340 \mathrm{E}-02$ & $3.524 \mathrm{E}-04$ & & & \\
\hline $1.2000 \mathrm{E}-01$ & $1.425 \mathrm{E}-02$ & $4.298 \mathrm{E}-04$ & & & \\
\hline $1.3000 \mathrm{E}-01$ & $1.491 \mathrm{E}-02$ & $5.240 \mathrm{E}-04$ & & & \\
\hline $1.4000 \mathrm{E}-01$ & $1.512 \mathrm{E}-02$ & 7.039E-04 & & & \\
\hline $1.4500 \mathrm{E}-01$ & $1.499 \mathrm{E}-02$ & $9.579 \mathrm{E}-04$ & & & \\
\hline 1.4750E-01 & $1.516 \mathrm{E}-02$ & $1.225 \mathrm{E}-03$ & & & \\
\hline $1.5000 \mathrm{E}-01$ & $1.627 \mathrm{E}-02$ & $1.635 \mathrm{E}-03$ & & & \\
\hline $1.5290 \mathrm{E}-01$ & $1.968 \mathrm{E}-02$ & $1.984 \mathrm{E}-03$ & & & \\
\hline $1.5500 \mathrm{E}-01$ & $2.201 \mathrm{E}-02$ & $1.845 \mathrm{E}-03$ & & & \\
\hline $1.5750 \mathrm{E}-01$ & $2.306 \mathrm{E}-02$ & $1.506 \mathrm{E}-03$ & & & \\
\hline $1.6000 \mathrm{E}-01$ & $2.311 \mathrm{E}-02$ & $1.251 \mathrm{E}-03$ & & & \\
\hline $1.6500 \mathrm{E}-01$ & $2.284 \mathrm{E}-02$ & $1.013 \mathrm{E}-03$ & & & \\
\hline $1.7000 \mathrm{E}-01$ & $2.279 \mathrm{E}-02$ & $9.371 \mathrm{E}-04$ & & & \\
\hline $1.7500 \mathrm{E}-01$ & $2.294 \mathrm{E}-02$ & $9.177 \mathrm{E}-04$ & & & \\
\hline $1.8000 \mathrm{E}-01$ & $2.322 \mathrm{E}-02$ & $9.221 \mathrm{E}-04$ & & & \\
\hline $1.9000 \mathrm{E}-01$ & $2.398 \mathrm{E}-02$ & $9.602 \mathrm{E}-04$ & & & \\
\hline 2.0000E-01 & $2.487 \mathrm{E}-02$ & $1.014 \mathrm{E}-03$ & 0.0000 & & \\
\hline $3.0000 \mathrm{E}-01$ & $3.390 \mathrm{E}-02$ & $1.947 \mathrm{E}-03$ & $6.334 \mathrm{E}-05$ & & \\
\hline 4.0000E-01 & 4.149E-02 & $3.012 \mathrm{E}-03$ & $1.281 \mathrm{E}-04$ & & \\
\hline $5.0000 \mathrm{E}-01$ & 4.780E-02 & 4.133E-03 & $2.231 \mathrm{E}-04$ & & \\
\hline
\end{tabular}


TABLE 8.14. LEGENDRE POLYNOMIAL COEFFICIENTS IN THE CENTRE OF MASS SYSTEM FOR THE ANGULAR DISTRIBUTION OF NEUTRONS FROM THE C(n,n) REACTION (cont.)

(linear interpolation in linear-linear scale is recommended)

\begin{tabular}{|c|c|c|c|c|c|}
\hline $\begin{array}{l}\text { Neutron } \\
\text { energy } \\
(\mathrm{MeV})\end{array}$ & $a_{1}$ & $a_{2}$ & $a_{3}$ & $a_{4}$ & $a_{5}$ \\
\hline $6.0000 \mathrm{E}-01$ & $5.315 \mathrm{E}-02$ & $5.274 \mathrm{E}-03$ & $3.477 \mathrm{E}-04$ & 0.0000 & \\
\hline 7.0000E-01 & $5.745 \mathrm{E}-02$ & $6.395 \mathrm{E}-03$ & 4.974E-04 & $-5.641 \mathrm{E}-05$ & \\
\hline $8.0000 \mathrm{E}-01$ & $6.079 \mathrm{E}-02$ & $7.486 \mathrm{E}-03$ & $6.651 \mathrm{E}-04$ & $-1.014 \mathrm{E}-04$ & \\
\hline $9.0000 \mathrm{E}-01$ & $6.323 \mathrm{E}-02$ & $8.554 \mathrm{E}-03$ & $8.402 \mathrm{E}-04$ & $-1.701 \mathrm{E}-04$ & \\
\hline $1.0000 \mathrm{E}+00$ & $6.480 \mathrm{E}-02$ & $9.618 \mathrm{E}-03$ & $1.008 \mathrm{E}-03$ & $-2.705 \mathrm{E}-04$ & \\
\hline $1.1000 \mathrm{E}+00$ & $6.550 \mathrm{E}-02$ & $1.071 \mathrm{E}-02$ & $1.147 \mathrm{E}-03$ & $-4.119 \mathrm{E}-04$ & \\
\hline $1.2000 \mathrm{E}+00$ & $6.536 \mathrm{E}-02$ & $1.188 \mathrm{E}-02$ & $1.235 \mathrm{E}-03$ & $-6.051 \mathrm{E}-04$ & \\
\hline $1.3000 \mathrm{E}+00$ & $6.436 \mathrm{E}-02$ & $1.320 \mathrm{E}-02$ & $1.241 \mathrm{E}-03$ & $-8.620 \mathrm{E}-04$ & 0.0000 \\
\hline $1.4000 \mathrm{E}+00$ & $6.248 \mathrm{E}-02$ & $1.475 \mathrm{E}-02$ & $1.123 \mathrm{E}-03$ & $-1.195 \mathrm{E}-03$ & $6.115 \mathrm{E}-05$ \\
\hline $1.5000 \mathrm{E}+00$ & $5.964 \mathrm{E}-02$ & $1.664 \mathrm{E}-02$ & $8.260 \mathrm{E}-04$ & $-1.616 \mathrm{E}-03$ & $8.829 \mathrm{E}-05$ \\
\hline $1.6000 \mathrm{E}+00$ & $5.578 \mathrm{E}-02$ & $1.897 \mathrm{E}-02$ & $2.492 \mathrm{E}-04$ & $-2.126 \mathrm{E}-03$ & $1.248 \mathrm{E}-04$ \\
\hline $1.6500 \mathrm{E}+00$ & $5.329 \mathrm{E}-02$ & $2.040 \mathrm{E}-02$ & $-2.552 \mathrm{E}-04$ & $-2.416 \mathrm{E}-03$ & $1.488 \mathrm{E}-04$ \\
\hline $1.6800 \mathrm{E}+00$ & $5.181 \mathrm{E}-02$ & $2.117 \mathrm{E}-02$ & $-5.907 \mathrm{E}-04$ & $-2.579 \mathrm{E}-03$ & $1.632 \mathrm{E}-04$ \\
\hline $1.7000 \mathrm{E}+00$ & $5.077 \mathrm{E}-02$ & $2.158 \mathrm{E}-02$ & $-8.679 \mathrm{E}-04$ & $-2.659 \mathrm{E}-03$ & $1.728 \mathrm{E}-04$ \\
\hline $1.7100 \mathrm{E}+00$ & 4.995E-02 & $2.185 \mathrm{E}-02$ & $-1.115 \mathrm{E}-03$ & $-2.661 \mathrm{E}-03$ & $1.790 \mathrm{E}-04$ \\
\hline $1.7200 \mathrm{E}+00$ & $4.879 \mathrm{E}-02$ & 2.244E-02 & $-1.387 \mathrm{E}-03$ & $-2.582 \mathrm{E}-03$ & $1.851 \mathrm{E}-04$ \\
\hline $1.7300 \mathrm{E}+00$ & $4.761 \mathrm{E}-02$ & $2.426 \mathrm{E}-02$ & $-1.410 \mathrm{E}-03$ & $-2.435 \mathrm{E}-03$ & $1.912 \mathrm{E}-04$ \\
\hline $1.7360 \mathrm{E}+00$ & 4.763E-02 & $2.514 \mathrm{E}-02$ & $-1.195 \mathrm{E}-03$ & $-2.454 \mathrm{E}-03$ & $1.949 \mathrm{E}-04$ \\
\hline $1.7400 \mathrm{E}+00$ & $4.771 \mathrm{E}-02$ & $2.509 \mathrm{E}-02$ & $-1.052 \mathrm{E}-03$ & $-2.525 \mathrm{E}-03$ & 1.973E-04 \\
\hline $1.7450 \mathrm{E}+00$ & 4.747E-02 & $2.455 \mathrm{E}-02$ & $-9.699 \mathrm{E}-04$ & $-2.661 \mathrm{E}-03$ & 2.004E-04 \\
\hline $1.7500 \mathrm{E}+00$ & $4.693 \mathrm{E}-02$ & $2.411 \mathrm{E}-02$ & $-1.024 \mathrm{E}-03$ & $-2.804 \mathrm{E}-03$ & $2.035 \mathrm{E}-04$ \\
\hline $1.7550 \mathrm{E}+00$ & 4.639E-02 & $2.402 \mathrm{E}-02$ & $-1.150 \mathrm{E}-03$ & $-2.917 \mathrm{E}-03$ & $2.065 \mathrm{E}-04$ \\
\hline $1.7600 \mathrm{E}+00$ & $4.596 \mathrm{E}-02$ & $2.415 \mathrm{E}-02$ & $-1.287 \mathrm{E}-03$ & $-2.997 \mathrm{E}-03$ & $2.096 \mathrm{E}-04$ \\
\hline $1.7700 \mathrm{E}+00$ & $4.529 \mathrm{E}-02$ & 2.459E-02 & $-1.529 \mathrm{E}-03$ & $-3.104 \mathrm{E}-03$ & $2.157 \mathrm{E}-04$ \\
\hline $1.7800 \mathrm{E}+00$ & $4.469 \mathrm{E}-02$ & $2.504 \mathrm{E}-02$ & $-1.737 \mathrm{E}-03$ & $-3.183 \mathrm{E}-03$ & $2.219 \mathrm{E}-04$ \\
\hline $1.7900 \mathrm{E}+00$ & 4.409E-02 & $2.546 \mathrm{E}-02$ & $-1.926 \mathrm{E}-03$ & $-3.252 \mathrm{E}-03$ & $2.280 \mathrm{E}-04$ \\
\hline $1.8000 \mathrm{E}+00$ & $4.348 \mathrm{E}-02$ & $2.586 \mathrm{E}-02$ & $-2.104 \mathrm{E}-03$ & $-3.317 \mathrm{E}-03$ & 2.341E-04 \\
\hline
\end{tabular}




\title{
9. JUSTIFICATION FOR RECOMMENDED UNCERTAINTIES
}

\author{
V.G. Pronyaev, S.A. Badikov, A.D. Carlson, Chen Zhenpeng, E.V. Gai, G.M. Hale, F.-J. Hambsch, \\ H.M. Hofmann, T. Kawano, N.M. Larson, D.L. Smith, Soo-Youl Oh, S. Tagesen, H. Vonach
}

\subsection{LOW UNCERTAINTIES FOR EVALUATED DATA}

The uncertainties obtained in an earlier standards evaluation $[9.1,9.2]$ were considered to be unrealistically low by experts of the US Cross Section Evaluation Working Group (CSEWG) $[9.2,9.3]$. Therefore, the CSEWG Standards Subcommittee replaced the covariance matrices of evaluated uncertainties by expanded percentage errors that were assigned to the data over wide energy groups. These changes were justified as follows: "these uncertainties are estimates such that if modern day experiments were performed today on a given standard using the best techniques, those results should fall within these expanded uncertainties $\left(2 / 3^{\text {rds }}\right.$ of the time). They take into account inconsistencies and concerns about R-matrix parameters. Note that it is not assumed that the uncertainties are totally correlated within the energy ranges given" $[9.2,9.3]$. Unfortunately, an estimate of the correlations was not given by the CSEWG experts, and the evaluated standards were released without any covariance matrices of the uncertainties.

There are a number of reasons that might lead to low uncertainties of the evaluated data:

(a) Underestimation of the correlations existing between the results of different measurements. Use of common samples, detectors and experimental facilities for different measurements can lead to $100 \%$ correlations for these components of the uncertainties in the results of different measurements. These correlations were very thoroughly analysed by Poenitz when data were entered (and updated) in the GMA database. Sets of experimental data obtained by the same group or at the same facility are usually combined in data blocks that account for the correlations between data sets.

(b) The presence of unrecognized 'systematic' uncertainties in the experimental data can lead to biases in the evaluated data as well as to underestimations of the resulting uncertainties. Discrepancies between different measurements show that some results contain unknown systematic uncertainties, and there are different types of data measured by disparate methods in the standards database. Outlying data relative to unknown true values can be identified as possessing unrecognized systematic uncertainties. Thus the additional component of the uncertainty assigned to these experimental data will increase the uncertainties of the evaluated data. Differences between experimental and evaluated data that are larger than their uncertainties should be analysed for each such data point since such 'local' discrepancies may affect the global $\chi^{2}$ value per degree of freedom. Data with large uncertainties were normally found to be the outliers in the case of the standards, and introducing an additional component of uncertainty to these data only increased the uncertainty of the evaluated data by a small amount (see Section 3 for details).

(c) Uncertainties for correlated data cannot be only characterized by percentage uncertainties or variances. The full covariance matrix should be analysed: large differences arise in the covariance matrices of evaluated data obtained with a mathematical or physical model and non-model (non-parametric) fits of the same experimental data. Strong correlations occur between points that are close to each other, the variances in the model fit are substantially reduced and near-diagonal covariances are increased by model fits compared with non-model fits. Although there is no known analytical proof, if the model and non-model fits of the same experimental data are close, the sum of all elements of the covariance matrices of the evaluated data for the non-model fit and those calculated at the same nodes from the covariance matrix of parameters evaluated in the model fit has been found to be also close in trial cases. This sum can be interpreted as the global measure of the uncertainty of the data [9.4], and can be used for comparisons of the uncertainties obtained in different least squares fits of the 
same experimental data; for example, the line of covariance matrices obtained in two different model and non-model fits of TEST1 data for the ${ }^{6} \mathrm{Li}(\mathrm{n}, \mathrm{t})$ reaction is shown in Fig. 9.1, and contains the variance at $0.2 \mathrm{MeV}$. The 'sum rule' referred to above for the elements of a covariance matrix in different fits even appears to work for a single line (or row) of a covariance matrix of uncertainty. From the data shown in Fig. 9.1, the value of the sum for a line (row) is $0.01116 \mathrm{~b}^{2}$ for GMA, $0.01119 b^{2}$ for RAC and $0.01101 b^{2}$ for PADE2 fits, but the differences between the model and non-model covariances and variances are large. A large variance in the non-model fit is compensated by higher covariances near the diagonal of the covariance matrix of the uncertainties in the model fit. The Appendix contains a rigorous analysis of the properties of the covariance matrices and the overall uncertainty measures that can be built into the model and nonmodel least squares fits.

A rather large source of uncertainty reduction in fits by the $\mathrm{R}$ matrix procedure involves the use of experimental reaction data that are coupled with the standard reaction through the model. These data include all integral and differential crosssections and polarizations for reactions that form the same compound system as for the standard reaction. Experimental data describing differential elastic scattering cross-sections of charged particles have very low assigned uncertainties (2\%) that

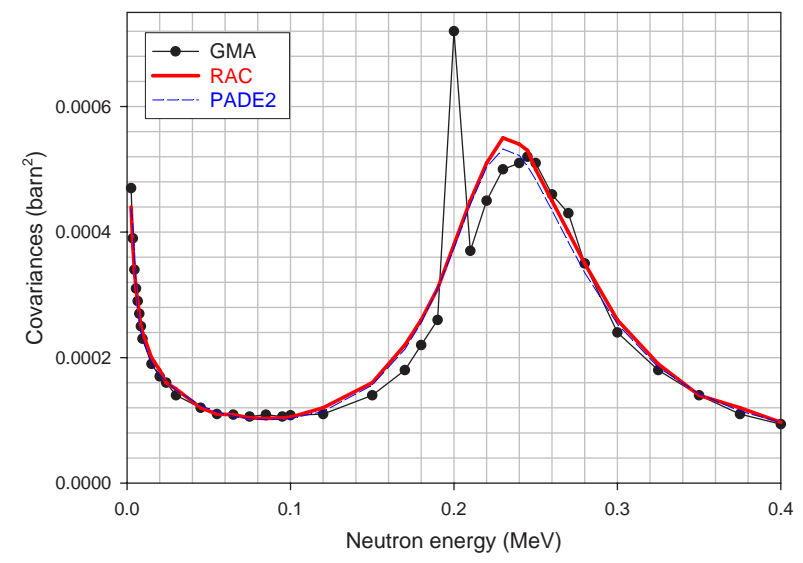

FIG. 9.1. Covariances between evaluated value at $0.2 \mathrm{MeV}$ and other points (line of the matrix elements) obtained in model (RAC R matrix and PADE2 analytical expansion) and non-model (GMA) fits of the ${ }^{6} \operatorname{Li}(n, t)$ TEST1 data. propagate to give low uncertainties for the integral standard reactions. Additional physical model constraints imposed by the laws of conservation also lead to reductions in the uncertainties.

EDA and RAC R matrix model fits use different expressions for the $\chi^{2}$ minimized function. The RAC expression is based on full implementation of the error propagation law, while the EDA $\chi^{2}$ is defined as the coherent sum of the statistical and normalization (systematic or long range energy correlation) components of the uncertainties. This difference leads to non-equivalent evaluated uncertainties, as well as some ambiguity in the evaluated parameters and cross-sections. Comparisons of the correlation coefficients and covariances obtained from the EDA and RAC fits of all the experimental data available for the ${ }^{7} \mathrm{Li}$ system are shown in Figs 9.2 and 9.3, and percentage uncertainties for

(a)

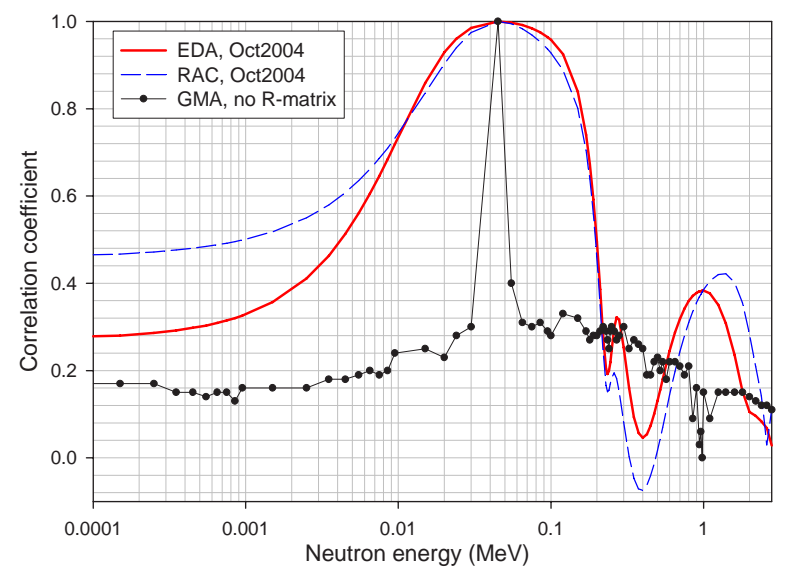

(b)

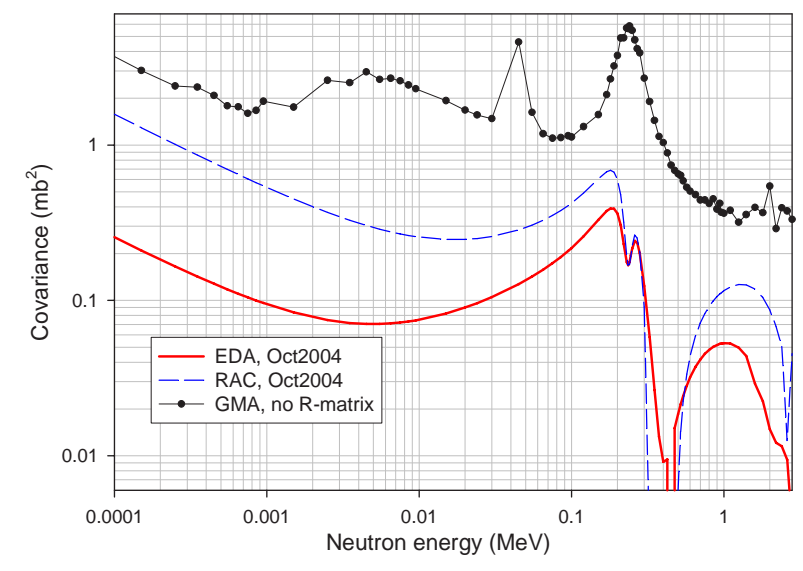

FIG. 9.2. Correlation coefficients (a) and covariances (b) between the evaluated value at $0.045 \mathrm{MeV}$ and other points (along the line or column of the matrix) as obtained in EDA and RAC $R$ matrix fits of the data available for reactions that pass through the formation of the ${ }^{7} \mathrm{Li}$ system. The GMA fit with the GMA database is shown for comparison. 
(a)

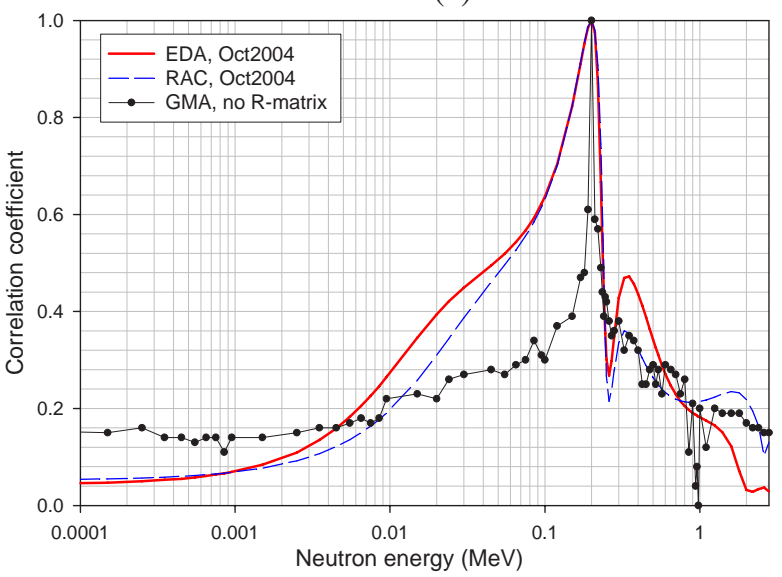

(b)

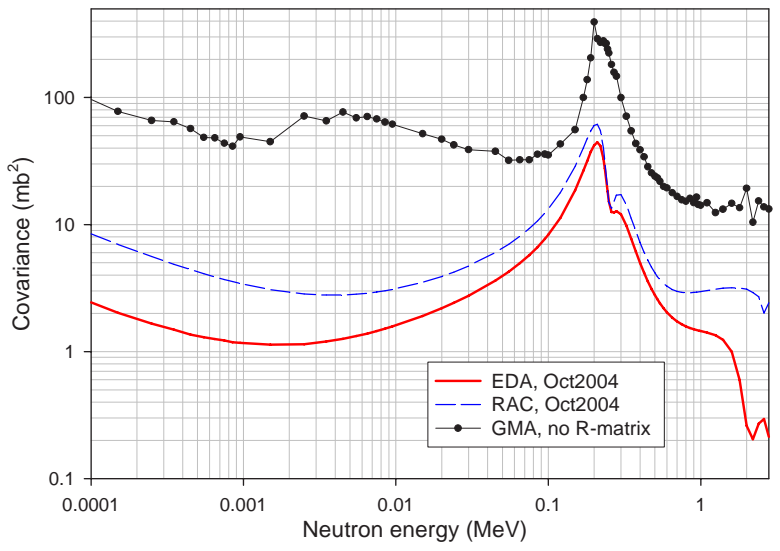

FIG. 9.3. Correlation coefficients (a) and covariances (b) between the evaluated value at $0.2 \mathrm{MeV}$ and other points (along the line or column of the matrix) as obtained in $E D A$ and RAC $R$ matrix fits of the data available for reactions that pass through the formation of the ${ }^{7}$ Li system. The GMA fit with the GMA database is shown for comparison.

the two fits are shown in Fig. 9.4. The percentage uncertainties (variances) evaluated with RAC are shown to be larger than equivalent data evaluated with EDA - this observation cannot be explained in terms of the reduced expression for the $\chi^{2}$ function used in the minimization for EDA (see the results of Test $2 b$ in Section 2). Rather, this difference is caused by different assignments of the uncertainties to the experimental data, and especially to the angular distributions of the secondary particles used in R matrix fits. RAC takes account of uncertainty components with different degrees of correlation, leading to covariance matrices for the experimental data that possess larger uncertainties. Correlations and covariances obtained with a GMA fit of all data from the GMA database are also shown in Figs 9.2 and 9.3 for

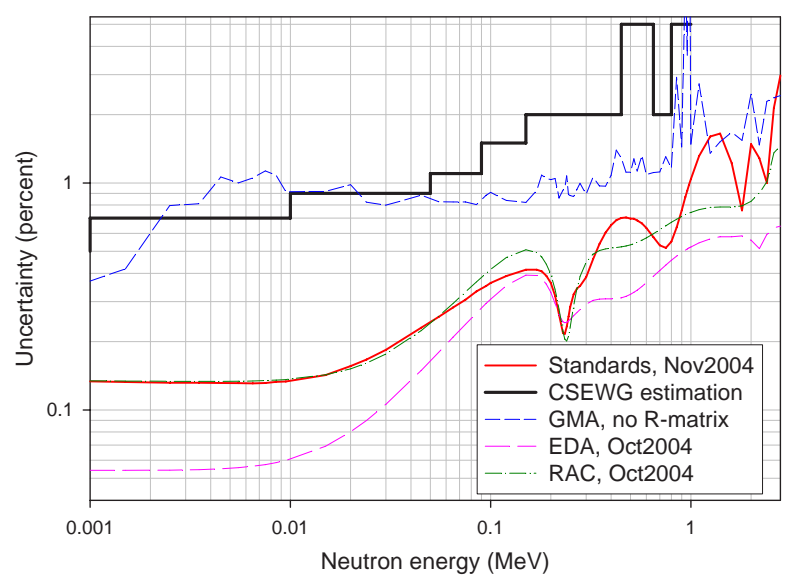

FIG. 9.4. Percentage uncertainties of the evaluated crosssection for the ${ }^{6} \mathrm{Li}(n, t)$ reaction. Thick solid line histogram: estimation given by CSEWG experts; short dashed line: GMA result with full GMA database, including experimental data for the ${ }^{6} \mathrm{Li}(n, t),{ }^{6} \mathrm{Li}(n, n)$ and ${ }^{6} \mathrm{Li}(n$, total $)$ reactions; thin solid line: uncertainties in the GMA combined fit for the standards; long dashed and dot dashed lines: EDA and RAC R matrix results, respectively.

comparison. While the GMA database contains data that are not accommodated in the $\mathrm{R}$ matrix fit (ratios to other cross-sections), these additional data cannot compensate for the reduction of uncertainties in the $\mathrm{R}$ matrix fit due to the inclusion of channels not adopted in the non-model fit and conservation laws.

\subsection{RECOMMENDED UNCERTAINTIES: ARE THEY REALISTIC?}

Figures 9.4 and 9.5 show the results of comparisons of the percentage uncertainties obtained in the $\mathrm{R}$ matrix model fit for ${ }^{6} \mathrm{Li}(\mathrm{n}, \mathrm{t})$ and non-model fit for ${ }^{235} \mathrm{U}(\mathrm{n}, \mathrm{f})$ reactions, along with CSEWG estimates and the combined fit. Percentage uncertainties in the GMA combined fit are about four times less than the experts' estimate for the ${ }^{6} \mathrm{Li}(\mathrm{n}, \mathrm{t})$, and two to four times lower for the ${ }^{235} \mathrm{U}(\mathrm{n}, \mathrm{f})$ reaction. These differences can be explained and justified in the context of the available experimental data and methods used in the present evaluation project.

The GMA fit for the ${ }^{6} \mathrm{Li}(\mathrm{n}, \mathrm{t})$ reaction without the inclusion of the $\mathrm{R}$ matrix results supports the estimation given by the CSEWG experts for energies less than $0.1 \mathrm{MeV}$, but is below the estimates over the range from 0.1 to $1 \mathrm{MeV}$. This 
difference can be partially explained by using additional data in the GMA fit (ten sets with total, elastic scattering cross-sections, and 28 sets with absolute and shape cross-section ratios to other reactions) that were possibly not considered by the experts. Uncertainties below $0.01 \mathrm{MeV}$ in the $\mathrm{R}$ matrix model fit are based on an uncertainty of $0.2 \%$ in the pre-evaluated thermal value for ${ }^{6} \mathrm{Li}(\mathrm{n}, \mathrm{t})$. Due to the strong model correlations (more than $99.95 \%$ ), this low uncertainty propagates through the $1 / v$ region along with other available experimental data to reduce the uncertainties further to $0.136 \%$ in RAC and to $0.055 \%$ in the EDA fits. An increase in the evaluated uncertainties over this energy range can only be justified through an increase in the pre-evaluated thermal value or by the observation of a deviation from $1 / v$ dependence. The $\mathrm{R}$ matrix uncertainties increase with energy above $0.01 \mathrm{MeV}$, but are still well below the nonmodel GMA fit and the experts' estimate because of two influential factors discussed above: reduction of variances in the model versus a non-model fit due to intrinsic model correlations; and inclusion in the $\mathrm{R}$ matrix fits of a large number of other differential and integral experimental data not accounted for by either GMA or the CSEWG experts.

An additional point of note should be borne in mind when we consider the uncertainties obtained by means of the R matrix fit. CSEWG experts refer to this factor as "inconsistencies and concerns about R-matrix parameters". Within multiparameter searches, the $\chi^{2}$ surface can be very complex, and there is no guarantee that the results represent global minima. Different treatments of the experimental data can also contribute to the ambiguity of the R matrix parameters. Only the EDA code was used in the previous standards evaluations, and the uncertainties proved difficult to estimate because of possible ambiguities in the $\mathrm{R}$ matrix fit. Present evaluation results of $\mathrm{R}$ matrix fits of the same data with EDA and RAC were compared, and the differences in experimental data presentation and treatment were removed when possible. Results of two fits are shown in Fig. 9.6 as ratios to the earlier evaluation in the region where the data are recommended as standards (below 1.0 MeV). The non-weighted average between the two fits was taken to be the final $\mathrm{R}$ matrix result, and half the difference between the fits was taken as an additional component of the uncertainties added quadratically to the total RAC uncertainty. The RAC correlation matrix is not too different from that of EDA, and was used in the combined fit. This

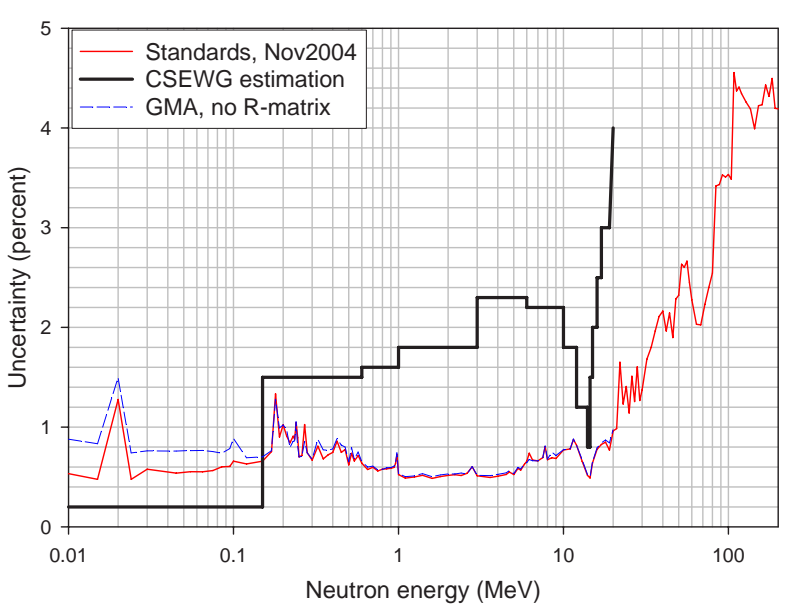

FIG. 9.5. Percentage uncertainties of the evaluated crosssection for the ${ }^{235} U(n, f)$ reaction. Thick solid line histogram: estimation given by CSEWG experts; short dashed line: GMA result with full GMA database, including experimental data for reactions induced by neutrons on ${ }^{6} \mathrm{Li}$ and ${ }^{10} \mathrm{~B}$; thin solid line: GMA combined fit for the standards.

component is interpreted as the uncertainty arising from the ambiguity in the $\mathrm{R}$ matrix fit. After the combined fit (Fig. 9.4), the total uncertainty in the standards region for the ${ }^{6} \mathrm{Li}(\mathrm{n}, \mathrm{t})$ cross-section is from about $0.5 \%$ to $1 \%$, excluding the $1 / v$ region and the area near the resonance at about $0.245 \mathrm{MeV}$. A non-model fit of the data by means of the GMA code and the database exhibited strong non-smooth fluctuations, with significant changes in

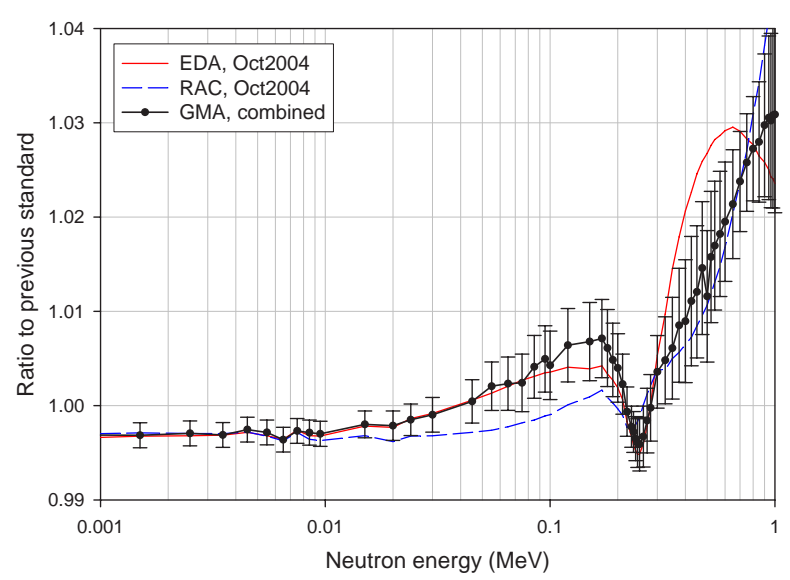

FIG. 9.6. Results of EDA and RAC $R$ matrix fits of the ${ }^{6} \mathrm{Li}(n, t)$ reaction cross-section, and GMA combined fit expressed as ratios to the previous standard evaluation. Solid line: EDA fit; dashed line: RAC fit; line with dots and uncertainty range: GMA combined fit. 
the evaluated values that encompassed their uncertainties. Thus the use of the $\mathrm{R}$ matrix approach improves the evaluation substantially, and generates justifiable uncertainties.

Low uncertainties obtained in the $\mathrm{R}$ matrix fit for the ${ }^{6} \mathrm{Li}(\mathrm{n}, \mathrm{t}),{ }^{10} \mathrm{~B}\left(\mathrm{n}, \mathrm{\alpha}_{0}\right)$ and ${ }^{10} \mathrm{~B}\left(\mathrm{n}, \mathrm{\alpha}_{1}\right)$ reactions have only a small effect on the reduction in the uncertainties of other standards because of the relatively high uncertainties of the cross-section ratios used in the combined fit. As seen in Fig. 9.5, inclusion of the ${ }^{6} \mathrm{Li}(\mathrm{n}, \mathrm{t}) \mathrm{R}$ matrix result in the GMA combined fit affects only the ${ }^{235} \mathrm{U}(\mathrm{n}, \mathrm{f})$ cross-sections below $0.1 \mathrm{MeV}$. Above $0.1 \mathrm{MeV}$, the uncertainty of the ${ }^{235} \mathrm{U}(\mathrm{n}, \mathrm{f})$ cross-section obtained from the GMA combined fit (Standards, Nov2004) is not sensitive to the uncertainty of the $\mathrm{R}$ matrix evaluations for the ${ }^{6} \mathrm{Li}(\mathrm{n}, \mathrm{t}),{ }^{10} \mathrm{~B}\left(\mathrm{n}, \alpha_{0}\right)$ and ${ }^{10} \mathrm{~B}\left(\mathrm{n}, \alpha_{1}\right)$ reactions. The low uncertainties obtained from the GMA combined fit of the ${ }^{235} \mathrm{U}(\mathrm{n}, \mathrm{f})$ cross-section (e.g. $0.5-0.8 \%$ for neutron energies between 0.5 and 10 $\mathrm{MeV})$ are the consequence of low uncertainties assigned by the experimentalists to the results of their absolute cross-section measurements. This same behaviour occurs at $14 \mathrm{MeV}$, where no large difference between the GMA result and the experts' estimation is observed.

Uncertainties at a level of $0.5 \%$ need to be justified over the 1-2 MeV energy region. Table 9.1 lists measurement uncertainties for the absolute cross-sections in this region, along with deviations between the measured and evaluated values (see also Fig. 9.7(a)). As can be seen from Table 9.1, there is good consistency between these data and their uncertainties, apart from data set 580 (2-4\% higher cross-section below $1.4 \mathrm{MeV}$, and a clear outlier). An additional component of uncertainty was assigned to this data set from 1 to $1.4 \mathrm{MeV}$ to achieve greater consistency. Assuming with some confidence that there are probably no unaccounted for correlations between all of these data and that the integral and cross-section shape and ratio data contribute to a further reduction in the uncertainties, we conclude that a least squares fit decreases the uncertainty of the evaluated data to about $0.6 \%$.

TABLE 9.1. UNCERTAINTIES OF ABSOLUTE AND ${ }^{252} \mathrm{Cf}$ FISSION SPECTRUM AVERAGED CROSSSECTION MEASUREMENTS, AND DEVIATIONS BETWEEN MEASURED AND EVALUATED VALUES FOR ${ }^{235} \mathrm{U}(\mathrm{n}, \mathrm{f})$ CROSS-SECTIONS IN THE NEUTRON ENERGY RANGE 1-2 MeV

\begin{tabular}{|c|c|c|c|c|c|}
\hline $\begin{array}{l}\text { GMA } \\
\text { data set } \\
\text { No. }\end{array}$ & Type of data & First author & Year & $\begin{array}{l}\text { Total percentage } \\
\text { uncertainty ( } \%)\end{array}$ & $\begin{array}{c}\text { Deviation from } \\
\text { posterior evaluatec } \\
\text { value }(\%)\end{array}$ \\
\hline 500 & Absolute cross-section & White & 1965 & 2.5 & +2.4 \\
\hline 505 & Absolute cross-section & Szabo & 1973 & $3.0-3.1$ & -0.9 to +3.5 \\
\hline 580 & Absolute cross-section & Barton & 1976 & $1.2-1.5$ & -2.1 to +4.8 \\
\hline 576 & $\begin{array}{l}\text { Spectrum averaged } \\
\text { cross-section }\end{array}$ & Heaton & 1976 & 1.64 & -0.58 \\
\hline 554 & Absolute cross-section & Poenitz & 1977 & $2.0-3.0$ & -3.1 to -0.4 \\
\hline 565 & $\begin{array}{l}\text { Spectrum averaged } \\
\text { cross-section }\end{array}$ & Davis & 1978 & 2.0 & -0.66 \\
\hline 570 & Absolute cross-section & Wasson & 1981 & $2.1-2.3$ & -1.6 to +0.7 \\
\hline 575 & $\begin{array}{l}\text { Spectrum averaged } \\
\text { cross-section }\end{array}$ & Adamov & 1982 & 1.6 & +2.53 \\
\hline 523 & Absolute cross-section & Carlson & 1984 & $1.8-2.0$ & -0.7 to +1.0 \\
\hline 517 & $\begin{array}{l}\text { Spectrum averaged } \\
\text { cross-section }\end{array}$ & Schroeder & 1984 & 1.46 & +0.89 \\
\hline 1025 & Absolute cross-section & Carlson & 1991 & $1.9-2.2$ & -1.8 to -0.6 \\
\hline 1026 & Absolute cross-section & Kalinin & 1991 & 2.3 & +0.3 \\
\hline
\end{tabular}


The experimental data shown in Fig. 9.7(a) have been reduced to the nodes used in the GMA non-model fit. Twenty-seven (or slightly more than two thirds) of the 37 data points fall within the corridor of the expert based uncertainties, and about 11 within the corridor of the present standards evaluation. If we define 1980 as the beginning of 'modern day experiments', the spread of experimental data is much less (Fig. 9.7(b)). All 17 data points lie within the uncertainties limits estimated by the CSEWG experts, and ten fall within or are very close to the uncertainty corridor of the standards evaluation.

Taking into account many other types of data (integral, shape and ratio) that contribute to the reduction of the uncertainties of the ${ }^{235} \mathrm{U}(\mathrm{n}, \mathrm{f})$ crosssection in the GMA fit, we can conclude that uncertainties between 0.5 and $0.6 \%$ for the evaluated cross-section in the $1-2 \mathrm{MeV}$ energy range can be

(a)

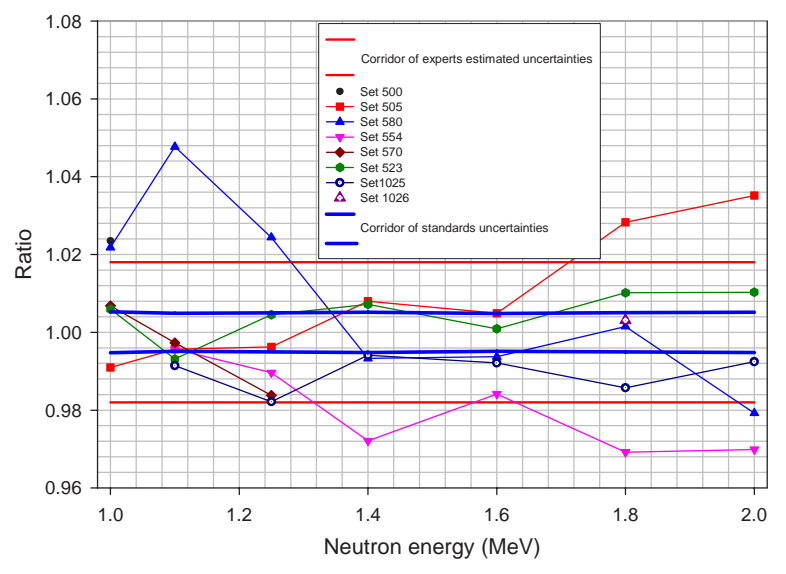

(b)

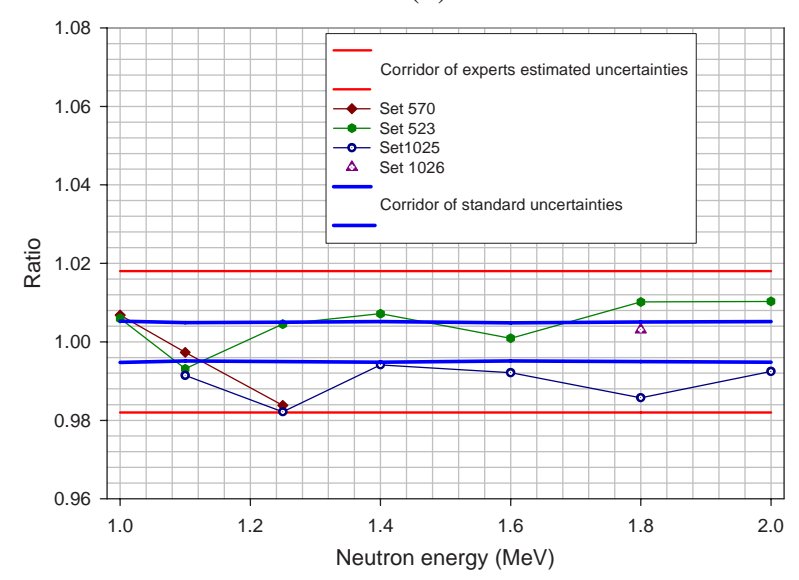

FIG. 9.7. (a) Ratio of all data sets and (b) data after 1980 for the absolute ${ }^{235} U(n, f)$ experimental cross-sections relative to the evaluated values of the standard. Corridors of errors estimated by CSEWG experts and obtained by means of a GMA combined fit are also shown. considered to be realistic estimates. Combined with correlations obtained from standards evaluations, a lower limit of $0.4 \%$ can be assigned with confidence to the uncertainty of the calculated integral data (e.g. fission spectrum averaged cross-sections). An independent conservative estimation of the uncertainties of some standard cross-sections and integral data calculated with these cross-sections show that there is no large difference between the conservative quantitative estimation and the results of the present standards evaluation based on a thorough analysis of all experimental data (see the Appendix). Similar arguments can be made for the small uncertainty of the ${ }^{235} \mathrm{U}(\mathrm{n}, \mathrm{f})$ cross-section in the $14 \mathrm{MeV}$ energy region. This low uncertainty is largely a result of several very accurate associated particle measurements.

Retrospectively, the CSEWG experts' concern about excessively optimistic low errors in the earlier standards evaluation was justified because new experimental data have uncovered and in some cases have resolved existing discrepancies. Furthermore, the effects of PPP were not recognized earlier (see Section 6), and this phenomenon accounted for biases of a few per cent, which were only uncovered and resolved in the present work. Finally, developments in $\mathrm{R}$ matrix analysis have also contributed significant improvements.

The extent to which new measurements and evaluation methodologies will lead to revised results that may differ significantly from the presently recommended data is imponderable. While the present standard values are likely to be closer to the truth than earlier versions, and the given errors are reasonably well justified in the context of contemporary data and evaluation methodology, a healthy open minded attitude remains the most sensible approach, consistent with the fundamental spirit of scientific endeavour and enquiry.

\section{REFERENCES TO SECTION 9}

[9.1] CONDÉ, H. (Ed.), Nuclear Data Standards for Nuclear Measurements, 1991 NEANDC/INDC Nuclear Standards File, Rep. NEANDC-311, INDC(SEC)-101, OECD, Paris (1992).

[9.2] CARLSON, A.D., et al., ENDF/B-VI Neutron Cross Section Measurement Standards, Rep. NISTIR-5177, National Institute of Standards and Technology, Gaithersburg, MD (1993); also ENDF/B-VI Neutron Cross Section Measurement 
Standards, Rep. ENDF-351, Brookhaven Natl Lab., Upton, NY (1993).

[9.3] DUNFORD, C.L., Summary of CSEWG Meeting, Enclosure 3A, 8-10 May 1990, Brookhaven Natl Lab., Upton, NY (1990).
[9.4] PRONYAEV, V.G., BYTCHKOVA, A.V., "Subjective judgment on measure of data uncertainty", Summary Report of the Second Research Coordination Meeting on Improvement of the Standards Cross Sections for Light Elements, Rep. INDC(NDS)-453, IAEA, Vienna (2004) 327-331. 
Appendix

\title{
AMBIGUITIES IN THE UNCERTAINTIES OF CROSS-SECTION DATA
}

\author{
E.V. Gai
}

\section{A.1. INTRODUCTION}

The relationships between the covariance matrices of experimental data and the least squares method of evaluation for any physical or mathematical model (regression equation) have been considered. Uncertainties of some weighted averages of evaluated values are independent of these models. The proximity of the uncertainties of the integral parameters of nuclear reactors to these invariant uncertainties has been assessed and then considered as an argument for the proposed solution of the ambiguity problem - any correctly derived covariance matrix of the evaluated data uncertainties can be used to estimate the uncertainty of the integral parameters.

A crucial aspect of nuclear data evaluation is associated with the selection and correction of the experimental data sets. This exercise is subjective and often results in discrepancies between the recommended data from different libraries. While this important facet of an evaluation will not be discussed in detail, we will investigate some mathematical properties of the subsequent stages of the process.

Evaluations of nuclear data can be performed by means of different methods and different model functions (see, for example, Ref. [A.1]). Naturally, the adoption of different model functions leads to variations in the estimated data; however, with increase in the accuracy of the experimental data, the results of different evaluations tend towards the true values and the estimated data are drawn together. Nevertheless, even for cases in which the estimates obtained in different ways are practically indistinguishable, covariance matrices of their uncertainties can noticeably differ. This observation is obvious for covariance matrices with approximate parameter uncertainties $\mathbf{W}$ :

$$
W_{\alpha, \beta}=<\Delta p_{\alpha} \Delta p_{\beta}>
$$

Different model functions are described by different sets of parameters, and even the rank of a covariance matrix of parameter uncertainties differs when the number of parameters varies. The order of covariance matrix $\mathbf{V}$ of evaluated cross-section uncertainties:

$$
V_{i, k}=<\Delta f\left(x_{i}\right) \Delta f\left(x_{k}\right)>=\sum_{\alpha, \beta} \frac{\partial f\left(x_{i}\right)}{\partial p_{\alpha}} W_{\alpha, \beta} \frac{\partial f\left(x_{k}\right)}{\partial p_{\beta}}
$$

does not depend on the number of parameters, but evaluations with larger numbers of model parameters (or larger number of knots for approximations defined as non-parametric) have higher diagonal elements in the $\mathbf{V}$ matrix (i.e. uncertainties in points or in groups) and smaller off-diagonal elements. Moreover, these covariance matrices differ when different models are adopted with the same number of parameters.

Dependence of the covariance on the model used for practically the same evaluated values raises a fundamental question - which of the evaluations is true (or the best) from the point of view of the covariance matrices? Undoubtedly the correct answer should be the 'model founded on true nuclear theory', emphasizing the role of nuclear theory in the evaluation of the nuclear data, although this requirement is not often feasible in the evaluation process.

From the point of view of nuclear data application files used in operational studies of nuclear reactors and other fuel related facilities, the uncertainties of some parameters weighted over a wide energy range are decisive (not the uncertainties of point values). The integral parameter linear with respect to the evaluated cross-section $(f(x))$ is given by:

$$
F=\int_{a}^{b} f(x) g(x) \mathrm{d} x
$$

When there is an absence of correlations between the uncertainties of the cross-section $f(x)$ and the weight function $g(x)$, this integral parameter uncertainty is defined by: 


$$
\begin{aligned}
<(\Delta F)^{2}>= & \iint\left(g\left(x_{1}\right) V_{1,2}^{(f)} g\left(x_{2}\right)\right. \\
& \left.+f\left(x_{1}\right) V_{1,2}^{(g)} f\left(x_{2}\right)\right) \mathrm{d} x_{1} \mathrm{~d} x_{2}
\end{aligned}
$$

where $\mathbf{V}^{(\mathrm{f})}$ and $\mathbf{V}^{(\mathrm{g})}$ are the covariance matrices of the uncertainties of the cross-section and the weight function, respectively. There are two limiting cases in such an approach:

(a) $g(x)=\delta\left(x-x_{i}\right)$, when $<(\Delta F)^{2}>$ is the mean square uncertainty of point $x_{i}$;

(b) $g(x)=1 /(b-a)$, in which Eq. (A.3) represents the one-group cross-section and $<(\Delta F)^{2}>$ is the mean square uncertainty of this one-group cross-section. $<(\Delta F)^{2}>$ depends weakly on the model used in the evaluation, and is normally close to the mean value of the covariance matrix of experimental errors.

The main objectives of this work are to show that some integral characteristics of the covariance matrices are independent of all possible models, and that the integral uncertainties defined by Eq. (A.4) are in reasonable agreement with these invariant characteristics.

\section{A.2. SIMPLE RELATIONSHIPS BETWEEN THE COVARIANCE MATRICES OF THE EXPERIMENTAL AND EVALUATED DATA UNCERTAINTIES}

The covariance matrix of the uncertainties of the estimated parameters is commonly given by inversion of the Fisher information matrix $\boldsymbol{I}$ (Ref. [A.2]). This technique is easier to apply than the customary error propagation law because such an approach can be directly applied to non-linear regression functions. The Fisher information matrix for the regression function $y(x, \vec{p})$ is given by the equation:

$$
I_{\alpha, \beta}=\sum_{i, k} \frac{\partial y\left(x_{i}, \vec{p}\right)}{\partial p_{\alpha}} \mathbf{R}_{i, k}^{-1} \frac{\partial y\left(x_{k}, \vec{p}\right)}{\partial p_{\beta}}
$$

and the covariance matrix of the parameters is:

$$
W_{\alpha, \beta}=<\Delta p_{\alpha} \Delta p_{\beta}>=I_{\alpha, \beta}^{-1}
$$

so the covariance matrix of the evaluation uncertainties is:

$$
\begin{aligned}
V_{i, k} & =\sum_{\alpha, \beta} \frac{\partial y\left(x_{i}, \vec{p}\right)}{\partial p_{\alpha}} \frac{\partial y\left(x_{k}, \vec{p}\right)}{\partial p_{\beta}}<\Delta p_{\alpha} \Delta p_{\beta}> \\
& =\sum_{\alpha, \beta} \frac{\partial y\left(x_{i}, \vec{p}\right)}{\partial p_{\alpha}} \frac{\partial y\left(x_{k}, \vec{p}\right)}{\partial p_{\beta}} I_{\alpha, \beta}^{-1}
\end{aligned}
$$

Use of this technique gives a simple relationship between the covariance matrices of the experimental and evaluated uncertainties for any model function $y(x, \vec{p})$ :

$$
\begin{aligned}
\operatorname{Spr}^{-1} \mathbf{v} & =\operatorname{Sp} \mathbf{R}^{-1} \mathbf{V}=\sum_{i, k} R_{i, k}^{-1} V_{k, i} \\
& =\sum_{\alpha, \beta} \frac{\partial y\left(x_{i}, \vec{p}\right)}{\partial p_{\alpha}} R_{i, k}^{-1} \frac{\partial y\left(x_{k}, \vec{p}\right)}{\partial p_{\beta}} I_{\alpha, \beta}^{-1} \\
& =\sum_{\alpha, \beta} I_{\alpha, \beta} I_{\alpha, \beta}^{-1}=M
\end{aligned}
$$

where $M$ is the number of parameters of the regression function, and $\mathbf{r}$ and $\mathbf{v}$ are the relative covariance matrices with elements:

$$
r_{i k}=\frac{R_{i k}}{y\left(x_{i}\right) y\left(x_{k}\right)}, \quad v_{i, k}=\frac{V_{i, k}}{y\left(x_{i}\right) y\left(x_{k}\right)}
$$

As distinct from the $\chi^{2}$ criterion, this relationship is strictly independent of the consistency of the observed data and the declared covariance matrix.

The same technique can be used to generate expressions that link the covariance matrix of the experimental data errors to the covariance matrix of the estimated uncertainties:

$$
\begin{aligned}
& \mathrm{Vr}^{-1} \mathbf{v}=\mathbf{v} \\
& \mathrm{VR}^{-1} \mathrm{~V}=\mathrm{V}
\end{aligned}
$$

This approach does not lead to $\mathbf{v}=\mathbf{r}$ and $\mathbf{V}=\mathbf{R}$ because the number of parameters $M$ is smaller than the number of experimental points. Hence detv $=\operatorname{det} \mathbf{V}=0$, and the inverse matrixes $\mathbf{v}^{\mathbf{- 1}}$ and $\mathbf{V}^{\mathbf{- 1}}$ do not exist.

While the model independent Eqs (A.8), (A.10) and (A.11) are useful in checking the formal correctness of the evaluation, discussion of the ambiguities in the evaluation uncertainties is merited. 


\section{A.3. EXAMPLE OF CONSTANT AND PIECEWISE CONSTANT REGRESSION FUNCTIONS}

This example illustrates the dependence of the evaluation uncertainty on the model used in the statistical processing of the experimental data. Consider the model: $A<x<C, 2 N$ uncorrelated measurements with elements of the experimental errors covariance matrix $R_{i, k}=\delta_{i k} \sigma_{i}^{2} ; \sigma_{i}^{2}=1$, and the regression function is constant, $y(x, c)=c$. Thus $\left(I_{1}\right)_{c, c}=2 \mathrm{~N}$ and the covariance matrix of the evaluation uncertainties in the experimental abscissas is given by:

$$
\mathbf{V}_{1}=\left(\begin{array}{ccc}
\frac{1}{2 N} & \cdots & \frac{1}{2 N} \\
\cdots & \cdots & \cdots \\
\frac{1}{2 N} & \cdots & \frac{1}{2 N}
\end{array}\right)
$$

matrix of order $2 N$, with all elements equal to $1 / 2 N$ and $\operatorname{det} \boldsymbol{V}_{1}=\boldsymbol{O}$ for $N>1, \operatorname{Sp} \mathbf{R}^{-1} \mathbf{V}_{\mathbf{1}}=\operatorname{Sp} \mathbf{V}_{\mathbf{1}}=1$ (one parameter model), $\mathbf{V}_{\mathbf{1}} \mathbf{R}^{-\mathbf{1}} \mathbf{V}_{\mathbf{1}}=\mathbf{V}_{\mathbf{1}}{ }^{\mathbf{2}}=\mathbf{V}_{\mathbf{1}}$.

Consider a second model: same experimental uncertainties covariance matrix, $N$ measurements for $A<x<B, N$ measurements for $B<x<C$, and the piecewise constant regression function:

$$
y\left(x, c_{1}, c_{2}\right)= \begin{cases}c_{1} & A<x<B \\ c_{2} & B<x<C\end{cases}
$$

Then $\mathbf{I}_{2}=\left(\begin{array}{cc}N & 0 \\ 0 & N\end{array}\right)$

and

$\mathbf{V}_{2}=\left(\begin{array}{cccccc}1 / N & \ldots & 1 / N & 0 & \ldots & 0 \\ \ldots & \ldots & \ldots & \ldots & \ldots & \ldots \\ 1 / N & \ldots & 1 / N & 0 & \ldots & 0 \\ 0 & \ldots & 0 & 1 / N & \ldots & 1 / N \\ \ldots & \ldots & \ldots & \ldots & \ldots & \ldots \\ 0 & \ldots & 0 & 1 / N & \ldots & 1 / N\end{array}\right)$

matrix of the same order $2 N$, consisting of two blocks of order $N$ with elements $1 / N$ and two order $N$ blocks with elements equal to 0 . This matrix determinant is $\operatorname{det} \boldsymbol{V}_{2}=\boldsymbol{O}$ for $N>2, \operatorname{Sp} \mathbf{R}^{-\mathbf{1}} \mathbf{V}_{\mathbf{2}}=\operatorname{Sp} \mathbf{V}_{\mathbf{2}}=2$ (two parameters model) and $\mathbf{V}_{\mathbf{2}} \mathbf{R}^{-\mathbf{1}} \mathbf{V}_{\mathbf{2}}=\mathbf{V}_{\mathbf{2}}{ }^{2}=\mathbf{V}_{\mathbf{2}}$.

Even when the experimental data are such that the estimated values are the same for both models $\left(c=c_{1}=c_{2}\right)$, their uncertainties and covariance are fundamentally different, reflecting the information contained in the model as well as the experimental data. All of the experimental information is used to determine a single parameter $c$ in the first model considered above, and therefore the estimation is more precise than the two independent parameters in the second model. However, this high level of precision in the estimation is compensated by the variations in the correlations - while the uncertainties in all the points are fully correlated in the first model, there are no correlations between points $x_{i}<B$ and $x_{k}>B$ in the second model. Such compensatory balances lead to conservation as proposed by Pronyaev [A.3] with respect to the general measure of uncertainty (GMU) $P_{s}$, and the mean value of the covariance matrix elements is the same for experiments and evaluations in both models:

$$
\begin{aligned}
P_{s} & =\frac{1}{(2 N)^{2}} \sum_{i, k} R_{i, k}=\frac{1}{(2 N)^{2}} \sum_{i, k}\left(V_{1}\right)_{i, k} \\
& =\frac{1}{(2 N)^{2}} \sum_{i, k}\left(V_{2}\right)_{i, k}=\frac{1}{2 N}
\end{aligned}
$$

This simple example illustrates the behaviour of covariance in nuclear data evaluations - models with a smaller number of parameters give a more precise estimation of the point values but increased correlations in the uncertainties compared with models with larger numbers of parameters. As shown below for correlated experimental errors and complicated models, instead of (GMU) $P_{s}$ the uncertainty of the weighted average of the evaluated data is the same for all reasonable models.

\section{A.4. GENERAL MEASURE OF UNCERTAINTY FOR CORRELATED EXPERIMENTAL ERRORS AND COMPLICATED MODELS}

The mean values of the experimental and evaluated data $Y_{i}$ and $f\left(x_{i}\right)$ for $N_{p}$ points are:

$$
\bar{Y}=\sum_{i} Y_{i} / N_{p}
$$

and

$$
\bar{f}=\sum_{i} f_{i} / N_{p}
$$


Both of these mean values possess uncertainties that are equal to the mean values of the corresponding covariance matrix elements and GMU $P_{s}$. This example of a constant regression function can be complicated - uncertainties of the experimental data are still uncorrelated, but differ, $R_{i, k}=\delta_{i, k} \sigma_{i}^{2}=5$ in the region $A<x<B$, and $R_{i, k}=\delta_{i, k} \sigma_{i}^{2}=1$ in region $B<x<C$. Under these circumstances, uncertainties of the mean values of the experimental and evaluated data for the oneparameter case differ:

$$
<(\Delta \bar{Y})^{2}>=3 / 2 N
$$

and

$$
<(\Delta f)^{2}>=5 / 6 N
$$

and GMU $P_{s}$ is inapplicable. However, GMU (invariant for experimental and evaluated data) can be applied to the uncertainties of the mean values, weighted with experimental uncertainties as defined by the equations:

$$
\begin{gathered}
\bar{Y}_{w}=\frac{1}{\sum_{i} \frac{1}{\sigma_{i}^{2}}} \sum_{i} Y_{i} / \sigma_{i}^{2} \\
\bar{f}_{w}=\frac{1}{\sum_{i} \frac{1}{\sigma_{i}^{2}}} \sum_{i} f_{i} / \sigma_{i}^{2}
\end{gathered}
$$

Uncertainties for both of these mean values are equal to $5 / 6 N$, and this coincidence is not accidental - such circumstances are a corollary of the proposed invariant measures of global uncertainties.

There are two measures of global uncertainty that are strictly invariant for a wide range of model evaluations. $P_{w a}$ is the uncertainty of the mean value of the evaluated function, weighted by the elements of the experimental covariance matrix:

$$
\bar{y}_{w a}=\frac{\sum_{i, k=1}^{N} R_{i . k}^{-1} y\left(x_{k}, \vec{p}\right)}{\sum_{i, k=1}^{N} R_{i . k}^{-1}}
$$

$$
\begin{gathered}
P_{w a}=<\left(\Delta \bar{y}_{w a}\right)^{2}>=<\left(\frac{\sum_{i, k} R_{i, k}^{-1} \Delta y\left(x_{k}\right)}{\sum_{i, k} R_{i, k}^{-1}}\right)^{2}> \\
=\frac{\sum_{i, k, l, m} R_{i, k}^{-1} V_{k, l} R_{l, m}^{-1}}{\left(\sum_{i, k} R_{i, k}^{-1}\right)^{2}}
\end{gathered}
$$

This criterion works for all model evaluations with regression functions that have a constant shift as one of the parameters:

$$
y(x, p)=p_{1}+g\left(x ; p_{2}, \ldots, p_{M}\right)
$$

The uncertainty of the weighted mean value of the evaluation as defined by Eq. (A.23) does not depend on the model adopted for $y(x)$, and is equal to the uncertainty of the weighted mean value of the experimental data:

$$
\begin{gathered}
P_{w a}=<\left(\Delta \bar{Y}_{w a}\right)^{2}>=<\left(\frac{\sum_{i, k} R_{i, k}^{-1} \Delta Y\left(x_{k}\right)}{\sum_{i, k} R_{i, k}^{-1}}\right)^{2}> \\
=\frac{\sum_{i, k, l, m} R_{i, k}^{-1} R_{k, l} R_{l, m}^{-1}}{\left(\sum_{i, k} R_{i, k}^{-1}\right)^{2}}=\left(\sum_{i . k} R_{i, k}^{-1}\right)^{-1}
\end{gathered}
$$

While sometimes impossible to single out a constant shift as one of the approximate parameters, the simplest case is given by the equation (pole approximant):

$$
y(x)=\frac{a}{b-x}
$$

If a constant factor can be singled out as one of the approximate parameters:

$$
\ln y(x, \vec{p})=p_{1}+g\left(x, p_{2} \ldots p_{n}\right)
$$

and the following relationship holds true for the relative covariance:

$$
P_{w r}=\frac{\sum_{i, k, l, m} \mathbf{r}_{i, k}^{-1} \mathbf{v}_{k, l} \mathbf{r}_{l, m}^{-1}}{\left(\sum_{i, k} \mathbf{r}_{i, k}^{-1}\right)^{2}}=\left(\sum_{i, k} \mathbf{r}_{i, k}^{-1}\right)^{-1}
$$


Equation (A.28) is strictly valid in the case of an approximant with constant shift, but not vice versa. Both relationships are invalid in some exotic cases, for example $y=x+f(x, p)$.

The mathematical proofs of Eqs (A.25) and (A.28) and the approximate fulfilment of Eq. (A.23) for regression functions with a constant factor are given in the annexes.

\section{A.5. PRACTICAL EXAMPLES}

The existence of invariant global measures that are independent of model functions does not solve the problem of ambiguity in the covariance matrices, although their interconnection with the uncertainties of the reactor integral parameters may partially address the situation from the point of view of the practical use of nuclear data files. Reactor integral parameters are weighted averages of the evaluated values of the cross-sections with different roles over different energy ranges [A.3]. Nuclear data files are assembled to supply the user with recommended nuclear characteristics that assist greatly in the design of nuclear power reactors. As a rule, the number of experimental measurements is maximal and their precision is higher in the energy regions of importance for practical applications. Thus weighting with the experimental uncertainties in both the invariant measures and the reactor integral parameters are implicitly interconnected, and therefore the uncertainties of the integral parameters are reasonably close to the invariant global measures and depend only slightly on the model used in the data evaluation. Some practical examples are given below.

The first stage in the standard cross-section evaluations was the selection, analysis and correction of the experimental data sets. Independent evaluations of these same crosssections were performed in terms of the calculation of the GMU and other integral characteristics of the covariance matrices.

Experimental data sets from EXFOR were treated as independent, and their statistical and systematic errors were estimated on the basis of analyses of the observable data scatter (see Ref. [A.4]). Such an approach without a thorough selection of the data sets (only clearly erroneous data sets were rejected) or correction of the experimental cross-sections led to evaluated uncertainties that were greater than in the above mentioned standards evaluations. These conservative results and some of their integral characteristics (californium spectrum averaged cross-section and one-group cross-section and their uncertainties) are compared in Table A.1 with evaluations of equivalent integral experiments [A.5].

Table A.1 shows that for all listed crosssection evaluations, with the exception of the values in the denominator for the ${ }^{197} \mathrm{Au}(\mathrm{n}, \gamma)$, the californium averaged cross-section uncertainty is close to the uncertainty $p_{m r} \%$ obtained from the relative covariance matrix, and to the uncertainty of the one-group cross-section. All of these characteristics are close to the model independent global uncertainty of the estimation $\mathrm{p}_{\mathrm{wr}}$. Note that we consider an observed difference of the order of tens of per cent of the listed integral characteristics uncertainties to be reasonably close.

The model dependence of the covariance matrices even in the case of the same evaluated values of the cross-section is illustrated by the use of two sets of parameters for the evaluation of ${ }^{235} \mathrm{U}(\mathrm{n}, \mathrm{f})$ - the second set of parameters was obtained by adding six additional pole components with negligible amplitudes to the first set. The approximants are indistinguishable, but the covariance matrices of their uncertainties in the low energy range differ significantly (see Tables A.2 and A.3). Some variances for the 36 parameter case are a factor of seven higher than for the 24 parameter case, whereas, as shown in Table A.1, the uncertainties of all of the calculated integral characteristics are very close for these two models $(\sim 1 \%)$.

The integral characteristics of the ${ }^{197} \mathrm{Au}(\mathrm{n}, \gamma)$ reaction merit detailed consideration (Table A.1). Values in the numerator for ${ }^{197} \mathrm{Au}(\mathrm{n}, \gamma)$ correspond to estimates up to $2.9 \mathrm{MeV}$, while values in the denominator represent estimates up to $5.55 \mathrm{MeV}$. There are no experimental data above $2.9 \mathrm{MeV}$, and the evaluated data in this energy region involves the extrapolation of small cross-sections with large uncertainties. The influence of this region is comparatively small in the californium averaged cross-section (compensated by californium spectrum roll-off), but the contribution of these poorly founded uncertainties leads to a significant increase in the uncertainty of the one-group crosssection (by a factor of $\sim 3$ ) and the GMU $p_{m r}$ (by a factor of $\sim 4.5)$. These data differ significantly from the invariant measure $\left(\mathrm{p}_{\mathrm{wr}} \%\right)$, which depends exclusively on the experimental covariance matrix. 
TABLE A.1. INTEGRAL CHARACTERISTICS OF CONSERVATIVE CROSS-SECTION ESTIMATES AND THEIR UNCERTAINTIES

\begin{tabular}{|c|c|c|c|c|c|}
\hline \multirow[b]{2}{*}{$\mathrm{L}$} & \multicolumn{2}{|c|}{${ }^{235} \mathrm{U}(\mathrm{n}, \mathrm{f})$} & \multirow{2}{*}{$\frac{{ }^{238} \mathrm{U}(\mathrm{n}, \gamma)}{21}$} & \multirow{2}{*}{$\frac{{ }^{197} \mathrm{Au}(\mathrm{n}, \gamma)}{12}$} & \multirow{2}{*}{$\frac{{ }^{6} \mathrm{Li}(\mathrm{n}, \mathrm{t})}{13}$} \\
\hline & 24 & 36 & & & \\
\hline $\mathrm{N}$ & \multicolumn{2}{|c|}{76} & 50 & 48 & 15 \\
\hline $\mathrm{N}_{\mathrm{p}}$ & \multicolumn{2}{|c|}{2075} & 551 & 1359 & 745 \\
\hline$\sigma^{C f} \exp (b)$ & \multicolumn{2}{|c|}{1.210} & - & 0.07679 & - \\
\hline$\delta^{C f} \% \exp$ & \multicolumn{2}{|c|}{1.20} & - & 1.59 & - \\
\hline$\sigma^{C f}(b)$ & \multicolumn{2}{|c|}{1.227} & 0.06465 & $0.07235 / 0.07536$ & 0.2891 \\
\hline$\sigma^{l g r}(b)$ & \multicolumn{2}{|c|}{1.667} & 0.098 & $0.097 / 0.057$ & 0.378 \\
\hline$\delta^{C f} \%$ & $0.723[0.764]$ & $0.731[0.771]$ & $3.16[3.20]$ & $1.06[1.07] / 1.28[1.29]$ & $1.29[1.30]$ \\
\hline$\delta^{1 \mathrm{~g}} \mathrm{r} \%$ & 0.71 & 0.71 & 2.98 & $1.05 / 2.85$ & 1.29 \\
\hline$p_{m r} \%$ & 0.631 & 0.639 & 2.94 & $1.058 / 4.59$ & 1.32 \\
\hline $\mathrm{p}_{\mathrm{wr}} \%$ & \multicolumn{2}{|c|}{0.59} & 2.2 & 1.00 & 1.08 \\
\hline
\end{tabular}

$\mathrm{L}$ : number of model function parameters used in the evaluation.

$\mathrm{N}$ : number of experimental data sets.

$\mathrm{N}_{\mathrm{p}}$ : number of experimental points.

$\sigma^{C f}(b)$ and $\delta^{C f} \%$ : californium spectrum averaged cross-section and uncertainty in conservative estimation.

$\sigma^{l g r}(b)$ and $\delta^{l g r} \%$ : conservative estimates of one-group cross-section and uncertainty.

$p_{m r} \%$ : square root of the mean value of the evaluated relative covariance matrix $P_{m r}=\sum_{i, k} v_{i, k} / N_{p}^{2}$ multiplied by 100 for
comparison with relative errors.

$\mathrm{p}_{\mathrm{wr}} \%$ : square root of $P_{w r}$ (Eq. (A.28)) invariant for relative errors, multiplied by 100 for comparison with the relative errors of evaluation.

Note: Italicized data were obtained in different multigroup approximations for ease of comparison with the standards evaluation. Values in parentheses along the row $\delta(C f) \%$ correspond to uncertainties calculated from the 'realistic' covariance matrix of ${ }^{252} \mathrm{Cf}$ spontaneous fission spectrum uncertainties - this matrix generates an uncertainty of $0.25 \%$ for the total number of ${ }^{252} \mathrm{Cf}$ prompt fission neutrons, whereas the Mannhart matrix [A.6] gives only $0.0033 \%$ for the spectrum sum uncertainty, which is judged to be unrealistic (although use of this matrix permits only an assessment of the contribution of the evaluated cross-section uncertainty to the uncertainty of the californium averaged crosssection).

\section{A.6. CONCLUSIONS}

The examples given above and many other model problems represent ample evidence that ambiguities in the covariance matrix of uncertainties from different evaluations of the same experimental data do not represent an obstacle to their use in estimates of operational uncertainties for power reactors and other nuclear facilities. Any reasonable model that does not seriously overstep the limits of the experimental data will generate sound evaluated data with the same value of the

TABLE A.2. RELATIVE COVARIANCE MATRIX FOR 24 PARAMETRIC ESTIMATE OF ${ }^{235} \mathrm{U}(\mathrm{n}, \mathrm{f})$ CROSS-SECTION

\begin{tabular}{lccccccc}
\hline Energy group (MeV) & No. & 1 & 2 & 3 & 4 & 5 & 6 \\
\hline $20.00-0.10000$ & 1 & $0.504 \mathrm{E}-04$ & $0.287 \mathrm{E}-04$ & $0.269 \mathrm{E}-04$ & $0.256 \mathrm{E}-04$ & $0.251 \mathrm{E}-04$ & $0.254 \mathrm{E}-04$ \\
$0.10000-0.04642$ & 2 & $0.287 \mathrm{E}-04$ & $0.478 \mathrm{E}-04$ & $0.428 \mathrm{E}-04$ & $0.390 \mathrm{E}-04$ & $0.383 \mathrm{E}-04$ & $0.388 \mathrm{E}-04$ \\
$0.04642-0.02154$ & 3 & $0.269 \mathrm{E}-04$ & $0.428 \mathrm{E}-04$ & $0.443 \mathrm{E}-04$ & $0.434 \mathrm{E}-04$ & $0.418 \mathrm{E}-04$ & $0.417 \mathrm{E}-04$ \\
$0.02154-0.01000$ & 4 & $0.256 \mathrm{E}-04$ & $0.390 \mathrm{E}-04$ & $0.434 \mathrm{E}-04$ & $0.459 \mathrm{E}-04$ & $0.458 \mathrm{E}-04$ & $0.438 \mathrm{E}-04$ \\
$0.01000-0.00464$ & 5 & $0.251 \mathrm{E}-04$ & $0.383 \mathrm{E}-04$ & $0.418 \mathrm{E}-04$ & $0.458 \mathrm{E}-04$ & $0.482 \mathrm{E}-04$ & $0.475 \mathrm{E}-04$ \\
$0.00464-0.00216$ & 6 & $0.254 \mathrm{E}-04$ & $0.388 \mathrm{E}-04$ & $0.417 \mathrm{E}-04$ & $0.438 \mathrm{E}-04$ & $0.475 \mathrm{E}-04$ & $0.566 \mathrm{E}-04$ \\
\hline
\end{tabular}


TABLE A.3. RELATIVE COVARIANCE MATRIX FOR 36 PARAMETRIC ESTIMATE OF ${ }^{235} \mathrm{U}(\mathrm{n}, \mathrm{f})$ CROSS-SECTION

\begin{tabular}{lccccccc}
\hline Energy group (MeV) & No. & 1 & 2 & 3 & 4 & 5 & 6 \\
\hline $20.00-0.10000$ & 1 & $0.516 \mathrm{E}-04$ & $0.292 \mathrm{E}-04$ & $0.279 \mathrm{E}-04$ & $0.233 \mathrm{E}-04$ & $0.223 \mathrm{E}-04$ & $0.289 \mathrm{E}-04$ \\
$0.10000-0.04642$ & 2 & $0.292 \mathrm{E}-04$ & $0.543 \mathrm{E}-04$ & $0.425 \mathrm{E}-04$ & $0.401 \mathrm{E}-04$ & $0.479 \mathrm{E}-04$ & $0.124 \mathrm{E}-05$ \\
$0.04642-0.02154$ & 3 & $0.279 \mathrm{E}-04$ & $0.425 \mathrm{E}-04$ & $0.535 \mathrm{E}-04$ & $0.431 \mathrm{E}-04$ & $0.222 \mathrm{E}-04$ & $0.423 \mathrm{E}-04$ \\
$0.02154-0.01000$ & 4 & $0.233 \mathrm{E}-04$ & $0.401 \mathrm{E}-04$ & $0.431 \mathrm{E}-04$ & $0.580 \mathrm{E}-04$ & $0.453 \mathrm{E}-04$ & $0.839 \mathrm{E}-05$ \\
$0.01000-0.00464$ & 5 & $0.223 \mathrm{E}-04$ & $0.479 \mathrm{E}-04$ & $0.222 \mathrm{E}-04$ & $0.453 \mathrm{E}-04$ & $0.127 \mathrm{E}-03$ & $-0.306 \mathrm{E}-04$ \\
$0.00464-0.00216$ & 6 & $0.289 \mathrm{E}-04$ & $0.124 \mathrm{E}-05$ & $0.423 \mathrm{E}-04$ & $0.839 \mathrm{E}-05$ & $-0.306 \mathrm{E}-04$ & $0.410 \mathrm{E}-03$ \\
\hline
\end{tabular}

invariant measure of their uncertainty. A fully coherent physical model is only indispensable for the evaluation of the uncertainty at a definite point or narrow energy region. While a rigorous validation of this statement demands a detailed consideration of the models used, we have observed that the uncertainties of the integral parameters for different models were always within a few per cent. The qualitative substantiation of this statement is derived in Section A.5 - in all listed examples only a few tens of per cent separate all the uncertainties of the integral parameters from the model independent invariant measure $\mathrm{p}_{\mathrm{wr}}$.

\section{REFERENCES TO THE APPENDIX}

[A.1] PRONYAEV, V.G., et al., "The status of the international neutron cross section standards file", Nuclear Data for Science and Technology (Proc. Int. Conf. Santa Fe, NM, 2004), American Institute of Physics Conf. Proc. 769, Part 1 (HAIGHT, R.C., CHADWICK, M.B., KAWANO, T., TALOU, P., Eds), American Institute of Physics, New York (2005) 808-815.
[A.2] COX, D.R., HINKLEY, D.V., Theoretical Statistics, Chapman and Hall, London (1974).

[A.3] PRONYAEV, V.G., "Does model fit decrease the uncertainty of the data in comparison with a general non-model least squares fit?", Summary Report of the First Research Coordination Meeting on Improvement of the Standard Cross Sections for Light Elements, Rep. INDC(NDS)438, IAEA, Vienna (2003) 172-183.

[A.4] BADIKOV, S.A., GAI, E.V., "Some sources of the underestimation of evaluated cross-section uncertainties", Summary Report of the First Research Coordination Meeting on Improvement of the Standard Cross Sections for Light Elements, Rep. INDC(NDS)-438, IAEA, Vienna (2003) 117-129.

[A.5] MANNHART, W., "Response of activation reactions in the neutron field of spontaneous fission of ${ }^{252} \mathrm{Cf}$ ", Summary Report of the Final Technical Meeting on International Reactor Dosimetry File: IRDF-2002, Rep. INDC(NDS)448, IAEA, Vienna (2003) 61-71.

[A.6] MANNHART, W., "Evaluation of the Cf-252 fission neutron spectrum between $0 \mathrm{MeV}$ and 20 $\mathrm{MeV}$ ", Properties of Neutron Sources, IAEATECDOC-410, IAEA, Vienna (1987) 158-170. 


\section{Annex I}

\section{CONSTANT SHIFT MODEL}

Proof of Eq. (A.25): consider the parameters of the regression function:

$$
\begin{aligned}
& q_{1}=\bar{y}_{w}=p_{1}+\frac{\sum_{i, k=1}^{N} R_{i, k}^{-1} g\left(x_{k} ; p_{2}, \ldots, p_{M}\right)}{\sum_{i, k=1}^{N} R_{i, k}^{-1}} \\
& q_{2}=p_{2}, \ldots, q_{M}=p_{M}
\end{aligned}
$$

expressed as:

$$
y(x, \vec{q})=q_{1}+h\left(x ; q_{2}, \ldots, q_{M}\right)
$$

where:

$$
\begin{aligned}
& h\left(x ; q_{2}, \ldots, q_{M}\right) \\
& =g\left(x ; q_{2}, \ldots, q_{M}\right)-\frac{\sum_{i, k=1}^{N} R_{i, k}^{-1} g\left(x_{k} ; q_{2}, \ldots, q_{M}\right)}{\sum_{i, k=1}^{N} R_{i, k}^{-1}}
\end{aligned}
$$

with:

$$
\frac{\sum_{i, k=1}^{n} R_{i, k}^{-1} h\left(x_{k} ; q_{2}, \ldots, q_{M}\right)}{\sum_{i, k=1}^{N} R_{i, k}^{-1}}=0
$$

Thus:

$$
\frac{\partial \bar{y}_{w}}{\partial q_{1}}=1, \frac{\partial \bar{y}_{w}}{d q_{2}}=\ldots=\frac{\partial \bar{y}_{w}}{d q_{M}}=0
$$

and the uncertainty of the mean value is given by the equation:

$<\left(\Delta \bar{y}_{w}\right)^{2}>=<\left(\sum_{l} \frac{\partial \bar{y}_{w}}{\partial q_{l}} \Delta q_{l}\right)^{2}>=<\left(\Delta q_{1}\right)^{2}>$ (I-6)

Consider Eqs (I-3) and (I-4) from which the Fisher information matrix for $y(x, \vec{q})=q_{1}+h\left(x ; q_{2}, \ldots, q_{M}\right)$ can be expressed as:

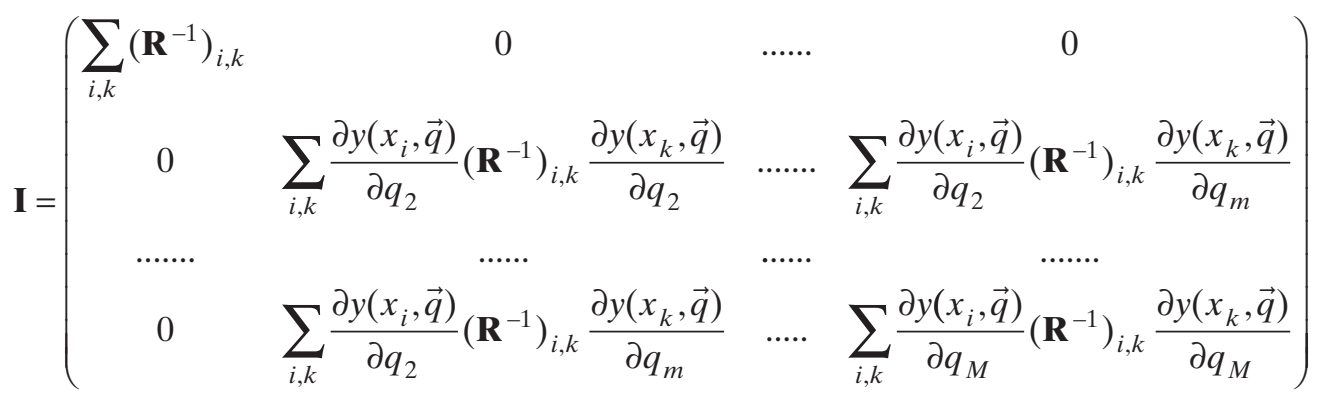

to give:

$$
P_{w a}=<\left(\Delta q_{1}\right)^{2}>=\left(\mathbf{I}^{(l)}\right)_{1,1}^{-1}=\left(\sum_{i, k}\left(\mathbf{R}^{-1}\right)_{i, k}\right)^{-1}
$$

and the $\mathbf{V}$ and $\mathbf{R}$ matrices are linked by:

$$
\sum_{i, k, l, m} R_{i, k}^{-1} V_{k, l} R_{l, m}^{-1}=\sum_{i, k} R_{i, k}^{-1}
$$




\section{Annex II}

\section{CONSTANT FACTOR MODEL}

Proof of Eq. (A.28): a constant factor can be adopted as one of the parameters and the following expression can be derived:

$\ln y(x, \vec{p})=p_{1}+g\left(x, p_{2} \ldots p_{n}\right)$

$$
=t_{1}+g\left(x, t_{2} \ldots t_{n}\right)-\frac{\sum_{i, k} \mathbf{r}_{i, k}^{-1} g\left(x_{k}, t_{2} \ldots t_{n}\right)}{\sum_{i, k} \mathbf{r}_{i, k}^{-1}}
$$

where:

$$
\begin{aligned}
& t_{1}=\frac{\sum_{i, k} \mathbf{r}_{i, k}^{-1} \ln y\left(x_{k}, p_{2} \ldots p_{n}\right)}{\sum_{i, k} \mathbf{r}_{i, k}^{-1}}, \\
& t_{2}=p_{2} \ldots t_{n}=p_{n}
\end{aligned}
$$

with:

$$
\begin{aligned}
& \mathbf{r}_{i, k}=\frac{\mathbf{R}_{i, k}}{y\left(x_{i}\right) y\left(x_{k}\right)}, \\
& \frac{\partial \ln y(x, \vec{t})}{\partial t_{1}}=1
\end{aligned}
$$

and:

$$
\frac{\sum_{i, k} \mathbf{r}_{i, k}^{-1} \frac{\partial \ln y\left(x_{k}, \vec{t}\right)}{\partial t_{\alpha}}}{\sum_{i, k} \mathbf{r}_{i, k}^{-1}}=\delta_{\alpha, 1}
$$

The Fisher matrix elements can be rewritten as:

$$
\begin{aligned}
& \sum_{i, k} \frac{\partial y\left(x_{i}, \vec{t}\right)}{\partial t_{\alpha}}\left(\mathbf{R}^{-1}\right)_{i, k} \frac{\partial y\left(x_{k}, \vec{t}\right)}{\partial t_{\beta}} \\
& =\sum_{i, k} \frac{\partial \ln y\left(x_{i}, \vec{t}\right)}{\partial t_{\alpha}} y\left(x_{i}, \vec{t}\right)\left(\mathbf{R}^{-1}\right)_{i, k} y\left(x_{k}, \vec{t}\right) \frac{\partial \ln y\left(x_{k}, \vec{t}\right)}{\partial t_{2}} \\
& =\sum_{i, k} \frac{\partial \ln y\left(x_{i}, \vec{t}\right)}{\partial t_{\alpha}}\left(\mathbf{r}^{-1}\right)_{i, k} \frac{\partial \ln y\left(x_{k}, \vec{t}\right)}{\partial t_{\beta}}
\end{aligned}
$$

Under these conditions:

$$
\begin{aligned}
& \left\langle\left(\frac{\Delta \sum_{i, k} \mathbf{r}_{i, k}^{-1} \ln y\left(x_{k}, \vec{t}\right)}{\sum_{i, k} \mathbf{r}_{i, k}^{-1}}\right)^{2}\right\rangle \\
& =\left\langle\left(\frac{\sum_{i, k, \alpha} \mathbf{r}_{i, k}^{-1} \frac{\partial \ln y\left(x_{k}, \vec{t}\right)}{\partial t_{\alpha}} \Delta t_{\alpha}}{\sum_{i, k} \mathbf{r}_{i, k}^{-1}}\right)^{2}\right\rangle
\end{aligned}
$$

$$
=<\Delta t_{1}^{2}>=\frac{\sum_{i, k, l, m} \mathbf{r}_{i, k}^{-1} \mathbf{v}_{k, l} \mathbf{r}_{l, m}^{-1}}{\left(\sum_{i, k} \mathbf{r}_{i, k}^{-1}\right)^{2}}
$$

with:

$$
\mathbf{v}_{i, k}=\frac{\mathbf{V}_{i, k}}{y\left(x_{i}\right) y\left(x_{k}\right)}
$$

Inserting:

$y=\exp \left(t_{1}+g\left(x, t_{2} \ldots t_{n}\right)-\frac{\sum_{i, k} \mathbf{r}_{i, k}^{-1} g\left(x_{k}, t_{2} \ldots t_{n}\right)}{\sum_{i, k} \mathbf{r}_{i, k}^{-1}}\right.$

into Eq. (A.5) produces an expression for $\left\langle\Delta t_{1}^{2}\right\rangle$ that differs from $<\Delta q_{1}^{2}>$ (Eq. (I-8)) by substituting $\mathbf{r}$ for $\mathbf{R}$ to give:

$$
\left(\Delta t_{1}\right)^{2}=\frac{\sum_{i, k, l, m} \mathbf{r}_{i, k}^{-1} \mathbf{v}_{k, l} \mathbf{r}_{l, m}^{-1}}{\left(\sum_{i, k} \mathbf{r}_{i, k}^{-1}\right)^{2}}=\left(\sum_{i, k} \mathbf{r}_{i, k}^{-1}\right)^{-1}
$$




\section{Annex III}

\section{GENERAL MEASURE OF UNCERTAINTY APPROXIMATION}

The GMA method is equivalent to linear spline with approximation knots in the points $x_{N}$ of the GMA energy grid. Consider the supporting ordinates formalism:

$$
\begin{aligned}
& f(x)=\frac{f_{N}\left(x-x_{N+1}\right)-f_{N+1}\left(x-x_{N+1}\right)}{x_{N}-x_{N+1}} \\
& x_{N} \leq x \leq x_{N+1}
\end{aligned}
$$

The same approximation can be written as:

$$
\begin{aligned}
& f(x)=a_{N}+b_{N}\left(x-\frac{\sum_{i, k} R_{i, k}^{-1} x_{k}}{\sum_{i, k} R_{i, k}^{-1}}\right) \\
& x_{N} \leq x \leq x_{N+1}
\end{aligned}
$$

with the following equalities in the approximation knots:

$$
\begin{gathered}
a_{N}+b_{N}\left(x_{N}-\frac{\sum_{i, k} R_{i, k}^{-1} x_{k}}{\sum_{i, k} R_{i, k}^{-1}}\right) \\
=a_{N+1}+b_{N+1}\left(x_{N}-\frac{\sum_{i, l} R_{i, k}^{-1} x_{l}}{\sum_{i, k} R_{i, k}^{-1}}\right)
\end{gathered}
$$

A new parameter can be introduced weighted average of the approximant $(q)$ :

$$
q=\frac{\sum_{i, m} R_{i, m}^{-1} f_{m}}{\sum_{i, k} R_{i, k}^{-1}}=\frac{\sum_{N} a_{N} \sum_{i, k_{N}} R_{i, k_{N}}^{-1}}{\sum_{i, k} R_{i, k}^{-1}}
$$

where $k_{N}$ are the experimental points that lie between knots $x_{N}$ and $x_{N+1}$.

Equations (III-3) and (III-4) permit the expression of all parameters $a_{N}$ through one of them and all parameters $b_{N}$, and also through parameter $q$ and all parameters $b_{N}$ :

$$
a_{N}=q+\sum_{M} \phi_{M} b_{M}
$$

where $\phi_{M}$ are linear combinations of the approximation knots and weighted experimental abscissas.

Using such parameterization of the GMA evaluation, both Eqs (A.23) (absolute) and (A.28) (relative) can be shown to be exactly true.

where $x_{N} \leq x_{k} \leq x_{N+1}$ and $x_{N+1} \leq x_{l} \leq x_{N+2}$. 


\section{Annex IV}

\section{APPROXIMATE INVARIANTS}

Many of the cases in which a constant factor was included in the parameter Eq. (A.23) resulted in violations of the absolute covariance to a very small degree. A qualitative estimation of this violation can be obtained from Eq. (A.26) by using the parameters $q, p$ in place of $a, b$ :

$$
q=a \bar{z}, \quad p=a \frac{\overline{x z}-\overline{x z}}{\overline{x x}-\bar{x}^{2}}
$$

where:

$z=\frac{1}{b-x}, \quad \bar{z}=\frac{\sum_{i, k} R_{i, k}^{-1} z_{k}}{\sum_{i, k} R_{i, k}^{-1}}, \quad \bar{x}=\frac{\sum_{i, k} R_{i, k}^{-1} x_{k}}{\sum_{i, k} R_{i, k}^{-1}}$,

$\overline{x z}=\frac{\sum_{i, k} x_{i} R_{i, k}^{-1} z_{k}}{\sum_{i, k} R_{i, k}^{-1}}$

$p$ minimizes $S$ :

$$
S=\sum_{i, k}\left(a z_{i}-q-p\left(x_{i}-\bar{x}\right)\right) R_{i, k}^{-1}\left(a z_{k}-q-p\left(x_{k}-\bar{x}\right)\right)
$$

Jacobians of the parameters transformation are:

$$
\mathbf{J}=\left(\begin{array}{ll}
\frac{\partial q}{\partial a} & \frac{\partial q}{\partial b} \\
\frac{\partial p}{\partial a} & \frac{\partial p}{\partial b}
\end{array}\right)=\left(\begin{array}{cc}
\bar{z} & -a \overline{z^{2}} \\
\overline{x z}-\overline{x z} & -a \frac{\overline{x z^{2}}-\bar{x} \bar{z}^{2}}{\overline{x x}-\bar{x}}
\end{array}\right)
$$

$$
\begin{aligned}
& \mathbf{J}^{-1}=\left(\begin{array}{ll}
\frac{\partial a}{\partial q} & \frac{\partial a}{\partial p} \\
\frac{\partial b}{\partial q} & \frac{\partial b}{\partial p}
\end{array}\right)=\frac{1}{\frac{\partial q}{\partial a} \frac{\partial p}{\partial b}-\frac{\partial q}{\partial b} \frac{\partial p}{\partial a}}\left(\begin{array}{cc}
\frac{\partial p}{\partial b} & -\frac{\partial q}{\partial b} \\
-\frac{\partial p}{\partial a} & \frac{\partial q}{\partial a}
\end{array}\right) \\
& =-\frac{\overline{x x}-\bar{x}^{2}}{a\left(\bar{z} \overline{x z^{2}}-\overline{z^{2}} \overline{x z}\right)}\left(\begin{array}{cc}
-a \frac{\overline{x z^{2}}-\bar{x} \bar{z}^{2}}{\overline{x x}-\bar{x}^{2}} & a \overline{z^{2}} \\
-\frac{\overline{x z}-\overline{x z}}{\overline{x x}-\bar{x}^{2}} & \bar{z}
\end{array}\right)
\end{aligned}
$$

and the function derivatives in the parameters are:

$$
\frac{\partial f}{\partial q}=\frac{\partial f}{\partial a} \frac{\partial a}{\partial q}+\frac{\partial f}{\partial b} \frac{\partial b}{\partial q}=\frac{z\left(\overline{x z^{2}}-\bar{x} \overline{z^{2}}\right)-z^{2}(\overline{x z}-\overline{x z})}{\overline{z x z^{2}}-\overline{z^{2}} \overline{x z}}
$$

$$
\frac{\partial f}{\partial p}=\frac{\partial f}{\partial a} \frac{\partial a}{\partial p}+\frac{\partial f}{\partial b} \frac{\partial b}{\partial p}=-\frac{\left(\overline{x x}-\bar{x}^{2}\right)\left(\overline{z z^{2}}-z^{2} \bar{z}\right)}{\overline{z x z^{2}}-\overline{z^{2}} \overline{x z}}
$$

Using these derivatives and decomposing $z$ in the powers of $x$ :

$$
\begin{aligned}
& \alpha=\frac{1}{b}, \quad z=\alpha\left(1+\alpha x+\alpha^{2} x^{2}+\ldots\right) \\
& z^{2}=\alpha\left(1+2 \alpha x+3 \alpha^{2} x^{2}+\ldots\right)
\end{aligned}
$$

expressions for the Fisher matrix elements are obtained:

$$
\begin{aligned}
& I_{q, q}= \sum_{i, k} \frac{\partial f_{i}}{\partial q} R_{i, k}^{-1} \frac{\partial f_{k}}{\partial q} \\
&= \sum_{i, k} R_{i, k}^{-1}\left(1+2 \alpha^{2} \frac{\bar{x} \overline{x x^{2}}-\overline{x^{2}} \overline{x x}}{\overline{x x}-\bar{x}^{2}}+\ldots\right) \\
& I_{q, p}=\sum_{i, k} R_{i, k}^{-1}\left(\alpha^{2}\left(\overline{x x^{2}}-\bar{x} \bar{x}^{2}\right)+\ldots\right)
\end{aligned}
$$

These equations explain the approximate fulfilment of Eq. (A.23) for the pole approximant outside the approximation range. Such deductions can be successfully extended to the arbitrary function with a pole component. 



\section{LIST OF PARTICIPANTS IN THE COORDINATED RESEARCH PROJECT}

S.A. Badikov

Chen Zhenpeng

A.D. Carlson

E.V. Gai

G.M. Hale

F.-J. Hambsch

H.M. Hofmann

T. Kawano

N.M. Larson

V.G. Pronyaev

D.L. Smith

Soo-Youl Oh

S. Tagesen

H. Vonach
Institute of Physics and Power Engineering, Russian Federation

Tsinghua University, China

National Institute of Standards and Technology, United States of America

Institute of Physics and Power Engineering, Russian Federation

Los Alamos National Laboratory, United States of America

EC Joint Research Centre, Institute for Reference Materials and Measurements, Belgium

Universität Erlangen-Nürnberg, Germany

Los Alamos National Laboratory, United States of America

Oak Ridge National Laboratory, United States of America

International Atomic Energy Agency

Argonne National Laboratory, United States of America

Korea Atomic Energy Research Institute, Republic of Korea

Institut für Isotopenforschung und Kernphysik, Austria

Institut für Isotopenforschung und Kernphysik, Austria 
Neutron cross-section standards are important in the measurement and evaluation of all other neutron reaction cross-sections. Previous evaluations of a set of specific neutron cross-sections were completed in 1987 and established as both international and national standards. After the dissemination of significant amounts of precise experimental data and developments in the methodology of analysis and evaluation, a decision was recently made to re-evaluate the standards. An IAEA coordinated research project was established to catalyse this evaluation process, which was an international effort utilizing full worldwide capabilities. This report presents the resulting recommended standards and describes how they were derived. 